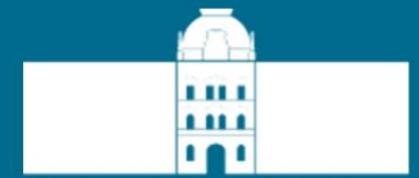

University of Maribor

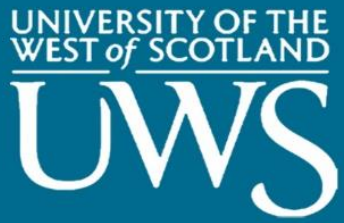

\title{
$10^{\mathrm{TH}}$ International Conference on Sustainable Energy and Environmental Protection:
}

\section{Renewable Energy Sources}

(June 27 ${ }^{T H}-30^{T H}, 2017$, Bled, Slovenia)

(Conference Proceedings)

\section{Editors:}

Emeritus Prof. dr. Jurij Krope Prof. dr. Abdul Ghani Olabi Prof. dr. Darko Goričanec Prof. dr. Stanislav Božičnik 
University of Maribor Press 


\title{
$10^{\mathrm{TH}}$ International Conference on Sustainable Energy and Environmental Protection
}

\author{
Renewable Energy Sources \\ (June 27 ${ }^{\mathrm{TH}}-30^{\mathrm{TH}}, 2017$, Bled, Slovenia) \\ (Conference Proceedings)
}

Editors:

Emeritus Prof. dr. Jurij Krope

Prof. dr. Abdul Ghani Olabi

Prof. dr. Darko Goričanec

Prof. dr. Stanislav Božičnik 
Title: $\quad 10^{\mathrm{TH}}$ International Conference on Sustainable Energy and Environmental Protection (June $27^{\mathrm{TH}}-30^{\mathrm{TH}}, 2017$, Bled, Slovenia) (Conference Proceedings)

Subtitle: Renewable Energy Sources

Editors: Emeritus Prof. Jurij Krope, Ph.D. (University of Maribor, Slovenia), Prof. Abdul Ghani Olabi, Ph.D. (University of the West of Scotland, UK), Asso. Prof. Darko Goričanec, Ph.D. (University of Maribor, Slovenia), Asso. Prof. Stanislav Božičnik (University of Maribor, Slovenia).

Review: Prof. Željko Knez, Ph.D. (University of Maribor, Slovenia), Prof. Niko Samec, Ph.D. (University of Maribor, Slovenia).

Tehnical editors : Jan Perša (University of Maribor Press), Armin Turanović (University of Maribor Press).

Design and layout: University of Maribor Press

Conference: $\quad 10^{\mathrm{TH}}$ International Conference on Sustainable Energy and Environmental Protection

Honorary Committee:

Abdul Ghani Olabi, Ph.D. (Honorary President, University of the West of Scotland, United Kingdom), Igor Tičar, Ph.D (Rector of the University of Maribor, Slovenia), Niko Samec $\mathrm{Ph} . D$. (Pro-rector of University of Maribor, Slovenia), Zdravko Kravanja, Ph-D. (Dean of the Faculty of Chemistry and Chemical Engineering, University of Maribor, Slovenia).

Organising Committee:

Jurij Krope, Ph.D. (University of Maribor, Slovenia), Darko Goričanec, Ph.D. (University of Maribor, Slovenia), Stane Božičnik, Ph.D. (University of Maribor, Slovenia), Peter Trop, Ph.D. (University of Maribor, Slovenia), Danijela Urbancl, Ph.D. (University of Maribor, Slovenia), Sonja Roj (University of Maribor, Slovenia), Željko Knez, Ph.D. (University of Maribor, Slovenia), Bojan Štumberger, Ph.D. (University of Maribor, Slovenia), Franci Čuš, Ph.D. (University of Maribor, Slovenia), Miloš Bogataj, Ph.D. (University of Maribor, Slovenia), Janez Žlak, Ph.D (Mine Trbovlje Hrastnik, Slovenia), LL. M. Tina Žagar (Ministry of Economic Development and Technology), Igor Ivanovski, MSc. (IVD Maribor, Slovenia), Nuša Hojnik, Ph.D. (Health Center Maribor).

Programme Committee:

Prof. Abdul Ghani Olabi (UK), Emeritus Prof. Jurij Krope (Slovenia), Prof. Henrik Lund (Denmark), Prof. Brian Norton (Ireland), Prof. Noam Lior (USA), Prof. Zdravko Kravanja (Slovenia), Prof. Jirí Jaromír Klemeš (Hungary), Prof. Stane Božičnik (Slovenia), Prof. Bojan Štumberger (Slovenia), Prof. Soteris Kalogirou (Cyprus), Prof. Stefano Cordiner (Italy), Prof. Jinyue Yan (Sweden), Prof. Umberto Desideri (Italy), Prof. M.S.J. Hashmi (Ireland), Prof. Michele Dassisti (Italy), Prof. Michele Gambino (Italy), Prof. S. Orhan Akansu (Turkey), Dr. David Timoney (Ireland), Prof. David Kennedy (Ireland), Prof. Bekir Sami Yilbas (Saudi Arabia), Dr. Brid Quilty (Ireland), Prof. B. AbuHijleh (UAE), Prof. Vincenc Butala (Slovenia), Prof. Jim McGovern (Ireland), Prof. Socrates Kaplanis (Greece), Dr. Hussam Jouhara (UK), Prof. Igor Tičar (Slovenia), Prof. Darko Goričanec (Slovenia), Dr. Joseph Stokes (Ireland), Prof. Antonio Valero (Spain), Prof. Aristide F. Massardo (Italy), Prof. Ashwani Gupta (USA), Dr. Aoife Foley (UK), Dr. Athanasios Megartis (UK), Prof. Francesco Di Maria (Italy), Prof. George Tsatsaronis (Germany), Prof. Luis M. Serra (Spain), Prof. Savvas Tassou (UK), Prof. Luigi Alloca (Italy), Prof. Faek Diko (Germany), Dr. F. Al-Mansour (Slovenia), Dr. Artur Grunwald (Germany), Dr. Peter Trop (Slovenia), Prof. Philippe Knauth (France), Prof. Paul Borza (Romania), Prof. Roy Douglas (UK), Prof. Dieter Meissner (Austria), Dr. Danijela Urbancl (Slovenia), Prof. Daniel Favrat (Switzerland), Prof. Erik Dahlquist (Sweden), Prof. Eric Leonhardt (USA), Prof. GianLuca Rospi (Italy), Prof. Giuseppe Casalino (Italy), Prof. J. Dawson (USA), Dr. Josè Simoes (Portugal), Prof. Kadir Aydin (Turkey), Dr. Khaled Benyounis (Ireland), Prof. Laszlo Garbai (Hungary), Prof. Mariano Martin (Spain), Prof. Masahiro Ishida (Japan), Prof. Michael Seal (USA), Prof. Marco Spinedi (Italy), Prof. Michio Kitano (Japan), Prof. Milovan Jotanović (BiH), Prof. Nafiz Kahraman (Turkey), Prof. Na Zhang (China), Prof. Naotake Fujita (Japan), Prof. Niko Samec (Slovenia), Prof. Oleksandr Zaporozhets (Ukraine), Prof. Osama Al-Hawaj (Kuwait), Prof. Petar Varbanov (Hungary), Prof. Peter Goethals (Belgium), Prof. Qi Zhang (China), Prof. Rik Baert (The Netherlands), Prof. Rolf Ritz (USA), Dr. Stephen Glover (UK), Prof. Signe Kjelstrup (Norway), Dr. Sumsun Naher (UK), Prof. Sven Andersson (Sweden), Dr. Salah Ibrahim (UK), Prof. Sebahattin Unalan (Turkey), Prof. Sabah Abdul-Wahab Sulaiman (Oman), Prof. Somrat Kerdsuwan (Thailand), Prof. T. Hikmet Karakoç (Turkey), Prof. Tahir Yavuz (Turkey), Prof. Hon Loong Lam (Thailand), LL.M. Tina Žagar (Slovenia), Prof. A.M.Hamoda (Qatar), Prof. Gu Hongchen (China), Prof. Haşmet Turkoglu (Turkey), Dr. Hussam Achour (Ireland), Dr. James Carton (Ireland), Dr. Eivind Johannes (Norway), Prof. Elvis Ahmetović (BiH), Prof. 
D.G.Simeonov (Bulgaria), Prof. Abdelakder Outzourhit (Morocco), Prof. Bilge Albayrak Çeper (Turkey), Prof. Bekir Zühtü Uysal (Turkey), Prof. D. Bradley (UK), Dr. Silvia Tedesco (UK), Dr. Valentin Ivanov (Germany), Dr. Vincent Lawlor (Austria), Prof. Yonghua Cheng (Belgium), Prof. Yasufumi Yoshimoto (Japan), Prof. Yahya Erkan Akansu (Turkey), Prof. Yunus Ali Çengel (Turkey), Prof. Zeljko Knez (Slovenia), Prof. Zoltan Magyar (Hungary), Dr. William Smith (Ireland), Dr. Abed Alaswad (UK).

First published in 2017 by

University of Maribor Press

Slomškov trg 15, 2000 Maribor, Slovenia

tel. +386225042 42, fax +38622523245

http://press.um.si, zalozba@um.si

\section{Co-published by}

University of Maribor, Faculty of Chemistry and Chemical Engineering

Smetanova ulica 17,2000 Maribor, Slovenia

tel. +386 (0)2 2294 400, faks + $386(0) 22527774$

http://www.fkkt.um.si, fkkt@um.si

Published: 5. July 2017

\section{(C) University of Maribor Press}

All rights reserved. No part of this book may be reprinted or reproduced or utilized in any form or by any electronic, mechanical, or other means, now known or hereafter invented, including photocopying and recording, or in any information storage or retrieval system, without permission in writing from the publisher.

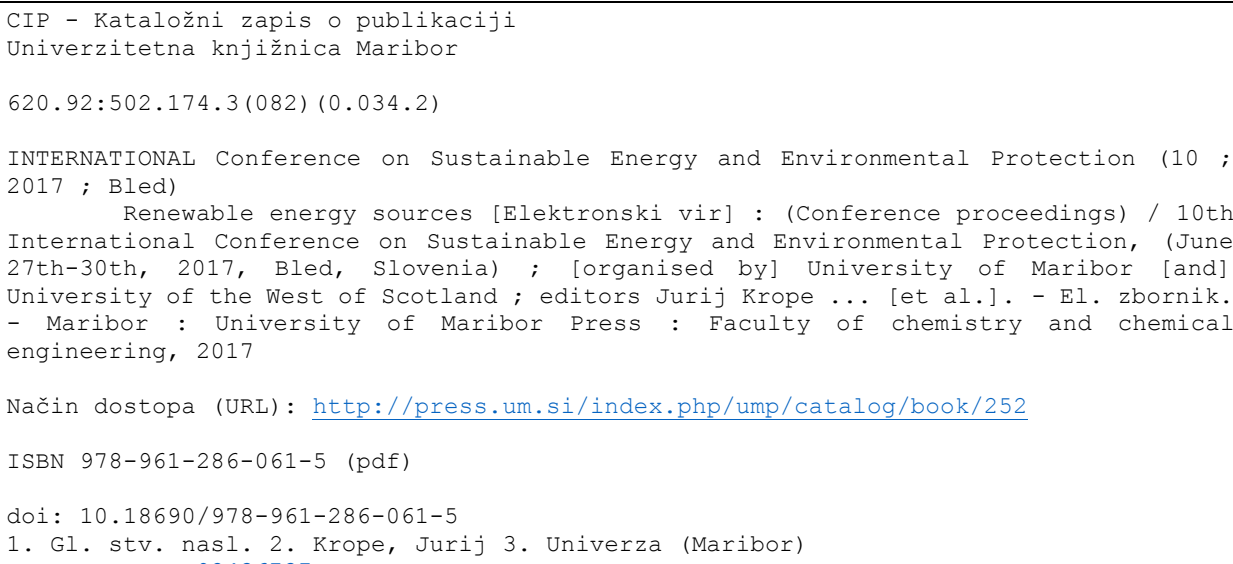

ISBN 978-961-286-061-5

DOI: https://doi.org/10.18690/978-961-286-061-5

Price: Free copy

For publisher: $\quad$ Prof. Igor Tičar, Ph.D., rector (University of Maribor) 
$10^{\mathrm{TH}}$ InTERNATIONAL CONFERENCE ON Sustainable ENERGy AND Environmental Protection (June 27 $7^{\mathrm{TH}}-30^{\mathrm{TH}}$, 2017, BLed, Slovenia), Renewable ENERgy Sources

J. Krope, A.Ghani Olabi, D. Goričanec \& S. Božičnik

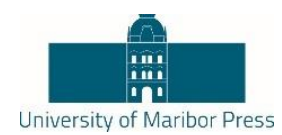

\section{Preface}

The $10^{\text {th }}$ International Conference on Sustainable Energy and environmental Protection SEEP 2017 was organised on June $27^{\text {th }}-30^{\text {th }} 2017$ in Bled, Slovenia, by:

- Faculty of Chemistry and Chemical Engineering, University of Maribor, Slovenia,

- University of the West of Scotland, School of Engineering and

The aim of SEEP2017 is to bring together the researches within the field of sustainable energy and environmental protection from all over the world.

The contributed papers are grouped in 18 sessions in order to provide access to readers out of 300 contributions prepared by authors from 52 countries.

We thank the distinguished plenary and keynote speakers and chairs who have kindly consented to participate at this conference. We are also grateful to all the authors for their papers and to all committee members.

We believe that scientific results and professional debates shall not only be an incentive for development, but also for making new friendships and possible future scientific development projects.

General chair

Emeritus Prof. dr. Jurij Krope
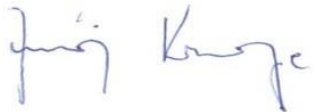
$10^{\mathrm{TH}}$ International CONFERENCE ON Sustainable ENERGY AND Environmental Protection (June 27 $7^{\mathrm{TH}}-30^{\mathrm{TH}}$, 2017, Bled, SLOVEnia), Renewable ENERGy Sources J. Krope, A.Ghani Olabi, D. Goričanec \& S. Božičnik

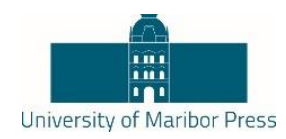

\title{
Plenary Talk on \\ The Relation between Renewable Energy and Circular Economy
}

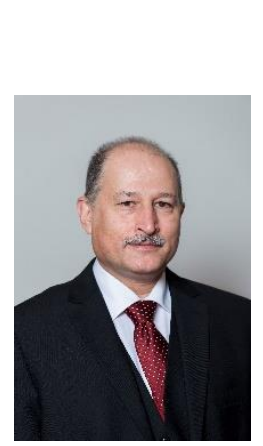

\author{
ABDUL GHANI OLABI - BIBLIOGRAPHY
}

Prof Olabi is director and founding member of the Institute of Engineering and Energy Technologies (www.uws.ac.uklieet) at the University of the West of Scotland. He received his M.Eng and Ph.D. from Dublin City University, since 1984 he worked at SSRC, HIAST, CNR, CRF, DCU and UWS. Prof Olabi has supervised postgraduate research students (10 M.Eng and 30PhD) to successful completion. Prof Olabi has edited 12 proceedings, and has published more than 135 papers in peer-reviewed international journals and about 135 papers in international conferences, in addition to 30 book chapters. In the last 12 months Prof Olabi has patented 2 innovative projects. Prof Olabi is the founder of the International Conference on Sustainable Energy and Environmental Protection SEEP, www.seepconference.co.uk

$\mathrm{He}$ is the Subject Editor of the Elsevier Energy Journal https://www.journals.elsevier.com/energy/editorial-board/abdul-ghani-olabi, also Subject editor of the Reference Module in Materials Science and Materials Engineering http://scitechconnect.elsevier.com/reference-module-material-science/ and board member of a few other journals. Prof Olabi has coordinated different National, EU and International Projects. He has produced different reports to the Irish Gov. regarding: Hydrogen and Fuel Cells and Solar Energy.

Correspondence AdDress: Abdul Ghani Olabi, Ph.D., Professor, University of the West of Scotland, School of Engineering and Computing, D163a, McLachlan Building, Paisley, United Kingdom, e-mail: Abdul.Olabi@uws.ac.uk.

https://doi.org/10.18690/978-961-286-061-5 ISBN 978-961-286-061-5

(C) 2017 University of Maribor Press

Available at: http://press.um.si. 
$10^{\mathrm{TH}}$ InTERNATIONAL CONFERENCE ON Sustainable ENERGy AND

Environmental Protection (June 27 $7^{\mathrm{TH}}-30^{\mathrm{TH}}$, 2017, Bled,

SLOVEnia), Renewable ENERgy Sources

J. Krope, A.Ghani Olabi, D. Goričanec \& S. Božičnik

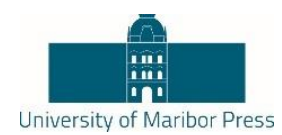

\title{
Plenary Talk on \\ Energy Footprints Reduction and Virtual Footprints Interactions
}

\author{
JIŘí JAROMÍR KLEMEŠ \& PETAR SABEV VARBANOV
}

Increasing efforts and resources have been devoted to research during environmental studies, including the assessment of various harmful impacts from industrial, civic, business, transportation and other economy activities. Environmental impacts are usually quantified through Life Cycle Assessment (LCA). In recent years, footprints have emerged as efficient and useful indicators to use within LCA. The footprint assessment techniques has provided a set of tools enabling the evaluation of Greenhouse Gas (GHG) - including $\mathrm{CO}_{2}$, emissions and the corresponding effective flows on the world scale. From all such indicators, the energy footprint represents the area of forest that would be required to absorb the GHG emissions resulting from the energy consumption required for a certain activity, excluding the proportion absorbed by the oceans, and the area occupied by hydroelectric dams and reservoirs for hydropower.

An overview of the virtual GHG flow trends in the international trade, associating the GHG and water footprints with the consumption of goods and services is performed. Several important indications have been obtained: (a) There are significant GHG gaps between producer's and consumer's emissions - US and EU have high absolute net imports GHG budget. (b) China is an exporting country and increasingly carries a load of GHG emission and virtual water export associated with consumption in the relevant importing countries. (c) International trade can reduce global environmental pressure by redirecting import to products produced with lower intensity of GHG emissions and lower water footprints, or producing them domestically.

To develop self-sufficient regions based on more efficient processes by combining neighbouring countries can be a promising development. A future direction should be focused on two main areas: (1) To provide the self-sufficient regions based on more efficient processes by combining production of surrounding countries. (2) To develop the shared mechanism and market share of virtual carbon between trading partners regionally and internationally.

CORRESPONDENCE ADDRESS: Jiří Jaromír Klemeš, DSc, Professor, Brno University of Technology - VUT Brno, Faculty of Mechanical Engineering, NETME Centre, Sustainable Process Integration Laboratory - SPIL, Technická 2896/2, 61669 Brno, Czech Republic, e-mail: klemes@fme.vutbr.cz. Petar Sabev Varbanov, Ph.D., Associate Professor, Brno University of Technology - VUT Brno, Faculty of Mechanical Engineering, NETME Centre, Sustainable Process Integration Laboratory - SPIL, Technická 2896/2, 61669 Brno, Czech Republic, e-mail: varbanov@fme.vutbr.cz. 
$10^{\mathrm{TH}}$ International CONFERENCE ON Sustainable ENERGY AND Environmental Protection (June 27 $7^{\mathrm{TH}}-30^{\mathrm{TH}}$, 2017, Bled, SLovenia), Renewable ENERgy Sources

J. Krope, A.Ghani Olabi, D. Goričanec \& S. Božičnik

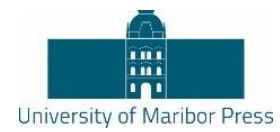

\section{JIŘÍ JAROMÍR KLEMEŠ - BIBLIOGRAPHY}

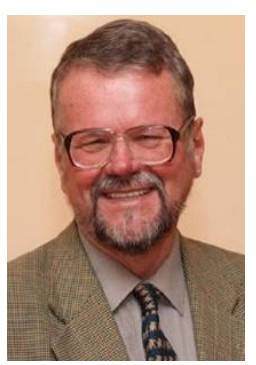

Head of "Sustainable Process Integration Laboratory - SPIL", NETME Centre, Faculty of Mechanical Engineering, Brno University of Technology - VUT Brno, Czech Republic and Emeritus Professor at "Centre for Process Systems Engineering and Sustainability", Pázmány Péter Catholic University, Budapest, Hungary.

Previously the Project Director, Senior Project Officer and Hon Reader at Department of Process Integration at UMIST, The University of Manchester and University of Edinburgh, UK. Founder and a long term Head of the Centre for Process Integration and Intensification - CPI2, University of Pannonia, Veszprém, Hungary. Awarded by the EC with Marie Curies Chair of Excellence (EXC). Track record of managing and coordinating 91 major EC, NATO and UK Know-How projects. Research funding attracted over $21 \mathrm{M€}$.

Co-Editor-in-Chief of Journal of Cleaner Production ( $\mathrm{IF}=4.959)$. The founder and President for 20 $\mathrm{y}$ of PRES (Process Integration for Energy Saving and Pollution Reduction) conferences. Chairperson of CAPE Working Party of EFCE, a member of WP on Process Intensification and of the EFCE Sustainability platform.

He authored nearly 400 papers, h-index 40. A number of books published by McGraw-Hill; Woodhead; Elsevier; Ashgate Publishing Cambridge; Springer; WILEY-VCH; Taylor \& Francis).

Several times Distinguished Visiting Professor for Universiti Teknologi Malaysia, Xi'an Jiaotong University; South China University of Technology, Guangzhou; Tianjin University in China; University of Maribor, Slovenia; University Technology Petronas, Malaysia; Brno University of Technology and the Russian Mendeleev University of Chemical Technology, Moscow. Doctor Honoris Causa of Kharkiv National University "Kharkiv Polytechnic Institute" in Ukraine, the University of Maribor in Slovenia, University POLITEHNICA Bucharest, Romania. "Honorary Doctor of Engineering Universiti Teknologi Malaysia", "Honorary Membership of Czech Society of Chemical Engineering", "European Federation of Chemical Engineering (EFCE) Life-Time Achievements Award" and "Pro Universitaire Pannonica" Gold Medal.

CORRESPONDENCE AdDRESS: Jiří Jaromír Klemeš, DSc, Professor, Brno University of Technology - VUT Brno, Faculty of Mechanical Engineering, NETME Centre, Sustainable Process Integration Laboratory - SPIL, Technická 2896/2, $616 \quad 69$ Brno, Czech Republic, e-mail: klemes@fme.vutbr.cz. 
$10^{\mathrm{TH}}$ InTERNATIONAL CONFERENCE ON Sustainable ENERGy AND Environmental Protection (June 27 $7^{\mathrm{TH}}-30^{\mathrm{TH}}$, 2017, BLed, SLOVEnia), Renewable ENERgy Sources

J. Krope, A.Ghani Olabi, D. Goričanec \& S. Božičnik

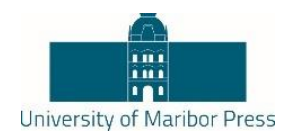

\title{
Plenary Talk on \\ Renewable energy sources for environmental protection
}

\author{
HAKAN SERHAD SOYHAN
}

Development in energy sector, technological advancements, production and consumption amounts in the countries and environmental awareness give shape to industry of energy. When the dependency is taken into account in terms of natural resources and energy, there are many risks for countries having no fossil energy sources. Renewable and clean sources of energy and optimal use of these resources minimize environmental impacts, produce minimum secondary wastes and are sustainable based on current and future economic and social societal needs. Sun is one of the main energy sources in recent years. Light and heat of sun are used in many ways to renewable energy. Other commonly used are biomass and wind energy. To be able to use these sources efficiently national energy and natural resources policies should be evaluated together with the global developments and they should be compatible with technological improvements. Strategic plans with regard to energy are needed more intensively and they must be in the qualification of a road map, taking into account the developments related to natural resources and energy, its specific needs and defining the sources owned by countries. In this presentation, the role of supply security was evaluated in term of energy policies. In this talk, new technologies in renewable energy production will be shown and the importance of supply security in strategic energy plan will be explained.

Correspondence Address: Hakan Serhad Soyhan, Ph.D., Professor, Sakarya University, Engineering Faculty, Esentepe Campus, M7 Building, 54187 - Esentepe /Sakarya, Turkey, e-mail: hsoyhan@sakarya.edu.tr. 
$10^{\mathrm{TH}}$ InTERNATIONAL CONFERENCE ON Sustainable ENERGY AND Environmental Protection (June 27 $7^{\mathrm{TH}}-30^{\mathrm{TH}}$, 2017, Bled, SLovenia), Renewable ENERgy Sources

J. Krope, A.Ghani Olabi, D. Goričanec \& S. Božičnik

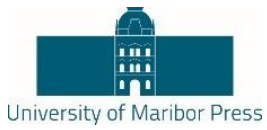

\section{HAKAN SERHAD SOYHAN - BIBLIOGRAPHY}

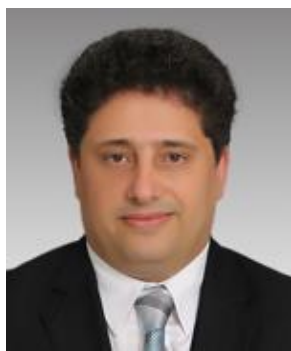

Professor at Sakarya University, Engineering Faculty. $50 \%$ fot teaching and the rest for reasearch activities.

Teaching, courses taught:

Graduate courses:

- Combustion technology;

- Modelling techniques;

Undergraduate courses:

- Combustion techniques;

- Internal combustion engines;

- $\quad$ Fire safety.

Tehnical skills and competences professional societies:

- 25 jurnal papers in SCI Index. 23 conference papers;

- $\quad$ Editor at FCE journal. Co-editor at J of Sakarya University;

- Head of Local Energy Research Society (YETA);

- Member od American Society of Mechanical engineers (ASME);

- Member of Turkish Society of Mechanical Engineers (TSME).

Correspondence AdDress: Hakan Serhad Soyhan, Ph.D., Professor, Sakarya University, Engineering Faculty, Esentepe Campus, M7 Building, 54187 - Esentepe /Sakarya, Turkey, e-mail: hsoyhan@sakarya.edu.tr. 

$10^{\mathrm{TH}}$ InTERnAtional CONFERENCE ON Sustainable ENERgy AND Environmental Protection (June $27^{\mathrm{TH}}-30^{\mathrm{TH}}$, 2017, Bled, SLOVENIA), RENEWABLE ENERGy SOURCES

J. Krope, A.Ghani Olabi, D. Goričanec \& S. Božičnik

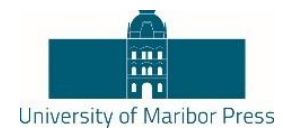

\section{Table of Contents}

\section{CONFERENCE PROCEEDINGS}

Development of an Efficient Heat Balance Concept for a TSA -

Process Considering Heat-Pump Integration

Hannes Vogtenhuber, René Hofmann, Gerhard Schöny, Julius Pirklbauer, Michaela Fraubaum, Franz Helminger, Andreas Werner \& Hermann Hofbauer

Effect of Addition of Biogas Slurry for Anaerobic Fermentation of Deer Manure on Biogas Production

Hanxi Wang, Jianling Xu, Lianxi Sheng \& Xuejun Liu

Thermal Energy Recovery from Drinking Water

Jan Peter van der Hoek, Stefan Mol, Jawairia Imtiaz Ahmad, Gang Liu $\&$ Gertjan Medema

Modeling and Performance Analysis of a Hybrid System for a Residential Application

Levent. Bilir \& Nnurdan Yildirim

Smart Solar Battery Charger for PV-Application

Khadija El Kamouny, Hassane Mahmoudi \& Brahim Lakssir

Substitution of Agro-Energetic Biomass with Bio-Waste for an Existing Anaerobic Digestion Plant: An Energetic and Environmental Analysis

Francesco Di Maria, Federico Sisani \& Marzio Lasagni

Feasibility Study of Integrating Renewables and Hydrogen Technologies Into Isolated Power Supply System of Mountain Hut

Boštjan Drobnič, Rok Stropnik, Boštjan Jurjevčič \& Mitja Mori

Microwave Co-Pyrolysis of Waste Cooking Oil and 81 Polystyrene-Based Plastic Waste

Wan Adibah Wan Mahari, Nurfarain Nasuha Ab Razak, Chin Kui Cheng \& Su Shiung Lam 
Unexploited Potential in the Field of Small Hydropower Production Units in Protected Areas

Klemen Deželak \& Jože Pihler

Review of Pem Fuel Cell Materials

101

Emmanuel Ogungbemi, Oluwatosin Ijaodola, Awortwe Wilberforce, Ahmed Al Makky \& Abdul Olabi

Ru-Containing Polymeric Catalyst for the Process of Cellulose Conversion

Oleg V. Manaenkov, Anastasia E. Filatova, Olga V. Kislitza, Yury.V. Lugovoy, Esther M. Sulman, Valentina G. Matveeva, Valentin Yu. Doluda \& Alexander I. Sidorov

Electrical Energy Production Simulation in SHP of Ultra123 Low Head Considering Environment Protection Conditions and Technical Limitations

Henrik Lavrič, Andraž Rihar \& Rastko Fišer

Possibilities for Micro Biogas Plants in Slovenian Agriculture Fouad Al-Mansour, Viktor Jejcic \& Igor Škrjanec

Short-Term Probabilistic Forecasting of Wind Energy Resources Using the Enhanced Ensemble Method

Deockho Kim \& Jin Hur

Numerical and Experimental Study of Laminar Burning Velocity of Syngas/Methane Mixtures Using Syngas Obtained from Biomass and Coal Gasification

Andrés A. Amell, Carlos E. Arrieta, Fabián E. Cano Ardila, Arley Cardona Vargas \& Hernando A. Yepes

Determination of the Concentration Ratio of a Parabolic Solar Concentrator Using Thermographic Image Processing Fabián E. Cano Ardila \& Sergio C. Agudelo Florez

Environmental Assessment of the Integration of Active Solar Energy Systems on Building Envelopes in Southern Europe Constantinos Vassiliades, Aimilios Michael, Andreas Savvides \& Soteris Kalogirou

Spatial Sustainability Assessment of Wind Energy Expansion Scenarios Marcus Eichhorn, Raik Becker, Frank Masurowski \& Daniela Thrän 
Comparison of the Shading Influence on PV Modules of 203 Different Technologies

Goran Knežević, Danijel Topić, Matej Žnidarec, Bojan Štumberger, Miralem Hadžiselimović \& Sebastijan Seme

Enhanced Biohydrogen Production and CO2 Sink by Powered 215 $\mathrm{Fe}^{\circ}$ Addition in Dark Fermentation Carlos E. Gómez Camacho, Francesco I. Romano \& Bernardo Ruggeri

CO2 Capture from Syngas Generated by a Biomass 227 Gasification Power Plant with Chemical Absorption Process Cristian Dinca, Nela Slavu \& Adrian Badea

Impact of a Big Power Plant Into the Network

Houria Smail \& Rezak Alkama

Small Kinetic Water Turbines Review, Possible Locations and Economoc Efficiency in Slovenia

Andrej Predin \& Gorazd Hren

Forecasting Tool for Assessing Environmental, Technical and 263 Economic Parameters Associated with Power Generation Alternatives

Andrés F. León Esteban, Ana M. Rosso Cerón, Viatcheslav Kafarov \& John F. Montañez

Photovoltaic Systems in Slovenia and Performance Ratios: A Review

Sebastijan Seme, Klemen Sredenšek, Bojan Štumberger \& Miralem Hadžiselimović

Reduction of PM Emissions by Highly Oxygenated Viscous Biofuel: Use of Glycerol in a Micro Gas Turbine

Tine Seljak \& Tomaž Katrašnik

Prediction of the Daily Direct Solar Radiation Using 303 Nonlinear Autoregressive Exogenous (Narx) Network Model Zina Boussaada, Ahmed Remaci, Octavian Curea, Haritza Camblong \& Najiba Mrabet Bellaaj 
Angular Speed Control of an Induction Motor Via a Solar Powered Boost Converter-Voltage Source Inverter Combination

Jesús Linares-Flores, Rodrigo Lescas-Hernández, José F. GuerreroCastellanos, Gerardo Mino-Aguilar, Hebertt Sira-Ramírez, Arturo Hernández-Méndez \& Marco Antonio Contreras Ordaz

Comparative Analysis of Electricity Production from Different Technologies of PV Modules

Jurica Perko, Matej Žnidarec \& Danijel Topić

Sustainable Energy Policies for Clean Environment in Turkey Ibrahim Yuksel, Hasan Arman \& Ibrahim Halil Demirel

Study and Simulation of the Energy Performances of a Grid Connected PV System Supplying a Residential House in North of Algeria

Ismail Laib, Abderrahman Hamidat, Mourad Haddadi, Naeem Ramzan \& Abdul G. Olabi

The Sustainability of Thermal Power Plant Unit Revitalization: Comparison of Two Multi-Criteria Methods Biljana Vučićević, Valentina Turanjanin, Marina Jovanović, Predrag Škobalj \& Vukman Bakić

A Case Study of Solar Energy Application in Enhanced Oil Recovery

Hamed A. Hamed, Ahmed A. Abdel-Rehim, Attia M. Attia \& Ahmed A. A. Attia

Performance Analysis of Solar Air Collector in North East Region of India

Suman Debnath, Abhilekh Sonowal, Biplab Das, Pitambar Randive \& K.M. Pandey

Green Diesel Synthesis by Catalytic Hydrogenation of Waste Cooking Oil: Catalyst Design and Effect of Solvent

Zhixia Li, Zhentao Huang \& Chengtong Wang

Structural Analysis of Hybrid Jute-Glass Fibre Composite Solar PTC Under Various Wind Conditions

K.S. Reddy \& Hitesh Singla

On the Stability of Natural Gas and Low Calorific Value Fuels in a Surface-Stabilized Combustion Burner

Carlos E. Arrieta, Alex M. García, Iván D. Bedoya \& Andrés A. Amell 
Challenges in the Practical Implementation of Concentrating

Solar Thermal Power Projects

Yosef Elia, Dorin Lucache, Marcel Istrate \& Valentin Nita

Spatio-Temporal Assessment of Integrating Intermittent Electricity in the EU Power Sector

Sennai Mesfun, Sylvain Leduc, Piera Patrizio, Ping Yowargana \& Florian Kraxner

Production of Biogas from Effluent of Pigs. Case Study

Eugênia Leandro Almeida, Cid Marcos Gonçalves Andrade \& José Ozinaldo Alves de Sena

A Review on Solar Dryer - Economic and Environmental Investigation for the Lebanese Case

Amal Herez, Mahmoud Khaled, Hasan Bazi \& Mohamad Ramadan

Geospatial Characteristics Investigation of Suitable Area for

Photovoltaic Water Pumping Erections, in the Southern Area of Ghardaia, Algeria

Azzedine Boutelhig \& Aicha Melit

PV Power Prediction to Provide Energy Demand by Load Forecasting

Samir H.Oudjana, Idriss H. Mahammed \& Khennane M. Benbitour

Comparison Study to Select an Optimum Photovoltaic PV Module Model Under Experimental Performances

Idriss Hadj Mahammed, Amar Hadj Arab, Smail Berrah, Yahia Bakelli, Messaouda Khennane Benbitour, Samir Hamid Oudjana, Amor Fezzani \& Laybachi Zaghba

Technical and Economical Part of Investments in Solar Power Plants and Small Hydro Power Plants - Comparison Between Technologies

Sebastijan Seme, Klemen Sredenšek, Bojan Štumberger \& Miralem Hadžiselimović.

An Innovative Low Enthalpy Geothermal System: Ground Source Heat Pump and Underground Tank for Heating and Cooling of Buildings

Gianluca Rospi, Nicola Cardinale, Francesca Intini \& Elisabetta Negro 
vi $\mid 10^{\mathrm{TH}}$ International CONFEREnCE on Sustainable Energy and ENVIRonmental Protection (June $27^{\mathrm{TH}}-30^{\mathrm{TH}}, 2017$, Bled, Slovenia), Renewable EnERGy SOurces Table of Contents 
$10^{\mathrm{TH}}$ InTERnATIONAL CONFERENCE ON Sustainable ENERgy AND ENVIRONMENTAL Protection (June $27^{\mathrm{TH}}-30^{\mathrm{TH}}$, 2017, Bled, SLOVENIA), RENEWABLE ENERGy SOURCES

J. Krope, A.Ghani Olabi, D. Goričanec \& S. Božičnik

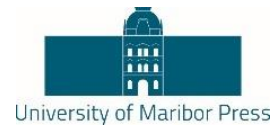

\title{
Development of an Efficient Heat Balance Concept for a TSA-Process Considering Heat-Pump Integration
}

\author{
HANnes VogtenHuber, RENÉ HOFMANn, GERHARd SCHÖNY, JULIUS PIRKLBAUER, \\ Michaela Fraubaum, Franz Helminger, ANDREAS WERnER \& HERMANN \\ HOFBAUER
}

\begin{abstract}
A multi-stage fluidized bed system for temperature swing adsorption (TSA) $\mathrm{CO} 2$ capture with solid amine sorbents, has been modelled and simulated for application in the field of biogas upgrading. For this purpose, a mass- and energy balance equilibrium model has been developed in the process simulation software IPSEpro ${ }^{\mathrm{TM}}$. A fluidized bed model is introduced that can calculate equilibrium adsorption loadings and the corresponding heating or cooling requirements within the individual fluidized bed stages of the adsorber and desorber column. The adsorption equilibrium calculations have been performed, using a Langmuir model that was fitted to $\mathrm{CO} 2$ adsorption data of an amine functionalized solid sorbent material. Within this work, the qualitative impact of the regeneration temperature and the stripping gas feeding rate on the overall process performance has been studied. Furthermore, the feasibility for integration of a high temperature process heat pump to recover heat from the adsorber to drive adsorbent regeneration within the desorber, has been assessed. Results obtained from this work clearly indicate a great potential of the multi-stage fluidized bed TSA process for application in the field of biogas upgrading, especially in combination with the proposed heat pump set-up.
\end{abstract}

Keywords: • TSA • biogas upgrading $\bullet$ heat balance $\bullet$ optimal heat pump integration • heat exchanger $\bullet$

CORRESPONDENCE AdDRESS: Hannes Vogtenhuber, MSc, TU Wien, Institute for Energy Systems and Thermodynamics, Getreidemarkt 9/302, 1060 Vienna, Austria, email: hannes.vogtenhuber@tuwien.ac.at. René Hofmann, Prof. TU Wien, Institute for Energy Systems and Thermodynamics, Getreidemarkt 9/302; 1060 Vienna, Austria, email: rene.hofmann@tuwien.ac.at. Gerhard Schöny, PhD, TU Wien, Institute of Chemical Engineering, Getreidemarkt 9/166, 1060 Vienna, Austria, email: gerhard.schoeny@tuwien.ac.at. Julius Pirkelbauer, MSc, TU Wien, Institute of Chemical Engineering, Getreidemarkt 9/166; 1060 Vienna, Austria, email: julius.pirkelbauer@tuwien.ac.at. Michaela Fraubaum, PhD, AIT, Center for Energy, Giefinggasse 2, 1210 Vienna, Austria, email: michaela.fraubaum@ait.ac.at. Franz Helminger, DI(FH), AIT, Center for Energy, Giefinggasse 2; 1210 Vienna, Austria, email: franz.helminger@ait.ac.at. Andreas Werner, Associate Prof., TU Wien, Institute for Energy Systems and Thermodynamics, Getreidemarkt 9/302, 1060 Vienna, Austria; email: andreas.werner@tuwien.ac.at. Hermann Hofbauer, Prof., TU Wien, Institute of Chemical Engineering, Getreidemarkt 9/166, 1060 Vienna, Austria, email: hermann.hofbauer@ tuwien.ac.at.

https://doi.org/10.18690/978-961-286-061-5.1

ISBN 978-961-286-061-5

(C) 2017 University of Maribor Press

Available at: http://press.um.si. 
$10^{\text {TH }}$ InTERnAtional CONFERENCE ON Sustainable ENERgy AND ENVIRONMENTAL Protection (June $27^{\mathrm{TH}}-30^{\mathrm{TH}}, 2017$, Bled, SLOVENIA), RENEWABLE ENERGY SOURCES H. Vogtenhuber, R. Hofmann, G. Schöny, J. Pirklbauer, M. Fraubaum, F. Helminger, A. Werner \& H. Hofbauer: Development of an Efficient Heat Balance Concept for a TSA-Process Considering Heat-Pump Integration

Today, biogas is primarily used for heat and power production. However, a growing economic pressure in the power sector as well as seasonal lows in district heat demands, set the need to find alternative applications for biogas. One promising option is to upgrade biogas to bio-methane and to feed it into existing natural gas grids. Here, the separation of $\mathrm{CO}_{2}$ from biogas usually represents the step that has the greatest impact on the overall bio-methane production costs $[1,2]$. In the past, several technologies have been applied to capture $\mathrm{CO}_{2}$ from biogas, whereas none of them showed to be superior in terms of separation costs $[1,2]$. Nevertheless, among the available technologies today, amine scrubbing shows several advantages such as an outstanding methane recovery rate and the fact that the biogas is treated at low pressure. The main technological drawback, however, is that the regeneration of the aqueous amine solvents requires significant amounts of heat at a relatively high temperature.

More recently, adsorption based processes have been proposed for post-combustion $\mathrm{CO}_{2}$ capture applications [3-5] as energy efficient alternative to amine scrubbing systems. Continuously operated, temperature swing adsorption (TSA) systems, such as the one recently proposed by authors of this work [6], seem to have a high potential to lower the energy demand and the associated costs for $\mathrm{CO}_{2}$ capture. Furthermore, since amine functionalized $\mathrm{CO}_{2}$ adsorbents can be utilized in such processes, TSA systems should also allow for selective separation of $\mathrm{CO}_{2}$. While continuous TSA systems have already been proposed for $\mathrm{CO}_{2}$ capture from stack flue gas, only little effort has been taken to assess the feasibility for biogas upgrading applications.

Hence, this work presents a basic assessment of the feasibility of a multi-stage fluidized bed TSA system for biogas upgrading. For this, a mass- and energy balance based adsorption equilibrium model is introduced and used to assess the impact of the main operating parameters on the overall process energy demand. Furthermore, the application of a high temperature process heat pump for heat recovery from the exothermic adsorption step and utilization of this heat for the endothermic $\mathrm{CO}_{2}$ desorption (i.e. adsorbent regeneration) is also studied in this work.

\section{$2 \quad$ Model}

The introduced model for simulation of biogas upgrading via $\mathrm{CO}_{2}$ capture in a multistage fluidized bed TSA system is based on the model, that has been previously introduced by Pröll et al., (2016) [4]. The TSA reactor basic scheme is given in Figure 1. Inside the thermodynamic process border (red rectangle), there are two interconnected five stage fluidized bed columns. Both columns facilitate counter current contact of the solid sorbent material and the respective gas streams that are used as fluidization agents. In the adsorber column the pre-treated biogas stream is introduced at the bottom, whereas the regenerated (lean) solid sorbent material is introduced at the top. In the desorber 
column, the $\mathrm{CO} 2$ loaded (rich) adsorbent is fed at the top while a stripping gas (air or steam) is introduced at the bottom.

\section{bio-methane \\ $\left(\mathrm{CH}_{4}, \mathrm{CO}_{2}\right.$ under $2 \%$ vol) stripping gas $+\mathrm{CO}_{2}$}

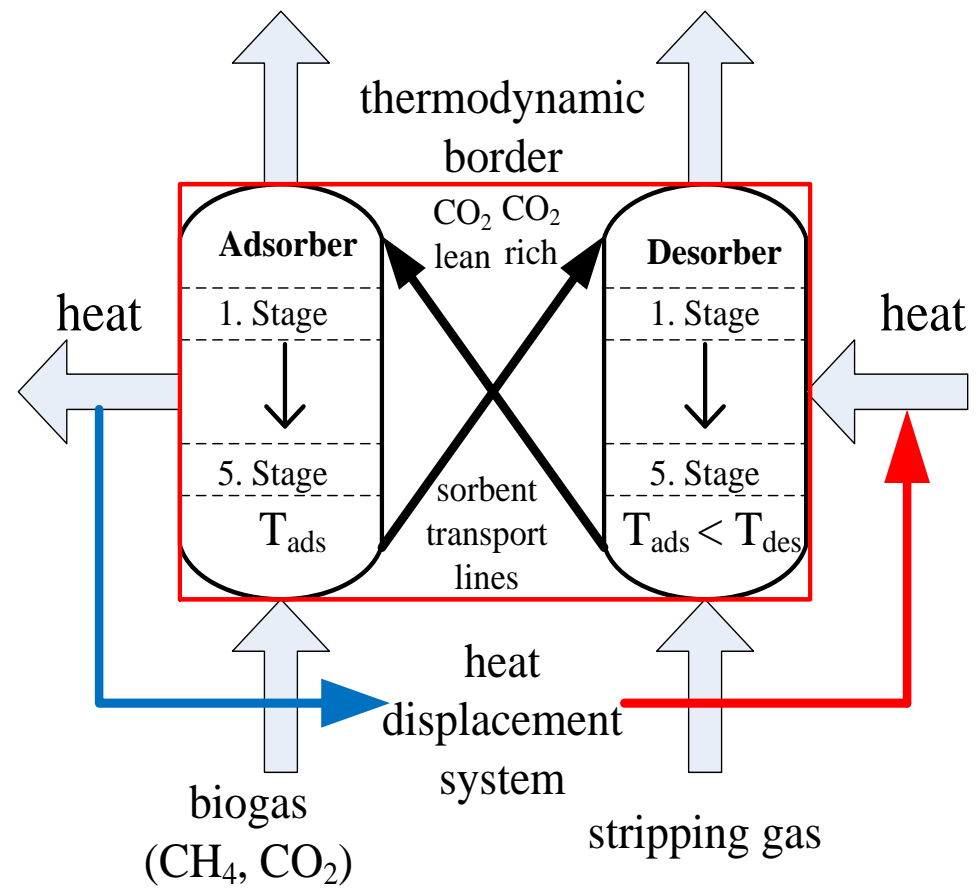

Figure 1. Basic scheme of the TSA

process

Every stage comprises immersed heat exchangers that provide the required cooling demand in the adsorber and the heating demand in the desorber, respectively.

The boundary conditions of all in-going and out-going mass- and energy streams of the TSA system that have been used for process evaluation are shown in Figure 1. The model has been developed within the process simulation software IPSEpro ${ }^{\mathrm{TM}}$ and is shown in Figure 3 .

In the present work, the adsorption thermodynamics of the adsorption material will be consistently described in the relevant temperature range through a Langmuir model. The adsorption data used in this work is taken from an amine functionalized sorbent material 
$10^{\mathrm{TH}}$ InTERnAtional CONFERENCE ON Sustainable EnERgy AND ENVIRONMENTAL Protection (June $27^{\mathrm{TH}}-30^{\mathrm{TH}}, 2017$, Bled, SLovenia), RenEwable ENERGy SOURCES H. Vogtenhuber, R. Hofmann, G. Schöny, J. Pirklbauer, M. Fraubaum, F. Helminger, A. Werner \& H. Hofbauer: Development of an Efficient Heat Balance Concept for a TSA-Process Considering Heat-Pump Integration

(PEI-based sorbent) that has been developed by Fauth et al. (2012) [7]. The corresponding adsorption isotherms are shown in Figure 2. Due to the properties of this adsorbent material (i.e. reported thermal stability) the operating temperature range of the simulated TSA process has been selected between $45^{\circ} \mathrm{C}$ (adsorber) and $100^{\circ} \mathrm{C}$ (desorber).

The unit model of a fluidized bed gas-solid contacting stage has been adopted from Pröll et al. (2016) [4]. The unit model assumes ideal adsorbent material mixing inside each stage and that $\mathrm{CO}_{2}$ adsorption equilibrium conditions are achieved.

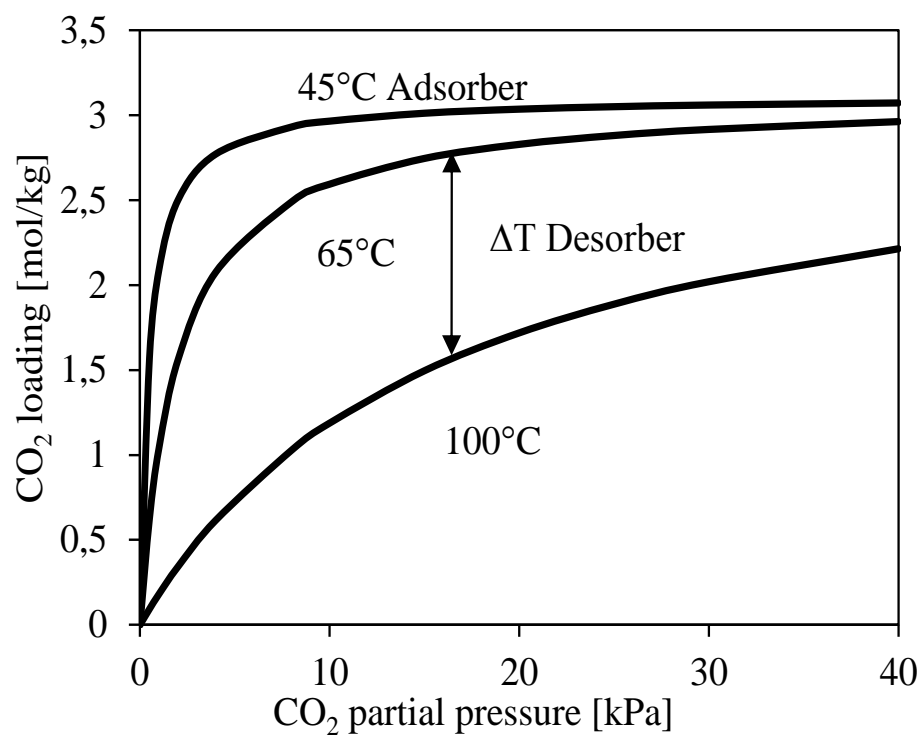

Figure 2. Fauth et al. (2012) research on $\mathrm{CO}_{2}$ sorption isotherms for PEI at diff. temp. and $\mathrm{CO}_{2}$ partial pressures fitted to Langmuir isotherm

Further, a heat displacement system will be introduced in the process. Applying a heat pump (HP) heat from the adsorption column is utilized to heat the stripping column. To evaluate the efficiency of the HP as well as of the overall system a concise heat pump model is implemented. The coefficient of performance $\left(\mathrm{COP}_{h}\right)$ of the HP is calculated according to Eq. (1) using the user-specified Carnot efficiency factor $f_{0}$, which is the ratio of the $\mathrm{COP}_{\mathrm{h}}$ of the HP to the idealized maximum COP of the Carnot cycle (COP $\left.\mathrm{Carnot}\right)$.

$$
C O P_{h}=\frac{\dot{Q}_{\text {heat }}}{P_{e l}}=C O_{\text {Carnot }} f_{0}
$$

The Carnot efficiency factor $f_{0}$ includes potential energy losses of a real heat pump e.g. attributed to component efficiency and refrigerant. 
The heat to be conducted between fluidized bed and stage heat exchanger is based on Fourier's law and can be written as

$$
\dot{Q}=k \cdot A_{h e x} \cdot \Delta T_{m}
$$

where $\mathrm{k}$ is the global overall heat transfer coefficient and will be assumed with $300 \mathrm{~W} / \mathrm{m}^{2} \mathrm{~K}$. This value depends on average heat transfer in fluidized bed. The conducted energy $\dot{Q}$ from Eq. 2 can also be written as

$$
\dot{Q}=\dot{m}_{f l} \cdot c_{p, f l}\left(T_{f l, \text { in }}-T_{f l, o u t}\right)
$$

\section{$3 \quad$ Simulation}

In order to assess the feasibility of the introduced TSA concept for biogas upgrading, the boundary conditions for $\mathrm{CO}_{2}$ separation have been defined as provided in Table 1 . The defined biogas $\mathrm{CO}_{2}$ concentration lies in the range of typical gases produced by breakdown of organic matter in absence of oxygen. The simulated TSA-process works with assumed $100 \mathrm{~kg} / \mathrm{h}$ biogas to treat for simple correlation of performance parameters such as energy requirements to the amount of bio-methane with defined $96 \% \mathrm{CO}_{2}$ capture rate.

Table 1. Definition of the streams

\begin{tabular}{cccl}
\hline biogas & $30,0 \%_{\mathrm{vol}} \mathrm{CO}_{2}$ & $45^{\circ} \mathrm{C}$ & $100 \mathrm{~kg} / \mathrm{h}$ \\
\hline bio-methane & $2,0 \%$ vol $\mathrm{CO}_{2}$ & $45^{\circ} \mathrm{C}$ & $48,5 \mathrm{~kg} / \mathrm{h}$ \\
\hline stripping-gas & air & var. & var. \\
\hline desorb. off-gas & air $+\mathrm{CO}_{2}$ & var. & var. \\
\hline
\end{tabular}

The pressure drop of each column has a limited value with 200mbar which is considered as the allowed maximum pressure drop for biogas upgrading. Within the simulation a value of $40 \mathrm{mbar}$ was assumed along each stage.

In Figure 3, the process flow scheme of the multi-stage TSA configuration is presented. Five unit models of contacting stages are combined and connected to represent each gassolid contactor column. Gas and solid streams flow counter-currently through the stages in each column. Heat exchange within each stage will be assumed to keep the temperature stable at a certain level.

In this simulation, according to Eq. 3, mass flow $\dot{m}_{f l}$ and inlet temperature $T_{f l, i n}$ are assumed in order to calculate the reflux temperature $T_{f l, o u t}$.

The HP extracts the required energy for evaporation from the heat transfer fluid of the 
$10^{\text {TH }}$ InTERnational CONFERENCE ON Sustainable ENERGy AND ENVIRONMENTAL Protection (June $27^{\mathrm{TH}}-30^{\mathrm{TH}}$, 2017, Bled, SLovenia), Renewable ENERGy SOURCES H. Vogtenhuber, R. Hofmann, G. Schöny, J. Pirklbauer, M. Fraubaum, F. Helminger, A. Werner \& H. Hofbauer: Development of an Efficient Heat Balance Concept for a TSA-Process Considering Heat-Pump Integration

adsorber. The heating and cooling demands are not equal in the TSA system. The cooling demand is higher than the extracted heat at the evaporator of the heat pump. Therefore, an additional heat sink $q_{\text {extra,cooling }}$ is needed to close the cooling circuit. For first approximation the immersed heat exchangers of adsorber/desorber with the heat pump model are serialized and shown in Figure 3

\section{$4 \quad$ Basic Assessment}

The desorber temperature and the stripping gas flow are varied to analyze the overall energy demand of the TSA system.

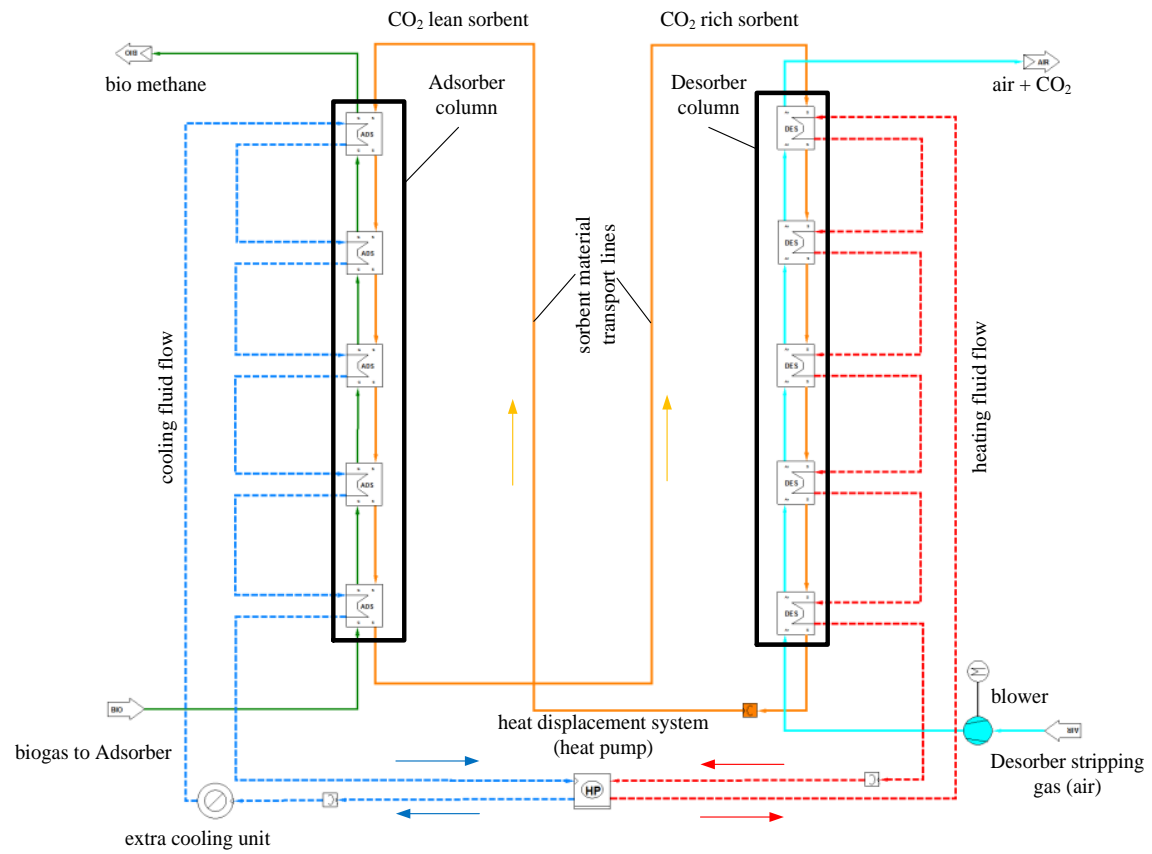

Figure 3. IPSEpro ${ }^{\text {TM }}$ biogas TSA model with five stages in the adsorber/desorber featuring a heat displacement system

One of the main process variables for the $\mathrm{CO}_{2}$ capture target is the solid sorbent circulation rate. It depends on the stripping gas flow which will be ranging from 80 to $150 \mathrm{~kg} / \mathrm{h}$. The variation of the desorber temperature is assumed with values ranging from 65 to $100^{\circ} \mathrm{C}$. The outcomes are different energy demands and of course different overall heat exchanger areas, respectively. This assumed variations and particular the temperature gap between adsorber and desorber are affecting the coefficient of the heat pump. 
Due to the described conditions the heating or cooling demand and an overall specific energy demand $\left(\Sigma q_{\text {des }}\right.$ and $\left.\Sigma q_{a d s}\right)$ per contactor column is assessed. Therefore a specific energy consumption is calculated and compared. Furthermore, to ensure the stripping gas flow, a blower is applied and the specific electrical energy demand $w_{\text {el,blower }}$ must be added to the overall process energy demand. To combine both energy demands (thermal and electrical), the factor $f_{t h}$ is multiplied to the electrical energy consumption. The factor is assumed with the value 2 in terms of electricity generation efficiency. In conclusion, Eq. 4 sums up the heat demand and necessary applied electrical power. Electrical consumption of pumps are not considered in this assessment.

Thus the overall process energy demand $q_{t o t}$ is approximated according to Eq. 4 .

$$
q_{\text {tot }}=\Sigma q_{\text {des }}+f_{\text {th }} \cdot w_{\text {el, blower }}
$$

For the case of the integration of the heat pump as the heat source for the needed desorber heat following Eq. 5. is introduced.

$$
q_{t o t, H P}=f_{t h}\left(w_{e l, b l o w e r} \cdot w_{e l, H P}\right)
$$

In chemisorption it is not usual to illustrate cooling power due to available cooling water. But to obtain the total energy demand and of course the overall heat balance it is very important to present the cooling demand. Therefor the cooling demand is given in following Eq. 6:

$$
q_{\text {cooling }}=\Sigma q_{a d s}
$$

\section{$5 \quad$ Results and Discussion}

The solid sorbent circulation rates at different stripping gas flow rates are shown for a variation of the desorber temperature in Figure 4. 
$10^{\text {TH }}$ International Conference on Sustainable Energy and Environmental Protection (June $27^{\mathrm{TH}}-30^{\mathrm{TH}}, 2017$, Bled, SLOVEnia), Renewable ENERGy SOURCES H. Vogtenhuber, R. Hofmann, G. Schöny, J. Pirklbauer, M. Fraubaum, F. Helminger, A. Werner \& H. Hofbauer: Development of an Efficient Heat Balance Concept for a TSA-Process Considering Heat-Pump Integration

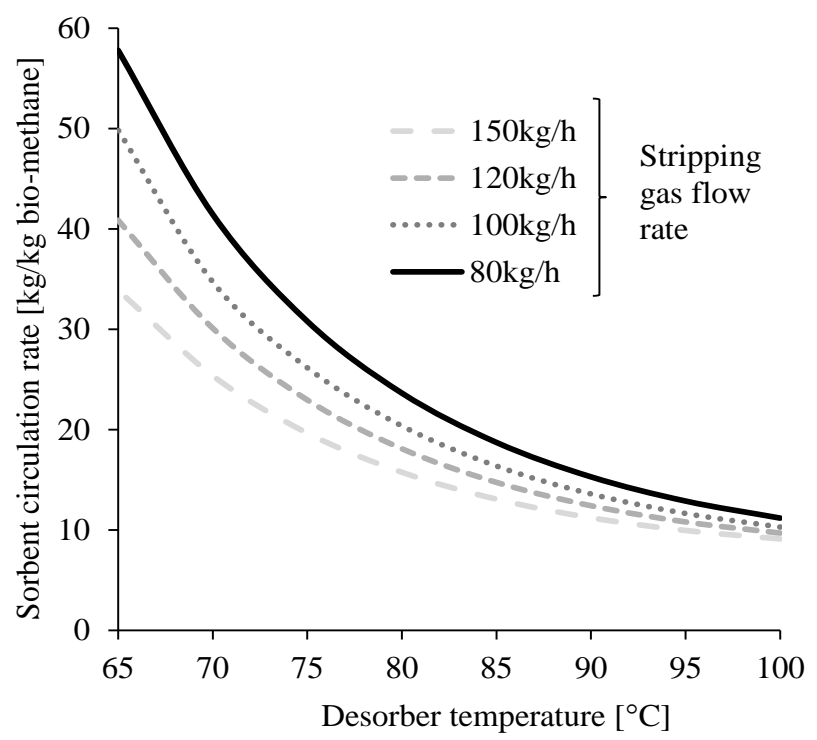

Figure 4. Different stripping gas flows in order to sorbent circulation rate during variation of the desorber temperature

The minimum stripping gas flow for this configuration is $80 \mathrm{~kg} / \mathrm{h}$ and goes up to $150 \mathrm{~kg} / \mathrm{h}$. Decreasing the desorber temperature, the sorbent circulation rate increases due to increasing lean sorbent loading. A significant gain can be observed at $80^{\circ} \mathrm{C}$ down to $65^{\circ} \mathrm{C}$. At desorber operating temperatures around $100^{\circ} \mathrm{C}$, the required solid sorbent circulation rates are in the range of $10 \mathrm{~kg}$ per $\mathrm{kg}$ bio-methane regardless of the amount of stripping gas used. On the other hand, at $65^{\circ} \mathrm{C}$, the impact of the stripping gas flow rate on the required sorbent circulation rate seems to be significant ( 34 to $58 \mathrm{~kg} / \mathrm{kg}$ bio-methane).

For further basic investigations the energy demand in the five stage configuration compared for one assumed stripping gas flow case $(120 \mathrm{~kg} / \mathrm{h})$ is analyzed. The following graph illustrates the heating demand to run the process and the effect of the high temperature heat pump. 
H. Vogtenhuber, R. Hofmann, G. Schöny, J. Pirklbauer, M. Fraubaum, F. Helminger,

A. Werner \& H. Hofbauer: Development of an Efficient Heat Balance Concept for a

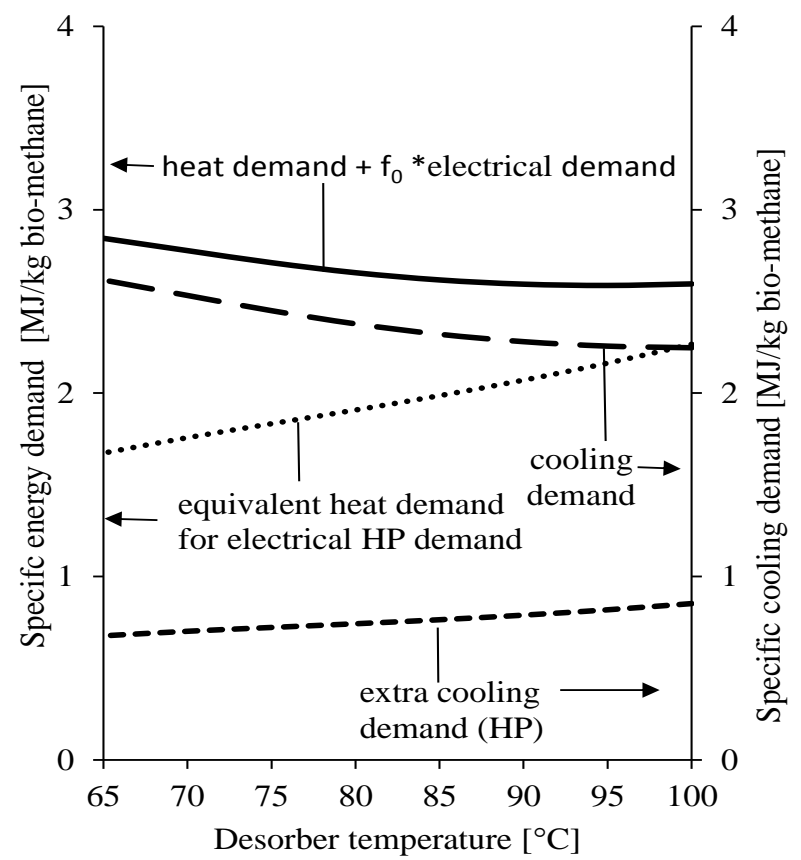

Figure 5. Energy demand for the five stage TSA process with/without high temperature heat pump

In Figure 5 the heating demand with the weighted electrical demand represents the total energy demand to maintain the process according to Eq. 4. Comparing Figure 4 and Figure 5, it appears that the energy for heating the circulating amine material correlates with the solid circulation rate due to the gain by decreasing temperature. The minimum energy demand is obtained around 2.6 and increased to the maximum of $2.8 \mathrm{MJ}$ per $\mathrm{kg}$ bio-methane. The cooling demand to keep the adjusted adsorber temperature constant, according to Eq. 6 is also valuated and presented in Figure 5 (cooling demand line). The electrical demand line indicates heat integration measure through the introduced heat pump model and follows Eq. 5. The specific energy minimum is observed at $65^{\circ} \mathrm{C}$ with $1.7 \mathrm{MJ} / \mathrm{kg}$ bio-methane due to the coefficient of performance of the HP. From this graphs, the energy saving increase from $13 \%$ to $41 \%$ with decreasing the desorber temperature due to the arising gap between process energy behaviors with and without HP. The extra cooling demand (HP) illustrates that the HP decreases the cooling demand under $1 \mathrm{MJ} / \mathrm{kg}$ bio-methane. These results clearly proof the concept of heat pump integration for the multi stage fluidized bed configuration.

Figure 6 shows the overall area of the immersed heat exchangers in gas-solid contactor columns. The calculated area $\mathrm{A}_{\mathrm{HEX}}$ has been calculated using Eq. (2). 
$10 \quad 10^{\mathrm{TH}}$ International Conference on Sustainable EnERgy and Environmental Protection (June $27^{\mathrm{TH}}-30^{\mathrm{TH}}, 2017$, Bled, SLOVENIA), RENEWABLE ENERGY SOURCES H. Vogtenhuber, R. Hofmann, G. Schöny, J. Pirklbauer, M. Fraubaum, F. Helminger, A. Werner \& H. Hofbauer: Development of an Efficient Heat Balance Concept for a TSA-Process Considering Heat-Pump Integration

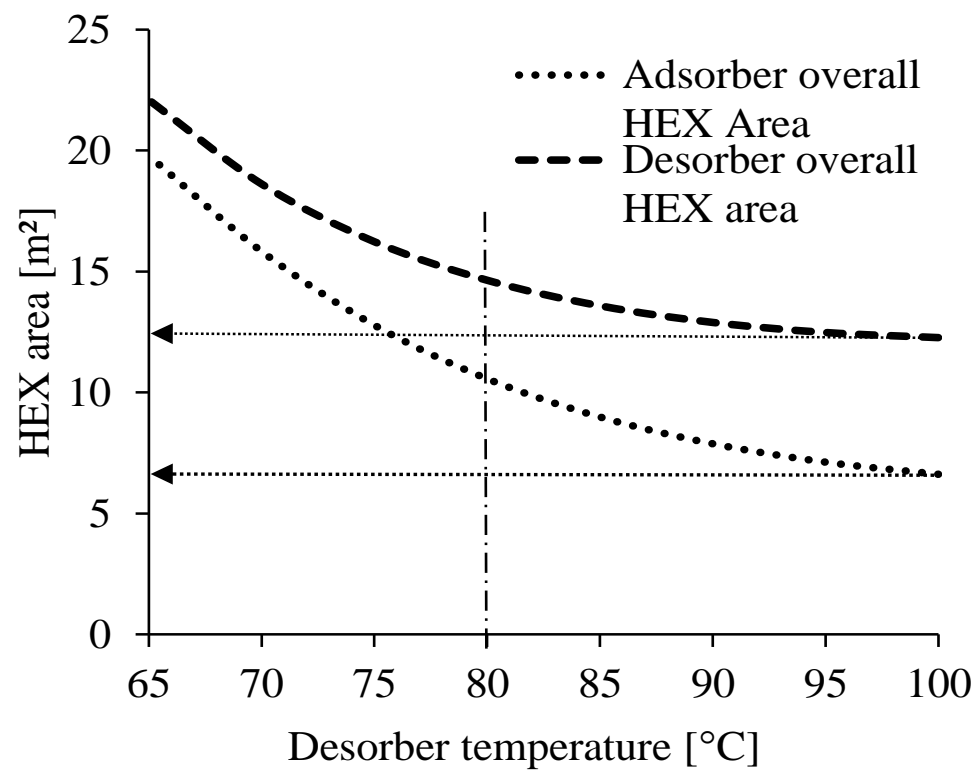

Figure 6. Overall heat exchanger area depending on desorber temperature

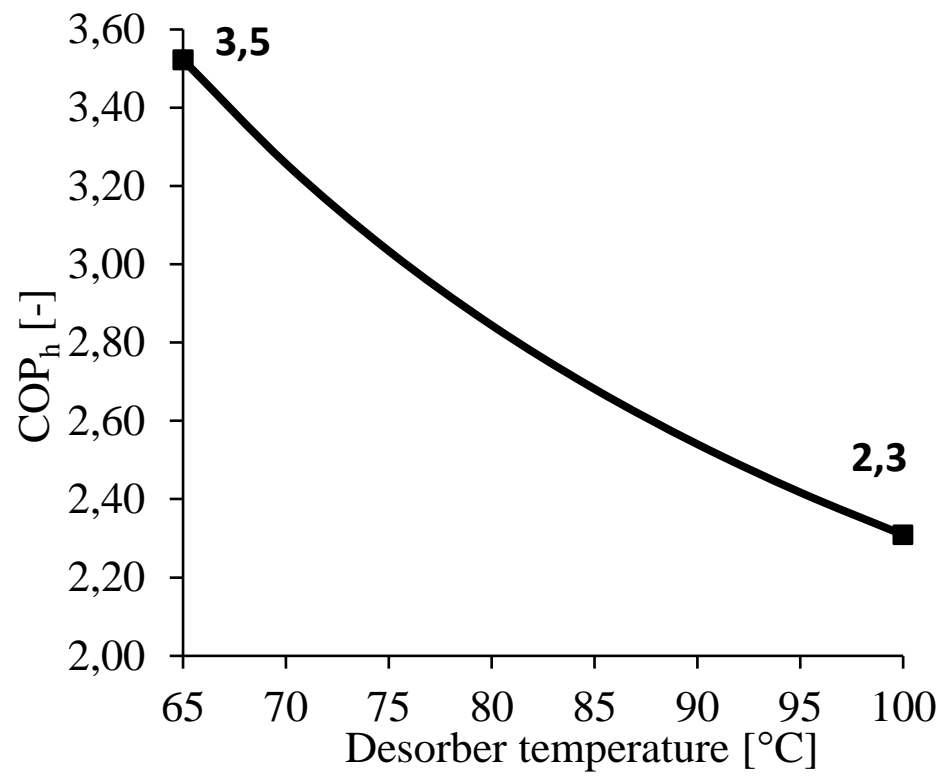

Figure 7. $\mathrm{COP}_{\mathrm{h}}$ of the high temperature heat pump model 
$10^{\mathrm{TH}}$ InTERnational CONFerence on Sustainable EnERgy AND Environmental Protection (June $27^{\mathrm{TH}}-30^{\mathrm{TH}}, 2017$, BLED, SLOVENIA), RENEWABLE ENERGY SOURCES

H. Vogtenhuber, R. Hofmann, G. Schöny, J. Pirklbauer, M. Fraubaum, F. Helminger,

A. Werner \& H. Hofbauer: Development of an Efficient Heat Balance Concept for a TSA-Process Considering Heat-Pump Integration

The minimum overall heat exchange area in the desorber column is about $12 \mathrm{~m}^{2}$ and increases to $22 \mathrm{~m}^{2}$ at a desorber operating temperature of $65^{\circ} \mathrm{C}$. It is shown, that the needed heat exchange area is $60 \%$ higher at $80^{\circ} \mathrm{C}$ as compared to the initial $\mathrm{HEX}$ area at $100^{\circ} \mathrm{C}$ and goes up to over $100 \%$ at $65^{\circ} \mathrm{C}$. These results should be interpreted with caution due to possible column design in terms of high HEX areas to ensure enough conducted heat (Eq. 2) at low desorber temperatures.

The performance of the heat pump is given through the coefficient of performance according to Eq. (1) and shown in Figure 7 for the five stage TSA configuration. The maximum $\mathrm{COP}_{\mathrm{h}}$ of 3,5 appears at $65^{\circ} \mathrm{C}$ and declines to 2,3 at $100^{\circ} \mathrm{C}$ regeneration bed temperature.

\section{Conclusion}

These results from chapter above may be interpreted to indicate possible regeneration bed temperature in terms of heat demand, passable column design in order to HEX area and best possible heat pump efficiency $\left(\mathrm{COP}_{h}\right)$.

Comparing Figure 4, Figure 5 and Figure 6 it should be pointed out that a desorber temperature of $65^{\circ} \mathrm{C}$ is perfect for low energy consumption of the process with a HP but at the same time the sorbent circulation rate and HEX areas are on a very high level.

As drawback of this method the $\mathrm{CO}_{2}$ capture efficiency of each stage can be mentioned, which is not the same as in real conditions due to equilibrium model. This work gives a basic assessment of the feasibility of TSA process for application in the field of biogas upgrading. Obtained results clearly motivate further work on the optimization of continuous TSA CO2 capture processes for application in the field of biogas upgrading:

- Development of a stage efficiency model, that considers a practical distance from the adsorption equilibrium in each stage

- For better assessment of the required heat transfer surface areas, the heat transfer coefficient will be evaluated through convenient correlation and will be introduced in the TSA-process model.

- The amount of the stripping gas for recovery is a big impact factor for energy consumption in terms for the sorbent circulation rate and column design.

- A possible addition of a rich/lean heat exchanger could be improving the heat balance due to lower sensible energy demand for the circulating sorbent material.

- The heat pump model is not considering a specific heat pump configuration (including refrigerant, refrigeration cycle configuration, etc.). For further investigations an advanced heat pump model will be implemented.

- Screening of literature to identify optimal adsorbent materials for application in TSA systems for biogas upgrading 
$10^{\mathrm{TH}}$ InTERnAtional CONFERENCE ON Sustainable EnERgy AND ENVIRONMENTAL Protection (June $27^{\mathrm{TH}}-30^{\mathrm{TH}}$, 2017, Bled, SLovenia), Renewable ENERGy SOURCES H. Vogtenhuber, R. Hofmann, G. Schöny, J. Pirklbauer, M. Fraubaum, F. Helminger, A. Werner \& H. Hofbauer: Development of an Efficient Heat Balance Concept for a TSA-Process Considering Heat-Pump Integration

\section{Acknowledgements}

The authors appreciate the financial support by the Austrian Climate and Energy Fund (FFG project no. 853612).

\section{References}

[1] IEA Bioenergy, "Biomethane-Status and Factors Affecting Market Development and Trade. A Joint Study by IEA Bioenergy Task 40 and Task 37," 2014.

[2] Bauer et al., "Biogas upgrading - Review of commercial technologies. SGC Rapport 2013:270," 2013.

[3] W.-C. Yang and J. Hoffman, "Exploratory Design Study on Reactor Configurations for Carbon Dioxide Capture from Conventional Power Plants Employing Regenerable Solid Sorbents," Ind. Eng. Chem. Res., vol. 48, no. 1, pp. 341-351, 2009.

[4] T. Pröll, G. Schöny, G. Sprachmann, and H. Hofbauer, "Introduction and evaluation of a double loop staged fluidized bed system for post-combustion $\mathrm{CO} 2$ capture using solid sorbents in a continuous temperature swing adsorption process," Chemical Engineering Science, vol. 141, pp. 166-174, 2016.

[5] G. Schöny, F. Dietrich, J. Fuchs, T. Pröll, and H. Hofbauer, "A multi-stage fluidized bed system for continuous $\mathrm{CO} 2$ capture by means of temperature swing adsorption - First results from bench scale experiments," Powder Technology, 2016.

[6] G. Schöny et al., "Design of a bench scale unit for continuous CO2 capture via temperature swing adsorption-Fluid-dynamic feasibility study," Chemical Engineering Research and Design, vol. 106, pp. 155-167, 2016.

[7] D. J. Fauth et al., "Investigation of Porous Silica Supported Mixed-Amine Sorbents for Post-Combustion CO 2 Capture,” Energy Fuels, vol. 26, no. 4, pp. 2483-2496, 2012. 
$10^{\mathrm{TH}}$ InTERnational CONFERENCE ON Sustainable ENERgy AND Environmental Protection (June 27 $7^{\mathrm{TH}}-30^{\mathrm{TH}}, 2017$, BLed, SLOVENIA), RENEWABLE ENERGy SOURCES

J. Krope, A.Ghani Olabi, D. Goričanec \& S. Božičnik

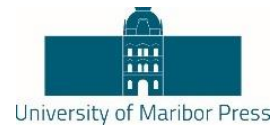

\title{
Effect of Addition of Biogas Slurry for Anaerobic Fermentation of Deer Manure on Biogas Production
}

\author{
HANXI WANG, JiANLING XU, LiANXI SHENG \& XUEJUN LiU
}

\begin{abstract}
By determining the methane production, $\mathrm{pH}$, and volatile fatty acids (VFA) content of deer manure anaerobic fermentation system we explored the effects of adding biogas slurry on biogas production for the anaerobic fermentation of deer manure. The initial mushroom slag amount that was added was $35 \mathrm{~g}$, total solid content was $6 \%$, and temperature was $35^{\circ} \mathrm{C}$. The results showed that the total amounts of biogas and $\mathrm{CH} 4$ produced were the largest when the amount of biogas slurry added to the fermented mixture was $30 \%$. The $\mathrm{pH}$ was generally increased when biogas slurry was added to the fermented mixture. Upon increasing the amount of biogas slurry, the trend of the VFA content in the fermented material first increased, then decreased and finally increased again.
\end{abstract}

Keywords: • deer manure $\bullet$ anaerobic fermentation $\bullet$ biogas slurry $\bullet$ biogas - $\mathrm{CH} 4 \cdot$

CORRESPONDENCE AdDRESS: Hanxi Wang, State Environmental Protection Key Laboratory of Wetland Ecology and Vegetation Restoration/ School of Environment, Northeast Normal University, email: xujl@foxmail.com. Jianling Xu, State Environmental Protection Key Laboratory of Wetland Ecology and Vegetation Restoration/ School of Environment, Northeast Normal University, email: xujl@foxmail.com. Lianxi Sheng, State Environmental Protection Key Laboratory of Wetland Ecology and Vegetation Restoration/ School of Environment, Northeast Normal University, email: xujl@foxmail.com. Xuejun Liu, Jilin Provincial Institute of Education, 130022, China. 
$10^{\mathrm{TH}}$ International Conference on Sustainable EnERgy AND Environmental Protection (June $27^{\mathrm{TH}}-30^{\mathrm{TH}}, 2017$, Bled, SLOVENIA), RENEWABle ENERGY SOURCES H. Wang, J. Xu, L. Sheng \& X. Liu: Effect of Addition of Biogas Slurry for Anaerobic Fermentation of Deer Manure on Biogas Production

\section{Introduction}

Biogas slurry is rich in organic content, and when the $\mathrm{SS}, \mathrm{COD}, \mathrm{BOD}_{5}$ and $\mathrm{TP}$ are high, the concentrations of COD in cow dung and straw (raw materials) have been shown to be higher than in other treatments, reaching $6800 \mathrm{mg} \cdot \mathrm{L}^{-1}$ and $5800 \mathrm{mg} \cdot \mathrm{L}^{-1}[1,2]$. The $\mathrm{TN}$, TP, TK and organic matter contents of 20 biogas slurry samples were analyzed, and the results showed that the organic matter contents in the biogas slurries from cow dung digesters and mixed raw material digesters were higher compared to those from pig manure digesters and chicken manure digesters [3].

Study showed that $\mathrm{CH}_{4}$ production increased by $20 \%$ compared to that of untreated wheat straw [4]. Another study showed that biochar application significantly increased the $\mathrm{CH}_{4}$ flux compared to untreated soil [5]. The best results for biogas slurry nutrient reduction, $\mathrm{CO}_{2}$ removal, and upgrade effects were obtained by treatment of $S$. obliquus under a moderate light intensity [6]. The best LED light wavelength mix ratio for improving both biogas and biogas slurry nutrient removal was a red:blue ratio of 5:5 [7]. Coupled microalgal and anaerobic biotechnology may be a sustainable alternative for integrated nutrient removal and biofuel production applications [8]. Microalgae that were cultured in a biogas slurry accumulated more carbohydrates in cells, making this biogas slurry a more suitable medium for improving the carbohydrate content [9]. The biogas model suggested using $21 \%$ of biogas for electricity and $79 \%$ for upgrading [10]. Methane emissions were measured over two years at an earthen storage facility that contained a digestate from a mesophilic biodigester in Ontario, Canada, and the annual $\mathrm{CH}_{4}$ emissions averaged $19 \mathrm{~g}$ $\mathrm{CH}_{4} \mathrm{~m}^{-3} \mathrm{~d}^{-1}$ and $0.27 \mathrm{~g} \mathrm{CH}_{4} \mathrm{~kg}^{-1} \mathrm{VS} \mathrm{d}^{-1}$ in the storage facility [11]. The dynamics of ammonium accumulation and mitigation control in the anaerobic digestion of chicken manure under the recycled utilization of a liquid digested slurry were investigated by using an integrated approach, and the accumulated VFAs and ammonium contents resulted in a decrease in biogas production of $43 \%$ [12]. The results demonstrated that forcing sugar beets into the feedstock mix resulted in generally higher GHG emissions and deteriorated energy balances [13]. Another study presented the life cycle environmental impacts of a system that produces biogas from agricultural wastes via anaerobic digestion while co-generating heat and electricity, and they found that this system can lead to significant reductions in most impacts compared to fossil-fuel alternatives, including the global warming potential, which was reduced by up to $50 \%$ [14]. Manure biogas is a renewable energy resource that is untapped in Europe compared to its full potential [15]. The use of anaerobic digestion to make biogas into an energy source is a mature technology in many European countries [16]. The study of biogas fermentation started earlier in China, but application of biogas is slow due because it is an immature technology $[17,18]$. As shown in previous studies, improving the utilization of livestock manure resources is difficult and emphasis in current research. The deer manure utilization rate is low, causing serious pollution problems, and anaerobic fermentation of deer manure to produce biogas has the appropriate ratio of carbon to nitrogen. Thus, it is important to study biogas production by anaerobic fermentation of deer manure. The total gas production, total methane content in the gas, and $\mathrm{pH}$ and VFA contents in the mixture were determined in our study. We aimed to explore the effects of 
adding a biogas slurry on biogas production upon anaerobic digestion of deer manure, the influence of anaerobic digestion of deer manure biogas on the amount of biogas produced, and the ability of methane gas to improve the yield of deer manure to increase methane production.

\section{$2 \quad$ Materials and Methods}

\subsection{Experimental materials}

(1) Deer manure: Fresh deer manure was collected from the Shuangyang District at the Changchun City deer farm. It was fully mixed after collection, installed in a valve bag, and hermetically preserved at $4^{\circ} \mathrm{C}$.

(2) Mushroom residue: Mushroom residue was collected from the polysaccharide waste of a mushroom production plant and sprayed with water every day after being retrieved to ensure the activity of the strain.

(3) Biogas slurry: Biogas slurry was the filtered supernatant of an anaerobic digestion of the deer manure and mushroom residue.

\subsection{Experimental methods}

Experiments were performed via batch fermentation. The method for determining the basic physical and chemical properties of TS, VS, TOC, TN, and TP are shown in Table 1. The composition of the experimental materials and $\mathrm{C} / \mathrm{N}$ ratio are shown in Table 2. In the experiment, $35 \mathrm{~g}$ of mushroom residue was added, the total solid content was $6 \%$, and the temperature was set to $35^{\circ} \mathrm{C}$. We used 4 group experiments. For the first experimental group, biogas slurry was not added during the experimental process. For the second experimental group, third experimental group and fourth experimental group, before the start of the experiment, biogas slurry was added at $10 \%, 30 \%$ and $50 \%$, respectively, to the fermented mixture. The determination indexes included the $\mathrm{pH}$, daily gas production, cumulative gas production, $\mathrm{CH}_{4}$ content, and VFA content.

Table 1. Determination methods for the fermentation raw material indexes

\begin{tabular}{ccc}
\hline Number & Item & Test method \\
\hline 1 & TS & $105^{\circ} \mathrm{C}$ Drying \\
2 & VS & $550^{\circ} \mathrm{C}$ Burning \\
3 & TOC & $\begin{array}{c}\text { Potassium dichromate method } \\
\text { Alkaline potassium persulphate } \\
\text { digestion- }\end{array}$ \\
4 & TN & $\begin{array}{c}\text { UV spectrophotometric method } \\
\text { Ammonium molybdate } \\
\text { spectrophotometric method }\end{array}$ \\
\hline
\end{tabular}


$10^{\mathrm{TH}}$ INTERNATIONAL CONFERENCE ON Sustainable ENERGY AND ENVIRONMENTAL Protection (June $27^{\mathrm{TH}}-30^{\mathrm{TH}}, 2017$, Bled, SLOVENIA), RENEWABle ENERGY SOURCES H. Wang, J. Xu, L. Sheng \& X. Liu: Effect of Addition of Biogas Slurry for Anaerobic Fermentation of Deer Manure on Biogas Production

Table 2. Fermentation substrate characteristics

\begin{tabular}{cccc}
\hline material & TS (\%) & VS (\%) & $\mathrm{C}(\%)$ \\
\hline $\begin{array}{c}\text { deer } \\
\text { manure } \\
\text { mushroom } \\
\text { residue }\end{array}$ & $67.82-73.69$ & $77.83-81.59$ & $49.89-54.43$ \\
\hline material & $\mathrm{N}(\%)$ & $\mathrm{P}(\%)$ & $\mathrm{C} / \mathrm{N}$ \\
\hline $\begin{array}{c}\text { deer } \\
\text { manure } \\
\text { mushroom } \\
\text { residue }\end{array}$ & $1.68-2.02$ & $0.49-0.65$ & $25.72-30.06$ \\
\hline
\end{tabular}

$3 \quad$ Results

\subsection{Changes in biogas production during the fermentation period}

The changes in daily gas are shown in Figure 1 under various conditions. The experimental results show that the four experimental gas production groups first increased and then decreased during anaerobic digestion. However, there was a difference in both the peak value and peak time of gas production in the different groups. The first group in the anaerobic digestion process had two peaks in gas production, at the $20^{\text {th }}$ day and at the $34^{\text {th }}$ day, in which gas production was $1118 \mathrm{~mL}$ and $1109 \mathrm{~mL}$, respectively. The other three groups were higher than the first group during the initial stage of gas production. The other three groups exhibited a relatively large amount of gas production relative to the first group during the initial stage, which indicates that the addition of biogas slurry can promote the production of biogas. Compared with the second group and fourth group, there was a large number of peak gas production days and the gas production rate was high during the stable gas production period in the third group.

The cumulative gas production statistics show that biogas slurry addition can increase biogas production. The cumulative gas production of the first group was lower during the initial stage of anaerobic digestion. The cumulative gas production of the first, second, third and fourth groups was $19,685 \mathrm{~mL}, 21,637 \mathrm{~mL}, 24,346 \mathrm{~mL}$ and $21891 \mathrm{~mL}$, respectively, and the gas production period was $36,35,36$ and 31 days, respectively. The cumulative gas production of the second group, third group and fourth group compared with the first group increased by 1,952 $\mathrm{mL}, 4,661 \mathrm{~mL}$ and 2,206 $\mathrm{mL}$, respectively, and gas production increased by $9.92 \%, 23.68 \%$ and $11.21 \%$, respectively. Adding biogas slurry had little effect on the fermentation cycle. 


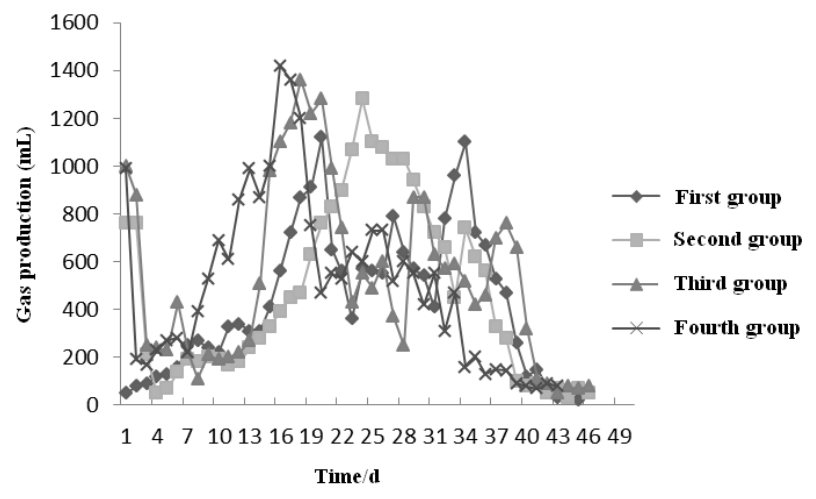

Figure 1. Gas production as a function of different factors

\subsection{Changes in the $\mathrm{pH}$ and $\mathrm{CH} 4$ content during the fermentation period}

The changes in $\mathrm{pH}$ were measured every 3 days, as shown in Figure 2, under different experimental conditions, and the $\mathrm{pH}$ of the fermentation materials in the four groups exhibited an overall increasing trend. The $\mathrm{pH}$ of the fermentation materials were adjusted to approximately 7 for the four groups before the start of the experiment, and the $\mathrm{pH}$ of the fermentation material in the first group was 5.5 during the initial stage of the reaction. The $\mathrm{pH}$ increased to 6.35 until the $22^{\text {nd }}$ day. The highest $\mathrm{pH}$ in the first group was 7.25 at the beginning of the $25^{\text {th }}$ day, and then, the $\mathrm{pH}$ showed a downward trend and the $\mathrm{pH}$ was maintained at more than 6.5. For the second group and first group, the acidification stage $(\mathrm{pH}<7)$ lasted more than 20 days and the $\mathrm{pH}$ was approximately 6 . The $\mathrm{pH}$ of the second group remained in the range of 7.1 to 7.5 from the $28^{\text {th }}$ to the $46^{\text {th }}$ day. The $\mathrm{pH}$ of the third group was higher than the $\mathrm{pHs}$ of the other three groups during the initial stage. The $\mathrm{pH}$ increased to 7.1612 days after the first peak and was approximately 7.35 until the end of the experiment. The $\mathrm{pH}$ change of the fourth group was similar to that of the first group, and the two obviously increased and decreased throughout the entire process. The peak $\mathrm{pH}$ was 7.2 on the $25^{\text {th }}$ day, and the $\mathrm{pH}$ was maintained at approximately 6.8 after reaching the highest value.

The $\mathrm{CH}_{4}$ content in biogas was measured once every 2 days, as shown in Figure 3, under different experimental conditions, and the four groups exhibited a trend of initial increase in the $\mathrm{CH}_{4}$ content followed by a decrease. The first group was determined to contain $\mathrm{CH}_{4}$ on the ninth day of anaerobic fermentation. The $\mathrm{CH}_{4}$ content increased from the $9^{\text {th }}$ to the $19^{\text {th }}$ day, and the peak amount of $\mathrm{CH}_{4}$ was $54.20 \%$ on the $19^{\text {th }}$ day. The $\mathrm{CH}_{4}$ content was maintained at more than $40 \%$ during the fermentation process from the $19^{\text {th }}$ to the $25^{\text {th }}$ day, and was then maintained at $15-20 \%$. The second group began to produce $\mathrm{CH}_{4}$ on the $5^{\text {th }}$ day compared with the first group and was observed as early as 4 days. Compared with the first group, the $\mathrm{CH}_{4}$ content of this group increased slowing during the early stage of the experiment. This group's $\mathrm{CH}_{4}$ content was above $40 \%$ from the $19^{\text {th }}$ to the $23^{\text {rd }}$ day. The peak value of $49.01 \%$ appeared on the $23^{\text {rd }}$ day compared with the 
$10^{\mathrm{TH}}$ InTERnAtional CONFERENCE ON Sustainable ENERgy AND ENVIRONMENTAL Protection (June $27^{\mathrm{TH}}-30^{\mathrm{TH}}, 2017$, BlED, SLOVENIA), RENEWABLE ENERGY SOURCES H. Wang, J. Xu, L. Sheng \& X. Liu: Effect of Addition of Biogas Slurry for Anaerobic Fermentation of Deer Manure on Biogas Production

first group, and the $\mathrm{CH}_{4}$ production time and cycle was long. The third group began to produce $\mathrm{CH}_{4}$ on the third day of anaerobic fermentation, and the peak value of $55.79 \%$ appeared on the $17^{\text {th }}$ day of anaerobic fermentation; this group was showed the earliest production of $\mathrm{CH}_{4}$ and the highest peak value. For the third group, the experimental methane content was greater than $40 \%$ from the $13^{\text {th }}$ to the $33^{\text {rd }}$ day throughout anaerobic digestion, and the $\mathrm{CH}_{4}$ content was more than $30 \%$ from the ninth day to the end of the reaction. For the fourth group, we detected $\mathrm{CH}_{4}$ on the third day of anaerobic fermentation and the $\mathrm{CH}_{4}$ content reached a peak of $61.21 \%$ on the $23^{\text {rd }}$ day. $\mathrm{The} \mathrm{CH}_{4}$ content was more than $40 \%$ from the $19^{\text {th }}$ to the end of the reaction. Compared with the first group, the fourth group had a higher $\mathrm{CH}_{4}$ content and $\mathrm{CH}_{4}$ appeared earlier. From the above analysis, it is indicated that addition of biogas slurry had an obvious effect on anaerobic digestion.

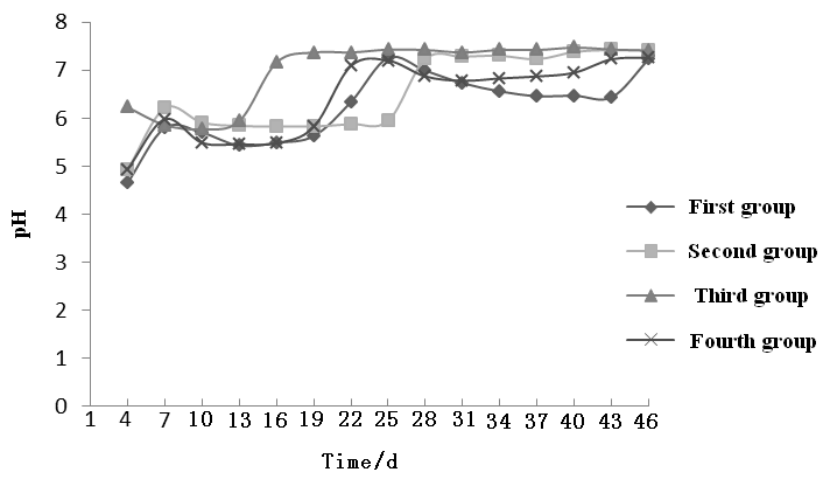

Figure 2. $\mathrm{pH}$ as a function of different factors

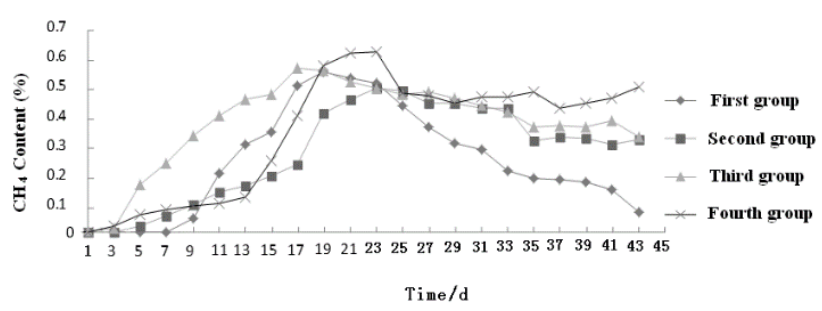

Figure 3. $\mathrm{CH}_{4}$ as a function of different factors

\subsection{Changes in the VFA content during the fermentation period}

The VFA contents were measured every 3 days, as shown in Figure 4, under different conditions. The VFA content of the first group showed two peaks throughout anaerobic fermentation 10 days before the experiments. The VFA content showed an upward trend and then a downward trend, and it reached $2.29 \mathrm{~g} / \mathrm{L}$ at the end of the reaction. The VFA content of the fermentation mixture in the second and third groups first exhibited an increasing trend and then decreased, and the peak value of $10.69 \mathrm{~g} / \mathrm{L}$ in the fourth group was higher than that of the other three groups on the $13^{\text {th }}$ day. The VFA content in the 
fourth group decreased in the following 13 days to $3.41 \mathrm{~g} / \mathrm{L}$ by the $19^{\text {th }}$ day and then slightly increased. Compared with the first group, the VFA content in the second group decreased quickly with time and reached $0.29 \mathrm{~g} / \mathrm{L}$ at the end of the experiment. Compared with the second group, the VFA value of the third group was the fastest.

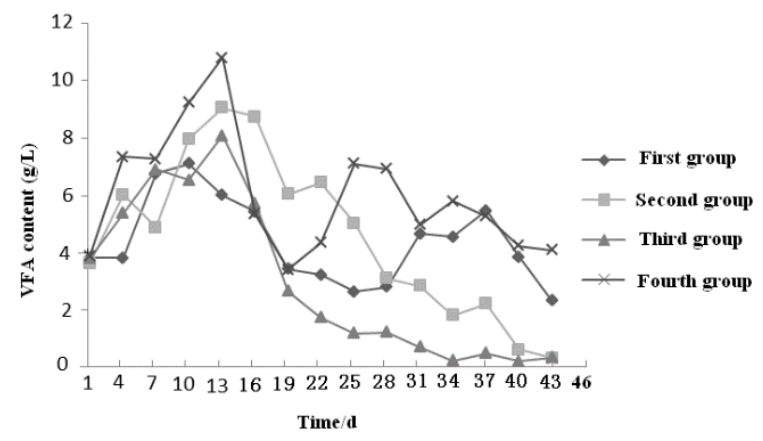

Figure 4. Volatile fatty acids as a function of different factors

\section{Discussion}

Methane produced from anaerobic digestion is generally divided into in four stages: hydrolysis, acid production, acid dehydrogenation and methane production. The main influencing factors of methane produced from anaerobic digestion include the ratio of raw materials, fermentation temperature, inoculum, carbon, nitrogen, feed concentration, $\mathrm{pH}$, among others [19-21]. The slurry contained large amounts of nutrients and microorganisms, and the total nutrient content was $0.94-15.4 \%$ [22]. Biogas production, which will play a key role in future energy systems largely based on renewable sources, is expected to grow significantly over the next few decades [23]. Biogas slurry treatment can significantly increase the soil saturated hydraulic conductivity and soil aggregate content [24]. When a biogas slurry is added to a mixed material, the anaerobic fermentation reaction is favorable and will produce methane in advance. However, adding an excessive amount of biogas, on the one hand, diluted the fermentation of raw materials and had an adverse effect on the anaerobic fermentation reaction, but on the other hand, it increased the concentrations of volatile fatty acids and of ammonia and inhibited the reaction. Therefore, adding the proper amount of biogas slurry can not only improve the mixture reaction speed and gas production but can also avoid producing high amounts of fatty acids index, which would lead to a negative effect. From the statistical results of the total gas and $\mathrm{CH}_{4}$ contents from our experiments, as the amount of biogas slurry was increased, the total gas production and methane content first increased and then decreased and the total amount of biogas and $\mathrm{CH}_{4}$ were highest when the amount of biogas slurry added to the fermented mixture was $30 \%$. The $\mathrm{pH}$ was generally increased when biogas slurry was added to the fermented mixture, and the increase in $\mathrm{pH}$ was most obvious when the amount of biogas slurry added was $30 \%$ of the fermented mixture. We determined that the trend of the VFA content in the fermented material first increased, then decreased and finally increased with an increasing amount of biogas slurry. The 
$10^{\mathrm{TH}}$ InTERnATIONAL CONFERENCE ON Sustainable EnERgy AND ENVIRONMENTAL Protection (June $27^{\mathrm{TH}}-30^{\mathrm{TH}}, 2017$, BlED, SLOVENIA), RENEWABLE ENERGY SOURCES H. Wang, J. Xu, L. Sheng \& X. Liu: Effect of Addition of Biogas Slurry for Anaerobic Fermentation of Deer Manure on Biogas Production

content of VFA was the lowest when the amount of biogas slurry that was added was $30 \%$ of the fermented mixture, which was the most favorable for $\mathrm{CH}_{4}$ production. Through this experimental study, to scientifically determine the amount of biogas slurry to add to anaerobic fermentation in an initial quick start fermentation device, for the sequencing batch anaerobic fermentation biogas slurry flow control is significant.

\section{$5 \quad$ Conclusion}

By using different amounts of biogas slurry, the optimum conditions for producing gas were explored for anaerobic digestion of deer manure. The main conclusions are as follows:

(1) The addition of biogas slurry to the fermentation of raw materials can improve the total biogas production, and the total amount of biogas produced was highest when the amount of biogas slurry added was $30 \%$ of the fermented mixture.

(2) The addition of biogas slurry to the fermentation of raw materials can improve the $\mathrm{CH}_{4}$ content and produce $\mathrm{CH}_{4}$ in advance. The total amount of $\mathrm{CH}_{4}$ was highest when the amount of biogas slurry added was $30 \%$ of the fermented mixture.

(3) The $\mathrm{pH}$ generally increased when biogas slurry was added to the fermented mixture, and the increase in $\mathrm{pH}$ was the most obvious when the amount of biogas slurry added was $30 \%$ of the fermented mixture.

(4) With an increasing amount of biogas slurry, the trend of the VFA content in the fermented material first increased, then decreased and finally increased.

\section{Acknowledgements}

This project was supported by the Project of Changchun city technology bureau (No.16SS06).

\section{References}

[1] L. Qi, F. Wang, X. Y. Pan, X. L. Zhang, Y. J. Mao, and W. Jiang, Monitoring and Evaluating of Pollution Factors of Biogas Slurry Produced by Small-scale Biogas Project. China Biogas, vol. 31, pp. 25-28, June. 2013.

[2] L. T. Ke, H. T. Wang, Y. P. Wang, N. He, and Q. B. Li, Component analysis and risk assessment of anaerobically digested slurry from households in China. CIESC Journal, vol. 65, pp. 1840-1847, May. 2014.

[3] M. S. Qu, N. Guo, Z. F. Liu, Y. F. Wang, G. L. Zhao, M. Jin, et al., Nutrient and heavy metal contents in biogas slurry of large scaled biogas project in suburb of Beijing. China Biogas, vol. 31, pp. 37-40, Apr. 2013.

[4] L. C. Ferreira, A. Donoso-Bravo, P. J. Nilsen, F. Fdz-Polanco, and S. I. Pérez-Elvira, Influence of thermal pretreatment on the biochemical methane potential of wheat straw. Bioresource Technology, vol. 143, pp. 251-257, Sept. 2013. 
[5] A. Singla, S. K. Dubey, A. Singh, and K. Inubushi, Effect of biogas digested slurry-based biochar on methane flux and methanogenic archaeal diversity in paddy soil. Agriculture, Ecosystems and Environment, vol. 197, pp. 278-287, Dec. 2014.

[6] Y. Ouyang, Y. J. Zhao, S. Q. Sun, C. W. Hu, and L.F. Ping, Effect of light intensity on the capability of different microalgae species for simultaneous biogas upgrading and biogas slurry nutrient reduction. International Biodeterioration \& Biodegradation, vol. 104, pp. 157-163, Oct. 2015.

[7] C. Yan, L. Zhang, X. Z. Luo, and Z. Zheng, Influence of influent methane concentration on biogas upgrading and biogas slurry purification under various LED (light-emitting diode) light wavelengths using Chlorella sp. Energy, vol. 69, pp. 419-426, Mar. 2014.

[8] O. Calicioglu, and G.N. Demirer, Biogas production from waste microalgal biomass obtained from nutrient removal of domestic wastewater. Waste Biomass Valor, vol. 7, pp. 1397-1408, Dec. 2016.

[9] F. Tan, Z. Wang, S.Y. Zhouyang, H. Li, Y. P. Xie, Y. P. Wang, et al., Nitrogen and phosphorus removal coupled with carbohydrate production by five microalgae cultures cultivated in biogas slurry. Bioresource Technology, vol. 221, pp. 385-393, Dec. 2016.

[10] R. O'Shea, D. Wall, and J. D. Murphy, Modelling a demand driven biogas system for production of electricity at peak demand and for production of biomethane at other times. Bioresource Technology, vol. 216, pp. 238-249, Sep. 2016.

[11] H. Baldé, A. C. VanderZaag, S. D. Burtt, C. Wagner-Riddle, A. Crolla, R. L. Desjardins, et al., Methane emissions from digestate at an agricultural biogas plant. Bioresource Technology, vol. 216, pp. 914-922, Sep. 2016.

[12] S. B. Wu, P. Ni, J. X. Li, H. Sun, Y. F. Wang, H. Z. Luo, et al., Integrated approach to sustain biogas production in anaerobic digestion of chicken manure under recycled utilization of liquid digestate: Dynamics of ammonium accumulation and mitigation control. Bioresource Technology, vol. 205, pp. 75-81, Apr. 2016.

[13] S. Auburger, A. Jacobs, B. Märländer, and E. Bahrs, Economic optimization of feedstock mix for energy production with biogas technology in Germany with a special focus on sugar beets e Effects on greenhouse gas emissions and energy balances. Renewable Energy, vol. 89, pp. 1-11, Apr. 2016.

[14] A. Whiting, and A. Azapagic, Life cycle environmental impacts of generating electricity and heat from biogas produced by anaerobic digestion. Energy, vol. 70, pp. 181-193, Jun 2014.

[15] L. Hamelin, I. Naroznova, and H. Wenzel, Environmental consequences of different carbon alternatives for increased manure-based biogas. Applied Energy, vol. 114, pp. 774-782, Feb. 2014.

[16] D. Goulding, and N. Power, Which is the preferable biogas utilisation technology for anaerobic digestion of agricultural crops in Ireland: Biogas to CHP or biomethane as a transport fuel? Renewable Energy, vol. 53, pp. 121-131, May. 2013.

[17] Y. Chen, G. H. Yang, S. Sweeney, and Y. Z. Feng, Household biogas use in rural China: a study of opportunities and constraints. Renewable and sustainable energy reviews, vol. 14, pp. 545-549, Jan. 2010.

[18] Y. Feng, Y. Guo, G. Yang, X. Qin, and Z. Song, Household biogas development in rural China: On policy support and other macro sustainable conditions. Renewable and Sustainable Energy Reviews, vol.16, pp. 5617-5624, Oct. 2012.

[19] L. H. Li, D. Li, Y.M. Sun, L.L. Ma, Z.H. Yuan, and X.Y. Kong, Effect of temperature and solid concentration on anaerobic digestion of rice straw in South China. International Journal of Hydrogen Energy, vol. 13, pp. 7261-7266, Jul. 2010.

[20] L. Yang, and Y. Li, Anaerobic digestion of giant reed for methane production. Bioresource technology, vol. 171, pp. 233-239, Aug. 2014. 

Protection (June $27^{\mathrm{TH}}-30^{\mathrm{TH}}, 2017$, Bled, SLOVEnia), Renewable ENERGy SOURCES H. Wang, J. Xu, L. Sheng \& X. Liu: Effect of Addition of Biogas Slurry for Anaerobic Fermentation of Deer Manure on Biogas Production

[21] H. X. Wang, J.L. Xu, H. X. Yu, X. J. Liu, W. Yin, Y.Y. Liu, et al., Study of the application and methods for the comprehensive treatment of municipal solid waste in northeastern China. Renewable and Sustainable Energy Reviews, vol. 52, pp. 1881-1889, Dec. 2015.

[22] C. Chen, Z.Y. Ruan, J. Wu, L. H. Gao, J. L. Song, Y. W. Wang, et al., Research Progress on the Comprehensive Disposal and Utilization of Biogas Slurry from Large Scale Biogas Engineering. China Biogas, vol. 31, pp. 25-28, Jan. 2013.

[23] A. Boldrin, K. R. Baral, T. Fitamo, A.H. Vazifehkhoran, I.G. Jensen, I. Kjærgaard, et al., Optimised biogas production from the co-digestion of sugar beet with pig slurry: Integrating energy, GHG and economic accounting. Energy, vol. 112, pp. 606-617, Oct. 2016.

[24] Z.J. Du, X.M. Chen, X.B. Qi, Z.Y. Li, J.K. Nan, and J.Q. Deng, The effects of biochar and hoggery biogas slurry on fluvo-aquic soil physical and hydraulic properties: a field study of four consecutive wheat-maize rotations. J Soils Sediments, vol. 16, pp. 2050-2058, Aug. 2016. 
$10^{\mathrm{TH}}$ INTERNATIONAL CONFERENCE ON Sustainable ENERgy AND ENVIRONMENTAL Protection (June $27^{\mathrm{TH}}-30^{\mathrm{TH}}$, 2017, Bled, SLOVENIA), RENEWABLE ENERGy SOURCES

J. Krope, A.Ghani Olabi, D. Goričanec \& S. Božičnik

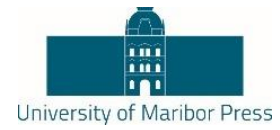

\title{
Thermal Energy Recovery from Drinking Water
}

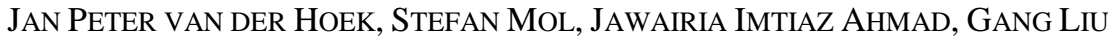 \\ \& GERTJAN MEDEMA
}

\begin{abstract}
Waternet, the water utility of Amsterdam and surroundings, has the ambition to operate climate neutrally in 2020. Although large progress has been made since 1990 to reduce Greenhouse Gas emissions (GHG), in 2016 the remaining emission was still 37,203 ton CO2-eq. A possibility to further decrease the GHG emission is thermal energy recovery from drinking water. As Waternet produces drinking water from surface water, the temperature varies between $1 \mathrm{oC}$ and $25 \mathrm{oC}$ which offers opportunities. The question is whether thermal energy recovery from drinking water really results in a reduction in GHG emissions, and especially at what costs. In addition, thermal energy recovery influences the drinking water temperature and thus may affect the microbiological drinking water quality. A specific case in Amsterdam showed that cold recovery from drinking water contributes to the reduction of GHG emissions, and reduces the costs of cooling. Preliminary laboratory experiments revealed no negative effects on the microbiological drinking water quality.
\end{abstract}

Keywords: • cold recovery $\bullet$ Greenhouse Gas emissions $\bullet$ drinking water • microbiological water quality • thermal energy •

CoRrespondence AdDress: Jan Peter van der Hoek, Ph.D., Professor, Delft University of Technology, Department of Water Management, Stevinweg 1, 2628 CN Delft, The Netherlands, email: j.p.vanderhoek@tudelft.nl. Stefan Mol, M.Sc., Researcher, Waternet, Department of Research \& Advice, Korte Ouderkerkerdijk 7, 1096 AC Amsterdam, The Netherlands, e-mail: stefan.mol@waternet.nl. Jawairia Imtiaz Ahmad, M.Sc., Ph.D. Candidate, Delft University of Technology, Department of Water Management, Stevinweg 1, 2628 CN Delft, The Netherlands, email: j.i.ahmad@tudelft.nl. Gang Liu, Ph.D., Associate Professor, Delft University of Technology, Department of Water Management, Stevinweg 1, 2628 CN Delft, The Netherlands, e-mail: g.liu$1 @$ @udelft.nl. Gertjan Medema, Ph.D., Professor, Delft University of Technology, Department of Water Management, Stevinweg 1, 2628 CN Delft, The Netherlands, e-mail: g.medema@tudelft.nl.

https://doi.org/10.18690/978-961-286-061-5.3

ISBN 978-961-286-061-5

(C) 2017 University of Maribor Press

Available at: http://press.um.si. 
$10^{\mathrm{TH}}$ InTERnAtional CONFERENCE ON Sustainable ENERGy AND ENVIRONMENTAL Protection (June $27^{\mathrm{TH}}-30^{\mathrm{TH}}, 2017$, BlED, SLOVENIA), RENEWABLE ENERGy SOURCES J. Peter van der Hoek, S. Mol, J. Imtiaz Ahmad, G. Liu \& G. Medema: Thermal Energy Recovery from Drinking Water

\section{$1 \quad$ Introduction}

Waternet is the public water utility of Amsterdam and surroundings. Waternet has the ambition to operate climate neutrally in 2020. A climate neutral operation is defined as an operation without a net greenhouse gas (GHG) emission. From 1990 to 2016 the GHG emission of Waternet decreased from 114,196 ton $\mathrm{CO}_{2}$-eq to 37,203 ton $\mathrm{CO}_{2}$-eq, as shown in Figure 1.

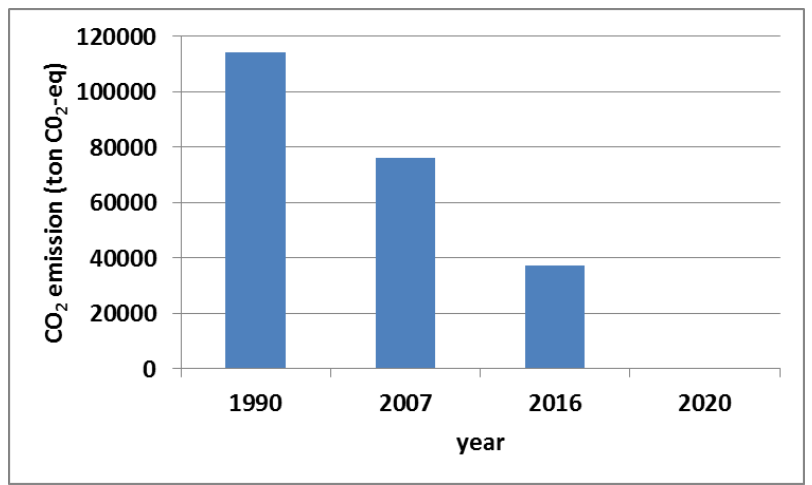

Figure 1. Greenhouse gas emissions of Waternet

Hence, additional measures have to be taken to realize the target in 2020. The policy of Waternet, and also a condition for the measures, is to select measures which can be incorporated in the operations of Waternet, and an inventory has been made recently [1]. An additional condition is that measures have to be cost neutral. One of the options concerns thermal energy recovery from drinking Water. As Waternet produces drinking water from surface water, which varies in temperature between $1{ }^{\circ} \mathrm{C}$ and $25^{\circ} \mathrm{C}$ [2], cold recovery for cooling and heat recovery for heating, from drinking water transport pipes, looks attractive. In case of cold recovery, the drinking water temperature after cold recovery increases, which may affect the microbiological drinking water quality [3].

The objective of this study was to analyse the potential of cold recovery from drinking water on three decisive criteria: the effect on the reduction of GHG emission of Waternet, the financial effects and the effects on microbiological drinking water quality.

\section{$2 \quad$ Materials and Methods}

GHG emissions were calculated based on the international Greenhouse Gas Protocol [4]. To determine the effect of GHG emissions on the climate footprint, the Intergovernmental Panel on Climate Change Global Warming Potential (IPCC GWP) 100a method [5] was used. Within this method, only the environmental problem of climate change is evaluated and the results are expressed in $\mathrm{CO}_{2}$ equivalents. 
Costs of cold recovery from drinking water were based on the Total Costs of Ownership (TCO) concept, in which total costs of acquisition and operating costs as well as costs related to replacement at the end of the life cycle are included. The evaluation period covered a period of 30 years.

For the GHG analysis and the cost analysis a specific case was selected: the "SanquinWaternet" case. Sanquin produces plasma products from blood and needs cooling capacity to store products. Just along Sanquin a $700 \mathrm{~mm}$ drinking water main of Waternet passes. From this main a supply pipe and return pipe are connected with a heat exchanger, as shown in Figure 2.

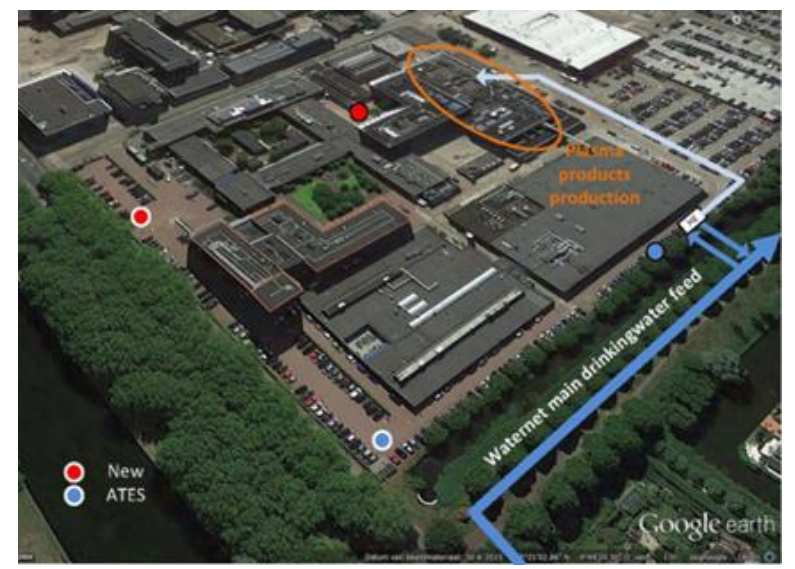

Figure 2. Delivery of cooling capacity, through a Waternet drinking water main, via a heat exchanger (HE), to Sanquin

Through this connection Waternet can supply Sanquin cooling capacity: during winter cooling capacity is delivered directly, and an aquifer thermal energy storage (ATES) is charged. In summer the ATES supplies the cooling capacity. Figure 3 shows the process set-up in winter and summer.

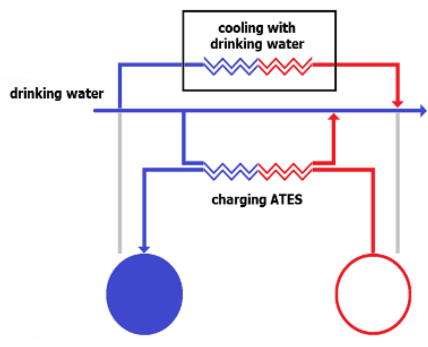

WINTER

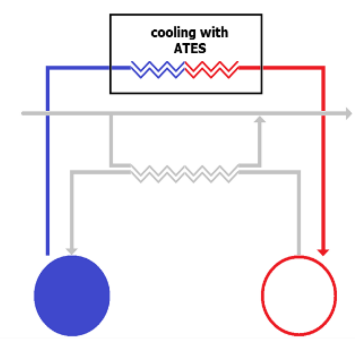

SUMMER

Figure 3. Process set-up of cooling with drinking water under winter and summer conditions 
$10^{\mathrm{TH}}$ InTERNATIONAL CONFERENCE ON SUSTAINABLE ENERGy AND ENVIRONMENTAL Protection (June $27^{\mathrm{TH}}-30^{\mathrm{TH}}, 2017$, BlED, SLOVENIA), RENEWABLE ENERGy SOURCES J. Peter van der Hoek, S. Mol, J. Imtiaz Ahmad, G. Liu \& G. Medema: Thermal Energy Recovery from Drinking Water

Effects on microbiological drinking water quality and biofilm formation were studied in three laboratory scale drinking water distribution systems (DWDS) [6]. Figure 4 shows the systems: system 1 is the study system with operational heat exchanger for cold recovery, system 2 is the control system with installed but not in operation heat exchanger to study the effect of additional surface area in the distribution system, while system 3 is the reference system without heat exchanger.

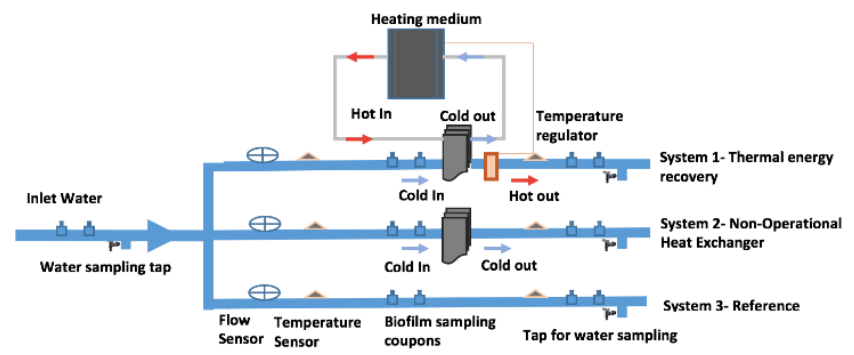

Figure 4. Laboratory scale drinking water distribution systems

Table 1 summarizes the operational conditions of the three laboratory scale systems. The systems were operated for a period of 6 months. As these preliminary laboratory experiments were carried out in the summer, the inlet drinking water temperature was relatively high $\left(18-19^{\circ} \mathrm{C}\right)$ compared to the inlet drinking water temperature at which the full-scale installation at Sanquin will be operated (temperatures below $15{ }^{\circ} \mathrm{C}$ ).

Table 1. Operational conditions of the laboratory scale DWDS

\begin{tabular}{|l|c|c|c|}
\hline \multirow{2}{*}{} & \multicolumn{3}{|c|}{ Laboratory scale DWDS } \\
\cline { 2 - 4 } & 1 & 2 & 3 \\
\hline Flow rate $(\mathrm{l} / \mathrm{m})$ & 4.5 & 4.5 & 4.5 \\
\hline Flow velocity $(\mathrm{m} / \mathrm{s})$ & 0.15 & 0.15 & 0.15 \\
\hline Inlet temperature $\left({ }^{\circ} \mathrm{C}\right)$ & 19 & 18 & 19 \\
\hline Outlet temperature $\left({ }^{\circ} \mathrm{C}\right)$ & 24 & 18 & 19 \\
\hline Pipe material & PVC & PVC & PVC \\
\hline Pipe diameter $(\mathrm{mm})$ & 25 & 25 & 25 \\
\hline Length of system $(\mathrm{m})$ & 10 & 10 & 10 \\
\hline
\end{tabular}

Microbiological water quality and biofilm analysis concerned Total Cell Concentrations (TCC), Adenosine Tri Phospate (ATP) concentrations, Aeromonas spp. and Legionella spp.. 


\section{$3 \quad$ Results and Discussion}

\subsection{Reduction of GHG emissions}

The results with respect to reduction of GHG emissions in the Sanquin case are shown in Table 2. This table compares two situations: the use of conventional cooling machines for cooling capacity, and the use of drinking water for cooling capacity.

Table 2. Electricity use and GHG emission of two systems for cooling in the "SanquinWaternet" case

\begin{tabular}{|l|c|c|}
\hline & $\begin{array}{c}\text { Electricity use } \\
(\mathrm{kWh} / \text { year })\end{array}$ & $\begin{array}{c}\text { GHG emission } \\
\text { (ton } \mathrm{CO}_{2} \text {-eq/year) }\end{array}$ \\
\hline $\begin{array}{l}\text { Traditional } \\
\text { cooling } \\
\text { machines }\end{array}$ & $2,000,000$ & 1,220 \\
\hline $\begin{array}{l}\text { Cooling with } \\
\text { drinking } \\
\text { water }\end{array}$ & 200,000 & 120 \\
\hline
\end{tabular}

Table 2 shows that in the case of cooling with drinking water, the GHG emission can be reduced with 1,100 ton $\mathrm{CO}_{2}$-eq. The potential may be even higher when it is allowed to heat up the drinking water after the heat exchange above $15^{\circ} \mathrm{C}$. Until now the limit has been set at $15^{\circ} \mathrm{C}$ for safety reasons. Research in the laboratory scale experiments have to reveal whether higher temperatures (without negative effects on microbiological water quality), and thus a higher GHG emission reduction, is feasible. In Amsterdam additional locations have to be found where thermal energy supply and demand matches and additional project can be realized to increase the contribution of thermal energy recovery in the target of 37,203 ton $\mathrm{CO}_{2}$-eq.

\subsection{Costs}

The results with respect to the costs are summarized in Table 3. Based on the TCO, the system using cooling with drinking water has a lower TCO than the system using traditional cooling machines. Specific aspects, characteristic for the "Sanquin-Waternet" case, contribute to this. By using cooling with drinking water it is not necessary to extend the existing electricity infrastructure, and noise reducing measures are not required. In addition, traditional cooling machines require a footprint which is not available. 
$10^{\mathrm{TH}}$ InTERnAtional CONFERENCE ON Sustainable ENERgy AND ENVIRONMENTAL Protection (June $27^{\mathrm{TH}}-30^{\mathrm{TH}}, 2017$, Bled, SLOVEnia), Renewable ENERGy SOURCES J. Peter van der Hoek, S. Mol, J. Imtiaz Ahmad, G. Liu \& G. Medema: Thermal Energy Recovery from Drinking Water

Table 3. Total costs of ownership of two systems for cooling in the "Sanquin-Waternet"

\begin{tabular}{|l|c|}
\hline \multicolumn{2}{|c|}{ Tase } \\
\hline $\begin{array}{l}\text { Traditional costs of Ownership } \\
\text { machines }\end{array}$ & 8.0 \\
\hline $\begin{array}{l}\text { Cooling with drinking } \\
\text { water }\end{array}$ & 5.4 \\
\hline
\end{tabular}

\subsection{Effect on microbiological drinking water quality and biofilm formation}

Figure 5 shows the Total Cell Concentrations (TTC) and ATP concentrations in the bulk water phase in the laboratory scale DWDSs. The results reveal similar microbiological water quality in both systems with a heat exchanger (operational heat exchanger - system 1 , and non-operational heat exchanger - system 2), before and after the heat exchanger, and in the reference system (system 3). This stable microbiological quality in the bulk water phase may be due to the short distance and retention time of the water (about one minute), which is too short for significant changes to occur.

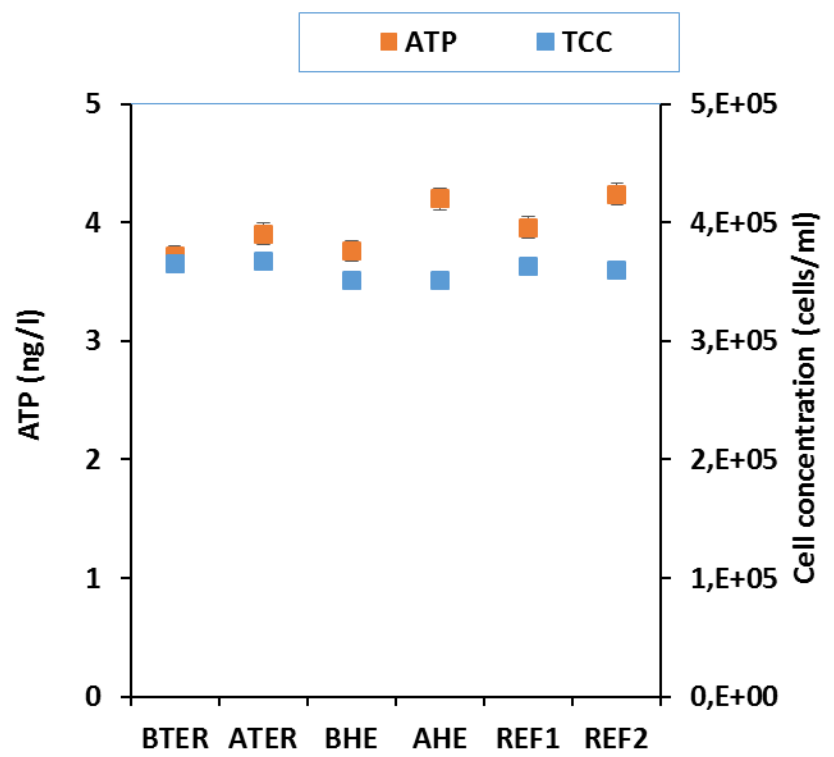

Figure 5. Microbiological water quality in DWDS 1 (BTER: before thermal energy recovery; ATER: after thermal energy recovery), DWDS 2 (BHE: before heat exchanger; AHE: after heat exchanger) and DWDS 3 (REF1: at start of DWDS; REF 2: at end DWDS $)(n=29)$ 

Protection (June $27^{\mathrm{TH}}-30^{\mathrm{TH}}, 2017$, BLED, SLOVENiA), RENEWABLE ENERGY SOURCES J. Peter van der Hoek, S. Mol, J. Imtiaz Ahmad, G. Liu \& G. Medema: Thermal Energy Recovery from Drinking Water

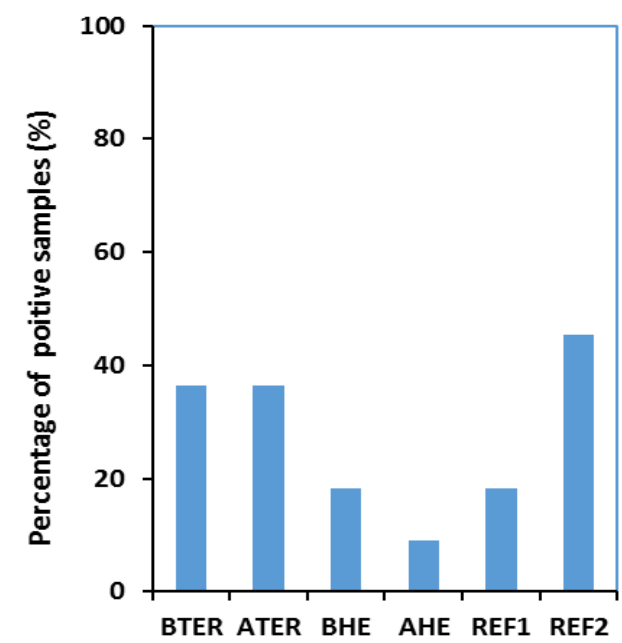

Figure 6. Positive Legionella spp. samples in bulk water in DWDS 1 (BTER: before thermal energy recovery; ATER: after thermal energy recovery), DWDS 2 (BHE: before heat exchanger; AHE: after heat exchanger) and DWDS 3 (REF1: at start of DWDS; REF 2: at end DWDS) $(n=11)$

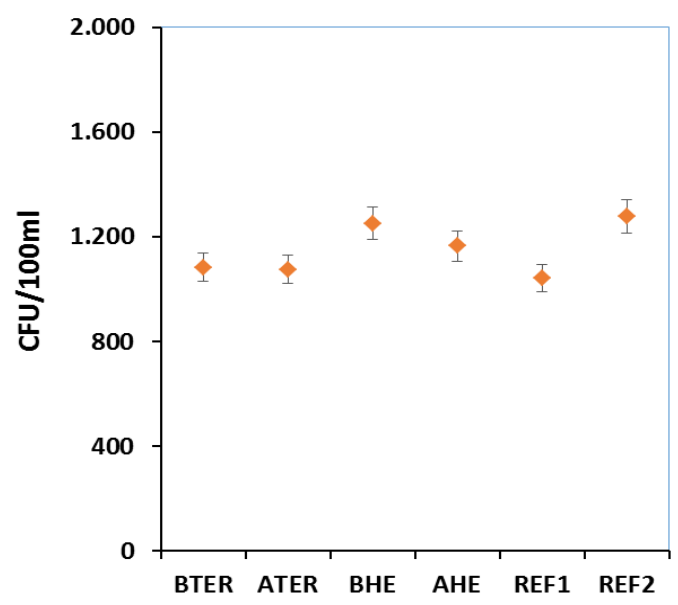

Figure 7. Aeromonas spp. in bulk water in DWDS 1 (BTER: before thermal energy recovery; ATER: after thermal energy recovery), DWDS 2 (BHE: before heat exchanger; AHE: after heat exchanger) and DWDS 3 (REF1: at start of DWDS; REF 2: at end DWDS $)(n=8)$ 
$10^{\mathrm{TH}}$ InTERnAtional CONFERENCE ON Sustainable ENERgy AND ENVIRONMENTAL Protection (June $27^{\mathrm{TH}}-30^{\mathrm{TH}}, 2017$, BlED, SLOVENIA), RENEWABLE ENERGy SOURCES J. Peter van der Hoek, S. Mol, J. Imtiaz Ahmad, G. Liu \& G. Medema: Thermal Energy Recovery from Drinking Water

Regarding the selected micro-organisms, Legionella spp. and Aeromonas spp., the water quality was also stable in the three DWDSs, as shown in Figures 6 and 7.

Figure 6 shows that Legionella was already present in the incoming water and does not increase after passing the heat exchanger, neither in the system with the operational heat exchanger (system 1), nor in the system with the non-operational heat exchanger (system 2). Figure 7 shows comparable numbers for Aeromonas spp. in all three systems, irrespective of higher temperature after cold recovery.

In contrast, higher cell numbers and biological activity were detected in biofilm formed after cold recovery compared to the biofilm before cold recovery (2.5 times higher TCC and ATP, Figure 8). The different results found for bulk water and biofilm phases is probably due to the big difference in their exposure time to higher temperature (one minute for bulk water and six months for biofilm). The increased growth of biofilm after cold recovery may lead to a change in microbial community composition and structure. This preliminary research only lasted for a period of six months. On the longer term a changed microbial community composition may affect the microbial water quality in the bulk water phase.

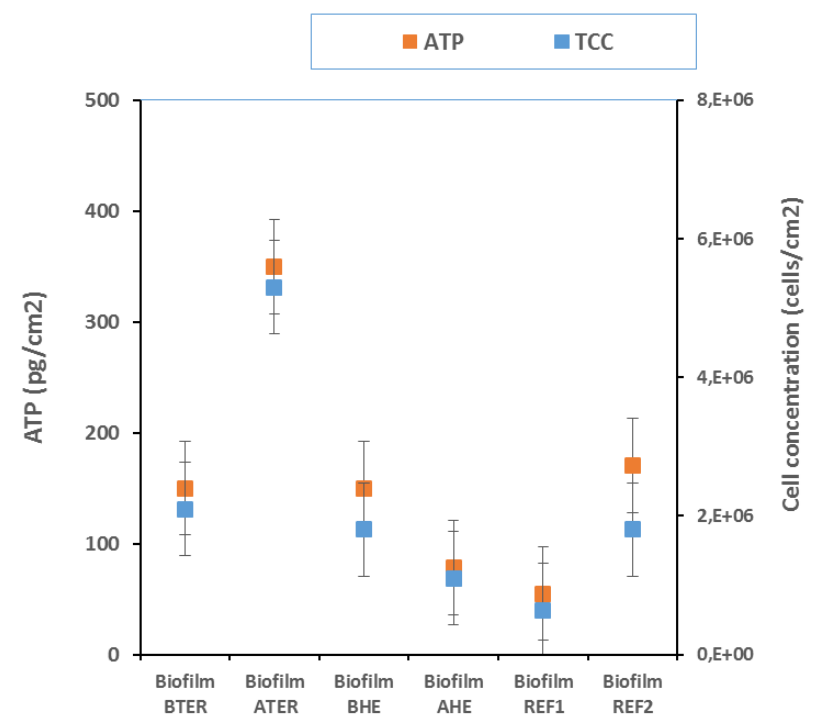

Figure 8. Biofilm development in DWDS 1 (BTER: before thermal energy recovery; ATER: after thermal energy recovery), DWDS 2 (BHE: before heat exchanger; AHE: after heat exchanger), DWDS 3 (REF1: at start of DWDS; REF 2: at end DWDS) and inside the operational heat exchanger in DWDS 1 (IHE) $(n=1)$ 


\section{Conclusions}

Thermal energy recovery from drinking water is applied at full scale and offers an alternative for the use of fossil fuel and thus contributes to the reduction of GHG emissions. Cold recovery, as applied in a specific case in Amsterdam, showed to have a positive business case: compared to a traditional system with cooling machines, TCO decreased from $€ 8.0 \mathrm{mln}$ to $€ 5.4 \mathrm{mln}$. Preliminary research at laboratory scale showed that the microbial drinking water quality, measured by TCC, ATP, Legionella spp. and Aeromonas spp., was not affected by cold recovery. However, biofilm formation increased after cold recovery and requires further research to reveal the potential role of enhanced biofilm growth on microbiological water quality.

\section{Acknowledgements}

The research was funded by water utility Waternet (Amsterdam, The Netherlands) and by Topsector Water TKI Water Technology Program of the Dutch Ministry of Economic Affairs, grant 2015 TUD003.

\section{References}

[1] J.P. van der Hoek, S. Mol, T. Janse, E. Klaversma and J. Kappelhof, "Selection and prioritization measures to realize climate neutral operation of a water cycle company", Journal of Water and Climate Change, vol. 7(1), pp. 29-38, 2016.

[2] J.P. van der Hoek, "Towards a climate neutral water cycle", Journal of Water and Climate Change, vol. 3(3), pp. 163-170, 2012.

[3] D. van der Kooij and P.W. van der Wielen, "Microbial growth in drinking water supplies: problems, causes, control and research needs", Water Intelligence Online, vol. 12, 9781780400419, 2013.

[4] World Resource Institute (WRI) and World Business Council for Sustainable Development (WBCSD), The Greenhouse Gas Protocol: A corporate Accounting and Reporting Standard, revised edition. Washington DC / Geneva: World Resource Institute / World Business Council for Sustainable Development, 2004.

[5] S. Solomon, D. Qin, M. Manning, Z. Chen, M. Marquis, K.B. Averyt, M. Tignor and H.L. Miller (eds), Contribution of Working Group I to the Fourth Assessment Report of the Intergovernmental Panel on Climate Change, Cambridge-UK and New York-USA: Cambridge University Press, 2007.

[6] J.I. Ahmad, G. Liu, J.P. van der Hoek and G. Medema, "Assessment of microbiological water quality changes linked to Thermal Energy Recovery from Drinking Water Distribution System", abstract submitted to the Leading Edge Technology Conference on Water and Wastewater Technologies, 29 May 2017 - 2 June 2017, Florianópolis, Brazil. 
$32 \quad 10^{\mathrm{TH}}$ International Conference on Sustainable EnERgy AND ENVIRONMENTAL Protection (June $27^{\mathrm{TH}}-30^{\mathrm{TH}}, 2017$, Bled, Slovenia), RenEWABle ENERGy SOURCES 
$10^{\mathrm{TH}}$ InTERnational CONFERENCE ON Sustainable ENERgy AND Environmental Protection (June 27 $7^{\mathrm{TH}}-30^{\mathrm{TH}}, 2017$, BLed, SLOVENIA), RENEWABLE ENERGy SOURCES

J. Krope, A.Ghani Olabi, D. Goričanec \& S. Božičnik

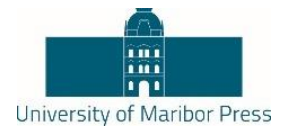

\title{
Modeling and Performance Analysis of a Hybrid System for a Residential Application
}

\author{
LEVENT BILIR \& NNURDAN YILDIRIM
}

\begin{abstract}
Heat pumps are generally used in providing heating/cooling energy to residents due to their capability of considerably higher energy supply compared to their electricity usage. The electricity use of a heat pump can be met from the grid or alternatively from a renewable energy system. In the present study, an on-grid hybrid system with a small scale wind turbine and photovoltaic panels, was focused on. The system supplies the electrical energy need of a heat pump for a $100 \mathrm{~m} 2$ detached house in İzmir, Turkey. A detailed dynamic hourly electricity generation analysis for the hybrid system was performed. The necessary cumulative electricity demand of the house was calculated using Design Builder and Energy Plus software. As a result, the coverage ratio of the hybrid system electricity generation for the total electricity demand of the house was calculated in monthly and yearly basis. The results showed a $124.5 \%$ yearly coverage ratio.
\end{abstract}

Keywords: $\bullet$ hybrid system $\bullet$ wind turbines $\bullet$ photovoltaic systems $\bullet$ heat pump $\bullet$ electricity coverage ratio $\bullet$.

CORRESPONDENCE AdDRESS: Levent Bilir, Yaşar University, Energy Systems Engineering Department, Kazımdirik Mahallesi, Üniversite Cd., 35100 Bornova/ İzmir, Turkey; e-mail: levent.bilir@yasar.edu.tr. Nnurdan Yildirim, Yaşar University, Energy Systems Engineering Department, Kazımdirik Mahallesi, Üniversite Cd., 35100 Bornova/ İzmir, Turkey; e-mail: nurdan.yildirim@yasar.edu.tr. 
$10^{\mathrm{TH}}$ INTERNATIONAL Conference ON Sustainable ENERGy and ENVIRONMENTAL PROTECTION (JuNE $27^{\mathrm{TH}}-30^{\mathrm{TH}}, 2017$, BLED, SLOVENIA), RENEWABLE ENERGY SOURCES L. Bilir \& N. Yildirim: Modeling and Performance Analysis of a Hybrid System for a Residential Application Introduction

The energy demand of residential buildings for air conditioning (heating, cooling) are increasing and the energy use for this purpose has reached high percentages in modern world total energy consumption recently. Heat pumps are widely used in order to provide the necessary heating/cooling energy to residents due to their capability of providing considerably higher heating/cooling energy than their electricity usage. The electrical energy required to operate a heat pump can be met from the grid or alternatively from a renewable energy system, which can also be connected to the grid. Additionally, hybrid systems which use more than one renewable energy sources are quite advantageous, because they can eliminate or at least vitiate the interrupted characteristics of the renewable sources. At regions where solar and wind energy potential is high (such as Aegean coast of Turkey), hybrid systems consisting of wind turbines and photovoltaic (PV) panels are generally favourable. Summary of recent simulation studies of such hybrid systems is given as follows. Nandi and Ghosh [1] took a wind-PV-battery hybrid system into consideration for a small community in Bangladesh. They analysed the energy generation of the system using HOMER software in Chittagong. They determined an optimum system and calculated an $89151 \mathrm{kWh}$ yearly electrical energy generation. Bakic et al. [2] performed the dynamical power generation simulation of a hybrid system in Belgrade, Serbia, consisting of 20 PVs with a total capacity of $3 \mathrm{~kW}$ and three different wind turbines. TRNSYS 16 software was used for the simulations. The yearly electrical energy generation of the hybrid systems were found as $5943 \mathrm{kWh}, 6800 \mathrm{kWh}$ and 8890 $\mathrm{kWh}$ for different cases. Li et al. [3] evaluated an autonomous wind/PV/battery hybrid power system for a household in Urumqi, China. They simulated a system with $5 \mathrm{~kW} \mathrm{PV}$ arrays and a $2.5 \mathrm{~kW}$ wind turbine using HOMER software. They estimated the yearly electricity generation as $11549 \mathrm{kWh}, 72 \%$ produced by PVs and $28 \%$ produced by the wind turbine. Belmili et al. [4] analysed a stand-alone PV-wind turbine hybrid system and they developed a program used in hybrid system sizing. The developed program simulated the hybrid system operation for each hour and calculated the electricity generation for the relevant hour. Sinha and Chandel [5] evaluated photovoltaic-micro wind based hybrid systems for 12 locations in western Himalayan state in India. They used estimated solar and wind data derived using artificial neural network. The simulation results obtained from HOMER software were used to determine the required number of PVs and wind turbines for the evaluated locations. Marchenko and Solomin [6] focused on a stand-alone hybrid energy system consisting of wind turbines, PVs, batteries and a hydrogen production system used for energy storage purpose. They evaluated the mentioned system for the coast of Baikal Lake in Russia and for maximum loads of 10 $\mathrm{kW}$ and $100 \mathrm{~kW}$. They calculated the efficiency of the evaluated systems as well as simultaneous electricity and hydrogen production amounts.

In the present study, a hybrid system, which consists of a small scale wind turbine and PV panels, was focused on. The hybrid system supplies the required electrical energy need of a heat pump, which will provide the necessary heating/cooling, for a detached house in İzmir, Turkey. A detailed dynamic hourly electricity generation analysis for the two components of the hybrid system was performed. The necessary heating/cooling 
cumulative electricity demand of the house was calculated using Design Builder and Energy Plus softwares. As a result, the coverage ratio of the hybrid system electricity generation for the total electricity demand of the house was calculated in monthly and yearly basis, using hourly generation values.

\section{Evaluated House and Heating / Cooling Loads}

A one storey detached house with a living room, a kitchen, a bathroom and two bedrooms, in İzmir, Turkey, was modelled using Design Builder software. The schematic view of the house is given in Figure 1 [7].

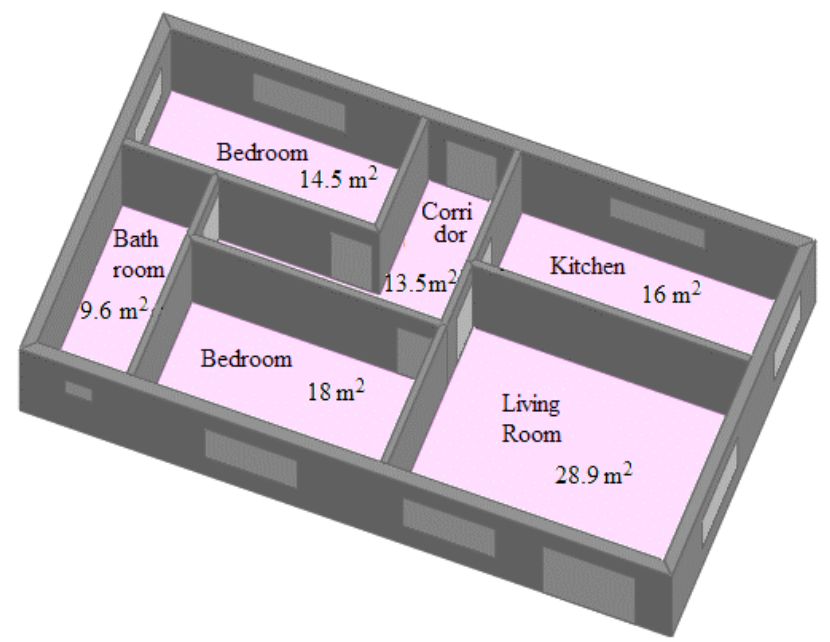

Figure 1. Schematic View of the House [7]

A summary of overall heat transfer coefficient for construction components, used in heating/cooling load of the house, are given in Table 1.

Table 1. Overall Heat Transfer Coefficient (U) for Construction Components [7]

\begin{tabular}{|c|c|}
\hline Construction Component & $\mathrm{U}\left(\mathrm{W} / \mathrm{m}^{2} \mathrm{~K}\right)$ \\
\hline Wall & 0.581 \\
\hline Roof & 0.447 \\
\hline Floor & 0.615 \\
\hline Window & 2.282 \\
\hline Exterior Door & 2.282 \\
\hline
\end{tabular}

The occupancy for the house and operation regime for heating and cooling were assumed as given in Table 2. The heating/cooling system was operated at half capacity for unoccupied periods. It was assumed that four people were living in the house. 
$10^{\text {TH }}$ International CONFEREnce on Sustainable Energy and Environmental Protection (June $27^{\mathrm{TH}}-30^{\mathrm{TH}}, 2017$, Bled, SLOVENIA), RENEWABLE ENERGY SOURCES L. Bilir \& N. Yildirim: Modeling and Performance Analysis of a Hybrid System for a Residential Application

Table 2. Occupancy and Operation Regime for the House [7]

\begin{tabular}{|c|c|c|c|}
\hline \multicolumn{2}{|c|}{} & Week days & Weekend days \\
\hline $\begin{array}{c}\text { Occupied } \\
\text { Hours }\end{array}$ & H & 18:00-08:00 & 24 hours \\
\cline { 2 - 4 } & C & $18: 00-08: 00$ & 24 hours \\
\hline $\begin{array}{c}\text { Operation } \\
\text { Regime }\end{array}$ & H & 17:00-08:00 & 24 hours \\
\cline { 2 - 4 } & C & $18: 00-24: 00$ & $11: 00-24: 00$ \\
\hline
\end{tabular}

H: Heating, C: Cooling

The indoor design and set back temperature values for heating and cooling periods were taken as $22{ }^{\circ} \mathrm{C} / 20^{\circ} \mathrm{C}$ and $24{ }^{\circ} \mathrm{C} / 26^{\circ} \mathrm{C}$, respectively. Hourly outdoor temperature values for a year in İzmir, Turkey, used in heating/cooling load calculations, are illustrated in Figure 2.

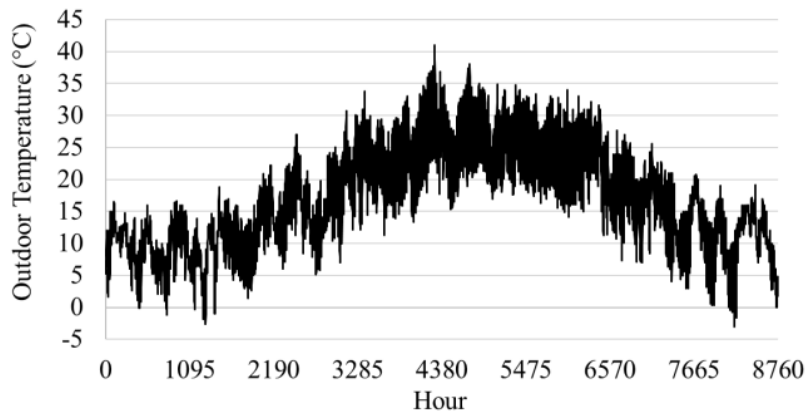

Figure 2. Hourly Outdoor Temperature for İzmir, Turkey

As a result, the heating and cooling load of the building was calculated as summarized in Table 3. The yearly total heating and cooling load of the evaluated house were determined as $8750.7 \mathrm{kWh}$ and $3773.1 \mathrm{kWh}$, respectively. 
Table 3. Monthly and Yearly Heating/Cooling Load of the House

\begin{tabular}{|c|c|c|}
\hline Month & $\begin{array}{c}\text { Heating Load } \\
\mathrm{kWh}\end{array}$ & $\begin{array}{c}\text { Cooling Load } \\
\mathrm{kWh}\end{array}$ \\
\hline January & 1802.8 & 0.0 \\
\hline February & 1616.3 & 0.0 \\
\hline March & 1211.2 & 0.0 \\
\hline April & 586.6 & 0.0 \\
\hline May & 59.3 & 361.3 \\
\hline June & 0.0 & 847.8 \\
\hline July & 0.0 & 993.5 \\
\hline August & 0.0 & 905.6 \\
\hline September & 0.0 & 591.9 \\
\hline October & 383.5 & 73.0 \\
\hline November & 1284.5 & 0.0 \\
\hline December & 1806.5 & 0.0 \\
\hline TOTAL & 8750.7 & 3773.1 \\
\hline
\end{tabular}

\section{$3 \quad$ Hybrid System Description}

The hybrid system, illustrated in Figure 3, is consisted of a small scale wind turbine with a rated capacity of $3.6 \mathrm{~kW}$ and $18 \mathrm{PV}$ panels, each of which has a capacity of $200 \mathrm{~W}$ (Total PV panel capacity is also $3.6 \mathrm{~kW}$, which is equal to the wind turbine capacity). A heat pump with a typical coefficient of performance (COP) value of 2.5 provides necessary heating/cooling to the house using the electricity generated by the on grid hybrid system. In this way, when the generation of the hybrid system is not sufficient, additional electricity can be taken from the grid. Similarly, when the generation of the hybrid system is higher than the heat pump need, the surplus electricity can be fed to the grid.

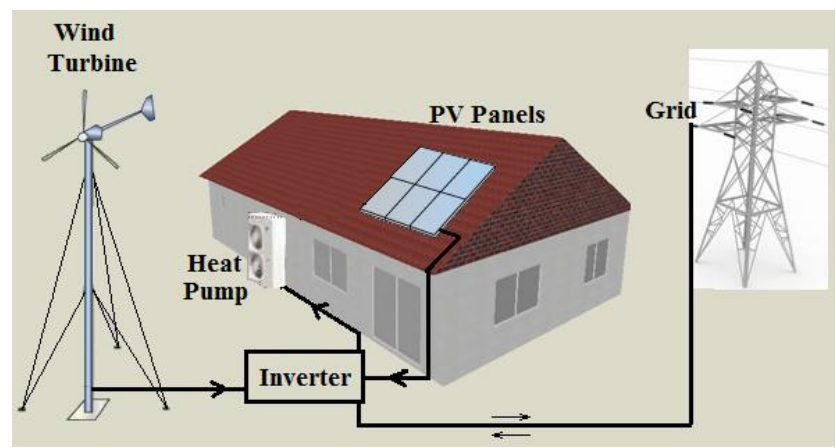

Figure 3. Evaluated Hybrid System 
$10^{\mathrm{TH}}$ InTERnATIONAL CONFERENCE ON Sustainable EnERgy AND ENVIRONMENTAL Protection (JuNE $27^{\mathrm{TH}}-30^{\mathrm{TH}}, 2017$, BLED, SLOVENIA), RENEWABLE ENERGY SOURCES L. Bilir \& N. Yildirim: Modeling and Performance Analysis of a Hybrid System for a Residential Application

\subsection{Properties of the selected PV panels}

Sanyo HIP-200BA3 PV panels were used for the evaluated hybrid system. The characteristics of these panels are given in Table 4.

Table 4. PV Panel Characteristics [8]

\begin{tabular}{|c|c|}
\hline Specification & Value \\
\hline Maximum Power & $200 \mathrm{~W}$ \\
\hline Conversion Efficiency $\left(\eta_{m p, r e f}\right)$ & $17 \%$ \\
\hline $\begin{array}{c}\text { Temperature Coefficient of Maximum } \\
\text { Power }\left(\mu_{m p}\right)\end{array}$ & $-0.29 \% /{ }^{\circ} \mathrm{C}$ \\
\hline Panel Area & $1.179 \mathrm{~m}^{2}$ \\
\hline Reference Temperature $\left(T_{r e f}\right)$ & $25^{\circ} \mathrm{C}$ \\
\hline $\begin{array}{c}\text { Solar Irradiance at Reference } \\
\text { Conditions }\left(G_{r e f}\right)\end{array}$ & $1000 \mathrm{~W} / \mathrm{m}^{2}$ \\
\hline
\end{tabular}

Properties of the selected small scale wind turbine

A FinnWind Tuule E200 wind turbine, with the characteristics given in Table 5, was selected to be used as a component in the hybrid system.

Table 5. Wind Turbine Characteristics [9]

\begin{tabular}{|c|c|}
\hline Specification & Value \\
\hline Rated Power $\left(P_{R}\right)$ & $3600(\mathrm{~W})$ \\
\hline Cut-In Speed $\left(v_{c i}\right)$ & $2.1(\mathrm{~m} / \mathrm{s})$ \\
\hline Rated Speed $\left(v_{R}\right)$ & $10(\mathrm{~m} / \mathrm{s})$ \\
\hline Hub Height & $12(\mathrm{~m})$ \\
\hline
\end{tabular}

\section{Calculation Procedure of Electrical Energy Generation for the Hybrid System}

Hourly solar radiation data and wind speed values measured at $10 \mathrm{~m}$ height for İzmir, Turkey were used in the electrical energy generation calculations.

\subsection{PV Panel Electrical Energy Generation}

The steps for hourly PV panel electricity generation are given as follows [10];

- Calculation of hourly radiation incident of the tilted PV panel; $\bar{I}_{T}$

- Calculation of hourly PV efficiency; $\bar{\eta}_{i}$

- Calculation of hourly PV electricity generation; $\bar{E}_{i}$ 
For the calculation of $\bar{I}_{T}$, firstly, daily solar radiation on horizontal surface in $\mathrm{Mj} / \mathrm{m}^{2}$ was calculated as [11];

$\bar{H}=I_{2}+\left(I_{1}-I_{2}\right)\left|\sin \left[\frac{\pi}{365}(d+5)\right]\right|^{1.5}$

where, $I_{1}=24.15$ and $I_{2}=5.27$ for İzmir.

Hourly solar radiation on the tilted surface can be determined for each hour with the daily value calculated using Equation 1 as [10];

$\bar{I}_{T}=\bar{K}_{T} \bar{H}_{o}\left[\left(r_{t}-\frac{\bar{H}_{d}}{\bar{H}} r_{d}\right) R_{b}+\frac{\bar{H}_{d}}{\bar{H}} r_{d}\left(\frac{1+\cos \beta}{2}\right)+\rho_{g} r_{t}\left(\frac{1-\cos \beta}{2}\right)\right]$

The slope angle of the PVs were taken as $\quad \beta=30^{\circ}$, which is the inclination angle of the house roof, and all 18 PVs were mounted only on the south faced half part of the roof.

Hourly PV efficiency can be found with the calculated solar radiation on the tilted panel as [12];

$\bar{\eta}_{i}=\eta_{m p, r e f} \times\left(1-\mu_{m p}\left(T_{c}-T_{r e f}\right)+\delta \cdot \ln \left(\frac{\bar{I}_{T}}{G_{r e f}}\right)\right)$

where, cell temperature [13]; $T_{c}=T_{a}+k \times \bar{I}_{T}$

The parameter $\mathrm{k}$ was taken as 0.02 for well cooled PV array type [13]. The hourly ambient temperature values, illustrated in Figure 2, were used in hourly cell temperature values. The solar radiation coefficient $(\delta)$ was chosen as 0.052 for monocrystalline silicon PVs [12].

Finally, hourly electrical energy generation of PV panels were calculated as [10];

$\bar{E}_{i}=\frac{\bar{\eta}_{i} \times \text { Module number } \times \text { Single modulearea } \times \bar{I}_{T}}{3600}$

\subsection{Wind turbine electrical energy generation}

Typical power generation of a wind turbine is given in Figure 4. The wind turbine does not generate any power when the wind speed is below cut-in or above cot-out wind speed. When the wind blows with a velocity between rated wind speed and cut-out wind speed, the wind turbine generates its rated power. When wind speed is between cut-in and rated wind speed values, the power generation increases with the increasing wind speed as shown in Figure 4. 

Protection (JuNE $27^{\mathrm{TH}}-30^{\mathrm{TH}}, 2017$, BLED, SLOVENIA), RENEWABLE ENERGY SOURCES L. Bilir \& N. Yildirim: Modeling and Performance Analysis of a Hybrid System for a Residential Application

The wind turbine power generation can be summarized as follows [14];

$$
P=\left\{\begin{array}{rrr}
0 & \text { when } v<v_{c i} \\
a+b v^{k} & \text { when } v_{c i} \leq v \leq v_{R} \\
P_{R} & \text { when } v_{R} \leq v \leq v_{c o} \\
0 & \text { when } v>v_{c o}
\end{array}\right.
$$

where, $a=\frac{P_{R} v_{c i}^{k}}{v_{c i}^{k}-v_{R}^{k}}$ and $b=\frac{P_{R}}{v_{R}^{k}-v_{c i}^{k}}$

In order to find the shape parameter $(\mathrm{k})$ of Weibull distribution, the hourly wind speed data, measured at $10 \mathrm{~m}$ height, were evaluated and numerical solution of maximum likelihood method given by Equation 6 was obtained

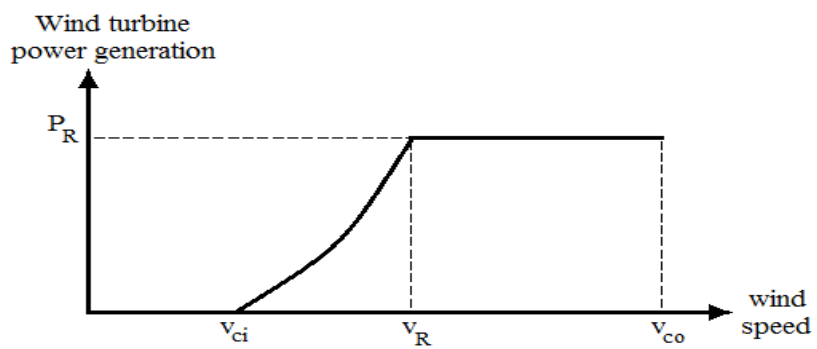

Figure 4. Power Generation of a Wind Turbine

$k=\left[\frac{\sum_{i=1}^{n} v_{l}^{k} \ln \left(v_{i}\right)}{\sum_{i=1}^{n} v_{i}^{k}}-\frac{\sum_{i=1}^{n} \ln \left(v_{i}\right)}{n}\right]^{-1}$

The scale parameter (c) can also be calculated when the shape parameter is calculated by Equation 7.

$c=\left(\frac{1}{n} \sum_{i=1}^{n} v_{i}^{k}\right)^{1 / k}$

As a result, the shape and scale parameters for $10 \mathrm{~m}$ height were calculated as 1.973 and $\quad 3.0936 \mathrm{~m} / \mathrm{s}$, respectively. However, the hub height of the selected wind turbine is $12 \mathrm{~m}$. For this reason, the shape and scale parameters for $12 \mathrm{~m}$ height were determined using Equations 8 and 9 [15].

$k_{z}=k_{a} \times \frac{\left[1-0.088 \times \ln \left(\frac{z_{a}}{10}\right)\right]}{\left[1-0.088 \times \ln \left(\frac{z}{10}\right)\right]}$ 
$c_{z}=c_{a} \times\left(\frac{z}{z_{a}}\right)^{n}$

where, $n=\frac{\left[0.37-0.088 \times \ln c_{a}\right]}{\left[1-0.088 \times \ln \left(\frac{z_{a}}{10}\right)\right]}$

Finally, the shape and scale parameters at the turbine's hub height were found as 2.0051 and $3.2501(\mathrm{~m} / \mathrm{s})$, respectively.

Hourly wind speed data] for İzmir, Turkey in 2014 [16] are presented in Figure 5.

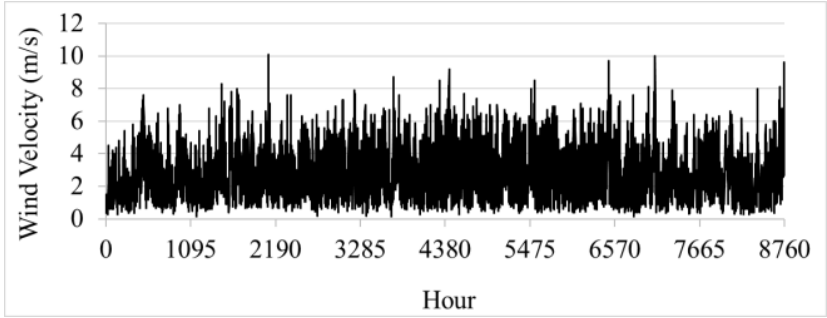

Figure 5. Hourly Wind Speed for İzmir, Turkey

The hourly wind speed data were compared with the characteristic wind speed values of the wind turbine and hourly wind turbine electricity generation was calculated considering the conditions indicated with Equation 5.

\section{$5 \quad$ Results and Discussion}

The hourly electricity demand of the heat pump, which covers the heating/cooling load of the investigated house, was computed by taking a COP value of 2.5 in heating and cooling. The electricity generation of the $18 \mathrm{PV}$ panels and the small scale wind turbine was also calculated in hourly basis. However, since the values for 8760 hours (for a year) cannot be practically shown here, monthly heat pump electricity demand and monthly hybrid system electricity generation values (calculated as the monthly sum of hourly values) are shown here.

Similarly, yearly heating/cooling and hybrid system electricity generation values were computed as the sum of the monthly values. Table 6 summarizes the monthly/yearly electricity demand of the heat pump and the monthly/yearly electricity generation of the PV panels and the wind turbine. Coverage ratio values indicated in Table 6 represent the percentages of the electrical energy given to the heat pump by the hybrid system for the relevant month/year. It can be seen from Table 6 that the hybrid system can provide all electricity demand of the heat pump between March and October. The maximum coverage ratio for PV panels was encountered in May with $272.3 \%$, as the heat pump electricity demand was very low and available solar irradiation is high. The maximum electricity generation of PV panels was in July with $489.6 \mathrm{kWh}$, due to very high solar 
$10^{\mathrm{TH}}$ InTERnAtional CONFERENCE ON Sustainable ENERgy AND ENVIRONMENTAL Protection (June $27^{\mathrm{TH}}-30^{\mathrm{TH}}, 2017$, Bled, SLOVENIA), RENEWABLE ENERGy SOURCES L. Bilir \& N. Yildirim: Modeling and Performance Analysis of a Hybrid System for a Residential Application

irradiation in this month. Similarly, the maximum coverage ratio for the small scale wind turbine was observed in May with $112.8 \%$. However, the maximum wind turbine electricity generation was in July with $241.9 \mathrm{kWh}$. The results indicated that if only PV panels were used to generate electricity, the coverage ratio would be between $22.4 \%$ (in December) and $272.3 \%$ (in May). Similarly, if only small scale wind turbine was installed for electricity generation, the coverage ratio would be between $14.1 \%$ (in February) and $112.8 \%$ (in May). The wind turbine had a yearly coverage ratio of $40.3 \%$, while $18 \mathrm{PV}$ panels, with the same capacity of the wind turbine, had a coverage ratio of $84.3 \%$ (around double of the wind turbine coverage ratio). It can be obviously seen that the use of only $18 \mathrm{PV}$ panels with a total capacity of $3.6 \mathrm{~kW}$ or the use of only selected small scale wind turbine with a capacity of $3.6 \mathrm{~kW}$ cannot provide all yearly electrical energy demand of the heat pump which will supply necessary heating/cooling to the evaluated house. The important outcome of the study is that the use of both PV panels and the wind turbine as a hybrid system increased the yearly coverage ratio to $124.5 \%$. The hybrid system has a maximum and minimum coverage ratio values in May and January with $385.1 \%$ and $41.9 \%$, respectively. The maximum and minimum hybrid system electrical energy generation values are $731.4 \mathrm{kWh}$ in July and $302.5 \mathrm{kWh}$ in January, respectively.

Table 6. Coverage Ratio Values

\begin{tabular}{|c|c|c|c|c|c|c|c|}
\hline & \multirow{2}{*}{$\begin{array}{c}\text { Heating } \\
\text { Electricity } \\
\text { Demand } \\
\mathrm{kWh}\end{array}$} & $\begin{array}{c}\text { Electricity } \\
\text { Demand } \\
\mathrm{kWh}\end{array}$ & $\begin{array}{c}\text { Electricity } \\
\text { Generation } \\
\mathrm{kWh}\end{array}$ & $\begin{array}{c}\text { Wind Turbine } \\
\text { Electricity } \\
\text { Generation } \\
\mathrm{kWh}\end{array}$ & $\begin{array}{c}\text { PV } \\
\text { Panels }\end{array}$ & $\begin{array}{c}\text { Wind } \\
\text { Turbine }\end{array}$ & $\begin{array}{c}\text { Hybrid } \\
\text { System }\end{array}$ \\
\hline January & 721.1 & 0.0 & 180.3 & 122.2 & 25.0 & 16.9 & 41.9 \\
\hline February & 646.5 & 0.0 & 240.5 & 91.2 & 37.2 & 14.1 & 51.3 \\
\hline March & 484.5 & 0.0 & 337.9 & 212.8 & 69.7 & 43.9 & 113.7 \\
\hline April & 234.6 & 0.0 & 390.1 & 137.4 & 166.2 & 58.5 & 224.8 \\
\hline May & 23.7 & 144.5 & 458.1 & 189.7 & 272.3 & 112.8 & 385.1 \\
\hline June & 0.0 & 339.1 & 470.2 & 159.0 & 138.7 & 46.9 & 185.6 \\
\hline July & 0.0 & 397.4 & 489.6 & 241.9 & 123.2 & 60.9 & 184.1 \\
\hline August & 0.0 & 362.2 & 469.9 & 234.3 & 129.7 & 64.7 & 194.4 \\
\hline September & 0.0 & 236.8 & 412.7 & 184.0 & 174.3 & 77.7 & 252.0 \\
\hline October & 153.4 & 29.2 & 359.3 & 144.9 & 196.8 & 79.4 & 276.1 \\
\hline November & 513.8 & 0.0 & 253.9 & 140.8 & 49.4 & 27.4 & 76.8 \\
\hline December & 722.6 & 0.0 & 162.0 & 158.5 & 22.4 & 21.9 & 44.3 \\
\hline TOTAL & 3500.3 & 1509.2 & 4224.5 & 2016.6 & 84.3 & 40.3 & 124.5 \\
\hline
\end{tabular}

6 Conclusion

A hybrid system consisting of $18 \mathrm{PVs}$ (with a total capacity of $3.6 \mathrm{~kW}$ ) and a small scale wind turbine was investigated in the study. The hourly heating/cooling load of a house with $100 \mathrm{~m}^{2}$ floor area in İzmir, Turkey was calculated using Design Builder and Energy Plus softwares. The hourly electricity demand of a heat pump with a COP value of 2.5 was determined in order to supply necessary heating/cooling to the house. Monthly and yearly coverage ratio values of the hybrid system for the electrical energy need of the heat pump were calculated. The results showed that the hybrid system can cover all 
monthly electrical energy need of the heat pump between March and October. The yearly coverage ratio was found to be $124.5 \%$. This final result showed that the surplus energy can be given to the grid in order to provide financial income.

\section{References}

[1] S. K. Nandi, H. R. Ghosh, "Prospect of wind-PV-battery hybrid power system as an alternative to grid extension in Bangladesh", Energy, vol. 35, pp. 3040-3047, 2010.

[2] V. Bakic, M. Pezo, Z. Stevanovic, M. Zivkovic, B. Grubor, "Dynamical simulation of PV/wind hybrid energy conversion system”, Energy, vol. 45, pp. 324-328, 2012.

[3] C. Li, X. Ge, Y. Zheng, C. Xu, Y. Ren, C. Song, C. Yang, "Techno-economic feasibility of autonomous hybrid wind/PV/battery power system for a household in Urumqi, China", Energy, vol. 55, pp. 263-272, 2013.

[4] H. Belmili, M. Haddadi, S. Bacha, M. F. Almi, B. Bendib, "Sizing stand-alone photovoltaic-wind hybrid system: Techno-economic analysis and optimization", Renewable and Sustainable Energy Reviews, vol. 30, pp. 821-832, 2014.

[5] S. Sinha, S. S. Chandel, "Prospects of solar photovoltaic-micro-wind based hybrid power systems in western Himalayan state of Himachal Pradesh in India”, Energy Conversion and Management, vol. 105, pp. 1340-1351, 2015.

[6] O. V. Marchenko, S. V. Solomin, "Modeling of hydrogen and electrical energy storages in wind/PV energy system on the Lake Baikal coast", International Journal of Hydrogen Energy, http://dx.doi.org/10.1016/j.ijhydene.2017.02.076, 2017.

[7] G. Gokcen, E. Kuzgunkaya, N. Yildirim, M. C. Yaman, "Türkiye'nin farklı iklim koşullarında isıl konfor sıcaklıklarına bağlı olarak konutların enerji performansının değerlendirilmesi”, TTMD Project (2010) (in Turkish).

[8] New Mexico Solar Energy Association. Sanyo HIT photovoltaic module specifications. http://www.nmsea.org/Solar_Fiesta/Solar_Fiesta2006/Tech_Sessions/Sanyo\%20HIPxxxBA3\%20Module.pdf, 2016.

[9] Finn Wind Tuule Wind Turbines. http://www.finnwind.fi/eng/smallwind/small-windturbine-finnwind.pdf, 2017.

[10] J.A. Duffie, W.A. Beckman, Solar Engineering of Thermal Processes, 4th ed., New Jersey: John Wiley \& Sons, 2013.

[11] H. Bulut, O. Büyükalaca, "Simple model for the generation of daily global solar-radiation data in Turkey", Applied Energy, vol. 84, pp. 477-491, 2007.

[12] M.E.A. Slimani, M. Amirat, I. Kurucz, S. Bahria, A. Hamidat, W.B. Chaouch, "A detailed thermal-electrical model of three photovoltaic/thermal (PV/T) hybrid air collectors and photovoltaic (PV) module: Comparative study under Algiers climatic conditions", Energy Conversion and Management, vol. 133, pp. 458-476, 2017.

[13] M. D’Orazio, C. Di Perna, E.Di Giuseppe, "Performance assessment of different roof integrated photovoltaic modules under Mediterranean climate”, Energy Procedia, vol. 42, pp. 183-192, 2013.

[14] G.L. Johnson, Wind Energy Systems. University Reprints, 2006.

[15] K. Tar, "Some statistical characteristics of monthly average wind speed at various heights", Renewable and Sustainable Energy Reviews, vol. 12, pp. 1712-1724, 2008.

[16] Turkish Republic Ministry of Forestry and Water Affairs - Meteorology General Directorate, 2014. 
$44 \quad 10^{\mathrm{TH}}$ International Conference on Sustainable EnERgy AND ENVIRONMENTaL Protection (June $27^{\mathrm{TH}}-30^{\mathrm{TH}}, 2017$, Bled, SLOVEnia), Renewable EnERGY SOURCES 
$10^{\mathrm{TH}}$ InTERnAtional CONFERENCE ON Sustainable ENERgy AND Environmental Protection (June 27 $7^{\mathrm{TH}}-30^{\mathrm{TH}}, 2017$, BLed, SLOVENIA), RENEWABLE ENERGy SOURCES

J. Krope, A.Ghani Olabi, D. Goričanec \& S. Božičnik

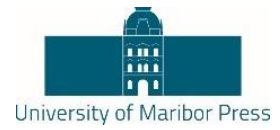

\title{
Smart Solar Battery Charger for PV-Application
}

\author{
KHADIJA EL KAMOUNY, HASSANE MAHMOUDI \& BRAHIM LAKSSIR
}

\begin{abstract}
This paper focuses on the sizing of a smart solar battery charger block and presents a new method to track the maximum power point and the load regulation. For this purpose, a specific architecture and design of a high-reliable, robust, stable and miniaturized system are proposed. A photovoltaic charger is designed to regulate the battery charging, the present system employs an intelligent algorithm including the criteria of reliability.
\end{abstract}

Keywords: $\bullet$ Solar battery charger $\bullet$ sizing $\bullet$ simulation $\bullet$ test $\bullet$ smart $\bullet$.

Correspondence AdDress: ADDRESSES: Khadija El Kamouny, Ph.D., Mohammed V-Agdal University, Ecole Mohammadia d'Ingénieurs, Electrical department. Avenue Ibn Sina, Rabat 10000, Morocco, e-mail: k.elkamouny@gmail.com. Brahim Lakssir, Engineer., Packaging \& assemblay department director, Moroccan foundation for Advanced Science, Innovation and Research Rabat Design Center, Avenue Mohamed El Jazouli - Madinat Al Irfane 10100 Rabat, Morocco, e-mail: b.lakssir@mascir.com. Hassane Mahmoudi, Ph.D., Professor, Mohammed VAgdal University, Ecole Mohammadia d'Ingénieurs, Electrical department. Avenue Ibn Sina, Rabat 10000, Morocco, e-mail: mahmoudi@emi.ac.ma. 
$10^{\mathrm{TH}}$ INTERNATIONAL CONFERENCE ON Sustainable ENERGY AND ENVIRONMENTAL Protection (June $27^{\mathrm{TH}}-30^{\mathrm{TH}}, 2017$, Bled, SLOVENIA), RENEWABLE ENERGY SOURCES K. EL Kamouny, H. Mahmoudi \& B. Lakssir: Smart Solar Battery Charger for PVApplication

\section{$1 \quad$ Introduction}

Batteries are devices for storing electrical energy in a chemical form. They are widely used in portable devices, emergency power supplies, electric bikes, Electric Vehicles (EV) and in Solar Fields, specially the solar energy, as one of the most important renewable energy sources [1], According to a report from the US Department of Energy, the production of renewable energy electricity in the US in 2011 was twice that in 2010 [2]. To benefit continuously from the renewable energy for some isolated communities, a means of energy storage is required. The more useful way is charging batteries. The charging of the batteries is performed by using an electronic system that has a considerable impact on the battery life. The present charger is based on a specific DC/DC [3],[4] converter that is dedicated to be used in this application. Portable electronic products, electric bikes and electric vehicles [5] have become more popular due to concerns over climate change and air pollution, in large urban cities [6],[7], and the progress of the battery industry in recent years. The performance of the batteries significantly affects the operation of portable electronic products and electric bikes. The performance and lifetime of a battery is affected by the battery charger. Therefore, the operation of a battery depends on a battery charger with good controllability. Battery chargers for portable electronic products and electric bikes require a power source with a low DC voltage. However, distribution power systems or PV sources supply a high AC voltage. Therefore, a battery charger acts as an interface between a distribution power system and the battery set [8].

In this paper, a particular attention is paid to the conception of an electronic BMS [9]. The steps of the design process and the test of a smart battery charger using a solar panel $250 \mathrm{~W}$ will be detailed. A lead acid battery with specifications described below will be used.

\section{Theoretical Aspects}

\subsection{Battery types}

A battery is characterized by a battery voltage in volt $(\mathrm{V})$, a battery capacity $\mathrm{C}$ in Amperehour (Ah), and a maximum current, which is important in the case of engine start. Depending on the technology, there are four major types of batteries: Lead (Pb), Nickel Cadmium (Ni-Cd), Nickel Metal Hydride (NiMH) and lithium (Li) batteries. 
Table 1. Four Major Types of Batteries

\begin{tabular}{|c|c|c|c|c|}
\hline Specifications & $\begin{array}{c}\text { Lead } \\
(\mathbf{P b})\end{array}$ & $\begin{array}{l}\text { Nickel- } \\
\text { Cadmium } \\
\text { (Ni-cd) }\end{array}$ & $\begin{array}{l}\text { Nickel } \\
\text { Métal } \\
\text { Hydride } \\
\text { (Nimh) }\end{array}$ & $\begin{array}{c}\text { Lithium } \\
\text { (Li):Li- } \\
\text { ion et } \\
\text { Lipo }\end{array}$ \\
\hline $\begin{array}{l}\text { Energy / } \\
\text { weight }\end{array}$ & $\begin{array}{c}20- \\
40 \mathrm{Wh} / \mathrm{kg}\end{array}$ & $\begin{array}{c}20- \\
40 \mathrm{Wh} / \mathrm{kg}\end{array}$ & $\begin{array}{c}30- \\
80 \mathrm{Wh} / \mathrm{kg}\end{array}$ & $\begin{array}{c}100- \\
250 \mathrm{Wh} / \mathrm{kg}\end{array}$ \\
\hline Energy/volume & $\begin{array}{c}40- \\
100 \mathrm{Wh} / 1\end{array}$ & $\begin{array}{c}50- \\
150 \mathrm{Wh} / \mathrm{l}\end{array}$ & $\begin{array}{c}140- \\
300 \mathrm{Wh} / 1\end{array}$ & $\begin{array}{c}200- \\
620 \mathrm{Wh} / 1\end{array}$ \\
\hline Life duration & $\begin{array}{l}4-5 \\
\text { years }\end{array}$ & 2 - 3 years & $\begin{array}{l}2-4 \\
\text { years }\end{array}$ & 7 years \\
\hline $\begin{array}{l}\text { number of } \\
\text { charge cycles }\end{array}$ & $\begin{array}{l}400- \\
1200 \\
\text { cycles }\end{array}$ & $\begin{array}{l}1500 \\
\text { cycles }\end{array}$ & $\begin{array}{l}500- \\
1200 \\
\text { cycles }\end{array}$ & $\begin{array}{l}1200 \\
\text { cycles }\end{array}$ \\
\hline Voltage / item & $2.1 \mathrm{~V}$ & $1.2 \mathrm{~V}$ & $1.2 \mathrm{~V}$ & $\begin{array}{c}3.6 \mathrm{~V} \text { or } \\
3.7 \mathrm{~V}\end{array}$ \\
\hline
\end{tabular}

A comparative study is made between the different types of batteries available in the market today, the lead acid technology is chosen to be used for this application, because this type of batteries represents nearly $65 \%$ of the battery market and are widely used in the automotive [10], traction, photovoltaic, power supplies appliances. Further, the technology of lead-acid batteries is considered in this paper.

\subsection{Battery specification and algorithm of the charging}

The charging of a battery follows several laws. A battery charges by applying DC for a limited time. This charge occurs in three phases. The first phase is a constant current charging step that is called also bulk phase, when a constant current is applied to the battery and the voltage increases up to a value $\mathrm{Vgaz}$ called voltage gasification electrolyte $(2.35 \mathrm{~V} /$ cell $)$ in this case is equal to $14.1 \mathrm{Vdc}$. The second phase is a constant voltage charging step or an absorption phase, when the battery voltage is set at $2.35 \mathrm{~V} /$ cell to continue the charge, and the current decreases to a minimum value. In the third phase or floating one, the battery can be left in a maintaining regime or be disconnected. The maintaining regime is characterized by sustaining the nominal voltage with a current, which is generally equal to the 0.001 th of the battery capacity. These phases are reported in Figure 1.

Battery charger is usually packaged around the converter as well as a rectifier and especially a chopper for solar chargers (synchronous chopper in this paper). Then, 
$10^{\mathrm{TH}}$ InTERnational CONFerence on Sustainable Energy and Environmental Protection (June $27^{\mathrm{TH}}-30^{\mathrm{TH}}, 2017$, Bled, Slovenia), RenEwable ENERGy SOURCES K. EL Kamouny, H. Mahmoudi \& B. Lakssir: Smart Solar Battery Charger for PVApplication

consider the implementation of, the well-known one, Buck synchronous converter in a battery charger.

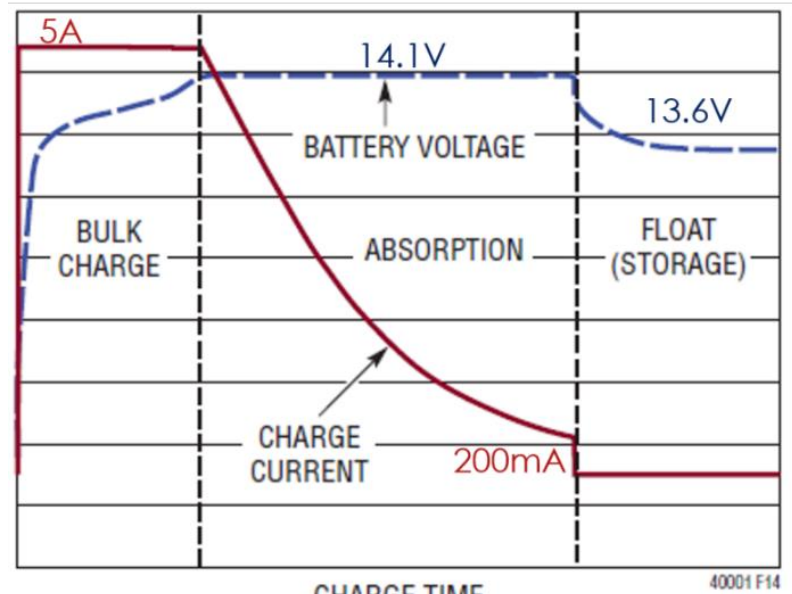

CHARGE TIME

Figure 1. Charging cycle of a Lead Acid Battery.

\section{$2.3 \quad$ LT3845A circuit}

LT3845A is an integrated circuit from Linear Technology. This circuit is dedicated to control the buck converter. It allows the control of the input and output voltage of the system. The circuitry around is used to set the desired technical specifications.

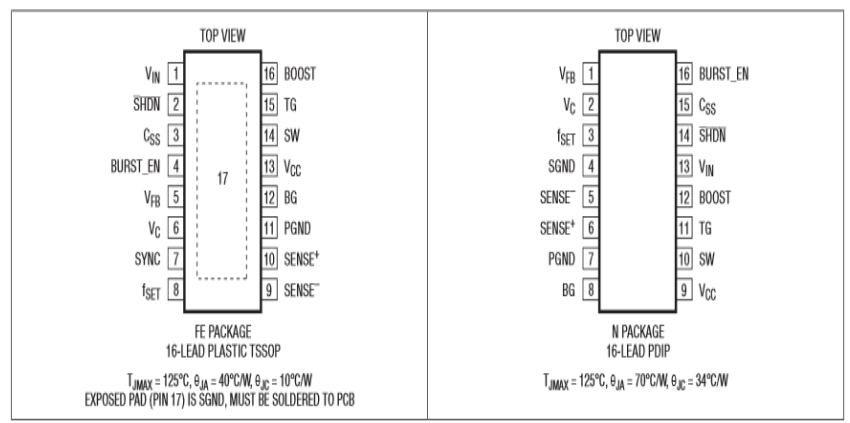

Figure 2. LT3845A Package [11]

\section{$2.4 \quad$ LTC4000-1 circuit}

The LTC4000-1 is an integrated circuit from LINEAR TECHNOLOGY [12], and is used to control the charge process of the batteries. It includes a MPPC controller (Maximum Power Point Controller) when the charger is connected to a photovoltaic panel. 


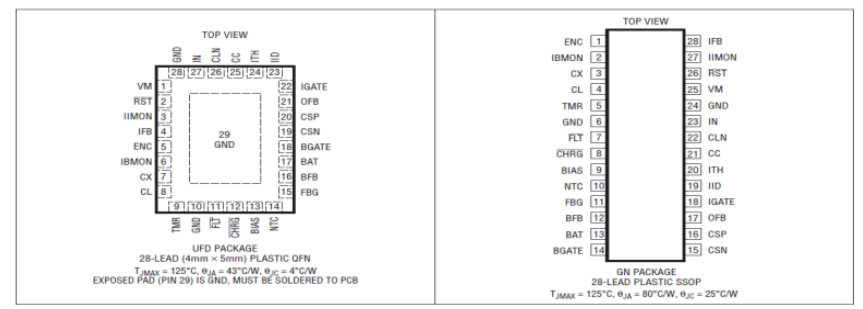

Figure 3. Package of LTC4000-1.

\section{$3 \quad$ Simulation and Results}

\subsection{LT3845A circuit}

A simulation of the LT3845A behaviour, provided by Linear Technology, has been customized for a $15 \mathrm{~V}$ output voltage as is the case in our project. The figure 4 summarizes the operation of the LT3845A.

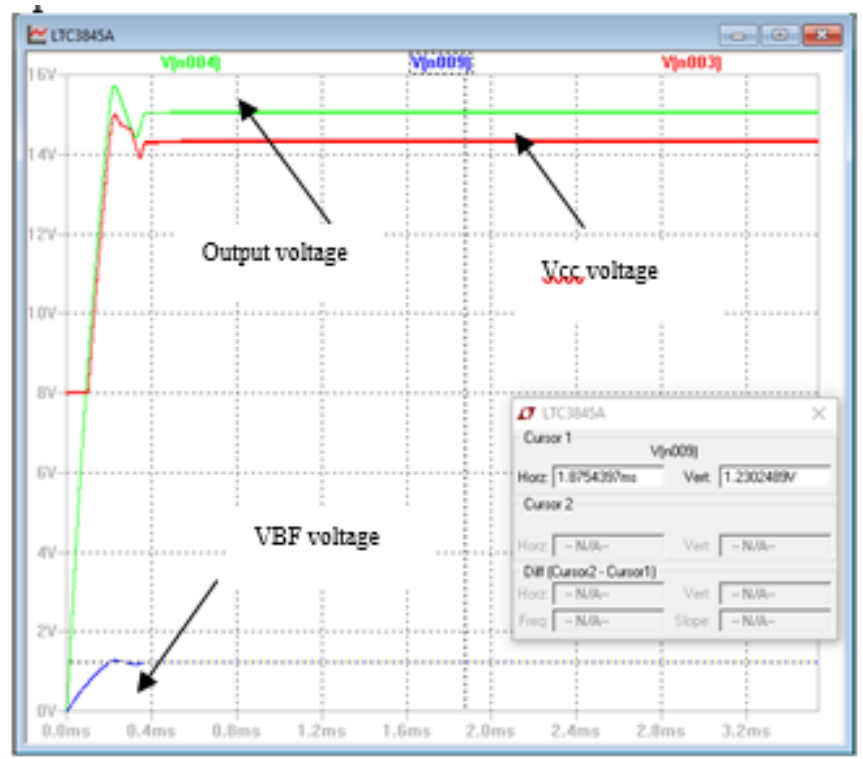

Figure 4. Regulating the Output Voltage

Starting the LT3845A, and depending on the time of programmed Soft-Start, the integrated circuit controls the output voltage so that the voltage $\mathrm{V}_{\mathrm{FB}}$ is equal to $1.231 \mathrm{~V}$, which is the theoretical threshold of regulating the output voltage. It is therefore stabilized at $15 \mathrm{~V}$ value. The voltage $\mathrm{Vcc}$ is equal to $8 \mathrm{~V}$ at startup, but when the output voltage exceeds $8 \mathrm{~V}$ and when it is more than the threshold voltage of the diode, the potential Vcc 
$10^{\mathrm{TH}}$ International Conference on Sustainable EnERgy AND Environmental Protection (June $27^{\mathrm{TH}}-30^{\mathrm{TH}}, 2017$, BlED, SLOVENIA), RENEWABLE ENERGY SOURCES K. EL Kamouny, H. Mahmoudi \& B. Lakssir: Smart Solar Battery Charger for PVApplication

follows the output voltage and thus supplies much the circuitry of the LT3845A, which increases the efficiency of the circuit.

The figure 5 shows the switching signals to transfer energy to the output:

The output voltage is now stable to the $15 \mathrm{~V}$ value (figure 5). The switching cycle begins with priming of the upper NMOS with a duty ratio calculated from the input and output voltage. Once the main MOSFET is in the OFF state, the synchronous MOSFET acts as a freewheeling diode and becomes ON. Since switching takes place very rapidly (300KHz as shown in the calculation from the sliders), there exists a period in which both MOSFETs are OFF. It was at that instant that the free-wheeling diode D2 becomes ON until the synchronous MOSFET operates again. This solution can greatly reduce switching losses. Note that the gate potential for initiating the upper MOSFET is greatly larger than that of the synchronous MOSFET. It is precisely the role of the driver included in the LT3845A for adjusting the boot $\mathrm{V}_{\mathrm{GS}}$ voltage of the main MOSFET taking into account the potential applied to the drain of the bottom MOSFET.

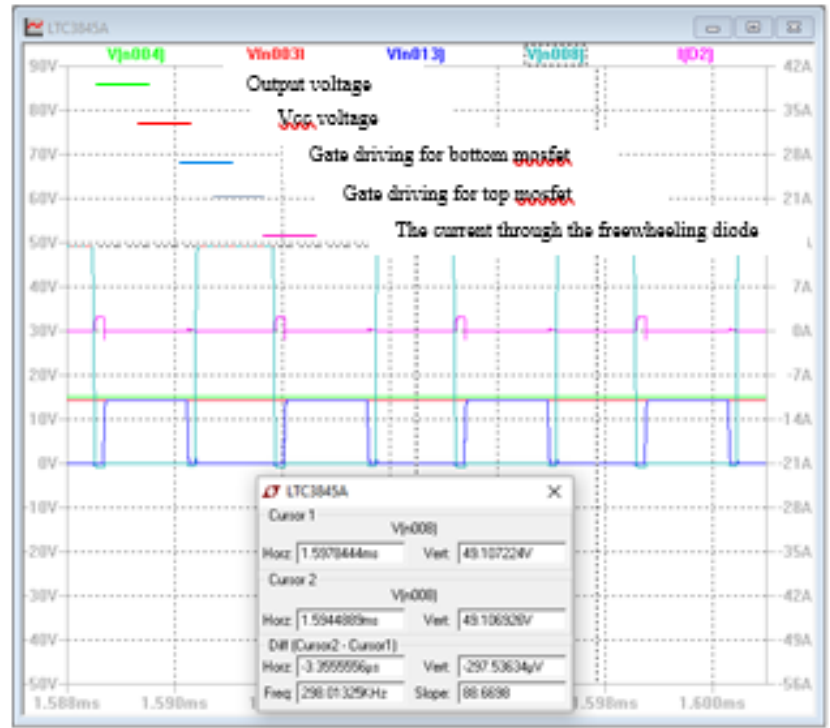

Figure 5. Chopping the Voltage after Stability of the Output Voltage.

\subsection{LTC4000-1 circuit:}

The figure 6 shows the waveforms of a battery charge cycle in 2 phases: the constant current phase with a current of $5 \mathrm{~A}$ and a constant voltage charging phase is equal to 13.6 $\mathrm{V}$ (float voltage). It also shows the signal form to read if the battery is defective. The output voltage is programmed to $15 \mathrm{~V}$ value. 
Starting the charge, the current is around $10 \%$ of the maximum value (5A) (Figure 6). Meanwhile, the battery voltage slowly changing and the output voltage is immediately attached to the $V_{\text {Out }}$ value (INST_ON) to supply the system load. At the end of the defective battery

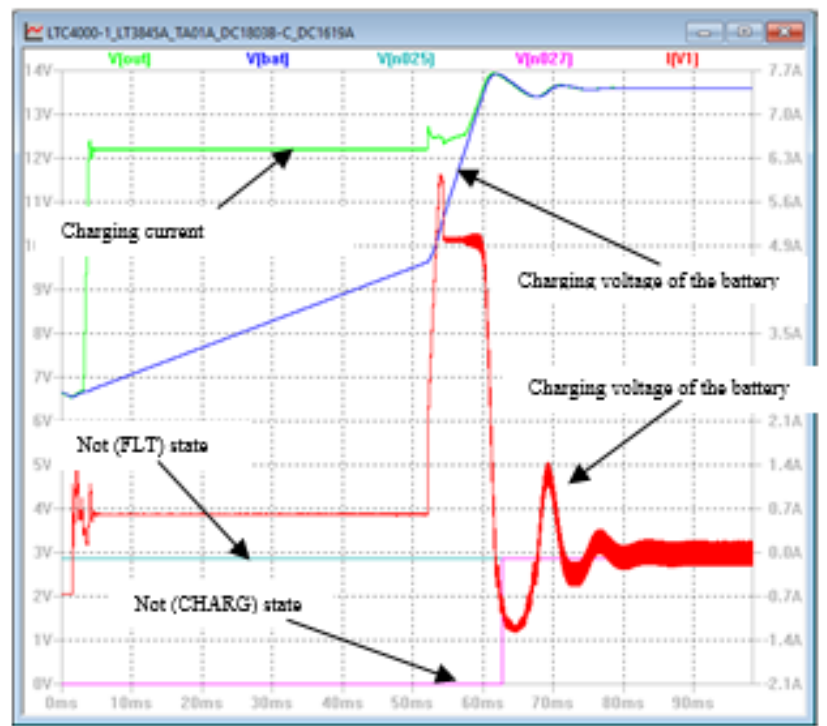

Figure 6. Simulation of a Battery Charging Cycle

detection time, and as the battery voltage has exceeded the threshold low battery $\mathrm{V}_{\mathrm{LOABT}}$, the full power load phase is triggered and the battery voltage increases more rapidly until the programmed value $(13.6 \mathrm{Vdc})$, where it remains fixed. The current decreases until it becomes zero (theoretically), thus indicate the end of charge. During the charging cycle, $\operatorname{NOT}($ FLT $)=1$ and $\operatorname{NOT}($ CHRG $)=0$, which indicates that the battery is in a normal charging cycle. Once the cycle ends $\mathrm{NOT}(\mathrm{FLT})=1$ and $\mathrm{NOT}(\mathrm{CHRG})=1$. This state means the end of charge.

\section{$4 \quad$ Practical Results}

As is shown in Figure 7, the overall architecture of the solution consists of two parts, the LT3845A and LTC4000-1. Once the simulation has been validated, it was decided to make two boards separate, each of which includes the 

Protection (June $27^{\mathrm{TH}}-30^{\mathrm{TH}}, 2017$, Bled, SLOVENIA), RENEWABle ENERGY SOURCES K. EL Kamouny, H. Mahmoudi \& B. Lakssir: Smart Solar Battery Charger for PVApplication

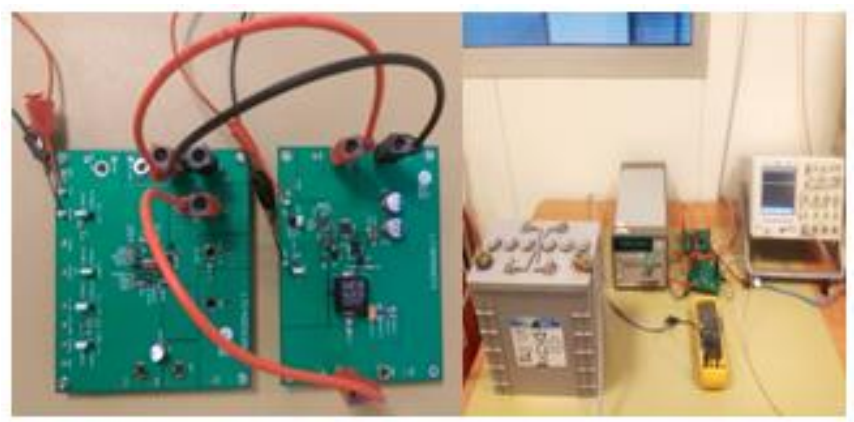

Figure 7. Test Platform

components necessary for its operation, and thus provide the necessary connectors for connecting two boards.

The choice of this method was adopted to facilitate the tests thereafter by first ensuring the independent functioning of Buck chopper controlled by the LT3845A, then test the entire system.

$\mathrm{V}_{\text {IN }}$ connector of the LTC4000-1 circuit allows the transmission of the power to the LT3845A circuit after the measurement of the input current. And its output is connected directly to the PMOS I $I_{\mathrm{GATE}}$ via $\mathrm{V}_{\mathrm{OUT}}$ from DC-DC connector. The grounds of both boards are also connected to GND connectors. Note that NOT(RST) and ITH of the LTC40001 are respectively connected to (SHDN) and VC of the LT3845A.

The figure 7 presents the test platform of the battery charger described in this paper, it includes the following elements:

- A photovoltaic panel with $\mathrm{V}_{\mathrm{MP}}=29 \mathrm{~V}$.

- A power supply dedicated to the signaling interface (LED)

- A resistive load of about $1 \mathrm{~K}$ connected to the system

- A battery Lead acid $12 \mathrm{~V}$.

- An ammeter in series with the battery to measure current

- An oscilloscope to view the signals form.

Tests performed on the operation of the smart charger are to check that the battery goes through the following states as is shown in Figure 1:

- A Constant Current (CC) phase where the battery is charging using a constant current of $5 \mathrm{~A}$ leaving freely voltage increase to the value $14.1 \mathrm{~V}$

- A Constant Voltage (CV) phase where the battery voltage is fixed at $14.1 \mathrm{~V}$ absorption value by letting the load current decrease freely until the value $200 \mathrm{~mA}$. 
- A floating stage where the voltage is set at 13.6 with theoretically zero charge current to compensate the phenomenon of self-discharge.

The duration of the test battery charge can be estimated using the following relationship: $\mathrm{C}=\mathrm{I} \times \mathrm{T}$ with $\mathrm{C}$ : battery capacity, $\mathrm{I}$ : charge current and $\mathrm{T}$ duration. Thus, with a maximum load current of $5 \mathrm{~A}$, and a capacity of $121 \mathrm{Ah}$, the charging time is estimated around $24 \mathrm{~h}$.

Note that the load current is measured with an ammeter in series with the battery, and the battery voltage has been detected using a probe to be displayed in an oscilloscope.

\subsection{Test of the Constant current phase}

Once the photovoltaic panel is connected, the current and the battery voltage have stabilized in the values as is shown in the figure 8:

The current is close to the value $5 \mathrm{~A}$ and the battery voltage is reaching the value 14.1 $\mathrm{Vdc}$. In fact, that moment is a point very close to the CV cycle stage; we can conclude that it is a step of transferring the CC phase to the CV phase. The test battery was purchased charged and spent several months in the laboratory.

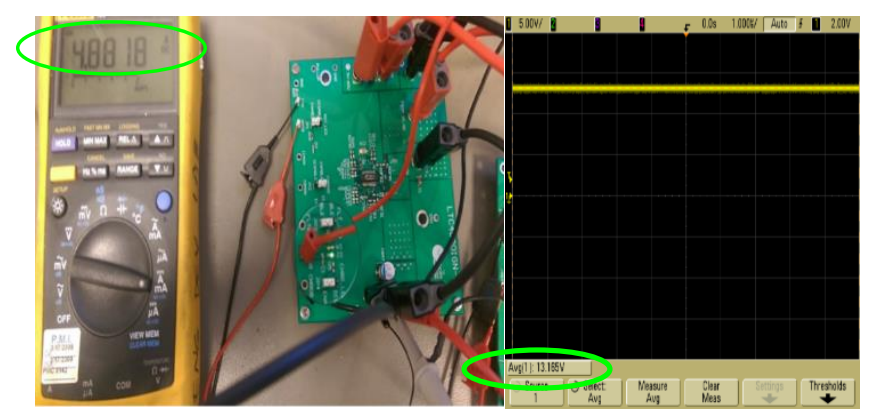

Figure 8. Current and Voltage of CC Phase

The self-discharge is why it falls on this point in the cycle when we plugged the charger circuit. D2 LED is lit, and D4 is OFF, the LED interface indicates that the battery is in a normal state of charge.

After several hours of charging, the following data was taken: 
$10^{\mathrm{TH}}$ International Conference on Sustainable EnERgy and Environmental Protection (June $27^{\mathrm{TH}}-30^{\mathrm{TH}}, 2017$, BlED, SLOVENIA), RENEWABLE ENERGY SOURCES K. EL Kamouny, H. Mahmoudi \& B. Lakssir: Smart Solar Battery Charger for PVApplication

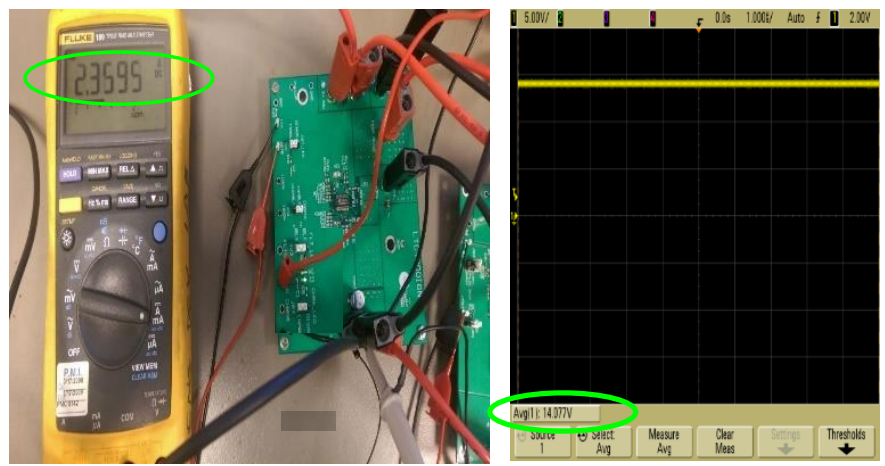

Figure 9. Current and voltage of CV voltage

The battery voltage is $14.1 \mathrm{Vdc}$ while the current value reached $2.36 \mathrm{~A}$, which means that this state corresponds to a point near the middle of the CV phase. The state of the LED, which has not changed, confirms that the battery is always in a normal state of charge.

\subsection{Test of the floating phase}

At the end of the charging process, the current in the CV phase does not vanish. It stabilizes at a lower value but not equal to zero no longer increases the state of charge. The current value in the end of charging which was set is $200 \mathrm{~mA}$ corresponding to a resistor $\mathrm{RC} / \mathrm{X}=10 \mathrm{~K}$. However, it was noticed during the test that the current stabilizes at a value of $0.8 \mathrm{~A}$. So, it would be practical to replace this with resistance by another RC / $\mathrm{X}=35.7 \mathrm{~K}$. Now, once the charging current value reaches the value $0.84 \mathrm{~A}$, battery charger cuts power through the PMOS. This is shown in figure 10 and 11:

Note that no LEDs are on (the Charge LED is off), indicating that the current status of the battery's state of charge termination. The float voltage has been displayed on the oscilloscope as shown in the figure 11:

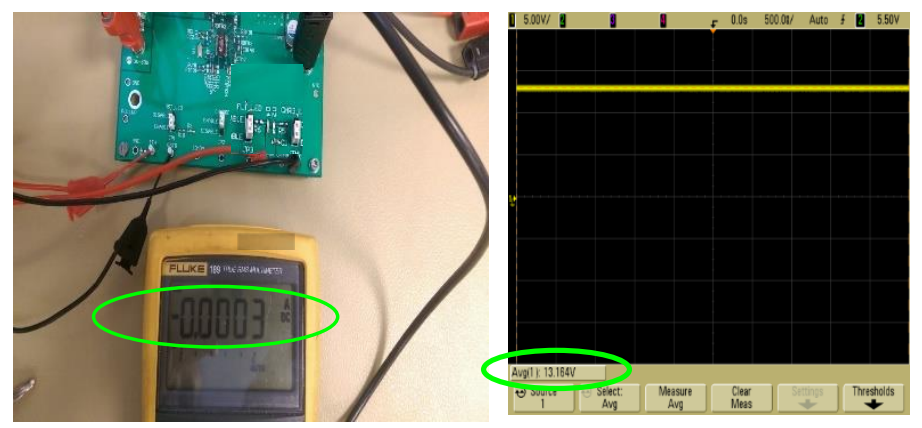

Figure 10. Current and voltage of floating phase 


\subsection{Test in absence of energy input case}

This test was also expected. The PV panel was disconnected and then the voltage and battery current was stabilized. The following results are seen on the ammeter and the oscilloscope:

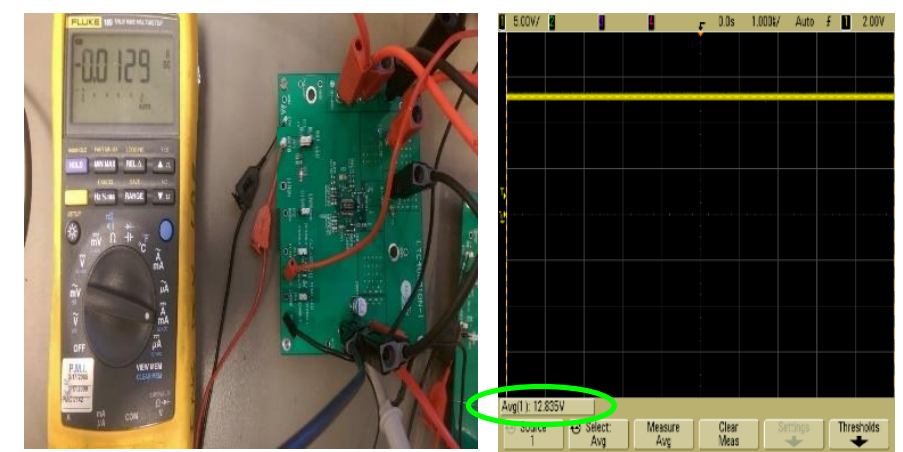

Figure 11. Voltage and Current Supplied to Power a Resistive Load of $1 \mathrm{~K}$.

The battery voltage returns to its nominal value (about $12.6 \mathrm{~V}$ ) and the current becomes negative. The battery supplied then a current of $12.9 \mathrm{~mA}$ corresponding to the load connected to the system which is of the order of $1 \mathrm{~K}$. The state of the LED D3 is ON proving that the buck chopper is operating in Shutdown mode.

\section{$5 \quad$ Conclusions}

It is clear from the results presented in this paper that the developed circuit allows not only to supply the load connected to the system while adjusting the extra power provided by the panel to the battery, but also to guarantee a charging process that takes into account its state of health and its state of charge, using a three-stage charging algorithm (constant current charging phase, constant voltage charging phase, floating stage), and using the various functions of monitoring and signaling. However, this battery charger could be improved by combining the two demonstration boards in one, reducing PCB space and clutter, and also using a signaling interface does not rely on external power, and adding function load percentage estimation.

For the validation of the proposed prototype, it is faced with many similar products in the market with results obtained through simulations and experimental measurements. The tests performed in MAScIR, the very rapid changes in environmental variables are considered. The results are satisfactory and ensure the feasibility of the solution. 
$10^{\mathrm{TH}}$ International Conference on Sustainable EnERgy and Environmental Protection (June $27^{\mathrm{TH}}-30^{\mathrm{TH}}, 2017$, Bled, SLOVENiA), RenEwable ENERGy SOURCES

K. EL Kamouny, H. Mahmoudi \& B. Lakssir: Smart Solar Battery Charger for PVApplication

\section{References}

[1] Jaber A. Abu Qahouq, Yuncong Jiang, and Mohamed Orab "MPPT Control and Architecture for Solar Panel with Sub-Module Integrated Converters" Journal of Power Electronics, Vol. 14, No. 6, pp. 1281-1292, November 2014.

[2] U. S. Departement of Energy, 2011 Renewable Energy Data Book, http://www.nrel.gov/docs/fy13osti/54909.pdf. Accessed Dec. 2013.

[3] Y. Zhang, Y. Gao, J. Li, M. Sumner, P. Wang, and L. Zhou "High Ratio Bidirectional DC/DC Converter with a Synchronous Rectification H-Bridge for Hybrid Energy Sources Electric Vehicles" Journal of Power Electronics, Vol 16, No 6, pp. 2035-2044, November 2016.

[4] Dmitri Vinnikov, Indrek Roasto, Liisa Liivik, and Andrei Blinov "Four Novel PWM Shoot Through Control Methods for Impedance Source DC-DC Converters" Journal of Power Electronics, Vol. 15, No. 2, pp. 299-308, March 2015.

[5] Najam ul Hassan, Yoon-Jae Kim, Byung-Moon Han, and JunYoung Lee "A Hybrid DC/DC Converter for EV OBCs Using Full-bridge and Resonant Converters with a Single Transformer" Journal of Power Electronics.2017.

[6] A.Y. Saber and K. enayagamoorthy, "Plug-In Vehicles and Renewable Energy Sources for Cost and Emission Reductions," IEEE Trans Ind Electron, Vol 8, no 4, pp 1229-1238, Apr. 2011.

[7] M. Rosekeit and R.W De Doncker, “ Smoothing power ripple in Single phase chargers at Minimized DC-link Capacitance,” in Proc.IEEE ICPE ECCE, 2011, pp. 2699-2703.

[8] Jinn-Chang Wu , Hurng-Liahng Jou , and Jie- Hao Tsai “A Buck-Boost Type Charger with a Switched Capacitor Circuit” Journal of Power Electronics, Vol. 15, No. 1, pp. 31-38, January 2015.

[9] W. He, N. Williard, C. Chen, M. Pecht, the role of the battery management system in ensuring battery safety, in: Proc. of Lithium Battery Power 2012, Knowledge Foundation, Las Vegas, NV, 2012.

[10] W. Josefowitz, et al., "Assessment and testing of advanced energy storage systems for propulsione European testing report", in: Proc. of the 21st Worldwide Battery, Hybrid and Fuel Cell Electric Vehicle Symposium \& Exhibition, EVS 21, Monaco, EU, 2005, p. 6.

[11] "LT3845A" Datasheet, Document ref 384 afa, linear technology corporation 2010.

[12] "LTC4000-1" atasheet ocument ref 40001 fa, linear technology corporation 2012.

[13] Yuan Zou, Xiaosong Hu, Hongmin Ma, Shengbo Eben Li "Combined State of Charge and State of Health estimation over lithium-ion battery cell cycle lifespan for electric vehicles" Journal of Power Sources 273 (2015) 793e803.

[14] Jin-Woo Jung and Ali Keyhani, "Control of a Fuel Cell Based Z-Source Converter", IEEE Transaction Son Energy Conversion, Volume 22, No. 2, June 2007, pp. 467-476

[15] T. Markvart and L. Castaner, Practical Handbook of Photovoltaics, Fundamentals and Applications. Elsevier, 2003.

[16] Adel El Shahat, "Maximum Power Point Genetic Identification unction for Photovoltaic System", International Journal of Research and Reviews in Applied Sciences, June 2010.

[17] Mikkel C.W. Høyerby, Michael A.E. Anderssen, "Envelope Tracking Power Supply with fully controlled 4th order Output Filter", Applied Power Electronics Conference and Exposition, 2006. Twenty-First Annual IEEE, 19-23 March 2006.

[18] S. Lalouni, D. Rekioua, T. Rekioua E. Matagne "Fuzzy logic control of stand-alone photovoltaic system with battery storage", Journal of power sources, vol. 193, no. 2.

[19] D. Rekioua and E. Ernest, Optimization of Photovoltaic Power System: Modulization, Ed. Springer; (2012). 
$10^{\mathrm{TH}}$ InTERnational CONFERENCE ON Sustainable ENERgy AND Environmental Protection (June 27 $7^{\mathrm{TH}}-30^{\mathrm{TH}}, 2017$, BLed, SLOVENIA), RENEWABLE ENERGy SOURCES

J. Krope, A.Ghani Olabi, D. Goričanec \& S. Božičnik

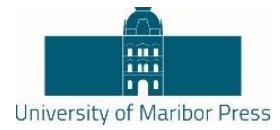

\title{
Substitution of Agro-Energetic Biomass with Bio-Waste for an Existing Anaerobic Digestion Plant: An Energetic and Environmental Analysis
}

\author{
FRANCESCO Di MARIA, FEDERICO SISANI \& MARZIO LASAGNI
}

\begin{abstract}
Two different scenarios aimed to energy recovery from biodegradable substrates, represented by energy crops and bio-waste, via anaerobic digestion (AD) were compared. In the base scenario $17,1760 \mathrm{Mg} /$ year of energy crops were processed in an existing AD facility generating about 7,700 MWh/year whereas 23,000 Mg/year of bio-waste were processed in an existing composting facility for organic fertilizer production. In this case the cumulative energy demand (CED) resulted of 11,000 MWh. In the modified scenario the energy crops were substituted by the bio-waste in the AD facility leading to the generation of about 5,000 MWh/year of energy with a correspondent CED of 8,600 MWh. The life cycle analysis detected an higher impact for the base scenario. On the other hand the amount of $\mathrm{kgCO} 2 \mathrm{eq}$ generated per each $\mathrm{kWh}$ recovered resulted practically the same for the two scenarios.
\end{abstract}

Keywords: • Anaerobic digestion $\bullet$ bio-waste $\bullet$ cumulative energy demand - energy crops $\bullet$ Life cycle assessment $\bullet$.

Correspondence Address: Francesco Di Maria, Ph.D., Ass. Professor, University of Perugia, Dipartimento di Ingegneria, Via G. Duranti 93, 06125 Perugia, Italy, e-mail: francesco.dimaria@unipg.it. Federico Sisani, MSc, University of Perugia, Dipartimento di Ingegneria, Via G. Duranti 93, 06125 Perugia, Italy, e-mail: sisanifederico@tiscali.it. Marzio Lasagni, Eng., Director, AISA Impianti, Strada vicinale dei Mori, 52100 Arezzo, Italy, e-mail: impianto@aisaimpianti.it. 
$10^{\mathrm{TH}}$ INTERNATIONAL CONFERENCE ON SUSTAINABLE ENERGy AND ENVIRONMENTAL Protection (June $27^{\mathrm{TH}}-30^{\mathrm{TH}}, 2017$, BlED, SLOVENIA), RENEWABLE ENERGY SOURCES F. Di Maria, F. Sisani \& M. Lasagni: Substitution of Agro-Energetic Biomass with BioWaste for an Existing Anaerobic Digestion Plant: An Energetic and Environmental Analysis

\section{Introduction}

Aerobic and anaerobic biological processes are widely exploited for the management of bio-waste and biomasses. In general aerobic processes such as composting are of particular interest because of their robustness and ability to return stabilized materials exploitable as soil improvers even if energetic consumption is high [1]. On the other hand, investment costs are higher for anaerobic digestion (AD) [2], but biodegradable substrates can be converted into two main streams: a biogas composed mainly of methane and carbon dioxide exploitable as fuel for renewable energy production; a quite stabilized soil improver for agricultural use [3]. Furthermore AD is also an important process for achieving the 2020 EU objectives [4] on greenhouse gas (GHG) reduction and renewable energy production. Concerning renewable energy production, waste materials like manure, crop residues, sewage sludge, the organic fraction of municipal solid waste (OFMSW) and fruit and vegetable waste are of particular interest since they do not compete with food crops as substrates for AD [5]. Several studies are available in literature concerning the $\mathrm{AD}$ of different biomasses as cheese whey an dairy manure [6] or animal waste, crop residues, energy crops and waste [7].

Also environmental benefits arising from the adoption of $\mathrm{AD}$ have been extensively reported in the literature. As example benefits arising from the agronomic exploitation of digestate was investigated by [8-10]. On the other hand [11] found that for the Danish context anaerobic digestion of OFMSW gave a higher net avoidance of GHG compared to incineration. These findings are in accordance with those of $[12,13]$ concerning the AD of OFMSW compared to incineration in Singapore and Uppsala (Sweden), respectively. On the contrary, a similar study performed by [14] for an Italian waste management district gave opposite values, confirming the importance of taking the energetic context into consideration in environmental analysis studies.

These findings highlight that there is a lack of knowledge on global energetic and environmental benefits achievable by $\mathrm{AD}$ and on which resulted the most suitable substrate. The present study aims to investigate the energetic and environmental consequences arising from the substitution of energy crops with bio-waste in an existing $\mathrm{AD}$ facility. The study was implemented on the basis of full-scale and experimental data using also a LCA approach.

\section{$2 \quad$ Material and Methods}

The comparative study was performed between two different scenarios. The first consisted in the separate treatment of OFMSW by composting and energy crops by AD. In the modified scenario the OFMSW was used for substitution of the energy crops in the AD. 

Protection (June $27^{\mathrm{TH}}-30^{\mathrm{TH}}, 2017$, BLED, SLOVENIA), RENEWABLE ENERGy SOURCES

F. Di Maria, F. Sisani \& M. Lasagni: Substitution of Agro-Energetic Biomass with Bio-Waste for an Existing Anaerobic Digestion Plant: An Energetic and Environmental Analysis

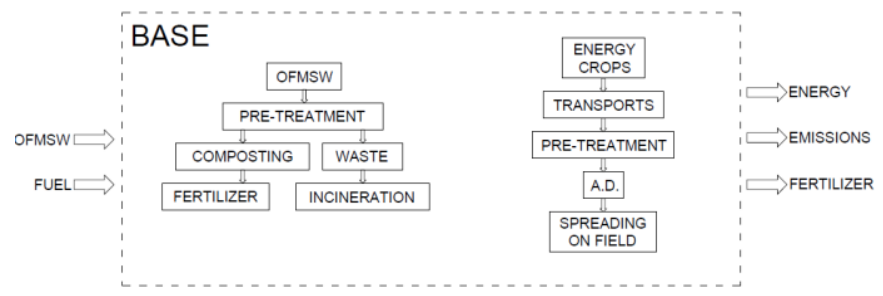

Figure 1. System boundaries and flow chart of the base scenario

Table 1. Main features of the composting facility (2016)

\begin{tabular}{|l|l|l|}
\hline Parameter & Amount & Unit \\
\hline OFMSW & 23,000 & $\mathrm{Mg}$ \\
\hline Waste & 6,210 to incineration & $\mathrm{Mg}$ \\
\hline $\begin{array}{l}\text { Energy } \\
\text { consumption }\end{array}$ & 920 & $\mathrm{MWh}$ \\
\hline $\begin{array}{l}\text { Energy from } \\
\text { incineration of } \\
\text { waste }\end{array}$ & 300 & $\mathrm{kWh} / \mathrm{Mg}$ \\
\hline $\mathrm{N}$ & 14 & $\mathrm{~kg} / \mathrm{Mg}$ compost \\
\hline $\mathrm{P}_{2} \mathrm{O}_{5}$ & 6.74 & $\mathrm{~kg} / \mathrm{Mg}$ compost \\
\hline $\mathrm{KO}_{2}$ & 19.3 & $\mathrm{~kg} / \mathrm{Mg}$ compost \\
\hline $\mathrm{C}_{\text {sink }}$ & 201 & $\mathrm{~kg} / \mathrm{Mg}$ compost \\
\hline
\end{tabular}

\subsection{The base scenario}

In the current scenario (Fig. 1) the 23,000 Mg/year of OFMSW are processed in an existing composting facility for recycling aims by the production of an organic fertilizer. Waste generated by this process, about $6,200 \mathrm{Mg}$ were incinerated with energy recovery [14]. Main features concerning this facility are reported in Table 1. 
$10^{\mathrm{TH}}$ INTERNATIONAL CONFERENCE ON SUSTAINABLE ENERGy AND ENVIRONMENTAL Protection (June $27^{\mathrm{TH}}-30^{\mathrm{TH}}$, 2017, Bled, SLOVENIA), RENEWABLE ENERGY SOURCES F. Di Maria, F. Sisani \& M. Lasagni: Substitution of Agro-Energetic Biomass with BioWaste for an Existing Anaerobic Digestion Plant: An Energetic and Environmental Analysis

Table 2. Main features of the AD facility (2016)

\begin{tabular}{|l|l|l|}
\hline Parameter & Amount & $\mathrm{Unit}$ \\
\hline Maize & 6,332 & $\mathrm{Mg}$ \\
\hline Sorghum & 5,802 & $\mathrm{Mg}$ \\
\hline Triticale & 3,740 & $\mathrm{Mg}$ \\
\hline Alfalfa & 1,793 & $\mathrm{Mg}$ \\
\hline Fuel for crops & 69 & $\mathrm{Mg}$ \\
\hline $\begin{array}{l}\text { Fuel for } \\
\text { transport on } \\
\text { fields }\end{array}$ & 82 & $\mathrm{Mg}$ \\
\hline $\begin{array}{l}\text { Fuel for } \\
\text { spreading }\end{array}$ & 23 & $\mathrm{Mg}$ \\
\hline $\begin{array}{l}\text { Fuel for plant } \\
\text { manag. }\end{array}$ & 14.5 & $\mathrm{Mg}$ \\
\hline $\begin{array}{l}\text { Fertilizer 60\% } \\
\mathrm{N} \\
40 \% \\
\text { diammonium } \\
\text { phosphate }\end{array}$ & 155 & $\mathrm{Mg}$ \\
\hline $\mathrm{Net}^{2}$ engy & 7,738 & $\mathrm{MWh}$ \\
\hline $\mathrm{N}$ & 0.34 & $\mathrm{~kg} / \mathrm{m}^{3}$ digestate \\
\hline $\mathrm{P}_{2} \mathrm{O}_{5}$ & 0.05 & $\mathrm{~kg} / \mathrm{m}^{3}$ digestate \\
\hline $\mathrm{KO}_{2}$ & 0.28 & $\mathrm{~kg} / \mathrm{m}^{3}$ digestate \\
\hline $\mathrm{C}_{\text {sink }}$ & 1.46 & $\mathrm{~kg} / \mathrm{m}^{3}$ digestate \\
\hline
\end{tabular}

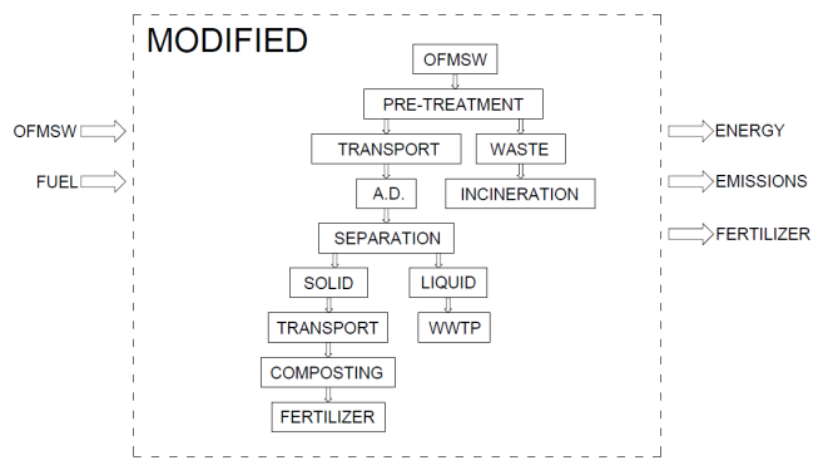

Figure 2. System boundaries and flow chart of the modified scenario

On the other hand the AD facility, located about $50 \mathrm{~km}$ far from the composting one, processed about $17,000 \mathrm{Mg} /$ year of energy crops (Table 2) generating about 4,000,000 $\mathrm{m}^{3} /$ year of biogas and about $8,000 \mathrm{MWh}$ of electricity. AD digesters are of wet type operate with TS of 9\%. For diluting energy crops a given amount of digestate is 
$10^{\mathrm{TH}}$ InTERnational CONFerence on Sustainable EnERgy AND Environmental Protection (June $27^{\mathrm{TH}}-30^{\mathrm{TH}}, 2017$, BLED, SLOVENIA), RENEWABLE ENERGY SOURCES

F. Di Maria, F. Sisani \& M. Lasagni: Substitution of Agro-Energetic Biomass with Bio-Waste for an Existing Anaerobic Digestion Plant: An Energetic and Environmental Analysis

recirculated after solid liquid separation. Both solid and liquid digestate are used as feriliazers.

\subsection{The modified scenario}

The modified scenario (Fig. 2) consisted in the substitution of the energy crop with the OFMSW for feeding the AD. After adequate pre-treatment the OFMSW is transported by truck to the AD (Table 3 ). Also in this case the waste generated by the pre-treatment, about $6,200 \mathrm{Mg}$, are incinerated with energy recovery. The resulting digestate is firstly separated in solid and liquid fractions, then the solid fraction is transported back to the composting facility. OFMSW is diluted to $9 \% \mathrm{TS}$ by a given amount of the liquid fraction of the digestate. The remaining amount is moved to waste water treatment plant (WWTP) $130 \mathrm{~km}$ far.

Table 3. Modified scenario mean features

\begin{tabular}{|l|l|l|}
\hline Parameter & Values & $\mathrm{U} . \mathrm{M}$. \\
\hline OFMSW & 23,000 & $\mathrm{Mg}$ \\
\hline $\begin{array}{l}\text { Waste to } \\
\text { incineration }\end{array}$ & 6,210 & $\mathrm{Mg}$ \\
\hline $\begin{array}{l}\text { OFMSW Pre- } \\
\text { treat. }\end{array}$ & 50 & $\mathrm{kWh} / \mathrm{Mg}$ \\
\hline Solid digestate & 0.909 & $\mathrm{Mg} / \mathrm{Mg}$ \\
\hline $\begin{array}{l}\text { Liquid } \\
\text { digestgate to } \\
\text { WWTP }\end{array}$ & 0.091 & $\mathrm{Mg} / \mathrm{Mg}$ \\
\hline
\end{tabular}

\subsection{Bio Methane Potential}

Data related to the biogas generated and to the amount of energy recovered by AD of energy crops were referred to the year 2016 (Table 2).

Otherwise the energetic potential of the OFMSW was determined by experimental tests.

OFMSW was withdrawn in different period from the existing composting facility then ground after bulky materials removal.

The bio-methane yield (BMP) (NLCH4/kgVS) was determined, on fresh OFMSW by digesting $100 \mathrm{ml}$ of each substrate in $500 \mathrm{ml}$ anaerobic bottles. TS concentration was maintained $\leq 4 \% \mathrm{w} / \mathrm{w}$ by dilution with demineralized water, if necessary. For the BMP test, inoculation was carried out with $300 \mathrm{ml}$ of digestate (Table 4) coming from the fullscale digester in order to maintain a VS of inoculum to VS of substrate ratio of about 2. Anaerobic batch reactors were flushed with nitrogen before starting the run and shaken manually one time each day during the test. Bio-methane was determined by adopting a volume displacement system with a solution of $2 \mathrm{~N} \mathrm{NaOH}$ in demineralized water for 
$10^{\mathrm{TH}}$ InTERnAtional CONFERENCE ON Sustainable ENERgy AND ENVIRONMENTAL Protection (June $27^{\mathrm{TH}}-30^{\mathrm{TH}}, 2017$, BlED, SLOVENIA), RENEWABLE ENERGY SOURCES F. Di Maria, F. Sisani \& M. Lasagni: Substitution of Agro-Energetic Biomass with BioWaste for an Existing Anaerobic Digestion Plant: An Energetic and Environmental Analysis

$\mathrm{CO} 2$ capture. The contribution of inoculum to bio-methane production was evaluated by the same method. All BMP runs were performed in triplicate in a controlled temperature chamber at a temperature of $35^{\circ} \mathrm{C} \pm 2^{\circ} \mathrm{C}$. TS $(\% \mathrm{w} / \mathrm{w})$ and consequently moisture content (MC) $(\% \mathrm{w} / \mathrm{w})$ were determined by measuring weight loss after heating at $105^{\circ} \mathrm{C}$ for $24 \mathrm{~h}$. VS (\% TS) was determined by measuring the change in weight of TS after burning at $550^{\circ} \mathrm{C}$ for $24 \mathrm{~h}$.

Table 4. Inoculum and OFMSW characterization

\begin{tabular}{|l|l|l|}
\hline Parameter & Inoculum & OFMSW \\
\hline TS $(\% \mathrm{w} / \mathrm{w})$ & 3.46 & $26.6 \pm 0.09$ \\
\hline $\mathrm{VS}(\% \mathrm{w} / \mathrm{w})$ & 86.2 & $90.3 \pm 0.03$ \\
\hline $\mathrm{pH}$ & 6.78 & $4.43 \pm 0.51$ \\
\hline $\mathrm{C}(\% \mathrm{TS})$ & 39.5 & $43.7 \pm 3.67$ \\
\hline $\mathrm{N}(\% \mathrm{TS})$ & - & $2.88 \pm 1.13$ \\
\hline $\begin{array}{l}\mathrm{BMP} \\
(\mathrm{NLCH} / / \mathrm{kgVS})\end{array}$ & - & $523 \pm 95$ \\
\hline
\end{tabular}

\subsection{Environmental analysis}

From the environmental point of view the goal of the present study was to compare two different scenario. In the first scenario $23,000 \mathrm{Mg}$ of OFMSW and 17,667 Mg of energy crops were processed separately by composting and $\mathrm{AD}$, respectively (Fig. 1). In the second scenario the OFMSW substituted the energy crops in the AD facility (Fig. 2). System boundaries were expanded for taking into account multifunctionality of the systems and the life cycle inventory (LCI) framework was consequential. Background were represented by OFMSW, fuels and mineral fertilizers. Foreground were represented by energy, nutrients and emissions. LCI was retrieved from Ecoinvent 3.0 database [15] (Wernet et al., 2016) and adjusted on the basis of the experimental and direct observed data. Foreground were not able to influence the background for which average market values were used. In accordance with [16], natural gas was considered as marginal energy to be substituted with the one generated by $\mathrm{AD}$ and incineration.

\subsubsection{Impact assessment method}

As impact assessment method was used ILCD midpoint [17]. Impact categories were (Table 5): Global Warming Potential at 100 years (GWP); Ozone Depletion Potential (ODP); Human toxicity, non-cancer effects (HTnc); Human toxicity, cancer effects (HTc); Particulate matter (PM); Photochemical Ozone Formation (POF); Acidification (A); Eutrophication Terrestrial (ET); Fresh Water Eutrophication (FWE); Fresh water ecotoxicity (FWec); Water resource depletion (WRD); Mineral, fossil and renewable Resource Depletion (RD). For obtaining an impression of which of the impact categories was most affected by the scenarios considered, normalization factors of the EU 27 
domestic extraction of resources and emissions per person with respect to the year 2010 were used.

Table 5. Impact assessment categories.

\begin{tabular}{|l|l|l|l|}
\hline Imp.cat. & Unit & $\begin{array}{l}\text { Norm. f. } \\
\text { EU27 } \\
(2010)\end{array}$ & Unit \\
\hline GWP & kgCO 2 eq. & $1.10 \mathrm{E}-04$ & $\begin{array}{l}\mathrm{kgCO}_{2} \\
\text { eq./a. }\end{array}$ \\
\hline ODP & kgCFC-11 eq. & 46.3 & $\begin{array}{l}\text { kgCFC- } \\
11 \text { eq./a. }\end{array}$ \\
\hline PM & kgPM2.5 eq. & $2.63 \mathrm{E}-01$ & $\begin{array}{l}\text { kgPM2.5 } \\
\text { eq./a. }\end{array}$ \\
\hline POF & $\begin{array}{l}\text { kgNMVOC } \\
\text { eq. }\end{array}$ & $3.15 \mathrm{E}-02$ & $\begin{array}{l}\text { kgNMV } \\
\text { OC eq./a. }\end{array}$ \\
\hline A & molc H ${ }^{+}$eq. & $2.11 \mathrm{E}-02$ & $\begin{array}{l}\text { molc H }{ }^{+} \\
\text {eq./a. }\end{array}$ \\
\hline ET & molc N eq. & $5.68 \mathrm{E}-03$ & $\begin{array}{l}\text { molc N } \\
\text { eq./a. }\end{array}$ \\
\hline FWE & kg P eq. & $6.76 \mathrm{E}-01$ & $\begin{array}{l}\text { kg P } \\
\text { eq./a. }\end{array}$ \\
\hline RD & kg Sb eq. & 9.9 & $\begin{array}{l}\text { kg Sb } \\
\text { eq./a. }\end{array}$ \\
\hline
\end{tabular}

Together with these impact categories also the cumulative energy demand (CED) (kWh) was quantified. This parameters represents the direct and indirect energy use through the life cycle including the energy consumed during the extraction, manufacturing and disposal of the raw and auxiliary materials [18]. Also an avoided CED was calculated on the basis of the energy recovered in the two scenario (i.e. $\mathrm{AD}$ and incineration).

\section{$3 \quad$ Results and Discussion}

In the base scenario the amount of electrical energy recovered from $\mathrm{AD}$ of energy crops and from incineration of waste from OFMSW pre-treatment were 1,863 MWh and 7,738 MWh, respectively. In the modified scenario the amount of energy recovered from the AD of OFMSW resulted of 4,109 MWh whereas the amount of energy recovered from incineration of waste from OFMSW was the same of the base scenario. 

Protection (June $27^{\mathrm{TH}}-30^{\mathrm{TH}}$, 2017, Bled, SLOVENIA), RENEWABLE ENERGY SOURCES F. Di Maria, F. Sisani \& M. Lasagni: Substitution of Agro-Energetic Biomass with BioWaste for an Existing Anaerobic Digestion Plant: An Energetic and Environmental Analysis

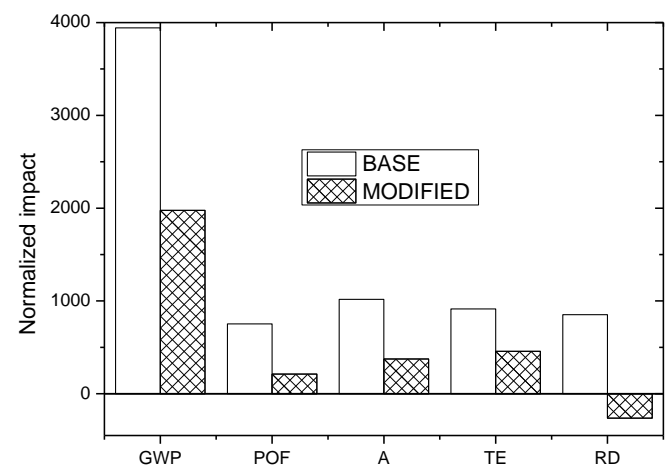

Figure 3. Normalized values of GWP, POF, A, TE and RD

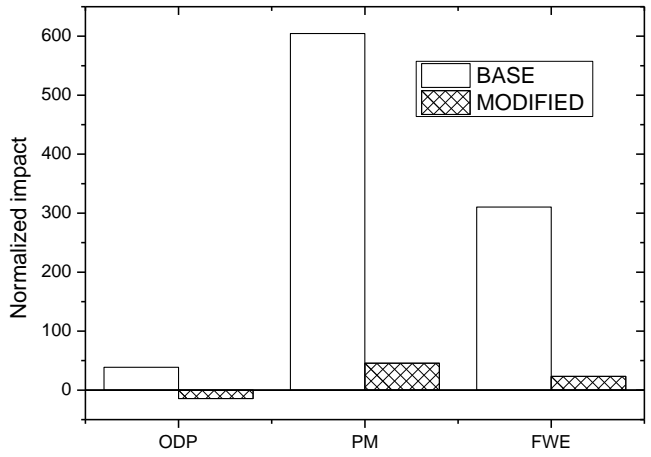

Figure 4. Normalized values of ODP, PM and FWE

From the environmental point of view the modified scenario showed lower level of impact (Figs. 3,4) and in some cases as for RD and ODP avoided impacts. PM resulted the impact category most affected by the base scenario mainly due to the fuels consumptions and for mineral fertilizer production. Process emissions were the main causes of the high values detected for the GWP (Fig. 3). As expected CED resulted higher for the base scenario (Fig. 5). By the way, for giving an impression of global energetic benefits, also the avoided CED was calculated on the basis of the amount of energy recovered in the two scenarios (i.e. 9,600 MWh for the base and 5,972 MWh for the modified). The higher biogas production per Mg of energy crop compared to the OFMSW was the main reason of the higher CED avoided detected for the base scenario. 

Protection (June $27^{\mathrm{TH}}-30^{\mathrm{TH}}, 2017$, BLED, SLOVENIA), RENEWABLE ENERGy SOURCES

F. Di Maria, F. Sisani \& M. Lasagni: Substitution of Agro-Energetic Biomass with Bio-Waste for an Existing Anaerobic Digestion Plant: An Energetic and Environmental Analysis

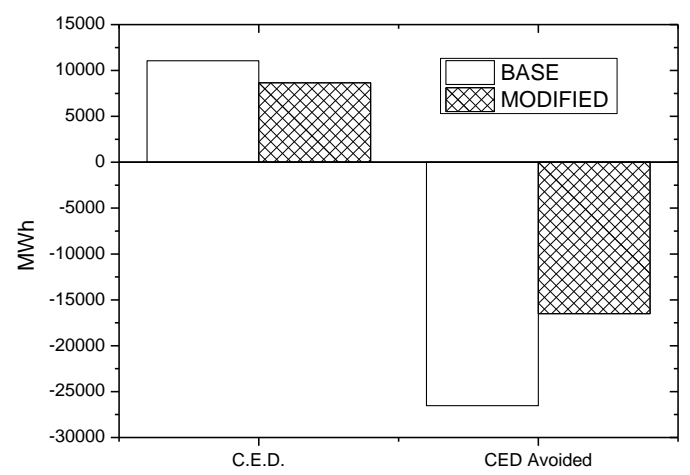

Figure 5. CED and CED avoided due to energy recovery for the base and modified scenario

Similarly for giving an impression of the carbon footprint of the energy generation by the two scenario the specific GWP $\left(\mathrm{kgCO}_{2 \mathrm{eq}} / \mathrm{kWh}\right)$ was also calcualted (Fig. 6). Resulted showed that $\mathrm{kgCO}_{2 \mathrm{eq}} / \mathrm{kWh}$ resulted practically similar for the two scenarios, indicating a substantial similitude from this point of view.

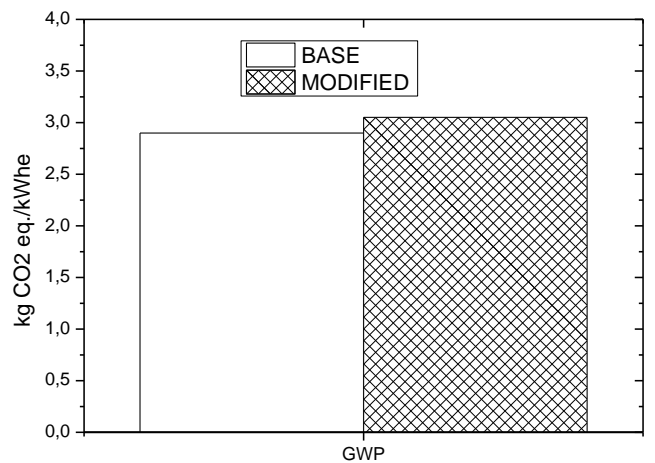

Figure 6. Specific GWP for the base and modified scenarios

\section{4}

\section{Conclusion}

The results of the present study indicates that the conversion of existing AD for energy crops to AD for bio-waste resulted in a reduction of the global impact on the environment. Main advantages arises from fuel consumption and fertilizer needs reduction even the 
$10^{\mathrm{TH}}$ International Conference on Sustainable EnERgy and Environmental Protection (June $27^{\mathrm{TH}}-30^{\mathrm{TH}}, 2017$, BlED, SLOVENIA), RENEWABLE ENERGY SOURCES F. Di Maria, F. Sisani \& M. Lasagni: Substitution of Agro-Energetic Biomass with BioWaste for an Existing Anaerobic Digestion Plant: An Energetic and Environmental Analysis

energy crops resulted characterized by an higher energetic potential. On the other hand the specific global warming potential referred to the single $\mathrm{kWh}$ generated in the two scenario resulted practically similar indicating a quite similar carbon footprint from the exclusively energetic point of view.

\section{References}

[1] Di Maria F. Upgrading of a Mechanical Biological Treatment (MBT) plant with a Solid Anaerobic Digestion Batch: A Real Case Study. Waste Management \& Research 2012;30(10): 1089-94.

[2] Di Maria F, Sordi A, Micale C. Energy production from mechanical biological treatment and composting plants exploiting solid anaerobic digestion batch: an Italian case study. Energ Conver Manag 2012;56;112-20.

[3] Martins das Neves LC, Concert A, Vessoni Penna TC. Biogas production: new trends for alternative energy sources in rural and urban zones. Chem Eng Technol 2009;32:1147-53.

[4] Beurskens LWM, Hekkenberg M, Vethman P. ECN - Renewable Energy Projection as Published in the National Renewable Energy Action Plans of the European Members States. <http://www.ecn.nl/docs/library/report/2010/e10069.pdf> (accessed 23.03.2012).

[5] Apples 1, Lauwers J, Degreve J, Helsen L, Lievens B, Willems K, Van Impe J, Dewill R. Anaerobic digestion in global bio-energy production: Potential and research challenges. Renew Sust Energ Rev 2011;15:4295-301.

[6] Kovacik B, Topaloglu B. 2010. Biogas production from co-digestion of a mixture of cheese whey and dairy manure. Biomass \& Bioenergy 34;1321-29.

[7] Poschl M, Ward S., Owende P. 2010. valuation of energy efficiency of various biogas production and utilization pathways. Applied Energy 87;3305-21.

[8] Alburquerque JA, de la Fuente C, Ferrer- Costa A, Carrasco L, Cegarra J, Abad M, Bernal MP. Assessment of the fertilser potential of digestate from farm and agroindustrial residues. Biomass \& Bioenergy 40,181-89.

[9] Moller K, Muller T. 2012. Effects of anaerobic digestion on digestate nutrient availability and crop growth. A review. Eng Life Sci. 12;242-57.

[10] Nkoa R. 2014. Agricultural benefits and environmental risks of soil fertilization with anaerobic digestate: a review. Agron. Sustain. Dev. 34;473-92.

[11] Bernstad A, La Cour Jansen J. A life cycle approach to the management of household food waste - A Swedish full-scale case study. Waste Management 2011;31:1879-96.

[12] Khoo HH, Lim TZ, Tan RBH. Food waste conversion options in Singapore: Environmental impacts based on an LCA perspective. Science of the Total Environment 2010;408:136773.

[13] Sonesson U, Bjorklund A, Carlsson M, Dalemo M. Environmental and economic analysis of management system for biodegradable waste. Resource Conservation and Recycling 2000;28:29-53.

[14] Di Maria F, Micale C. Life cycle analysis of incineration compared to anaerobic digestion followed by composting for managing organic waste: The influence of system components for an Italian district. The International Journal of LCA 2015;20:377-88.

[15] Wernet, G., Bauer, C., Steubing, B., Reinhard, J., Moreno-Ruiz, E., and Weidema, B. 2016. The ecoinvent database version 3 (part I): overview and methodology. The International Journal of Life Cycle Assessment, [online] 21(9), pp.1218-1230. Available at: <http://link.springer.com/10.1007/s11367-016-1087-8> (Accessed 1309 2016). 
[16] Turconi R, Butera S, Boldrin A, Grosso M, Rigamonti L, Astrup T. Life cycle assessment of waste incinerations in Denmark and Italy using two LCA models. Waste Management \& Research 2011;29:78-90.

[17] EC- European Commission. 2012. Characterization factors of the ILCD Recommended Life Cycle Impact Assessment methods, Database and Supporting Information, First edition, Joint Research Centre, Institute for Environment and Sustainability, Publications Office of the European Union, Luxembourg.

[18] Huijbregts MAJ, Rombouts LIA, Hellweg S, Frischknecht R, Hendriks AJ, Van de Meent D., Ragas AMJ, Reijnders L, Struijs J. Is cumulative fossil energy demand a useful indicator for the environmental performance of products? Environmental Science \& Technology 40;641-8. 
$68 \mid 10^{\mathrm{TH}}$ International CONFERENCE on Sustainable ENERgy AND ENVIRONMENTAL Protection (June $27^{\mathrm{TH}}-30^{\mathrm{TH}}, 2017$, Bled, Slovenia), RenEWABle ENERGy SOURCES 
$10^{\mathrm{TH}}$ InTERnational CONFERENCE ON Sustainable ENERgy AND ENVIRONMENTAL Protection (June $27^{\mathrm{TH}}-30^{\mathrm{TH}}$, 2017, Bled, SLOVENIA), RENEWABLE ENERGy SOURCES

J. Krope, A.Ghani Olabi, D. Goričanec \& S. Božičnik

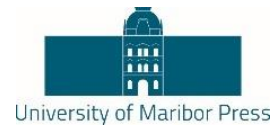

\title{
Feasibility Study of Integrating Renewables and Hydrogen Technologies Into Isolated Power Supply System of Mountain Hut
}

\author{
BOŠTJAN DROBNIČ, ROK STROPNIK, BOŠTJAN JURJEVČIČ \& MITJA MORI
}

\begin{abstract}
Mountain huts are specific power consumers due to their sometimes limited operational season, specific load dynamics and the fact that they are usually off-grid systems. Furthermore their location is typically in emission free environment where emission of $\mathrm{CO} 2$, noise etc. should be mitigated. Renewable energy sources are therefore a suitable alternative to the most commonly used diesel powered electrical generators. Due to their random nature renewable sources based power supply must also include appropriate energy storage technology. To find suitable and feasible solution numerical simulations of an existing mountain hut were performed with several alternatives for power supply. The study showed that replacement of considerably oversized diesel generators with renewables is possible with some adjustments of operating regimes, additional power production capacity and energy storage. Further studies will be carried out within EU funded SustainHuts project which will also result in fully functional demo system.
\end{abstract}

Keywords: • Off-grid power system • hydrogen technologies $\bullet$ renewable energy sources $\bullet$ sustainable energy production $\bullet$ HOMER pro ${ }^{\bullet} \bullet$

CORRESPONDENCE ADDRESS: Boštjan Drobnič, Ph.D., Assistant, University of Ljubljana, Faculty of Mechanical Engineering, Aškerčeva 6, 1000 Ljubljana, Slovenia, e-mail: bostjan.drobnic@fs.uni-lj.si. Rok Stropnik, Young researcher, University of Ljubljana, Faculty of Mechanical Engineering, Aškerčeva 6, 1000 Ljubljana, Slovenia, e-mail: rok.stropnik@fs.uni-lj.si. Boštjan Jurjevčič, Researcher, University of Ljubljana, Faculty of Mechanical Engineering, Aškerčeva 6, 1000 Ljubljana, Slovenia, e-mail: bostjan.jurjevcic@fs.uni-lj.si. Mitja Mori, Ph.D., Assistant Professor, University of Ljubljana, Faculty of Mechanical Engineering, Aškerčeva 6, 1000 Ljubljana, Slovenia, e-mail: mitja.mori@fs.uni-lj.si.

https://doi.org/10.18690/978-961-286-061-5.7

ISBN 978-961-286-061-5

(C) 2017 University of Maribor Press

Available at: http://press.um.si. 
$10^{\mathrm{TH}}$ InTERnAtional CONFERENCE ON Sustainable ENERgy AND ENVIRONMENTAL Protection (June $27^{\mathrm{TH}}-30^{\mathrm{TH}}, 2017$, Bled, Slovenia), RenEwable ENERGy SOURCES B. Drobnič, R. Stropnik, B. Jurjevčič \& M. Mori: Feasibility Study of Integrating Renewables and Hydrogen Technologies Into Isolated Power Supply System of Mountain Hut

\section{Introduction}

The electricity as one of basic commodities is not granted everywhere, especially in third world countries. Even in more developed countries there still exist remote areas without connection to electrical grid. The universal provision of electricity remains far from being achieved due to the geographical obstacles, the dispersion of inhabitants, the lack of appropriate technologies, and the economic issues [1], [2], [3].

In many remote locations, stand-alone systems (off-grid systems) are more cost-effective than extending a power line to the electricity grid [2]. Furthermore remote off-grid mountain huts have specific micro-grid systems with characteristic power consumption [4]. As they are not connected to utility grids they require their own energy supply for both heat and electricity. While heat is typically provided by fossil fuels and/or biomass, electricity is usually provided by diesel fuelled generators. This type of power generation inevitably includes emissions and is not suitable in otherwise emission-free environment regarding to several environmental impacts [5]. A small stand-alone system including photovoltaic (PV), batteries and fuel cells (FC) of appropriate size can be an alternative to diesel generators in means of power supply. Hydrogen offers many opportunities and may, in combination with fuel cells, play an important role in the transformation of energy systems. It may be regarded as an eco-friendly fuel when extracted from water using the electricity obtained from renewable energy sources [6].

Planning a cost-effective micro-grid is a complex process due to all alternatives to consider at any decision level. To find the best combination of renewable energy technologies from the available resources some of existing modelling tools can be employed [7]. Due to popularity, ease of use and flexibility HOMER pro ${ }^{\circledR}$ seems to be an appropriate choice [3], [8].

Within the SustainHuts project (funded by Programme for the Environment and Climate Action - LIFE [9], [10]) several possibilities of providing electric power for existing mountain huts in Slovenia with specific power consumption characteristics will be studied.

Preliminary numerical studies were performed with HOMER Energy software for simulation of dynamic operation of small sized electric grids. While available input data was not accurate and reliable the results show some basic characteristics of the observed systems and serve as a starting point for more accurate studies that will follow throughout the project.

\section{$2 \quad$ Simulation}

Numerical simulations of the observed systems were performed with HOMER pro ${ }^{\circledR}$ simulation software by HOMER Energy. The system operation is observed in sequential time steps through energy balance calculations. Electric demand is compared to the 
$10^{\text {TH }}$ InTERnAtional CONFERENCE on Sustainable EnERgy AND ENVIRONMENTAL Protection (June $27^{\mathrm{TH}}-30^{\mathrm{TH}}, 2017$, BLED, SLOVENIA), RENEWABLE ENERGY SOURCES

B. Drobnič, R. Stropnik, B. Jurjevčič \& M. Mori: Feasibility Study of Integrating Renewables and Hydrogen Technologies Into Isolated Power Supply System of Mountain Hut

available energy and the energy flows to and from each component of the system are calculated. Various system configurations can be simulated to find their feasibility, i.e. whether sources can provide adequate amount of energy for the specified demand.

Simulation procedure is divided in several steps [11] that are shortly summed in subsections below.

\section{$2.1 \quad$ Resources}

Available resources such as solar radiation, wind speed, fossil fuel data etc. need to be explicitly defined. Renewable resources are typically entered as hourly time series of measured or synthetic data. Since actually measured data for the particular locations were not available, solar radiation data was generated with information from NASA database [12] using a method proposed in [13].

\subsection{Grid structure}

The system is modelled as a grid comprising various components and their connections to the grid. Figure 1 shows a simplified grid schematic of a typical mountain hut electrical system.

Electric power is produced by a diesel generator and photovoltaic panels. The diesel generator is a flexible energy source that can adapt its power output to the current situation. Its operation is restricted by a predefined schedule allowing generator to run only during daytime.

Photovoltaic panels' output on the other hand depends on available solar radiation. The calculation of power output is based on the models from [14]. The available radiation is split into direct and diffuse fraction based on the current clearness index and the radiation reflected from the ground is also considered. Another important parameter is the orientation of the panel and the panel performance under non-standard temperature conditions. Temperature of the panel is estimated with respect to the current solar radiation and heat transfer to the surroundings and the effect on the power output is calculated based on an estimated temperature coefficient of power.

Energy storage is provided by lead-acid batteries, while conversion from AC to DC and vice versa is done by appropriate inverter and chargers (rectifiers). Batteries are modelled with the kinetic battery model proposed by [15]. The stored energy is divided into readily available and bound fraction. Consequently such battery has limited maximum charge and discharge power which are calculated on the basis of battery's characteristic parameters according to the kinetic battery model. Both charging and discharging is further limited by charger and inverter maximum power. 
$10^{\mathrm{TH}}$ INTERNATIONAL CONFERENCE ON Sustainable ENERGY AND ENVIRONMENTAL Protection (June $27^{\mathrm{TH}}-30^{\mathrm{TH}}, 2017$, Bled, SLOVEnia), RENEWABle ENERGy SOURCES B. Drobnič, R. Stropnik, B. Jurjevčič \& M. Mori: Feasibility Study of Integrating Renewables and Hydrogen Technologies Into Isolated Power Supply System of Mountain Hut

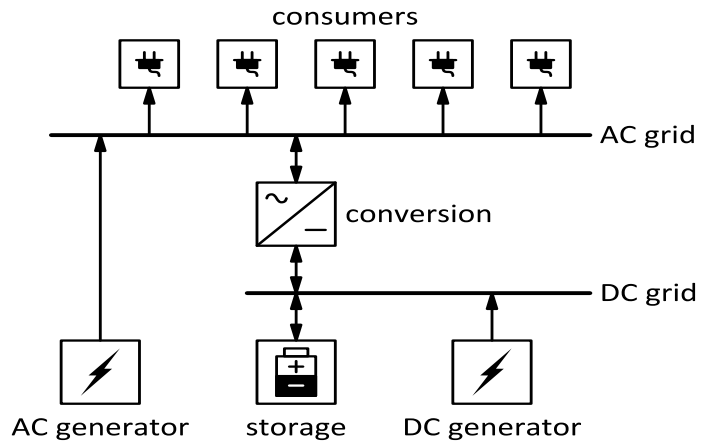

Figure 1. Schematic of existing electric grid

Each component is therefore characterized by its own set of technical, economic and other parameters. Some components can have additional constraints regarding operating regime (minimum load, forced on and off intervals, etc.). In order to find the most adequate configuration several different sizes or capacities of some of the components were considered in the simulations.

\subsection{Load dynamics}

Electric load, the sum of all consumers operating during particular time step, is entered as daily load profiles for each month of the year. Different profiles can be entered for weekdays (Monday to Friday) and for weekends (Saturday and Sunday). The actual all year hourly profile is then created using the basic profile and random daily and hourly variations. Thorough analysis of actual load behaviour is required, possibly through longterm recording. Since measurements were not available, information from huts' caretakers were used to model load dynamics. Power consumers were divided into two groups - devices that are always on and consume energy according to their needs and devices that are manually started and stopped usually in regular intervals. Figures 2 and 3 show the basic 24-hour profiles and a randomly generated one week profile respectively.

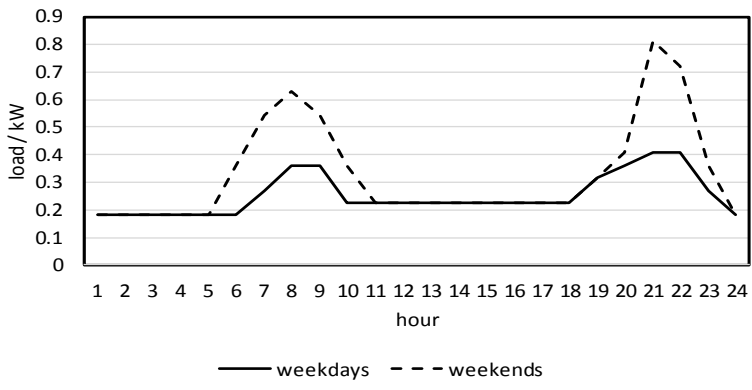

Figure 2. Basic 24-hour load profile 
B. Drobnič, R. Stropnik, B. Jurjevčič \& M. Mori: Feasibility Study of Integrating Renewables and Hydrogen Technologies Into Isolated Power Supply System of

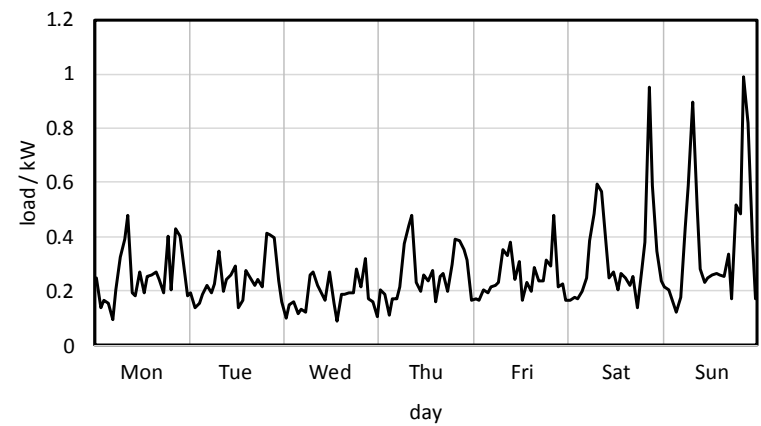

Figure 3. One week load profile

\subsection{Configurations}

Numerical simulations of operation were performed for different configurations of the system. All the configurations are first checked for feasibility and only the feasible ones are simulated over entire lifetime with hourly energy and mass balances for the entire system. Four different system configurations were modelled (Figures 4 and 5):

- reference case (REF): Parameters of an existing system were used to validate the model by comparison of numerical results and actual data. There were some differences between simulation results and actual operation since it was not possible to include all details of the actual system operation in the numerical models. Nevertheless, the relative comparisons of reference and modified cases are believed to be relevant and point to the actual advantages and disadvantages of the modified configurations.

- additional photovoltaic capacity (PV): The installed power of roof mounted PV panels was increased to cover all energy requirements of the load. The increase of battery capacity was optional but was found not to be necessary.

- replacement of diesel generator with fuel cell (FC): Fuel cell is included in the system to provide electric energy during time when solar energy and stored energy is not available.

- hydrogen based energy storage (H2): Diesel generator and batteries are fully replaced by hydrogen energy storage system (electrolyzer, high pressure hydrogen tank, fuel cell), photovoltaic capacity needs to be increased to provide sufficient energy. 
\begin{tabular}{l|l}
74 & $10^{\mathrm{TH}}$ International CONFEREnce on Sustainable EnERgy AND ENVIRONMENTAL
\end{tabular} Protection (June $27^{\mathrm{TH}}-30^{\mathrm{TH}}, 2017$, Bled, SLOVEnia), Renewable EnERGy SOURCES B. Drobnič, R. Stropnik, B. Jurjevčič \& M. Mori: Feasibility Study of Integrating Renewables and Hydrogen Technologies Into Isolated Power Supply System of Mountain Hut

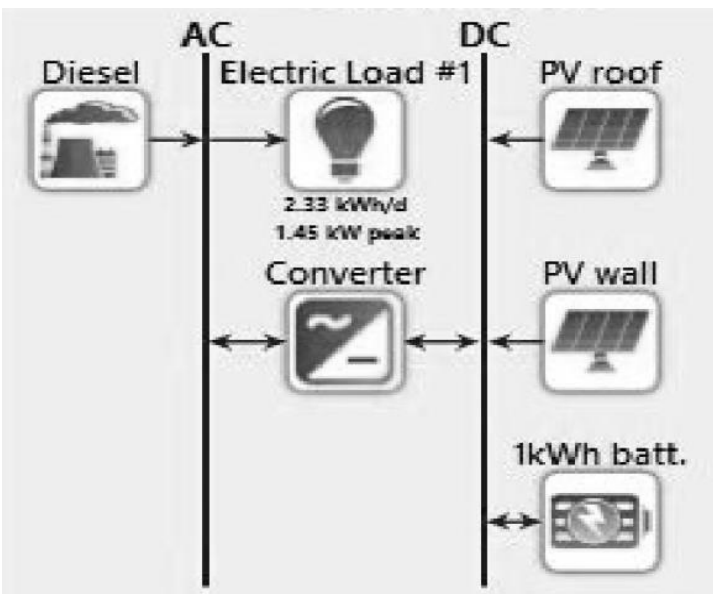

Figure 4. Configuration of reference (REF) and increased photovoltaic capacity (PV) system

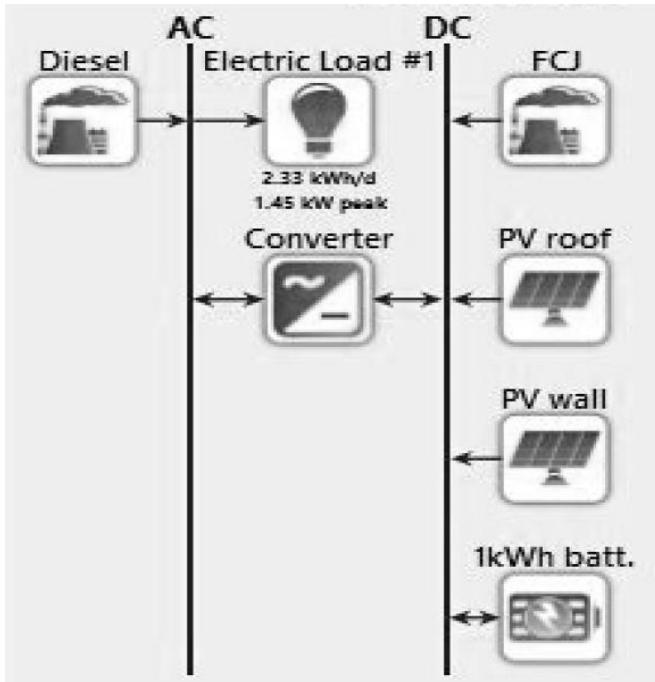

Figure 5. System with fuel cell (FC) 

Protection (June $27^{\mathrm{TH}}-30^{\mathrm{TH}}, 2017$, BLED, SLOVENIA), RENEWABLE ENERGY SOURCES

B. Drobnič, R. Stropnik, B. Jurjevčič \& M. Mori: Feasibility Study of Integrating Renewables and Hydrogen Technologies Into Isolated Power Supply System of

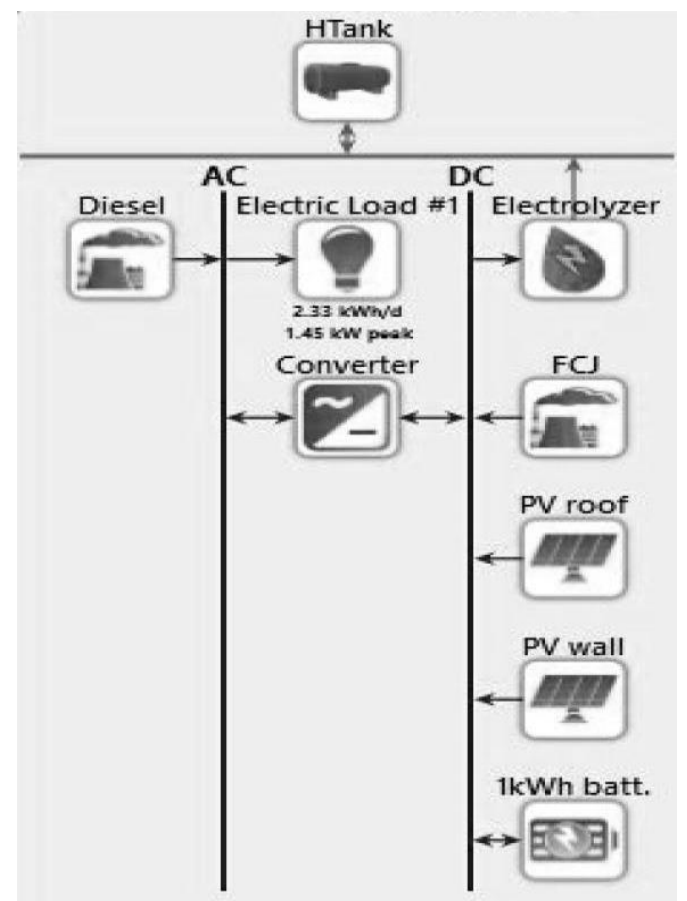

Figure 6. System with hydrogen based energy storage (H2)

All the presented systems were configured in a way that makes them feasible, i.e. the power supply provides adequate energy for the load requirements with no unmet load and no capacity shortage. Several iterations were needed in some cases to find the feasible configurations but only final solutions are shown in the results.

\section{$3 \quad$ Results and Discussion}

Simulation results are series of 8760 hourly energy flows to and from each of the system's component and levels of stored energy. Due to large amount of data only some integral values of total energy consumption and production are presented in Table 1. 

$10^{\mathrm{TH}}$ INTERNATIONAL CONFERENCE ON Sustainable ENERGY AND ENVIRONMENTAL Protection (June $27^{\mathrm{TH}}-30^{\mathrm{TH}}, 2017$, BlED, SLOVENIA), RENEWABLE ENERGy SOURCES B. Drobnič, R. Stropnik, B. Jurjevčič \& M. Mori: Feasibility Study of Integrating Renewables and Hydrogen Technologies Into Isolated Power Supply System of Mountain Hut

Table 2. Simulation results

\begin{tabular}{|l|c|r|r|r|c|}
\hline \multicolumn{3}{|c|}{ REF } & PV & FC & H2 \\
\hline total load & $\begin{array}{c}\mathrm{kWh} / \\
\mathrm{a}\end{array}$ & 821 & 821 & 821 & 821 \\
\hline $\begin{array}{l}\text { diesel gen. } \\
\text { output }\end{array}$ & $\begin{array}{c}\mathrm{kWh} / \\
\mathrm{a}\end{array}$ & 408 & & & \\
\hline solar 1 output & $\begin{array}{c}\mathrm{kWh} / \\
\mathrm{a}\end{array}$ & 796 & 796 & 796 & 796 \\
\hline solar 2 output & $\begin{array}{c}\mathrm{kWh} / \\
\mathrm{a}\end{array}$ & 909 & 3634 & 909 & 4543 \\
\hline fuel cell & $\begin{array}{c}\mathrm{kWh} / \\
\mathrm{a}\end{array}$ & & & 339 & 413 \\
\hline total production & $\begin{array}{c}\mathrm{kWh} / \\
\mathrm{a}\end{array}$ & 2112 & 4430 & 2043 & 5752 \\
\hline $\begin{array}{l}\text { excess } \\
\text { electricity }\end{array}$ & $\begin{array}{c}\mathrm{kWh} / \\
\mathrm{a}\end{array}$ & 1080 & 3442 & 1044 & 625 \\
\hline renew. fraction ${ }^{1}$ & $\%$ & 50 & 100 & $59^{2}$ & 100 \\
\hline $\begin{array}{l}1 \\
\text { 2 of total load served } \\
\text { off-site produced hydrogen is not considered as RES }\end{array}$ \\
\hline
\end{tabular}

Figure 7 shows comparison of power production for all observed cases. Cases PV and $\mathrm{H} 2$ which are completely renewable show significant increase in required capacity of photovoltaic modules. Table 2 shows the summary of both parameters for the observed cases.

Table 3. Simulation results

\begin{tabular}{|l|r|r|r|r|r|}
\hline \multicolumn{7}{|c|}{ REF } & PV & FC & H2 \\
\hline $\begin{array}{l}\text { excess } \\
\text { electricity }\end{array}$ \\
\hline absolute & $\begin{array}{c}\mathrm{kWh} / \\
\mathrm{a}\end{array}$ & 1080 & 3442 & 1044 & 625 \\
\hline relative & $\%$ & 51 & 78 & 51 & 11 \\
\hline capacity factor \\
\hline diesel & $\%$ & 1 & & & \\
\hline fuel cell & $\%$ & & & 4 & 4 \\
\hline solar & $\%$ & 15 & 15 & 15 & 15 \\
\hline
\end{tabular}

Amount of excess electricity is by far the largest in PV case since there is no accumulation of energy during closed season. On the other hand $\mathrm{H} 2$ case has seasonal accumulation through hydrogen tank, therefore solar energy produced during closed season is stored and consequently less excess electricity is produced. 

Protection (June $27^{\mathrm{TH}}-30^{\mathrm{TH}}, 2017$, BLED, SLOVENIA), RENEWABLE ENERGY SOURCES

B. Drobnič, R. Stropnik, B. Jurjevčič \& M. Mori: Feasibility Study of Integrating Renewables and Hydrogen Technologies Into Isolated Power Supply System of Mountain Hut
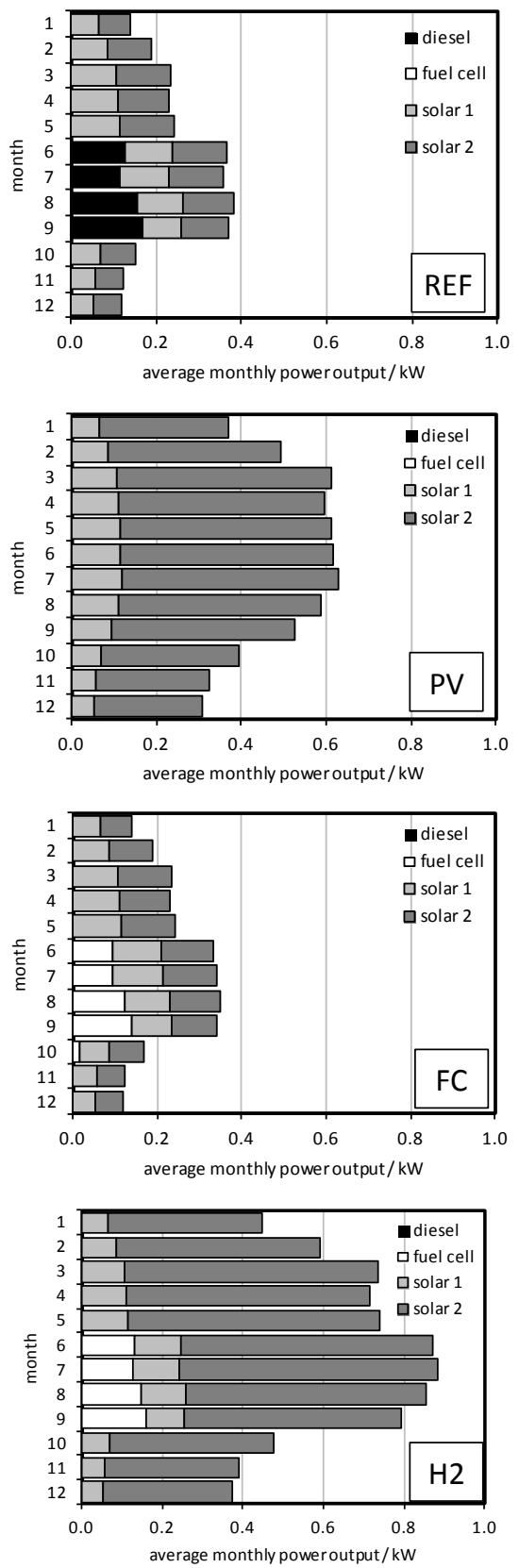

Figure 7. Average power outputs per power source for all compared cases (solar output is available, not actually produced) 
$10^{\mathrm{TH}}$ InTERnAtional CONFERENCE ON Sustainable EnERgy AND ENVIRONMENTAL Protection (June $27^{\mathrm{TH}}-30^{\mathrm{TH}}, 2017$, BlED, SLOVENIA), RENEWABLE ENERGy SOURCES B. Drobnič, R. Stropnik, B. Jurjevčič \& M. Mori: Feasibility Study of Integrating Renewables and Hydrogen Technologies Into Isolated Power Supply System of Mountain Hut

This does, however, require a considerable volume for hydrogen storage as well as a reliable and robust electrolyzer that will produce hydrogen during the closed season with environment conditions that are not suitable for this kind of technology. It should also be noted that the efficiency of energy storage with hydrogen is expected to be around $25 \%$, which is much lower than conventional batteries. All these facts will have to be taken into consideration during designing an appropriate power supply system for remote mountain huts.

\section{Conclusion}

Numerical simulations of the observed system were performed for a 10-year operating period, during which no component needed to be replaced due to exceeded lifetime. The most important results of the data analysis are as follows.

1) The reference model proved to be feasible and its operation was similar to the observed operation of the actual system, therefore the assumption and estimates in the input data can be considered accurate.

2) Three types of modifications of the systems were simulated - increased capacity of photovoltaic modules (PV), addition of fuel cell based power supply (FC) and replacement of lead-acid battery storage with hydrogen energy storage system $(\mathrm{H} 2)$ to test feasibility of proposed solutions and to estimate the required capacity of additional power sources. Load profiles remained unchanged for the modified cases.

3) Increased capacity of PV modules proved to be sufficient solution since storage capacity is oversized for the existing system and still adequate for the modified system. The total capacity needs to be increased by $160 \%$, but lower values might be possible with further optimization of the system.

4) Replacement of considerably oversized diesel generators with fuel cell system is also possible. Simulations showed that a $1 \mathrm{~kW}$ unit would be adequate but the operating regimes need to be appropriately set to provide sufficient amount of energy for normal operation of the system.

5) Installation of hydrogen energy storage system (electrolyzer, hydrogen tank and fuel cell) also requires installation of additional power production capacities (e.g. photovoltaic) much larger than existing ones (by factor 3 to 4 ). Furthermore, since the energy storage needs to be seasonal for the observed cases, the storage capacity is very large $\left(50 \mathrm{~kg}\right.$ or $1.3 \mathrm{~m}^{3}$ at $700 \mathrm{bar}$ of hydrogen).

\section{Acknowledgements}

This project has received funding from Programme for the Environment and Climate Action (LIFE) and repealing Regulation (EC) No 614/2007. 

Protection (June $27^{\mathrm{TH}}-30^{\mathrm{TH}}, 2017$, BLED, SLOVENiA), RENEWABLE ENERGY SOURCES

B. Drobnič, R. Stropnik, B. Jurjevčič \& M. Mori: Feasibility Study of Integrating Renewables and Hydrogen Technologies Into Isolated Power Supply System of Mountain Hut

\section{Refferences}

[1] C. a M. Silva, M. R. Parise, F. V. Silva, and O. P. Taranto, 'Control of fluidized bed coating particles using Gaussian spectral pressure distribution', Powder Technol., vol. 212, no. 3, pp. 445-458, Oct. 2011.

[2] R. Dufo-López, I. R. Cristóbal-Monreal, and J. M. Yusta, 'Stochastic-heuristic methodology for the optimisation of components and control variables of PV-wind-dieselbattery stand-alone systems', Renew. Energy, vol. 99, pp. 919-935, 2016.

[3] R. Sen and S. C. Bhattacharyya, 'Off-grid electricity generation with renewable energy technologies inIndia: An application of HOMER', Renew. Energy, vol. 62, pp. 388-398, 2014.

[4] B. Jurjevčič, A. Lotrič, R. Stropnik, B. Drobnič, M. Sekavčnik, and M. Mori, 'Identification of technologies used in mountain huts and specifications of huts construction in Pyrenees, Alps and Carpathian mountains', Ljubljana, 2017.

[5] M. Mori, M. Jensterle, T. Mržljak, and B. Drobnič, 'Life-cycle assessment of a hydrogenbased uninterruptible power supply system using renewable energy', Int. J. Life Cycle Assess., 2014.

[6] P. C. Ghosh, B. Emonts, and D. Stolten, 'Comparison of hydrogen storage with dieselgenerator system in a PV-WEC hybrid system', Sol. Energy, vol. 75, no. 3, pp. 187-198, 2003.

[7] D. Connolly, H. Lund, B. V. Mathiesen, and M. Leahy, 'A review of computer tools for analysing the integration of renewable energy into various energy systems', Appl. Energy, vol. 87, no. 4, pp. 1059-1082, 2010.

[8] S. B. Silva, M. M. Severino, and M. A. G. De Oliveira, 'A stand-alone hybrid photovoltaic, fuel cell and battery system: A case study of Tocantins, Brazil', Renew. Energy, vol. 57, pp. 384-389, 2013.

[9] 'LIFE programme'. [Online]. Available: http://ec.europa.eu/environment/life/. [Accessed: 08-Mar-2017].

[10] 'SUSTAINHUTS'. [Online]. Available: http://sustainhuts.eu/. [Accessed: 08-Mar-2017].

[11] Homer Energy, 'HOMER Pro Version 3.6 User Manual', no. August, p. 416, 2016.

[12] NASA, 'Surface meteorology and Solar Energy'. [Online]. Available: https://eosweb.larc.nasa.gov/sse/. [Accessed: 08-Mar-2017].

[13] V. A. Graham, K. G. T. Hollands, and O. Canada, 'A method to generate synthetic hourly solar radiation globally', Sol. Energy, vol. 44, no. 6, pp. 333-341, 1990.

[14] J. a. Duffie, W. a. Beckman, and W. M. Worek, Solar Engineering of Thermal Processes, 4nd ed., vol. 116. 2003.

[15] J. F. Manwell and J. G. McGowan, 'Lead Acid Battery Storage Model for Hybrid Energy Systems', Sol. Energy, vol. 50, no. 5, pp. 399-405, 1993. 


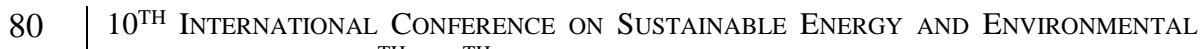
Protection (June $27^{\mathrm{TH}}-30^{\mathrm{TH}}, 2017$, Bled, SLOVEnia), Renewable EnERGY SOURCES 
$10^{\mathrm{TH}}$ InTERnational CONFEREnCE ON Sustainable ENERgy AND ENVIRONMENTAL Protection (June $27^{\mathrm{TH}}-30^{\mathrm{TH}}$, 2017, Bled, SLOVENIA), RENEWABLE ENERGy SOURCES

J. Krope, A.Ghani Olabi, D. Goričanec \& S. Božičnik

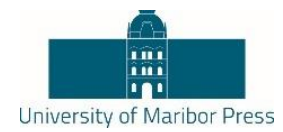

\title{
Microwave Co-Pyrolysis of Waste Cooking Oil and Polystyrene-Based Plastic Waste
}

\author{
Wan Adibah Wan Mahari, Nurfarain Nasuha Ab RaZaK, Chin Kui ChEng \& Su \\ SHIUNG LAM
}

\begin{abstract}
Waste cooking oil (WCO) and polystyrene-based plastic wastes (PW) were detected to have high volatile matter (97-98 wt\%) and low ash content $(<3 \mathrm{wt} \%)$, thus showing potential to be converted by pyrolysis into fuel products. Microwave pyrolysis of a mixture of WCO and PW was investigated for this potential at different ratios of $\mathrm{PW}$ added to $\mathrm{WCO}(\mathrm{W} / \mathrm{P}$ ratio). The co-pyrolysis approach demonstrated positive synergistic effects in providing fast heating rate (up to $40^{\circ} \mathrm{C} / \mathrm{min}$ ) and low process temperature $\left(400^{\circ} \mathrm{C}\right)$. The pyrolysis produced up to $58 \mathrm{wt} \%$ yield of pyrolysis gases and $25 \mathrm{wt} \%$ yield of pyrolysis oil for use as potential fuel. W/P ratio showed a significant influence on the yield and formation of these pyrolysis products. Our results demonstrated that this co-pyrolysis approach shows great potential in transforming these household wastes into an alternative fuel source.
\end{abstract}

Keywords: $\bullet$ pyrolysis $\bullet$ microwave $\bullet$ waste cooking oil $\bullet$ plastic waste $\bullet$ biofuel •

Correspondence Address: Wan Adibah Wan Mahari, Ph.D., Universiti Malaysia Terengganu, Pyrolysis Technology Group, Eastern Corridor Renewable Energy Group, 21030 Kuala Terengganu, Malaysia, e-mail: adibah.mahari@gmail.com. Nurfarain Nasuha Ab Razak, Pyrolysis Technology Group, Eastern Corridor Renewable Energy Group, 21030 Kuala Terengganu, Malaysia, e-mail: faranasuha93@gmail.com. Chin Kui Cheng, Ph.D., Faculty of Chemical and Natural Resources Engineering, University Malaysia Pahang, Lebuhraya Tun Razak, 26300 Gambang, Pahang, Malaysia, e.mail: chinkui@ump.edu.my. Su Shiung Lam, Ph.D., Pyrolysis Technology Group, Eastern Corridor Renewable Energy Group, 21030 Kuala Terengganu, Malaysia, e-mail: lam@umt.edu.my. 
$10^{\mathrm{TH}}$ InTERnAtional CONFERENCE ON Sustainable ENERgy AND ENVIRONMENTAL Protection (June $27^{\mathrm{TH}}-30^{\mathrm{TH}}, 2017$, Bled, Slovenia), Renewable ENERGy SOURCES W. Adibah Wan Mahari, N. Nasuha Ab Razak, C. Kui Cheng \& S. Shiung Lam:

Microwave Co-Pyrolysis of Waste Cooking Oil and Polystyrene-Based Plastic Waste

The fossil fuel is a limited non-renewable energy source and it is unable to satisfy the world's growing energy demand incessantly. Therefore, research on production of alternative energy source has been intensified in recent years. Currently, waste materials such as waste cooking oil, waste engine oil and plastic waste have shown potential as renewable resource to generate alternative fuel source [1-4]. Many researchers have reported the capability of thermochemical conversion processes such as pyrolysis, gasification and combustion to produce alternative fuel from waste materials [5-8]. Nevertheless, the fuel products possess undesirable properties such as high water content, acidity and oxygenated compounds compared to traditional fossil fuels such as gasoline and diesel $[9,10]$. These shortcomings could lead to high viscosity, reducing the combustion efficiency and limiting their application as fuel source.

Owing to these problems, co-processing of waste materials using microwave pyrolysis technique has attracted attention due to its potential to simultaneously treat and convert several wastes to produce cleaner fuel [11-13]. Microwave pyrolysis is a microwaveheated thermal process performed in an inert environment from which oxygen is excluded from the heating process. This pyrolysis process heats and thermally decomposes waste and biomass materials to produce pyrolysis products in the form of gases, liquid oil and char products. The advantages and unique heating characteristics of microwave pyrolysis have been reported in details in previous works [14-16].

Co-pyrolysis of an organic-based waste material (e.g. waste oil) with a plastic-based waste material could produce a positive synergistic effect that leads to better yield and properties of pyrolysis products. The plastic-based waste material could transfer its hydrogen content to the organic-based waste materials via aromatization reactions that occurred during the co-pyrolysis process [17]. The hydrogen transfer could enhance cracking of the heavier hydrocarbons in waste materials into lighter hydrocarbons for potential use as a fuel product [18]. In addition, the fact that most plastic wastes are free of oxygen content could lead to lower production of undesirable oxygenated by-products such as acidic tar, sludge, $\mathrm{NO}_{\mathrm{x}}$ and $\mathrm{SO}_{\mathrm{x}}$, producing a potentially 'cleaner' fuel product. In addition, it has been reported that the co-pyrolysis promoted the occurrence of secondary reactions (e.g. aromatization, condensation, reforming, polymerization) to convert the compounds containing carbonyl and carboxyl functional groups (e.g. free fatty acids) in organic-based waste material to form light aliphatic and aromatic hydrocarbons that could be used as chemical feedstock or fuel $[18,19]$.

Waste cooking oil (WCO) and polystyrene-based plastic wastes (PW) are waste materials that are abundantly available as household waste. This study was initiated with thermogravimetric and proximate analysis of the WCO and PW in order to examine their potential as feedstocks for pyrolysis conversion into fuel products. This was followed by microwave co-pyrolysis of a mixture of WCO and PW over a range of different ratios of PW added to WCO to assess the potential of using this co-pyrolysis approach to treat and convert these household wastes into an alternative fuel source. 
$10^{\mathrm{TH}}$ InTERnational CONFerence on Sustainable EnERgy AND Environmental 83

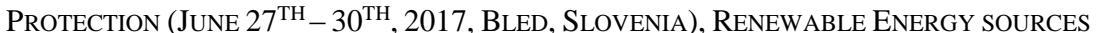
W. Adibah Wan Mahari, N. Nasuha Ab Razak, C. Kui Cheng \& S. Shiung Lam: Microwave Co-Pyrolysis of Waste Cooking Oil and Polystyrene-Based Plastic Waste

\section{$2 \quad$ Materials and Methods}

\subsection{Materials}

WCO was collected from fried chicken restaurant in Kuala Terengganu, Malaysia. The waste oil was produced from frying foods at temperatures ranging from 170 to $200{ }^{\circ} \mathrm{C}$. PW was collected from the household area nearby and both the WCO and PW were then used as feedstock to be treated by microwave co-pyrolysis process.

Thermogravimetric analysis was conducted using Mettler-Toledo TGA/SDTA851e (Mettler-Toledo, Switzerland) to investigate the thermal behaviour and the different stages of decomposition that could occur during the pyrolysis of these waste materials. The sample $(\sim 20 \mathrm{mg})$ was heated from ambient temperature to $900{ }^{\circ} \mathrm{C}$ at a heating rate of $25^{\circ} \mathrm{C} / \mathrm{min}$ with high purity $\mathrm{N}_{2}$ as the carrier gas.

Proximate analysis was also conducted using the similar TGA instrument to determine the content of volatile matter, fixed carbon and ash of the pyrolysis feedstock. The weight loss observed between 100 and $600{ }^{\circ} \mathrm{C}$ indicates the volatile matter content of the sample[20]. The fixed carbon refers to the decomposition between 600 and $900{ }^{\circ} \mathrm{C}$, and the weight loss observed at $900{ }^{\circ} \mathrm{C}$ and above indicates the ash content of the sample[20, 21].

The sample was heated from ambient temperature to $400{ }^{\circ} \mathrm{C}$ at a heating rate of $25^{\circ} \mathrm{C} / \mathrm{min}$ with $\mathrm{N}_{2}$ as the carrier gas, which then switched to $\mathrm{O}_{2}$ gas and the thermal balance was ramped to $900{ }^{\circ} \mathrm{C}$ with a final holding time of $20 \mathrm{~min}$; the carrier gases were vented through the apparatus at a flow rate of $0.1 \mathrm{~L} / \mathrm{min}$.

\subsection{Experimental procedure}

Co-pyrolysis of WCO and PW was conducted in a stirred batch reactor heated by a modified $800 \mathrm{~W}$ microwave oven. The schematic diagram of microwave pyrolysis system has been described in previous studies[14, 15]. Activated carbon was added to the reactor for use as a heating medium and reaction bed. WCO and PW were the inserted into the reactor. The reactor was purged with nitrogen gas at a flow rate of $0.2 \mathrm{~L} / \mathrm{min}$ in order to maintain the reactor in an inert atmosphere.

$50 \mathrm{~g}$ of $\mathrm{WCO}$ and different amounts of PW were added to a quartz reactor to produce different ratios of WCO to PW (termed "W/P ratio"). The W/P ratios of 1:1.5, 1:1, 1.5:1 were investigated. The temperature during microwave co-pyrolysis of WCO and PW was measured using temperature controller that was connected with a stainess steel type $\mathrm{K}$ thermocouple. The temperature versus time profile during the microwave co-pyrolysis of WCO and PW was measured as an indication of their heating characteristic. The amount of pyrolysis oil was calculated from the addition of the weight of the collecting vessels after pyrolysis experiments. The char yield was determined by measuring the difference of reactor weight its contents before and after pyrolysis. The yield of gas product was 
$10^{\mathrm{TH}}$ InTERnAtional CONFERENCE ON Sustainable ENERgy AND ENVIRONMENTAL Protection (June $27^{\mathrm{TH}}-30^{\mathrm{TH}}, 2017$, BlED, SLOVENIA), RENEWABLE ENERGY SOURCES W. Adibah Wan Mahari, N. Nasuha Ab Razak, C. Kui Cheng \& S. Shiung Lam: Microwave Co-Pyrolysis of Waste Cooking Oil and Polystyrene-Based Plastic Waste

determined by calculating the mass difference. The pyrolysis oil was collected and kept in glass bottles for further analysis.

\subsection{Product analysis}

The elemental analysis of oil sample was performed to determine the content of carbon, hydrogen, nitrogen, sulphur and oxygen using Vario MACRO Elemental Analyzer (Elementar Analysemsysteme GmbH, Germany). The calorific value of the oil sample was also determined according to ASTM D240 using a 1341 Plain Jacket bomb calorimeter instrument (Parr Instrument Company, Moline, USA).

\section{$3 \quad$ Results and Discussion}

\subsection{Thermogravimetric analysis}

Figure 1 shows the thermal decomposition of WCO under pyrolysis environment. The first stage of decomposition of WCO is indicated by the weight loss observed at $345{ }^{\circ} \mathrm{C}$ to $410^{\circ} \mathrm{C}$, which showed a weight loss of approximately $21 \mathrm{wt} . \%$. This could be attributed to the volatilisation of compounds derived from the decomposition of triglycerides molecules (e.g. unsaturated fatty acids) present in WCO. The highest weight loss was observed in the second stage of decomposition $\left(410{ }^{\circ} \mathrm{C}\right.$ to $\left.500{ }^{\circ} \mathrm{C}\right)$ with a weight loss of approximately $76 \mathrm{wt} . \%$. This was likely derived from the volatilisation of saturated fatty acids (e.g. palmitic acid, stearic acid) and short-chain fatty acids[20]. Overall, the decomposition of $\mathrm{WCO}$ were found to occur in the temperature ranging from $345^{\circ} \mathrm{C}$ to $500{ }^{\circ} \mathrm{C}$, and the weight loss of up to $98 \mathrm{wt} \%$ was observed. This weight loss indicates the volatile matter content in the WCO. The high volatile matter content makes the waste cooking oil desirable as a feedstock for pyrolysis because this volatile matter could be pyrolyzed to produce volatile hydrocarbons for use as potential liquid and gaseous fuel. No further weight loss was observed between $600{ }^{\circ} \mathrm{C}$ to $900{ }^{\circ} \mathrm{C}$, which indicates very little or none fixed carbon exists in the oil. The ash content was obtained by calculating the difference of volatile matter and other elements (e.g. fixed carbon, ash content). It was found that $<3 \mathrm{wt} . \%$ of ash content exists in the oil. This low ash content is desirable since the ash content may become a component of char residue, which is considered an impurity or by-product from the pyrolysis process. 


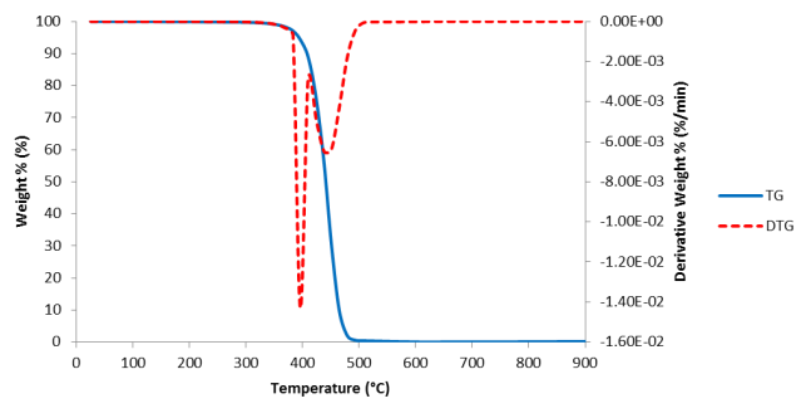

Figure. 1 Thermogravimetric analysis (TGA) and derivative thermogravimetric (DTG) curve of WCO in pyrolysis environment

Figure 2 shows the thermal decomposition of $\mathrm{PW}$ under pyrolysis environment. PW was found to decompose from $310^{\circ} \mathrm{C}$ to $520^{\circ} \mathrm{C}$. A high weight loss of $98 \mathrm{wt} \%$. was observed from the decomposition of PW. PW is made of styrene monomers and it has a long hydrocarbon chain with phenyl group (benzene ring) attached to each carbon atom [22]. Therefore, it can easily decompose at high process temperatures. The high weight loss also indicates the high volatile matter content of PW, which represents desirable feature to be converted by pyrolysis to produce potentially useful pyrolysis products.

The thermogravimetric analysis also indicated that the suitable temperature for pyrolysis of WCO and PW on their own is at $\geq 500{ }^{\circ} \mathrm{C}$ in order to decompose and recover the majority of the volatile matter of these waste materials.

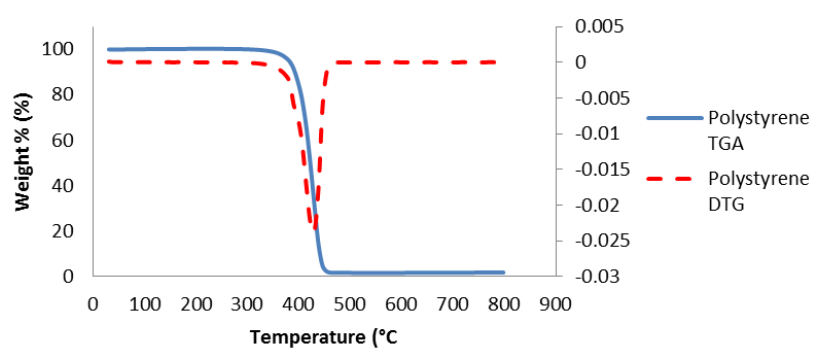

Figure. 2 Thermogravimetric analysis (TGA) and derivative thermogravimetric (DTG) curve of PW in pyrolysis environment

\subsection{Temperature profile during microwave co-pyrolysis of WCO and PW}

The temperature profile during microwave co-pyrolysis of $\mathrm{WCO}$ and $\mathrm{PW}$ is shown in Figure 3. The microwave co-pyrolysis showed a a heating rate of about $20-40{ }^{\circ} \mathrm{C} / \mathrm{min}$ to heat the mixture $\mathrm{WCO}$ and $\mathrm{PW}$ to $400{ }^{\circ} \mathrm{C}$ for pyrolysis decomposition. In particular, the co-pyrolysis performed at a W/P ratio of 1:1.5 and 1.5:1 demonstrated a faster heating rate $\left(40{ }^{\circ} \mathrm{C} / \mathrm{min}\right)$, achieving $400{ }^{\circ} \mathrm{C}$ in only $10 \mathrm{~min}$. This is faster than heating rates $(6-$ $26^{\circ} \mathrm{C} / \mathrm{min}$ ) reported in microwave pyrolysis of waste cooking oil on its own [14]. In 


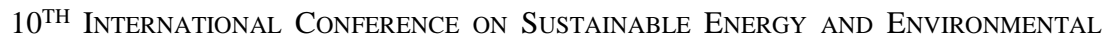
Protection (June $27^{\mathrm{TH}}-30^{\mathrm{TH}}, 2017$, BlED, SLOVENIA), RENEWABLE ENERGY SOURCES W. Adibah Wan Mahari, N. Nasuha Ab Razak, C. Kui Cheng \& S. Shiung Lam: Microwave Co-Pyrolysis of Waste Cooking Oil and Polystyrene-Based Plastic Waste

addition, it was found that a lower process temperature $\left(\sim 400^{\circ} \mathrm{C}\right)$ was required compared to that required by pyrolysis of plastic and waste oil on its own $\left(\geq 500^{\circ} \mathrm{C}\right)[14,23]$. These results indicate that the microwave co-pyrolysis approach has positive synergistic effects in rapidly heating the waste materials to achieve high temperature for pyrolysis while simulataneously showing advantage in the need of a lower process temperature to pyrolyze the waste materials.

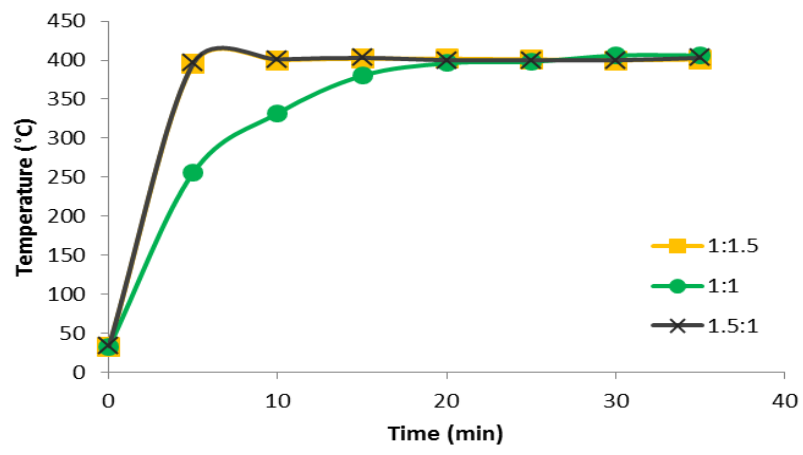

Figure. 3 Temperature profile during microwave co-pyrolysis of WCO and PW at different W/P ratios.

\subsection{Product yield}

Figure 4 presents the product yield in the form of pyrolysis oil, pyrolysis gases and char residue during microwave co-pyrolysis of $\mathrm{WCO}$ and $\mathrm{PW}$ at different $\mathrm{W} / \mathrm{P}$ ratios. The pyrolysis products were dominated by pyrolysis gases. The high yield of pyrolysis gases could be explained by increased occurrence of secondary reactions (particularly secondary cracking reactions) during the co-pyrolysis process, resulting in higher conversion of the waste materials into ligther compounds present in gaseous form [18, 19]. The production of pyrolysis gases is favourable since it could be used as gaseous fuel in gas turbines to generate electricity [22].

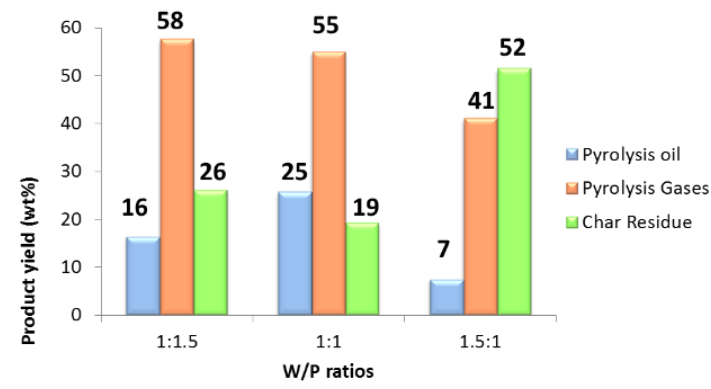

Figure. 4 Product yield of microwave co-pyrolysis of WCO and PW at different W/P ratios. 
Higher yield of pyrolysis gases were obtained at higher ratio of PW added to WCO. This suggests that PW contained light compounds that was likely to be decomposed to produce gaseous compounds, which contributed the higher yield of pyrolysis gas when higher amount of PW was added to the co-pyrolysis process.

The highest yield of char residue (52 wt $\%$ ) was obtained at W/P ratio of 1.5:1. The char residue obtained at this W/P ratio was found to be a waxy mixture of char and unpyrolysed $\mathrm{WCO}$ and $\mathrm{PW}$. This could be due to the incomplete pyrolysis cracking occurred at this $\mathrm{W} / \mathrm{P}$ ratio. The higher amount of $\mathrm{WCO}$ at this ratio may require higher process temperature $\left(>400{ }^{\circ} \mathrm{C}\right)$ for a more extensive pyrolysis cracking to generate pyrolysis volatiles.

The highest yield of pyrolysis oil ( $25 \mathrm{wt} \%)$ was observed at a W/P ratio of 1:1. It is thought that this represents the optimum balance between a sufficiently high W/P ratio to produce condensable vapor and not being so high as to promote secondary or tertiary cracking that led to production of only the pyrolysis gases or undesirable char residue. Our results have demonstrated that a recovery of approximately $80 \mathrm{wt} \%$ of pyrolysis products containing pyrolysis gases and pyrolysis oil is possible.

\subsection{Elemental composition and energy content of pyrolysis oil}

The pyrolysis oil obtained from microwave co-pyrolysis of WCO and PW at different W/P ratios were analyzed for their elemental composition and energy content. Data are not presented for pyrolysis gases due to limitation of analytical instrument for gas analyses.

As shown in Table 1, the pyrolysis oil were dominated by carbon element (73-81 wt\%). Hydrogen and nitrogen was detected in low concentration and sulphur was not detected in pyrolysis oil. These represent favourable characteristics since the pyrolysis oil could be used as a "greener" fuel source with potentially low emissions of NOx and SOx during fuel combustion process. Nevertheless, the oxygen content in pyrolysis oil (10-17 wt\%) was considered high to be used as fuel source. Therefore, pyrolysis oil needs to undergo upgrading treatment (e.g. reforming, deoxygenation and refining) to reduce the oxygen content. 
$10^{\mathrm{TH}}$ InTERNATIONAL CONFERENCE ON SuSTAINABLE ENERGY AND ENVIRONMENTAL Protection (June $27^{\mathrm{TH}}-30^{\mathrm{TH}}, 2017$, BlED, SLOVENIA), RENEWABLE ENERGY SOURCES W. Adibah Wan Mahari, N. Nasuha Ab Razak, C. Kui Cheng \& S. Shiung Lam: Microwave Co-Pyrolysis of Waste Cooking Oil and Polystyrene-Based Plastic Waste

Table 1 Elemental analysis and energy content

\begin{tabular}{|c|c|c|c|}
\hline \multirow[t]{2}{*}{ Elemental Analysis } & \multicolumn{3}{|c|}{$\mathrm{W} / \mathrm{P}$ ratios } \\
\hline & $1: 1.5$ & $1: 1$ & $1.5: 1$ \\
\hline $\mathrm{C}(\mathrm{wt} \%)$ & 76 & 81 & 73 \\
\hline $\mathrm{H}(\mathrm{wt} \%)$ & 7 & 8 & 8 \\
\hline $\mathrm{N}(\mathrm{wt} \%)$ & 1 & 1 & 2 \\
\hline $\mathrm{S}(\mathrm{wt} \%)$ & 0 & 0 & 0 \\
\hline $\mathrm{O}(\mathrm{wt} \%)$ & 16 & 10 & 17 \\
\hline $\begin{array}{ll}\text { Calorific } & \text { value } \\
(\mathrm{MJ} / \mathrm{kg}) & \end{array}$ & 30.8 & 35.3 & 30.0 \\
\hline
\end{tabular}

The pyrolysis oil produced from W/P ratio of 1:1 showed the highest energy content (35 $\mathrm{MJ} / \mathrm{kg}$ ) compared to other W/P ratios. This could be attributed to the higher fraction of carbon and hydrogen present in the pyrolysis oil as shown in Table 1. The energy content of pyrolysis oil ranged from $30 \mathrm{MJ} / \mathrm{kg}$ to $35.3 \mathrm{MJ} / \mathrm{kg}$. This calorific value is comparable to biodiesel (36-40 MJ/kg)[24] and showed the potential to be used as alternative fuel. Nevertheless, the energy content is lower than that commercial diesel fuel $(45 \mathrm{MJ} / \mathrm{kg})$ [15].

\section{Conclusion}

This study has shown that WCO and PW have high volatile matter and low ash content, thus showing potential to be transformed into fuel product via pyrolysis process. The microwave co-pyrolysis of $\mathrm{WCO}$ and $\mathrm{PW}$ demonstrated fast heating rate (up to $\left.40^{\circ} \mathrm{C} / \mathrm{min}\right)$, low process temperature $\left(400^{\circ} \mathrm{C}\right)$, and $80 \mathrm{wt} \%$ of pyrolysis products containing pyrolysis gases and pyrolysis oil.

\section{References}

[1] Undri A, Rosi L, Frediani M, Frediani P. Upgraded fuel from microwave assisted pyrolysis of waste tire. Fuel. 2014;115:600-8.

[2] Zhang X, Lei H, Yadavalli G, Zhu L, Wei Y, Liu Y. Gasoline-range hydrocarbons produced from microwave-induced pyrolysis of low-density polyethylene over ZSM-5. Fuel. 2015;144:33-42.

[3] Chen G, Liu C, Ma W, Zhang X, Li Y, Yan B, et al. Co-pyrolysis of corn cob and waste cooking oil in a fixed bed. Bioresource technology. 2014;166:500-7.

[4] Lam SS, Liew RK, Cheng CK, Chase HA. Catalytic microwave pyrolysis of waste engine oil using metallic pyrolysis char. Applied Catalysis B: Environmental. 2015;176-177:60117.

[5] Demirbas A. Biorefineries: Current activities and future developments. Energy Conversion and Management. 2009;50(11):2782-801.

[6] Demirbas A. Biofuels securing the planet's future energy needs. Energy Conversion and Management. 2009;50(9):2239-49.

[7] Chattopadhyay J, Pathak TS, Srivastava R, Singh AC. Catalytic co-pyrolysis of paper biomass and plastic mixtures (HDPE (high density polyethylene), PP (polypropylene) and 
$10^{\text {TH }}$ InTERnational CONFEREnCe on Sustainable EnERgy AND ENVIRonmental Protection (June 27 $7^{\mathrm{TH}}-30^{\mathrm{TH}}, 2017$, BLED, Slovenia), RenEwable ENERGy SOURCES W. Adibah Wan Mahari, N. Nasuha Ab Razak, C. Kui Cheng \& S. Shiung Lam: Microwave Co-Pyrolysis of Waste Cooking Oil and Polystyrene-Based Plastic Waste

[8] Kabir G, Hameed BH. Recent progress on catalytic pyrolysis of lignocellulosic biomass to high-grade bio-oil and bio-chemicals. Renewable and Sustainable Energy Reviews. 2017;70:945-67.

[9] Phung TK, Casazza AA, Perego P, Capranica P, Busca G. Catalytic pyrolysis of vegetable oils to biofuels: Catalyst functionalities and the role of ketonization on the oxygenate paths. Fuel Processing Technology. 2015;140:119-24.

[10] Chen G, Zhang X, Ma W, Yan B, Li Y. Co-pyrolysis of Corn-cob and Waste Cooking-oil in a Fixed Bed Reactor with HY Upgrading Process. Energy Procedia. 2014;61:2363-6.

[11] Chen W, Shi S, Zhang J, Chen M, Zhou X. Co-pyrolysis of waste newspaper with highdensity polyethylene: Synergistic effect and oil characterization. Energy Conversion and Management. 2016;112:41-8.

[12] Wang J, Zhong Z, Zhang B, Ding K, Xue Z, Deng A, et al. Upgraded bio-oil production via catalytic fast co-pyrolysis of waste cooking oil and tea residual. Waste management. 2016.

[13] Wang Y, Dai L, Fan L, Duan D, Liu Y, Ruan R, et al. Microwave-assisted catalytic fast copyrolysis of bamboo sawdust and waste tire for bio-oil production. Journal of Analytical and Applied Pyrolysis. 2017;123:224-8.

[14] Lam SS, Wan Mahari WA, Jusoh A, Chong CT, Lee CL, Chase HA. Pyrolysis using microwave absorbents as reaction bed: An improved approach to transform used frying oil into biofuel product with desirable properties. Journal of Cleaner Production. 2017;147:263-72.

[15] Lam SS, Wan Mahari WA, Cheng CK, Omar R, Chong CT, Chase HA. Recovery of diesellike fuel from waste palm oil by pyrolysis using a microwave heated bed of activated carbon. Energy. 2016;115:791-9.

[16] Wan Mahari W, Zainuddin N, Wan Nik W, Chong C, Lam S. Pyrolysis Recovery of Waste Shipping Oil Using Microwave Heating. Energies. 2016;9(10):780.

[17] Romero MJ, Pizzi A, Toscano G, Busca G, Bosio B, Arato E. Deoxygenation of waste cooking oil and non-edible oil for the production of liquid hydrocarbon biofuels. Waste management. 2016;47(Pt A):62-8.

[18] Hassan H, Lim JK, Hameed BH. Recent progress on biomass co-pyrolysis conversion into high-quality bio-oil. Bioresource technology. 2016;221:645-55.

[19] Tang C-Y, Zhang D-X. Mechanisms of aliphatic hydrocarbon formation during copyrolysis of coal and cotton stalk. Chin Chem Lett. 2016;27(10):1607-11.

[20] de Medeiros E, de Cássia Ramos do Egypto Queiroga R, de Souza A, de M. Cordeiro A, de Medeiros A, de Souza D, et al. Thermal and quality evaluation of vegetable oils used in ruminant feed. J Therm Anal Calorim. 2013;112(3):1515-21.

[21] Lam SS, Russell AD, Lee CL, Lam SK, Chase HA. Production of hydrogen and light hydrocarbons as a potential gaseous fuel from microwave-heated pyrolysis of waste automotive engine oil. International Journal of Hydrogen Energy. 2012;37(6):5011-21.

[22] Sharuddin SDA, Abnisa F, Daud WMAW, Aroua MK. A review on pyrolysis of plastic wastes. Energy Conversion and Management. 2016;115:308-26.

[23] Russell AD, Antreou EI, Lam SS, Ludlow-Palafox C, Chase HA. Microwave-assisted pyrolysis of HDPE using an activated carbon bed. RSC Advances. 2012;2(17):6756.

[24] Hoekman SK, Broch A, Robbins C, Ceniceros E, Natarajan M. Review of biodiesel composition, properties, and specifications. Renewable and Sustainable Energy Reviews. 2012;16(1):143-69. 
$90 \quad 10^{\text {TH }}$ International Conference on Sustainable ENERgy AND ENVIRONMENTaL Protection (June $27^{\mathrm{TH}}-30^{\mathrm{TH}}, 2017$, Bled, Slovenia), RenEWABle ENERGy SOURCES 
$10^{\mathrm{TH}}$ InTERnational CONFERENCE ON Sustainable ENERgy AND Environmental Protection (June 27 $7^{\mathrm{TH}}-30^{\mathrm{TH}}, 2017$, BLed, SLOVENIA), RENEWABLE ENERGy SOURCES

J. Krope, A.Ghani Olabi, D. Goričanec \& S. Božičnik

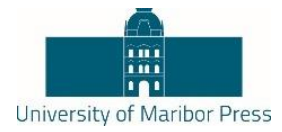

\title{
Unexploited Potential in the Field of Small Hydropower Production Units in Protected Areas
}

\author{
KLEMEN DEŽELAK \& JOŽE PIHLER
}

\begin{abstract}
Small hydropower production units and similar projects receive a considerable amount of funds and financial support from governments. However, despite their doubtless advantages, the aforementioned small hydropower projects can lead to several environmental risks, such as lower water quality, biodiversity loss, ecosystem destruction, etc. The main difficulty is often to find an acceptable compromise between the commercial interest of the operator and the environmental demands on the construction and operation of small hydropower plants. This paper presents some alternative possibilities for construction of small hydro power plants in the areas, where the nature is partly protected by special environmental laws. The technical solutions regarding the exploitation of the energetic potential are indicated, together with the results of SWOT and an economic justification analysis of the investments. In that sense, some suitable locations are defined and analysed in Slovenia for hydro power plant construction.
\end{abstract}

Keywords: • small hydropower • environmental protection • SWOT analysis $\bullet$ economic analysis $\bullet$ movable power plant $\bullet$

Correspondence AdDress: Klemen Deželak, Ph.D., Associate Professor, University of Maribor, Faculty of Electrical Engineering and Computer Science, Smetanova ulica 17, 2000 Maribor, Slovenia, e-mail: klemen.dezelak@um.si. Jože Pihler, Ph.D., Professor, University of Maribor, Faculty of Electrical Engineering and Computer Science, Smetanova ulica 17, 2000 Maribor, Slovenia, e-mail: joze.pihler@um.si. 
$10^{\mathrm{TH}}$ INTERNATIONAL CONFERENCE ON SUSTAINABLE ENERGy AND ENVIRONMENTAL Protection (June $27^{\mathrm{TH}}-30^{\mathrm{TH}}, 2017$, BlED, SLOVENIA), RENEWABLE ENERGY SOURCES K. Deželak \& J. Pihler: Unexploited Potential in the Field of Small Hydropower Production Units in Protected Areas Introduction

When considering the status of the global energy shortages, the emphasis to reduce $\mathrm{CO}_{2}$ emissions, development of alternative energy generation methods and growing energy consumption, there is a need to change the way energy is created and used [1]. An ideal energy source should be renewable and should have minimal effect on the environment. Renewable technologies are offering clean and reliable energy to reduce greenhouse gas emission that lead to global warming while saving money and creating jobs [2].

Among the renewable energy sources, small hydropower plants have gained the highest attraction. They are a mature and reliable technology, with easy operation and having a life cycle of more than 50 years. Hydropower is the world's largest and cheapest source of renewable energy. It is also the most efficient way to produce electricity [3]. Small hydropower plants (SHPs) can be the best, most economical option for rural electrification in developing countries [4]. One-third of the world's population does not have access to electricity, but does have access to moving water [2]. Moreover, smallscale renewable technology is a very good option for supplying electric power to isolated rural areas.

Development of small hydropower plant (SHP) is mentioned frequently and promoted actively within climate change and renewable energy policy frameworks. Sector reviews, academic literature and financing trends indicate that SHP has gained significant traction over the past few years, and continues to gain momentum [5], [6].

A SHP consists mainly of a small reservoir or irrigation canal, governor, turbine and generator. The water is passed from reservoir to turbine through a penstock. When water strikes at the blades of the turbine, it converts hydraulic energy into mechanical energy. The water flow in the turbine is controlled through the governor. The turbine is coupled with a generator which converts mechanical energy into electrical energy [4].

It is notorious that, despite their doubtless advantages, SHPs projects can lead to several environmental risks, such as lower water quality, ecosystem destruction or biodiversity loss [7]. Nevertheless, the use of hydropower causes environmental problems [8], [9]. In order to develop a small hydropower plant in a sustainable manner, it is important to make a detailed Environmental Impact Assessment Report, to know the site-specific ecological conditions, and to have a monitoring system established at the SHP to control the flow, sediment and fish passages, as well as water quality parameters [7].

This paper presents alternative possibilities for construction of small hydro power plants in the bed of the river Drava (the Slovenian part near Maribor city). The nature in this area is protected by special environmental laws. The results of an economic analysis of the investment are indicated, together with an appropriate SWOT (Strengths, Weaknesses, Opportunities, Threats) analysis. 


\section{$2 \quad$ Protected Natural Areas}

The Nature Conservation Act [10] regulates the formation of the network of specially protected Natura 2000 areas legally. The Act deals with:

- Habitat types;

- Protection of internationally protected species;

- Assessment of plans and acts;

- Ecologically important environment.

The Government defines the habitat types that have priority in conservation in favourable conditions and prescribes guidelines for their conservation that need to be taken into consideration in spatial planning and use of natural resources.

The Environmental Protection Act [11] is designed to promote and guide such development of society that enables long-term conditions for human health, well-being and quality of life, as well as conservation of biodiversity. The basic purpose of the Act is to prevent and reduce the environmental burden, to ensure sustainable use of natural resources and to promote use of renewable energy sources. In the case of the siting and construction of hydro power plants, it is necessary to take into consideration the principle of cooperation, which specifies that the State and Municipalities have to enable the participation of polluters and the public in the process of adoption of environmental protection related programmes and plans. The second principle that has to be applied is the precautionary principle, which states that the new technologies can be applied only if there are no adverse effects to the environment and human health, taking into consideration all potential protection measures.

\subsection{Areas of Natura 2000}

They are defined in the Directive on the Conservation of Natural Habitats and of Wild Fauna and Flora [12] and represent the areas that are important for the community, since they, in their local biogeographic region or regions, contribute significantly to the conservation or re-establishment of favourable conditions of natural habitat types or species, to the network integration and to the conservation of biodiversity.

\subsection{Special areas of conservation}

The Directive [12] specifies the habitat types and species the conservation of which lies in the interest of the EU, and for which the European environmental network is being established. The areas of the network that are important for the conservation of these wild fauna and flora, as well as the natural habitats, are called Special Areas of Conservation $-\mathrm{SAC}$.

The areas that meet the criteria laid down by the Directive on the Conservation of Wild Birds (hereinafter referred to as The Bird Directive [13]) are called Special Protected 
$10^{\mathrm{TH}}$ InTERnAtional CONFERENCE ON Sustainable ENERgy AND ENVIRONMENTAL Protection (June $27^{\mathrm{TH}}-30^{\mathrm{TH}}, 2017$, Bled, SLOVENIA), RENEWABle ENERGY SOURCES K. Deželak \& J. Pihler: Unexploited Potential in the Field of Small Hydropower Production Units in Protected Areas

Areas - SPA. They are the areas on which the Member States try to protect, maintain or re-establish sufficient diversity and size of habitats for all wild birds.

\subsection{Protected natural areas}

They are the areas for which State measures ensure protection of natural values and biodiversity. The Nature Conservation Act [10] defines the following types of protected areas: National Parks, Nature Parks, regional parks, and, in a narrower aspect, strict natural reserves, natural reserves and natural monuments.

\subsection{Protected areas}

These areas are defined by the International Union for Conservation of Nature (IUCN) as a part of the land or sea dedicated especially to the protection and conservation of biodiversity and natural and associated cultural wealth, whose management is legally or otherwise defined effectively. The protected areas include protected areas of nature, such as natural monuments and reserves, as well as natural, nature or regional parks. Any interventions in these areas require obtaining of nature protection conditions and/or Nature Protection Permit.

\subsection{Habitat type}

It is a biotically characteristic and spatially competed unit of the ecosystem, the conservation of which contributes to the conservation of ecosystems [14].

\subsection{Biodiversity}

According to the Convention on Biological Diversity the term "biodiversity" means the diversity of living creatures from all sources that include land, sea and other ecosystems and ecological complexes, of which they are part; it includes diversity within species themselves, between the species and diversity of ecosystems.

\subsection{Ecologically important area}

This is an area of a habitat type, of a part of a habitat type, or a larger ecological system unit, which contributes significantly to the conservation of biodiversity. On these areas, interventions and activities are possible, but they have to be planned in such a way that the natural distribution of habitat types and habitats of flora and fauna are conserved to the maximum possible extent.

\section{$3 \quad$ The Drava River Case}

The Drava River has, due to its glacial headwaters (Grossglockner - 3,797 $\mathrm{m}$ above sea level) characteristics of a nival watercourse with higher flows in the period of late spring and summer, which is caused by simultaneous snow melting and heavy rain. The flow 
usually reaches maximum in June, while its minimum is in February. In presented Slovenian case, the natural hydrological conditions are influenced partly by the operation of hydro power plants on the Drava River, where the natural hydrological regime is essentially changed at the derivation hydro power plants (HPPs) Zlatoličje and Formin. When the discharge of the Drava is lower than or equal to the installed discharge of an individual hydro power plant (HPP), only the biological minimum flows through the Drava riverbed, which for the HPP Zlatoličje amounts to $Q_{\mathrm{ES}}=10 \mathrm{~m}^{3} / \mathrm{s}$ in winter and $Q_{\mathrm{ES}}$ $=20 \mathrm{~m}^{3} / \mathrm{s}$ in summer.

The Drava River is, with the river meadow between Maribor and Ptuj, designated as a natural hydrological value. The requirements for behaviour within a natural value are defined by Rules on the Designation and Protection of Natural Values. These rules can be summarised as follows:

- Nobody is allowed to treat natural values in a way that threatens their existence;

- A natural value can be visited and watched in a way that does not threaten its existence and impede its protection;

- If visiting or sightseeingof a natural value could cause danger for its protection, visiting or sightseeing of the natural value or a part of it shall be prohibited or restricted;

- General use of a natural resource or a natural good that is designated as a natural value can be performed in a way that does not threaten its existence and impede its protection;

- Interventions and activities are performed on natural values if there are no other spatial or technical possibilities for performing these interventions or activities.

If there are no other spatial or technical possibilities the interventions and activities are performed:

- On the surface and underground geomorphological, geological or hydrological natural value to the extent and in a way that does not cause destruction, damage or significant changes of the properties that were the reason for the designation as a natural value, or to the extent and in a way that causes the least possible changes of other physical, chemical, visual and functional characteristics of the natural value;

- On an arboreal natural value in a way that does not reduce its vitality, does not deteriorate its health condition and does not worsen the living conditions at the growing site;

- On a botanical or zoological natural value in a way that does not worsen the living conditions of the plants and animals that were the reason for the designation as a natural value, to the extent that makes their survival in the long-term impossible; 
$10^{\mathrm{TH}}$ International Conference on Sustainable EnERgy AND Environmental Protection (June $27^{\mathrm{TH}}-30^{\mathrm{TH}}, 2017$, BlED, SLOVENIA), RENEWABLE ENERGY SOURCES K. Deželak \& J. Pihler: Unexploited Potential in the Field of Small Hydropower Production Units in Protected Areas

- On a landscape natural value in a way that does not decrease landscape diversity and that does not destroy, damage or significantly change the characteristics of the landscape elements and their distribution in space;

- On an ecosystem natural value in a way that does not change the ecosystem's quality and natural processes within the ecosystem to the extent that destroys the natural balance;

- On a man-made natural value in a way that does not worsen the living conditions for the flora that are an essential part of the natural value, where in the areas of horticultural architectural heritage the interventions and activities are performed in accordance with the rules from the field of Protection of Cultural Heritage.

Different technical solutions for exploitation of the energetic potential in the bed of the river Drava and the results of the SWOT and economic justification analysis of investment are dealt with in this contribution (Fig. 1).

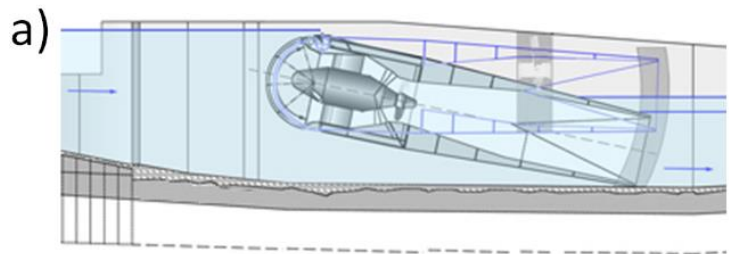

b)

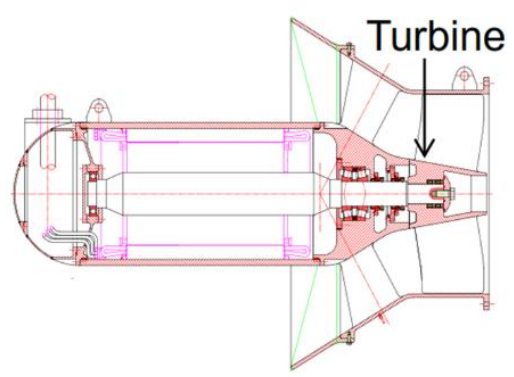

Figure 1. a) Movable power plant [15] and b) matrix power plant [16]

So, the proposed solution is construction of a so-called movable power plant that is currently used widely in Germany. The central part of such power plant is a doubleregulated Kaplan turbine for heads of 2-3 m and discharges up to $20 \mathrm{~m}^{3} / \mathrm{s}$. The realisation of a movable power plant is a combination of a backfilled dam and an artificial concrete barrier with built-in lock for larger alluvia. The entire mechanical and electrical equipment of the SHP is installed inside the concrete barrier. In the case of high waters, the entire dam structure is overflowed [15], [17].

Similar, the matrix power plants represent an innovative solution of a robust power plant with a low impact on changing the environment. The power plant is made of one or more 
matrix units, each of them containing a turbine-generator assembly. The main peculiarity of this system is the large number of small turbines instead of one large. The turbine is a simplified axial propeller turbine that operates in a way that the stator blades direct the water to the rotor blades with a fixed pitch angle, where the water releases a part of its energy and drains through the enlarged output part that acts as a diffusor. The unregulated turbine is connected fixedly to the synchronous generator, and the entire assembly is integrated in a single unit [16], [17].

\section{$4 \quad$ Swot and Economic Analysis}

This following section supports the selection of the most suitable solution of the construction of a SHP using SWOT analysis. This analysis got its name from the first letters of the four examined aspects (Strengths, Weaknesses, Opportunities, and Threats).

In principle, the strengths and weaknesses are defined by internal factors from which the project initiative originates (strengths) or should be removed (weaknesses). The internal factors can be affected directly to be developed, removed or somehow intervened in another way. The opportunities and threats are related to external factors that cannot be influenced directly, but can only be used for our own favour in a way that are foreseen in advance and, if necessary, adapted adequately.

In the subsequent parts, a closer look will be taken at a movable power plants (A) and a matrix power plant with several turbines (B) for discussed case. The aspects of internal and external factors are presented separately.

\section{A) Strengths}

- In the case of high waters it is overflowed;

- In the wide range of discharges it achieves good efficiencies;

- Higher annual availability;

- Higher electricity production;

- Better cohabitation with nature.

A) Weaknesses

- Higher investment costs (costs of dam);

- Longer earthmoving and construction works.

A) Opportunities

- Wider riverbed with a lower drop;

- Lower impact on undermining of the river bottom;

- Favourable impact on the underground water. 

Protection (June $27^{\mathrm{TH}}-30^{\mathrm{TH}}, 2017$, BlED, SLOVENIA), RENEWABLE ENERGY SOURCES K. Deželak \& J. Pihler: Unexploited Potential in the Field of Small Hydropower Production Units in Protected Areas

A) Threats

- Negative impact on the Drava River hydrology;

- Climate changes - drought;

- Damming, deposition of silt.

B) Strengths

- Modular Hydromatrix concept is standardised;

- The use of a Hydromatrix system with an innovative solution and proven technology is used;

- Due to the need for only minor construction interventions in the environment and use of water, a clean and environmentally friendly energy is obtained even more than in other types of HPPs;

- The existing river flow remains more or less unchanged;

- The existing dam or spillway can be used; major construction works are thus avoided;

- As there are no major interventions to the environment, no additional geological and hydrological hazards are caused;

- The time from the beginning of the project to the start of operation is very short; between 1 and 1.5 years.

B) Weaknesses

- Fixed blades; at the wide range of discharges the efficiency is lower;

- Lower annual availability of operation;

- Lower level of cohabitation with nature in comparison with a movable HPP;

- Longer payback period of the investment.

B) Opportunities

- Favourable impact on the underground water.

B) Threats

- Decrease of hydrology on the Drava River;

- Climate changes - drought;

- Increased risk of flooding;

- Damming, deposition of silt;

- Higher impact on undermining of the river bottom.

Within the financial part, the curve of cumulative cash flow (CCF) could be calculated by yearly income and outcome difference, where parameters like 10 years credit period, inflation and varying cost of energy could have essential influence. Regarding to the 
cumulative cash flow curve (Fig. 2) the parameter of the year-to-positive cash flow (1013 years) could has an important meaning.

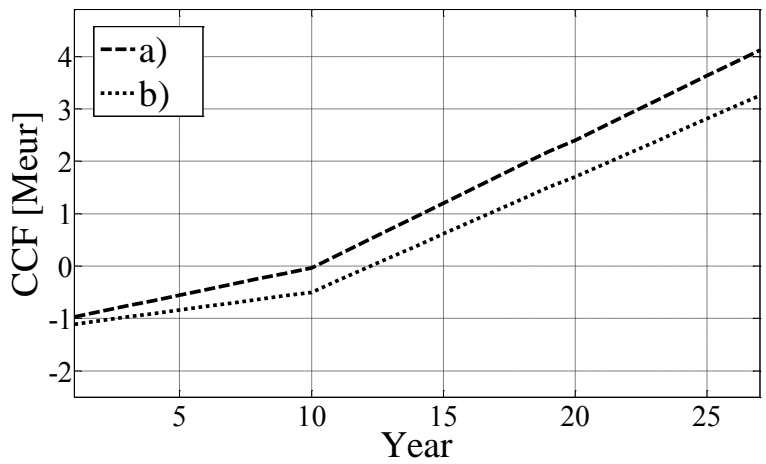

Figure 2. Cumulative Cash Flow curve; a) movable power plant, b) matrix power plant

\section{$5 \quad$ Conclusion}

In presented paper discussed area of the bed of the river Drava belongs into the network of the areas Natura 2000. Natura 2000 is a network of protected nature areas within the European Union for the conservation and recovery of biodiversity. Its final goal is to ensure the survival of essential flora and fauna. When working in a protected area with such legislation, a special license is required whenever there is a risk that certain activity could harm the area in any way. The overall SWOT analysis for the placement of proposed technological solutions to the environment was dealt in the paper together with an economic justification analysis of the investments.

\section{References}

[1] I. Loots, M. Van Dijk, B. Barta, S. J. Van Vuuren, and J. N. Bhagwan, "A review of low head hydropower technologies and applications in a South African context," Renewable and Sustainable Energy Reviews, vol. 50, pp. 1254-1268, 2015.

[2] H. J. Vermaak, K. Kusakana, and S. P. Koko, "Status of micro-hydrokinetic river technology in rural applications: A review of literature," Renewable and Sustainable Energy Reviews, vol. 29, pp. 625-633, 2014.

[3] M. I. Yuce, and A. Muratoglu, "Hydrokinetic energy conversion systems: a technology status review," Renewable and Sustainable Energy Reviews, vol. 43, pp. 72-82, 2015.

[4] J. A. Laghari, H. Mokhlis, A. H. A. Bakar, and H. Mohammad, "A comprehensive overview of new designs in the hydraulic, electrical equipments and controllers of mini hydro power plants making it cost effective technology," Renewable and Sustainable Energy Reviews, vol. 20, pp. 279-293, 2013.

[5] T. N. Manders, J. I. Höffken, and E. B. van der Vleuten, "Small-scale hydropower in the Netherlands: Problems and strategies of system builders," Renewable and Sustainable Energy Reviews, vol. 59, pp. 1493-1503, 2016. 
$100 \quad 10^{\mathrm{TH}}$ InTERnational CONFERENCE ON Sustainable ENERGy AND ENVIRONMENTAL Protection (June $27^{\mathrm{TH}}-30^{\mathrm{TH}}, 2017$, Bled, SLOVENIA), RENEWABle ENERGY SOURCES K. Deželak \& J. Pihler: Unexploited Potential in the Field of Small Hydropower Production Units in Protected Areas

[6] S. Kelly-Richards, N. Silber-Coats, A. Crootof, D. Tecklin, and C. Bauer, "Governing the transition to renewable energy: A review of impacts and policy issues in the small hydropower boom," Energy Policy, vol. 101, pp. 251-264, 2017.

[7] S. Kucukali, "Environmental risk assessment of small hydropower (SHP) plants: A case study for Tefen SHP plant on Filyos River," Energy for sustainable development, vol. 19, pp. 102-110, 2014.

[8] R. Carapellucci, L. Giordano, and F. Pierguidi, "Techno-economic evaluation of smallhydro power plants: Modelling and characterisation of the Abruzzo region in Italy," Renewable Energy, vol. 75, pp. 395-406, 2015.

[9] B. Spänhoff, "Current status and future prospects of hydropower in Saxony (Germany) compared to trends in Germany, the European Union and the World," Renewable and Sustainable Energy Reviews, vol. 30, pp. 518-525, 2014.

[10] Government of the Republic of Slovenia, "Nature Conservation Act," u.l. RS, no. 56/99, 31/00, 119/02, 22/03, 41/04, 96/04, 46/14.

[11] Government of the Republic of Slovenia, "Environmental Protection Act," u.l. RS, no. 41/04, 20/06, 39/06, 70/08, 108/09, 48/12, 57/12, 92/13.

[12] The Council Directive 92/43/EEC, "On the Conservation of Natural Habitats and of Wild Fauna and Flora," The Habitat Directive.

[13] The Council Directive 79/409/EEC, "On the Conservation of Wild Birds," The Bird Directive.

[14] Government of the Republic of Slovenia, "Decree on habitat types," u.l. RS, no. 112/03, 36/09, 33/13.

[15] Hydro - Energie Roth GMBH, "Bewegliche WKA," www.hydroenergie.de, 2017.

[16] Andritz Hydro, "Water. Power. Hydromatrix," www.andritz.com, 2017.

[17] K. Deželak, J. Pihler, and G. Štumberger, "Possibilities for small hydro power plant construction in the old bed of the river Drava," presented at the International Conference on Renewable Energies and Power Quality (ICREPQ'14), Cordoba, 2014, pp. 845-848. 
$10^{\mathrm{TH}}$ InTERnational CONFEREnCE ON Sustainable ENERgy AND Environmental Protection (June $27^{\mathrm{TH}}-30^{\mathrm{TH}}$, 2017, Bled, SLOVENIA), RENEWABLE ENERGy SOURCES

J. Krope, A.Ghani Olabi, D. Goričanec \& S. Božičnik

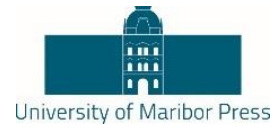

\title{
Review of Pem Fuel Cell Materials
}

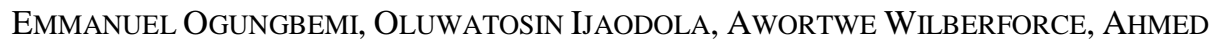 \\ AL MAKKY \& ABDUL OLABI
}

\begin{abstract}
In the light of intensive research on PEM fuel cells and other fuel cells in general, there is still a huge challenge with the commercialization of proton electron membrane fuel cells(PEMFC) technology. The major challenge being faced is with the cost of materials being too high. In this review, special consideration was given to materials. Using the right materials is very important to ensure high performance and durability and that the technology works at an acceptable level. Using materials that are too expensive no matter how good can pose a major challenge to commercialization by driving the cost too high thereby making it unaffordable. However there is a need to maintain a subtle equilibrium between performance and cost; these are the main drivers when considering the acceptability of technology. This paper presents an intensive study into PEM fuel cell materials. Currently effort is directed towards improving each component as it is believed that this will improve the overall performance of the system. This review supports this ideal.
\end{abstract}

Keywords: - PEM fuel cells - electro-catalyst layer • proton electron membrane $(\mathrm{PEM}) \bullet$ bipolar plate (BP) and gas diffusion layer (GDL) • materials •

CORRESPONDENCE ADDRESS: Emmanuel Ogungbemi, University of the West of Scotland, Institute of Engineering and Energy Technologies, High St Paisley PA 12BE, UK, e-mail: emmanuel.ogungbemi@uws.ac.uk. Oluwatosin Ijaodola, University of the West of Scotland, Institute of Engineering and Energy Technologies, High St Paisley PA 12BE, UK, e-mail: oluwatosin.Ijadda@uws.ac.uk. Awortwe Wilberforce, University of the West of Scotland, Institute of Engineering and Energy Technologies, High St Paisley PA 12BE, UK, e-mail: awortwe.wiuserkorce@uws.ac.uk. Ahmed Al Makky, University of the West of Scotland, Institute of Engineering and Energy Technologies, High St Paisley PA 12BE, UK, e-mail: ahmed.makky@uws.ac.uk. Abdul Olabi, University of the West of Scotland, Institute of Engineering and Energy Technologies, High St Paisley PA 12BE, UK, e-mail: abdul.Olabi@uws.ac.uk. 
$10^{\mathrm{TH}}$ International Conference on Sustainable EnERgy and Environmental Protection (June $27^{\mathrm{TH}}-30^{\mathrm{TH}}, 2017$, BlED, SLOVENIA), RENEWABLE ENERGY SOURCES E. Ogungbemi, O. Ijaodola, A. Wilberforce, A. Al Makky \& A. Olabi: Review of Pem Fuel Cell Materials

\section{Introduction}

Renewable energy is now very important in the society. It forms one of the major issues in the US election in November 2016 and also in the just concluded French election (May 2017). This is because of the need for a cleaner environment and to reduce the ever growing cost of energy due to population increase. PEM fuel cell is regarded as an alternative because it gives near zero emission and also efficient.

Work on the fuel cell was dated back to 1839. After more than a century the first PEM fuel cell was developed. Development on fuel cell if properly analysed could be attributed to the discovery of materials which offers properties that improves the durability of the product.

In spite of all the notable achievement in the development of the PEM fuel cell commercialization is still a major concern. However it is believed that discovering the right material can be a lasting solution to the problem.

Improving PEM components like the membrane, bipolar flow plate, gas diffusion layer, electro-catalyst layers, etc. has shown over time to have direct impact on the performance and durability of the cell. This review will discuss the current state of materials for PEM fuels cells and areas for future research.

\section{The Pem Fuel Cell}

Fuel cells generally got their names according to the type of electrolyte and reacting substances. In a PEM fuel cell, a reaction between hydrogen and oxygen gives water, electricity and waste heat. Figure 1 below shows a schematic diagram of a PEMFC. At the cathode the hydrogen ion $\left(\mathrm{H}^{+}\right)$gained two electrons to become hydrogen gas. On the other side at the anode the oxygen ion lost two oxygen ions to become oxygen gas. This reaction gave electricity with water and heat as bye product.

It is necessary to measure the performance of fuel cell while in operation. This helps to know the present condition of the cell and also predict possible breakdown or defects. Performance of a PEMFC can be determined by identifying the losses. Figure 2 below shows the 3 major type of losses in the fuel cell. They are (1) activation losses (2) ohmic losses (3) concentration losses. This is as shown in figure 2. The image in figure 2 can also be referred to as polarization curve. 


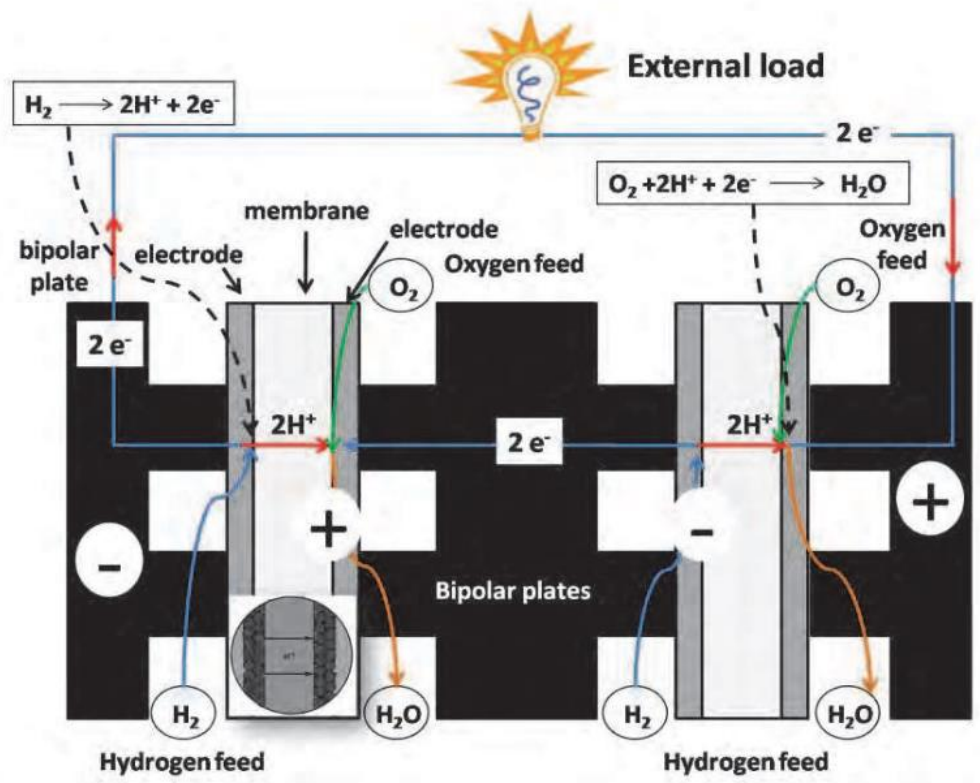

Figure 1. Detailed analysis of PEM fuel cell[1]

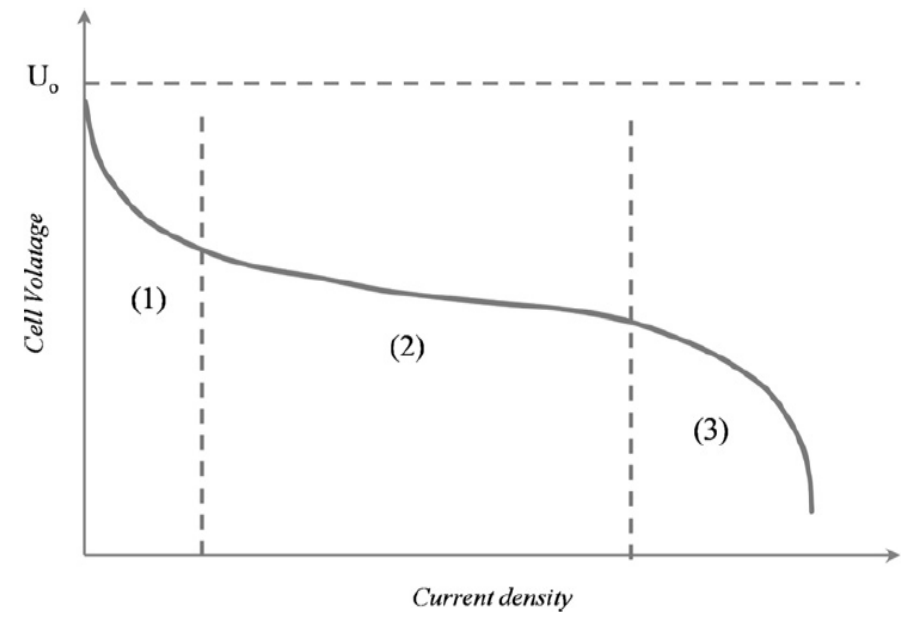

Figure 2. Shows PEM fuel cell losses[2]

\section{$3 \quad$ Pem Materials and Component}

Figure 3 shows the detailed planar image of a PEMFC at UWS fuel cell laboratory before assembling and figure 4 and figure 5, after assemblage. Although there are other 
104 10 $10^{\mathrm{TH}}$ InTERnational CONFERENCE ON Sustainable EnERgy and ENVIRONMENTAL Protection (June $27^{\mathrm{TH}}-30^{\mathrm{TH}}, 2017$, BlED, SLOVENIA), RENEWABLE ENERGY SOURCES E. Ogungbemi, O. Ijaodola, A. Wilberforce, A. Al Makky \& A. Olabi: Review of Pem Fuel Cell Materials

components, the major components of the PEMFC are membrane, gas diffusion layer and electro-catalyst layer popularly referred to as MEA - Membrane electrode assembly and the bipolar plates. Figure 1 shows how the different component of the PEMFC relates during reaction.

To ensure better performance, there is a need to have a good understanding of each component that makes the proton electron membrane fuel cell in order to make the right decision during material selection. Table 1 gives a summary of the failure modes for each of the major component of the PEM fuel cells and its root causes.

Table 1. PEM fuel cells failure modes and causes[3]

\begin{tabular}{|c|c|c|}
\hline Component & Failure modes & Causes \\
\hline Membrane & Conductivity loss & $\begin{array}{l}\text { Contamination } \\
\text { Non-uniform distribution of } \\
\text { reactants/water/coolant } \\
\text { Mechanical stress } \\
\text { Drying of membrane } \\
\text { Contamination } \\
\text { Thermal/mechanical stress }\end{array}$ \\
\hline Active layer & $\begin{array}{l}\text { Decrease in mass transport } \\
\text { rate of reactants } \\
\text { Loss of reformate tolerance } \\
\text { Decrease in control of water } \\
\text { management }\end{array}$ & $\begin{array}{l}\text { Sintering of electrocatalyst } \\
\text { Corrosion of electrocatalyst } \\
\text { Poisoning } \\
\text { Mechanical stress } \\
\text { Contamination } \\
\text { Dealloying of electrocatalyst } \\
\text { Change in hydrophobicity of } \\
\text { materials }\end{array}$ \\
\hline GDL & $\begin{array}{l}\text { Decrease in mass transport } \\
\text { rate of reactants } \\
\text { Conductivity loss } \\
\text { Decrease in control of water } \\
\text { management }\end{array}$ & $\begin{array}{l}\text { Degradation of backing material } \\
\text { Mechanical stress } \\
\text { Corrosion } \\
\text { Change in hydrophobicity of } \\
\text { materials }\end{array}$ \\
\hline Bipolar plate & $\begin{array}{l}\text { Conductivity loss } \\
\text { Fracture/deformation }\end{array}$ & $\begin{array}{l}\text { Corrosion } \\
\text { Mechanical stress }\end{array}$ \\
\hline
\end{tabular}

\subsection{The proton electron membrane}

The most widely used membrane is Nafion-based membranes. They are only used when operating at low temperature. It has a lot of problem with water (Swelling). All the alternatives to Nafion membranes have failed to achieve an acceptable level of conductivity. Therefore a lot of work is ongoing to determine a low cost and high proton conductive membrane[4]. 


\subsection{The electro-catalyst layer}

The platinum-based catalyst layer is the most widely used electro-catalyst layer for PEM fuel cell. It has two major disadvantages; it is expensive and can easily be contaminated. When the platinum in the catalyst layer is contaminated, the performance reduces. Efforts to reduce the cost of platinum used are targeted towards reducing the amount of platinum used in the reaction without affecting performance. Baroutaji et al [2] explained that in the last few years, success has been made and that from 2008 to 2012, platinum loadings has been greatly reduced. In addition to this, Lister and McLean [5] reported platinum loading $0.014 \mathrm{mg} / \mathrm{cm}^{2}$ by sputtering. Success in these will means that cost of platinum will no longer be a challenge in terms of commercialization.

\subsection{The gas diffusion layer}

The gas diffusion layer is very important in the transportation of reactant and water. Although other materials such as titanium, copper, nickel mesh etc. has been used, carbon fibre paper and carbon cloth are the two most widely used materials used as GDL[6]. The performance of a gas diffusion layers can be optimised through focusing on its characteristics properties like porosity, hydrophobicity, hydrophilicity, electron transport, permeability, compression and structure[7].

\subsection{The bipolar flow plates}

The role of bipolar plates cannot be overestimated. In fact it is responsible for about $80 \%$ of the total weight of the PEMFC. It can be non-metal based, metal based or composites. Figure 6 shows. 
$106 \quad 10^{\mathrm{TH}}$ International Conference on Sustainable Energy and EnVIRONMENTAL Protection (June $27^{\mathrm{TH}}-30^{\mathrm{TH}}, 2017$, Bled, SLOVENIA), RENEWABLE ENERGY SOURCES E. Ogungbemi, O. Ijaodola, A. Wilberforce, A. Al Makky \& A. Olabi: Review of Pem Fuel Cell Materials

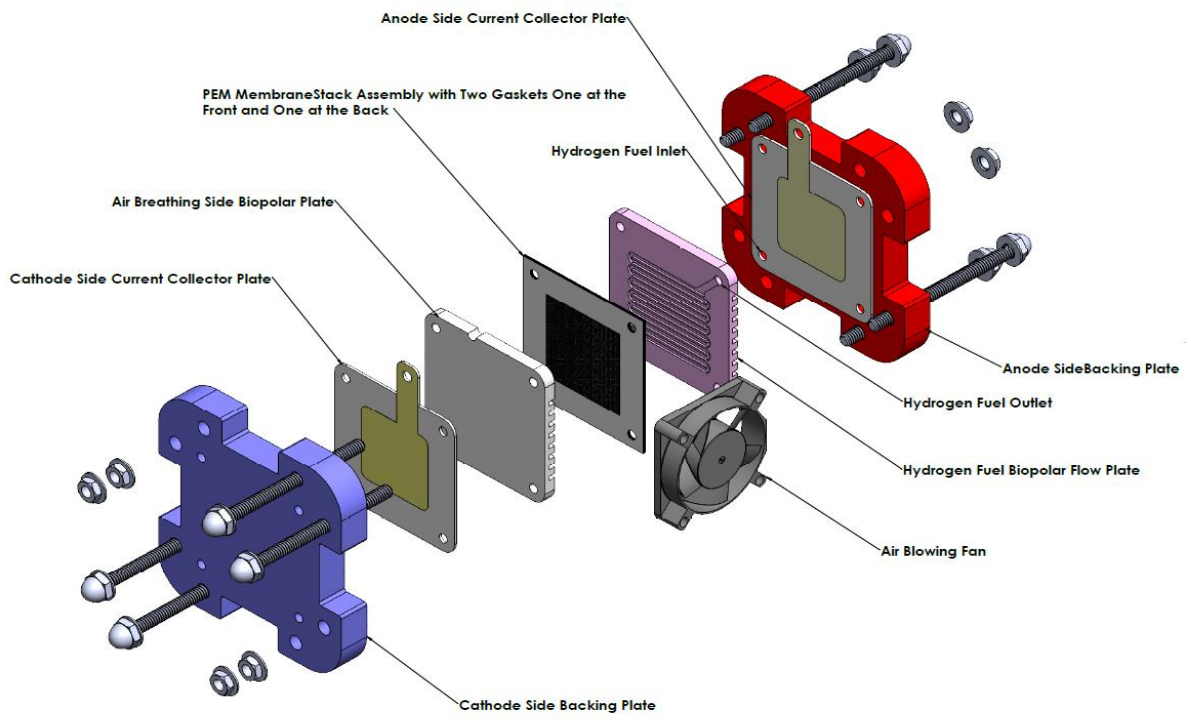

Figure 3. PEM fuel cell planar diagram at UWS fuel cell laboratory

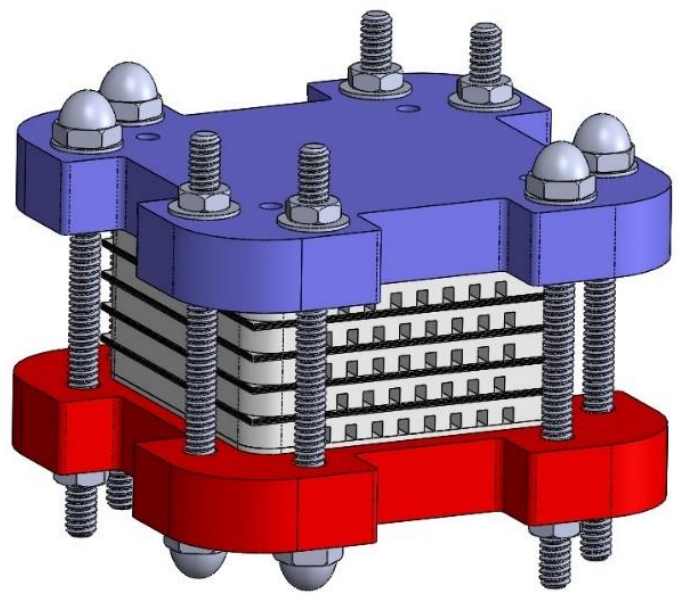

Figure 4. Assembled PEM fuel cell at UWS laboratory 

Protection (June $27^{\mathrm{TH}}-30^{\mathrm{TH}}, 2017$, BLED, SLOVENIA), RENEWABLE ENERGy SOURCES E. Ogungbemi, O. Ijaodola, A. Wilberforce, A. Al Makky \& A. Olabi: Review of Pem Fuel Cell Materials

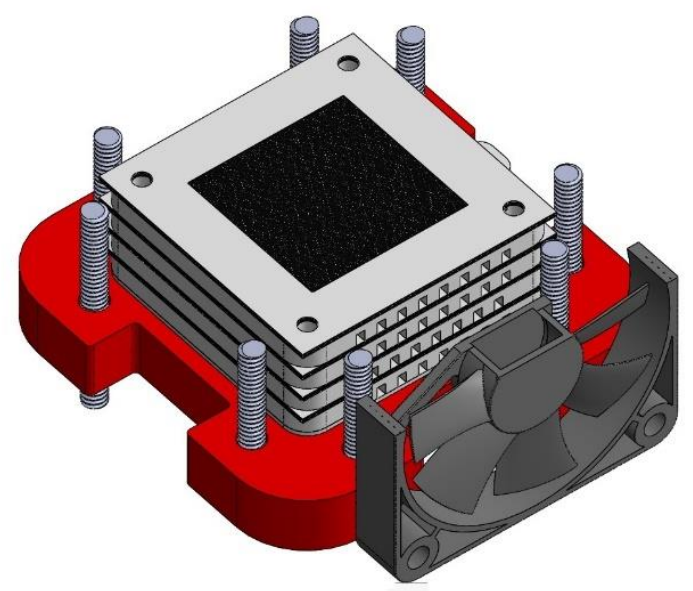

Figure 5. Assembled PEM fuel cell with the fan at UWS laboratory

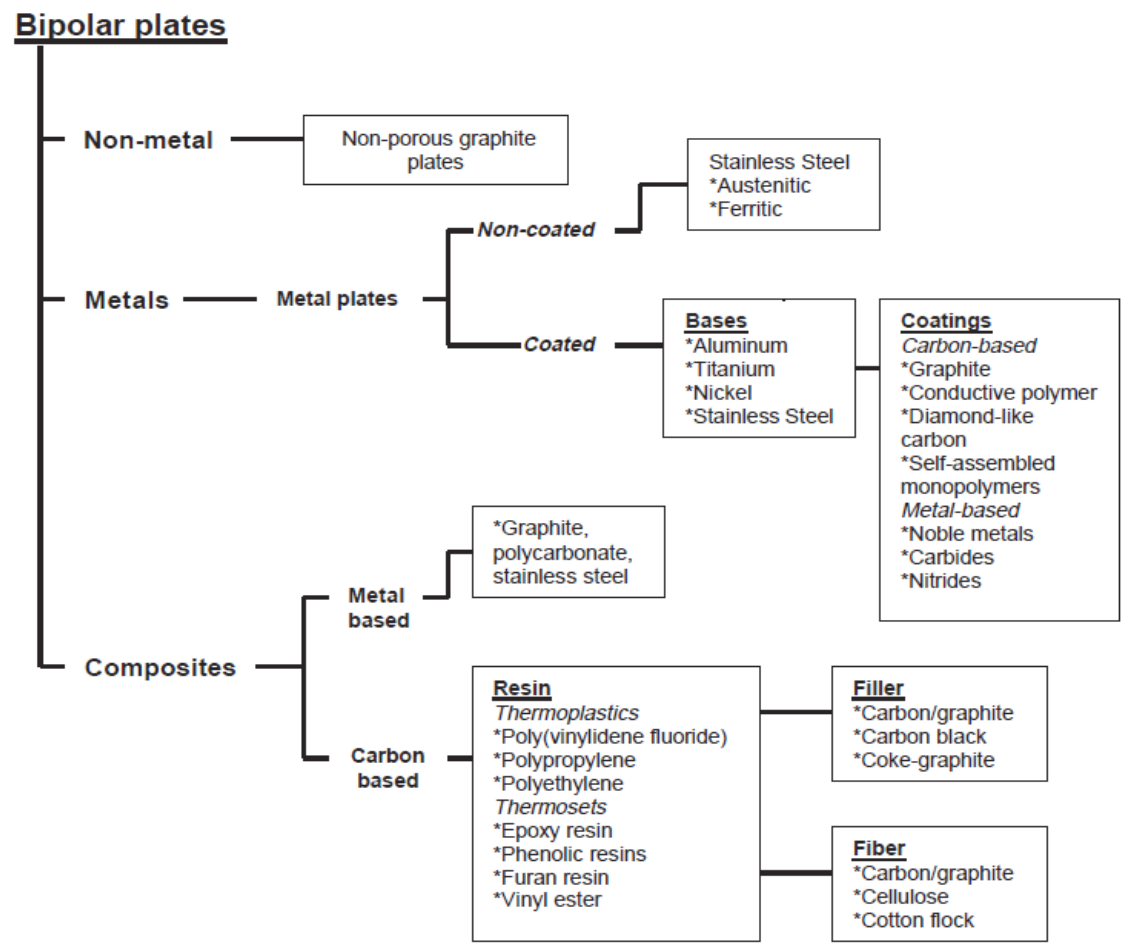

Figure 6. Diagram showing the materials used for BP of a PEM fuel cell[8] 
$10810^{\mathrm{TH}}$ International Conference on Sustainable Energy and EnVIRONMENTAL Protection (June $27^{\mathrm{TH}}-30^{\mathrm{TH}}$, 2017, Bled, SLOVENIA), RENEWABLE ENERGY SOURCES E. Ogungbemi, O. Ijaodola, A. Wilberforce, A. Al Makky \& A. Olabi: Review of Pem Fuel Cell Materials

Table 2. Composite bipolar plate[1]

\begin{tabular}{|c|c|}
\hline Electrical conductivity & $>100 \mathrm{Scm}^{-1}$ \\
\hline Contact resistance & $0.1-0.2 \mathrm{ohmcm}^{2}$ \\
\hline Thermal conductivity & $>10 \mathrm{~W}(\mathrm{mK})^{-1}$ \\
\hline Weight & $<0.4 \mathrm{kgkW}^{-1}$ \\
\hline Flexural strength & $\geq 25 \mathrm{MPa}$ \\
\hline Flexibility & $\begin{array}{l}3-5 \% \text { deflection } \\
\text { at mid-spa }\end{array}$ \\
\hline Compression strength & $\geq 50 \mathrm{MPa}$ \\
\hline Tensile strength & $\geq 41 \mathrm{MPa}$ \\
\hline Gas permeability & $\begin{array}{l}<2 \times 10^{-6} \mathrm{~cm}^{3} \mathrm{~s}^{-} \\
{ }^{1} \mathrm{~cm}^{-2}\end{array}$ \\
\hline Cost & $\begin{array}{l}\$ 25 / \mathrm{kW} \text { or } \\
<\$ 10 / \text { plate }\end{array}$ \\
\hline Corrosion resistance & $<1 \mu \mathrm{A} \mathrm{cm}{ }^{-2}$ \\
\hline
\end{tabular}

how the different materials used for BPs in PEM fuel cells were classified[9]. The earliest BPs was non-metal or graphite based. However the Metallic-based bipolar flow plates have proved to be better. It cost is lower, has more strength and ultimately higher conductivity. The major challenge encountered is that associated with corrosion. To reduce that problem some materials were used for coating. Present efforts by researchers is to discover a material which have high conductivity and not corrosive. It is believed that this will be the future of BPs and it is called composite based BP. The US department of Energy has set a target for researchers on bipolar plates. This is shown in table 2[1].

\section{Conclusion}

Work on PEM fuel cell is currently attracting a lot of attention. In the light of discussions in the body of this paper it can be concluded that good material selection will improve the performance, durability and increase efficiency. Furthermore it is established that using the best materials alone cannot guarantee successful commercialization. An example is in the case of the electro-catalyst layer where there is a need to reduce or replace the platinum content. There is a need to maintain a balance between the quality of materials and cost and these has led to large scale research on development of low cost material for PEM fuel cell. 


\section{Acknowledgements}

I would like to thank my supervisor Prof Abdul Olabi for his support and also my parents Dr and Mrs Ogungbemi for their encouragement.

\section{References}

[1] By P. World â $€^{\mathrm{TM}} \mathrm{s}$ largest Science, Technology \& Medicine Open Access book publisher A Performance Review of 3D TOF Vision Systems in Comparison to Stereo Vision Systems n.d. doi:10.1145/1838002.1838017.

[2] Baroutaji A. Materials in PEM Fuel Cells 2015. doi:10.1016/B978-0-12-803581-8.040066.

[3] Hinds G. Performance and Durability of PEM Fuel Cells : A Review 2004.

[4] Hu H, Contact P. V . C . 9 Low-Cost Proton Conducting Membranes for PEM Fuel Cells Fiscal Year ( FY ) 2016 Objectives 2016:1-4.

[5] Litster S, McLean G. PEM fuel cell electrodes. J Power Sources 2004;130:61-76. doi:10.1016/j.jpowsour.2003.12.055.

[6] Park S, Lee J, Popov BN. A review of gas diffusion layer in PEM fuel cells : Materials and designs. Int J Hydrogen Energy 2012;37:5850-65. doi:10.1016/j.ijhydene.2011.12.148.

[7] Cindrella L, Kannan AM, Lin JF, Saminathan K, Ho Y, Lin CW, et al. Gas diffusion layer for proton exchange membrane fuel cells - A review 2009;194:146-60. doi:10.1016/j.jpowsour.2009.04.005.

[8] Hermann A, Chaudhuri T, Spagnol P. Bipolar plates for PEM fuel cells: A review 2005;30:1297-302. doi:10.1016/j.ijhydene.2005.04.016.

[9] Hermann A, Chaudhuri T, Spagnol P. Bipolar plates for PEM fuel cells: A review. Int. J. Hydrogen Energy, 2005. doi:10.1016/j.ijhydene.2005.04.016. 
$110 \quad 10^{\mathrm{TH}}$ International CONFERENCE ON Sustainable EnERgy and ENVIRONMENTAL Protection (June 27 $7^{\mathrm{TH}}-30^{\mathrm{TH}}, 2017$, Bled, SLOVEnia), RENEWABLE ENERGy SOURCES 
$10^{\mathrm{TH}}$ InTERnATIONAL CONFERENCE ON Sustainable ENERgy AND ENVIRONMENTAL Protection (June $27^{\mathrm{TH}}-30^{\mathrm{TH}}$, 2017, Bled, SLOVENIA), RENEWABLE ENERGy SOURCES

J. Krope, A.Ghani Olabi, D. Goričanec \& S. Božičnik

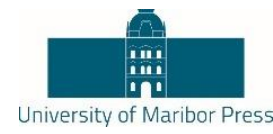

\title{
Ru-Containing Polymeric Catalyst for the Process of Cellulose Conversion
}

\author{
Oleg V. Manaenkov, Anastasia E. Filatova, Olga V. Kislitza, Yury.V. \\ Lugovoy, Esther M. Sulman, VALENTina G. MATVEeVA, VALENTin Yu. DoludA \& \\ ALEXANDER I. SIDOROV
}

\begin{abstract}
Various Ru-containing catalysts based on non-functionalized hypercrosslinked polystyrene (HPS) MN-270 as well as its functionalized analogues: NH2-HPS (MN-100) and SO3H-HPS (MN-500) were tested in cellulose hydrolytic hydrogenation process in subcritical water to obtain hexitols. The results showed that the most active catalysts was $1.0 \% \mathrm{Ru}$ based on MN-270 while the catalysts based on MN-270 functional analogues (MN-100 and MN-500) do not exhibit any activity in this process. The chosen catalyst allowed achieving the total sorbitol and mannitol yield up to $50 \%$ at $85 \%$ cellulose conversion. Moreover the proposed catalyst had high stability in the multiple uses without any decrease in activity that makes it promising for biomass conversion into various chemicals.
\end{abstract}

Keywords: • cellulose $\bullet$ hydrolytic hydrogenation $\bullet$ subcritical water • hypercrosslinked polystyrene $\bullet$ sorbitol $\bullet$

Correspondence AdDress: Oleg V. Manaenkov, Ph.D., Associate Professor, Tver State Technical University, Faculty of Chemical Engineering, A.Nikitin emb. 22, 170026 Tver, Russia, e-mail: ovman@yandex.ru. Anastasia E. Filatova, Ph.D., Assistant, Tver State Technical University, Faculty of Chemical Engineering, A.Nikitin emb. 22, 170026 Tver, Russia, e-mail: afilatowa@mail.ru. Olga V. Kislitza, Ph.D., Associate Professor, Tver State Technical University, Faculty of Chemical Engineering, A.Nikitin emb. 22, 170026 Tver, Russia, e-mail: science@science.tver.ru. Yury V. Lugovoy, Ph.D., Associate Professor, Tver State Technical University, Faculty of Chemical Engineering, A.Nikitin emb. 22, 170026 Tver, Russia, e-mail: pn-just@yandex.ru. Esther M. Sulman, Dr. of Sc., Professor, Tver State Technical University, Faculty of Chemical Engineering, A.Nikitin emb. 22, 170026 Tver, Russia, e-mail: sulman@online.tver.ru. Valentina G. Matveeva, Dr. of Sc., Professor, Tver State Technical University, Faculty of Chemical Engineering, A.Nikitin emb. 22, 170026 Tver, Russia, e-mail: matveeva@science.tver.ru. Valentin Yu. Doluda, Ph.D., Associate Professor, Tver State Technical University, Faculty of Chemical Engineering, A.Nikitin emb. 22, 170026 Tver, Russia, e-mail: doludav@yandex.ru. Alexander I. Sidorov, Ph.D., Professor, Tver State Technical University, Faculty of Chemical Engineering, A.Nikitin emb. 22, 170026 Tver, Russia, e-mail: sidorov_science@mail.ru.

https://doi.org/10.18690/978-961-286-061-5.11

ISBN 978-961-286-061-5

(C) 2017 University of Maribor Press

Available at: http://press.um.si. 
$10^{\mathrm{TH}}$ InTERNATIONAL CONFERENCE ON Sustainable ENERGy AND ENVIRONMENTAL Protection (June $27^{\mathrm{TH}}-30^{\mathrm{TH}}, 2017$, Bled, SLOVENiA), RENEWABle ENERGY SOURCES O.V. Manaenkov, A.E. Filatova, O.V. Kislitza, Yu.V. Lugovoy, E.M. Sulman, V.G. Matveeva, V.Yu. Doluda \& A.I. Sidorov: Ru-Containing Polymeric Catalyst for the Process of Cellulose Conversion

Cellulose is a wide spread material that can be a good alternative to fossil fuels as a renewable source to produce numerous chemicals as well as second-generation biofuels on a large scale [1]. Due to a large number of hydroxyl groups cellulose is a promising raw material to obtain polyols [2]. A classical two-stage process of polyols production from cellulose includes acid catalysed cellulose hydrolysis to monosaccharides [3] and metal catalysed hydrogenation of the latter to the corresponding alcohols [4, 5]. Hydrolytic hydrogenation as one of the possible ways of "one-pot" cellulose conversion is a complex process combining both cellulose hydrolysis to glucose and the following its hydrogenation. This process is conducted in the medium of polar (protonic) solvent in the presence of metal-based catalysts. The first investigation of a one-stage process of cellulose conversion in the presence of Ru-containing catalysts were done by A.A. Balandin and his colleagues [6]. Nowadays there is a growing interest to the use of subcritical water in cellulose hydrolytic hydrogenation [7]. This can be possible due to the unique properties of subcritical water that in the temperature range of $100-374{ }^{\circ} \mathrm{C}$ and at a pressure over $4 \mathrm{MPa}$ can serve both as acid and base catalyst for cellulose hydrolysis. There are numerous studies devoted to the use of transition metal based catalysts in hydrolytic hydrogenation of cellulose in subcritical water; among them are Pt [4, 11-15], Pd [4] and Ni [8]. Although these catalysts provide rather high cellulose conversion they require higher temperature and the polyol yield does not exceed $50 \%$. As it is known Ru-containing catalysts are the most active in the complex cellulose processing $[4,9]$. The catalyst support also plays a great role in the total product yield. Carbon materials $[4,9,10]$, aluminium oxide $[4,10]$, zeolites $[4,10]$ are used as supports for Ru particles. The analysis of literature data shows that the presence of a negligible amount of strong mineral acid or acid sites on a catalyst support allows increasing both cellulose conversion and polyol yield due to the increase in the rate of the hydrolysis step. However the problem of choosing a suitable support has not been solved yet as the studied materials do not provide high catalyst stability under cellulose conversion conditions due to thermal and mechanical destructibility of the support as well as the leaching of the active metal from the catalyst.

In this work we proposed novel Ru-containing catalysts on the base of non-functionalized and functionalized HPS for cellulose hydrolytic hydrogenation to hexitols. HPS is a promising support due to its high porosity, excellent sorption properties and swell possibility in any solvent [11-13]. Moreover HPS has high thermal and mechanical stability and allows stabilizing of the active metal in a rigid polymeric matrix.

\section{Experimental}

For the catalyst synthesis different types of HPS Macronet (MN) purchased from Purolite Int., U.K: MN-270 (without functional groups), MN-100 (functionalized with amino groups), and MN-500 (functionalized with sulphate groups) were used. Preliminarily washed with water, acetone, and methyl alcohol, dried and crushed to particle size less 
$10^{\mathrm{TH}}$ InTERnAtional CONFERENCE ON SUSTAINABLE ENERGy AND ENVIRONMENTAL 113 Protection (June $27^{\mathrm{TH}}-30^{\mathrm{TH}}, 2017$, BLED, SLOVENIA), RENEWABLE ENERGY SOURCES O.V. Manaenkov, A.E. Filatova, O.V. Kislitza, Yu.V. Lugovoy, E.M. Sulman, V.G. Matveeva, V.Yu. Doluda \& A.I. Sidorov: Ru-Containing Polymeric Catalyst for the Process of Cellulose Conversion

than $60 \mu \mathrm{m}$ HPS granules were impregnated with a solution of ruthenium (IV) hydroxychloride (pure, OJSC Aurat, Russia) via four-steps synthesis according to a procedure described in [2]. The as-received, reduced in hydrogen flow at $300{ }^{\circ} \mathrm{C}$ and used catalyst samples were analysed by low-temperature nitrogen physisorption, transmission electron microscopy and thermogravimetric analysis.

Microcrystalline cellulose (degree of crystallinity $75-80 \%$, Chimmedservice, Russia) conversion to polyols was performed in a steel reactor $\left(50 \mathrm{~cm}^{3}\right.$, Parr Instrument, USA) in subcritical water medium under the temperature $245^{\circ} \mathrm{C}$, hydrogen partial pressure $6 \mathrm{MPa}$. In a typical experiment microcrystalline cellulose $(0.5 \mathrm{~g})$, a catalyst $(0.07 \mathrm{~g})$ and $30 \mathrm{~mL}$ of distilled water were loaded into the reactor. Then the reactor was flushed three times with hydrogen under a working pressure. The reaction mixture was heated up to $245^{\circ} \mathrm{C}$ under continuous stirring $(\approx 100 \mathrm{rpm})$ to prevent the local hot spots formation. Then the stirrer speed was increased up to $600 \mathrm{rpm}$ to eliminate the external mass-transfer. The amount of the process main products was determined by chromatographic methods using gas chromatograph Crystallux-4000M (MetaKhrom, Russia) for the gaseous phase and highly effective liquid chromatograph UltiMate 3000 (Dionex, USA) for the liquid phase. Mass spectrometer GCMS-QP2010S (SHIMADZU, Japan) was used for the identification of the products in the liquid phase. In order to estimate the ruthenium content of the liquid phase the atomic absorption analysis was performed.

Total cellulose conversion was calculated as (1)

$X=\frac{\left(m_{c 0}-m_{c}\right) \cdot 100}{m_{c 0}}$,

where $m_{c}$ is non-hydrolysed cellulose weight and $m_{c 0}$ is cellulose initial weight.

The total hexitol yield was calculated as (2)

$\eta_{\text {hex. }}=\frac{m_{\text {hex }} \cdot 100}{m_{c 0}}$,

where $m_{\text {hex. }}$ is sorbitol (or mannitol) weight.

The selectivity regarding to the individual alcohol was calculated as (3)

$S=\frac{m_{p} \cdot 100}{\left(m_{c 0}-m_{c}\right)}$,

where $m_{p}$ is the weight corresponding product.

\section{$3 \quad$ Results and Discussion}

HPLC and GC-MS analysis of the liquid phase samples showed the presence of the following main products of cellulose hydrolytic hydrogenation: sorbitol and mannitol as 
$10^{\mathrm{TH}}$ InTERnAtional CONFERENCE ON Sustainable ENERgy AND ENVIRONMENTAL Protection (June $27^{\mathrm{TH}}-30^{\mathrm{TH}}, 2017$, Bled, SLOVENIA), RENEWABLE ENERGY SOURCES O.V. Manaenkov, A.E. Filatova, O.V. Kislitza, Yu.V. Lugovoy, E.M. Sulman, V.G. Matveeva, V.Yu. Doluda \& A.I. Sidorov: Ru-Containing Polymeric Catalyst for the Process of Cellulose Conversion

major hexitols, among other polyols xylitol, glycerol, erythritol, ethylene glycol, propylene glycol and 1,4-sorbitan were observed.

The typical experiments on the activity of the synthesized catalysts were carried out under the following conditions: temperature $-245{ }^{\circ} \mathrm{C}$, hydrogen pressure $-6 \mathrm{MPa}_{2}$, water volume $-30 \mathrm{~mL}$, stirring speed $-600 \mathrm{rpm}, \mathrm{Ru} /$ cellulose ratio $-0.028 \mathrm{mmol} / \mathrm{g}$, process duration $-5 \mathrm{~min}$. Figure 1 represents the results of cellulose hydrolytic hydrogenation in subcritical water in the presence of the synthesized catalysts.

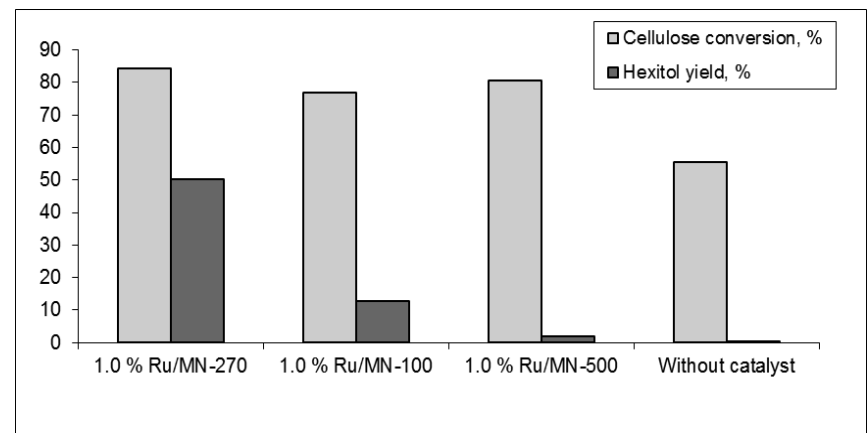

Figure 1. Cellulose conversion and hexitols total yield dependences on the catalyst type

$1 \% \mathrm{Ru} / \mathrm{MN}-500$ catalyst showed rather high cellulose conversion but the lowest hexytol yield (Figure 1). While using this catalyst the darkening of the reaction mixture was observed that is explained by the products of glucose degradation as it was confirmed by chromatographic analysis. Thus this catalyst only provides cellulose hydrolysis step and its low activity in hydrolytic hydrogenation process can be explained by the poisoning of the catalyst due to the MN-500 desulfurization. $1 \% \mathrm{Ru} / \mathrm{MN}-100$ catalyst showed a slightly better result. This catalyst provides almost the same cellulose conversion but hexitol yield increases by $10 \%$. As it was found for these both catalysts the main reaction products were lower polyols and methane. While conducting the experiments without any catalyst, the same picture as for $1 \% \mathrm{Ru} / \mathrm{MN}-500$ was observed indicating the first cellulose hydrolysis step and the following glucose caramelization.

In the case of $1 \% \mathrm{Ru} / \mathrm{MN}-270$ both high cellulose conversion (over $80 \%$ ) and high hexytol total yield (up to 50\%) were obtained. This fact indicates that the presence of the catalyst leads to both hydrolysis and hydrogenolysis processes flow, which does not take place without any catalyst. Most likely the high efficiency of this catalyst is connected with a combination of high specific surface area; narrow pore size distribution, and small, monodispersed $\mathrm{Ru}$ nanoparticles. Thus the further experiments were done with $1 \%$ $\mathrm{Ru} / \mathrm{MN}-270$ catalyst.

The surface area analysis data obtained from low-temperature nitrogen physisorption are presented in Figure 2. As it can be seen non-functionalized MN-270 type of HPS has the 
highest surface area (about $1500 \mathrm{~m}^{2} / \mathrm{g}$ ) in comparison with the other types of HPS. Moreover it has the highest area of micropores. Besides, the analysis showed that for both supports and synthesized catalysts the pores with the size of $4.0-4.5 \mathrm{~nm}$ in diameter were dominative basing on the total pore volume. Thus it can be supposed that Ru particles had been preferably formed in the micropores of the support that was confirmed by the decrease in micropores surface area of the catalysts compared to the initial support. $\mathrm{Ru}$ particle size distribution obtained by TEM analysis amounted $1.4 \pm 0.3 \mathrm{~nm}$.

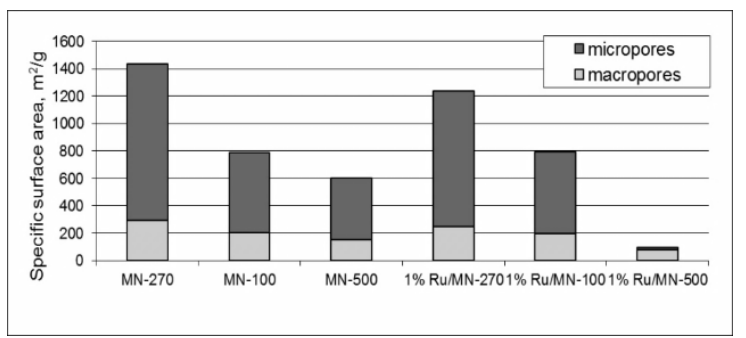

Figure 2. Specific surface area of HPS types and the developed catalysts

The decrease in the specific surface area of the catalyst based on MN-270 does not exceed $15 \%$ as it can be seen from Figure 2. It can be explained by the fact that Ru nanoparticles fill the pores of the matrix during its reduction by hydrogen conducted at $300{ }^{\circ} \mathrm{C}$. It is interesting to note that the specific surface area of $1 \% \mathrm{Ru} / \mathrm{MN}-100$ catalyst was the same as that of the initial support that is probably connected with uniform deposition of $\mathrm{Ru}$ nanoparticles on pore walls. High decrease in the surface area in the case of $1 \% \mathrm{Ru} / \mathrm{MN}$ 500 , by a factor of 5, can be connected with desulfurization of MN-500 HPS type which takes place at $200-300{ }^{\circ} \mathrm{C}$ according to [10] and as a result with the changes in the support structure. This assumption was confirmed by the results of thermogravimetric analysis of the initial samples of hypercrosslinked polystyrene reported in [2]. These data agree well with the activity of the catalysts in cellulose hydrolytic hydrogenation.

The influence of such parameters as $\mathrm{Ru}$ loading, $\mathrm{Ru} /$ substrate ratio, temperature, hydrogen partial pressure and the process time on the activity of the $1 \% \mathrm{Ru} / \mathrm{MN}-270$ catalyst in cellulose hydrolytic hydrogenation process was studied. The highest hexitol yield $\left(\eta_{\text {hex. }}\right)$ up to $50 \%$ was observed while using the chosen catalyst under the typical experimental conditions (temperature $-245^{\circ} \mathrm{C}$, hydrogen pressure - $6 \mathrm{MPa}$, water volume - $30 \mathrm{~mL}$, cellulose mass - $1 \mathrm{~g}, 600 \mathrm{rpm}$, process duration - $5 \mathrm{~min}$ ) as it is shown in Figure 3 . It is noteworthy that the chosen catalyst provides the increase in cellulose conversion $(X)$ (Figure 1). The variation of $\mathrm{Ru} /$ cellulose $(\mathrm{mmol} / \mathrm{g}$ ) ratio showed that its decrease resulted in the increase in the total hexitol yield (Figure 4). Basing on the data obtained, further experiments were done using 1.0 wt. \% Ru/MN-270 catalysts with Ru/cellulose ratio equal to $0.028: 1 \mathrm{mmol} / \mathrm{g}$. 
$10^{\text {TH }}$ International Conference on Sustainable Energy and Environmental Protection (June $27^{\mathrm{TH}}-30^{\mathrm{TH}}, 2017$, Bled, SLOVENIA), RENEWABLE ENERGY SOURCES O.V. Manaenkov, A.E. Filatova, O.V. Kislitza, Yu.V. Lugovoy, E.M. Sulman, V.G. Matveeva, V.Yu. Doluda \& A.I. Sidorov: Ru-Containing Polymeric Catalyst for the Process of Cellulose Conversion

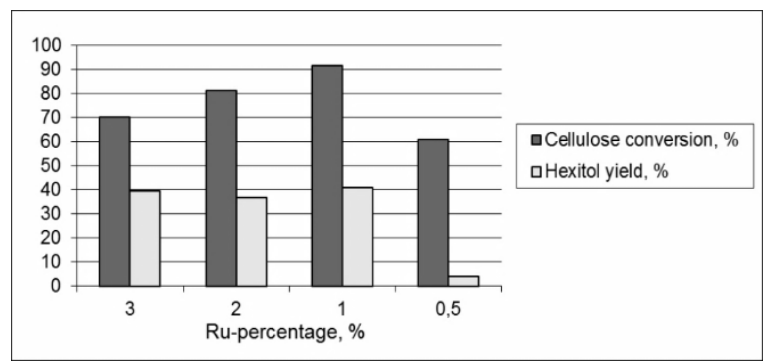

Figure 3. Ru percentage influence on cellulose conversion and hexitol yield

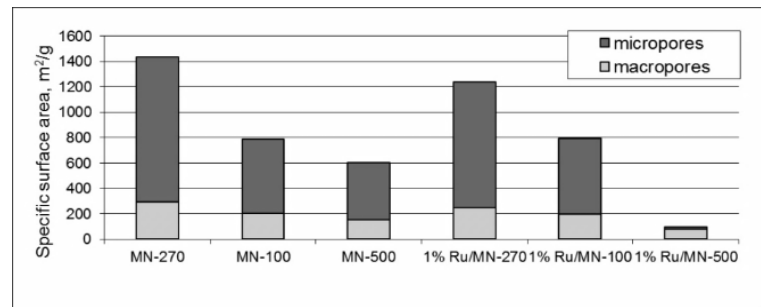

Figure 4. Ru/substrate ratio influence on cellulose hydrolytic hydrogenation in terms of conversion and hexitol yield

The study of the temperature effect on cellulose hydrolytic hydrogenation process showed that the increase in temperature from 200 up to $260{ }^{\circ} \mathrm{C}$ resulted in cellulose conversion increase from 33.3 up to $93.2 \%$, due to the acceleration of the hydrolysis reaction. At high temperatures the concentration of $\mathrm{H}_{3} \mathrm{O}^{+}$and $\mathrm{OH}^{-}$ions in water increases, which causes the increase in the acidity of the medium needed for the hydrolysis of cellulose. The selectivity to hexitol increases when the temperature rises from 200 up to $245^{\circ} \mathrm{C}$ and decreases at $260{ }^{\circ} \mathrm{C}$. Thus, the maximum of selectivity to hexitol was observed at $245^{\circ} \mathrm{C}$ (Figure 5). The amount of hydrogen in the liquid phase and the degree of its adsorption on the catalyst surface directly depends on the pressure. The highest cellulose conversion was obtained at $6 \mathrm{MPa}$ (Figure 6). At a pressure below this value a twofold decrease in the selectivity to hexitol was observed, due to the slowdown in the glucose hydrogenation reaction. In this case we also observed the glucose caramelization. At a hydrogen pressure above $6 \mathrm{MPa}$ the selectivity decreased. This is probably due to the fact that a significant proportion of the active catalyst sites are occupied by hydrogen, thus preventing the access of glucose molecules to the catalyst surface. 

Protection (June 27 $7^{\mathrm{TH}}-30^{\mathrm{TH}}, 2017$, BLED, SLOVENIA), RENEWABLE ENERGY SOURCES

O.V. Manaenkov, A.E. Filatova, O.V. Kislitza, Yu.V. Lugovoy, E.M. Sulman, V.G.

Matveeva, V.Yu. Doluda \& A.I. Sidorov: Ru-Containing Polymeric Catalyst for the

Process of Cellulose Conversion

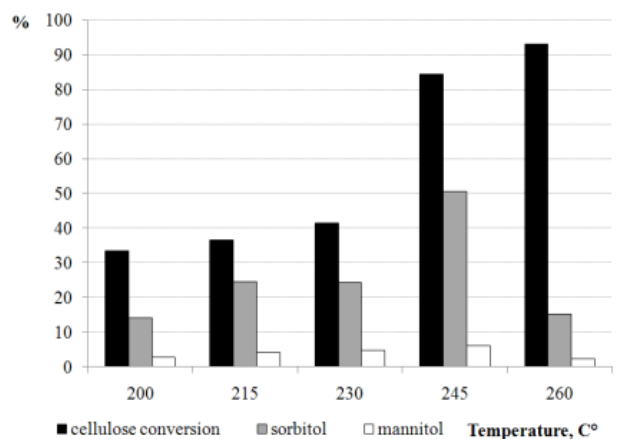

Figure 5. Dependence of cellulose conversion and polyols selectivity on temperature

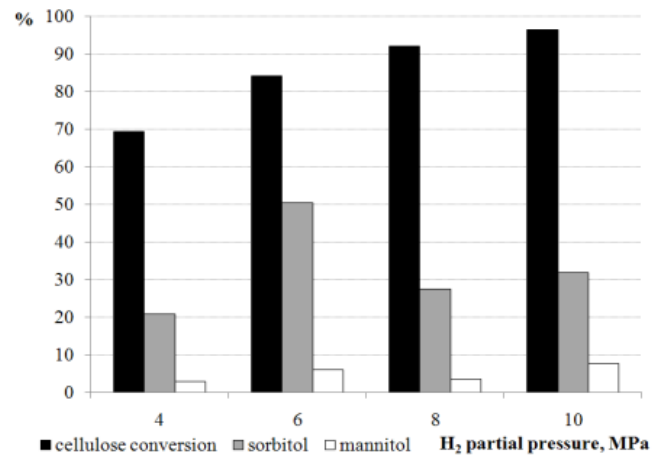

Figure 6. Dependence of cellulose conversion and polyols selectivity on hydrogen partial pressure

In the work the effect of the process time was also studied. The maximal selectivity to hexitol was obtained at the fifth minute (Figure 7). Shorter period of time does not provide a sufficient degree of cellulose conversion. The increase in the process time increases the conversion while lowering the selectivity due to the hydrogenolysis of hexitols. 
$10^{\mathrm{TH}}$ InTERnATIONAL CONFERENCE ON Sustainable EnERgy AND ENVIRONMENTAL Protection (June $27^{\mathrm{TH}}-30^{\mathrm{TH}}, 2017$, Bled, SLovenia), Renewable EnERGy SOURCES O.V. Manaenkov, A.E. Filatova, O.V. Kislitza, Yu.V. Lugovoy, E.M. Sulman, V.G. Matveeva, V.Yu. Doluda \& A.I. Sidorov: Ru-Containing Polymeric Catalyst for the Process of Cellulose Conversion

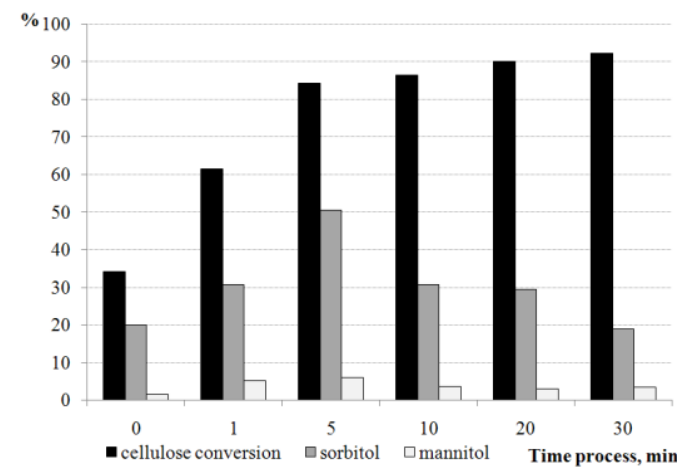

Figure 7. Dependence of cellulose conversion and polyols selectivity on the process time

To estimate the stability of the chosen catalyst, it was separated from the reaction mixture after the process completion and used again with fresh cellulose. It was obtained that the multiple reuse of $1 \% \mathrm{Ru} / \mathrm{MN}-270$ catalyst in three consecutive reaction cycles leads to a slight decrease in its activity (Figure 8) which can be explained by a loss of some amount of the catalyst during the filtration.

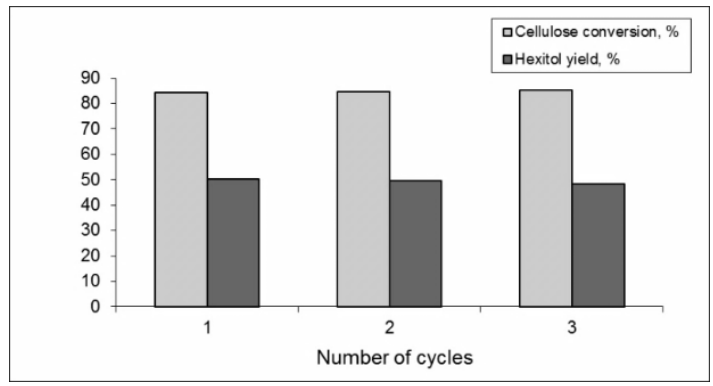

Figure 8 . The results of the catalyst multiple reuses

Basing on the experiments the hypothesis on the mechanism of cellulose hydrolytic hydrogenation is suggested taking into consideration the fact that the process proceeds in two steps: (i) cellulose hydrolysis to glucose and then (ii) glucose hydrogenolysis to polyols according to Figure 9. Experiments showed that the last one is the limiting stage of the whole process, thus the kinetics of this stage was studied.

Basing on the data shown in Figure 9 the following mathematical model was proposed:

$W_{A}=\frac{-K_{1}[A]-K_{2}[A]}{Z}$ 


$$
\begin{aligned}
& W_{B}=\frac{K_{1}[A]-K_{3}[B]-K_{4}[B]-K_{5}[B]-K_{6}[B]}{Z} ; \\
& W_{C}=\frac{K_{3}[B]-K_{7}[C]}{Z} ; \\
& W_{D}=\frac{K_{6}[B]+K_{7}[C]}{Z} ; \\
& W_{E}=\frac{K_{2}[A]+K_{4}[B]}{Z} ; \\
& W_{F}=\frac{K_{5}[B]}{Z} .
\end{aligned}
$$

Here $\mathrm{W}_{\mathrm{i}}$ - the rate of hydrogenolysis reaction at the single initial concentration of the substrate $\mathrm{C}_{0}=1 \mathrm{~mol} / \mathrm{L}$ and the single concentration of the catalyst $\mathrm{C}_{\mathrm{c}}=1 \mathrm{~mol} / \mathrm{L}, \mathrm{Z}-$ denominator of the kinetic equation reflecting reagents adsorption on the solid phase.

The kinetic study experiments of glucose hydrogenolysis step were carried out varying the same parameters: reaction time, hydrogen partial pressure and temperature. The study of hydrogen partial pressure influence on glucose hydrogenolysis showed (in terms of $\mathrm{ln}$ $\mathrm{k}=\mathrm{F}(\operatorname{lnP})$ ) that the reaction has pseudo-zero order with respect to hydrogen; the calculated value was 0.028 . It indicates that hydrogen partial pressure does not affect glucose hydrogenolysis reaction rate. Objectively the reaction proceeded with the excess amount of hydrogen thus its concentration might be considered a constant. The analysis of the kinetic curves of glucose conversion obtained at different reaction temperature showed that glucose hydrogenolysis process behaved the most intensively at a temperature $235{ }^{\circ} \mathrm{C} .300$ seconds was chosen as the time for the estimation of the temperature influence as well as for the calculation of the apparent activation energy that amounted $45 \pm 5 \mathrm{~kJ} /(\mathrm{mol})$. It is noteworthy that the value of the apparent activation energy calculated basing on the chosen kinetic model agree well with the experimental data. The other Arrhenius equation parameters calculated for both experimental data and mathematical model were the following: the rate constant $\left.0.103(\mathrm{~mol} / \mathrm{mol})^{\mathrm{n}} \cdot \mathrm{s}^{-1}\right)$ and preexponential factor $8.92 \cdot 10^{6}$. 
$120 \quad 10^{\mathrm{TH}}$ International Conference on Sustainable Energy and EnVIRONMENTAL Protection (June $27^{\mathrm{TH}}-30^{\mathrm{TH}}, 2017$, Bled, SLOVENIA), RENEWABle ENERGY SOURCES O.V. Manaenkov, A.E. Filatova, O.V. Kislitza, Yu.V. Lugovoy, E.M. Sulman, V.G. Matveeva, V.Yu. Doluda \& A.I. Sidorov: Ru-Containing Polymeric Catalyst for the Process of Cellulose Conversion

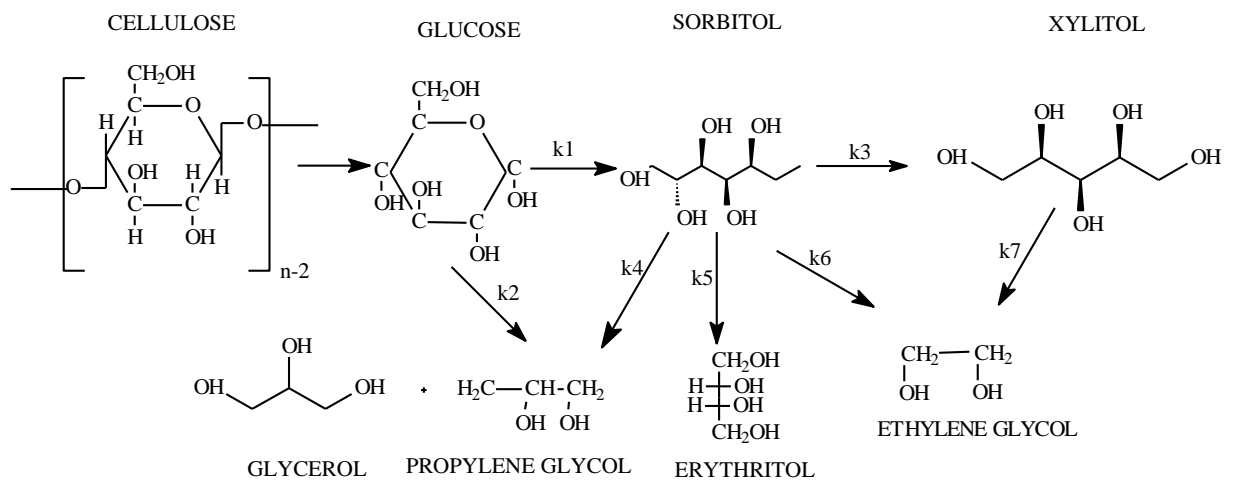

Figure 9. Possible ways of cellulose hydrogenolysis on Ru-containing catalysts

4

\section{Conclusions}

A novel type of Ru-containing catalyst based on HPS was proposed for hydrolytic hydrogenation of cellulose in order to obtain hexitols with high yield. It was shown that the catalyst based on non-functionalized MN-270 provided high efficiency of the reaction due to the stability of the polymeric matrix resulting in high porosity of the catalyst and well-dispersed Ru nanoparticles. The catalysts based on MN-270 amino- and sulphatefunctionalized analogues ( $\mathrm{MN}-100$ and $\mathrm{MN}-500)$ did not show any activity in this process. It was revealed that the use of $1.0 \% \mathrm{Ru} / \mathrm{MN}-270$ allows achieving the total hexitol yield up to $50 \%$ at $\sim 85 \%$ conversion that is comparable with the results obtained for more complex and expensive catalytic systems. This catalyst also had high stability in the multiple uses without any loss in activity and selectivity. Basing on the kinetic experiments the adequate kinetic model of the process was chosen and the main kinetic parameters were calculated.

\section{Acknowledgements}

This work was financially supported by the Ministry of Science and Education of Russian Federation (grant RFMEFI58615X0024).

\section{References}

[1] G. Huber, S. Iborra, and A. Corma, "Synthesis of Transportation Fuels from Biomass: Chemistry, Catalysts, and Engineering”, Chem. Rev., vol. 106, pp. 4044-4098. 2006.

[2] O. Manaenkov, V. Matveeva, E. Sulman, A. Filatova, O. Makeeva, O. Kislitza, A. Sidorov, V. Doluda, and M. Sulman, "Ru-Containing Polymeric Catalysts for Cellulose Conversion to Polyols", Top. in Cat., vol. 57(17-20), pp. 1476-1482. 2014.

[3] R. Palkovits, K. Tajvidi, J. Procelewska, R. Rinaldi, and A. Ruppert, "Heteropolyacids as efficient acid catalysts in the one-step conversion of cellulose to sugar alcohols", Green Chem., vol. 12, pp. 972-978. 2010. 
[4] J. Geboers, S. Van de Vyver, K. Carpentier, K. Blochouse, P. Jacobs, and B. Sels, 'Efficient catalytic conversion of concentrated cellulose feeds to hexitols with heteropoly acids and Ru on carbon", Chem Commun, vol. 46(20), pp. 3577-3579. 2010.

[5] D.K. Mishra, A.A. Dabbawala, J.J. Park, S.H. Jhung, and J.-S. Hwang, „Ruthenium nanoparticles supported on zeolite $\mathrm{Y}$ as an efficient catalyst for selective hydrogenation of xylose to xylitol" Catalysis Today, vol. 232, pp. 99-104. 2014.

[6] S.V. Chepigo, A.A. Balandin, N.A> Vasyunina, "Polyol production via catalytic conversion of plant polysaccharides", Chemical Science and Industry (in Russian), vol. 2, pp. 416-424. 1957.

[7] D.T. Yin, S.J. Ying, and L.H. Chao, "Cellulose conversion to polyols on supported Ru catalysts in aqueous basic solution", Science China Chemistry, vol. 53(7), pp. 1476-1480. 2010.

[8] A.V. Kirilin, A.V. Tokarev, E.V. Murzina, L.M. Kustov, J.-P.Mikkola, and D.Yu. Murzin, „Reaction products and transformations of intermediates in the aqueous-phase reforming of sorbitol", ChemSusChem, vol. 3, pp. 708-718. 2010

[9] H. Kobayashi, Y. Ito, T. Komanoya, Y. Hosaka, P. Dhepe, K. Kasai, K. Haraa, and A. Fukuoka, „Synthesis of sugar alcohols by hydrolytic hydrogenation of cellulose over supported metal catalysts", Green Chem., vol. 13, p. 326. 2011.

[10] H. Kobayashi, T. Komanoya, K. Hara, and A. Fukuoka, „Water tolerant mesoporous carbon supported ruthenium catalysts for the hydrolysis of cellulose to glucose", ChemSusChem., Vol. 3, p. 440. 2010.

[11] V.N. Sapunov, M.Ye. Grigoryev, E.M. Sulman, M.B. Konyaeva, V.G. Matveeva, Hydrogenation over $\mathrm{Ru}$ Nanoparticles Embedded in Mesoporous Hypercrosslinked Polystyrene", The Journal of Physical Chemistry A, vol. 117, pp. 4073-4083. 2013.

[12] V.Yu. Doluda, E.M. Sulman, V.G. Matveeva, M.G. Sulman, A.V. Bykov, N.V. Lakina, A.I. Sidorov, P.M. Valetsky, and L.M. Bronstein, ,Phenol catalytic wet air oxidation over Ru nanoparticles formed in hypercrosslinked polystyrene", Topics in Catalysis, vol. 56, pp. 688-695. 2013.

[13] V. Doluda, J. Warna, A. Aho, A. Bykov, A. Sidorov, E.M. Sulman, L.M Bronstein, T.O. Salmi, and D.Yu. Murzin, "Kinetics of lactose hydrogenation over ruthenium nanoparticles in hypercrosslinked polystyrene", Industrial \& Engineering Chemistry Research, vol. 52(39), pp. 14066-14080. 2013. 
$12210^{\mathrm{TH}}$ International CONFERENCE ON Sustainable EnERgy and EnVIRONMENTAL Protection (June 27 $7^{\mathrm{TH}}-30^{\mathrm{TH}}, 2017$, Bled, Slovenia), Renewable EnERGy SOURCES 
$10^{\mathrm{TH}}$ INTERNATIONAL CONFERENCE ON Sustainable ENERgy AND EnVironmental Protection (June $27^{\mathrm{TH}}-30^{\mathrm{TH}}, 2017$, BLed, SLOVENIA), RENEWABLE ENERGy SOURCES

J. Krope, A.Ghani Olabi, D. Goričanec \& S. Božičnik

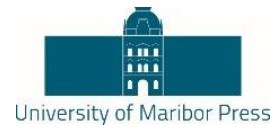

\title{
Electrical Energy Production Simulation in SHP of Ultra- Low Head Considering Environment Protection Conditions and Technical Limitations
}

\author{
HENRIK LAVRIČ, ANDRAŽ RIHAR \& RASTKO FIŠER
}

\begin{abstract}
Archimedes screw (AS) is a water engine technology that makes efficient energy utilization of water streams with ultra-low heads possible. Consequently, abandoned water mills became interesting for revitalization, as the small hydropower plants (SHP) can be installed in the existing millrace on the existing weir. Detailed analysis of highly dynamic hydrologic conditions is presented for one such site. The foreseen SHP consists of two identical parallel lines, together yielding nominal power of $47.6 \mathrm{~kW}$, when utilizing $5 \mathrm{~m} 3 / \mathrm{s}$ flow and $1.39 \mathrm{~m}$ head. For this SHP a simulation model was built, in which measured parameters from the site, manufacturer's characteristics, and conditions for the start and shutdown of AS are considered in combination with the flow utilization limitations from February to June in order to preserve the biotic diversity. Calculated average annual electrical energy for the era of 35 years is $291.5 \mathrm{MWh}$. If flow limitation is omitted, expected electrical energy is increased by $6 \%$.
\end{abstract}

Keywords: - Alternative energy - Archimedes screw - water mill • revitalization $\bullet$ hydrology •

CORRESPONDENCE ADDRESS: Henrik Lavrič, Ph.D., Assistant, University of Ljubljana, Faculty of electrical engineering, Tržaška cesta 25, 1000 Ljubljana, Slovenia, e-mail: henrik.lavric@ @e.unilj.si. Andraž Rihar, Ph.D., Assistant, University of Ljubljana, Faculty of electrical engineering, Tržaška cesta 25, 1000 Ljubljana, Slovenia, e-mail: andraz.rihar@fe.uni-lj.si. Rastko Fišer, Ph.D., Associate Professor, University of Ljubljana, Faculty of electrical engineering, Tržaška cesta 25, 1000 Ljubljana, Slovenia, e-mail: rastko.fiser@ fe.uni-lj.si.

https://doi.org/10.18690/978-961-286-061-5.12

ISBN 978-961-286-061-5

(C) 2017 University of Maribor Press

Available at: http://press.um.si. 
$10^{\text {TH }}$ International CONFEREnce on Sustainable Energy and Environmental Protection (June $27^{\mathrm{TH}}-30^{\mathrm{TH}}, 2017$, Bled, SLOVENIA), RENEWABle ENERGY SOURCES H. Lavrič, A. Rihar \& R. Fišer: Electrical Energy Production Simulation in SHP of Ultra-Low Head Considering Environment Protection Conditions and Technical Limitations

\section{Introduction}

Archimedes screw is an interesting water engine technology, which makes the energy utilization of water streams with ultralow heads reasonable. Its first commercial use was seen in Germany at the break of the millennium [1]. Before the introduction of AS there was no motivation for ultralow head exploitation, since existing technologies were convenient only for heads above $3 \mathrm{~m} \mathrm{[2].} \mathrm{It} \mathrm{took} \mathrm{some} \mathrm{time} \mathrm{for} \mathrm{the} \mathrm{"new"} \mathrm{technology} \mathrm{to}$ become noted and for further use in the environmentally sound energy production on heads down to $1 \mathrm{~m}$ [3], [4]. AS is now enabling technology to build SHP on places where water streams had once already propelled the water wheels. This opportunity was soon recognized in the UK. From 2010 on strong intentions also exist in Slovenia, where 14 owners of mostly abandoned and some even ruined mills and sawmills on the border river Kolpa and its left-bank tributaries have joined in an EU co-founded project "With revitalization of mills towards green energy". The idea had spread in Europe inside the project "Restore Hydro", which started in 2012 under the coordination of ESHA [5]. The aim of this project was to map and ascertain the power capacity of abandoned locations, to identify the prospective ones, and to further promote the marketing model of regional cooperatives for funding the potential projects.

Construction of SHP on abandoned mill locations increases the number of decentralized power sources, which are closer to the consumers. It has very low negative impact, since the basic infrastructure is already available or, in less favorable circumstances, only needs minor repair. The SHP equipment is installed in place of the existing millrace, while the existing weir already provides the necessary head. Consequently, less opposition of local initiatives is to be encountered. In case of mills on river Kolpa, these are on the list of cultural heritage and some are even protected as cultural monuments. The river is with its surroundings included in Natura 2000, in which protected area under the Habitat's directive is specified with the code SI3000175. Consequently, when searching for appropriate technologies and their inclusion in the site, besides cultural heritage preservation, stringent demands for environmental protection and protection of life in the river, and near the river were taken into account. In Slovenia a variety of environmental constraints in general heavily decreases possibilities for economically feasible hydro energetic potential exploitation [6]. Building the SHP using AS needs relatively little civil work and smaller concrete structures. AS itself is amongst the most fish friendly technologies of water engines that allows the fish to pass without harming them [7].

Even if the idea sounds attractive and is technically feasible, it is still the question of profitability of such a project to be solved before committing it. How much electrical energy (EE) can be produced and sold with the foreseen SHP under given conditions is the most important unknown. Some initial assessments have already been done for one upstream located mill on Kolpa, when we were searching for appropriate technologies [8]. This paper, however, presents a detailed EE production simulation for a downstream positioned location Krasinec, considering plenty newly arrived conditions and guidelines. This location is a pilot project, with a building permit being issued just recently. 


\section{$2 \quad$ Hydrological Conditiones}

River Kolpa is a very dynamical water course with low water extremes in dry periods, and very large discharges during spring and autumn rains causing floods. This is a capital problem for the SHP. The rotating part of the electromechanical equipment must withstand flooding for several days. Control cabinet can be installed at an upper level inside the mill. During floods water level rises for more than $4 \mathrm{~m}$ above normal levels and no evacuation system is reasonable [9]. Average values for daily discharges (river flow $Q_{r}$ ), on which the EE production simulation is based, are for Krasinec obtained indirectly from the archived average daily discharges of the closest downstream measuring station Metlika by using a multiplication factor of 0.8 [10]. We analyzed the era of last 35 years recorded in the archive, from 1981 to 2015. 35 years is long enough to compensate for extreme years and can also be a life time of the SHP equipment. Flow duration and head duration curves for the given 35 years are shown in Figure 8. Maximum values of the average river flow can reach $800 \mathrm{~m}^{3} / \mathrm{s}$ (Figure 16), whereas annual distribution of flow indicates a torrential behavior. Numbers of days inside the individual flow segments of $2.5 \mathrm{~m}^{3} / \mathrm{s}$ are provided in Figure 9. Considering the $6 \mathrm{~m}$ width of the mill race and the way how the water for mill operation was derived in the past the nominal flow of SHP was fixed to $5 \mathrm{~m}^{3} / \mathrm{s}$.

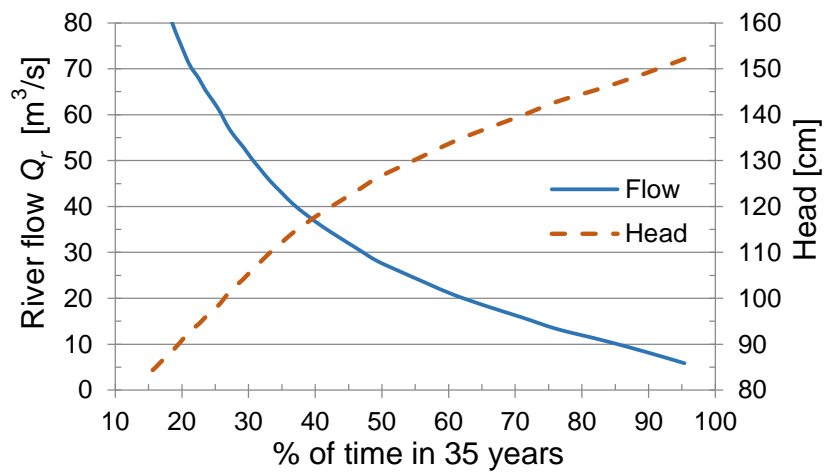

Figure 8. Flow and head duration curves of the analyzed site 
$126 \quad 10^{\mathrm{TH}}$ International Conference on Sustainable Energy and EnVironmental Protection (June $27^{\mathrm{TH}}-30^{\mathrm{TH}}, 2017$, Bled, SLOVENIA), RENEWABle ENERGY SOURCES H. Lavrič, A. Rihar \& R. Fišer: Electrical Energy Production Simulation in SHP of Ultra-Low Head Considering Environment Protection Conditions and Technical Limitations

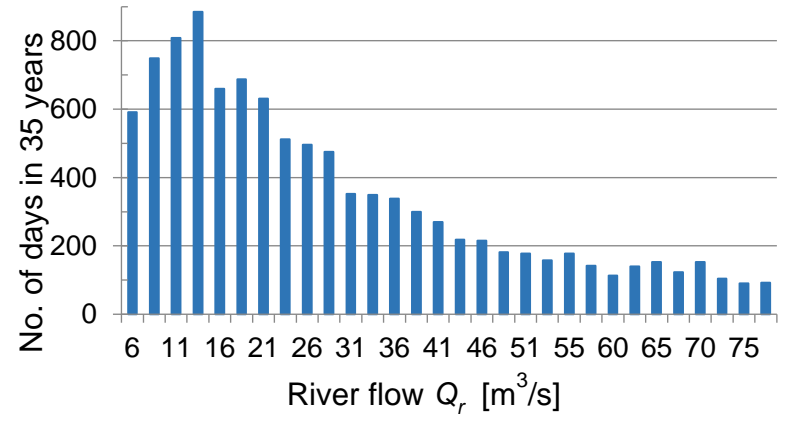

Figure 9. River flow distribution

Normative points of upper and lower water level and nominal head, which occurs at $15 \mathrm{~m}^{3} / \mathrm{s}$ river flow and amounts to $1.39 \mathrm{~m}$, were defined by the hydrologists, according to the river flow distribution and the acquired measurements. Dependence of upper and lower water levels and available head versus river flow was determined by three years of measurements. Discrete points on markers are the measured level differences, while the lines in Figure 10 are polynomial interpolations, represented by (1), (2), and (3):

$$
\begin{aligned}
\Delta h_{u p}= & -0.005692 \cdot Q_{r}{ }^{2}+0.867003 \cdot Q_{r}- \\
& -9.782655, \\
\Delta h_{\text {low }}= & -0.0121 \cdot Q_{r}{ }^{2}+2.2729 \cdot Q_{r}-31.035,
\end{aligned}
$$

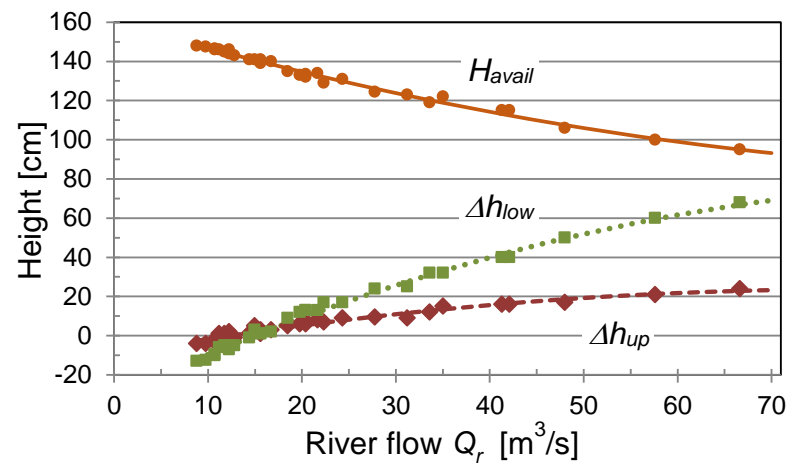

Figure 10. Water level differences from nominal points and resulting head

$$
H_{\text {avail }}=0.0064 \cdot Q_{r}^{2}-1.4059 \cdot Q_{r}+160.25 \text {. }
$$


The limitation of water use due to the biotic diversity preservation is defined for five months, from February to June, for river flows below $20 \mathrm{~m}^{3} / \mathrm{s}$. Below $7 \mathrm{~m}^{3} / \mathrm{s}$ of river flow, no flow is available for the SHP. The graph of limited SHP flow is shown in Figure 11 and is fitted by

$$
\begin{aligned}
Q_{L I M}= & -0.000131 \cdot Q_{r}{ }^{4}+0.00961 \cdot Q_{r}{ }^{3}- \\
& -0.261 \cdot Q_{r}{ }^{2}+3.35 \cdot Q_{r}-13.6 .
\end{aligned}
$$

In practice sluice gate on the intake needs to be controlled appropriately to ensure limitation.

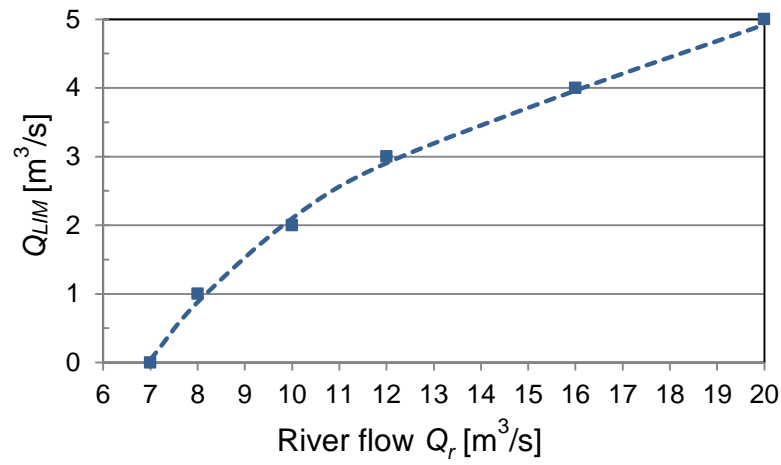

Figure 11. SHP flow limitation from February to June

\section{Equipment Characteristics}

Relatively high SHP nominal flow and ultra-low nominal head demand two AS to operate in parallel. SHP thus has two identical parallel lines, whereas each line consists of AS, speed multiplier, and an induction generator with nominal electrical power equal to $23.8 \mathrm{~kW}$, resulting in SHP nominal power $P_{n}$ of $47.6 \mathrm{~kW}$. Dependence of electrical power versus AS flow is shown in Figure 12. Solid line with markers represents manufacturer data, which are provided only up to nominal AS flow of $2.5 \mathrm{~m}^{3} / \mathrm{s}$. This is normally obtained at $15 \mathrm{~m}^{3} / \mathrm{s}$ of river flow. For higher river flows, when water levels exceed the design points, more water enters the AS and it can generate more power. The relation between $Q_{A S}$ and $\Delta h_{u p}$ is defined by

$$
\begin{aligned}
Q_{A S}= & 0.2973 \cdot\left(1.3+\Delta h_{u p} / 100\right)^{2}+1.6225 . \\
& \cdot\left(1.3+\Delta h_{u p} / 100\right)-0.0758
\end{aligned}
$$


$10^{\mathrm{TH}}$ InTERnATIONAL CONFERENCE ON Sustainable ENERgy AND ENVIRONMENTAL Protection (June $27^{\mathrm{TH}}-30^{\mathrm{TH}}, 2017$, BlED, SLOVENIA), RENEWABLE ENERGY SOURCES H. Lavrič, A. Rihar \& R. Fišer: Electrical Energy Production Simulation in SHP of Ultra-Low Head Considering Environment Protection Conditions and Technical Limitations

For example, when $\Delta h_{u p}$ is $24 \mathrm{~cm}, 3.1 \mathrm{~m}^{3} / \mathrm{s}$ of water enters the AS at $Q_{r}$ of $70 \mathrm{~m}^{3} / \mathrm{s}$. Dashed line of $P_{C S}$ is obtained by extrapolation of manufacturer's data (7).

However, when $Q_{r}$ exceeds $15 \mathrm{~m}^{3} / \mathrm{s}$, flooding of the lower end of AS starts and actual electrical output power is lower as shown in Figure 12. Despite our requests to several manufacturers we were not able to get details on the AS behavior in such conditions. The only reachable result of experimental measurements on a relatively large AS in flooding conditions is reported by Lyons [11] It is shown that output power decreases almost linearly and falls to zero, when effective head is half of the nominal head. This dependence is transferred to our circumstances and is taken into account in the output power ratio $k$ (see Figure 13), represented by

$$
\begin{aligned}
k= & P_{1 L} / P_{C S}=0.00000104 \cdot Q_{r}{ }^{3}-0.00019179 . \\
& \cdot Q_{r}{ }^{2}+0.00018196 \cdot Q_{r}+1.03762994 ; \\
15 & <Q_{r}<70 \mathrm{~m}^{3} / \mathrm{s}, \quad k=1 ; \quad Q_{r}<15 \mathrm{~m}^{3} / \mathrm{s} .
\end{aligned}
$$

There are two limitations of AS operation defined by the manufacturer, which are also taken into account in our simulations:

1. Minimal flow for AS operation is $1.5 \mathrm{~m}^{3} / \mathrm{s}$.

2. AS must be stopped when the upper water level exceeds the design point for $24 \mathrm{~cm}$.

Second condition is met at $70 \mathrm{~m}^{3} / \mathrm{s}$ river flow (Figure 10).

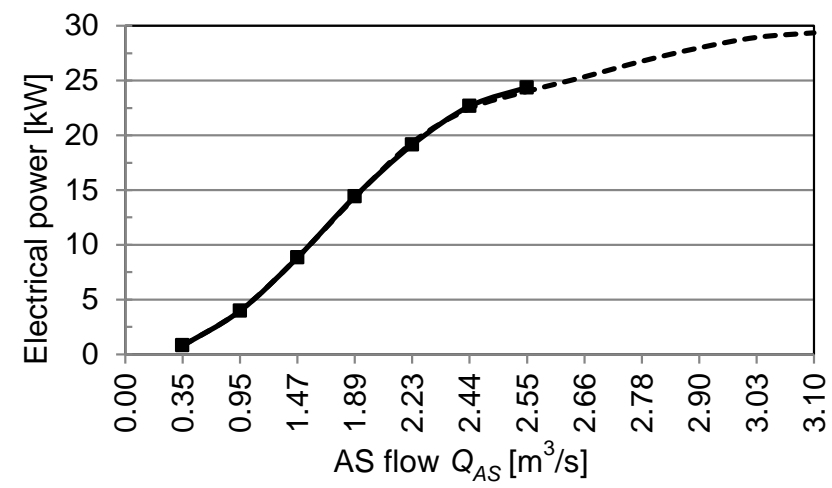

Figure 12. Output electrical power of one line 


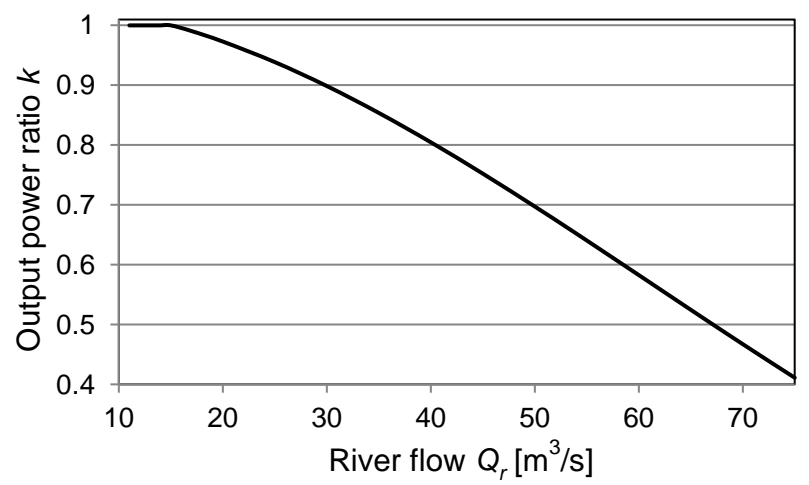

Figure 13. Output power ratio

\section{$4 \quad$ SHP Simulation Model}

The main guideline at designing the simulation model architecture was to obtain maximum output power of SHP from the available flow, taking into account all known circumstances and limitations. It is thus reasonable to design the control algorithm of SHP on the basis of the simulation model scheme, presented in Figure 14. Input data of the simulation model are average daily river flows $Q_{r}$. In the first branch, conditions for the SHP operation are tested. Ecological minimum for the weir is $2 \mathrm{~m}^{3} / \mathrm{s}$ and additional $1.5 \mathrm{~m}^{3} / \mathrm{s}$ is needed to start the first SHP line. If $Q_{r}$ is below $3.5 \mathrm{~m}^{3} / \mathrm{s}$ or exceeds $70 \mathrm{~m}^{3} / \mathrm{s}$, the output electrical power $P_{e l}$ for the current date is zero.

In the second branch, the date is tested. From February to June SHP flow limitation is due for river flows below $20 \mathrm{~m}^{3} / \mathrm{s}$, thus according to the $Q_{L I M}$ value, further branches are provided. First line can start operating when $Q_{L I M}$ exceeds $1.5 \mathrm{~m}^{3} / \mathrm{s}$, which is when $Q_{r}$ exceeds $8.5 \mathrm{~m}^{3} / \mathrm{s}$. Up to $Q_{L I M}$ of $2.5 \mathrm{~m}^{3} / \mathrm{s}$ the working flow $Q_{C S}$ equals $Q_{L I M}$ and output power of one line $P_{C S}$ is calculated by

$$
\begin{aligned}
P_{C S}= & -0,7701 \cdot Q_{C S}{ }^{4}+3,7065 \cdot Q_{C S}{ }^{3}-2,3959 . \\
& \cdot Q_{C S}{ }^{2}+4,4179 \cdot Q_{C S}-0,6145 .
\end{aligned}
$$

Since only one line is in operation, $P_{C S}$ becomes $P_{e l}$. If $Q_{L I M}$ of the current date is above $2.5 \mathrm{~m}^{3} / \mathrm{s}$, SHP will still operate with only one line up to $3.45 \mathrm{~m}^{3} / \mathrm{s}$, because $P_{e l}$ is higher than it would be if $Q_{L I M}$ above $3 \mathrm{~m}^{3} / \mathrm{s}$ is divided into two lines. However, $Q_{C S}$ in this case is equal to the flow $Q_{A S}$ that can enter the AS considering $\Delta h_{u p}(5)$.

For $Q_{L I M}$ above $3.45 \mathrm{~m}^{3} / \mathrm{s}$ both lines get equal share of water flow. When determining $P_{e l}$ we need to apply $k$, since $Q_{r}$ can be higher than $15 \mathrm{~m}^{3} / \mathrm{s}$. When $Q_{r}$ exceeds $20 \mathrm{~m}^{3} / \mathrm{s}$, both lines are filled with $Q_{A S}$, because limitation does not apply. 
$130 \quad 10^{\mathrm{TH}}$ InTERnational CONFERENCE ON Sustainable ENERGy AND ENVIRONMENTAL Protection (June $27^{\mathrm{TH}}-30^{\mathrm{TH}}, 2017$, BLED, SLOVENIA), RENEWABLE ENERGY SOURCES H. Lavrič, A. Rihar \& R. Fišer: Electrical Energy Production Simulation in SHP of Ultra-Low Head Considering Environment Protection Conditions and Technical Limitations

For the period from July to February no flow limitation is due and regarding $Q_{r}$ the program is branched into four paths. Sequences of calculations are very similar to those already described and can be followed in Figure 14.

When values of $P_{e l}$ are obtained for all dates, daily, annual, and the entire era EE values are calculated. For a defined year, EE is obtained by

$$
W_{\text {year }}=\sum_{\text {date }=1.1 . \text { year }}^{31.12 . \text { year }} P_{e l}(\text { date }) \cdot 24 h,
$$

and average annual energy for 35 years era by

$$
W_{A V, y}=\left(\sum_{\text {year }=1981}^{2015} W_{\text {year }}\right) / 35 \text { years. }
$$

\section{$5 \quad$ Results}

In the observed era of 35 years the total amount of EE that could be produced, considering all the known circumstances, is $10.202 \mathrm{GWh}$ and $W_{A V, y}$ is $291.492 \mathrm{MWh}$. If the flow limitation for five months a year is not applied, thus all $Q_{r}$ are proccesed through the right side of the 


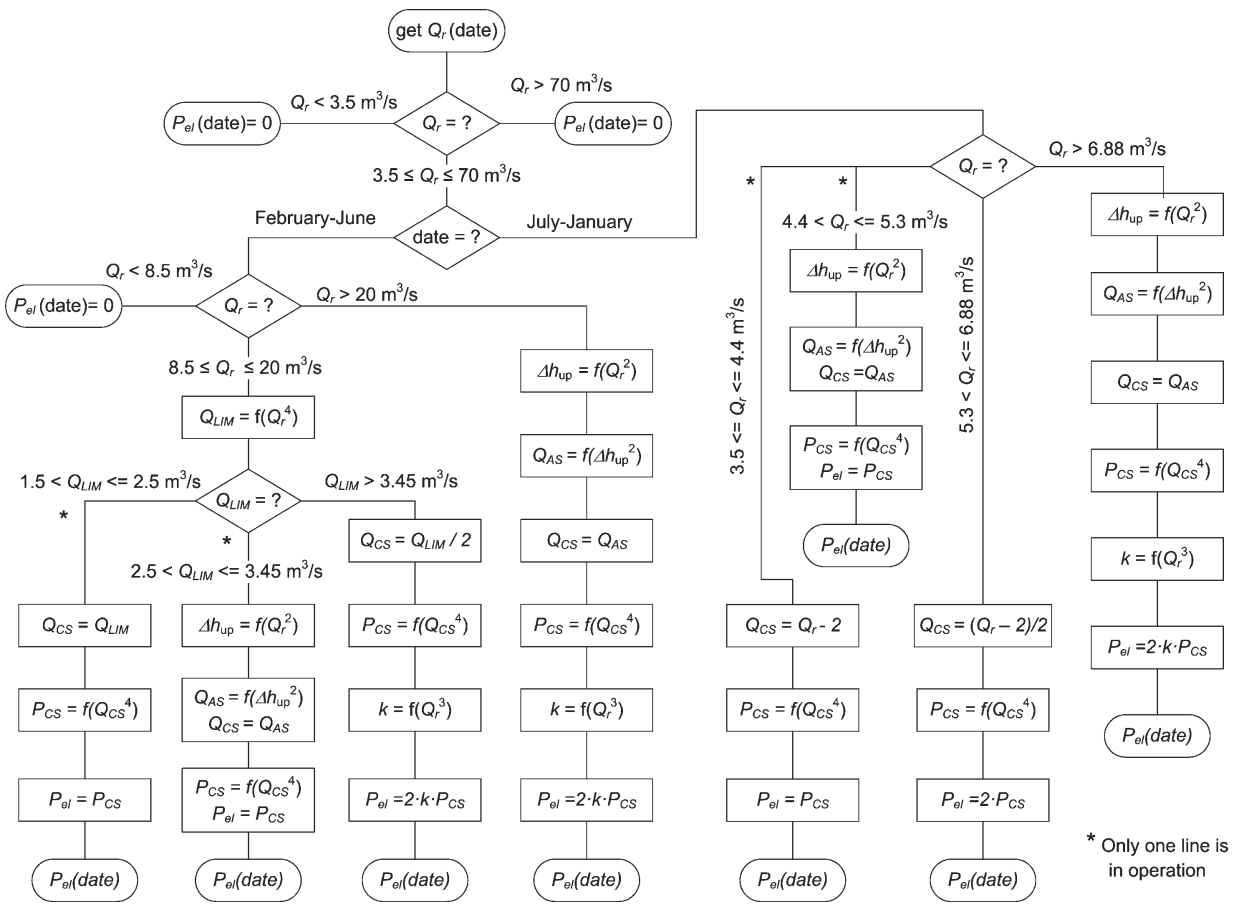

Figure 14. Scheme of the SHP simulation model

simulation model scheme (Figure 14), the total EE is $10.809 \mathrm{GWh}$ and $W_{A V, y}$ is $308.84 \mathrm{MWh}$, which is an increase of $6 \%$. How hydrological conditions and the required limitations influence EE production is shown in the following, more detailed simulation results.

In the time of the year the flow limitation is used, SHP is put into operation at higher $Q_{r}$ and up to $20 \mathrm{~m}^{3} / \mathrm{s}$ operates at lower $P_{e l}$. This difference is observed in Figure 15, where $P_{e l}$ for March and $P_{e l}$ for September versus $Q_{r}$ are shown. $P_{I L}\left(P_{C S} \cdot k\right)$, the output power for the line put into operation first, added for both months, is also provided. Where deeps are observed, the second lines are put ino operation and after the point of switchover, $P_{C S}$ of the first and of the second line are equal, processing equal $Q_{C S}$. Since the point of switchover is optimized, after the transition $P_{e l}$ monotonously rises. In Figure 16 graphs of $P_{e l}, Q_{r}$, critical flood flow $Q_{c r i t}$ and SHP utilized flow $Q_{S H P}$ are shown for three years. Year 2009 is selected among all 35 years as a year, which has $W_{\text {year }}$ close to the average value of all 35 years (Table 1). Year 2011 has the highest value of $W_{\text {year }}$, although it was the droughtiest year, as can be seen from the average and median values of $Q_{r}$. In contrast 2014 was the most water rich year with the highest 
$10^{\text {TH }}$ International Conference on Sustainable Energy and Environmental Protection (June $27^{\mathrm{TH}}-30^{\mathrm{TH}}, 2017$, Bled, SLOVENIA), RENEWABle ENERGY SOURCES H. Lavrič, A. Rihar \& R. Fišer: Electrical Energy Production Simulation in SHP of Ultra-Low Head Considering Environment Protection Conditions and Technical Limitations

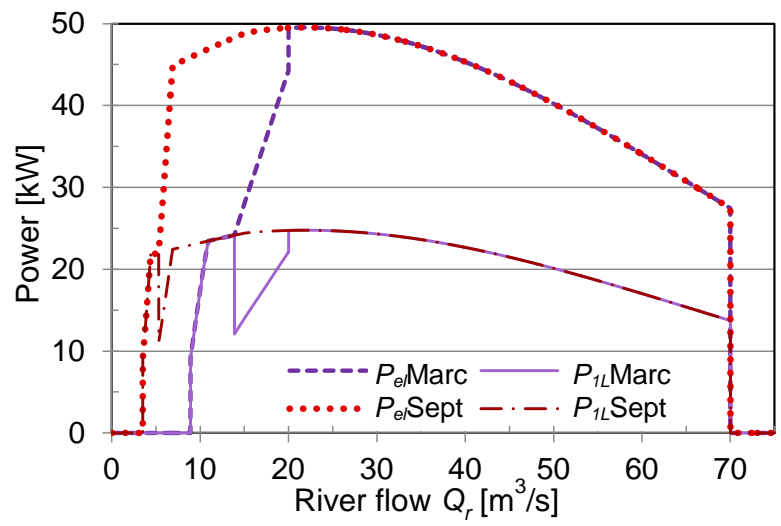

Figure 15. Total SHP output power and power for the lines put into operation first

Table 4. EE production in characteristic years

\begin{tabular}{|c|c|c|c|}
\hline \multirow{2}{*}{} & \multicolumn{2}{|c|}{$Q_{r}\left[\mathrm{~m}^{3} / \mathrm{s}\right]$} & $W_{\text {year }}$ \\
\cline { 2 - 4 } & Median & Average & {$[\mathrm{MWh}]$} \\
\hline 2009 (aver.) & 18.43 & 44.40 & 291.84 \\
\hline 2011 (dry) & 17.97 & 28.78 & 354.74 \\
\hline 2014 (wet) & 49.63 & 84.94 & 239.61 \\
\hline 35 years & 29.25 & 54.24 & 291.49 \\
\hline No $Q_{L I M}$ & 29.25 & 54.24 & 308.84 \\
\hline \hline \multicolumn{2}{|c|}{$P_{n} \cdot 1$ year $(47.6 \mathrm{~kW} \cdot 7860 \mathrm{~h})$} & 416.98 \\
\hline
\end{tabular}

values of average and median $Q_{r}$, but it yields the smallest $W_{\text {year }}$. The reason is explained by the diagrams. Due to frequent and abundant rainfalls in 2014, high flows were present through the entire year, causing high water levels and thus reducing available height by flooding the lower end of AS. In addition $Q_{r}$ exceeded $Q_{c r i t}$ many times, causing the SHP to stop operating, occasionaly even abnormally long. On the other hand in 2011 only few shorter intervals of $Q_{r}$ exceeding $Q_{c r i t}$ appeared and the summer season was ideal, having SHP runing close to the nominal power all the time. In Figure 17 graphs of $W_{\text {year }}$, average, and median values of $Q_{r}$ are shown for 35 years. Reverse dependence between EE and especially average $Q_{r}$ is distinguishable. Figure 18 shows how long the SHP operates within the indicated power intervals at $5 \mathrm{~kW}$ resolution. $23 \%$ of time in 35 years, the SHP is out of operation and $48 \%$ of time it operates around nominal power. Because of the manufacturer's $1^{\text {st }}$ limitation, SHP under $9.2 \mathrm{~kW}$ doesn't operate at all. Up to $20 \mathrm{~kW}$ it is in operation for less than $1 \%$ alltogether. If we multiply SHP nominal power with hours in one year we get EE of 416.98 MWh (

Table 4). 

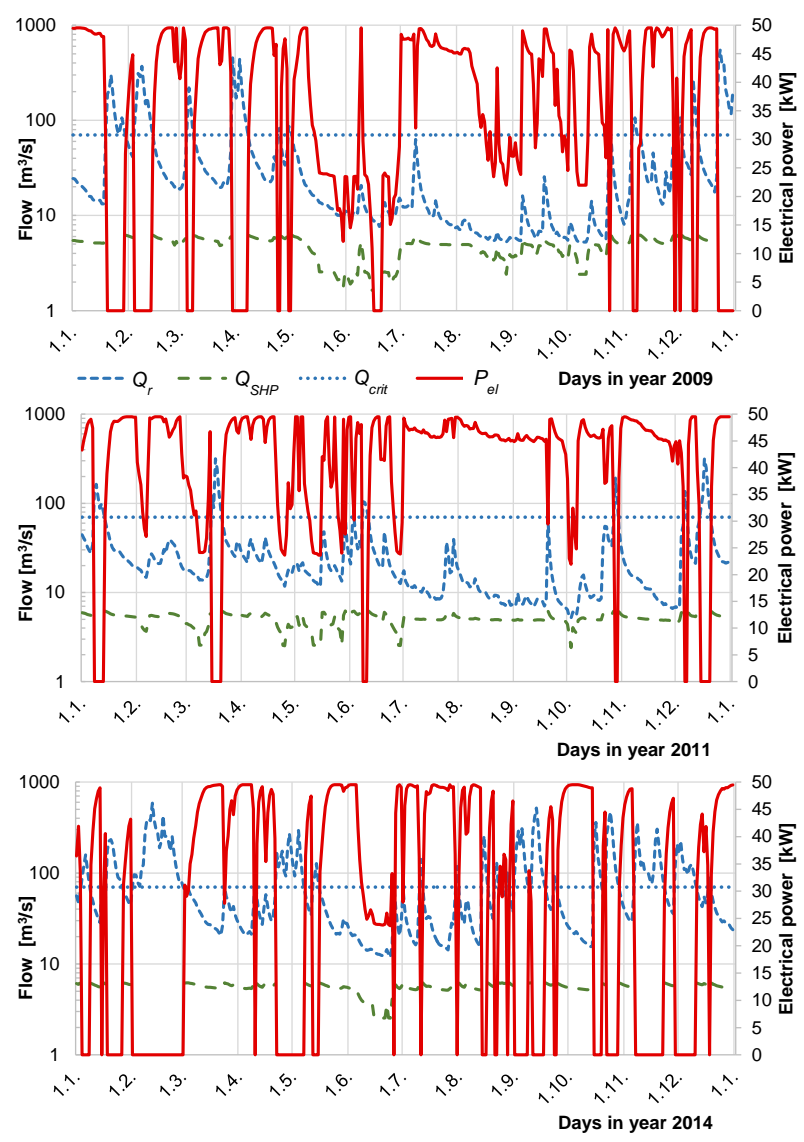

Figure 16. SHP output electrical power, river-, SHP-, and critical flow for three years

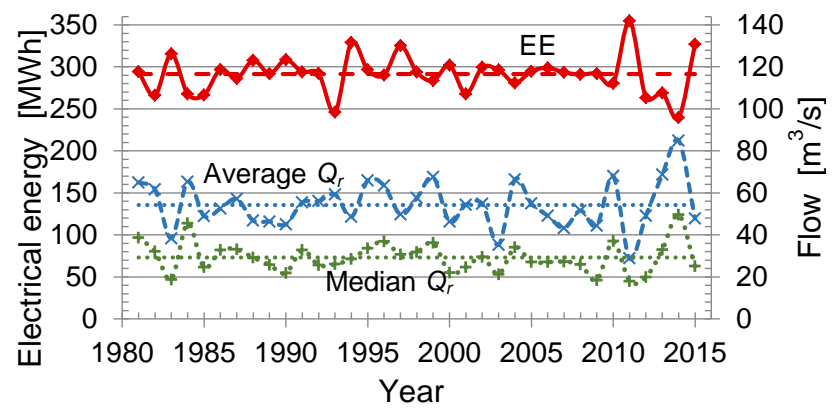

Figure 17. Average and median values of river flow and annual EE for 35 years 
$134 \quad 10^{\mathrm{TH}}$ InTERnational CONFERENCE ON Sustainable ENERGy AND ENVIRONMENTAL Protection (June $27^{\mathrm{TH}}-30^{\mathrm{TH}}, 2017$, Bled, SLOVENIA), RENEWABle ENERGy SOURCES H. Lavrič, A. Rihar \& R. Fišer: Electrical Energy Production Simulation in SHP of Ultra-Low Head Considering Environment Protection Conditions and Technical Limitations

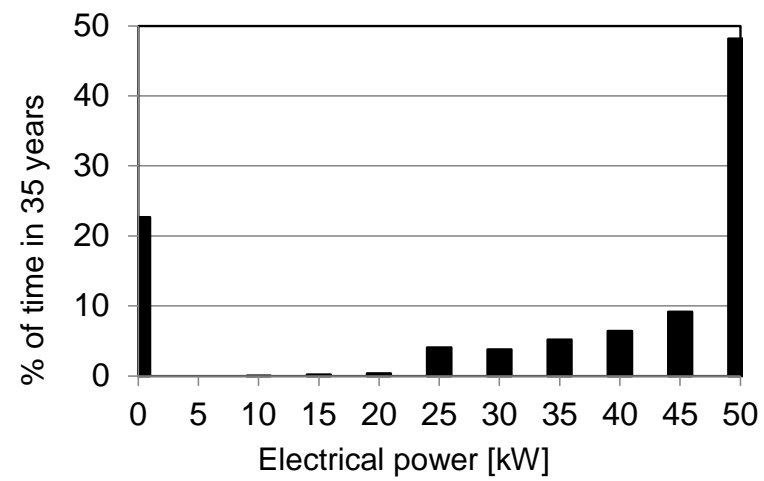

Figure 18. Relative time of SHP operation versus power intervals

SHP is a source of clean, alternative energy and can thus also be a source of income for maintenance of cultural heritage buildings, tourism and some jobs development. If this can really happen in reality, or when can it start happening depends on whether the investment is economically feasible and what the payback period is, respectively. Accurate estimation of possible EE production is the best starting point for potential income and further profitability evaluation.

When utilizing the energy potential of ultra-low heads, the variable river flow has essential influence on the output power of SHP. To some extent due to variation of SHP flow, but to a greater extent, because of lower water level rising and consequential flooding of AS lower end. In water rich years total shutdowns and several days' of SHP standstills are expected due to flooding. There are 20 of such shutdowns in the most water rich year and only 6 in the droughtiest year. Consequently $48 \%$ of EE is produced in the droughtiest year than in the most water rich year. In the year with average water levels, 12 shutdowns appear and SHP can produce $18 \%$ less EE in comparison to the droughtiest year.

\section{References}

[1] A. Lashofer, F. Kaltenberger und B. Pelikan, "Wie gut bewährt sich die Wasserkraftschnecke in der Praxis?," Wasserwirtschaft, vol. 7-8, pp. 2-7, 2011.

[2] O. Paish, "Small hydro power: technology and current status," Renewable and Sustainable Energy Reviews, vol. 6, pp. 537-556, Dec. 2002.

[3] D. K. Okot, "Review of small hydropower technology," Renewable and Sustainable Energy Reviews, vol. 26, pp. 515-520, 2013.

[4] S.J. Williamson, B.H. Stark, J.D. Booker, "Low head pico hydro turbine selection using a multi-criteria analysis," Renewable Energy, vol. 61, pp. 43-50, Jan. 2014. 
[5] http://www.restor-hydro.eu/sl/dobrodosli-v-restor-hydro/konzorcij/, accessed 2.4.2017.

[6] P. Punysa, B. Pelikan, "Review of small hydropower in the new Member States and Candidate Countries in the context of the enlarged European Union," Renewable and Sustainable Energy Reviews, vol. 11, pp. 1321-1360, Sept. 2007.

[7] F. S. A. Bracken, M. C. Lucas, "Potential impacts of small-scale hydro-electric power generation on downstream moving lampreys," River Res. Applic., vol. 29, pp. 1073-1081, Nov. 2013.

[8] H. Lavrič, A. Rihar, R. Fišer, "Assessment of electrical energy production in small hydropower plant with ultra-low head," Proceedings of 8. Int. Conference-Workshop Compatibility and Power Electronics, pp. 103-108, 2013.

[9] J. Caban, L. Gardyński, "Evacuation systems of screw-type water turbines in small hydropower plant," Advances in Science and Technology Research Journal, vol. 7, pp. 2026, Sept. 2013.

[10] http://vode.arso.gov.si/hidarhiv/pov_arhiv_tab.php?p_vodotok=Kolpa, accessed 8.4.2017. M. Lyons, Lab Testing and Modeling of Archimedes Screw Turbines, Master Thesis, University of Guelph, Ontario, 2014. 
136 10 $10^{\mathrm{TH}}$ International CONFERENCE ON Sustainable EnERgy and ENVIRONMENTAL

Protection (June $27^{\mathrm{TH}}-30^{\mathrm{TH}}, 2017$, Bled, SLOVENIA), RENEWABLE ENERGy SOURCES 
$10^{\mathrm{TH}}$ InTERnational CONFERENCE ON Sustainable ENERgy AND ENVIRONMENTAL Protection (June $27^{\mathrm{TH}}-30^{\mathrm{TH}}$, 2017, Bled, SLOVENIA), RENEWABLE ENERGy SOURCES

J. Krope, A.Ghani Olabi, D. Goričanec \& S. Božičnik

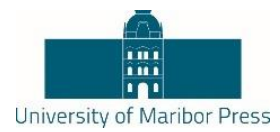

\title{
Possibilities for Micro Biogas Plants in Slovenian Agriculture
}

\author{
FOUAD AL-MANSOUR, VIKTOR JEJCIC \& IGOR ŠKRJANEC
}

\begin{abstract}
The share of GHG emission from agriculture sector in Slovenia is about $10 \%$ of the total inventory GHG emissions. The utilization of agricultural wastes for energy production presents one of the measures to decrease GHG emissions. Hence, the substantial development of technology for biogas production from biodegradable wastes, including agricultural wastes, and consequently for heat and electricity production or as bio-methane, increases the possibility to extend the installation of micro biogas plants in agriculture sector. Breeding farms with more than 50 livestock animal units (LSU) present a group with the greatest potential for the construction of micro biogas plants. The number of breeding farms in Slovenia, according to data from 2013, with more than 100 LSU is 165 farms, and 2142 breeding farms with 50-100 LSU. For the purposes of monitoring the functioning of micro biogas plants, we have developed and built a biogas plant on a dairy farm, which has started the testing operation in April 2015. The biogas plant has a modular structure. The paper will present the possible additional potential of micro biogas plants in Slovenia and will analysis the results of the first year of the pilot micro biogas plant.
\end{abstract}

Keywords: • Biogas $\bullet$ micro biogas plant $\bullet$ agriculture breeding farms • Slovenian agriculture $\bullet$ emissions $\bullet$

CORRESPONDENCE AdDRESS: Fouad Al-Mansour, Ph.D., Jozef Stefan Institute, Jamova cesta 39, 1000 Ljubljana, Slovenia, e-mail: fouad.al-mansour@ijs.si. Viktor Jejcic, Agricultural institute of Slovenia, Hacquetova ulica 17. 1000 Ljubljana, Slovenia; email: viktor.jejcic@kis.si. Igor Skrajanec, Omega Air d.o.o., Tržaška 12, 1000 Ljubljana, Slovenia, e-mail: igor.skrjanec@ omegaair.si. 
$138 \quad 10^{\mathrm{TH}}$ InTERnational CONFERENCE ON Sustainable ENERGy AND ENVIRONMENTAL Protection (June $27^{\mathrm{TH}}-30^{\mathrm{TH}}, 2017$, Bled, SLOVENIA), RENEWABle ENERGY SOURCES F. Al-Mansour, V. Jejcic \& I. Škrjanec: Possibilities for Micro Biogas Plants in Slovenian Agriculture

\section{Introduction}

Agriculture sector contributes a significant share of greenhouse gas emissions and concurrently represents a carbon dioxide $\left(\mathrm{CO}_{2}\right)$ sink; it thus has twofold opposing impacts on climate change. Agriculture is the largest contributor to anthropogenic emissions of greenhouse gases [1]. Agriculture covers approximately $35 \%$ of the land area and accounts for nearly $13.5 \%$ of the total global anthropogenic GHG emissions, contributing about $25 \%, 50 \%$, and $70 \%$ of $\mathrm{CO}_{2}, \mathrm{CH}_{4}$, and $\mathrm{N} 2 \mathrm{O}$, respectively [2, and will be faced in the future with significant requirements as regards reducing greenhouse gas emissions. Share of GHG emissions from the agriculture sector in Slovenia is about $10 \%$ of the total inventory of greenhouse gas (GHG) emissions (Fig. 1) in Slovenia (without emissions caused by energy consumption in agriculture) [38-40].

Share of natural gas in the global energy supply is currently at more than $21 \%$ of all total primary energy supply. Share of natural gas in the energy supply balance of Slovenia was $10.3 \%$ in 2015. Petroleum products have the highest share in primary energy consumption, followed by nuclear power and coal [3]. Share of fossil fuels in the energy balance of Slovenia exceeds $60 \%$ of total primary energy consumption, while the share of renewable energy sources (including waste) is about $17 \%$ and the share of nuclear energy is around 23\%. The structure of primary energy consumption in Slovenia is shown in Figure 1.

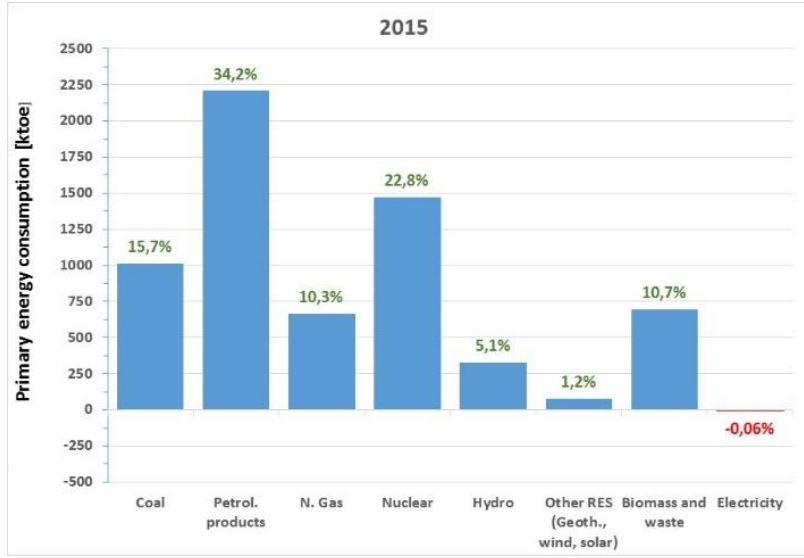

Figure 1: Structure of primary energy consumption in Slovenia for year 2015

All natural gas covering Slovenian needs is imported from abroad. One of the possible solutions for reducing dependence on imported natural gas is the use of biogas, which is becoming recently increasingly important in the exploitation of alternative energy sources in the EU and in our country. The great advantage of biogas or biomethane compared to some other renewable energy sources is the possibility of their storage and use according to the energy demand (at any place and at any time). 


\section{Biogas Production and Potential}

Biogas production is mainly used for electricity generation and is separated (by the statistical data) to three different types of biogas:

- sewage gas,

- landfill gas and

- other gas (biogas from agricultural and other biomass wastes...).

The electricity production from biogas has considerably increased after 2008 with a fast increase in the installation of biogas plants in agriculture using corn silage as substrate, which caused a revolution in agriculture. The system support for electricity production in biogas plants provides two types of supplements for electricity from biogas: biogas from biomass and biogas from biodegradable waste, as well as the sewage and landfill gas.

Support for biogas plants was changed in 2011 for the use of grains or silage of the first crop of corn and other true cereals.

Information on the electricity production from biogas in Slovenia, according to the Agency of the Republic of Slovenia for energy, and other information available to us, shows that there were twenty-six biogas plants (data for 2015) with a total rated power output of 28.2 MWe [4]. The share of electricity production from biogas was about $3 \%$ $(132,3 \mathrm{GWh})$ of electricity production from renewable energy sources (RES) in 2015 [5] as is shown in Figure 2.

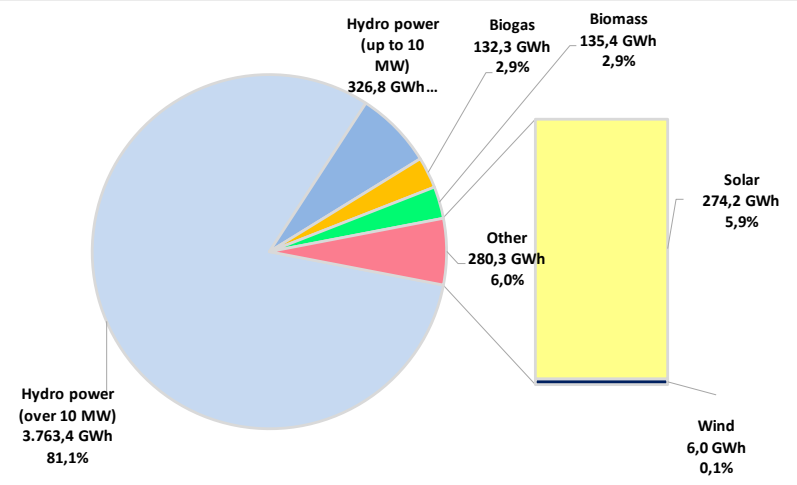

Figure 2: Structure of electricity production from renewable energy sources in 2015.

Biogas plants are interesting for livestock farms, as the farms produce a large amount of slurry and manure, which may represent an environmental problem, and should be temporarily stored up to 6 months according to the Regulation. The estimated potential of biogas production in livestock farms in Slovenia is dependenton the number of livestock in individual location [3]. The potential in Slovenia, with regard to the size of farms is as following: 
$140 \quad 10^{\mathrm{TH}}$ InTERnational CONFERENCE ON Sustainable ENERGy AND ENVIRONMENTAL Protection (June $27^{\mathrm{TH}}-30^{\mathrm{TH}}, 2017$, Bled, SLOVENIA), RENEWABle ENERGY SOURCES F. Al-Mansour, V. Jejcic \& I. Škrjanec: Possibilities for Micro Biogas Plants in Slovenian Agriculture

- Farms with more than 100 LSU with potential of 8.97 M Sm3/year of methane, represent the group with the greatest potential for the building of new biogas plants.

- Ffarms with 50 to 100 LSU have a theoretical potential of o $10.94 \mathrm{M} \mathrm{Sm3/year.}$

- Farms with number of cattle in the size classes from 5 to 20 LSU and between 20 to $50 \mathrm{LSU}$ have a theoretical potential of $64 \mathrm{M} \mathrm{Sm3/year.}$

These theoretical values for potential of bio-methane, are lower due to the technical and economic potential of biogas. The technical potential is approximately $80 \%$ of the theoretical potential, but the economic potential is estimated at 40 to $50 \%$ of the theoretical potential biomethane. At a substantial number of farms, there is also a possibility of use of additional feedstock from agricultural biomass residues from food processing and similar wastes. There is also the possibility of using various organic wastes from households, public facilities, communal activities (maintenance of grass lawns, playgrounds, sports facilities, etc.), food industry, etc.

\subsection{Micro biogas plants}

The modular type of micro biogas plants is the most suitable type for the size of aforementioned livestock farms. The focus will hence be on the modular micro biogas plants with power/size between 20 in $50 \mathrm{kWe}$.

Increasing of the effiency of processes will have an important role on the development of biogas plants in the future.

One possibility would include the use of new technologies allowing for higher production of biogas by improving the processes of feedstock preparation. Alternatively, there could be an increased production of biogas from substrates, which until now have not been used - eg. lignocellulosic materials, which will have a greater role in the future.

There is also a very promising technology, which will become increasingly more widespread, which is the technology of cleaning and upgrading biogas to biomethane phase. The gas that is cleaned and upgraded to biomethane phase, can then be injected into the natural gas grid or stored and could be used at any time and location for vehicles and other energy purposes.

The current method of construction of biogas plants with small power requires more time and higher investments, due to needs for providing construction and other technical works major volumes, as each facility needs a lot of project documentation, which is prepared individually. Development and introduction of standardized modular design of micro biogas plants, can simplify and accelerate the process of installation in an inexpensive way and consequently motivate the farms to opt for this type of technology in the future.

Micro biogas plants could also be used for processing organic waste of food industry, organic waste from households, communal activities, etc. 
Annual theoretical electricity production of micro biogas plants in Slovenia is estimated at a range from $80,000 \mathrm{kWh}$ to $400,000 \mathrm{kWh}$ (depending on the type and quantity of available substrate). Electrical and thermal energy can be fully consumed on the farm in its operational processes.

Surplus electricity can be put in the public network. For the heat there is possibility to include it in the system of district heating or in the system heating of different consumers/objects.

The main weakness of micro biogas plants is the fact that they represent a high investment, ranging from 8,000 to $12,000 \mathrm{EUR} / \mathrm{kWe}$, which has an impact on their implementation/installation on a larger scale within the EU and in Slovenia.

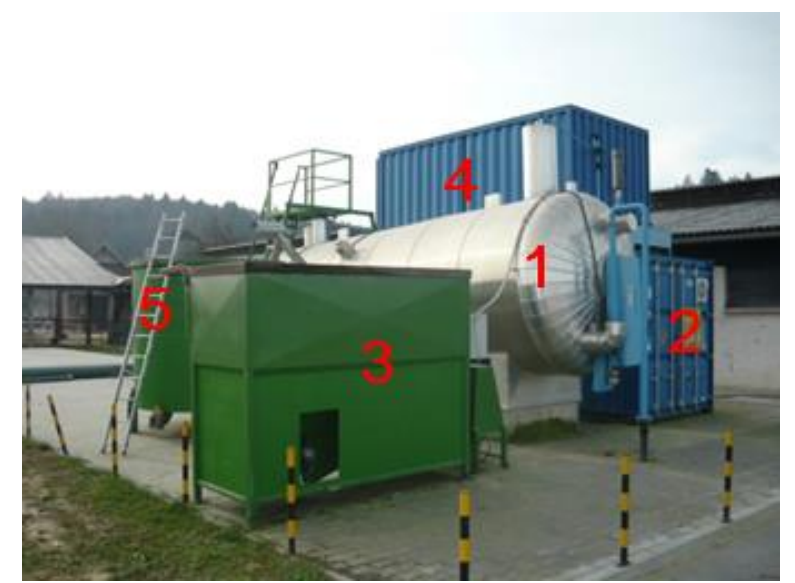

(source: Agricultural Institute of Slovenia, Department of Agricultural Engineering and Energy)

1. digester, 2. container unit with cleaning of biogas, CHP and heat storage, 3. pretreatment of solid substrate, 4. biogas storage, 5. pretreatment of liquid substrate hydrolysis tank

Figure 3: Micro biogas plant modular type ${ }^{1}$.

A pilot of modular micro biogas plant has been installed on the location of the Agricultural Institute of Slovenia- Infrastructure Center Jablje (joint project of company Omega Air, Ljubljana and the Agricultural Institute of Slovenia) [6].

The pilot unit (Figure 3) operates intensively since 2015, currently having a horizontal reactor with a horizontal stirring of the substrate, a container for mixing the manure with the return flow of the liquid phase from the intended separation digestate, a separator for digestate (separation of the solid and the liquid phase), and so on. 
$14210^{\mathrm{TH}}$ InTERnAtional CONFERENCE ON Sustainable ENERGy AND ENVIRONMENTAL Protection (June $27^{\mathrm{TH}}-30^{\mathrm{TH}}, 2017$, Bled, SLOVENIA), RENEWABle ENERGY SOURCES F. Al-Mansour, V. Jejcic \& I. Škrjanec: Possibilities for Micro Biogas Plants in Slovenian Agriculture

Feedstock to biogas plant is cattle manure from 100 LSU with average of $83 \mathrm{~g} / \mathrm{kg}$ dry matter and solid agricultural biomass (residue of processing of cereal seed). Solid agricultural biomass (50 kg / day) is added in the hydrolysis tank, where it is mixed with cattle slurry.

Biogas production amounts to an average of $9000 \mathrm{Sm} 3$ / year. All biogas is used for heat and electricity production in CHP unit with $7 \mathrm{kWe}$ power and $15 \mathrm{kWth}$ thermal power. Electricity is mainly used for own consumption of livestock facilities (milk production), and the excess electricity could be put to the public network. Operation of $\mathrm{t}$ biogas plant is fully automated, so the user does not have any special additional work. The biogas plant is also used for various research and development activities, related to establishing the possibility of using different substrates, monitoring the production of electricity and thermal energy, reducing greenhouse gas emissions, the impact of substrate on germination of seeds of various weeds and invasive alien species of plants, etc.

\section{$3 \quad$ Application of Biogas}

The feasibility of installing biogas plants is actual for farms with more than 50 LSU, but the economic viability of biogas plants in smaller farms (up to $50 \mathrm{LSU}$ ) is questionable.

For these smaller farms it would be essential to form a new solution in the direction of installation of "joint biogas plants", which would receive substrate (manure/slurry and other waste) from a number of farms, as well as industrial and household biodegradable/green waste.

Smaller farms (from 5 to 20 LSU) should transport the substrate to the joint biogas plants and the transportation could be done by tractors with tanks for transporting manure or, in some suitable locations, with short pipelines for slurry or liquid substrate. In the future, we could include also farms with the number of livestock from 20 to 50 LSU. The produced biogas (which can be partly cleaned from impurities) has to be transported via low pressure pipelines to a joint cleaning plant or cogeneration units, which would be located close to major settlements, in order to facilitate supplying the of district heating facilities with heat (Figure 4).

Special vehicles could be used in the above mentioned case for transportation of biogas, its partial purification, and delivery to location of the central cleaning unit to upgrade biogas to biomethane phase. 


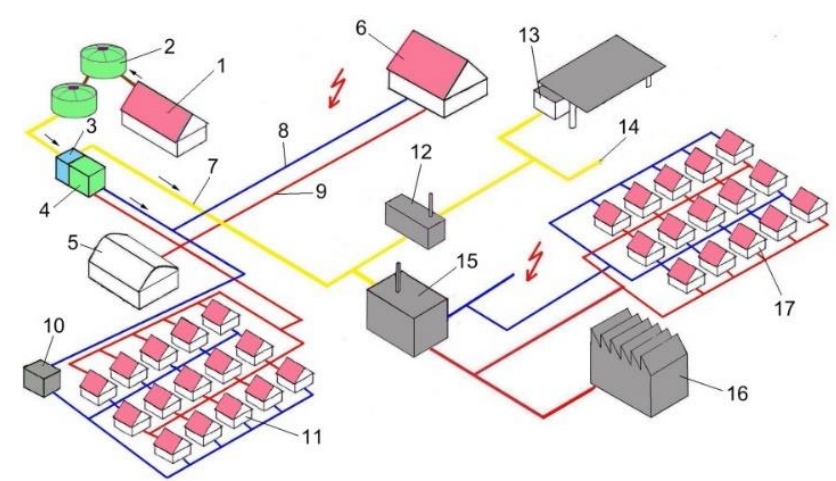

1. farm, 2. digester, 3. raw biogas cleaning, 4. CHP, 5. greenhouse 6. household object on farm, 7. pipeline for roughly cleaned biogas, 8. electricity, 9. heat, 10. transformer station, 11,16,17. electricity/heat users, 12. unit for cleaning and upgrading biogas to biomethane, 13. biomethane station, 14. biomethane, 15. CHP using biogas

Figure 4: The connectivity options of agricultural biogas plants with end users of biogas.

In the case when the production of biogas is less than $70 \mathrm{Nm} 3 / \mathrm{h}$, the costs of cleaning would start rising and due to the currently commercially available technologies, this would not be economically viable [7]. Therefore, the use of joint unit for cleaning and upgrading biogas is envisaged in the future .

Smaller farms will install only micro (or little) biogas plants, equipped with reactors (digesters) and units for the storage of gas (gas tank). The storage unit will have to have sufficient capacity for storage of biogas (at least for a few days). Partial biogas cleaning would be carried out during transport, inside the very vehicles for taking and transport of biogas and the final cleaning of biogas and its upgrading to biomethane phase would be done in the central unit for cleaning (Figure 5). The cleaned and upgraded biogas could be injected into the natural gas pipelines network or into the tank for storage of gas.

a special modular form of tank (reservoir) - containers intended for road, rail or water transport of gas in compressed or liquid form (compressed gas is compressed under a pressure of 220-250 bar, while liquefied is necessary to carry cooled in insulated containers) is being used. The advantage of this technology is that thecontainer delivering the gas to the place of use, is rapidly and easily connected with a station for reducing the gas pressure and the gas is supplied to a local network or to vehicles [8]. 
$10^{\text {TH }}$ International CONFEREnce on Sustainable Energy and Environmental Protection (June $27^{\mathrm{TH}}-30^{\mathrm{TH}}, 2017$, Bled, SLOVEnia), RENEWABle ENERGy SOURCES F. Al-Mansour, V. Jejcic \& I. Škrjanec: Possibilities for Micro Biogas Plants in Slovenian Agriculture

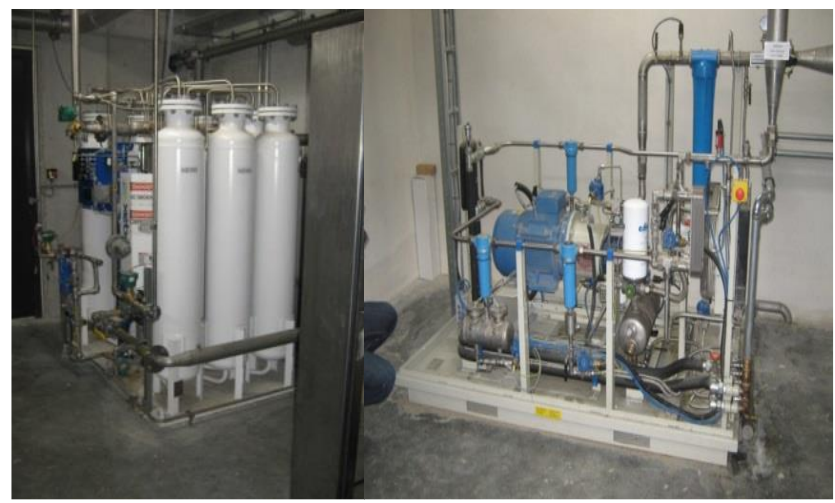

(a)

(b)

(a) Unit for cleaning and upgrading biogas

(b) Unit for compressing the biomethane

Figure 5: Cleaning and and upgrading biogas ${ }^{2}$.

after purification and upgrading biogas to a biomethane phase, it would become suitable for injection into the public gas piplines network, where it would be mixed with natural gas. The advantage of injecting biomethane into the natural gas network would be very useful for biogas plants, which are located far from larger settlements or cities. Gas network in Slovenia is well developed, so the connection of biogas plants that produce bio-methane to gas networks will be feasible when there will be a legal and technical legislation making allowances for the injection of biomethane into the gas grid and for the feed-in tariffs for biomethane production.

\subsection{The use of biomethane as a fuel for agricultural machinery}

Some manufacturers of tractors, trucks and heavy machinery in the EU and the world have recently begun to develop upgrades for diesel engines, which allow the use of biomethane.

Natural gas and biomethane can be used as fuel for specific tractor engines (modified models, which are developed for experimental purposes in some of tractor's factories) .

There are two types of engines with internal combustion using biomethane, either using one or two types of fuel.

The engines that use only one type of fuel are gas engines.

there is another type of engines, which are increasingly advocated by vehicle manufacturers, that allow for a simultaneous use of two types of fuels (England. Dual Fuel Engines), biomethane and diesel (mineral diesel, biodiesel B 100, vegetable oil PPO, a mixture of diesel fuel by different proportions). 
Diesel fuel is a source of ignition for biomethane in engines that use two types of fuel.

Biomethane can not be ignited, such as diesel fuel, which is ignited in the stage of compression to the hot air in the engine, so the function of the ignition is carried out with diesel fuel, which has a low ignition point in comparison with biomethane. The engineusing two types of fuels has a higher efficiency in comparison with a gas engine which uses only bio-methane.

\section{Conclusion}

Utilization of renewable energy sources is one of the main measures to increase energy security, decrease energy dependency and reduce green house gas emissions. As the substantial share of GHG comes from agriculture sector, the increased utilization of biogas in agriculture would contribute to the reduction of GHG emissions, energy consumption (fossil fuels) and the consequent reduction of energy costs.

There is unused potential for biogas production in smaller and medium livestock farms. in Slovenia farms with more than 100 LSU represent a group with the greatest potential for building new biogas plants and have shown to have a great potential for using micro biogas plants in the modular design.

Farms can, by using their own source of energy, significantly contribute to the economy of agricultural production and greater competitiveness of the agricultural products market.

Development of new biogas plants in modular design enable increasing the utilization of biogas potential, if it is supported with suitable financial, legal and informative support.

\section{Notes}

1 Source: Agricultural Institute of Slovenia, Department of Agricultural Engineering and Energy

2 Source: Biogas plant Graskraft Anlage, Austria

\section{References}

[1] D. Pandey, M. Agrawal, Carbon Footprint Estimation in the Agriculture Sector, Book: S. S. Muthu, Assessment of Carbon Footprint in Different Industrial Sectors, Volume 1, EcoProduction, DOI: 10.1007/978-981-4560-41-2_2.

[2] [4b] Montzka SA, Dlugokencky EJ, Butler JH (2011) Non-CO2 greenhouse gases and climate change. Nature 476:46-50

[3] Statistični urad Republike Slovenije, Ljubljana, Statistični podatki, 2015, www.stat.si.

[4] Poje, T. : Bioplinarne: število bioplinarn počasi narašča. Monografija: Obnovljivi viri energije v Sloveniji - prerez časa in prostora. Borzen, Ljubljana, 75-80, 2016. 
146 1 $10^{\mathrm{TH}}$ InTERnational CONFERENCE ON Sustainable ENERGy AND ENVIRONMENTAL Protection (June $27^{\mathrm{TH}}-30^{\mathrm{TH}}, 2017$, BLed, Slovenia), RENEWABLE ENERGY SOURCES F. Al-Mansour, V. Jejcic \& I. Škrjanec: Possibilities for Micro Biogas Plants in Slovenian Agriculture

[5] Fouad Al-Mansour: Stanje in možnosti proizvodnje bioplina v Sloveniji, Slovenskonemška gospodarska zbornica, Simpozij Obnovljivi viri energije: pridobivanje energije iz biomase in bioplina, 2016, Ljubljana.

[6] Kmetijski institute Slovenije: Mikro bioplinska naprava modularne izvedbe, http://www.kis.si/Inovacije_in_izdelki.

[7] 3. Guide to cooperative biogas to biomethane developments: As part delivery of: Biomethane regions, Promotion of biomethane and its market development through local and regional partnerships, Technische Universität Wien - Vienna University of Technology, Institute of Chemical Engineering, Research Division Thermal Process Engineering and Simulation, Wien, 2012.

[8] Udaeta, M., E., M., Bernal, J., L., Galvao, L.,C.,R., Grimoni., J., A., B.: Natural Gas Virtual-Pipeline for Alternative Energy Distribution, USP, GEPEA/EPUSP (Grupo de Energia do Departamento de Engenharia de Energia e Automação Elétricas de Escola Politécnica da Universidado de São Paulo, São Paulo, 2012. 
$10^{\mathrm{TH}}$ InTERnational CONFERENCE ON Sustainable ENERgy AND Environmental Protection (June 27 $7^{\mathrm{TH}}-30^{\mathrm{TH}}, 2017$, BLed, SLOVENIA), RENEWABLE ENERGy SOURCES

J. Krope, A.Ghani Olabi, D. Goričanec \& S. Božičnik

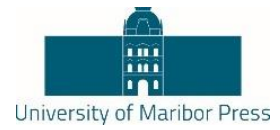

\title{
Short-Term Probabilistic Forecasting of Wind Energy Resources Using the Enhanced Ensemble Method
}

\author{
DEOCKHO KIM \& JIN HUR
}

\begin{abstract}
Unlike other traditional energy resources, wind power outputs depend on natural wind resources that vary over space and time. Accurate wind power forecasting can reduce the burden of balancing energy equilibrium in electrical power systems. In this paper, we propose the shortterm probabilistic forecasting of wind energy resources using the enhanced ensemble method. The enhanced ensemble forecasting methods are grouped into two main categories: temporal ensemble and spatial ensemble forecasting. The temporal ensemble forecasting is implemented by autoregressive integrated moving average with explanatory variable model and polynomial regression with time-series data. The spatial ensemble forecasting is implemented by geostatistical model and interpolation with geographical property data. In addition, the stochastic approach is applied to reduce the uncertainty in wind power forecasting and use of Numerical Weather Prediction models for accurate wind power forecasting is considered.
\end{abstract}

Keywords: - probabilistic wind forecasting - short-term forecasting • ensemble method $\bullet$ temporal ensemble $\bullet$ spatial ensemble $\bullet$

CORRESPONDENCE ADDRESS: Deockho Kim, Graduate student, Sangmyung University, Department of Electrical Engineering, 20, Hongjimun 2-gil, Jongno-gu, Seoul, Republic of Korea, e-mail: 201737009@sangmyung.kr. Jin Hur, Ph.D., Assistant Professor, Sangmyung University, Department of Electrical Engineering, 20, Hongjimun 2-gil, Jongno-gu, Seoul, Republic of Korea, e-mail: jinhur@smu.ac.kr. 
148 10 $10^{\mathrm{TH}}$ InTERnational CONFERENCE ON Sustainable ENERGy AND ENVIRONMENTAL Protection (June $27^{\mathrm{TH}}-30^{\mathrm{TH}}, 2017$, Bled, Slovenia), Renewable Energy SourCes D. Kim \& J. Hur: Short-Term Probabilistic Forecasting of Wind Energy Resources Using the Enhanced Ensemble Method

\section{Introduction}

Installed capacity of wind energy is rapidly increasing around the world. The Global Wind Energy Council (GWEC) predicts that wind power capacity will reach $320 \mathrm{GW}$ of electricity by 2020 [1]. The wind energy penetration is also under consideration all over the world. The National Renewable Energy Laboratory (NREL) examines a large-scale integration of wind power which considers up to $30 \%$ wind energy penetration for the western and eastern interconnections. The New England Independent System Operator (NE ISO) also examines up to $24 \%$ wind energy integration [2]. The European Wind Energy Association (EWEA) announces that the wind energy capacity penetrated in the EU would provide in an average $315 \mathrm{TWh}$ of electricity. It shares $11.4 \%$ of the total electricity consumption [3].

Since wind energy is a variable generation resource, unlike conventional generation resources, its constant output is not always possible without auxiliary equipment. As the wind energy integration increases, forecasting technique for wind energy is also becoming important. In this paper, we propose the short-term probabilistic forecasting of wind energy resources using the enhanced ensemble method. Here, the enhanced ensemble indicates a method that combines the temporal ensemble including an AutoRegressive Integrated Moving Average with Exogenous variable (ARIMAX) model, polynomial regression, and an Analog Ensemble (AnEn) method, spatial ensembles including spatial interpolation and wind profile power law. To verify the proposed method, we apply the method to a wind farm in Jeju island, Korea. We use three-week historical time series data for temporal ensemble and local Numerical Weather Prediction (NWP) models and its coordinate data for spatial ensemble to forecast the day-ahead wind turbine output.

\section{Enhanced Ensemble Method}

In this section, we describe the proposed method involving two different approaches. The one is spatial ensemble to forecast the day-ahead wind speed at the specific wind farm using the 10 local NWP models and coordinates data. The other is temporal ensemble to forecast the day-ahead probabilistic wind turbine output using the three statistical ensemble members such as ARIMAX model, polynomial model, and Analog ensemble. The algorithm of proposed method is shown as Figure 1. 


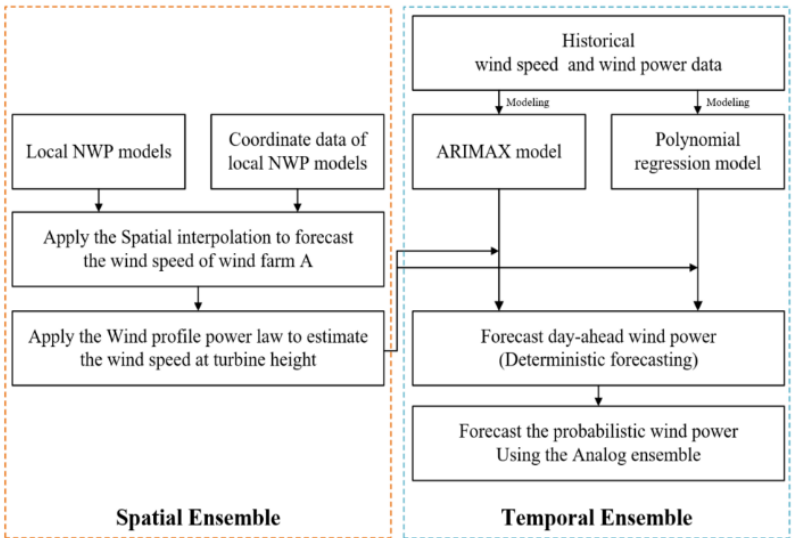

Figure 1. Proposed algorithm

\subsection{Spatial Ensemble}

In proposed method, spatial ensemble is applied to forecast the wind speed of turbine height at the point of interest using the wind speeds of adjacent points. For this method, we propose the spatial interpolation method called Kriging, and wind profile power law based on the terrain characteristic of installed wind turbine.

\subsubsection{Spatial interpolation: Kriging}

The Kriging method is one of the spatial modelling technique. The spatial modelling is useful technique for estimating the values of a specific point through the values of spatially different points. The spatial modelling method is used in various fields [4-7]. The Kriging method forecasts the value through the regression relationship between adjacent spatial ensemble members and point of interest. The general equation of Ordinary Kriging is described in the Equation (1), where $n$ is a number of adjacent spatial ensemble members, $\alpha$ is the value of adjacent members, $\lambda$ is weight for the each adjacent members with regard to spatial covariance, and $\alpha^{*}$ is the value of interest point [8-9].

$$
\begin{aligned}
& \alpha^{*}=\sum_{i=1}^{n} \lambda_{i} \alpha_{i} \\
& \text { s.t } \sum_{i=1}^{n} \lambda_{i}=1
\end{aligned}
$$

The weights can be determined according to the distance correlation based on the coordinate data and the value of each spatially different members. The sum of weights for Ordinary Kriging is ideally one in order not to be biased. 
$150 \quad 10^{\mathrm{TH}}$ InTERnational CONFERENCE ON Sustainable ENERGy AND ENVIRONMENTAL Protection (June $27^{\mathrm{TH}}-30^{\mathrm{TH}}, 2017$, Bled, SLOVENIA), RENEWABLE ENERGy SOURCES D. Kim \& J. Hur: Short-Term Probabilistic Forecasting of Wind Energy Resources Using the Enhanced Ensemble Method

\subsubsection{Wind profile power law}

In this paper, we use wind profile power law to estimate the wind speed of turbine height. Wind speed varies depending on altitude, and terrain characteristic. This relationship between the altitude and wind speed is shown as Equation (2) where, $u$ is the wind speed at specific height $h$ and $u_{0}$ is the wind speed at reference height $h_{o}$. The variable $x$ is wind speed shear exponent which is rely on the terrain characteristic, and stability [10].

$u=u_{0}\left(\frac{h}{h_{o}}\right)^{x}$

We determined the wind speed shear exponent depending on the terrain characteristic in this paper. The cited values of wind speed shear exponent are described in Table 1 [11].

Table 1. Wind speed shear exponent depending on terrain characteristics [11]

\begin{tabular}{|c|c|}
\hline $\begin{array}{l}\text { Wind speed } \\
\text { shear }\end{array}$ & Terrain characteristic \\
\hline 0.95 & Coastal waters of inland sea \\
\hline 0.121 & Flat shore of ocean small islands \\
\hline $0.130-0.135$ & Open grasslands without trees \\
\hline 0.143 & Open slightly rolling farm land \\
\hline $0.128-0.170$ & $\begin{array}{c}\text { Open level agricultural land with } \\
\text { isolated trees }\end{array}$ \\
\hline 0.200 & Open fields divided by los stone walls \\
\hline 0.220 & Rough coast \\
\hline 0.230 & $\begin{array}{l}\text { Gently rolling country with bushes and } \\
\text { small trees }\end{array}$ \\
\hline $0.250-0.303$ & $\begin{array}{l}\text { Level country uniformly covered with } \\
\text { scrub oak and pine }\end{array}$ \\
\hline 0.357 & Wooded and treed farm land \\
\hline
\end{tabular}

\section{$2.2 \quad$ Temporal ensemble}

In proposed method, temporal ensemble is used to forecast probabilistic day-ahead wind turbine output using the three statistical models. To derive the deterministic wind turbine output, two statistical models including ARIMAX and polynomial regression and estimated wind speeds determined through the spatial ensemble method are used in our proposed method. Then, we use derive a stochastic wind power outputs using the analog ensemble method. 


\subsubsection{ARIMAX model}

The ARIMAX model is composed a combination of the Auto-regressive Integrated Moving Average (ARIMA) and linear regression model [12-13]. The ARIMA term represents the past wind power as an integrated model for auto-regressive and white noise, and the $\mathrm{X}$ term is modelled for the past wind speed as a linear regression model. The ARIMA with one exogenous variable is described in Equation (3),

$$
Z_{t}=\sum_{i=1}^{p} \phi_{i} Z_{t-i}+\sum_{j=1}^{q} \theta_{j} \varepsilon_{t-j}+\alpha w s_{t}
$$

where $Z_{t}$ is stationary time series data for the past wind power outputs, the first term on the right represents Auto-Regressive (AR), $p$ is order of AR and $\phi$ indicates coefficient of AR term. The second term on the right represents Moving Average (MA), $q$ is order of MA and means the number of time lag. The coefficient $\theta$ is associated with MA terms, and $\varepsilon$ represents white noise. The third term on the right indicates the exogenous variable term, variable $w s_{t}$ indicates wind speed data at time $t$ and $\alpha$ represents coefficient of $\mathrm{X}$ term. In proposed method, the ARIMAX modelling process is shown as Figure 2.

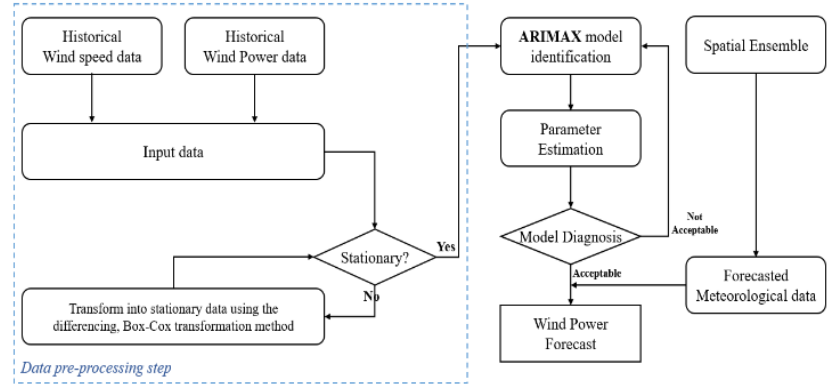

Figure 2. ARIMAX modelling algorithm

In the data pre-processing step, when the time series data is not stationary, the differences method and the Box-Cox transformation method are applied. The order of the ARIMAX model is considered by choosing the order of the model with the smallest Bayesian Information Criterion (BIC) which is one of the model selection statistics [14]. The model parameters are estimated using the least squares method or maximum likelihood method. Finally, in order to derive the forecasting value, the forecasted wind speed data for same period as the forecast period is required. In this paper, the forecasted values obtained through the spatial ensemble is applied. 
$15210^{\mathrm{TH}}$ InTERnational CONFERENCE ON Sustainable ENERGY AND ENVIRONMENTAL Protection (June $27^{\mathrm{TH}}-30^{\mathrm{TH}}, 2017$, Bled, SLOVEnia), Renewable ENERGy SOURCES D. Kim \& J. Hur: Short-Term Probabilistic Forecasting of Wind Energy Resources Using the Enhanced Ensemble Method

\subsubsection{Polynomial regression}

Using polynomial regression, the relationship between wind speed and turbine output can be modelled as curve-linear [15]. The kth order polynomial regression is expressed as Equation (4), where $\beta$ is coefficient of polynomial regression, $\beta_{0}$ is intercept, $w s$ means wind speed, and $y$ represents turbine output [16]. The order of the polynomial regression is determined by the order that best reflects the characteristics of the input data.

$$
y=\sum_{i=1}^{k} \beta_{i} w s^{i}+\beta_{0}
$$

\subsubsection{Analog ensemble}

The analog ensemble is a method that converts the current deterministic value to the probabilistic one by selecting the measured samples of the past situation which is most similar to the current situation [17]. It is expressed as a Figure 3. First, the analog ensemble finds past forecasts that are similar to the current forecast. After that, the current forecast is converted into a stochastic value based on measured values at the same time as the past forecasts found. Here, we determine similar historic forecasts called analogs according to the metric distance equation (5), where $n$ is number of predictors, $F_{i, t}$ represents current forecast of predictor $i$ at time t, $A_{i, t}$ represents past forecast of predictor $i, \sigma_{i}$ is standard deviation of predictor $i$ over whole available time series, and $w_{i}$ indicates the weight of predictor $i$ [18]. The analogs with the small distance metric scores are chosen.

$\left\|F_{t} A_{t}\right\|=\sum_{i=1}^{n} \frac{w_{i}}{\sigma_{i}} \sqrt{\sum_{j=-t}^{t}\left(F_{i, t+j}-A_{i, t+j}\right)^{2}}$

The analog ensemble method provides probabilistic forecasts and it can also derive deterministic forecasts through the ensemble mean. The ensemble spread represents the uncertainty of the forecasts at each time point.

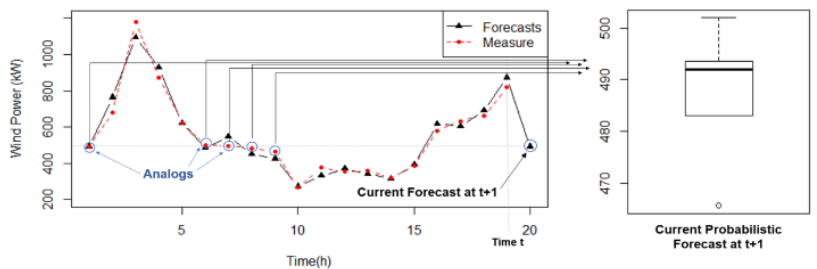

Figure 3. Analog Ensemble 
$10^{\text {TH }}$ InTERnAtional CONFERENCE on Sustainable EnERgy AND ENVIRonmental 153 Protection (June $27^{\mathrm{TH}}-30^{\mathrm{TH}}, 2017$, BLED, SLOVENiA), RENEWABLE ENERGY SOURCES

D. Kim \& J. Hur: Short-Term Probabilistic Forecasting of Wind Energy Resources Using the Enhanced Ensemble Method

\section{Case Study: JEJU ISLAND, Korea}

We forecast the day-ahead turbine outputs of wind farm A in Jeju island, Korea. The name of the wind farm is not revealed due to the security of the technical data. We use the following kinds of data for forecasting model using our proposed method.

- The forecasted wind speed data from each of the eight local NWP members

- Coordinate data in which eight local NWP members and wind farm A

- Three-weeks historical turbine output and wind speed data measured at wind farm A

- Turbine height and terrain characteristic installed in wind farm A

- One day turbine output data for model evaluation

We build a temporal ensemble based on three week's past data of wind farm A from February 3rd to February 23th, and forecast the wind speed of wind farm A of February 24 using a spatial ensemble through adjacent eight local NWP models. Here, the spatial ensemble provides the forecasted wind speed needed to derive the day-ahead forecasts of wind farm A. The overall simulation outline is as follows.

- Training period: $2016.02 .03-2016.02 .23$

- Evaluation period: 2016.02.24

\subsection{Simulation: Spatial ensemble}

The eight adjacent local NWP models used for the spatial ensemble and the wind farm A, the forecasting point, are shown in the Figure 4 using the Google Maps.

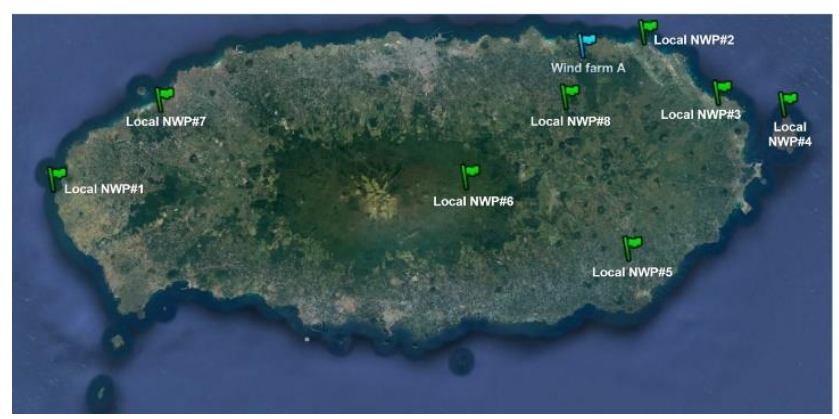

Figure 4. Location for local NWP models and wind farm A

The coordinates of the local NWP models and wind farm A used in this simulation are described in the Table 2 . 
$154 \quad 10^{\mathrm{TH}}$ InTERnational CONFERENCE ON Sustainable ENERGy AND ENVIRONMENTAL Protection (June $27^{\mathrm{TH}}-30^{\mathrm{TH}}, 2017$, Bled, SLOVENIA), RENEWABle ENERGy SOURCES D. Kim \& J. Hur: Short-Term Probabilistic Forecasting of Wind Energy Resources Using the Enhanced Ensemble Method

Table 2. Coordinates of local NWP models and wind farm A

\begin{tabular}{|c|c|c|c|}
\hline Name & $\begin{array}{c}\text { Latitude } \\
\text { (degree) }\end{array}$ & $\begin{array}{c}\text { Longitude } \\
\text { (degree) }\end{array}$ & $\begin{array}{c}\text { Altitude } \\
\text { (meter) }\end{array}$ \\
\hline Local NWP\#1 & 33.2938 & 126.1628 & 72 \\
\hline Local NWP\#2 & 33.5616 & 126.7794 & 34 \\
\hline Local NWP\#3 & 33.5198 & 126.6877 & 18 \\
\hline Local NWP\#4 & 33.5228 & 126.9541 & 6 \\
\hline Local NWP\#5 & 33.3535 & 126.8167 & 77 \\
\hline Local NWP\#6 & 33.3852 & 126.6194 & 760 \\
\hline Local NWP\#7 & 33.3926 & 126.2582 & 40 \\
\hline Local NWP\#8 & 33.4824 & 126.7090 & 252 \\
\hline Wind farm A & 33.5281 & 126.7175 & 62 \\
\hline
\end{tabular}

We use the forecasted wind speed of 8 local NWP members and the Kriging method to forecast the wind speeds for wind farm A on February 24th. The weight of the Kriging method for each local NWP model is shown in the Table 3.

Table 3. The weights for local NWP models

\begin{tabular}{|c|c|c|c|}
\hline $\begin{array}{c}\text { NWP } \\
\text { members }\end{array}$ & Weight & $\begin{array}{c}\text { NWP } \\
\text { members }\end{array}$ & Weight \\
\hline$\# 1$ & 0.1587 & $\# 5$ & 0.1754 \\
\hline$\# 2$ & 0.1410 & $\# 6$ & 0.0728 \\
\hline$\# 3$ & 0.2069 & $\# 7$ & 0.1087 \\
\hline$\# 4$ & 0.1328 & $\# 8$ & 0.0225 \\
\hline
\end{tabular}

We also calibrate the forecasted wind speed to the value of the turbine height based on the equation (2). The height of the turbine installed in the wind farm A is $80 \mathrm{~m}$, and the suitable value of wind shear exponent is 0.143 considering the terrain characteristic. Based on the Kriging method and the wind profile power law, the forecasted wind speeds of the wind farm A and the eight spatial ensemble members on February 24th are shown in the following Figure 5.

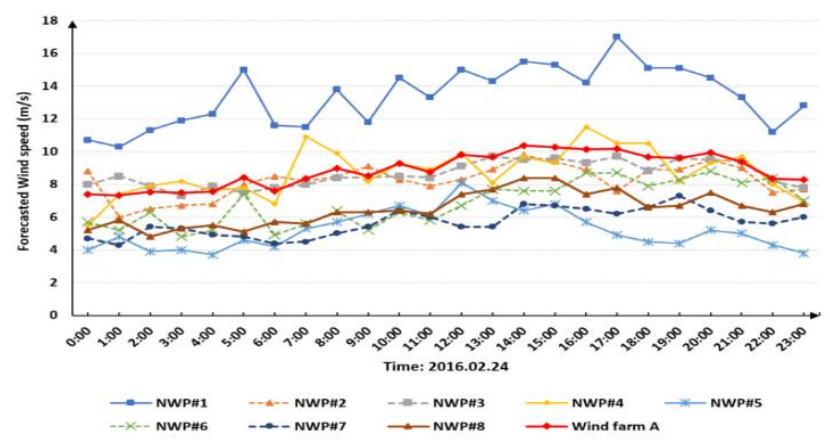

Figure 5. Forecasted wind speeds 
The mean absolute percentage error (MAPE) is about $6.66 \%$ in comparison with the wind speed measured in the wind farm A. The comparison between the forecasts and the measured values at each forecasting point are shown in the Figure 6.

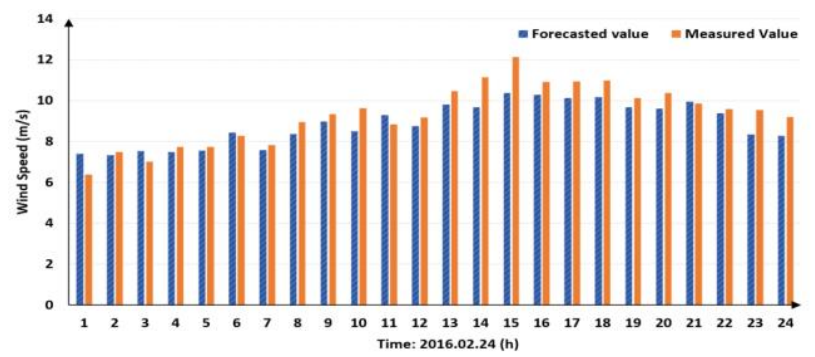

Figure 6. Comparison with measured values

\subsection{Simulation: Temporal Ensemble}

The temporal ensemble combines the statistical models constructed based on the three weeks of historical data to derive the day-ahead wind power forecasting. The three-week historical data used in the modelling are shown in the Figure 7.

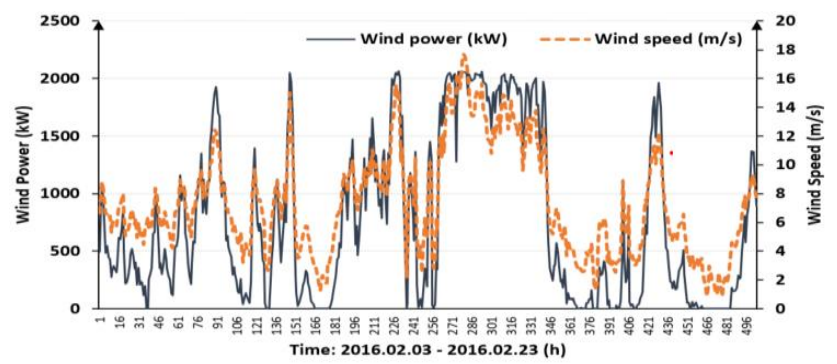

Figure 7. Historical data for modelling

We construct the ARIMAX model and the polynomial regression model using the past output and wind speed data for 3 weeks. The established ARIMAX model is as follow Equation (6). We apply the first-difference and the Box-Cox transformation method to transform the stationary data.

$$
Z_{t}=\varepsilon_{t}-0.0848 \varepsilon_{t-1}-0.3885 \varepsilon_{t-2}+1.964 w s_{t}
$$

The established $5^{\text {th }}$-order polynomial regression model is as follows Equation (7), and the coefficient of determination between the model and historical data is about 0.996.

$$
\begin{aligned}
y= & 0.027 w s^{5}-1.148 w s^{4}+15.808 w s^{3} \\
& -67.15 w s^{2}+123.15 w s-86.528
\end{aligned}
$$


156 10 $10^{\mathrm{TH}}$ InTERnational CONFERENCE ON Sustainable ENERGy AND ENVIRONMENTAL Protection (June $27^{\mathrm{TH}}-30^{\mathrm{TH}}, 2017$, Bled, SLOVENIA), RENEWABle ENERGy SOURCES D. Kim \& J. Hur: Short-Term Probabilistic Forecasting of Wind Energy Resources Using the Enhanced Ensemble Method

The wind speed of above two predictors uses the value obtained through the spatial ensemble to derive the forecasts. We apply an analog ensemble method using two statistical predictors including ARIMAX and $5^{\text {th }}$-order polynomial regression model. The weights for each predictor are as follows: The ARIMAX model is 0.6 and polynomial regression is 0.4. Based on equation (5), we calculate the number of optimal analog members and determine 19 analog members finally.

We compare the forecasts of February $24^{\text {th }}$, derived from two predictors and ensemble mean-19 analogs, with measured turbine power from wind farm A. The comparison result is shown in the Figure 8, and the mean absolute percentage error (MAPE) for each model are shown in the Table 4.

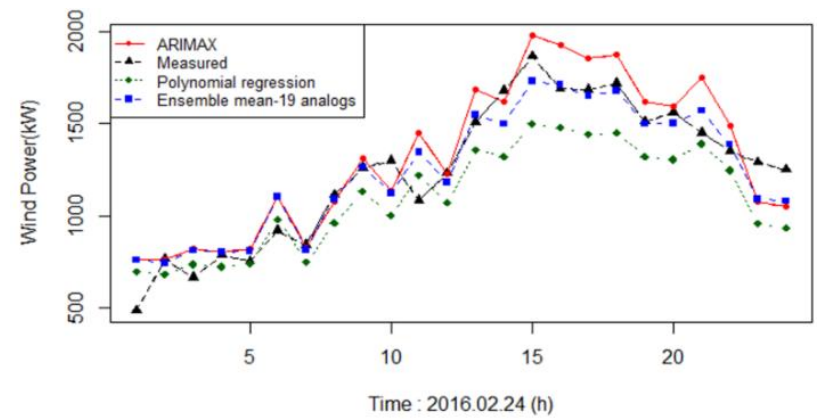

Figure 8. Comparison for each model

Table 3. Model Evaluation

\begin{tabular}{|c|c|c|c|}
\hline Model & ARIMAX & $\begin{array}{c}\text { Polynomial } \\
\text { regression }\end{array}$ & $\begin{array}{c}\text { Ensemble-19 } \\
\text { analogs }\end{array}$ \\
\hline $\begin{array}{c}\text { MAPE } \\
(\%)\end{array}$ & 10.65 & 16.32 & 8.50 \\
\hline
\end{tabular}

The ensemble with 19 analogs model can derive probabilistic forecasts based on the statistical analog values. Each forecasts represents in form of a box plot, and the spread of the box is proportional to the degree of the uncertainity. The probabilistic forecasts based on the analog ensemble method is shown in Figure 9. It can be seen that most of the measured values are contained within the probabilistic forecasting range. 


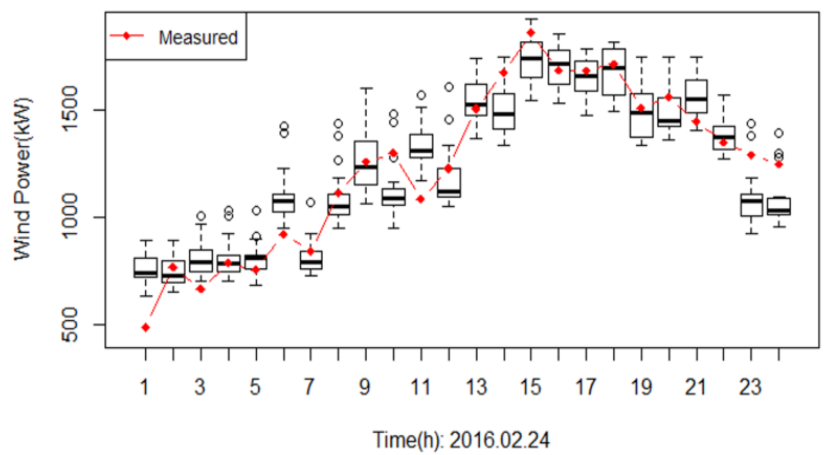

Figure 9. Probabilistic forecasts

\section{Conclusion}

Wind energy with variable output characteristics depending on climate requires forecasting techniques for stable grid integration or operation. In this paper, we proposed the short-term probabilistic forecasting of wind energy resources using the enhanced ensemble method. The proposed method shows higher accuracy than the single forecasting model and indicates the uncertainty of forecasting at each time point through the probabilistic approach. It will play a role to make economic benefits to the power grid operation.

In future, we will add more ensemble members for temporal ensemble model and apply various seasonal variables to practical wind farm sites.

\section{Acknowledgements}

This research was supported by the MSIP (Ministry of Science, ICT and Future Planning), Korea, under the ITRC (Information Technology Research Center) support program (IITP-2016-R099216-1014) supervised by the IITP (Institute for Information \& communications Technology Promotion)

\section{References}

[1] Global Wind Energy Council, Global Wind Report 2015, 2015

[2] M.Milligan, B.Kirby, T.Acker, M.Ahlstom, B.Frew, and M.Goggin, "Review of Status of Wind Integration and Transmission in the United States: Key Issues and Lessons Learned", NREL/TP-5D00-61911, 2015

[3] The European Wind Energy Association, Wind in power: 2015 European statistics, 2016

[4] Daniel A.Griffith, Pedro R.Peres-Neto, "Spatial Modeling in Ecology: The Flexibility of Eigenfunction Spatial Analysis", Ecological Society of America, pp.2603-2613, 2006

[5] Francisco Gonzalez-Longatt, Humberto Medina, Javier Serrano Gonzalez, "Spatial interpolation and orographic correction to estimate wind energy resource in Venezuela", Renewable and Sustainable Energy Reviews, 48, 2015 
158 10 $10^{\mathrm{TH}}$ InTERnAtional CONFERENCE ON Sustainable ENERGy AND ENVIRONMENTAL Protection (June $27^{\mathrm{TH}}-30^{\mathrm{TH}}, 2017$, Bled, SLOVEnia), RENEWABle ENERGy SOURCES D. Kim \& J. Hur: Short-Term Probabilistic Forecasting of Wind Energy Resources Using the Enhanced Ensemble Method

[6] Margaret R.Holdaway, "Spatial modeling and interpolation of monthly temperature using kriging", Climate Research, Vol.6, 1996

[7] L.Matejicek, "Spatial Modelling of Air Pollution in Urban Areas with GIS: A Case Study on Integrated Database Development", Advances in Geosciences, 2005

[8] Michael L.Stein, Interpolation of Spatial Data: Some Theory for Kriging, Springer, 1999

[9] Jose-Maria Montero, Gema Fernandez-Aviles, Jorge Mateu, Spatial and Spatio-Temporal Geostatistical Modeling and Kriging, Wiley, 2015

[10] R.Wagner, M.Courtney, J.Gottschall, P.Lindelow-Marsden, "Accounting for the speed shear in wind turbine power performance measurement", Wind Eenerg., 2011

[11] Devenport A.G, "Rationale for determining Design Wind Velocities", American Society of Civil Engineers, 1960

[12] DH.Kim, J.Hur, HS.Han, "Enhanced Short-term wind power forecast using the Augmented Time Series model for Power Grid Integration", Proceedings of Wind Integration Workshop, 2016

[13] J.E.P. Box, G.M Jenkins, "Time Series Analysis: Forecasting and Control", Holden-Day, San Francisco, 1976

[14] Kenneth P.Burnham, David R.Anderson, "Multimodel Inference Understanding AIC and BIC in Model selection", Sociological Method \& Research 2004, Volume 33, No.2, pp.261-304.

[15] Rajesh Wadhvani, Sanyam Shukla, "Analysis of Statistical Techniques to Estimate Wind Turbine Power Generation", International Journal of Computer Science and Network Security, Vol.17, No.2, 2017

[16] S. Shokrzadeh, M. Jozani, and E. Bibeau, "Wind Turbine Power Curve Modeling Using Advanced Parametric and Nonparametric Methods", In IEEE Journal of Sustainable Energy, Volume 5, No. 4, pp. 1262-1269, October 2014.

[17] Aoife M.Foley, Paul G. Leahy, Antonino Marvuglia, "Current methods and advances in forecasting of wind power generation", Renewable Energy, 37, 2012

[18] Jesper Nissen, Luca Delle Monache, Sue Ellen Haupt, "Analog Ensemble based power forecasting", ES1002: Workshop, 2012 
$10^{\mathrm{TH}}$ InTERnational Conference on Sustainable Energy and ENVIRONMENTAL Protection (June $27^{\mathrm{TH}}-30^{\mathrm{TH}}$, 2017, Bled, SLOVENIA), RENEWABLE ENERGy SOURCES

J. Krope, A.Ghani Olabi, D. Goričanec \& S. Božičnik

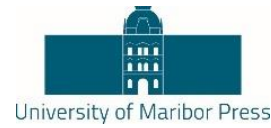

\title{
Numerical and Experimental Study of Laminar Burning Velocity of Syngas/Methane Mixtures Using Syngas Obtained from Biomass and Coal Gasification
}

\author{
Andrés A. Amell, Carlos E. Arrieta, Fabián E. Cano Ardila, Arley Cardona \\ VARGAS \& HERNANDO A. YEPES
}

\begin{abstract}
In this work we evaluated the effect of two different syngas compositions and syngas addition on the laminar burning velocity (SL) of syngas-methane mixtures. The syngas obtained from biomass gasification has a composition of $20 \% \mathrm{H} 2,20 \% \mathrm{CO}$ and $60 \% \mathrm{~N} 2$ (syngas 1) and the syngas obtained from coal gasification has a composition of $40 \% \mathrm{H} 2,40 \%$ $\mathrm{CO}$ and $20 \% \mathrm{CO} 2$ (syngas 2). Measurements were carried out at atmospheric conditions of $297 \mathrm{~K}$ and $1007.5 \mathrm{mbar}$. Flames were generated using a contoured slot-type nozzle burner and the angle method was used to determine SL. To calculate the flame angle, $\mathrm{CH}^{*}$ chemiluminescence was captured with and ICCD camera and the images were processed using Matlab. Experimental results were compared with numerical simulations using the Gri-Mech 3.0 detailed mechanism. A good agreement between numerical and experimental results was obtained. For all equivalence ratios, the addition of syngas 1 to methane strongly increases the laminar burning velocity compared with syngas 2 .
\end{abstract}

Keywords: • Syngas • Methane • Laminar Burning Velocity • Hydrogen • Chemiluminescence •

CorRespondence AdDress: Andrés A. Amell, M.Sc., Professor, Universidad de Antioquia, Facultad de Ingeniería, Grupo de Ciencia y Tecnología del Gas y Uso Racional de la Energía, Cl. 67 \#53 - 108, Medellín, Colombia, e-mail: andres.amell@udea.edu.co. Carlos E. Arrieta, M.Sc., Ph.D student, Universidad de Antioquia, Facultad de Ingeniería, Grupo de Ciencia y Tecnología del Gas y Uso Racional de la Energía, Cl. 67 \#53 - 108, Medellín, Colombia, e-mail: ernesto.arrieta@udea.edu.co. Fabián E. Cano Ardila, Mechanical Engineer, M.Sc. student, Universidad de Antioquia, Facultad de Ingeniería, Grupo de Ciencia y Tecnología del Gas y Uso Racional de la Energía, Cl. 67 \#53 - 108, Medellín, Colombia, e-mail: fabian.cano@udea.edu.co. Arley Cardona Vargas, Mechanical Engineer, M.Sc. student, Universidad de Antioquia, Facultad de Ingeniería, Grupo de Ciencia y Tecnología del Gas y Uso Racional de la Energía, Cl. 67 \#53 - 108, Medellín, Colombia, e-mail: johany.cardona@udea.edu.co. Hernando A. Yepes, Mechanical Engineer, M.Sc., Universidad de Antioquia, Facultad de Ingeniería, Grupo de Ciencia y Tecnología del Gas y Uso Racional de la Energía, Cl. 67 \#53 - 108, Medellín, Colombia, e-mail: hernando.yepes @udea.edu.co. 
$160 \quad 10^{\mathrm{TH}}$ InTERnAtional CONFERENCE ON Sustainable ENERGy AND ENVIRONMENTAL Protection (June $27^{\mathrm{TH}}-30^{\mathrm{TH}}, 2017$, Bled, SLOVEnia), RENEWABle ENERGy SOURCES A. A. Amell, C. E. Arrieta, F. E. Cano Ardila, A. Cardona Vargas \& H. A. Yepes: Numerical and Experimental Study of Laminar Burning Velocity of Syngas/Methane Mixtures Using Syngas Obtained from Biomass and Coal Gasification

Nowadays, there is a worldwide interest in developing alternative fuels, which is of great importance for countries and regions with reserves of biomass and coal. Synthetic gas (syngas, SG) obtained from the gasification of biomass and coal is considered to be one of the most promising alternative fuels in developed and developing countries [1][2][3].

However, depending on the type of reactor and the gasifying agent, syngas generally has lower heating values between 1.0 and $2.6 \mathrm{kWh} / \mathrm{m}^{3}$ and Wobbe index values between 1.5 and $\sim 4 \mathrm{kWh} / \mathrm{m}^{3}$, which are very low compared to the values for pure $\mathrm{CH}_{4}\left(9.425 \mathrm{kWh} / \mathrm{m}^{3}\right.$ and $14.09 \mathrm{kWh} / \mathrm{m}^{3}$, respectively).

A solution that has been proposed at a global level is mixing hydrocarbons with syngas to take advantage of the energy value produced by the hydrocarbons and the high reactivity provided by the $\mathrm{H}_{2}$ as syngas component [4], which also offers alternatives to increase the use of available fuels. The characterization of this fuel mixture is of great importance in practical terms in order to evaluate its possible behaviour in existing technologies, however, there is low information regarding to the combustion properties of this kind of fuels [5].

Through the years, it has been demonstrated that without an adequate knowledge of combustion properties negative effects, like low efficiencies, high pollutant emissions and unstable operation conditions may prevail.

Laminar burning velocity $\left(\mathrm{S}_{\mathrm{L}}\right)$ is one of the most important fuels and fuel mixtures property since it is essential for characterizing several combustion processes. Information on $\mathrm{S}_{\mathrm{L}}$ is fundamental for the analysis of the combustion phenomena such as the structure and stability of premixed flames, flashback, blow-off and extinction; turbulent premixed combustion; and the validation of reaction mechanisms in the presence of diffusive transport at high temperatures [6][7][8].

Due to the importance of $S_{\mathrm{L}}$, different methods have been used to its determination. One of the most important, because of its simplicity and accurately, is the angle method that consists in calculate the angle of a Bunsen-type flame. However, to obtain a correct value of this angle it is necessary to determine appropriately the flame front by means of an optical technique.

An optical diagnostic technique based in chemiluminescence was used. Such process consists in the spontaneous emission of electromagnetic radiation due to chemical reactions in a spectral range between Ultra Violet and visual [9]. In the case of hydrocarbons like methane the peak of this emission is produced by $\mathrm{CH}$ and $\mathrm{OH}$ radicals [10][11][12]. The chemiluminiscense emitted from these radicals can be used to register the flame front and determine the laminar burning velocity using the angle method. 

Protection (June 27 $7^{\mathrm{TH}}-30^{\mathrm{TH}}, 2017$, Bled, Slovenia), RenEWABle ENERGy SOURCES

A. A. Amell, C. E. Arrieta, F. E. Cano Ardila, A. Cardona Vargas \& H. A. Yepes: Numerical and Experimental Study of Laminar Burning Velocity of Syngas/Methane Mixtures Using Syngas Obtained from Biomass and Coal Gasification

Laminar burning velocities of syngas/methane flames were determined experimentally and numerically within a wide range of equivalence ratios (0.8-1.4) capturing spontaneous chemiluminiscense $\left(\mathrm{CH}^{*}\right)$.

In the present study, we evaluated the effect of two different syngas compositions and syngas addition on the laminar burning velocity of syngas-methane mixtures

\section{$2 \quad$ Methodology}

\subsection{Experimental setup}

Figure 1 is a schematic diagram of the experimental configuration implemented in this study. The flames were generated in three contoured slot burners with different outlet geometries. The selection of the burner depends on the estimated burning velocity of the mixture, considering that the slot output speed is directly related to $\mathrm{S}_{\mathrm{L}}$. The contoured slot-type nozzles $(13.8 \mathrm{~mm} \times 5 \mathrm{~mm}, 21 \mathrm{~mm} \times 6.7 \mathrm{~mm}$ and $29.8 \mathrm{~mm} \times 9.4 \mathrm{~mm})$ helps to reduce the effect of flame stretch and curvature in the direction of the burner axis. A contoured slot-type nozzle also allows to have laminar Reynolds numbers for all the equivalence ratios to be studied, as well as nearly uniform exit velocity profiles. Additionally, a cooling water circuit inside the burner keeps the mixtures at a constant temperature.

Several lean and rich methane and syngas flames were generated in the burner described above. Table 1 and 2 list the volumetric composition of these gases. The air was supplied by an air compressor and dried using two inline water traps. Each air-to-fuel ratio and exit velocity were ensured using rotameters that were specifically calibrated for each component gas, similar to those used in [6], [8]. The errors in the final composition were estimated to be lower than $2 \%$.

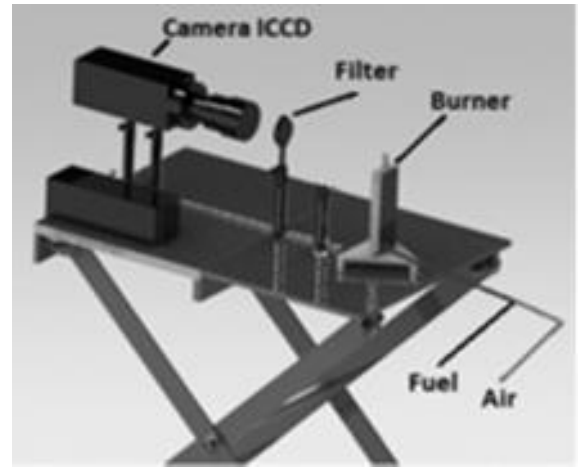

Figure 1. Schematic diagram of the experimental setup. 
$16210^{\mathrm{TH}}$ InTERnational CONFERENCE ON Sustainable ENERGy AND ENVIRONMENTAL Protection (June $27^{\mathrm{TH}}-30^{\mathrm{TH}}, 2017$, Bled, SLOVEnia), RENEWABle ENERGy SOURCES A. A. Amell, C. E. Arrieta, F. E. Cano Ardila, A. Cardona Vargas \& H. A. Yepes: Numerical and Experimental Study of Laminar Burning Velocity of Syngas/Methane Mixtures Using Syngas Obtained from Biomass and Coal Gasification

In the present study, we evaluated the effect of two different syngas compositions and syngas addition on the laminar burning velocity of syngas-methane mixtures (equivalence ratios between 0.8 and 1.4). The syngas obtained from coal gasification has a composition of $40 \% \mathrm{H}_{2}, 40 \% \mathrm{CO}$ and $20 \% \mathrm{CO}_{2}$ (syngas 1) and the syngas obtained from biomass gasification has a composition of $20 \% \mathrm{H}_{2}, 20 \% \mathrm{CO}$ and $60 \% \mathrm{~N}_{2}$ (syngas 2).

The addition of syngas to the fuel mixture was of 50\%, $70 \%$ and $90 \%$ in volume, the measurements were carried out at $297 \mathrm{~K}$ and $1007.5 \mathrm{mbar}$ of atmospheric pressure. The Experiments were conducted using an ICCD camera equipped with a colored filter centered at $430 \mathrm{~nm}$, values of $S_{\mathrm{L}}$ were determined with the angle method and were compared with simulations performed with CHEMKIN PRO package using the reaction mechanism GRI-Mech 3.0.

Table 1. Volumetric composition of

syngas $1 /$ methane used in the study

\begin{tabular}{ll}
\hline Mixture & Fuel composition \\
\hline $100-0$ & $40 \% \mathrm{H}_{2}+40 \% \mathrm{CO}+20 \% \mathrm{CO}_{2}$ \\
$90-10$ & $36 \% \mathrm{H}_{2}+36 \% \mathrm{CO}+18 \% \mathrm{CO}_{2}+10 \%$ \\
& $\mathrm{CH}_{4}$ \\
$70-30$ & $28 \% \mathrm{H}_{2}+28 \% \mathrm{CO}+14 \% \mathrm{CO}_{2}+30 \%$ \\
& $\mathrm{CH}_{4}$ \\
$50-50$ & $20 \% \mathrm{H}_{2}+20 \% \mathrm{CO}+10 \% \mathrm{CO}_{2}+50 \%$ \\
& $\mathrm{CH}_{4}$ \\
$0-100$ & $100 \% \mathrm{CH}_{4}$ \\
\hline
\end{tabular}

Table 2. Volumetric composition of syngas $2 /$ methane used in the study

\begin{tabular}{ll}
\hline Mixture & Fuel composition \\
\hline $100-0$ & $20 \% \mathrm{H}_{2}+20 \% \mathrm{CO}+60 \% \mathrm{~N}_{2}$ \\
$90-10$ & $18 \% \mathrm{H}_{2}+18 \% \mathrm{CO}+54 \% \mathrm{~N}_{2}+10 \%$ \\
& $\mathrm{CH}_{4}$ \\
$70-30$ & $14 \% \mathrm{H}_{2}+14 \% \mathrm{CO}+42 \% \mathrm{~N}_{2}+30 \%$ \\
& $\mathrm{CH}_{4}$ \\
$50-50$ & $10 \% \mathrm{H}_{2}+10 \% \mathrm{CO}+30 \% \mathrm{~N}_{2}+50 \%$ \\
& $\mathrm{CH}_{4}$ \\
$0-100$ & $100 \% \mathrm{CH}_{4}$ \\
\hline
\end{tabular}

To determine the laminar burning velocity the angle method was used. The measurement is based on the principle that the velocity at the nozzle exit of the unburnt gases is equal to the velocity at which the flame front propagates from the burnt to the unburnt zone at an angle $\theta$ as shown in Figure 2a. The laminar burning velocity is related to $\theta$ according to equation 1 
$10^{\text {TH }}$ InTERnAtional CONFERENCE on Sustainable EnERgy AND ENVIRONMENTAL Protection (June 27 $7^{\mathrm{TH}}-30^{\mathrm{TH}}, 2017$, BLed, Slovenia), Renewable EnERGY SOURCES

A. A. Amell, C. E. Arrieta, F. E. Cano Ardila, A. Cardona Vargas \& H. A. Yepes: Numerical and Experimental Study of Laminar Burning Velocity of Syngas/Methane Mixtures Using Syngas Obtained from Biomass and Coal Gasification

$\mathrm{S}_{\mathrm{L}}=\mathrm{U} \sin (\theta)$

Where $\mathrm{U}$ is the mean velocity of the unburnt gases at the exit of the burner.

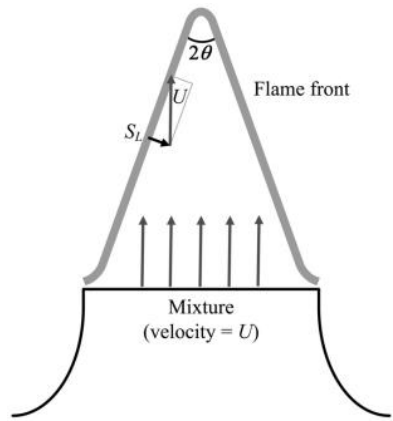

a)

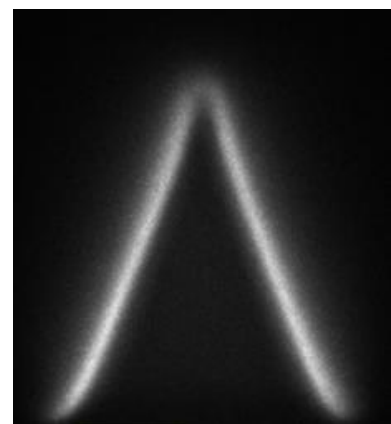

b)

Figure 2. a. Burner stabilized flame technique (angle method). b.

Instantaneous photography of flame front of methane at equivalence ratio $\phi=1.0$.

The mean velocity at the exit of the burner nozzle was calculated from the nozzle area and the flows of the fuel-air mixtures while the flame angle was measured from chemiluminiscense $\left(\mathrm{CH}^{*}\right)$ photographs as follows. First, the digital photographs obtained by the ICCD camera are stored as a pixel array of $1024 \times 1024$. Then using a Matlab code a background image previously taken before experiments is subtracted and the flame is located where the maximum intensity is registered. The code detected the edges of the flame fronts, and thus the corresponding flame angles are calculated.

For the measurement of chemiluminescence, an ICCD camera (PI-MAX; Princeton Instrument) was used. To capture the light emission of the $\mathrm{CH}$ radicals $\left(\mathrm{CH}^{*}\right)$, the lens was equipped with an interference filter. The center wavelength of the filter was $430 \mathrm{~nm}$. The full-width-half-maximum (FWHM) was $11.02 \mathrm{~nm}$ and the minimum transmissivity was $45 \%$. In chemiluminescence measurements, the $\mathrm{CH}^{*}$ images were taken 25 times at each condition and the signal-to-noise ratio was less than $10 \%$ of the maximum intensity.

\subsection{Numerical methodology}

Numerical calculations of $S_{L}$ were conducted using the one-dimensional premixed flame code PREMIX of the CHEMKIN PRO package. The present simulations considered the GRI-mech 3.0 mechanism [13]. For an accurate calculation of $S_{L}$ recommendations of Bongers and De Goey [14] were followed; transport properties were evaluated using the multicomponent diffusion model and thermal diffusion (Soret effect) was included in the 
$10^{\mathrm{TH}}$ InTERnATIONAL CONFERENCE ON Sustainable ENERgy AND ENVIRONMENTAL Protection (June $27^{\mathrm{TH}}-30^{\mathrm{TH}}, 2017$, BlED, SLOVENIA), RENEWABLE ENERGY SOURCES A. A. Amell, C. E. Arrieta, F. E. Cano Ardila, A. Cardona Vargas \& H. A. Yepes: Numerical and Experimental Study of Laminar Burning Velocity of Syngas/Methane Mixtures Using Syngas Obtained from Biomass and Coal Gasification

calculations due to its importance on the hydrogen oxidation. Additionally, it has been reported that the accuracy of the calculated $S$ is highly sensitive to the number of grid points used in the calculations; using a low number of points can lead to errors from 5 to $10 \%$ [15]. Therefore, according to Dlugogorski et al. [16], GRAD and CURV values were set lower than 0.01 to generate a grid of more than 1000 points, where $S_{L}$ values converged and the flame temperature approached the adiabatic flame temperature. This same methodology has been used successfully to study other fuel gases [6],[8].

\section{$3 \quad$ Results}

$2 \mathrm{~b}$ shows an example of flame profile obtained in the experiment for methane without addition of syngas at equivalence ratio of 1.0. The reaction zone is clearly visualized by means of an ICCD camera equipped with a colored filter centered at $430 \mathrm{~nm}$ and the postprocessing technique is able to determine the angle of this profile to compute the flame velocity of this investigation.

Napaka! Vira sklicevanja ni bilo mogoče najti.The experimental and numerical results for laminar burning velocities using syngas obtained from coal gasification are shown in Figure 3. Equivalence ratios from 0.8 to 1.4 are located in $\mathrm{x}$ direction, and in y direction the laminar burning velocity in $\mathrm{cm} / \mathrm{s}$. As syngas contains hydrogen and the laminar burning velocity of this is very high, $\mathrm{S}_{\mathrm{L}}$ is higher for mixtures with higher content of syngas. This increase can be explained by the addition of $\mathrm{H}_{2}$ to the mixture due $\mathrm{H}_{2}$ promotes formation of $\mathrm{OH}$ radicals increasing the concentration of $\mathrm{H}$ producing an increment of the reactivity of the mixture and consequently of laminar burning velocity [17], [18] [19], [20]. At the same time the addition of syngas generates that the peak of $\mathrm{S}_{\mathrm{L}}$ moves to rich mixtures.

According with measurements the percent of increase in $\mathrm{S}_{\mathrm{L}}$ peak from the mixture with $0 \%$ syngas to $50 \%$ syngas mixture is about $22 \%$ which is in concordance with previous studies [17], [21]. And for this study $\mathrm{S}_{\mathrm{L}}$ peak for the mixture with $90 \%$ syngas in content is 2.4 times $S_{L}$ peak of pure methane.

Regarding with numerical results Figure 3 shows good agreement between numerical and experimental data at lean conditions, however, GRI-Mech 3.0 underestimates $\mathrm{S}_{\mathrm{L}}$ values for rich conditions especially near the maximum $S_{L}$ value. This behaviour has been already registered by Natarajan [22]. For peak $S_{L}$, the maximum error between numerical and experimental results is $12 \%$.

Figure 4 shows the experimental and numerical results for laminar burning velocities using syngas obtained from biomass gasification.

For the syngas obtained from biomass gasification the addition of hydrogen to methane increase the laminar burning velocity considerably. 
The syngas 2 obtained from the biomass gasification has a minor content of hydrogen respect to the syngas 1 obtained from the coal gasification, therefore the percent of increase of the laminar burning velocity of syngas 2 for all equivalence ratios is less compared to syngas 1 .

In fact, the percent of the increase in $\mathrm{S}_{\mathrm{L}}$ peak from the mixture with $0 \%$ syngas 2 to $50 \%$ syngas 2 mixture is about $13 \%, 9 \%$ less regarding syngas $1 . S_{\mathrm{L}}$ peak for the mixture with $90 \%$ syngas in content is 1.2 times $S_{L}$ peak of pure methane, much less compared with syngas obtained from coal gasification.

Regarding with numerical results Figure 4 shows a very good agreement between numerical and experimental data at higher $\mathrm{H}_{2}$ contents and for all equivalence ratios. However, for $50 \% \mathrm{H}_{2}$ addition, numerical data does not fit experimental data very well mainly on rich mixtures. For peak SL, the maximum error between numerical and experimental results is $9 \%$.

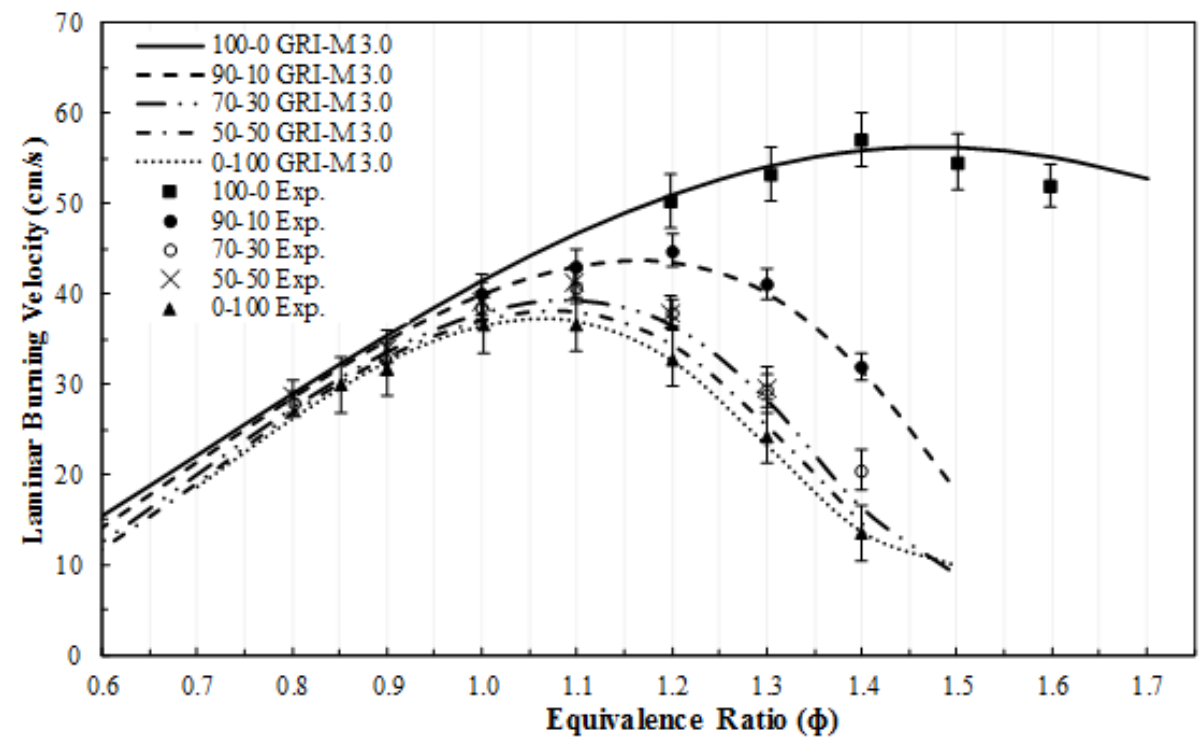

Figure 4. Experimental and numerical results for laminar burning velocities using syngas obtained from biomass gasification

\section{$4 \quad$ Conclusions}

Measurements of the laminar burning velocity of syngas/methane mixtures using chemiluminescence of $\mathrm{CH}$ radicals were made. Numerical calculations of $\mathrm{S}_{\mathrm{L}}$ using GRIMech 3.0 were also performed to be compared with experimental results and a good agreement was found besides measurements agree with reported literature. 
$10^{\text {TH }}$ International Conference on Sustainable Energy and Environmental Protection (June $27^{\mathrm{TH}}-30^{\mathrm{TH}}, 2017$, BlED, SLOVENIA), RENEWABLE ENERGy SOURCES A. A. Amell, C. E. Arrieta, F. E. Cano Ardila, A. Cardona Vargas \& H. A. Yepes: Numerical and Experimental Study of Laminar Burning Velocity of Syngas/Methane Mixtures Using Syngas Obtained from Biomass and Coal Gasification

With the increase of $\mathrm{S}_{\mathrm{L}}$, for the syngas/methane mixture, the blow off tendency is expected to improve when compared to a flame of pure methane.

GRI-Mech 3.0 mechanism was in agreement with the experimental results. Numerically, small differences were observed between all mixtures for syngas obtained from coal gasification and syngas obtained from biomass gasification. The greatest deviations between experiment and calculations occurred at rich fuel-air ratios $(\phi>1.1)$. However, future work should investigate additional mixtures to evaluate with certainty the effect of substituting syngas by methane.

The syngas 1 has a major laminar burning velocity respect to the syngas 2 for all equivalence ratios, this behaviour is related to the hydrogen content, which increases the reactivity to the mixtures.

\section{Acknowledgements}

The authors would like to acknowledge the GASURE group and the program "Sostenibilidad 20162017" of the University of Antioquia for the valuable economic contribution for the development of this research. The support of COLCIENCIAS through the financing of the project "Laminar Burning Velocities of Natural Gas/Synthesis Gas mixtures: Numerical and Experimental Study" is gratefully acknowledged too.

\section{References}

[1] Casleton KH, Breault RW, Richards GA. (2008) System Issues and Tradeoffs Associated with Syngas Production and Combustion. Combust Sci Technol;180:1013-52.

[2] Richards G., McMillian M., Gemmen R., Rogers W., Cully S. (2001) Issues for lowemission, fuel-flexible power systems. Prog Energy Combust Sci;27:141-69.

[3] Chaos M, Dryer FL. (2008) Syngas Combustion Kinetics and Applications. Combust Sci Technol;180:1053-96.

[4] Lieuwen, T. et al. Synthesis gas combustion: fundamentals and applications, (2009). CRC Press, 2009.

[5] Londoñó, L. F. et al. Determinación de la velocidad de deflagración laminar empleando el método del cono y la emisión espontánea de $\mathrm{CH}$ en llamas metano-aire, V Simp. Int. BIOFÁBRICAS. I Congr. Int. FLUJOS React., (2011).

[6] Pareja, J. et al. Measurements of the laminar burning velocity of hydrogen-air premixed flames, Int. J. Hydrogen Energy, 35 (4) (2010), pp. 1812-1818.

[7] Marques, C.ST. Benvenutti, L.H. and Bertran, C.A., (2001) Experimental Study of $\mathrm{OH}^{*}$, $\mathrm{HO}^{*}, \mathrm{CH}^{*}$, and $\mathrm{C} 2 *$ Radicals in $\mathrm{C} 2 \mathrm{H} 2 / 02$ and $\mathrm{C} 2 \mathrm{H} 2 / \mathrm{O} 2 / \mathrm{Air} \mathrm{fl}$ ames in a closed chamber, Combustion cience and Technology, 167, pp. 113-129.

[8] Burbano, H. J. et al. Laminar burning velocities and flame stability analysis of H2/CO/air mixtures with dilution of $\mathrm{N} 2$ and CO2, Int. J. Hydrogen Energy, 36 (4) (2011), pp. 3232 3242 .

[9] Ballester, J. and García-Armingol, T. Diagnostic techniques for the monitoring and control 
Protection (June $27^{\mathrm{TH}}-30^{\mathrm{TH}}, 2017$, Bled, Slovenia), RenEwable ENERGy SOURCES

A. A. Amell, C. E. Arrieta, F. E. Cano Ardila, A. Cardona Vargas \& H. A. Yepes:

Numerical and Experimental Study of Laminar Burning Velocity of Syngas/Methane

Mixtures Using Syngas Obtained from Biomass and Coal Gasification

[10] García-Armingol, T., \& Ballester, J. (2014). Flame chemiluminescence in premixed combustion of hydrogen-enriched fuels. International Journal of Hydrogen Energy, 39(21), 11299-11307.

[11] Gupta, V. V. A. (2009). Chemiluminescence Study of Propane-Air Flame inside a Mesoscale Combustor.

[12] Ballester, J., Hernández, R., Sanz, A., Smolarz, A., Barroso, J., \& Pina, A. (2009). Chemiluminescence monitoring in premixed flames of natural gas and its blends with hydrogen. Proceedings of the Combustion Institute, 32(2), 2983-2991.

[13] Smith, G. P., Golden, D. M., Frenklach, M., Moriarty, N. W., Eiteneer, B., Goldenberg, M., Bowman, C. T., Hanson, R. K., Song, S., Gardiner, W. C., Jr., Lissianski, V. V., and Qin, Z., http://www.me.berkeley.edu/gri_mech/.

[14] Bongers, H. and De Goey, L. P. H. The effect of simplified transport modeling on the burning velocity of laminar premixed flames, Combust. Sci. Technol., 175 (10) (2003), pp. 1915-1928.

[15] Egolfopoulos FN, Law CK. (1990) Chain mechanisms in the overall reaction orders in laminar flame propagation. Combust Flame; 80(1):7-16.

[16] Dlugogorski, B. Z. et al. Propagation of Laminar Flames in Wet Premixed Natural Gas-Air Mixtures, Process Saf. Environ. Prot., 76 (2) (1998), pp. 81-89.

[17] Cardona, C. et al. Laminar Burning Velocity of Natural Gas/Syngas-Air Mixture, Dyna, 80 (180) (2013), pp. 136-143.

[18] Halter, F., C. Chauveau, N. Djebaili-Chaumeix, et al. (2005) Characterization of the Effects of Pressure and Hydrogen Concentration on Laminar Burning Velocities of MethaneHydrogen-Air Mixtures, Proc Combus inst, 30(1), 201-208.

[19] Le Cong, T. and P. Dagaut. (2007) Experimental and Detailed Kinetic Modeling of the Oxidation of natural Gas, Natural Gas/Syngas Mixtures and Effect of Burnt Gas. Third European Combustion Meeting. 1-6.

[20] Saxena, P. and K. Seshadri. (2009) The Infl uence of Hydrogen and Carbon Monoxide on Structure and Burning Velocity of Methane Flames. Fall Technical Meeting of the Western States Section of the Combustion Institute, Irvine, CA.

[21] Burbano, H. J. et al. Laminar burning velocities and flame stability analysis of syngas mixtures at sub-atmospheric pressures, Int. J. Hydrogen Energy, 36 (4) (2011), pp. 32433252.

[22] Natarajan, J., S. Nandula, T. Lieuwen, et al. (2005) Laminar Flame Speeds Of Synthetic Gas Fuel Mixtures ASME Turbo Expo 2005: Power for Land, Sea and Air Reno-Tahoe, Nevada, USA. 
168 10 $10^{\mathrm{TH}}$ InTERnational CONFERENCE ON Sustainable EnERgy and ENVIRONMENTAL Protection (June 27 $7^{\mathrm{TH}}-30^{\mathrm{TH}}, 2017$, Bled, Slovenia), Renewable EnERGy SOURCES 
$10^{\mathrm{TH}}$ InTERnational CONFERENCE ON Sustainable ENERgy AND Environmental Protection (June 27 $7^{\mathrm{TH}}-30^{\mathrm{TH}}, 2017$, BLed, SLOVENIA), RENEWABLE ENERGy SOURCES

J. Krope, A.Ghani Olabi, D. Goričanec \& S. Božičnik

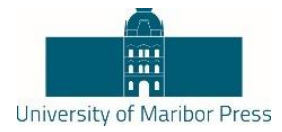

\title{
Determination of the Concentration Ratio of a Parabolic Solar Concentrator Using Thermographic Image Processing
}

\author{
Fabián E. CANo Ardila \& Sergio C. Agudelo Florez
}

\begin{abstract}
The concentration ratio is the most important geometric parameter of a solar concentrator. However, its value is usually given regarding the area of the receiver and not regarding the area of the image generated by the concentrator on the receiver. In this work, a thermographic image processing methodology is used to determine the exact concentration ratio of a parabolic solar concentrator. For the experimental procedure, a parabolic solar concentrator and a water-cooled opaque plate were used. Both the radiation incident on the solar concentrator and the radiation concentrated on the opaque plate were characterized using a thermographic camera. The thermographic images were processed using MATLAB resulting in the exact value of the concentration ratio of the solar concentrator used. Also, it was possible to evidence the curvature imperfections of the concentrator. It was found that the concentration ratio varies from 20 to 151 depending on the selected radiation flux.
\end{abstract}

Keywords: • Concentration Ratio $\bullet$ Image processing $\bullet$ Solar concentrator

- Radiation flux • Thermographic camera •

CoRrespondence AdDREss: Fabián E. Cano Ardila, Mechanical Engineer, M.Sc. student, Universidad de Antioquia, Facultad de Ingeniería, Grupo de Ciencia y Tecnología del Gas y Uso Racional de la Energía, Cl. 67 \#53 - 108, Medellín, Colombia, e-mail: fabian.cano@udea.edu.co. Sergio C. Agudelo Florez, Ph.D., Universidad de Antioquia, Facultad de Ingeniería, Grupo de Energía Alternativa, Cl. 67 \#53 - 108, Medellín, Colombia, e-mail: sergio.agudelo@udea.edu.co. 
$170 \quad 10^{\mathrm{TH}}$ InTERnational CONFERENCE ON Sustainable ENERGy AND ENVIRONMENTAL Protection (June $27^{\mathrm{TH}}-30^{\mathrm{TH}}, 2017$, Bled, SLOVENIA), RENEWABle ENERGy SOURCES F. E. Cano Ardila \& S. C. Agudelo Florez: Determination of the Concentration Ratio of a Parabolic Solar Concentrator Using Thermographic Image Processing

\section{$1 \quad$ Introduction}

The great solar potential that exists on the planet can be used, among other forms, using solar concentrators [1], [2]. These are intended to transform solar radiation into thermal energy that can be transported or stored in a working fluid [3].

The transformation of solar energy into thermal energy through solar concentrators involves an optical analysis [4]. Systems such as solar thermal plants, dish concentrators, solar cookers require such an optical analysis since the efficiency of the collectors must be known [5].

The concentration ratio (CR) is the most important geometric parameter of a solar concentrator, and it can be determined using optical methods [6]. However, its value is usually given in terms of the area of the receiver and not in terms of the area of the image generated by the concentrator on the receiver [7]-[9]. This method produces an error in the estimated concentrated solar radiation.

Additionally, the radiation flux reflected by the concentrator does not always prove to be homogeneous, and this, for the design and location of the receiver in the focus of the concentrator must be taken into account [10]. Recent studies have been conducted to evaluate the performance of such parabolic concentrators [7], [8].

It is important to know how exactly the energy flow and the concentration ratio (CR) behave and thus how efficient a solar concentrator is. It is proposed to use thermographic image processing due solar radiation is absorbed by the surface of the receiver and is converted into thermal energy that can be captured by a thermographic camera. This technique is widely used in the research and industrial level to determine heat transfer through surfaces or for qualitative analysis of hot and cold surfaces [11].

For this reason, in this work thermographic images were taken to the surface of the solar concentrator and the surface of the receiver to determine if the concentrated radiation flux is uniform and to determine the concentration ratio (CR) of a parabolic solar concentrator. The thermographic images were processed using two MATLAB codes. 


\section{$2 \quad$ Methodology}

\subsection{Experimental setup}

Figure 1 shows a schematic of the experimental setup used.

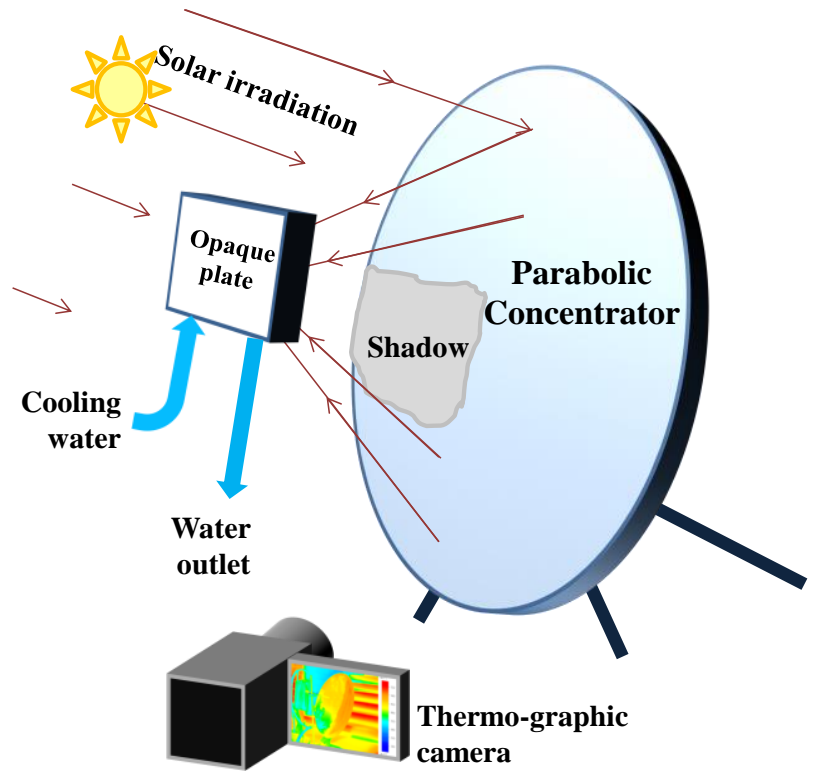

Figure 1. Schematic of the experimental setup used

The concentrator, also called reflector, consists of an elliptic paraboloid with $0.33 \mathrm{~m}$ semi-major axis, $0.3 \mathrm{~m}$ semi-minor axis and $0.06 \mathrm{~m}$ depth. Constructed of a steel sheet of $1 \mathrm{~mm}$ thickness and completely covered with mirror pieces of $1.5 \mathrm{~cm} \times 1.5 \mathrm{~cm}$ and $3 \mathrm{~mm}$ of thickness. The concentrator was normal to the incident solar radiation, as indicated by the arrows in figure 1 .

The receiving opaque plate has external dimensions of $30 \mathrm{~cm} \times 30 \mathrm{~cm} \times 2 \mathrm{~cm}$ and is constructed of $3 \mathrm{~mm}$ plastic sheets stuck with silicone. A water pumping system at $22^{\circ}$ $\mathrm{C}$ cools this opaque plate inside. The water flow used ensures that the concentrated radiation only warms the area of incidence and does not heat the rest of the area of the opaque plate by the heat conduction mechanism. The opaque plate was fixed in the focus of the elliptic paraboloid and just as the concentration was located normal to the incident solar radiation.

For thermal imaging, we used a TESTO $8769 \mathrm{~Hz}$ thermal imager. Concentrator temperatures were first recorded to identify the area that reflects solar radiation. Then the temperatures of the receiving surface of the opaque plate were recorded to calculate the 
$10^{\text {TH }}$ International Conference on Sustainable Energy and Environmental Protection (June $27^{\mathrm{TH}}-30^{\mathrm{TH}}, 2017$, Bled, SLOVENIA), RENEWABLE ENERGy SOURCES F. E. Cano Ardila \& S. C. Agudelo Florez: Determination of the Concentration Ratio of a Parabolic Solar Concentrator Using Thermographic Image Processing

area of the image generated by the concentrator on the receiver. The experiments were carried out in Medellín, Colombia and five replicates of the experiment were performed.

\subsection{Image processing}

Thermographic image processing was performed using two codes developed in MATLAB. To determine the surface area of the concentrator that reflects the solar radiation, the image processing shown in Figure 2.

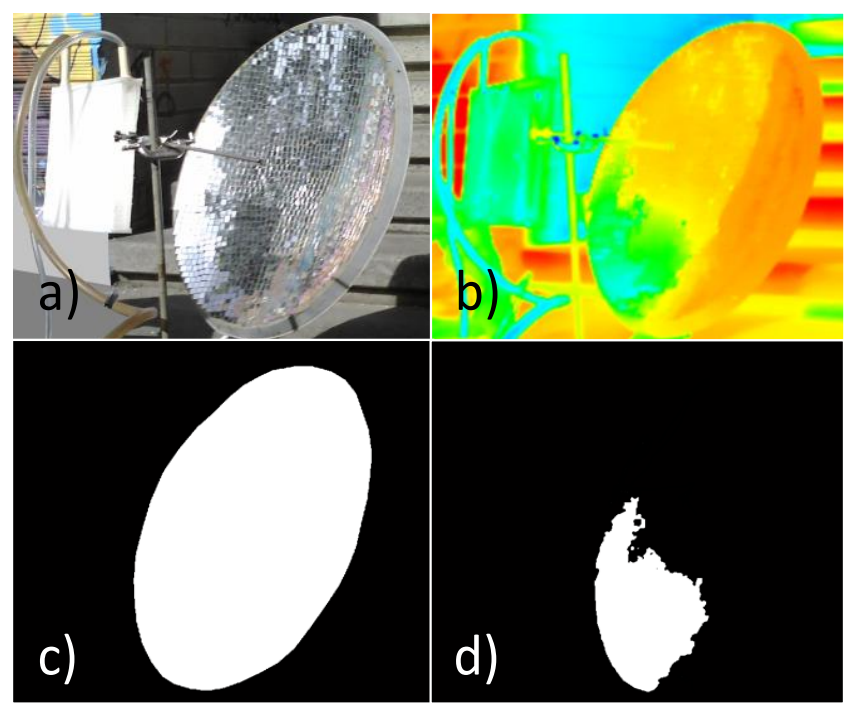

Figure 2. Concentrator Image Processing

Figure $2 \mathrm{~b}$ shows a thermographic picture of the solar concentrator used, to which the elliptical profile of the parabola is determined. Subsequently, a binary image with a value of 1 in all the pixels within the elliptical profile in Figure 2c. This process is performed to determine the region of interest (ROI) of the concentrator.

Figure 1 shows that, because of the arrangement of the experimental setup, the opaque plate generates a shadow over the concentrator, evidencing a lower temperature in such region. In this way, pixels within the region of interest (ROI) which have a lower temperature than the rest of the concentrator were identified in Figure 2d.

The ratio of the concentrator area reflecting the solar radiation to the concentrator area is calculated using equation (1).

$\mathrm{R}=\frac{\mathrm{A}_{\mathrm{c}, \mathrm{a}}-\mathrm{A}_{\text {shadow, }} \mathrm{a}}{\mathrm{Ac}, \mathrm{a}}$ 
$10^{\mathrm{TH}}$ InTERnational CONFerence on Sustainable EnERgy AND Environmental 173 Protection (June 27 $7^{\mathrm{TH}}-30^{\mathrm{TH}}, 2017$, BLED, SLOVENIA), RENEWABLE ENERGY SOURCES

F. E. Cano Ardila \& S. C. Agudelo Florez: Determination of the Concentration Ratio of a Parabolic Solar Concentrator Using Thermographic Image Processing

Where $A_{c, a}$ is the apparent collector area in pixels that is determined using Figure $2 \mathrm{c}$. $\mathrm{A}_{\text {shadow,a }}$ is the apparent shadow area in pixels caused by the opaque plate on the concentrator.

Since in Figures $2 \mathrm{c}$ and $2 \mathrm{~d}$ there are apparent areas that do not take into account the nonperpendicularity of the photograph of the concentrator, $\mathrm{R}$ is needed. To calculate the area in $\mathrm{m}^{2}$ that reflects the solar radiation reaching the concentrator $\left(\mathrm{A}_{\mathrm{eff}, \mathrm{c}}\right)$ equation (2) was used.

$\mathrm{A}_{\mathrm{eff}, \mathrm{c}}=\mathrm{R} \mathrm{A}_{\mathrm{c}}$

Where $A_{c}$ is the real area of the elliptical paraboloid that takes a value of $0.311 \mathrm{~m}^{2}$. The surface area of the image generated by the concentrator on the surface of the receiving opaque plate was determined using the image processing in Figure 3.

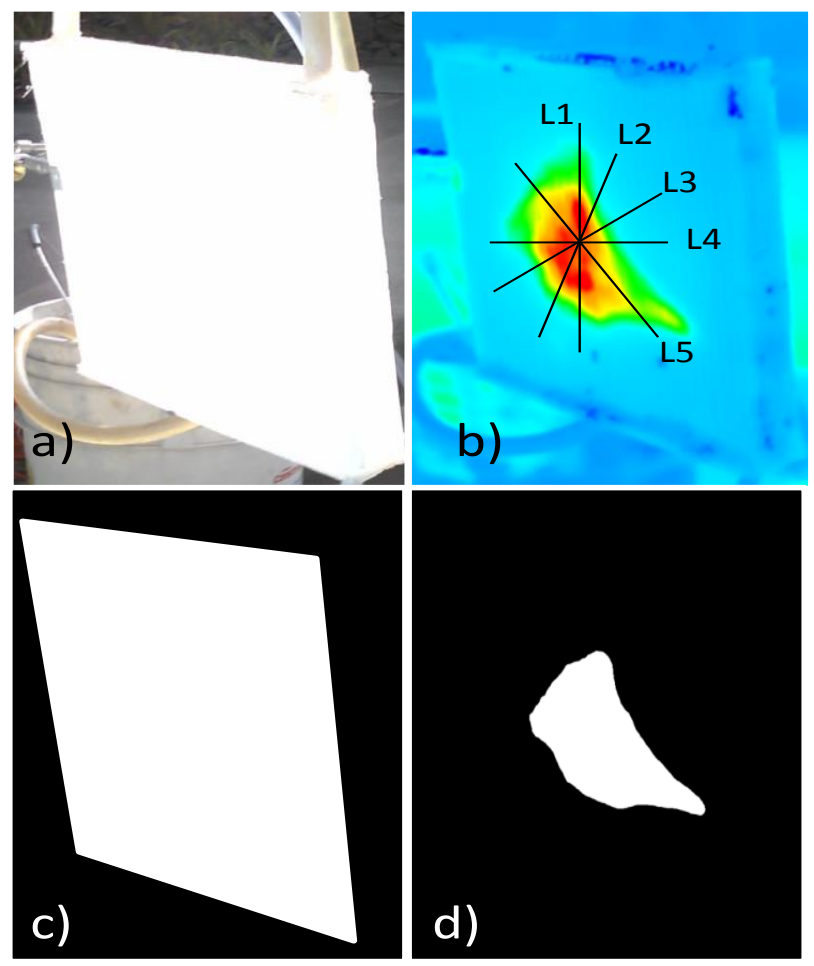

Figure 3. Image processing in opaque plate

Figure $3 b$ shows the thermographic image of the surface of the opaque plate where the red color indicates higher temperatures, however, to this picture, a region of interest 
$174 \quad 10^{\mathrm{TH}}$ InTERnAtional CONFERENCE ON Sustainable ENERGy AND ENVIRONMENTAL Protection (June $27^{\mathrm{TH}}-30^{\mathrm{TH}}, 2017$, Bled, SLOVENIA), RENEWABle ENERGy SOURCES F. E. Cano Ardila \& S. C. Agudelo Florez: Determination of the Concentration Ratio of a Parabolic Solar Concentrator Using Thermographic Image Processing

shown in Figure $3 \mathrm{c}$ must be determined. Figure $3 \mathrm{c}$ is a binary image used to perform a FOR cycle in which the area of incidence of the concentrated radiation is calculated.

Because there are areas that are hotter than others, the area of impact of radiation at four different temperatures $\left(45^{\circ} \mathrm{C}, 55^{\circ} \mathrm{C}, 65^{\circ} \mathrm{C}\right.$ and $\left.75^{\circ} \mathrm{C}\right)$ was determined. As a result of this process, the area of incidence of the concentrated radiation on the opaque plate is shown in Figure 3d.

In this experiment, it was not possible to take a photograph in a normal way to the opaque plate. Therefore, the relationship between the apparent surface area of the opaque plate and the apparent incidence area of the radiation should be calculated. Using equation (3), we can determine the real area of impact of radiation.

$A_{\text {eff,rec }}=\frac{A_{\text {inc,a }}}{A_{\text {rec, a }}} A_{\text {rec }}$

Where $A_{\text {eff,rec }}$ is the actual area of incidence of the concentrated radiation, $A_{\text {inc,a }}$ is the apparent area of incidence of the radiation in pixels found in Figure $3 d, A_{\text {rec,a }}$ is the apparent area of the receiving opaque plate shown in Figure $3 \mathrm{c}$. Finally, $\mathrm{A}_{\mathrm{rec}}$ is the real area of the receiving plate whose value is $0.09 \mathrm{~m}^{2}$. Concentration ratio $(\mathrm{CR})$ of the solar concentrator was calculated using equation (4).

$\mathrm{CR}=\frac{\mathrm{A}_{\mathrm{eff}, \mathrm{c}}}{\mathrm{A}_{\mathrm{eff}, \mathrm{rec}}}$

Five temperature lines were drawn to know the uniformity of the radiation flux. The radiation flux q" was calculated at each temperature using equation (5), corresponding to Stefan-Boltzmann's law.

$q^{\prime \prime}=\frac{\mathrm{Q}}{\mathrm{A}_{\mathrm{eff}, \mathrm{rec}}}=\varepsilon \sigma \mathrm{T}_{\mathrm{S}}^{4}$

Where the emissivity of the opaque surface takes a value of $0.95, \sigma$ is the StefanBoltzmann constant, which takes a value of $5.67037 \times 10^{-8} \mathrm{~W} \cdot \mathrm{m}^{-2} \cdot \mathrm{K}^{-4}$ and $\mathrm{T}_{\mathrm{s}}$ is the surface temperature. $\mathrm{Q}$ is the radiation power over the opaque plate by bearing in mind the area of incidence of the concentrated radiation calculated with equation (3).

\section{$3 \quad$ Results}

The thermographic image processing of the solar concentrator delivered the results presented in Table 1. 
Table 1. Results obtained from image processing for the solar concentrator

\begin{tabular}{|c|c|}
\hline Parameter & Value \\
\hline $\mathrm{R}=\frac{\mathrm{A}_{\mathrm{c}, \mathrm{a}}-\mathrm{A}_{\text {shadow, } \mathrm{a}}}{\mathrm{Ac}, \mathrm{a}}$ & $0.7776 \pm 0.0039$ \\
\hline $\mathrm{A}_{\text {eff }, \mathrm{c}}$ & $0.2419 \pm 0.0004 \mathrm{~m}^{2}$ \\
\hline
\end{tabular}

The effective area of reflection of the solar concentrator was $78 \%$ of the total area of the parabolic concentrator. Thus, there exists a significant effect of the shadow generated by the opaque plate on the concentrator.

Figure 4 shows the results of thermographic image processing of the surface of the receiving opaque plate.
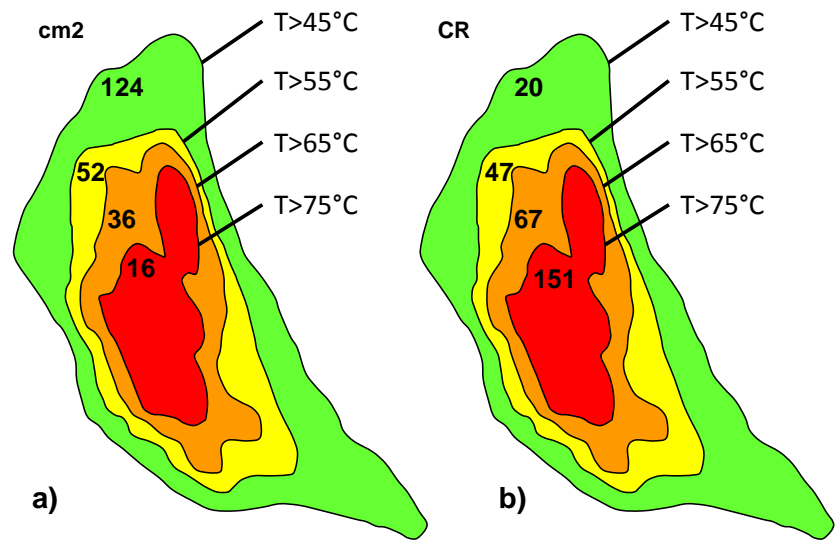

Figure 4. Area $\left(\mathrm{cm}^{2}\right)$ and concentration ratio $(\mathrm{CR})$ as function of temperature in the opaque plate

Figure 4a shows the area of the image generated by the solar concentrator on the receiving opaque plate. Some areas are warmer than others when the system operates in steady state. Additionally, the morphology of the image is irregular and not symmetrical, maybe due to the irregularity in the curvature of the concentrator used, which generates a nonuniform radiation flux due to the intersecting errors of the light rays concentrated in focus.

In the analysis, four regions are selected. For example, the green region contains the area of the image with a temperature higher than $45^{\circ} \mathrm{C}$; the yellow region includes the area of the picture with a temperature greater than $55^{\circ} \mathrm{C}$ and so on until the hottest part of the image $\left(\mathrm{T}>75^{\circ} \mathrm{C}\right)$. The maximum incidence area of the radiation was $124 \mathrm{~cm}^{2}$.

There are areas where the concentrated radiation flux is higher, therefore; they are the hottest regions. For the different regions, the concentration ratio (CR) was calculated. CR is greater for the warmer regions, as shown in Figure 4b. According to the four selected 
$176 \quad 10^{\mathrm{TH}}$ International Conference on Sustainable Energy and EnVIRONMENTAL Protection (June $27^{\mathrm{TH}}-30^{\mathrm{TH}}, 2017$, Bled, SLOVENIA), RENEWABle ENERGy SOURCES F. E. Cano Ardila \& S. C. Agudelo Florez: Determination of the Concentration Ratio of a Parabolic Solar Concentrator Using Thermographic Image Processing

regions, $\mathrm{CR}$ is lower for the larger areas and then varies from 20 to 151 , because the radiation flux varies.

In fact, in Figure 5 the radiation flux is shown on five temperature lines as specified in Figure $3 b$.

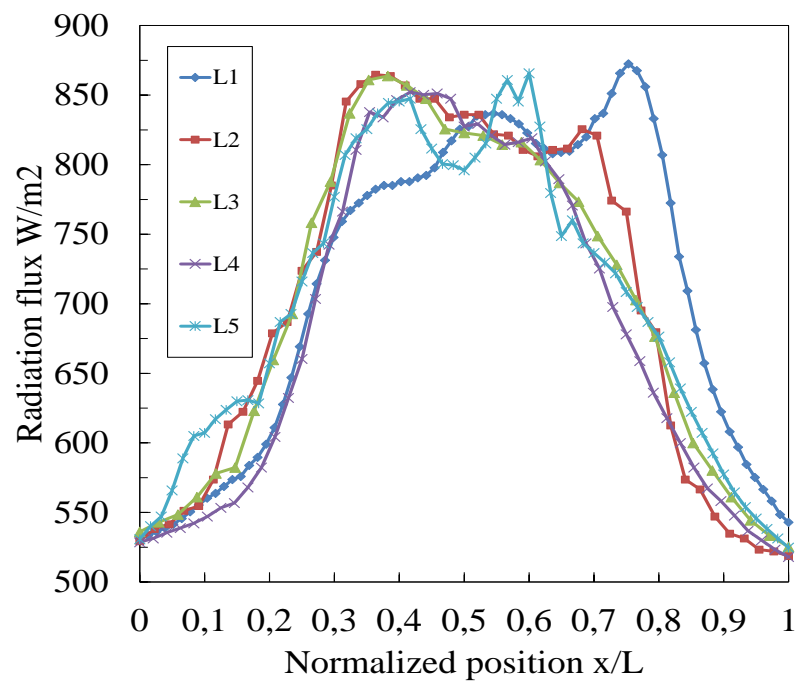

Figure 5. Radiation flux over five temperature lines in the area of radiation concentration.

Figure 5 shows that with the variation of the position the radiation flux also varies. Also, the radiation is not symmetrical for all lines due to irregularities of the parabolic concentrator. The radiation flux is further concentrated in the center of Figure $4 \mathrm{~b}$. For this reason, there will be a higher temperature in the center, where there is a higher concentration factor, as shown in figure 6 .

Figure 6 shows that the radiation flux increases with increasing CR, but there is a downward trend for power. The radiation flux increases from $700 \mathrm{~W} \cdot \mathrm{m}^{-2}$ to $830 \mathrm{~W} \cdot \mathrm{m}^{-2}$ for CR between 20 and 151, respectively. Power decreases from $8.7 \mathrm{~W}$ to $1.3 \mathrm{~W}$ for CR between 20 and 151, respectively. 


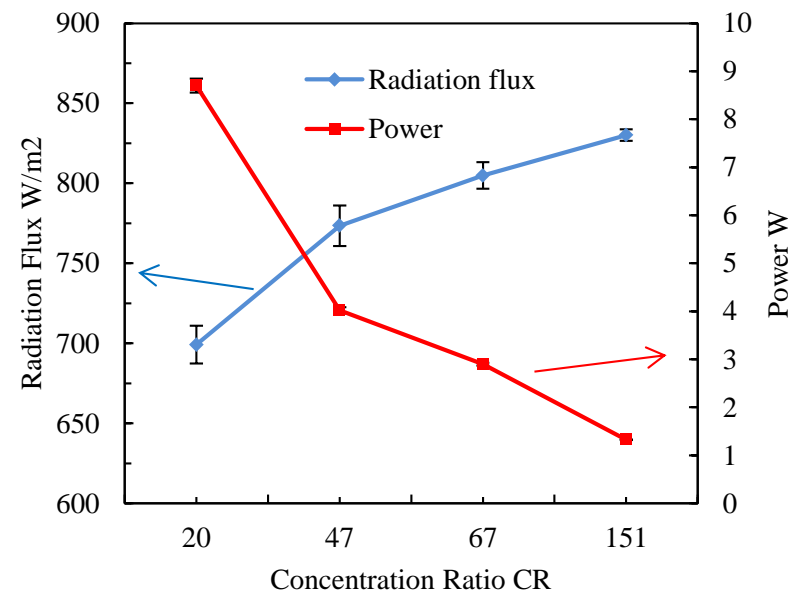

Figure 6. Radiation flux and power as a function of concentration ratio CR.

When the CR and the radiation flux are maximum, the power is minimal since the available area is lower for a higher CR. Thus, for a CR of 151 , a power of only $1.3 \mathrm{~W}$ is obtained, which is equivalent to $15 \%$ of the total power, while for a CR of 47 a power of $4 \mathrm{~W}$ is obtained, corresponding to $46 \%$ of the total power. The remaining area, although it is between $45^{\circ} \mathrm{C}$ and $55^{\circ} \mathrm{C}$, has a significant surface area, so it represents $54 \%$ of the remaining power. The total power obtained was $8.7 \mathrm{~W}$.

\section{Conclusions}

In this work we determined the concentration ratio of a parabolic solar concentrator using thermographic image processing and we found that CR can be determined with good accuracy using thermographic image processing. CR varies depending on the radiation flux that is required for the heating of the receiving surfaces.

The maximum concentrated radiation flux and the maximum CR can be obtained only in a small central region where the temperatures are higher, due to irregularities of the concentrator. However, the power is lower when the area is smaller.

This behavior is because the incident radiation on the plate is not properly concentrated and the energy distribution is not uniform due to irregularities in the concentrator.

The irregularities of curvature in the concentrators significantly deteriorate the uniformity of the radiation flux and the symmetry of the same on the receiver.

For optimum design of solar concentrators, it is necessary to minimize the receiver surface area to avoid reducing the area of reflection by generated shadows over concentrator. 
$178 \quad 10^{\mathrm{TH}}$ InTERnAtional CONFERENCE ON Sustainable ENERGy AND ENVIRONMENTAL Protection (June $27^{\mathrm{TH}}-30^{\mathrm{TH}}, 2017$, Bled, SLOVENIA), RENEWABle ENERGy SOURCES F. E. Cano Ardila \& S. C. Agudelo Florez: Determination of the Concentration Ratio of a Parabolic Solar Concentrator Using Thermographic Image Processing

\section{Acknowledgements}

The authors would like to acknowledge the program "Sostenibilidad 2016-2017" of the University of Antioquia for the contribution for the development of this research. The authors also appreciate the collaboration of Carolina Valencia Tobón in the development of this work.

\section{References}

[1] Q. Li, A. Shirazi, C. Zheng, G. Rosengarten, J. A. Scott, and R. A. Taylor, "Energy concentration limits in solar thermal heating applications," Energy, vol. 96, pp. 253-267, 2016.

[2] H. L. Zhang, J. Baeyens, J. Degrève, and G. Cacères, "Concentrated solar power plants: Review and design methodology," Renewable and Sustainable Energy Reviews, vol. 22, pp. 466-481, 2013.

[3] J. A. Duffie and W. A. Beckman, Solar engineering of thermal processes. John Wiley \& Sons, 2013.

[4] S. M. Jeter, "The distribution of concentrated solar radiation in paraboloidal collectors," Journal of Solar Energy Engineering, vol. 108, no. 3, pp. 219-225, 1986.

[5] J. P. N. Bootello, H. Price, M. S. Pérez, and M. D. Castellano, "Optical Analysis of a Two Stage XX Simultaneous Multiple Surface Concentrator for Parametric Trough Primary and Flat Absorber With Application in Direct Steam Generation Solar Thermal Plants," Journal of Solar Energy Engineering, vol. 138, no. 2, p. 21002, 2016.

[6] D. Rodriguez-Sanchez and G. Rosengarten, "Improving the concentration ratio of parabolic troughs using a second-stage flat mirror," Applied Energy, vol. 159, pp. 620-632, 2015.

[7] N. Mbodji and A. Hajji, "Performance Testing of a Parabolic Solar Concentrator for Solar Cooking," Journal of Solar Energy Engineering, vol. 138, no. 4, p. 41009, 2016.

[8] D. Xu and M. Qu, "Experimental Performance Analysis of External Compound Parabolic Concentrators With Low Concentration Ratios for Medium Temperature Applications," in ASME 2014 8th International Conference on Energy Sustainability collocated with the ASME 2014 12th International Conference on Fuel Cell Science, Engineering and Technology, 2014, pp. V002T10A008-V002T10A008.

[9] J. W. Baughn and J. B. Bergquam, "Optimum concentration ratio for a solar centralreceiver electric power plant," Journal of Engineering for Power, vol. 99, no. 3, pp. 490491, 1977.

[10] D. Y. Goswami and F. Kreith, Handbook of energy efficiency and renewable energy. Crc Press, 2007.

[11] M. Vollmer and K.-P. Möllmann, Infrared thermal imaging: fundamentals, research and applications. John Wiley \& Sons, 2010. 
$10^{\mathrm{TH}}$ InTERnational CONFEREnCE ON Sustainable ENERgy AND ENVIRONMENTAL Protection (June $27^{\mathrm{TH}}-30^{\mathrm{TH}}$, 2017, Bled, SLOVENIA), RENEWABLE ENERGy SOURCES

J. Krope, A.Ghani Olabi, D. Goričanec \& S. Božičnik

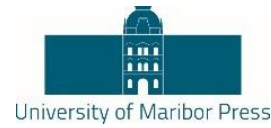

\title{
Environmental Assessment of the Integration of Active Solar Energy Systems on Building Envelopes in Southern Europe
}

\author{
Constantinos Vassiliades, Aimilios Michael, AndREAs SAVVides \& Soteris \\ KALOGIROU
}

\begin{abstract}
This study aims at making an environmental assessment of the integration of active solar energy systems on building envelopes in southern Europe. More specifically, it focuses on the investigation of shading and insolation of indoor spaces in relation to the energy requirements and the visual comfort of inhabitants. For the needs of the present research, five active solar systems and three representative space typologies were selected for in-depth investigation. Autodesk Ecotect Analysis software v.5.2 and Desktop Radiance v2.0 Beta were used for the simulations. The simulation results are presented and discussed comparatively. The findings indicate that the integration of active solar systems contributes to drastic reductions of the cooling and heating loads. In terms of natural lighting, the integration of active solar systems enables high levels of natural lighting, minimizes glare issues in the majority of systems. The research highlights the role of integrated active solar systems in buildings both in the indoor built environment and in energy performance.
\end{abstract}

Keywords: - Environmental Assessment - Active Solar Systems • Architectural Integration • Thermal and Visual Comfort • Southern Europe

Correspondence AdDress: Constantinos Vassiliades, Ph.D. Candidate, University of Cyprus, School of Engineering, Department of Architecture, P.O. Box 20537, 1678, Nicosia, Cyprus, email: vassiliades. constantinos@ucy.ac.cy. Aimilios Michael, Ph.D., Lecturer, University of Cyprus, School of Engineering, Department of Architecture, P.O. Box 20537, 1678, Nicosia, Cyprus, e-mail: aimilios@ucy.ac.cy. Andreas Savvides, Ph.D., Assistant Professor, University of Cyprus, School of Engineering, Department of Architecture, P.O. Box 20537, 1678, Nicosia, Cyprus, e-mail: als@ucy.ac.cy. Soteris Kalogirou, Ph.D., Professor, Cyprus University of Technology, Department of Mechanical Engineering and Materials Science and Engineering, Dorothea Building, 4th and 5th floor, 45 Kitiou Kyprianou Str., 3041 Limassol, Cyprus, e-mail: soteris.kalogirou@cut.ac.cy. 
$180 \quad 10^{\mathrm{TH}}$ InTERnAtional CONFERENCE ON Sustainable ENERGy AND ENVIRONMENTAL Protection (June $27^{\mathrm{TH}}-30^{\mathrm{TH}}, 2017$, Bled, SLOVENIA), RENEWABle ENERGY SOURCES C. Vassiliades, A. Michael, A. Savvides \& S. Kalogirou: Environmental Assessment of the Integration of Active Solar Energy Systems on Building Envelopes in Southern Europe

\section{$1 \quad$ Introduction}

The integration of active solar energy systems on building envelopes contributes effectively to the reduction of heating and cooling loads of the building sector, through the in-situ production of energy [1]. Solar energy systems' key role is increasingly becoming evident wherever high values of annual solar energy are recorded [2].

The research investigates the integration of active solar systems in buildings in terms of energy production, shading and insolation of building facades, as well as in terms of visual comfort of inhabitants.

\section{$2 \quad$ Literature Review}

Apart from their active use, certain active solar systems integrated in building, i.e. BIPV and BISTS, are also suitable to act as passive design elements. A comparative assessment of BIPV and BISTS performed by Vassiliades et al. $(2014,2015)$ indicates that a number of active solar systems can be viably integrated into the building envelope [3,4]. The architectural integration of active solar systems is thoroughly analysed in the relevant literature. Bougiatioti and Michael have investigated the architectural integration of active solar systems in building facades and roofs in the Eastern Mediterranean region [5]. An energy performance assessment of photovoltaic panels integrated into shading devices was performed by Mandalaki et al. (2012) [6]. Further research investigates the geometrical optimization of a shading device with integrated PVs in terms of energy production and energy savings resulting from the minimization of direct solar gains and visual comfort conditions [2]. However, related literature on both the active and passive role of solar energy systems remains rather limited. This research aims at making a comprehensive investigation of BIPV and BISTS and at establishing a multi-criteria evaluation methodology of the building integrated active solar energy systems.

3

Methodology

The current study focuses on two main pillars, i.e., the investigation of shading and insolation of glazed surfaces in relation to energy consumption and the investigation of the visual comfort of inhabitants in terms of lighting levels and glare issues.

\subsection{Building typologies}

Three representative building typologies were selected for in-depth investigation, as shown in Figure 1. Specifically, typology A has plan dimensions of $5 \mathrm{~m}$ width and $3 \mathrm{~m}$ depth, namely, shallow plan; typology B has plan dimensions of $5 \mathrm{~m}$ width and $5 \mathrm{~m}$ depth, namely, medium plan; and typology $\mathrm{C}$ has plan dimensions of $5 \mathrm{~m}$ width and $7 \mathrm{~m}$ depth, namely, deep plan. The height of the space in all three cases is the same, i.e., $3 \mathrm{~m}$.

The three spaces have a fully glazed elevation towards the south, while the other three sides were solid walls. The thermal properties of the building envelope elements were selected based on the energy performance of buildings directive 2002/91/EC. 

the Integration of Active Solar Energy Systems on Building Envelopes in Southern

Europe

The glazed surface of the building unit was south facing due to the high levels of solar exploitation, as well as to the need for sun protection during the hot summer period in the southern orientation. Increased glare issues in south facing spaces during the entire year render the reduction of unwanted levels of glare and the improvement of visual comfort.

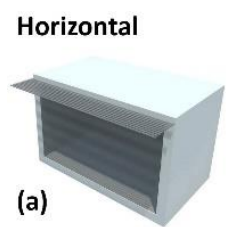

Vertical

(a)

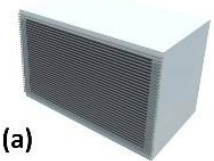

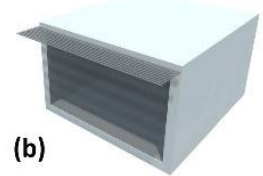

(b) (b)

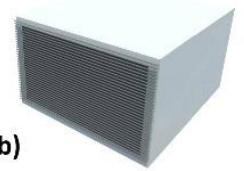

(c)

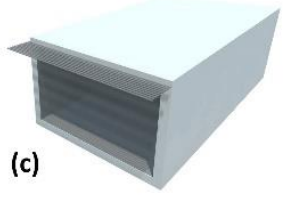

(c)

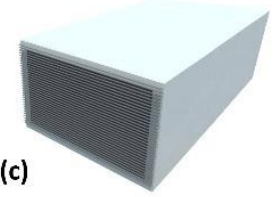

Figure 1. Building integrated active solar systems at horizontal and vertical configuration in the three different building typologies under study, (a) shallow, (b) medium and (c) deep typology.

Two configurations, namely the horizontal and vertical integration, are examined in the investigation of active solar systems (Figure 1). The horizontal configuration refers to the placement of the active solar systems under study in the form of a 1,5 $\mathrm{m}$ long horizontal canopy[7]. The vertical layout refers to the placement of active solar systems in front of the glazed surface, or in the glazed surface in the case of specific photovoltaic technologies. The selected configurations ensure $7.5 \mathrm{~m}^{2}$ and $15 \mathrm{~m}^{2}$ of effective surface of active solar systems for horizontal and vertical configurations, respectively.

\subsection{Technologies}

A number of active solar systems that could operate as passive shading devices were selected for simulation purposes. Analysis from previous research work [3], [4], indicates that appropriate BIPV systems include the aSi thin film with $10 \%$ of transparency, the monocrystalline with $0.02 \mathrm{~m}$ space between the cells and the polycrystalline with $0.05 \mathrm{~m}$ space between the cells, while appropriate BIST systems include vacuum tubes and unglazed cylindrical solar collectors.

\subsection{Simulations}

The environmental assessment of active solar systems was carried out through simulations. 
$10^{\mathrm{TH}}$ InTERnAtional Conference on Sustainable EnERgy AND ENVIRONMENTAL Protection (June $27^{\mathrm{TH}}-30^{\mathrm{TH}}, 2017$, BlED, SLOVENIA), RENEWABLE ENERGy SOURCES C. Vassiliades, A. Michael, A. Savvides \& S. Kalogirou: Environmental Assessment of the Integration of Active Solar Energy Systems on Building Envelopes in Southern Europe

\section{Shading and Insolation}

The shading and insolation strategies were evaluated using shading masks for all active solar systems integrated in the building façade. The shading masks were prepared for high overshadowing accuracy using the stereographic diagram tool of Autodesk Ecotect Analysis software v.5.2. The investigation was performed at $36^{\circ}$ south latitude for representative periods of the year, i.e., solstices and equinoxes at 09:00, 12:00 and 15:00 h.

The active solar systems integrated in the building façades were also examined in terms of energy consumption. Without the integration of any active solar system, the energy consumption was taken as reference value. Heating and cooling loads were calculated using a mixed mode air-condition system with a $95 \%$ efficiency rate. The temperature limits were set from 21 to $25{ }^{\circ} \mathrm{C}$ according to ASHRAE 55 (2013) standard for $80 \%$ occupant thermal acceptability. The annual energy consumption, i.e., heating and cooling loads, is presented in $\mathrm{kWh}$ per square meter of the plan area $\left(\mathrm{kWh} / \mathrm{m}^{2}\right)$, allowing the comparative evaluation of the systems.

\section{Energy Consumption}

Autodesk Ecotect Analysis software v5.2 [8], was used for the simulation of the passive behaviour of active solar systems. Desktop Radiance v2.0 Beta [9] was used for natural lighting analysis, while Ecotect software v5.2 was employed as a modelling and visualization tool.

\section{Visual Comfort}

The evaluation of visual comfort was performed for representative periods of the year, i.e., solstices and equinoxes at solar noon. The sky model was set as cloudy for winter, intermediate for spring and sunny for the summer period, thus providing results for the climatic extremes during the entire year; the reference standard year of Nicosia was used. The typical reflectance values for representative interior materials were used based on literature references, using material files for Desktop Radiance software. Calculations were made using three indirect reflections, employing an analysis grid at $0.75 \mathrm{~m}$ height from floor level.

Efficient lighting levels are taken to be $75 \%$ of the area of the plan exceeding 500 Lux and minimum possible percentage of the area exceeding 3000 Lux since overillumination leads to potential glare issues [10].

Moreover, the preferred conditions for the most efficient function of the space are indicated by daylighting performance indicators, i.e., the daylight factor (DF) and the uniformity daylight factor (UDF). The daylight factor, DF, expresses the ratio of interior illuminance on a horizontal surface, to the exterior illuminance on a horizontal surface 
$10^{\mathrm{TH}}$ InTERnational CONFERENCE ON SUSTAINABle ENERgy AND ENVIRONMENTAL 183 Protection (June $27^{\mathrm{TH}}-30^{\mathrm{TH}}, 2017$, BLED, SLOVENIA), RENEWABLE ENERGy SOURCES C. Vassiliades, A. Michael, A. Savvides \& S. Kalogirou: Environmental Assessment of the Integration of Active Solar Energy Systems on Building Envelopes in Southern

Europe

under an overcast CIE sky. An average DF of $2 \%$ for $75 \%$ of the space is deemed as acceptable, according to CIBSE [11]. Uniformity Daylight Factor, UDF, indicates the homogeneity level of lighting distribution, expressed by the singular minimum Lux value divided by the average value of the entire plan, i.e., $\mathrm{UDF}=\mathrm{DFmin} / \mathrm{DFmean}$. According to BREEAM 2.08, the required UDF for an efficient work space should be at least 0,4 [12].

\section{$4 \quad$ Results}

\subsection{Shading and Insolation}

The simulation results of the shading and insolation of indoor spaces, as well as of the visual comfort of occupants, are presented in Table 1 and discussed comparatively below. 

$10^{\mathrm{TH}}$ InTERnATIONAL CONFERENCE ON Sustainable EnERgy AND ENVIRONMENTAL Protection (June $27^{\mathrm{TH}}-30^{\mathrm{TH}}$, 2017, Bled, SLOVENIA), RENEWABLE ENERGY SOURCES C. Vassiliades, A. Michael, A. Savvides \& S. Kalogirou: Environmental Assessment of the Integration of Active Solar Energy Systems on Building Envelopes in Southern Europe

Table 1. Shading percentages for horizontal and vertical configuration of the active solar systems under study.

\begin{tabular}{|c|c|c|c|c|c|c|}
\hline \multirow[b]{3}{*}{ Period } & \multirow[b]{3}{*}{ Time } & \multicolumn{5}{|c|}{ Active Solar System } \\
\hline & & \multicolumn{3}{|c|}{ PV } & \multicolumn{2}{|c|}{ STS } \\
\hline & & 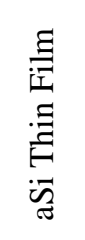 & 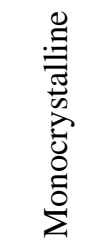 & 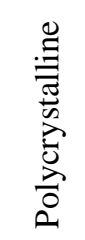 & 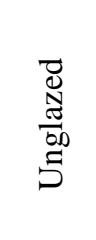 & 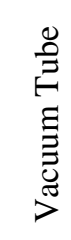 \\
\hline \multicolumn{7}{|c|}{ Horizontal Configuration } \\
\hline \multirow{3}{*}{$\begin{array}{l}\text { Winter } \\
\text { Solstice }\end{array}$} & 09:00 & $29 \%$ & $29 \%$ & $29 \%$ & $29 \%$ & $29 \%$ \\
\hline & $12: 00$ & $30 \%$ & $32 \%$ & $24 \%$ & $32 \%$ & $28 \%$ \\
\hline & $15: 00$ & $39 \%$ & $34 \%$ & $37 \%$ & $39 \%$ & $37 \%$ \\
\hline \multirow{3}{*}{$\begin{array}{c}\text { Autumn } \\
\text { Spring } \\
\text { Equinox }\end{array}$} & 09:00 & $58 \%$ & $58 \%$ & $58 \%$ & $58 \%$ & $58 \%$ \\
\hline & $12: 00$ & $69 \%$ & $70 \%$ & $62 \%$ & $57 \%$ & $53 \%$ \\
\hline & 15:00 & $76 \%$ & $75 \%$ & $69 \%$ & $70 \%$ & $68 \%$ \\
\hline \multirow{3}{*}{$\begin{array}{l}\text { Summer } \\
\text { Solstice }\end{array}$} & 09:00 & $96 \%$ & $96 \%$ & $96 \%$ & $96 \%$ & $96 \%$ \\
\hline & $12: 00$ & $95 \%$ & $94 \%$ & $85 \%$ & $88 \%$ & $86 \%$ \\
\hline & $15: 00$ & $99 \%$ & $99 \%$ & $99 \%$ & $99 \%$ & $99 \%$ \\
\hline \multicolumn{7}{|c|}{ Vertical Configuration } \\
\hline \multirow{3}{*}{$\begin{array}{l}\text { Winter } \\
\text { Solstice }\end{array}$} & 09:00 & $29 \%$ & $29 \%$ & $29 \%$ & $67 \%$ & $29 \%$ \\
\hline & $12: 00$ & $15 \%$ & $15 \%$ & $15 \%$ & $60 \%$ & $52 \%$ \\
\hline & $15: 00$ & $30 \%$ & $30 \%$ & $30 \%$ & $72 \%$ & $55 \%$ \\
\hline \multirow{3}{*}{$\begin{array}{c}\text { Autumn } \\
\text { Spring } \\
\text { Equinox }\end{array}$} & 09:00 & $58 \%$ & $100 \%$ & $64 \%$ & $97 \%$ & $58 \%$ \\
\hline & $12: 00$ & $41 \%$ & $100 \%$ & $69 \%$ & $96 \%$ & $61 \%$ \\
\hline & $15: 00$ & $59 \%$ & $100 \%$ & $72 \%$ & $95 \%$ & $73 \%$ \\
\hline \multirow{3}{*}{$\begin{array}{l}\text { Summer } \\
\text { Solstice }\end{array}$} & 09:00 & $96 \%$ & $96 \%$ & $96 \%$ & $96 \%$ & $96 \%$ \\
\hline & $12: 00$ & $86 \%$ & $96 \%$ & $88 \%$ & $100 \%$ & $94 \%$ \\
\hline & $15: 00$ & $98 \%$ & $99 \%$ & $98 \%$ & $99 \%$ & $99 \%$ \\
\hline
\end{tabular}

Shading through the application of shading masks indicates that the horizontal integration of active solar systems during the winter solstice provides limited shading of approximately $28 \%$, i.e., from $24 \%$ to $39 \%$, which allows adequate insolation. During the autumn and spring equinoxes, the active systems provide shading of approximately $64 \%$, i.e., from $53 \%$ to $76 \%$, while during the summer solstice, the integration of active systems provides shading of approximately $95 \%$, i.e., from $85 \%$ to $99 \%$. The shading results do not significantly differ between the active solar systems under study or between different times of the day. During the winter solstice, photovoltaic systems in the vertical layout provide limited shading of approximately $25 \%$, i.e., from $15 \%$ to $30 \%$, which allow adequate insolation. Solar thermal systems provide high percentages of shading, i.e., 

the Integration of Active Solar Energy Systems on Building Envelopes in Southern

Europe

approximately $45 \%$ for vacuum tubes and $66 \%$ for unglazed cylindrical solar collectors. The systems in question are unsuitable for use during the winter. In the autumn and spring equinoxes, specific active solar systems, i.e., aSi thin film, polycrystalline and vacuum tubes, provide a shading of approximately $62 \%$ i.e., from $41 \%$ to $72 \%$. By contrast, monocrystalline and unglazed cylindrical solar collectors provide high levels of shading, i.e., $100 \%$ and $96 \%$ respectively. During the summer solstice, the integration of all active solar systems provides shading of $96 \%$, i.e., from $86 \%$ to $100 \%$, and ensures adequate protection from solar gains.

\subsection{Energy consumption}

The investigation of energy consumption aims to define the positive contribution of each system as a passive shading device. More specifically, it is expected that the cooling loads required during the warm period will be reduced due to the sun protection offered by the systems. The heating loads required during the cold period will increase due to the reduction of direct solar gains. The results are presented in Figure 2.

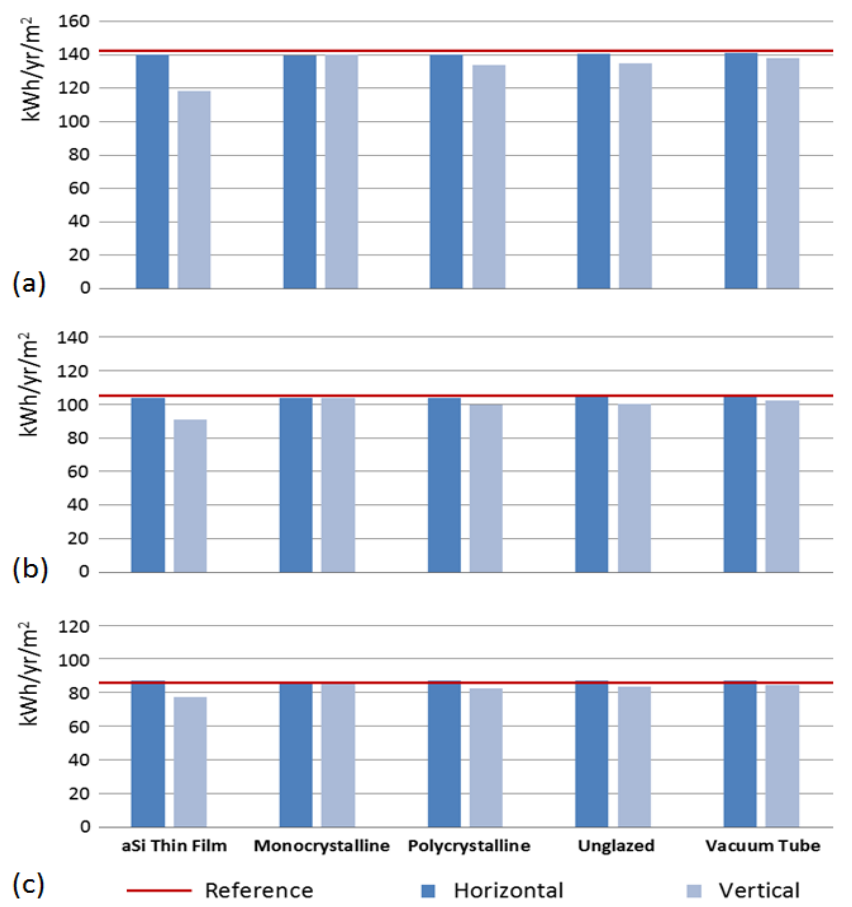

Figure 2. Energy consumption of the building typologies under study,(a) shallow, (b) medium and (c) deep plan, for horizontal and vertical configuration of active solar systems. 
186 10 $10^{\mathrm{TH}}$ InTERnAtional CONFERENCE ON Sustainable ENERGy AND ENVIRONMENTAL Protection (June $27^{\mathrm{TH}}-30^{\mathrm{TH}}, 2017$, BLED, SLOVENIA), RENEWABLE ENERGY SOURCES C. Vassiliades, A. Michael, A. Savvides \& S. Kalogirou: Environmental Assessment of the Integration of Active Solar Energy Systems on Building Envelopes in Southern

Europe

The annual energy consumptions of the three building typologies in horizontal configuration, show that the systems' total annual contribution is negligible, fluctuating at $\pm 2 \%$ of the consumption before the integration of the system.

By contrast, the vertical integration indicates a positive contribution in the annual energy consumption. Specifically, the positive contribution of the vertical integration of the systems ranges from 1.5-23.2 $\mathrm{kWh}$ per square meter of the plan area in the shallow plan to $0.2-13.1 \mathrm{kWh} / \mathrm{m}^{2}$ in the medium plan and to $0.1-8.7 \mathrm{kWh} / \mathrm{m}^{2}$ in the deep plan. It is also noted that the positive contribution of the vertically integrated aSi thin film is comparatively higher than that of the other systems.

\subsection{Visual Comfort}

\section{Lighting Levels}

The integration of the active solar systems in both horizontal and vertical configuration, manages to keep the high levels of natural lighting in the indoor space. In all cases, the daylight levels exceed 500 lux for more than $75 \%$ of the plan area, satisfying international lighting standards. The integration of active solar systems eliminates high daylight levels (> 3000 lux) and minimizes glare issues and improves visual comfort.

\section{Daylight Performance Indicators}

The daylight factor (DF) and uniformity daylight factor (UDF) were calculated under overcast conditions for all three typologies without any shading device (reference scenarios) and with the integration of active solar systems in both horizontal and vertical configuration. Table 2 shows the comparative evaluation. 

the Integration of Active Solar Energy Systems on Building Envelopes in Southern

Europe

Table 2. Daylight performance indicators of the building typologies under study for horizontal and vertical configuration of active solar systems.

\begin{tabular}{|c|c|c|c|c|c|c|}
\hline \multirow{3}{*}{ : } & \multirow{3}{*}{ 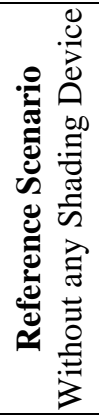 } & \multicolumn{5}{|c|}{ Active Solar System } \\
\hline & & \multicolumn{3}{|c|}{ PV } & \multicolumn{2}{|c|}{ STS } \\
\hline & & 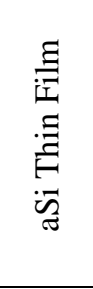 & 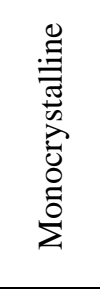 & 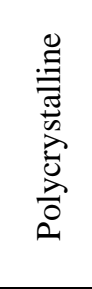 & 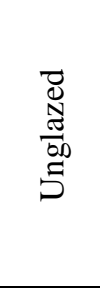 & 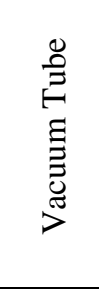 \\
\hline \multicolumn{7}{|c|}{ Horizontal Configuration } \\
\hline & \multicolumn{6}{|c|}{ Percentage of space area with DF $>2 \%$} \\
\hline Shallow & $100 \%$ & $100 \%$ & $100 \%$ & $100 \%$ & $100 \%$ & $100 \%$ \\
\hline Medium & $100 \%$ & $100 \%$ & $100 \%$ & $100 \%$ & $100 \%$ & $100 \%$ \\
\hline \multirow[t]{2}{*}{ Deep } & $95 \%$ & $81 \%$ & $93 \%$ & $94 \%$ & $82 \%$ & $88 \%$ \\
\hline & \multicolumn{6}{|c|}{ Uniformity Daylight Factor (UDF) } \\
\hline Shallow & 0.42 & 0.47 & 0.49 & 0.45 & 0.45 & 0.46 \\
\hline Medium & 0.31 & 0.35 & 0.37 & 0.32 & 0.34 & 0.34 \\
\hline Deep & 0.21 & 0.27 & 0.26 & 0.24 & 0.24 & 0.25 \\
\hline \multicolumn{7}{|c|}{ Vertical Configuration } \\
\hline & \multicolumn{6}{|c|}{ Percentage of area with DF $>2 \%$} \\
\hline Shallow & $100 \%$ & $0 \%$ & $74 \%$ & $100 \%$ & $100 \%$ & $100 \%$ \\
\hline Medium & $100 \%$ & $0 \%$ & $41 \%$ & $94 \%$ & $78 \%$ & $100 \%$ \\
\hline Deep & $95 \%$ & $0 \%$ & $32 \%$ & $57 \%$ & $65 \%$ & $77 \%$ \\
\hline & \multicolumn{6}{|c|}{ Uniformity Daylight Factor (UDF) } \\
\hline Shallow & 0.42 & 0.57 & 0.31 & 0.38 & 0.72 & 0.51 \\
\hline Medium & 0.31 & 0.40 & 0.24 & 0.24 & 0.43 & 0.39 \\
\hline Deep & 0.21 & 0.25 & 0.16 & 0.17 & 0.28 & 0.24 \\
\hline
\end{tabular}

The DF indicator of the spaces without the integration of any shading device is observed to exceed $2 \%$ DF is $100 \%$ in the shallow plan, $100 \%$ in the medium plan and $95 \%$ in the deep plan. In the case of the shallow plan the UDF value exceeds the threshold of 0.40, i.e., $0.42 \mathrm{UDF}$, indicating satisfactory uniformity of daylight. In the case of medium and deep plan the UDF is 0.31 and 0.21 respectively, failing to reach the threshold of 0.40 UDF.

In the horizontal configuration, the lighting level analysis shows that the percentage of the plan area exceeding $2 \%$ DF remains at $100 \%$ in the case of the shallow and medium plan, while, in the case of the deep plan it remains at high levels, i.e., $81 \%$ to $94 \%$. Moreover, the uniformity daylight factor increases after the integration of active solar 
$10^{\text {TH }}$ InTERnAtional CONFERENCE ON Sustainable ENERgy AND ENVIRONMENTAL Protection (June $27^{\mathrm{TH}}-30^{\mathrm{TH}}, 2017$, Bled, SLOVENIA), RENEWABle ENERGY SOURCES C. Vassiliades, A. Michael, A. Savvides \& S. Kalogirou: Environmental Assessment of the Integration of Active Solar Energy Systems on Building Envelopes in Southern Europe

systems in horizontal configuration from $0.42 \mathrm{UDF}$ in the reference case to $0.45-0.49$ UDF in the case of the shallow plan, from 0.31 UDF to 0.32 - 0.37 UDF in the case of the medium plan and from 0.21 UDF to 0.24 - 0.27 UDF in the case of the deep plan. In the case of the shallow plan, satisfactory UDF values exceeding the threshold of 0.40 are recorded after the integration of active solar systems in horizontal configuration. Despite the increase of the UDF values in the cases of the medium and deep plan, the UDF values remain below the threshold of 0.40 UDF and thus fail to satisfy the lighting standards.

In the vertical configuration, photovoltaics and solar thermal systems demonstrate different performance in terms of lighting levels regulation. The lighting level analysis shows that the photovoltaics systems are not effective solutions for lighting regulation, since the percentage of the plan area exceeding $2 \%$ DF is significantly reduced. In the majority of cases, the UDF values decreased after the integration of the photovoltaics systems in vertical configuration.

The lighting level analysis shows that the integration of solar thermal systems is effective for lighting levels regulation since the percentages of the plan area exceeding $2 \%$ DF remain at high levels. The percentage of the plan area exceeding $2 \%$ DF remains at $100 \%$ in the case of the shallow plan, at $78 \%$ to $100 \%$ in the case of the medium plan and at $65 \%$ to $77 \%$ in the case of the deep plan. Moreover, the uniformity daylight factor increases significantly after the integration of solar thermal systems in vertical configuration from 0.42 UDF in the reference case to 0.51-0.72 UDF in the case of the shallow plan, from $0.31 \mathrm{UDF}$ to $0.37-0.43 \mathrm{UDF}$ in the case of the medium plan and from 0.21 UDF to $0.24-0.28 \mathrm{UDF}$ in the case of the deep plan.

In the case of the shallow and medium plan, high UDF values, approaching or exceeding the threshold of 0.40 , are recorded after the integration of solar thermal systems in vertical configuration. Despite the increase of the UDF values in the case of deep plans, the UDF values remain below the threshold of $0.40 \mathrm{UDF}$ and fail to satisfy the lighting standards.

\section{$5 \quad$ Synopsis and Conclusions}

The research presented investigates the building integration of active solar systems in terms of shading and insolation of building facades and in terms of visual comfort of inhabitants, ensuring thus a comprehensive environmental approach to integrated active solar energy systems.

The investigation of shading and insolation presented indicates that all active solar systems integrated horizontally into the building envelope offer suitable shading and insolation during the cooling and heating period. In the case of vertical integration, better shading and insolation conditions are exhibited throughout the entire year.

The investigation of energy consumption of the building typologies in question shows that the horizontal integration of active solar systems has minimal impact on the annual energy consumption of the three building typologies. In the case of vertical integration of 
$10^{\text {TH }}$ InTERnational CONFEREnCe on Sustainable EnERgy AND ENVIRONMENTAL 189 Protection (June 27 $7^{\mathrm{TH}}-30^{\mathrm{TH}}, 2017$, BLED, SLOVENiA), RENEWABLE ENERGY SOURCES

C. Vassiliades, A. Michael, A. Savvides \& S. Kalogirou: Environmental Assessment of the Integration of Active Solar Energy Systems on Building Envelopes in Southern

Europe

active solar systems, a positive contribution in the reduction of the annual energy consumption is recorded.

The simulation results and the analysis of lighting levels, indicate that the integration of active solar systems in both horizontal and vertical configuration, maintains high levels of natural lighting, i.e., 500 lux for more than $75 \%$ of the plan area, while it eliminates extremely high daylight levels, that is $>3000$ lux. Moreover, all the active solar systems under study integrated horizontally into the building envelope offer high levels of lighting performance. In the case of vertical integration, better lighting performance is exhibited by solar thermal systems. The integration of both photovoltaic and solar thermal systems in horizontal configuration and the integration of solar thermal systems in vertical configurations, offer higher uniformity daylight factor values, and thus minimize the possibility of glare issues.

In conclusion, the research introduces a comprehensive investigation of BIPV and BISTS and establishes a multi-criteria evaluation methodology for building integrated active solar energy systems. The study presents in a quantitative manner the active and passive role of integrated active solar energy systems and validates the importance of their building integration in buildings of southern Europe.

\section{References}

[1] S. A. Kalogirou, "Building integration of solar renewable energy systems towards zero or nearly zero energy buildings," Int. J. Low-Carbon Technol., p. ctt071, 2013.

[2] M. Mandalaki, T. Tsoutsos, and N. Papamanolis, "Integrated PV in shading systems for Mediterranean countries: Balance between energy production and visual comfort," Energy Build., vol. 77, pp. 445-456, 2014.

[3] C. Vassiliades, A. Savvides, and A. Michael, "Architectural Implications in the Building Integration of Photovoltaic and Solar Thermal systems--Introduction of a taxonomy and evaluation methodology," in International conference on sustainable buildings (WSB14), 2014.

[4] C. Vassiliades, A. Savvides, and A. Michael, "Investigation of Sun Protection Issues of Building Envelopes via Active Energy Production Systems," in Euro Elecs 2015, 2015, pp. 697-706.

[5] F. Bougiatioti and A. Michael, "The architectural integration of active solar systems. Building applications in the Eastern Mediterranean region," Renew. Sustain. Energy Rev., vol. 47, pp. 966-982, 2015.

[6] M. Mandalaki, K. Zervas, T. Tsoutsos, and a. Vazakas, "Assessment of fixed shading devices with integrated PV for efficient energy use," Sol. Energy, vol. 86, no. 9, pp. 25612575, 2012.

[7] G. Kim, H. S. Lim, T. S. Lim, and L. Schaefer, "Comparative advantage of an exterior shading device in thermal performance for residential buildings," Energy Build., vol. 46, pp. 105-111, 2012.

[8] "Ecotect software v.5.2 [Computer Software]," Square One Research PTY Ltd, 2014. [Online]. Available: http://www.squ1.com. [Accessed: 15-Jan-2014].

[9] "Desktop Radiance v.1.02 [Computer Software]," Lawrence Berkeley National 
$190 \quad 10^{\mathrm{TH}}$ InTERnational CONFERENCE ON Sustainable EnERgy and ENVIRONMENTAL Protection (June 27 $7^{\mathrm{TH}}-30^{\mathrm{TH}}, 2017$, BLED, SLOVENIA), RENEWABLE ENERGY SOURCES C. Vassiliades, A. Michael, A. Savvides \& S. Kalogirou: Environmental Assessment of the Integration of Active Solar Energy Systems on Building Envelopes in Southern Europe

Laboratory, 2014. [Online]. Available: http://radsite.lbl.gov/deskrad. [Accessed: 15-Jan2014].

[10] C. F. Reinhart and J. Wienold, "The daylighting dashboard--A simulation-based design analysis for daylit spaces,” Build. Environ., vol. 46, no. 2, pp. 386-396, 2011.

[11] CIBSE, Daylighting and Window Design. Lighting Guide LG10. London: Chartered Institution of Building Services Engineers, 1999.

[12] A. Iversen, N. Roy, M. Hvass, M. Jørgensen, J. Christoffersen, W. Osterhaus, and K. Johnsen, "Daylight calculations in practice: An investigation of the ability of nine daylight simulation programs to calculate the daylight factor in five typical rooms," Danish Build. Res. Institute, Aalborg SBi, vol. 26, 2013. 
$10^{\mathrm{TH}}$ INTERNATIONAL CONFERENCE ON Sustainable ENERgy AND ENVIRONMENTAL Protection (June $27^{\mathrm{TH}}-30^{\mathrm{TH}}$, 2017, Bled, SLOVENIA), RENEWABLE ENERGy SOURCES

J. Krope, A.Ghani Olabi, D. Goričanec \& S. Božičnik

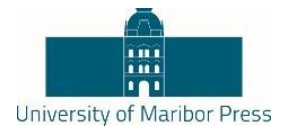

\title{
Spatial Sustainability Assessment of Wind Energy Expansion Scenarios
}

\author{
MARCUS EICHHORN, RAIK BECKER, FRANK MASUROWSKI \& DANIELA THRÄN
}

\begin{abstract}
Wind power plays an integral role in the transition of the German energy system. In addition to its positive effects, e.g. reduction of greenhouse gas emissions, wind power also has negative effects on the environment and human well-being. With this in mind, it is important to identify most suitable locations for wind turbines (WTs) considering different aspects of sustainability. Here a new performance index that combines environmental aspects, human wellbeing (settlement distances) and energetic performance (annual energy production) is applied. The index allows comparing the sustainability of different spatial distribution scenarios of WTs. This index is applied to fife different wind power extension scenarios, which are aiming to fulfil a certain share of the final power consumption in Germany considering standard wind technologies and different power market expectations. Finally, the respective spatial expansion scenarios are compared in terms of the lowest combined impact and their sustainability performance.
\end{abstract}

Keywords: • wind power • sustainable allocation • expansion scenarios • WTs • Germany •

CORRESPONDENCE AdDRESS: Marcus Eichhorn, Ph.D., Scientist, Helmholtz-Centre for Environmental Research GmbH - UFZ, Department Bioenergy, Permoserstraße 15, 04318 Leipzig, Germany, e-mail: marcus.eichhorn@ufz.de. Raik Becker, Ph.D., Assistant, Helmholtz-Centre for Environmental Research GmbH - UFZ, Department Bioenergy, Permoserstraße 15, 04318 Leipzig, Germany, e-mail: raik.becker@ufz.de. Frank Masurowsky, Ph.D., Scientist, Helmholtz-Centre for Environmental Research GmbH - UFZ, Department Ecological Modelling, Permoserstraße 15, 04318 Leipzig, e-mail: frank.masurowsky@ufz.de. Daniela Thrän, Ph.D., Professor, Department Bioenergy Systems, Deutsches Biomasseforschungszentrum DBFZ, Torgauer Straße 116, 04 Leipzig, Germany. e-mail: daniela.thraen@dbfz.de. 
$10^{\mathrm{TH}}$ International Conference on Sustainable EnERgy and Environmental Protection (June $27^{\mathrm{TH}}-30^{\mathrm{TH}}, 2017$, Bled, Slovenia), RenEwable ENERGy SOURCES M. Eichhorn, R. Becker, F. Masurowski \& D. Thrän: Spatial Sustainability Assessment of Wind Energy Expansion Scenarios

\section{Introduction}

A main challenge of the 21st century is mitigating global warming to sustain biodiversity and living conditions for human well-being. The transformation of the energy supply system towards renewable resources is seen as one step to reach the Paris Climate Protection objectives. In Germany, 158.8 Million tons $\mathrm{CO}_{2}$ equivalent have been avoided by renewable energies in 2016 [1]. The share of renewable energy in gross power production was about $32 \%$ [1] whereby wind power (on- and off-shore) held about $40 \%$. Wind power is actually seen as the most promising renewable power source in Germany because it is a mature technology producing at comparably low costs. However, wind power is a source of negative environmental impacts, mainly on birds and bats [2-6]. Disturbance or displacement of birds $[7,8]$ or collision events causing individual death [7, 9-11] with probably negative consequences on populations [4] are the most prominent conflicts. Secondly, wind power extension leads to conflicts with the local population, because most people prefer wind turbines (WTs) to be more distant from their homes [1214] even if all legal requirements regarding emission protection are fulfilled [15-17].

The main political objective of wind power expansion is to fulfil a certain energy target considering high economic efficiency. This means generating power with minimal resource consumption under market optimal conditions. In other words, a sustainable wind power expansion is characterized by (i) minimal potential impacts on birds and bats (avifauna), (ii) minimal potential impacts on human well-being and (iii) an efficient wind power production. These three criteria form the framework of this study. A multi criteria approach is applied to identify optimal WT allocations according the assessment criteria. Furthermore, four mono criteria optimisation Scenarios are investigated. Their results are compared with the multi criteria scenario to identify and compare the respective performance of wind power vis-a-vis trade-offs.

\section{$2 \quad$ Study Region and Data}

\subsection{Study region}

The study region corresponds to the Federal Republic of Germany. It has an area of $357,375.62 \mathrm{~km}^{2}$ and a population of approximately 82.18 million people with an average population density of 230 people per $\mathrm{km}^{2}$. By the end of 2016, 45,384 MW of wind power capacity hosted by $27,220 \mathrm{WTs}$ have been installed [1]. Taking into account that WT are erected in increasing number since the early 1990s, a significant number of these WTs will be reaching the end of their 20-year technical life span [13]. This opens a window of opportunity to improve the allocation of WTs while taking into consideration potential impacts on environmental and human well-being. 


\subsection{Data}

The main data for this analysis are land use/ land cover data, wind resource data, wind turbine parameters ( $3 \mathrm{MW}, 101 \mathrm{~m}$ rotor diameter and $149 \mathrm{~m}$ hub height) data and the geo data of national protected areas. The input data are displayed in Table 1.

Table 1. Overview of input data

\begin{tabular}{|c|c|}
\hline Data Type & Source \\
\hline Land use data & $\begin{array}{l}\text { - Land cover database DLM-DE } \\
\text { 2012. European Commission } \\
\text { programme to COoRdinate } \\
\text { INformation on the Environment } \\
\text { (Corine). } \\
\text { - Official Topographic- } \\
\text { Cartographic Information System } \\
\text { ATKIS, Working Committee of } \\
\text { the Surveying Authorities of the } \\
\text { Laender of the Federal Republic } \\
\text { of Germany }\end{array}$ \\
\hline $\begin{array}{l}\text { Wind resource } \\
\text { data }\end{array}$ & $\begin{array}{l}\text { GWS - Meso Data } \\
\text { Weibul- Data } \\
\text { AL-PRO GmbH \& Co. KG } \\
\text { Hub height: } 149 \mathrm{~m} \\
\text { Resolution: } 2 \text { x } 2 \mathrm{~km}\end{array}$ \\
\hline $\begin{array}{l}\text { Wind turbine } \\
\text { parameters }\end{array}$ & $\begin{array}{l}\text { Enercon E101 [18] } \\
\text { ENERCON GmbH } \\
\text { Dreekamp 5, D-26605 Aurich }\end{array}$ \\
\hline
\end{tabular}

\section{$3 \quad$ Methodology}

In this study, a three stage allocation and assessment approach is applied. First, suitable locations (cf. section 2.3) for WTs are selected. Location refers to an individual WT location, while the term site refers to areas able to carry several WT. Second, these locations are assessed by impact scores according to their potential impacts (avifauna and human well-being) and their annual energy production (AEP). These potential impacts then are aggregated to a dimensionless index value. Third, four scenarios are applied according to the objectives minimizing potential impacts (i) on nature conservation issues, (ii) on human well-being and according an resource efficient wind power production by (iii) minimizing the number of WT and (iv) improving market integration. A fifth scenario investigates possible improvements or the consequences of a multicriteria optimisation approach. According to the scenario framework conditions, potential WT locations are selected and their impacts are compared with each other. 
$19410^{\mathrm{TH}}$ International Conference on Sustainable Energy and EnVIRONMENTAL Protection (June $27^{\mathrm{TH}}-30^{\mathrm{TH}}, 2017$, Bled, SLOVEnia), RENEWABle ENERGY SOURCES M. Eichhorn, R. Becker, F. Masurowski \& D. Thrän: Spatial Sustainability Assessment of Wind Energy Expansion Scenarios

\subsection{Identification of suitable locations, wind turbine allocation and power production}

To identify suitable WT locations to fulfil a certain energy objective, a national energy potential mapping for wind power is applied. This process is illustrated in Figure 1.

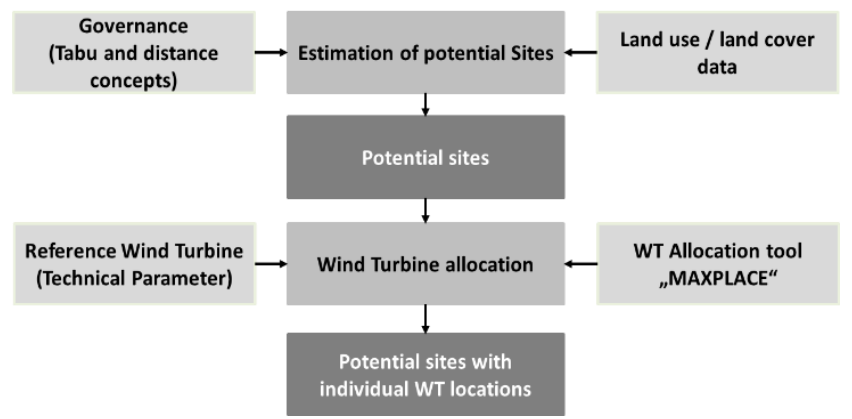

Figure 1: Flowchart of identification of suitable locations

Applying legal and physical constraints and distance criteria[19], a pool of suitable sites for erecting wind turbines was identified. In a next step a new software solution for allocating WT locations within multiple suitable sites is applied for the selected reference WT in Germany[20]. To estimate how many WTs are needed to fulfil a certain energy objective and to assess its individual performance, the annual energy production of each potential location is calculated [21].

\subsection{Assessment criteria and potential impact}

In this study the basic assumption is that the negative potential impacts on threatened species and human well-being decrease with increasing distance of a WT from protected areas [22-24] or settlements [12-14] and with decreasing number of WTs in total. Thus the respective assessment criteria are (i) distance to protected areas, (ii) distance to settlements and (iii) number of WTs. The distances between the potential WT location and the nearest neighbouring protected area or settlements are estimated using a geographical information system. To avoid boundary effects, protected areas and settlements within a $50 \mathrm{~km}$ buffer around Germany are considered. The measured distances (D) were then transferred into a potential impact (I) value (cf. equation 2) where large distances stand for low potential impacts and small distances stand for large impacts. The impact is a dimensionless value between 0 (low impact) and 1 (high impact) but allows for a better versus worse comparison.

$$
l=1-\frac{\left(D-D_{\min }\right)}{\left(D_{\max }-D_{\min }\right)}
$$


Finally, the impact values are aggregated to an also dimensionless sustainability index $\left(\mathrm{I}_{\mathrm{x}}\right)$ for every potential location where a lower Index value outperforms a higher value (cf. equation 3).

$$
I_{x}=\frac{I_{1}+I_{2}+I_{n}}{n}
$$

\subsection{Wind power expansion scenarios}

The framing condition for the investigated scenarios are taken from Nitsch et al. [25]. This so-called "lead study" assumes in Scenario 2011B that in 2050 about 279 TWh wind energy will be made up by $141 \mathrm{TWh}$ on-shore and $138 \mathrm{TWh}$ off-shore wind energy. In this manuscript, $141 \mathrm{TWh}$ wind power on-shore is set as the energy objective. The introduced selection and assessment approach is independent from a specific energy objective. Hence, changing energy objectives for on-shore wind power can always be considered.

In this study five wind power expansion scenarios are applied and investigated. Four of these scenarios are based on mono-criterion optimisation techniques and one applies a multi-criteria optimisation and allocation. An overview of the scenarios is shown in Table 2.

Table 2. Overview of the scenarios

\begin{tabular}{|c|c|}
\hline Type & Conditions \\
\hline $\begin{array}{l}\text { Scenario A Multi- } \\
\text { criteria optimisation }\end{array}$ & $\begin{array}{l}\text { Selecting WT in descending order based on the sum of } \\
\text { the reclassified distances to protected areas and settle- } \\
\text { ments and reclassified AEP. }\end{array}$ \\
\hline $\begin{array}{lrr}\text { Scenario } & \text { B } & \text { Wind } \\
\text { turbine } & & \text { minimal } \\
\text { allocation } & & \end{array}$ & $\begin{array}{l}\text { Selecting WT in decreasing order of their respective } \\
\text { AEP (WT with highest electricity production is the first } \\
\text { to be used and so on until the energy objective is } \\
\text { fulfilled) }\end{array}$ \\
\hline $\begin{array}{l}\text { Scenario } \\
\text { Environmental } \\
\text { protection }\end{array}$ & $\begin{array}{l}\text { Selecting WT in increasing order by their potential } \\
\text { impact on protected areas (WT with largest distance to } \\
\text { protected area is the first to be used and so on until } \\
\text { energy objective is fulfilled) }\end{array}$ \\
\hline $\begin{array}{l}\text { Scenario D Human } \\
\text { well-being }\end{array}$ & $\begin{array}{l}\text { Selecting WT in increasing order by their potential } \\
\text { impact on human well-being (WT with the largest } \\
\text { distance to settlement is the first to be used and so one } \\
\text { until energy objective is fulfilled) }\end{array}$ \\
\hline $\begin{array}{l}\text { Scenario } \mathbf{E} \quad \text { Market } \\
\text { integration scenario }\end{array}$ & $\begin{array}{l}\text { A transition towards fully market integrated renewables } \\
\text { is assumed after } 100 \mathrm{TWh} \text { under the WT minimal } \\
\text { allocation. Then, the location with the least sum of wind } \\
\text { power correlations to all other already existing WT is } \\
\text { picked first. }\end{array}$ \\
\hline
\end{tabular}


196 10 $10^{\mathrm{TH}}$ InTERnational CONFERENCE ON Sustainable EnERgy and ENVIRONMENTAL Protection (June $27^{\mathrm{TH}}-30^{\mathrm{TH}}, 2017$, Bled, SLOVEnia), RENEWABle ENERGY SOURCES M. Eichhorn, R. Becker, F. Masurowski \& D. Thrän: Spatial Sustainability Assessment of Wind Energy Expansion Scenarios

\section{Multi-criteria optimisation}

In this study, techniques following the multi-attributes value theory $[26,27]$ are applied. In accordance, a sustainable WT location is characterised by (1) a maximum distance to protected areas, (2) a maximum distance to settlements and (3) with the highest possible annual electricity production compared to other potential WT locations in Germany.

To estimate the sustainability of WT locations, the individual scores of annual electricity production, distance to protected areas and distance to settlements for one WT location are cumulated on a cardinal scale. This is possible because a higher value (greater distance or higher electricity generation) is better than a lower one for every criterion. Finally, the suitable WT locations are ranked in descending order, which indicates the best location according to the assessment criteria.

\section{Market integration scenario}

Here it is assumed that renewable energy generators will be fully integrated into the power markets after a phase with renewable energy subsidies (e.g. fixed energy feed-in tariffs) and that wind power is the price driving technology. Hence, WTs compete with other WTs in the market and locations with less average wind yield but negatively correlated wind speeds to the majority of wind farms become attractive for investors. To still yield minimum revenues, the minimum average wind speed is introduced and set to $5.5 \mathrm{~m} / \mathrm{s}$. This approach is elaborated in more detail in [28].

\section{$4 \quad$ Results}

\subsection{Identification of suitable locations, wind turbine allocation and power production}

As theoretical feasible potential according to the applied method, 129,896 potential WT locations could be identified (cf. Figure 2). These locations fulfil all physical and legal requirements for erecting WTs. The power output per potential WT location ranges from 1.7 Giga Watt hours (GWh) to $14 \mathrm{GWh}$. In total 1,165 Terra Watt hours (TWh) per year could be harvested. 
$10^{\mathrm{TH}}$ InTERnational CONFERENCE on Sustainable EnERgy AND Environmental Protection (June $27^{\mathrm{TH}}-30^{\mathrm{TH}}, 2017$, Bled, SLOVEniA), RENEWABLE ENERGy SOURCES M. Eichhorn, R. Becker, F. Masurowski \& D. Thrän: Spatial Sustainability Assessment of Wind Energy Expansion Scenarios

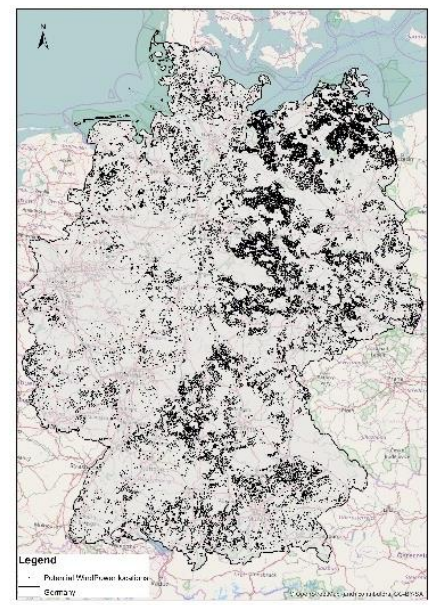

Figure 2: Maximal number of legally possible WT locations

\subsection{Wind power expansion scenarios}

The four mono criteria scenarios and the one multi criterion scenario lead to quite different results both in terms of spatial allocation of WTs and the resulting potential impacts. Figures $3 \mathrm{a}$ to $3 \mathrm{e}$ illustrate the spatial distribution of WTs according to the different scenarios. 

$10^{\text {Th }}$ International Conference on Sustainable Energy and Environmental Protection (June $27^{\mathrm{TH}}-30^{\mathrm{TH}}, 2017$, BlED, SLOVENIA), RENEWABLE ENERGy SOURCES M. Eichhorn, R. Becker, F. Masurowski \& D. Thrän: Spatial Sustainability Assessment of Wind Energy Expansion Scenarios

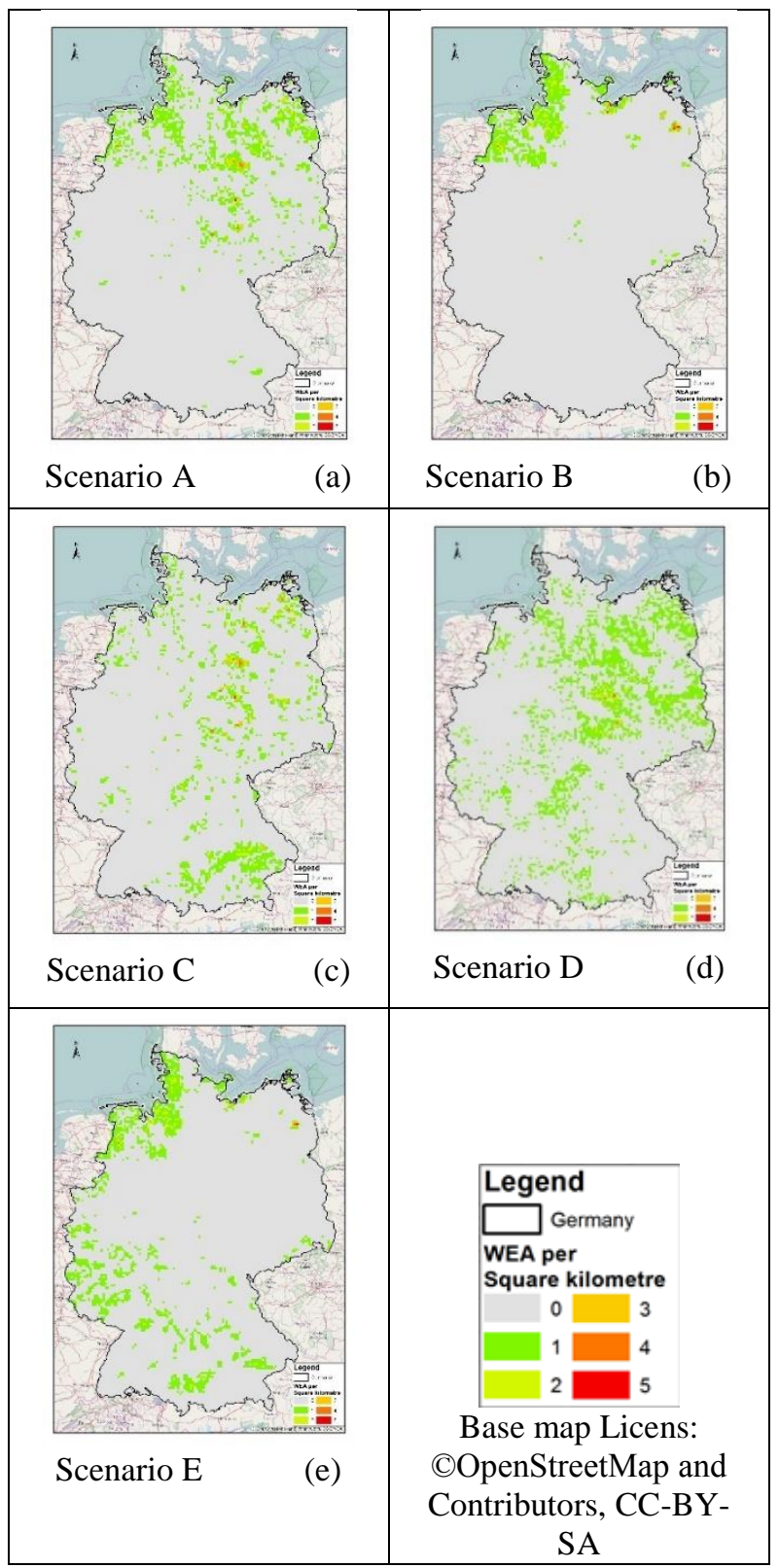

Figure 3: Spatial distribution of WT (WT per square kilometre). 3a Multi-criteriascenario, 3b Wind turbine minimal allocation scenario, 3c Nature Conservation scenario, 3d Human well-being scenario, 3e Market integration scenario. 
$10^{\mathrm{TH}}$ InTERnational CONFerence on Sustainable EnERgy AND Environmental 199 Protection (June $27^{\mathrm{TH}}-30^{\mathrm{TH}}, 2017$, BLED, SLOVENIA), RENEWABLE ENERGY SOURCES M. Eichhorn, R. Becker, F. Masurowski \& D. Thrän: Spatial Sustainability Assessment of Wind Energy Expansion Scenarios

The results of the scenario assessment according to the deduced index are illustrated in Table 3.

Table 3. Results of the analysis

\begin{tabular}{|l|c|c|c|}
\hline & $\begin{array}{c}\text { Number } \\
\text { of WT }\end{array}$ & $\begin{array}{c}\text { Pot. Impact } \\
\text { on Nature } \\
\text { Conservatio } \\
\text { n Issues } \\
{[-]}\end{array}$ & $\begin{array}{c}\text { Pot. Impact } \\
\text { on Human } \\
\text { well-being }\end{array}$ \\
\hline Scenario A & 13,171 & 10,357 & 8595 \\
\hline Scenario B & 11,814 & 10,799 & 9312 \\
\hline Scenario C & 15,949 & 11,212 & 12,225 \\
\hline Scenario D & 15,603 & 13,986 & 8916 \\
\hline Scenario E & 14,020 & 12,686 & 11,105 \\
\hline
\end{tabular}

\begin{tabular}{|l|c|c|}
\hline & $\begin{array}{c}\text { Number of WT } \\
{[\mathrm{n}]}\end{array}$ & $\begin{array}{c}\text { Index } \\
{[-]}\end{array}$ \\
\hline Scenario A & 13,171 & 9485 \\
\hline Scenario B & 11,814 & 10,055 \\
\hline Scenario C & 15,949 & 11,718 \\
\hline Scenario D & 15,603 & 11,451 \\
\hline Scenario E & 14,020 & 11,895 \\
\hline
\end{tabular}

\section{5}

\section{Conclusion}

The objective of this study was to identify WT locations that cause as less as possible potential impacts on nature conservation issues as well as human wellbeing and that save resources by allocating the minimal necessary amount of WTs. Hence, it is demonstrated that by simple means such locations can be identified meanwhile accounting for different trade-offs. According to the number of WTs, Scenario B performs best. This was expected because only highly productive locations have been selected and, thus, a minimal number of WTs were needed to fulfil the energy objective. Scenario C and D perform worse. This is due to the fact that the allocation was based on the distance to the protected areas and settlements and the the AEP of individual locations was not considered. Therefore, more locations are needed since not only the productive ones are selected. Scenario A offers a compromise. Here more plants are needed then in Scenario $\mathrm{B}$ but less than in Scenario $\mathrm{C}$ and D. Considering further the sustainability index gives a clearer picture. Here Scenario A outperforms all other scenarios. Scenario B performs second best however based more on the low total number of wind turbines then because of preferable locations. Likewise the worse total performance of Scenarios C and D are caused by the needed total number of WTs. Scenario E performs worst although only energetic issues are considered. However, in this scenario market conditions as well as system stabilisation concerns are considered. This illustrates that new concepts needed from a market or system perspective can bring new trade-offs in sustainable performance 
$200 \quad 10^{\mathrm{TH}}$ International Conference on Sustainable EnERgy AND ENVIRONMENTAL Protection (June $27^{\mathrm{TH}}-30^{\mathrm{TH}}, 2017$, Bled, SLovenia), Renewable EnERGy SOURCES M. Eichhorn, R. Becker, F. Masurowski \& D. Thrän: Spatial Sustainability Assessment of Wind Energy Expansion Scenarios

of wind power production. In conclusion, a joint consideration of multiple interests of the different stakeholders results in more sustainable solutions for all parties than emphasising individual interests.

\section{Acknowledgements}

We would like to thank the Helmholtz-Centre for Environmental Research GmbH - UFZ for its kind support.

\section{References}

[1] UBA. Erneuerbare Energien in Deutschland. Daten zur Entwicklung im Jahr 2016. In: Umweltbundesamt, 2.5 FI, editors. Dessau-Roßlau: Umweltbundesamt; 2017.

[2] Wang S, Wang S. Impacts of wind energy on environment: A review. Renewable and Sustainable Energy Reviews. 2015;49:437-43.

[3] Al Zohbi G, Hendrick P, Bouillard P. Evaluation of the impact of wind farms on birds: The case study of Lebanon. Renewable Energy. 2015;80(0):682-9.

[4] Bellebaum J, Korner-Nievergelt F, Dürr T, Mammen U. Wind turbine fatalities approach a level of concern in a raptor population. Journal for Nature Conservation. 2013;21(6):394400.

[5] Arnett EB, Baerwald EF, Mathews F, Rodrigues L, Rodríguez-Durán A, Rydell J, et al. Impacts of wind energy development on bats: a global perspective. In: Voigt CC, Kingston T, editors. Bats in the Anthropocene: Conservation of Bats in a Changing World: SpringerVerlag; 2016. p. 295-323.

[6] May R, Gill AB, Köppel J, Langston RHW, Reichenbach M, Scheidat M, et al. Future Research Directions to Reconcile Wind Turbine-Wildlife Interactions. In: Köppel J, editor. Wind Energy and Wildlife Interactions: Presentations from the CWW2015 Conference: Springer International Publishing; 2017. p. 255-76.

[7] Hötker H, Thomsen KM, Jeromin H. Impacts on biodiversity of exploitation of renewable energy sources: the example of birds and bats - facts, gaps in knowledge, demands for further research, and ornithological guidelines for the development of renewable energy exploitation. Michael-Otto-Institut im NABU, Bergenhusen.2006.

[8] Rees EC. Impacts of wind farms on swans and geese: A review. Wildflow. 2012;62:37-72.

[9] Rydell J, Bach L, Dubourg-Savage M-J, Green M, Rodrigues L, Hedenström A. Bat Mortality at Wind Turbines in Northwestern Europe. Acta Chiropterologica. 2010;12(2):261-74.

[10] Drewitt AL, Langston RH. Assessing the impacts of wind farms on birds. Ibis. 2006;148(s1):29-42.

[11] Linn S. Lehnert, Stephanie Kramer-Schadt, Sophia Schönborn, Oliver Lindecke, Ivo Niermann, Voigt CC. Wind Farm Facilities in Germany Kill Noctule Bats from Near and Far. PLOS One. 2014;9(8).

[12] Meyerhoff J. Do turbines in the vicinity of respondents' residences influence choices among programmes for future wind power generation? Journal of Choice Modelling. 2013;7:5871.

[13] Meyerhoff J, Ohl C, Hartje V. Landscape externalities from onshore wind power. Energy Policy. 2010;38(1):82-92.

[14] Petrova MA. From NIMBY to acceptance: Toward a novel framework - VESPA — For organizing and interpreting community concerns. Renewable Energy. 2016;86:1280-94. 
[15] Lärm T. Sechste Allgemeine Verwaltungsvorschrift zum Bundes-Immissionsschutzgesetz (Technische Anleitung zum Schutz gegen Lärm - TA Lärm). VSGA 1998.

[16] BImSchG. Gesetz zum Schutz vor schädlichen Umwelteinwirkungen durch Luftverunreinigungen, Geräusche, Erschütterungen und ähnliche Vorgänge (BundesImmissionsschutzgesetz - ImSchG). 1974 2016. p. 56.

[17] Bund-Länder-Initiative-Windenergie. Überblick $\mathrm{zu}$ den landesplanerischen Abstandsempfehlungen für die Regionalplanung zur Ausweisung von Windenergiegebieten. Bund-Länder Initiative Windenergie; 2013. p. 5.

[18] Enercon. Technologie \& Service. 2016.

[19] Eichhorn M, Drechsler M. Spatial trade-offs between wind power production and bird collision avoidance in agricultural landscapes. Ecology and Society. 2010;15((2):10).

[20] Masurowski F, Drechsler M, Frank K. A spatially explicit assessment of the wind energy potential in response to an increased distance between wind turbines and settlements in Germany. Energy Policy. 2016;97:345-50.

[21] Eichhorn M, Tafarte P, Thraen D. Towards energy landscapes - Pathfinder for sustainable wind power locations. Energy. 2017; accepted.

[22] LAG-VSW. Abstandsempfehlungen für Windenergieanlagen $\mathrm{zu}$ bedeutsamen Vogellebensräumen sowie Brutplätzen ausgewählter Vogelarten. in der Überarbeitung vom 15. April 2015. Länderarbeitsgemeinschaft der Staatlichen Vogelschutzwarten in Deutschland LAG VSW; 2015. p. 29.

[23] Schlacke S, Schnittker D. Abstandsempfehlungen für Windenergieanlagen zu bedeutsamen Vogellebensräumen sowie Brutplätzen ausgewählter Vogelarten - Gutachterliche Stellungnahme zur rechtlichen Bedeutung des Helgoländer Papiers der Länderarbeitsgemeinschaft der Staatlichen Vogelschutzwarten (LAG VSW 2015). Berlin2015.

[24] VSW LdVL. Vorgaben und Empfehlungen der Länder. In: VSW LdVL, editor.2017.

[25] Nitsch J, Pregger T, Naegler T, Heide D, Tena DLd, Trieb F, et al. Langfristszenarien und Strategien für den Ausbau der erneuerbaren Energien in Deutschland bei Berücksichtigung der Entwicklung in Europa und global - Leitstudie 2011. Stuttgart, Kassel, Teltow: Deutsches Zentrum für Luft- und Raumfahrt (DLR), Institut für Technische Thermodynamik, Abt. Systemanalyse und Technikbewertung Fraunhofer Institut für Windenergie und Energiesystemtechnik (IWES), Ingenieurbüro für neue Energien (IFNE); 2012. p. 345.

[26] Ferretti V, Comino E. An integrated framework to assess complex cultural and natural heritage systems with Multi-Attribute Value Theory. Journal of Cultural Heritage. 2015;16(5):688-97.

[27] Herwijnen Mv. Multiple-attribute value theory (MAVT). IVM Institut for Environmental Studies, VRIJE University Amsterdam. p. 5.

[28] Becker R, thrän D. Optimal Siting of Wind Farms in Wind Energy Dominated Power Systems. 12th Conference on Sustainable Development of Energy, Water and Environment Systems. Dubrovnik, Croatia.2017. 
202 10 $10^{\mathrm{TH}}$ International CONFERENCE on Sustainable ENERgy AND ENVIRONMENTAL Protection (June $27^{\mathrm{TH}}-30^{\mathrm{TH}}, 2017$, Bled, Slovenia), Renewable ENERGy SOURCES 
$10^{\mathrm{TH}}$ InTERnational CONFEREnCE ON Sustainable ENERgy AND ENVIRONMENTAL Protection (June $27^{\mathrm{TH}}-30^{\mathrm{TH}}$, 2017, Bled, SLOVENIA), RENEWABLE ENERGy SOURCES J. Krope, A.Ghani Olabi, D. Goričanec \& S. Božičnik

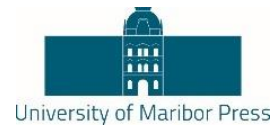

\title{
Comparison of the Shading Influence on PV Modules of Different Technologies
}

\author{
GORAN KNEŽEVIĆ, DANIJEL TOPIĆ, MATEJ ŽNIDAREC, BOJAN ŠTUMBERGER, MIRALEM \\ HADŽISELIMOVIĆ \& SEBASTIJAN SEME
}

\begin{abstract}
The characteristics of different PV modules are provided in this paper. The influence of shading on PV module characteristics of different technologies (different crystalline silicon and thin film technologies) is investigated. The study also took into account the orientation of PV modules (portrait or landscape), a by-pass diode number and a type of connections. An inter-row shading factor for different PV modules has also been determined. A comparison of shading influence on PV module characteristics of different technologies has been drawn. A shading factor comparison of different technology PV modules has also been made. The influence of shading on PV system electricity production has been modelled based on a study which examined the influence of shading on characteristics of different technology PV modules.
\end{abstract}

Keywords: • shading • influence - shading factor • PV modules technologies $\bullet$ comparison $\bullet$

Correspondence Address: Goran Knežević, Ph.D., Assistant Professor, J.J. Strossmayer University of Osijek, Faculty of Electrical Engineering, Computer Science and Information Technology Osijek, K. Trpimira 2B, 31000 Osijek, Croatia, e-mail: goran.knezevic@etfos.hr. Danijel Topić, Ph.D., Assistant Professor, J.J. Strossmayer University of Osijek, Faculty of Electrical Engineering, Computer Science and Information Technology Osijek, K. Trpimira 2B, 31000 Osijek, Croatia, e-mail: danijel.topic@etfos.hr. Matej Žnidarec, Assistant, J.J. Strossmayer University of Osijek, Faculty of Electrical Engineering, Computer Science and Information Technology Osijek, K. Trpimira 2B, 31000 Osijek, Croatia, e-mail: matej.znidarec@etfos.hr. Bojan Štumberger, Ph.D., Full Professor, University of Maribor, Faculty of Energy Technology, Hočevarjev trg 1, 8270 Krško, Slovenia, e-mail: bojan.stumberger@uni-mb.si. Miralem Hadžiselimović, Ph.D., Associate Professor, University of Maribor, Faculty of Energy Technology, Hočevarjev trg 1, 8270 Krško, Slovenia, e-mail: miralem.h@uni-mb.si. Sebastijan Seme, Ph.D., Associate Professor, University of Maribor, Faculty of Energy Technology, Hočevarjev trg 1, 8270 Krško, Slovenia, e-mail: sebasijan.seme@um.si.

https://doi.org/10.18690/978-961-286-061-5.19

ISBN 978-961-286-061-5

(C) 2017 University of Maribor Press

Available at: http://press.um.si. 
$10^{\text {TH }}$ International CONFEREnce on Sustainable Energy and Environmental Protection (June $27^{\mathrm{TH}}-30^{\mathrm{TH}}, 2017$, BlED, SLOVENIA), RENEWABLE ENERGY SOURCES G. Knežević, D. Topić, M. Žnidarec, B. Štumberger, M. Hadžiselimović \& S. Seme: Comparison of the Shading Influence on PV Modules of Different Technologies

World's power generation is still mostly on fossil fuels based. Due to the problems of limited reserves of fossil fuels and climate changes in previous years, usage of renewable sources had significantly increased. In order to reduce $\mathrm{CO}_{2}$ emissions and increase share of renewables many international agreements were signed (Kyoto, 1997 and 2005; Cancun, 2010; Lima, 2014; Paris 2015). On October 2014, EU adopted 2030 Climate and Energy Policy Framework with following conclusions [1]:

- At least $40 \%$ domestic reduction in greenhouse gas emissions by 2030 compared to 1990.

- At least $27 \%$ is set for the share of renewable energy consumed in the EU in 2030.

- At least $27 \%$ is set for improving energy efficiency in 2030 compared to projections of future energy consumption.

According to [2], photovoltaics (PV) is a key technology option for implementing the shift to a decarbonised energy supply and can be deployed in a modular way almost everywhere on this planet and solar resources in Europe and across the world are abundant and cannot be monopolised by one country. PV is one of the fastest growing capacity in recent years. According to [2] PV capacity in 2014 was $177 \mathrm{GW}$ and in the end of 2015 was $227 \mathrm{GW}$. That is nearly 10 times the world's cumulative PV capacity of a decade earlier [3]. Most of PV modules used in PV capacity are crystalline (mono or multi) modules. Production capacity of PV modules in 2015 was estimated in range of $63 \mathrm{GW}$ to $69 \mathrm{GW}$. According to [3], production of the thin film PV modules in 2015 increased by an estimated $13 \%$, accounting for $8 \%$ of total global PV production (down from $10 \%$ in 2014).

Many different factors influence on electricity generation of the PV modules. One of the factors that significantly influences on output power of the PV module is shading. Many researches about influence of shading are already conducted. In [4], shading effects on current - voltage characteristic of a mono-crystalline PV module is investigated. Experimental model for estimation of energy losses in PV arrays caused by shading is presented in [5]. In [6], influence of partial shading on of characteristics of the PV modules with different connection configuration of cells is investigated. Electrical characteristics and operation of series connected modules in condition of partial shading using MATLAB model is investigated in [7]. Shading factor which depends on the ratio of sunny part of the module and total module area is introduced by [8]. Discrete currentvoltage model for partially shaded PV arrays using Newton-Raphson algorithm, interpolation methods and analytical approximations is presented in [9]. In [10], influence of shading on CIGS PV modules is presented. Effects of shading on PV systems are also investigated in [11], [12], [13] and [14].

Aim of this paper is to investigate influence of shading on characteristics of different PV modules technologies and drawn comparison. Following PV module technologies are 

Protection (June $27^{\mathrm{TH}}-30^{\mathrm{TH}}$, 2017, BLED, SLOVEnia), RenEwABLE ENERGY SOURCES

G. Knežević, D. Topić, M. Žnidarec, B. Štumberger, M. Hadžiselimović \& S. Seme: Comparison of the Shading Influence on PV Modules of Different Technologies

investigated: mono-crystalline, multi crystalline, high-efficient monocrystalline, a-Si thin film and CIS thin film. Based on measurements results, the influence of shading on PV system electricity production has been modelled.

\section{$2 \quad$ Methodology}

In this chapter proposed methodology will be described. Methodology consists: measurement procedure, calculation of shading factor and description of the used mathematical model.

\subsection{Measurement procedure}

Measurements of influence of the shading on the characteristics of PV modules of different technologies is conducted. Following PV modules technologies were tested: mono-crystalline, multi crystalline, high-efficient monocrystalline, a-Si thin film and CIS thin film. Measurements were conducted in ResLAB. In Figure 1, measurement procedure is presented.

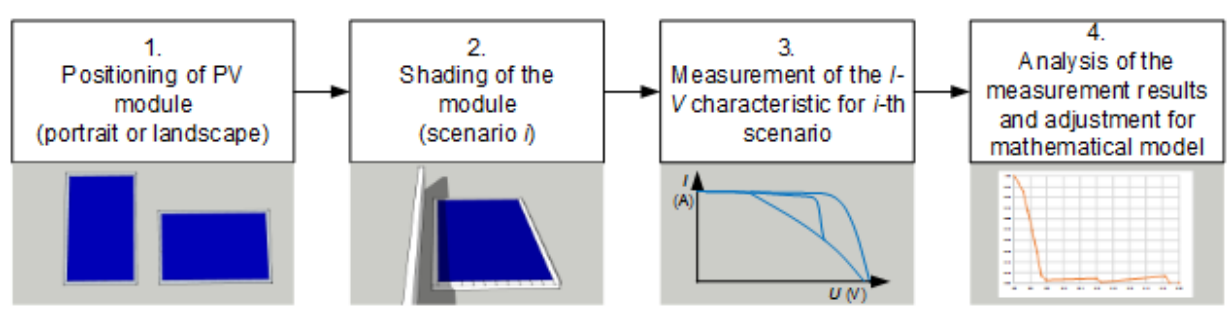

Figure 1. Measurement Procedure

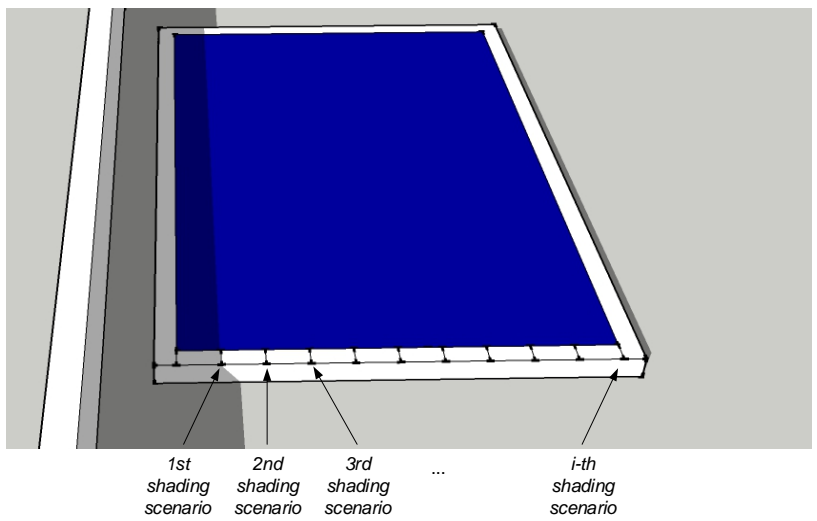

Figure 2. Shading Scenarios

Influence of shading on characteristics of PV modules for landscape and portrait orientations of PV modules is investigated. Shading of the module scenarios are presented 
$206 \quad 10^{\mathrm{TH}}$ INTERNATIONAL CONFERENCE ON Sustainable ENERGy AND ENVIRONMENTAL Protection (June $27^{\mathrm{TH}}-30^{\mathrm{TH}}, 2017$, BlED, SLOVENIA), RENEWABLE ENERGY SOURCES G. Knežević, D. Topić, M. Žnidarec, B. Štumberger, M. Hadžiselimović \& S. Seme: Comparison of the Shading Influence on PV Modules of Different Technologies

in figure 2. First scenario is: $8 \%$ of the module area in landscape orientation is shaded, second scenario: $16 \%$ of the module area in landscape orientation is shaded, etc. Then same procedure is applied for portrait orientation with step of $5 \%$ of area. Same shading scenarios for all five PV module technologies are repeated.

\subsection{Calculation of the shading factor}

As presented in [8], the influence of shading on PV module output power can be taken into account by shading factor $\eta_{\mathrm{s}}$ depending on the ratio of the sunny part of the module $A_{\mathrm{s}}$ and the total module surface $A$ as in (1):

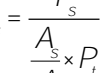

where $P_{s}$ is the measured output power of the partially shaded module and $P_{t}$ is the output power of the unshaded module. In this way, calculated shading factor can be represented as a function of the ratio $A_{\mathrm{s}} / A$. In addition, piecewise linear approximation of obtained function $\eta_{\mathrm{s}}\left(A_{s} / A\right)$ can be performed so the shading factor then can be easily calculated according to the given ratio of the sunny part and the total module surface.

\subsection{Description of the used mathematical model}

Expression for calculating an annual energy production of PV system for the given installation area taking into account the influence of the inter-row shading on the PV module output power is presented in (2) [8].

$W_{\beta, r}=\sum_{i}^{365} \sum_{j}^{n p} \frac{0,25}{1000} G_{\beta, i, j} A \cdot \eta_{r} \cdot n_{\theta_{\beta, j}} \cdot n_{d_{\beta}} \cdot\left(1+(r-1) \cdot \frac{1+\frac{d}{b \cdot \cos \beta}}{1+\frac{\tan \beta}{\operatorname{tg} \alpha_{i, j}}} \cdot \eta_{s}\right)[\mathrm{kWh}]$

Where:

$n p \quad$ - the number of 15-minute periods in one day

$G_{\beta, i, j} \quad$ - average insolation in a 15 -minute period $j$ in a day $I$ for the given module angle $\beta$;

A - size of a total PV module surface in one row;

$\eta_{r} \quad$ - rated efficiency of the observed PV module;

$n_{\theta_{\beta, i, j}}$ - temperature factor in a 15 -minute period $j$ in a day $i$ for the given module angle $\beta$;

$n_{d_{\beta}} \quad$ - dust factor for the given module angle $\beta$;

$r \quad$ - number of rows in the solar power plant; 
$d \quad$ - distance between PV module rows;

$b \quad$ - PV module width;

$a \quad$ - PV module length;

$\beta \quad$ - PV module angle;

$\alpha_{i, j} \quad$ - the angle of the sun for period $j$ in a day $i$.

$\eta_{s} \quad$ - shading factor.

The distance between module rows can be calculated as in (3) [8].

$$
d=\frac{a p-b \cdot r \cdot \cos \beta}{r-1}
$$

Where:

ap - width of the parcel (across the module rows);

$b p \quad$ - length of the parcel (along the module rows);

$n m r$ - number of modules in one row.

The number of modules in one row and the size of the total module surface in one row can be calculated as:

$$
\begin{aligned}
& n m r=\text { floor }\left(\frac{b p}{a}\right) \\
& A=n m r \cdot a \cdot b
\end{aligned}
$$

The correlation between the ratio of the sunny and the total part of the module surface of the row following the first row, angle of the sun, angle of the PV module, distance between module rows and module equals [8]:

$$
\frac{A s}{A}=\frac{1+\frac{d}{b \cdot \cos \beta}}{1+\frac{\tan \beta}{\operatorname{tg} \alpha}}
$$

In order to maximize the annual energy production on the observed installation area, the optimal number of rows and a module angle can be determined by calculating the annual production for the given range of $r$ and $\beta$ and finding the maximal value of the production whose indexes show the optimal $r$ and $\beta$.

The model is created in MATLAB. In a double for loop for the given range of $r$ and $\beta$, $W_{\beta, r}$ is calculated for each pair of $r$ and $\beta$ using expression (2) and taking into account expressions (3)-(5). The obtained matrix of annual energy production related to tested $r$ 
208 10 $10^{\text {TH }}$ International Conference on Sustainable ENERgy AND ENVIRONMENTAL Protection (June $27^{\mathrm{TH}}-30^{\mathrm{TH}}, 2017$, BlED, SLOVENIA), RENEWABLE ENERGY SOURCES G. Knežević, D. Topić, M. Žnidarec, B. Štumberger, M. Hadžiselimović \& S. Seme: Comparison of the Shading Influence on PV Modules of Different Technologies

and $\beta$ is then searched for the maximal value which then reveals the optimal value of $r$ and $\beta$.

\section{Case Study}

\subsection{Case scenario description}

Optimal configuration of PV systems providing maximal annual energy production for different module types and different module orientation are determined for available installation area in Osijek, Croatia, oriented as it is shown in Fig. 3.

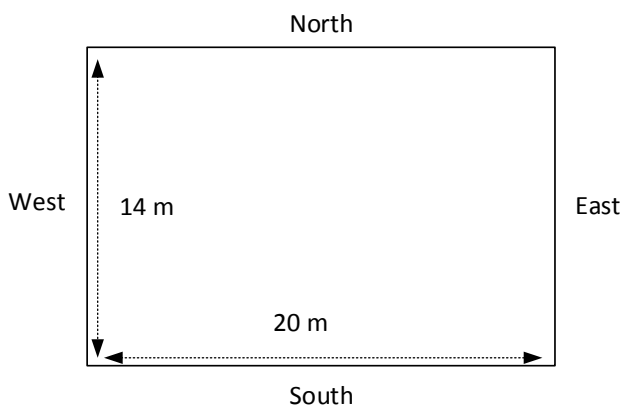

Figure 3. Orientation of Observed Area of the Installation of the PV Modules

For the given latitude $\left(45^{\circ} 33^{\prime} 24^{\prime \prime} \mathrm{N}\right)$ and longitude $\left(18^{\circ} 41^{\prime} 44^{\prime \prime} \mathrm{E}\right)$, the average daily solar irradiance $G$ for a 15 -minute periods on a fixed plane are taken from PVGIS [15] for the south orientation and inclination $\beta$ in the step of 1 degree for a range of 5 to 40 degrees. Cases with module angle less than 5 degrees are not considered due to significant influence of dust deposition [16], [17] and [18]. Technical characteristics of PV modules on which measurements were conducted are given in Table 1 
$10^{\mathrm{TH}}$ International CONFERENCE on Sustainable EnERgy AND ENVIRONMENTAL 209 Protection (June $27^{\mathrm{TH}}-30^{\mathrm{TH}}, 2017$, BLED, SLOVENIA), RENEWABLE ENERGY SOURCES

G. Knežević, D. Topić, M. Žnidarec, B. Štumberger, M. Hadžiselimović \& S. Seme: Comparison of the Shading Influence on PV Modules of Different Technologies

Table 2. Technical characteristics of the tested PV modules [19], [20],[21],[22] and [23]

\begin{tabular}{|c|c|c|c|c|c|}
\hline & $\begin{array}{c}\text { Bisol } \\
\text { BMO 250 }\end{array}$ & $\begin{array}{c}\text { Bisol } \\
\text { BMU } \\
250\end{array}$ & $\begin{array}{c}\text { Panasonic } \\
\text { VBHN240 }\end{array}$ & $\begin{array}{c}\text { Solar } \\
\text { Frontier } \\
\text { SF-150 }\end{array}$ & $\begin{array}{c}\text { Masdar } \\
\text { MPV100-S }\end{array}$ \\
\hline $\begin{array}{c}\text { Maximum Power } \\
\text { (W) }\end{array}$ & 250 & 250 & 240 & 150 & 100 \\
\hline $\begin{array}{c}\text { Short Circuit } \\
\text { Current (A) }\end{array}$ & 8.8 & 8.75 & 5.85 & 2.2 & 1.57 \\
\hline $\begin{array}{c}\text { Open Circuit } \\
\text { Voltage (V) }\end{array}$ & 37.9 & 38.4 & 52.4 & 108 & 100 \\
\hline MPP Current (A) & 8.2 & 8.25 & 5.51 & 1.85 & 1.33 \\
\hline MPP Voltage (V) & 30.5 & 30.3 & 43.7 & 81.5 & 76 \\
\hline $\begin{array}{c}\text { Power } \\
\text { Temperature } \\
\text { Coefficient } \gamma \\
\left.\text { (\%/ }{ }^{\circ} \mathrm{C}\right)\end{array}$ & -0.39 & -0.35 & -0.3 & -0.31 & -0.2 \\
\hline NOCT (\%) & 44 & 44 & 48.3 & 47 & N/A \\
\hline $\begin{array}{c}\text { Module } \\
\text { Efficiency (\%) }\end{array}$ & 15.3 & 15.3 & 19 & 12.2 & 6.99 \\
\hline $\begin{array}{c}\text { Module } \\
\text { Efficiency under } \\
\text { Real-Life }\end{array}$ & 14.15 & 14.15 & N/A & 9.04 & N/A \\
Conditions* (\%) & $1649 \times$ & $1649 \times$ & $1580 \times 798$ & $1257 \times$ & $1300 \times 32$ \\
\hline $\begin{array}{c}\text { Length (mm) } \\
\text { Width (mm) } \\
\text { Thickness (mm) }\end{array}$ & $991 \times 40$ & $991 \times 40$ & $\times 35$ & $977 \times 35$ & $1100 \times 32$ \\
\hline
\end{tabular}

\subsection{Measurement results}

In order to determine the influence of shading on the output power of each tested PV module, the measurement is conducted in the Laboratory for sources of Faculty of Electrical Engineering, Computer Science and Information Technology Osijek. Measurement is performed as it is described in Chapter 2.1. 

$10^{\text {TH }}$ International Conference on Sustainable Energy and Environmental Protection (June $27^{\mathrm{TH}}-30^{\mathrm{TH}}, 2017$, Bled, SLOVENIA), RENEWABLE ENERGY SOURCES G. Knežević, D. Topić, M. Žnidarec, B. Štumberger, M. Hadžiselimović \& S. Seme: Comparison of the Shading Influence on PV Modules of Different Technologies

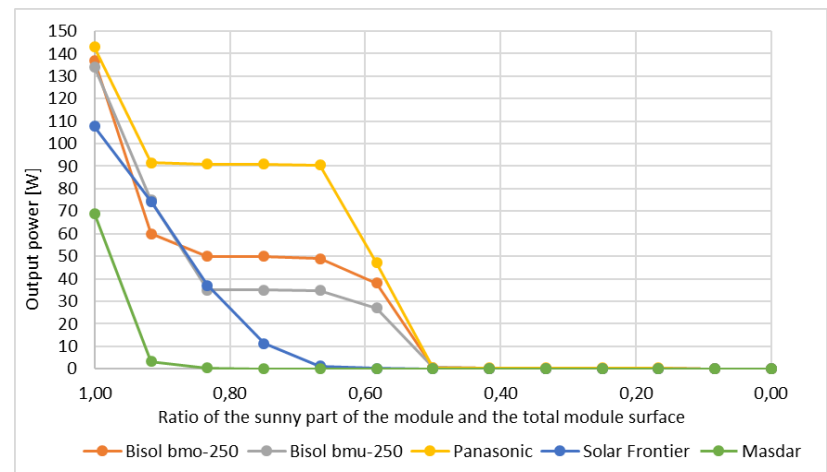

Figure 4. Measurement Results of the Output Power of the Landscape Oriented PV Modules in Respect to $A s / A$

Measurement results of the output power of the landscape oriented PV modules in respect to the ratio of the sunny part and the total module surface are presented in Figure 4.

The shading factor is calculated for each measurement step using expression (1). Calculated values of the shading factor of the landscape oriented PV modules in respect to the ratio of the sunny part and the total surface is presented in figure 5.

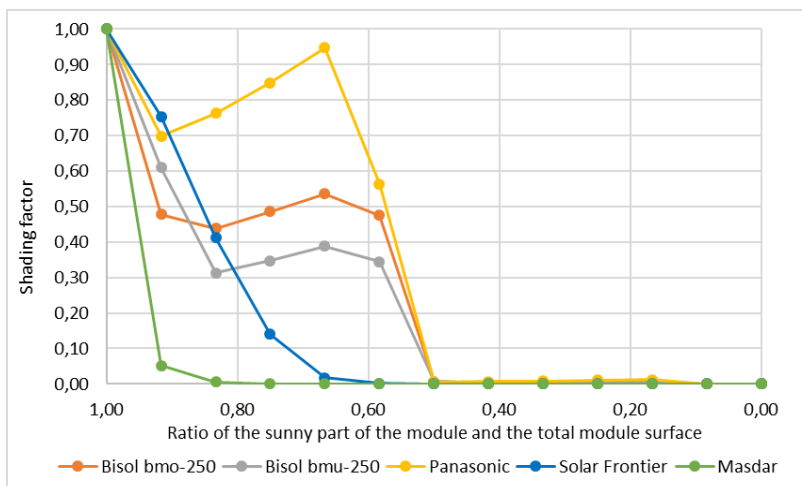

Figure 5. Calculated values of the shading factor of the landscape oriented PV modules in respect to $A s / A$ 

Protection (June $27^{\mathrm{TH}}-30^{\mathrm{TH}}, 2017$, Bled, SLOVEnia), RenEwable ENERGy SOURCES

G. Knežević, D. Topić, M. Žnidarec, B. Štumberger, M. Hadžiselimović \& S. Seme: Comparison of the Shading Influence on PV Modules of Different Technologies

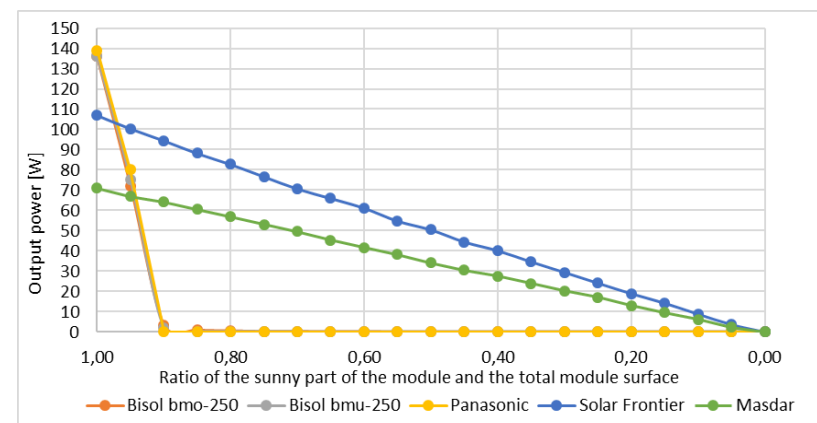

Figure 6. Measurement Results of the Output Power of the Portrait Oriented PV Modules in Respect to $A s / A$

Piecewise linear approximation is conducted and the function $\eta_{\mathrm{s}}\left(A_{\mathrm{s}} / A\right)$ is obtained. Thus, when calculating energy production using (2), a shading factor is calculated according to the given ratio of the sunny part and the total module surface that can be calculated using (6). Measurement results of the output power of the portrait oriented PV modules in respect to the ratio of the sunny part and the total module surface are presented in Figure 6.

Calculated values of the shading factor of the portrait oriented PV modules in respect to the ratio of the sunny part and the total module surface are presented in Figure 7. Piecewise linear approximation is conducted and the function $\eta_{\mathrm{s}}\left(A_{\mathrm{s}} / A\right)$ is obtained.

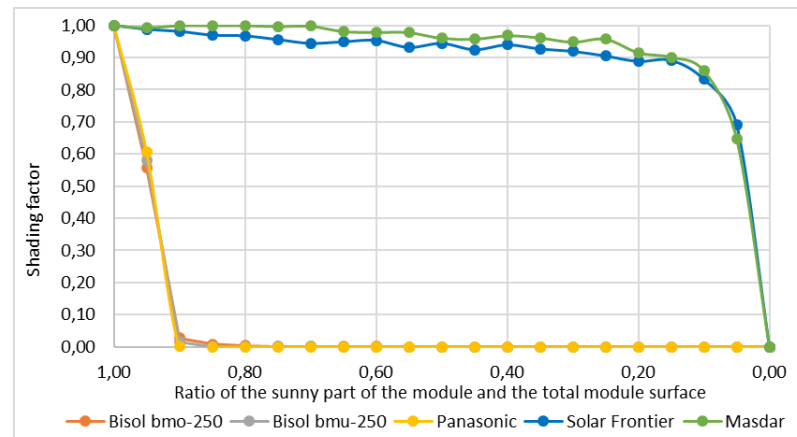

Figure 7. Calculated values of the shading factor of the portrait oriented PV modules in respect to $A s / A$

\subsection{Calculation of expected energy production for different PV modules}

Optimal configuration of PV systems providing maximal annual energy production for different module types and different module orientation are determined as it is described in Chapter 2.3. 
$10^{\mathrm{TH}}$ International Conference on Sustainable EnERgy and Environmental Protection (JuNE $27^{\mathrm{TH}}-30^{\mathrm{TH}}, 2017$, BlED, SLOVENIA), RENEWABLE ENERGY SOURCES G. Knežević, D. Topić, M. Žnidarec, B. Štumberger, M. Hadžiselimović \& S. Seme: Comparison of the Shading Influence on PV Modules of Different Technologies

For example, annual energy production of BMU 250 PV module (landscape orientation) in respect to the number of rows for the given module angle is presented in Figure 8.

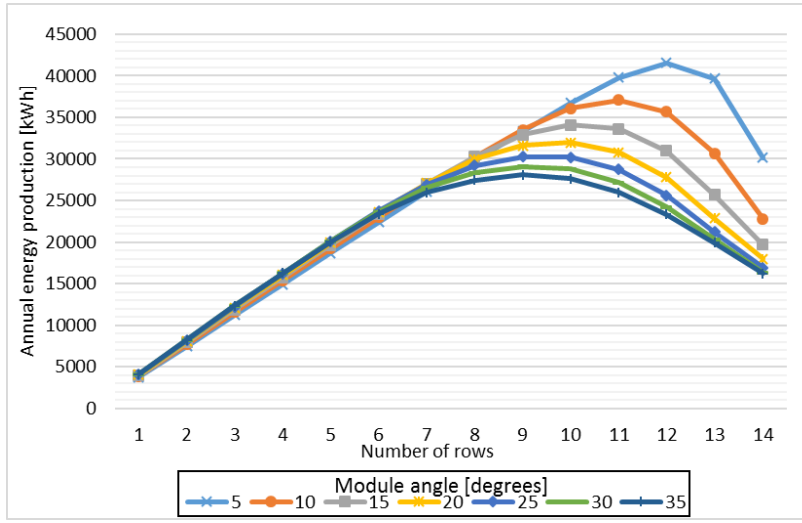

Figure 8. Annual energy production of BMU 250 PV module (landscape orientation) in respect to the number of rows

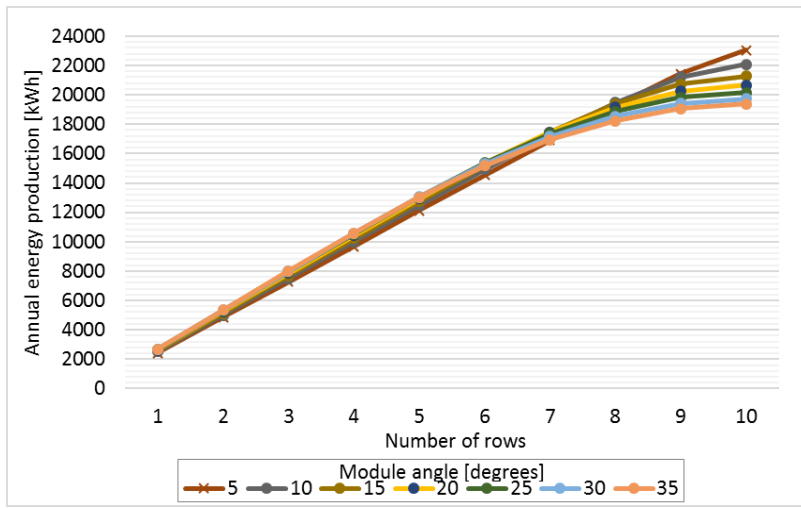

Figure 9 Annual energy production of Masdar PV module (portrait orientation) in respect to the number of rows

The annual energy production of Masdar PV module (portrait orientation) in respect to the number of rows for the given module angle is presented in Figure 9. 
$10^{\mathrm{TH}}$ InTERnational CONFerence on Sustainable EnERgy AND Environmental Protection (June 27 $7^{\mathrm{TH}}-30^{\mathrm{TH}}, 2017$, BLED, SLOVENIA), RENEWABLE ENERGY SOURCES

G. Knežević, D. Topić, M. Žnidarec, B. Štumberger, M. Hadžiselimović \& S. Seme: Comparison of the Shading Influence on PV Modules of Different Technologies

Table 2. Optimal configuration of PV power system providing maximal annual production for landscape $(\mathrm{L})$ and portrait $(\mathrm{P})$ orientation

\begin{tabular}{|c|c|c|c|c|c|c|}
\hline Module Type & $\begin{array}{c}\text { Optimal } \\
\text { number of } \\
\text { rows }\end{array}$ & $\begin{array}{c}\text { Optimal } \\
\text { angle } \\
\text { [degrees] }\end{array}$ & $\begin{array}{c}\text { Number of } \\
\text { modules in } \\
\text { one row }\end{array}$ & $\begin{array}{c}\text { Total number of } \\
\text { modules }\end{array}$ & $\begin{array}{c}\text { Maximum } \\
\text { power [kWp] }\end{array}$ & $\begin{array}{c}\text { Annual } \\
\text { production } \\
{[\mathrm{kWh}]}\end{array}$ \\
\hline Biscl BMO & $12(\mathrm{~L}) ;$ & $5(\mathrm{~L}) ;$ & $12(\mathrm{~L}) ;$ & $144(\mathrm{~L}) ;$ & $36(\mathrm{~L}) ;$ & $41395,7(\mathrm{~L}) ;$ \\
250 & $7(\mathrm{P})$ & $5(\mathrm{P})$ & $20(\mathrm{P})$ & $140(\mathrm{P})$ & $35(\mathrm{P})$ & $46782,2(\mathrm{P})$ \\
\hline Biscol BMU & $12(\mathrm{~L}) ;$ & $5(\mathrm{~L}) ;$ & $12(\mathrm{~L}) ;$ & $144(\mathrm{~L}) ;$ & $36(\mathrm{~L}) ;$ & $41550,4(\mathrm{~L}) ;$ \\
250 & $7(\mathrm{P})$ & $5(\mathrm{P})$ & $20(\mathrm{P})$ & $140(\mathrm{P})$ & $35(\mathrm{P})$ & $43927,0(\mathrm{P})$ \\
\hline \multirow{2}{*}{ Panasonic } & $14(\mathrm{~L}) ;$ & $5(\mathrm{~L}) ;$ & $12(\mathrm{~L}) ;$ & $168(\mathrm{~L}) ;$ & $40,32(\mathrm{~L}) ;$ & $52649,1(\mathrm{~L}) ;$ \\
& $7(\mathrm{P})$ & $5(\mathrm{P})$ & $25(\mathrm{P})$ & $175(\mathrm{P})$ & $42(\mathrm{P})$ & $53842,4(\mathrm{P})$ \\
\hline \multirow{2}{*}{ Solar Frontier } & $12(\mathrm{~L}) ;$ & $5(\mathrm{~L}) ;$ & $15(\mathrm{~L}) ;$ & $180(\mathrm{~L}) ;$ & $27(\mathrm{~L}) ;$ & $34209,1(\mathrm{~L}) ;$ \\
& $11(\mathrm{P})$ & $(\mathrm{P})$ & $20(\mathrm{P})$ & $220(\mathrm{P})$ & $33(\mathrm{P})$ & $39675,3(\mathrm{P})$ \\
\hline \multirow{2}{*}{ Masdar } & $10(\mathrm{~L}) ;$ & $5(\mathrm{~L}) ;$ & $15(\mathrm{~L}) ;$ & $150(\mathrm{~L}) ;$ & $15(\mathrm{~L}) ;$ & $19096,1(\mathrm{~L}) ;$ \\
& $10(\mathrm{P})$ & $(\mathrm{P})$ & $18(\mathrm{P})$ & $180(\mathrm{P})$ & $18(\mathrm{P})$ & $23059,0(\mathrm{P})$ \\
\hline
\end{tabular}

In this paper influence of shading on output power of different PV modules technologies in respect to shaded area is presented. Optimal configuration of the PV system with different PV module technologies providing maximal annual production for landscape and portrait orientation of the modules is determined.

\section{References}

[1] European Commission, "2030 climate \&amp; energy framework | Climate Action," Ec.Europa.Eu, 2016. [Online]. Available: https://ec.europa.eu/clima/policies/strategies/2030_en. [Accessed: 23-Mar-2017].

[2] W. E. Commission, P. V. S. Report, and F. E. Technologies, PV Status Report 2016 PV Status Report 2016, no. October. 2016.

[3] Kristin Seyboth et al., Renewables 2016 Global Status Report. 2016.

[4] S. Seme, "XII International PhD Workshop Shading effects in the IU characteristic of a mono-crystalline PV module," no. October, pp. 23-26, 2010.

[5] F. Martínez-Moreno, J. Muñoz, and E. Lorenzo, "Experimental model to estimate shading losses on PV arrays," Sol. Energy Mater. Sol. Cells, vol. 94, no. 12, pp. 2298-2303, 2010.

[6] Y. J. Wang and P. C. Hsu, "An investigation on partial shading of PV modules with different connection configurations of PV cells," Energy, vol. 36, no. 5, pp. 3069-3078, 2011.

[7] A. Mäki, S. Valkealahti, and J. Leppäaho, "Operation of series-connected silicon-based photovoltaic modules under partial shading conditions," Prog. Photovoltaics Res. Appl., 2012.

[8] D. Topić, G. Knežević, and K. Fekete, "The mathematical model for finding an optimal PV system configuration for the given installation area providing a maximal lifetime profit," Sol. Energy, vol. 144, pp. 750-757, 2017.

[9] E. Díaz-Dorado, J. Cidrás, and C. Carrillo, "Discrete I-V model for partially shaded PVarrays," Sol. Energy, vol. 103, pp. 96-107, 2014.

[10] N. G. Dhere, E. Schneller, and A. Kaul, "Effect of shading on CIGS thin film photovoltaic modules," 2015 IEEE 42nd Photovolt. Spec. Conf. PVSC 2015, no. 321, pp. 0-2, 2015.

[11] M. A. Ghasemi, H. Mohammadian Forushani, and M. Parniani, "Partial shading detection 
214 10 $10^{\mathrm{TH}}$ International CONFERENCE on Sustainable ENERgy AND ENVIRONMENTAL Protection (June $27^{\mathrm{TH}}-30^{\mathrm{TH}}, 2017$, BlED, SLOVENIA), RENEWABLE ENERGY SOURCES G. Knežević, D. Topić, M. Žnidarec, B. Štumberger, M. Hadžiselimović \& S. Seme: Comparison of the Shading Influence on PV Modules of Different Technologies

and smooth maximum power point tracking of PV arrays under PSC," IEEE Trans. Power Electron., vol. 31, no. 9, pp. 6281-6292, 2016.

[12] L. Fialho, R. Melicioa, V. M. F. Mendes, J. Figueiredo, and M. Collares-Pereiraa, "Effect of Shading on Series Solar Modules: Simulation and Experimental Results," Procedia Technol., vol. 17, pp. 295-302, 2014.

[13] S. Pareek and R. Dahiya, "Enhanced power generation of partial shaded photovoltaic fields by forecasting the interconnection of modules," Energy, vol. 95, pp. 561-572, 2016.

[14] M. Seyedmahmoudian, S. Mekhilef, R. Rahmani, R. Yusof, and E. T. Renani, "Analytical modeling of partially shaded photovoltaic systems," Energies, vol. 6, no. 1, pp. 128-144, 2013.

[15] "PV potential estimation utility." [Online]. Available: http://re.jrc.ec.europa.eu/pvgis/apps4/pvest.php\#. [Accessed: 10-Apr-2017].

[16] A. Sayyah, M. N. Horenstein, and M. K. Mazumder, "Energy yield loss caused by dust deposition on photovoltaic panels," Sol. Energy, vol. 107, pp. 576-604, 2014.

[17] M. Mani and R. Pillai, "Impact of dust on solar photovoltaic (PV) performance: Research status, challenges and recommendations," Renew. Sustain. Energy Rev., vol. 14, pp. 31243131, 2010.

[18] R. Appels et al., "Effect of soiling on photovoltaic modules," Sol. ENERGY, vol. 96, pp. 283-291, 2013.

[19] Bisol, "Bisol BMO 250 datasheet," 2015. .

[20] Bisol, "Bisol BMU 250 datasheet," 2014. .

[21] S. Frontier, "Solar FrontierSF150-S.".

[22] Masdar, "Masdar MPV100-S datasheet," 2014. .

[23] Panasonic, "Panasonic VBHN240SE10 datasheet," 2012. . 
$10^{\mathrm{TH}}$ InTERnational CONFERENCE ON Sustainable ENERgy AND ENVIRONMENTAL Protection (June $27^{\mathrm{TH}}-30^{\mathrm{TH}}$, 2017, Bled, SLOVENIA), RENEWABLE ENERGy SOURCES

J. Krope, A.Ghani Olabi, D. Goričanec \& S. Božičnik

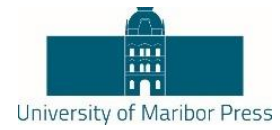

\title{
Enhanced Biohydrogen Production and $\mathrm{CO}_{2}$ Sink by Powered $\mathrm{Fe}^{\circ}$ Addition in Dark Fermentation
}

\author{
Carlos E. Gómez CAmacho, Francesco I. Romano \& Bernardo RugGeri
}

\begin{abstract}
This paper deals with experimental tests on dark fermentation (DF) carried out with different powered $\mathrm{Fe}^{\circ}$ concentrations. The anaerobic corrosion (AC) of $\mathrm{Fe}^{\circ}$ and the production of $\mathrm{H}_{2}$ through fermentation, were tested separately, while tests with $\mathrm{Fe}^{\circ}$ supplement on $\mathrm{DF}$ at $1 \mathrm{~g} / \mathrm{L}$ and $2 \mathrm{~g} / \mathrm{L}$ of $\mathrm{Fe}^{\circ}$ were conducted to ascertain synergic effects. Results of the Röels approach of relaxation times $(\tau R)$ suggested that $\mathrm{Fe}^{\circ} \mathrm{AC}$ and $\mathrm{DF}$ are concurrent phenomena. A positive synergic effect was experimentally verified: $\mathrm{H}_{2}$ production increased of $44 \%$ than the control test and of $35 \%$ compared with summation effect of $\mathrm{AC}$ and $\mathrm{DF}$. In addition, $\mathrm{Fe}^{\circ}$ supplement provokes decreases of $\mathrm{CO}_{2}$ yield of $56 \%$ in the case of $2 \mathrm{~g} / \mathrm{L}$ of $\mathrm{Fe}^{\circ}$ addition. This is in agreement with literature references, which advance the enzymatic activity enhancement due to the action of S-Fe clusters of Pyruvate: ferredoxin oxidoreductase (PFOR) enzyme to shift electrons towards hydrogenases.
\end{abstract}

Keywords: • dark fermentation - iron-supplementation $-\mathrm{CO}_{2}$ sink • biohydrogen $\bullet \mathrm{PV} \bullet$

Correspondence AdDress: Carlos E. Gómez Camacho, M.S.Che.E., Ph.D Student, Politecnico di Torino, Dep. of Applied Science and Technology (DISAT), C/so Ducadegli Abruzzi 24, 10129 Torino, Italy, email: carlos.gomezcamacho@polito.it. Francesco I. Romano, M.S.Che.E., Politecnico di Torino, Dep. of Applied Science and Technology (DISAT), C/so Ducadegli Abruzzi 24, 10129 Torino, Italy, email: francescoivan.romano@ studenti.polito.it. Bernardo Ruggeri, Ph.D., Associate Professor, Politecnico di Torino, Dep. of Applied Science and Technology (DISAT), C/so Ducadegli Abruzzi 24, 10129 Torino, Italy, email: bernardo.ruggeri@ polito.it.

https://doi.org/10.18690/978-961-286-061-5.20

ISBN 978-961-286-061-5

(C) 2017 University of Maribor Press

Available at: http://press.um.si. 
$10^{\text {TH }}$ International CONFEREnce on Sustainable Energy and Environmental Protection (June $27^{\mathrm{TH}}-30^{\mathrm{TH}}, 2017$, BlED, SLOVENIA), RENEWABLE ENERGY SOURCES C. E. Gómez Camacho, F. I. Romano \& B. Ruggeri: Enhanced Biohydrogen Production and $\mathrm{CO}_{2}$ Sink by Powered $\mathrm{Fe}^{\circ}$ Addition in Dark Fermentation

\section{Introduction}

Iron cycles are being extensively under studied in different areas, from groundwaters remediation techniques [1] to iron fertilization in ocean's geobiochemistry [2]. In the field of anaerobic digestion (AD), recent researches have addressed the topic of metals supplementation to biological systems for the enhancement of biohydrogen and/or biomethane production making the anaerobic fermentation process more attractive. However, the metal interactions with the biological phase of AD has not been fully assessed, due to the great variety of involved microorganisms, each of them containing a large number of different enzymes. The use of $\mathrm{AD}$ is widely diffused, not only in developed countries but also in developing countries where alternative energies are also gaining ground at different scales [3]. Nevertheless, biogas composition reaches at maximum $70 \% \mathrm{CH}_{4}$, but in most cases is around $40-60 \%$ with large fraction of $\mathrm{CO}_{2}$ (> $30 \%)$. Biogas upgrading represents additional steps with important repercussions in operational and capital expenditures, which ultimately reduces the energetic gain of the process [4].

Recent studies show a clear trend: the addition of zero-valent metals positively influences the generation of methane in $\mathrm{AD}$ and hydrogen in dark fermentation (DF). For example, the first studies of Yang et al. in 2013 [5] showed that at low doses $1.7 \mathrm{~g} / \mathrm{L}$ of nanostructured $\mathrm{Fe}^{\circ}, \mathrm{CH}_{4}$ production increased up to $10 \%$. More encouraging results were obtained by $\mathrm{Hu}$ et al. [6], achieving more than $60 \%$ increase in methane yield, using different doses up to $20 \mathrm{~g} / \mathrm{L}$ of nanostructured $\mathrm{Fe}^{\circ}$ and waste iron scraps. Abdelsalam et al. [7] tested cobalt, nickel, iron and magnetite at a very small scale (around 7-28 nm) and low concentrations (1-20 mg/L) discovering a bio-stimulatory effect with biomethane production increase of $50 \%$ or more.

Furthermore, Meng et al. [8] observed the degradation of propionate into acetate in DF using a $\mathrm{Fe}^{\circ}$ supplemented consortium of microorganisms. Their results suggested that the addition of $\mathrm{Fe}^{\circ}$, and the generation of ions $\mathrm{Fe}^{2+}$ as product of corrosion, might be correlated to a significant enhancement in the activity of iron-containing enzymes. Particularly, the activity of the Pyruvate: ferredoxin oxidoreductase (PFOR), which presents active $\mathrm{S}-\mathrm{Fe}$ sites involved in the hydrogen production process with different anabolic pathways [9].

Owing the present interest into the separation of the biological steps in AD into phases, as two steps $\mathrm{AD}$ (TSAD) [10] and, in order to increase the overall energy production, the present study concerns the evaluation of the effects of $\mathrm{Fe}^{\circ}$ addition in the first step: the acidogenic one where $\mathrm{H}_{2}$ is produced. The aim is to evaluate whether the dynamics of the two main phenomena involved, $\mathrm{AC}$ of $\mathrm{Fe}^{\circ}$ and DF play a synergic effect. For this purpose, several experimental tests were carried out with and without $\mathrm{Fe}^{\circ}$ addition on DF, and the obtained data were analysed using the Röels approach [11], which evaluates dynamic interactions between concurrent processes. 

Protection (June $27^{\mathrm{TH}}-30^{\mathrm{TH}}, 2017$, BLED, SLOVENIA), RENEWABLE ENERGY SOURCES

C. E. Gómez Camacho, F. I. Romano \& B. Ruggeri: Enhanced Biohydrogen Production and $\mathrm{CO}_{2}$ Sink by Powered $\mathrm{Fe}^{\circ}$ Addition in Dark Fermentation

\section{$2 \quad$ Relaxation Times $\left(\tau_{R}\right)$ Approach}

Röels demonstrated that for a given phenomenon [11], with a first order rate, the passage from an equilibrium $C_{s i}$ to a new one under an external perturbation, of matter and/or energy, $C_{s i}{ }^{\prime}$ could be considered occurred, relaxed, after a time called relaxation time $\left(\tau_{R}\right)$. The $\tau_{R}$ for first order systems corresponds to a time interval between $C_{s i}$ and a fraction of (1-1/e) of $C_{s i}{ }^{\prime}$ (Figure 1). Following Röels, only phenomena having $\tau_{R}$ of the same order of magnitude are mutually effecting the dynamics of the apparent phenomena. Two phenomena with $\tau_{R}$ different than one order of magnitude are not concurrent (i.e. there is no interaction because they are frozen or relaxed). For a general flux process of first order, where the flux $(J)$ is directly proportional to the driving force $(\Delta X)$ :

$J=k \Delta X$

the relaxation time is:

$$
\tau_{R}=\frac{1}{k}
$$

However, within biological systems, first order kinetics are rarely applicable, hence the rate expression corresponds to a higher order relationship:

$r=f(X)$

In the case of higher order systems, Eq. 3 can be linearized [12] and written in a form similar to flux equation:

$r=\frac{f(X)}{X} * X$

hence the relaxation time is:

$\tau_{R}=\frac{X}{f(X)}$

since Eq. (5) for higher order systems is not a constant, a proper X (i.e. mean value of X, within the studied interval) should be selected for the evaluation of $\tau_{R}$. 

$10^{\mathrm{TH}}$ International Conference on Sustainable EnERgy and Environmental Protection (June $27^{\mathrm{TH}}-30^{\mathrm{TH}}, 2017$, BlED, SLOVENIA), RENEWABLE ENERGy SOURCES C. E. Gómez Camacho, F. I. Romano \& B. Ruggeri: Enhanced Biohydrogen Production and $\mathrm{CO}_{2}$ Sink by Powered $\mathrm{Fe}^{\circ}$ Addition in Dark Fermentation

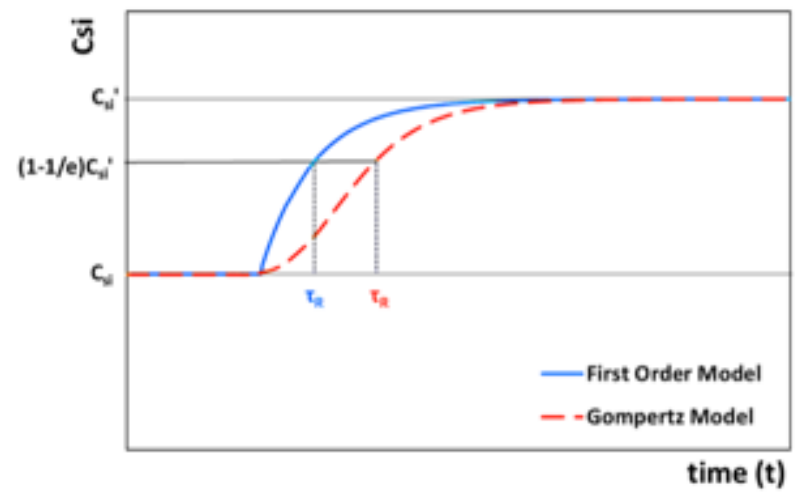

Figure 1. Relaxation time of phenomena

Ruggeri et al. [13] noted that Eq. (5) allows the estimation of an actual relaxation time from experimental data, using the difference between the actual state and a new one due to the dynamic interactions of the system, experimentally evaluated.

\section{$3 \quad$ Anaerobic Corrosion (Ac) Of Iron}

The supplementation of $\mathrm{Fe}^{\circ}$ to biological systems represents an additional challenge for the study of the very complex biological systems. The interaction of $\mathrm{Fe}^{\circ}$ with water, under anaerobic conditions, can be easily visualized using $\mathrm{pH} / \mathrm{Red}-\mathrm{Ox}$ potential plots or Pourbaix diagrams [14]. Water can be reduced with evolution of hydrogen or oxidized with evolution of oxygen. Other products of AC include solid oxides (e.g. magnetite and haematite) and dissolved ferrous and ferric compounds.

Table 1 reports the reaction involved in the anaerobic corrosion of $\mathrm{Fe}^{\circ}$. Since the supplemented $\mathrm{Fe}^{\circ}$ in this type of experiments is granular, with dimensions in the order of micrometres, with large specific surface, it is expected to interact actively to reach thermodynamic equilibrium stated by Pourbaix diagram.

Table 1. Reactions involved in the anaerobic corrosion of iron

\begin{tabular}{|c|c|}
\hline Reaction & $\begin{array}{c}\Delta E^{\circ} \\
(V)\end{array}$ \\
\hline a) $\mathrm{Fe}(\mathrm{s}) \rightarrow \mathrm{Fe}^{2+}(\mathrm{l})+2 e^{-}$ & +0.41 \\
\hline b) $\mathrm{O}_{2}+4 \mathrm{H}^{+}+4 e^{-} \rightarrow 2 \mathrm{H}_{2} \mathrm{O}$ & $+1.23^{1}$ \\
\hline c) $2 H^{+}+2 e^{-} \rightarrow H_{2}$ & $0.00^{2}$ \\
\hline d) $\begin{array}{rl}\mathrm{Fe}(\mathrm{s})+2 \mathrm{H}_{2} & \mathrm{O} \\
& (\mathrm{l}) \\
& \rightarrow \mathrm{Fe}^{2+}(\mathrm{l})+2 \mathrm{OH}^{-}(\mathrm{l}) \\
& +\mathrm{H}_{2}(\mathrm{~g})\end{array}$ & \\
\hline
\end{tabular}


In the case under study, the anaerobic environment is characterized by a $\mathrm{pH}$ ranging in 5.2-6.6 and Red-Ox potential $<-350 \mathrm{mV}$; from Pourbaix diagram the stable form of iron is $\mathrm{Fe}^{2+}$, hence reaction $a$ ) and $c$ ) of Table 1 occur. The progress of the corrosion was experimentally observed through the evolution of hydrogen gas in the system, which follows a saturation logistic behaviour described as:

$$
H_{A C}(t)=H_{\max } * \frac{t}{K_{S}+t}
$$

$H_{A C}(t)$ represents the cumulative specific hydrogen production $(\mathrm{mL} / \mathrm{gFe})$ at a given time $(t)$ and $H_{\max }$ is the overall quantity of produced gas $(\mathrm{ml} / \mathrm{gFe})$, which is the asymptotic value, and $K_{s}$ is the half-saturation constant of the system. In order to evaluate the $\tau_{R}$ of AC, Eq. (6) was used to best-fit the experimental data and by applying the definition of $\tau_{R}$ and using $H_{\max }$ value, its numerical estimation was performed.

\section{$4 \quad$ Dark Fermentation}

Bioreactors used for DF contain a different microbial culture, where methanogenic species are not present, and the population is mainly dominated by fermentative organisms, producing volatile fatty acids (VFA), $\mathrm{H}_{2}$ and $\mathrm{CO}_{2}$. Hydrogen Producing Bacteria (HPB) in DF systems are strict or facultative anaerobic microorganisms [15] using several metabolic pathways with similar enzymatic mechanisms. Hydrogen production is mediated at cellular level through the action of metalloenzymes, named hydrogenases, which can present different metallic active sites: $\mathrm{Ni}-\mathrm{Fe}$ for [Ni-Fe]hydrogenases and $\mathrm{Fe}-\mathrm{Fe}$ for [Fe-Fe]-hydrogenases [16].

$$
H_{D F}(t)=G_{\max } * \exp \left\{-\exp \left[\frac{R_{\max } * e}{G_{\max }}(\lambda-t)+1\right]\right\}
$$

The modified Gompertz model (Eq. 7) has been extensively used for describing gas evolution kinetics for fermentative systems [17]. In the afore mentioned equation, $H_{D F}(t)$ represents the cumulative specific hydrogen production $(\mathrm{mL} / \mathrm{gSV})$ at a given time $(t)$ due to DF phenomenon, $G_{\max }$ is the overall quantity of produced gas $(\mathrm{ml} / \mathrm{gSV}), R_{\max }$ the maximum gas production rate (mL/g SV*h), $\lambda$ is the lag phase $(h)$ and $e$ is the Euler's number. The production of hydrogen, modelled through Eq. (7) permits the description of the dynamics of the system and the evaluation of $\tau_{R}$. The modelling and the calculation of the $\tau_{R}$ for DF is then a comprehensive approach, which contains a contribution due to characteristics of the biomass and substrate (e.g. composition, structure, reactivity) and to the operational conditions (i.e. mixing rate, initial $\mathrm{pH}$, Red-Ox potential and temperature) imposed for the tests, describing macroscopically the performance of the system. 
$220 \quad 10^{\text {TH }}$ InTERnAtional CONFERENCE ON Sustainable ENERGy AND ENVIRONMENTAL Protection (June $27^{\mathrm{TH}}-30^{\mathrm{TH}}, 2017$, Bled, SLOVENIA), RENEWABLE ENERGY SOURCES C. E. Gómez Camacho, F. I. Romano \& B. Ruggeri: Enhanced Biohydrogen Production and $\mathrm{CO}_{2}$ Sink by Powered $\mathrm{Fe}^{\circ}$ Addition in Dark Fermentation

\section{$5 \quad$ Materials and Methods}

\subsection{Preparation of the feedstock and batch procedure}

The tests were performed in batch mode and they are divided into two types: AC tests and DF. For the first set of test (Series A), the corrosive phenomenon was studied under similar operative conditions of DF, without the organic and biological phase. The second batch of tests (Series B) included the presence of the biological phase (inoculum) and the substrate using a fermentation broth with three types of configurations: $i$ ) a nonsupplemented $\mathrm{Fe}^{\circ}$ (i.e. the DF system alone), ii) a fermentation broth supplemented with iron filings at a concentration of $1 \mathrm{~g} / \mathrm{L}$ and iii) a fermentation broth supplemented with $\mathrm{Fe}^{\circ}$ at $2 \mathrm{~g} / \mathrm{L}$.

The Series A tests were conducted with samples placed in closed $500 \mathrm{~mL}$ serum bottles, using a working volume of $100 \mathrm{~mL}$ of deionized water and adding $\mathrm{Fe}^{\circ}$ (Kremer Pigmente $\mathrm{GmbH} \&$ Co. 54600, Sieve mesh $315 \mu \mathrm{m})$ to reach an approximate concentration of 1 $\mathrm{g} / \mathrm{L}$. The $\mathrm{pH}$ was adjusted in the range 5.2-6.6 with $2 \mathrm{M} \mathrm{HCl}, \mathrm{N}_{2}$ was flushed for 5 minutes to reach anaerobic conditions, and then bottles were sealed with rubber bungs and silicone to avoid gas leaks. The selected carbon source for tests of Series B was an assorted residue of Organic Market Waste (OWM), collected from a local market.

Mixed fruit and vegetable wastes were collected and crumbled by a kitchen food grinder, diluted with tap water in an approximate ratio of 1:1. Subsequently a basic pre-treatment was applied adding a $2 \mathrm{~N} \mathrm{NaOH}$ solution to stabilize the substrate at $\mathrm{pH}=12$, and it was placed for 24 hours in a thermostatic chamber at $30 \pm 1{ }^{\circ} \mathrm{C}$. After the basic pre-treatment, the substrate was reset at $\mathrm{pH}=7$ using a $2 \mathrm{M} \mathrm{HCl}$ solution. The fermentation broth was composed by the pre-treated substrate, pre-treated cow manure (in order to kill all the methanogens present [13]) as inoculum in a ratio of $10 \%(v / v)$; anaerobic conditions were also assured by flushing $\mathrm{N}_{2}$ for 10 minutes. Series A and B were conducted in triplicate, in a thermostatic chamber at $30 \pm 1{ }^{\circ} \mathrm{C}$ continuously stirred by an orbital shaker at $120 \mathrm{rpm}$ until the gas production ceased.

\subsection{Analytical measurements}

The Total Solids (TS) and Total Volatile Solids (VS) were evaluated according to the standard procedure [18]. The $\mathrm{pH}$ was measured using a CONSORT P903 device (LAISS Apparecchi Scientifici, Turin, Italy). The acid water-displacement $(\mathrm{pH}=2)$ method was used to measure the cumulative gas production, employing a gas meter flask connected to a collector bottle. The produced gases were analysed using an off-line gas chromatograph device (Varian Micro-GC CP-4900, Palo Alto, USA) equipped with two columns: $i$ ) Poroplot $\mathrm{U}$ column for $\mathrm{CO}_{2}$ determination $\left(85^{\circ} \mathrm{C}\right.$ injection temperature, 200 $\mathrm{KPa}, \mathrm{Ar}$ as carrier) and ii) molecular Sieve type device for $\mathrm{H}_{2}, \mathrm{CH}_{4}, \mathrm{CO}, \mathrm{O}_{2}$ and $\mathrm{N}_{2}$ determination $\left(95^{\circ} \mathrm{C}\right.$ injection temperature, $200 \mathrm{KPa}, \mathrm{He}$ as carrier). 

Protection (June $27^{\mathrm{TH}}-30^{\mathrm{TH}}, 2017$, BLED, SLOVENIA), RENEWABLE ENERGY SOURCES

C. E. Gómez Camacho, F. I. Romano \& B. Ruggeri: Enhanced Biohydrogen Production and $\mathrm{CO}_{2}$ Sink by Powered $\mathrm{Fe}^{\circ}$ Addition in Dark Fermentation

\section{$6 \quad$ Results}

\subsection{Anaerobic corrosion}

Data from corrosion exhibit no lag phase, which is expectable since the corrosive phenomenon does not required an activation step to occur (i.e. the corrosion rate is maximal at $t=0$ and then it progressively reduces). By using Eq. (6) with a correlation coefficient of $0.97\left(R^{2}=0.97\right), H_{\max }$ and $K_{s}$ were evaluated (see Table 3 ). However, it should be noted that the selected iron powder is not micro-structured but consists of particles of random size (not exceeding $300 \mu \mathrm{m}$ ) and provided an experimental $\mathrm{H}_{2}$ yield of $23 \%$ of the stochiometric value; this yield is, nevertheless, similar to AC of nanostructured $\mathrm{Fe}^{\circ}[6]$. A closer look to the corrosion reaction (Table 1) suggests that the reaction between $\mathrm{Fe}^{\circ}$ in water can be considered as first order kinetics differently than other authors that consider $\mathrm{H}_{2}$ production in AC as autocatalytic kinetics [19].

\subsection{Dark fermentation with $\mathrm{Fe}^{\circ}$}

The chromatographic analysis of the produced biogas revealed that there was no $\mathrm{CH}_{4}$ in it, and that the gaseous mixtures for each sample consisted of $\mathrm{CO}_{2}, \mathrm{H}_{2}$ and $\mathrm{N}_{2}$, guaranteeing, as planned, that methanogenesis did not develop during the tests. Experimental data for produced gas during $\mathrm{DF}\left(\mathrm{H}_{2}\right.$ and $\left.\mathrm{CO}_{2}\right)$ were best fitted satisfactorily $\left(R^{2}>0.99\right)$ by Eq. 7, as reported in Figure 2. This figure also advances possible synergistic effects of iron supplementation on the system, even at low concentration of $\mathrm{Fe}^{\circ}$. Some interesting effects can be revealed observing experimental data reported in Table 2.

Table 2. Fermentation Parameters

\begin{tabular}{llccc}
\hline $\mathrm{Fe}^{\circ}(\mathrm{g} / \mathrm{l})$ & & 0 & 1 & 2 \\
\hline $\mathrm{TS}(\mathrm{g} / \mathrm{l})$ & Initial & 43,46 & 43,46 & 43,46 \\
\cline { 2 - 5 } & Final & 31,77 & 33,75 & 35,55 \\
\cline { 2 - 5 } & $\Delta \mathbf{S T}$ & 11,69 & 9,71 & 7,91 \\
\hline \multirow{2}{*}{$\mathrm{VS}(\mathrm{g} / \mathrm{l})$} & Initial & 34,98 & 34,98 & 34,98 \\
\cline { 2 - 5 } & Final & 20,85 & 22,17 & 23,79 \\
\cline { 2 - 5 } & $\Delta \mathbf{S V}$ & 14,13 & 12,81 & 11,19 \\
\hline $\mathrm{pH}$ & Initial & 7,4 & 7,4 & 7,4 \\
\cline { 2 - 5 } & Final & 5,75 & 5,79 & 6,03 \\
\hline
\end{tabular}

In the supplemented $\mathrm{Fe}^{\circ} \mathrm{DF}$ tests, the final broth was filtered, carefully separating visible iron traces. The concentration of VS and similarly the concentration of TS, showed a minor removal as the amount of iron increased.

\subsection{Synergic effects and dynamic phenomena}

The planned macroscopic analysis of the system was conducted using the collected parameters from the Series A and Series B, obtained through the modelling of gas 
$10^{\text {TH }}$ International CONFEREnce on Sustainable Energy and Environmental Protection (June $27^{\mathrm{TH}}-30^{\mathrm{TH}}, 2017$, Bled, Slovenia), RenEwable ENERGy SOURCES C. E. Gómez Camacho, F. I. Romano \& B. Ruggeri: Enhanced Biohydrogen Production and $\mathrm{CO}_{2}$ Sink by Powered $\mathrm{Fe}^{\circ}$ Addition in Dark Fermentation

evolution for each case, presenting an image of the associated dynamics. The values of the $\tau_{R}$ applying the procedure reported in Section 2, for each phenomenon separately and for $\mathrm{Fe}^{\circ}$ supplemented DF samples showed that both phenomena AC and DF have $\tau_{R}$ of the same order of magnitude: between 33 to 58 hours suggesting that there is a dynamic interaction among them (Table 3).

Moreover, the reported Gompertz parameters exhibited an increased lag phase with the addition of $\mathrm{Fe}^{\circ}$. This indicates that the activation period required for fermentation is longer when corrosion takes place, probably because of the interaction between the generated $\mathrm{Fe}^{2+}$ ions with the microorganisms, which might be able to metabolize it at cellular level, generating an enzymatic enhancement in iron-containing enzymes related to $\mathrm{H}_{2}$ generation, as suggested in literature [8].

Table 3. Model parameters and $\tau \mathrm{R}$

\begin{tabular}{llccc}
\hline & & \multicolumn{3}{c}{$\mathrm{Fe}^{\circ}$ concentration (g/l) } \\
\hline \multirow{3}{*}{ Series A } & \multicolumn{1}{c}{ Parameter } & 0 & 1 & 2 \\
\cline { 2 - 5 } & $\mathrm{H}_{\max }(\mathrm{ml} / \mathrm{g}$ Fe $)$ & - & 119,0 & - \\
\cline { 2 - 5 } & $\mathrm{K}_{\mathrm{a}}(\mathrm{h})$ & - & 34,0 & - \\
\cline { 2 - 5 } & $\tau_{R}(\mathrm{~h})$ & - & 58 & - \\
\hline \multirow{3}{*}{ Series B } & $\mathrm{G}_{\max }(\mathrm{ml} / \mathrm{g}$ VS) & 121,2 & 125,2 & 137,6 \\
\cline { 2 - 5 } & $\mathrm{R}_{\max }\left(\mathrm{ml}^{*}{ }^{*} \mathrm{~g}\right.$ VS $)$ & 2,50 & 4,61 & 4,62 \\
\cline { 2 - 5 } & $\lambda(\mathrm{h})$ & 11,8 & 15,4 & 17,7 \\
\cline { 2 - 5 } & $\tau_{R}(\mathrm{~h})$ & 43 & 33 & 37 \\
\hline
\end{tabular}

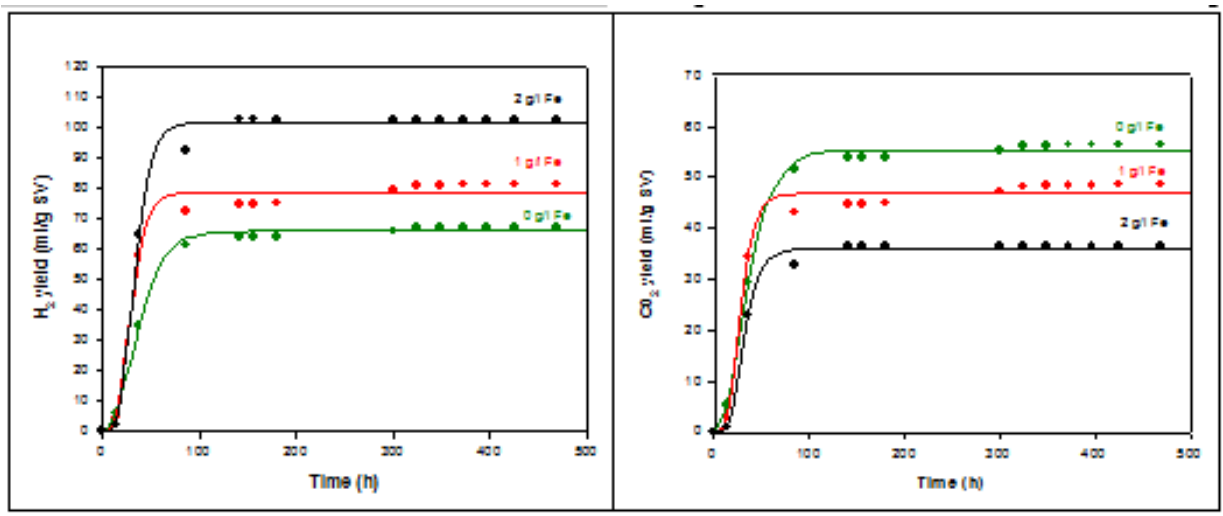

Figure 2. $\mathrm{H} 2$ and $\mathrm{CO} 2$ evolution during dark fermentation

Figure 3 shows the cumulative of the $\mathrm{H} 2$ evolution, where synergic effects predicted by Röels approach are confirmed 
C. E. Gómez Camacho, F. I. Romano \& B. Ruggeri: Enhanced Biohydrogen Production and $\mathrm{CO}_{2}$ Sink by Powered $\mathrm{Fe}^{\circ}$ Addition in Dark Fermentation

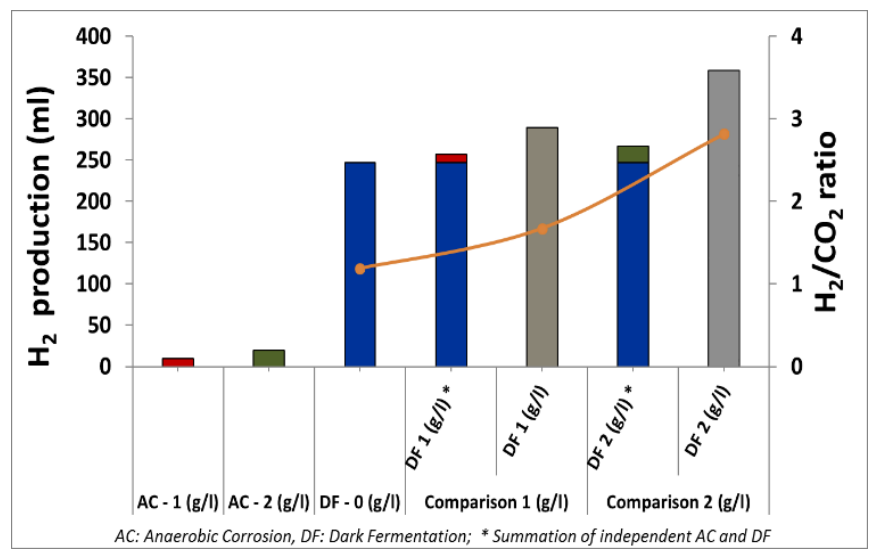

Figure 3. Cumulative $\mathrm{H} 2$ evolution and $\mathrm{H} 2 / \mathrm{CO} 2$ ratio

The quantity of $\mathrm{H}_{2}$ generated in $\mathrm{AC}$ is very low compared to the $\mathrm{H}_{2}$ generated by DF. The contribution of $\mathrm{AC}$ hydrogen, considering it as a purely additive phenomenon to the dark fermentation, does not explain, in any case, the greater amount of $\mathrm{H}_{2}$ assessed for the supplemented samples, as reported in Figure 3, which is of $44 \%$ greater than the control test and 35\% compared with summation effect of AC and DF. The products of AC might promote an enzymatic enhancement in DF.

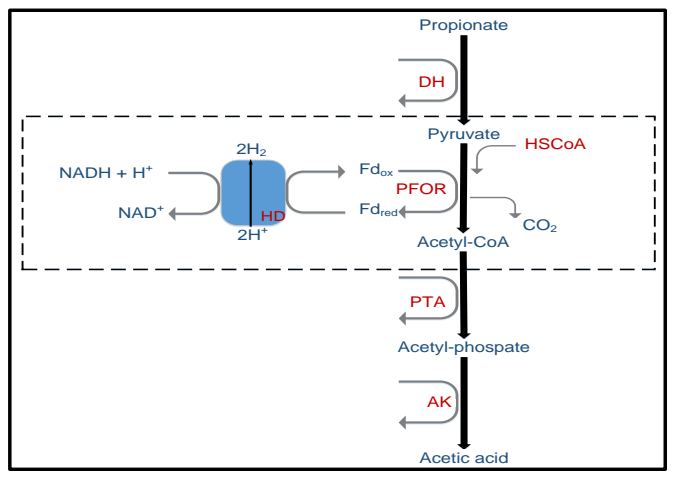

Figure 4. Simplified propionic acid degradation pathway for Clostridia

For example, the degradation of propionate to acetic acid, which is a common metabolic pathway in Clostridium species [10] is possible due to concatenated activity of several enzymes (Figure 4). The action of dehydrogenase, PFOR, phosphotransacetylase and acetate-kinase supported by Ferredoxin $(\mathrm{Fd})$ redox mediator play a fundamental role for the production of $\mathrm{H}_{2}$. The PFOR and $\mathrm{Fd}$ are iron-containing proteins, whose active sites strongly depends of Fe coordination; in addition Fd formation and its function as electron carrier in bacteria has been related to the availability of iron [20]. There is evidence that suggests the PFOR catalyses also the reverse reaction (the carboxylation of Acetyl-CoA into pyruvate), which ultimately serves to biomass formation [9]. This latest fact might 
$10^{\text {TH }}$ International Conference on Sustainable Energy and Environmental Protection (June $27^{\mathrm{TH}}-30^{\mathrm{TH}}, 2017$, BlED, SLOVENIA), RENEWABLE ENERGY SOURCES C. E. Gómez Camacho, F. I. Romano \& B. Ruggeri: Enhanced Biohydrogen Production and $\mathrm{CO}_{2}$ Sink by Powered $\mathrm{Fe}^{\circ}$ Addition in Dark Fermentation

help elucidating the higher amount of VS found in the exhausted broths (Table 3) and the lower $\mathrm{CO}_{2}$ production, which is $56 \%$ lower than $\mathrm{DF}$ alone.

\section{$7 \quad$ Conclusions}

The effects of the supplementation of metals to the fermentative systems have generated a wide field of study, where, concurrent phenomena affect different parameters of the process. Chemotropic organisms obtain their energy by extracting an electron flow passing through different Red-Ox cycles, relying on enzymes and carries at different potentials. Iron supplementation and metabolization by the biological phase suggest an increased activity and availability of the metallo-enzymes and electron carriers. The presented results and the Röels macro-analysis of the system indicate that $\mathrm{Fe}^{\circ}$ supplementation on DF is able to increase the production of hydrogen confirming that synergistic effects are present and that there is a synchronized dynamic between $\mathrm{Fe}^{2+}$ and microorganism's activity due to the same relaxation time. This leads to beneficial effects on $\mathrm{H}_{2}$ production as well as on increasing microorganism growth with $\mathrm{CO}_{2}$ capture. Finally, more research is needed to assess the impact of iron in the overall performance of larger-scale reactors.

\section{References}

[1] F. Fu, D. D. Dionysiou, and H. Liu, "The use of zero-valent iron for groundwater remediation and wastewater treatment: A review," J. Hazard. Mater., vol. 267, pp. 194205, 2014.

[2] K. Güssow, A. Proelss, A. Oschlies, K. Rehdanz, and W. Rickels, "Ocean iron fertilization: Why further research is needed," Mar. Policy, vol. 34, no. 5, pp. 911-918, 2010.

[3] T. Bond and M. R. Templeton, "History and future of domestic biogas plants in the developing world,” Energy Sustain. Dev., vol. 15, no. 4, pp. 347-354, 2015.

[4] Q. Sun, H. Li, J. Yan, L. Liu, Z. Yu, and X. Yu, "Selection of appropriate biogas upgrading technology-a review of biogas cleaning, upgrading and utilisation," Renew. Sustain. Energy Rev., vol. 51, pp. 521-532, 2015.

[5] Y. Yang, J. Guo, and Z. Hu, "Impact of nano zero valent iron (NZVI) on methanogenic activity and population dynamics in anaerobic digestion," Water Res., vol. 47, no. 17, pp. 6790-6800, 2013.

[6] Y. Hu, X. Hao, D. Zhao, and K. Fu, "Enhancing the $\mathrm{CH}_{4}$ yield of anaerobic digestion via endogenous $\mathrm{CO}_{2}$ fixation by exogenous $\mathrm{H}_{2}$.," Chemosphere, vol. 140, pp. 34-9, 2015.

[7] E. Abdelsalam, M. Samer, Y. A. Attia, M. A. Abdel-Hadi, H. E. Hassan, and Y. Badr, "Comparison of nanoparticles effects on biogas and methane production from anaerobic digestion of cattle dung slurry," Renew. Energy, vol. 87, pp. 592-598, 2016.

[8] X. Meng, Y. Zhang, Q. Li, and X. Quan, "Adding Fe ${ }^{0}$ powder to enhance the anaerobic conversion of propionate to acetate," Biochem. Eng. J., vol. 73, pp. 80-85, 2013.

[9] C. Furdui and S. W. Ragsdale, "The role of pyruvate ferredoxin oxidoreductase in pyruvate synthesis during autotrophic growth by the Wood-Ljungdahl pathway.," J. Biol. Chem., vol. 275 , no. 37, pp. 28494-9, Sep. 2000.

[10] B. Ruggeri, T. Tommasi, and S. Sanfilippo, $\mathrm{BioH}_{2}$ \& BioCH $\mathrm{BH}_{4}$ Through Anaerobic Digestion: From Research to Full-scale Applications. Springer London, 2015.

[11] J. A. Röels, Energetics and kinetics in biotechnology. Elsevier Biomedical Press, 1983. 
C. E. Gómez Camacho, F. I. Romano \& B. Ruggeri: Enhanced Biohydrogen Production and $\mathrm{CO}_{2}$ Sink by Powered $\mathrm{Fe}^{\circ}$ Addition in Dark Fermentation

[12] F. Bosco, B. Ruggeri, and G. Sassi, "Macro Approach to Study Alginate and Entrapped Biocatalyst Interations. Note II: Mass Transfer and Biokinetics," Recent Research Developments Chemical Engineering, vol. 4, pp. 77-84, 2000.

[13] B. Ruggeri, T. Tommasi, and G. Sassi, "Experimental kinetics and dynamics of hydrogen production on glucose by hydrogen forming bacteria (HFB) culture," Int. J. Hydrogen Energy, vol. 34, no. 2, pp. 753-763, 2009.

[14] M. Pourbaix, Atlas of electrochemical equilibria in aqueous solutions. Houston, Texas, 1974.

[15] C. T. Gray and H. Gest, "Biological Formation of Molecular Hydrogen," Science (80), vol. 148, no. 0036-8075 (Print), pp. 186-192, 1965.

[16] P. M. Vignais, B. Billoud, and J. Meyer, "Classification and phylogeny of hydrogenases," FEMS Microbiol. Rev., vol. 25, no. 4, pp. 455-501, 2001.

[17] A. C. Luongo Malave', M. Bernardi, D. Fino, and B. Ruggeri, "Multistep anaerobic digestion (MAD) as a tool to increase energy production via $\mathrm{H}_{2}+\mathrm{CH}_{4}$," Int. J. Hydrogen Energy, vol. 40, pp. 5050-5061, 2015.

[18] American Public Health Association, "Standard Methods for the Examination of Water and Wastewater," APHA, 1999.

[19] E. J. Reardon, R. Fagan, J. L. Vogan, and A. Przepiora, "Anaerobic Corrosion Reaction Kinetics of Nanosized Iron," Environ. Sci. Technol., vol. 42, no. 7, pp. 2420-2425, Apr. 2008.

[20] E. Knight, A. J. D’Eustachio, and R. W. F. Hardy, "Flavodoxin: A flavoprotein with ferredoxin activity from Clostridium pasteurianum," Elsevier, 1966. 
$226 \quad 10^{\mathrm{TH}}$ International CONFERENCE on Sustainable ENERgy AND ENVIRONMENTAL

Protection (June $27^{\mathrm{TH}}-30^{\mathrm{TH}}, 2017$, Bled, SLOVEnia), Renewable ENERGy SOURCES 
$10^{\mathrm{TH}}$ InTERnational CONFERENCE ON Sustainable ENERgy AND Environmental Protection (June 27 $7^{\mathrm{TH}}-30^{\mathrm{TH}}, 2017$, BLed, SLOVENIA), RENEWABLE ENERGy SOURCES

J. Krope, A.Ghani Olabi, D. Goričanec \& S. Božičnik

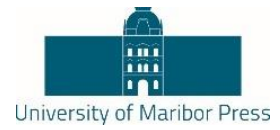

\title{
$\mathrm{CO}_{2}$ Capture from Syngas Generated by a Biomass Gasification Power Plant with Chemical Absorption Process
}

\author{
CRISTIAN DinCA, Nela SLAVU \& ADRIAN BADEA
}

\begin{abstract}
Biomass gasification is a technology which presents several important advantages of the bioenergy for producing heat, power and biofuels for useful applications. In this article, the biomass gasification with $\mathrm{CO} 2$ capture technology was studied for converting the treated syngas into electricity by means of a combined cycle power plant. Thus, the $\mathrm{CO} 2$ precombustion capture by means of the chemical absorption technology was studied for determining its effects on the syngas quality and consequently, the performances of a gas turbine power plant with an HRSG (Heat Recovery Steam Generator) with a total power installed of $10 \mathrm{MW}$. The chemical solvent used for the $\mathrm{CO} 2$ capture separation was monoethanolamine with a mass concentration of $30 \mathrm{wt}$. \% considering a CO2 capture efficiency of $90 \%$. The efficiency penalty imposed by the solvent regeneration was approximately of $20 \%$.
\end{abstract}

Keywords: $\bullet \mathrm{CO}_{2}$ capture $\cdot$ chemical absorption $\bullet$ syngas $\bullet$ biomass $\bullet$ gasification $\bullet$

Correspondence AdDress: Cristian Dincă, Ph.D., Associate Prof, University Politehnica of Bucharest, Power Engineering Department, Splaiul Independenţei 313, 060042 Bucharest, Romania, e-mail: crisflor75@yahoo.com. Nela Slavu, PhD Student, University Politehnica of Bucharest, Power Engineering Department, Splaiul Independenței 313, 060042 Bucharest, Romania, e-mail: slavunela@yahoo.com. Adrian Badea, Ph.D., Professor and President of the Romanian Academy of Scientists, The Romanian Academy of Scientists, Bucharest 050094, and University Politehnica of Bucharest, Power Engineering Department, Splaiul Independenţei 313, 060042 Bucharest, Romania, e-mail: badea46@yahoo.fr. 
$10^{\text {TH }}$ International CONFEREnce on Sustainable Energy and Environmental Protection (June $27^{\mathrm{TH}}-30^{\mathrm{TH}}, 2017$, Bled, SLOVEnia), Renewable ENERGy SOURCES C. Dinca, N. Slavu \& A. Badea: $\mathrm{CO}_{2}$ Capture from Syngas Generated by a Biomass Gasification Power Plant with Chemical Absorption Process

The energy sector is one of the responsible factors for increasing the greenhouses gases concentration in our atmosphere due to the contribution of the fossil fuels, especially coal, in the worldwide energy mix. Thus, the targets of the European Union (EU) consist in reducing the GHG emissions with $20 \%$ until 2020 (1990 level is considered as reference) [1]. In this context, more solutions have already been proposed: to increase the global efficiency for whole life cycle energy chain; to replace the fossil fuels with renewable energy sources or nuclear resources; or to integrate the Carbon Capture, Transport and Storage (CCS) technologies into the power plants [2]. Each solution has some restrictions but the most relevant restriction is based on the electricity generation cost increase [2-3].

So as to reduce the climate change effects, the CCS technologies were developed into three main processes: post-combustion; pre-combustion; and oxy-combustion. The carbon dioxide captured is transported to different sites in order to be stored into natural or artificial underground reservoirs [2].

In the scientific literature the Integrated Gasification Combined Cycle (IGCC) plant with CCS is considered a promising way of producing electricity [4-5]. In this case, the $\mathrm{CO}_{2}$ capture efficiency is around $90 \%$, with a smaller efficiency penalty due to the CCS integration [6-9].

In this paper, we analyzed two schemes for integrating the chemical absorption process into an IGCC power plant with a gas turbine of $10 \mathrm{MW}$ and an HRSG (heat recovery steam generator) unit: the pre-combustion and post-combustion. In the pre-combustion scheme, the chemical absorption process is integrated prior to the combustion chamber in order to separate the $\mathrm{CO}_{2}$ from the syngas produced by the gasification unit. In the post-combustion case, the carbon dioxide is separated from the flue gasses after leaving the gas turbine. For the chemical solvent regeneration (in this paper, we chose $30 \mathrm{wt}$. \% ethanolamine), the steam provided by the HRSG unit was used. The results obtained (the net efficiency of the IGCC plant, the levelized cost of electricity and the $\mathrm{CO}_{2}$ cost avoided) were compared with the IGCC without CCS capture unit (considered as reference).

\section{Biomass Power Plant Configurations}

The biomass power plant is presented in Figure 1. The syngas obtained in the sawdust gasification process with oxygen is transported to the gas turbine but not before removing from it the undesirable components such as dust and sulphur dioxide in the syngas cleaning system.

The IGCC plant presented in Figure 1 contains a gas turbine (GT) and a steam turbine. The parameters of the steam turbine depend on the heat amount generated in the HRSG unit. If the heat amount is low, the natural gas is introduced in the HRSG post-combustion 
unit. The total power generated by the IGCC is the sum of the power generated by each steam and gas turbine.

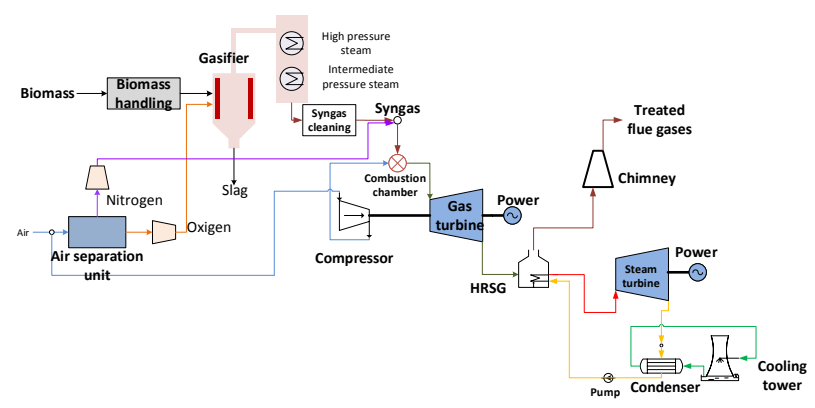

Figure 1. Biomass power plant

For reducing the $\mathrm{CO}_{2}$ emissions generated in the atmosphere together with the flue gases, the chemical absorption process could be integrated before (first case) the combustion chamber or after (second case) the HRSG (Heat Recovery Steam Generator). In the first case, less carbon dioxide participates in the syngas combustion. However, due to the presence of the $\mathrm{CO}$ in the syngas, the carbon dioxide will be found in the flue gases but in a lower concentration as compared with the reference case. In the second case the $\mathrm{CO}_{2}$ concentration in the flue gases will be smaller than in the first case but a higher amount of biomass is needed in order to have the same power generated.

For simplifying the analysis of the IGCC plant, the followings assumptions were made:

a) The exhaust flue gases temperature was considered to be of $150-170{ }^{\circ} \mathrm{C}$;

b) The oxygen compression work for gasification unit was neglected in the net efficiency determination;

c) For all the cases analysed, the net power of the gas turbine SGT-400 was considered to be of $10 \mathrm{MW}$;

d) The steam for solvent regeneration was extracted at 3.5 bar from the steam turbine, thus, the net power of the steam turbine was changed according to the $\mathrm{L} / \mathrm{G}$ ratio in the $\mathrm{CO}_{2}$ capture process;

e) The parameters of the steam at the inlet in the steam turbine were considered to be of 90 bar and $500{ }^{\circ} \mathrm{C}$;

f) The net $\mathrm{CO}_{2}$ capture efficiency was considered to be of $90 \%$; the $\mathrm{L} / \mathrm{G}$ ratio was changed for the cases studied;

g) The chemical solvent used was ethanolamine in a weight concentration of 30 $\%$;

h) The mechanical work for the $\mathrm{CO}_{2}$ compression has not been taken into account in this study.

It is worth mentioning that the amount of the biomass was the same for the cases analysed. For the reference case, the amount of the biomass (sawdust) was of $105775.4 \mathrm{~kg} / \mathrm{h}$ so as 

$10^{\text {TH }}$ International Conference on Sustainable Energy and Environmental Protection (June $27^{\mathrm{TH}}-30^{\mathrm{TH}}, 2017$, Bled, SLOVEnia), Renewable ENERGy SOURCES C. Dinca, N. Slavu \& A. Badea: $\mathrm{CO}_{2}$ Capture from Syngas Generated by a Biomass Gasification Power Plant with Chemical Absorption Process

to generate $10 \mathrm{MW}$ in the gas turbine and $3.8 \mathrm{MW}$ in the steam turbine. The cases presented will be compared according different indicators such as: total power generated; net efficiency of the IGCC; $\mathrm{CO}_{2}$ emissions factor.

The net efficiency of the IGCC was determined with Eq. 1.

$$
\eta=\frac{P_{T G}+P_{T A}-P_{C}-P_{P}}{B_{s} \cdot L H V+Q_{H R S G}}
$$

where, the $P_{T G}, P_{T A}, P_{C}, P_{P}$ is the net power of the gas turbine, steam turbine, compressor and pump respectively, in $\mathrm{MW}$; the $B_{s}$ - the syngas flow before the combustion chamber, in $\mathrm{kg} / \mathrm{s}$; the $L H V$ - the low heating value of the syngas, in $\mathrm{MJ} / \mathrm{kg}$; the $Q_{H R S G}$ - the thermal energy flow consumption in the Heat Recovery Steam Generator with post-combustion, in MJ/s. The post-combustion in the HRSG is needed for generating steam with 90 bar and $500{ }^{\circ} \mathrm{C}$.

The $\mathrm{CO}_{2}$ emissions factor was determined with Eq. 2 .

$$
f_{c o 2}=\frac{m_{C O 2}}{P_{T G}+P_{T A}-P_{C}-P_{P}}
$$

where, the $\mathrm{m}_{\mathrm{CO} 2}-$ is the carbon dioxide flow in the exhaust flue gases, in $\mathrm{kg} / \mathrm{h}$.

\section{$2.1 \quad \mathrm{CO}_{2}$ capture by chemical absorption}

The chemical absorption process for the carbon dioxide capture is one of the promising ways to reduce the climate change associated to the energy sector. The chemical absorption process is represented in Figure 2 consisting in two columns: absorption and stripper unit.

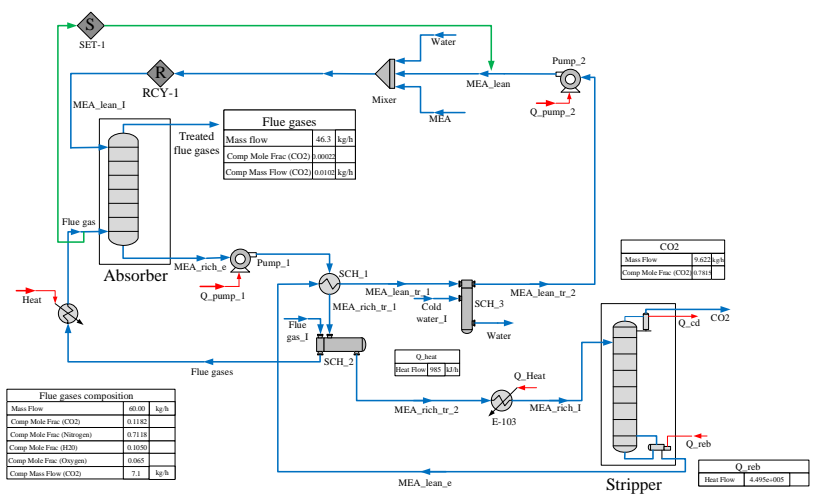

Figure 2. $\mathrm{CO}_{2}$ capture by chemical absorption technology 

Protection (June $27^{\mathrm{TH}}-30^{\mathrm{TH}}, 2017$, BLED, SLOVENIA), RENEWABLE ENERGY SOURCES

C. Dinca, N. Slavu \& A. Badea: $\mathrm{CO}_{2}$ Capture from Syngas Generated by a Biomass Gasification Power Plant with Chemical Absorption Process

For the chemical solvent regeneration, a certain steam flow from the steam turbine is extracted. The parameters of the steam extracted are established according to the chemical solvent flow and the lean loading solvent imposed. In both cases, pre- and postcombustion, the $\mathrm{CO}_{2}$ capture efficiency was of $90 \%$.

\subsection{Pre-combustion integration of the chemical absorption process in power plants}

By the pre-combustion integration of the chemical absorption process into the power plant, we aim to increase the quality of the syngas produced before the combustion process. For this case, the $\mathrm{L} / \mathrm{G}$ ratio was of 2.19 mole liquid/mole flue gases.

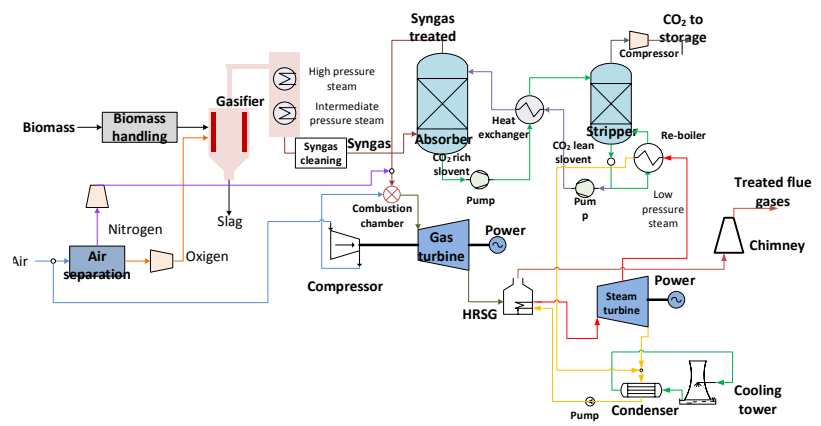

Figure 3. IGCC with $\mathrm{CO}_{2}$ pre-combustion

\subsection{Post-combustion integration of the chemical absorption process in power plants}

In this case, the flue gases are treated after the combustion stage and before being evacuated in the atmosphere. As in the previous case, the amount of the steam is extracted from the steam turbine according to the amount of the chemical solvent and the lean loading solvent after leaving the stripper unit.

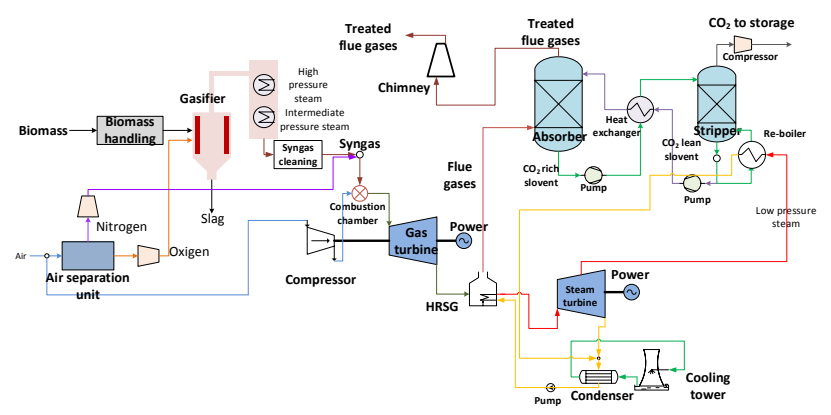

Figure 4. IGCC with $\mathrm{CO}_{2}$ post-combustion 
232 10 $10^{\mathrm{TH}}$ International CONFEREnCE on Sustainable EnERgy AND ENVIRONMENTAL Protection (June $27^{\mathrm{TH}}-30^{\mathrm{TH}}, 2017$, Bled, SLOVENIA), RENEWABle ENERGy SOURCES C. Dinca, N. Slavu \& A. Badea: $\mathrm{CO}_{2}$ Capture from Syngas Generated by a Biomass Gasification Power Plant with Chemical Absorption Process

\section{IGCC with $\mathrm{Co}_{2}$ Carbon Capture Assessment}

In this study, the characteristics of the fuel $100 \%$ sawdust were presented in Table 1.

Table 1. Thermal characteristics of sawdust

\begin{tabular}{|l|c|}
\hline Parameter & Sawdust \\
\hline Proximate analysis (\% wt.) & 10 \\
\hline Moisture & 80 \\
\hline Volatile matter (dry) & 50 \\
\hline Ultimate analysis (\% wt. dry) & 6 \\
\hline Carbon & 0.95 \\
\hline Hydrogen & 42 \\
\hline Nitrogen & 0.05 \\
\hline Oxygen & 1 \\
\hline Sulphur & 17984 \\
\hline Ash & 16629 \\
\hline Low heating value (kJ/kg dry) \\
\hline Gross (HHV) & \\
\hline Net (LHV) &
\end{tabular}

In all the cases studied in this paper, the Siemens Gas Turbine SGT-400 up to 14 MW and Steam turbine SST-150 up to $20 \mathrm{MW}$ were used.

The syngas composition before the combustion chamber is presented in Table 2.

Table 2. Syngas composition

\begin{tabular}{|l|c|}
\hline Component & Value, [\%] \\
\hline Nitrogen & 0.4797 \\
\hline Carbon dioxide & 12.7268 \\
\hline Carbon monoxide & 45.6096 \\
\hline Hydrogen & 40.6297 \\
\hline Methane & 0.5542 \\
\hline Low heating value, $\mathrm{kJ} / \mathrm{kg}$ & 11882.5 \\
\hline
\end{tabular}

In the pre-combustion case (see Figure 3), before the combustion chamber, the syngas with the volumetric composition presented in Table 2 is treated in the chemical absorption for the $\mathrm{CO}_{2}$ separation. Thus, the $\mathrm{CO}_{2}$ content is reduced from $37690.61 \mathrm{~kg} / \mathrm{h}$ to 3822.166 $\mathrm{kg} / \mathrm{h}$ (see the Table 3). The flow of the chemical solvent used was of $286000 \mathrm{~kg} / \mathrm{h}$ for a flue gases flow of $130723 \mathrm{~kg} / \mathrm{h}$.

The mathematical model and design assumptions for the gasification process are detailed in the paper [10]. 

Protection (June $27^{\mathrm{TH}}-30^{\mathrm{TH}}, 2017$, BLED, SLOVENIA), RENEWABLE ENERGY SOURCES

C. Dinca, N. Slavu \& A. Badea: $\mathrm{CO}_{2}$ Capture from Syngas Generated by a Biomass Gasification Power Plant with Chemical Absorption Process

Table 3. Syngas composition after the $\mathrm{CO}_{2}$ pre-combustion process

\begin{tabular}{|l|c|}
\hline Component & Value, [\%] \\
\hline Nitrogen & 0.4192 \\
\hline Carbon dioxide & 1.155 \\
\hline Carbon monoxide & 40.1856 \\
\hline Hydrogen & 35.655 \\
\hline Methane & 0.3852 \\
\hline Water & 22.2 \\
\hline Low heating value, $\mathrm{kJ} / \mathrm{kg}$ & 12257.38 \\
\hline
\end{tabular}

All the processes were modelled in the ChemCAD program. For all the processes it is a assumed thermodynamic equilibrium; the SRK - Soave-Redlich-Kwong thermodynamic model was used for the gasification process and the Amine package for chemical absorption process.

In the post-combustion case, the flue gases composition before the chemical absorption process is presented in Table 4.

Table 4. Flue gases composition before the $\mathrm{CO}_{2}$ post-combustion process

\begin{tabular}{|l|c|}
\hline Component & Value, [\%] \\
\hline Nitrogen & 73.9724 \\
\hline Carbon dioxide & 5.4666 \\
\hline Oxygen & 15.807 \\
\hline Argon & 0.9 \\
\hline Water & 3.854 \\
\hline
\end{tabular}

\section{$4 \quad$ Results and Discussion}

All the cases were simulated considering the electricity as the only product. First of all, the performance of the IGCC without the chemical absorption process is highlighted in Figure 5 and 6 for different steam pressures at the inlet steam turbine according to the temperature in the combustion chamber. 
234 10 $10^{\mathrm{TH}}$ International CONFEREnCE on Sustainable EnERgy AND ENVIRONMENTAL Protection (June $27^{\mathrm{TH}}-30^{\mathrm{TH}}, 2017$, Bled, SLOVENIA), RENEWABle ENERGy SOURCES C. Dinca, N. Slavu \& A. Badea: $\mathrm{CO}_{2}$ Capture from Syngas Generated by a Biomass Gasification Power Plant with Chemical Absorption Process

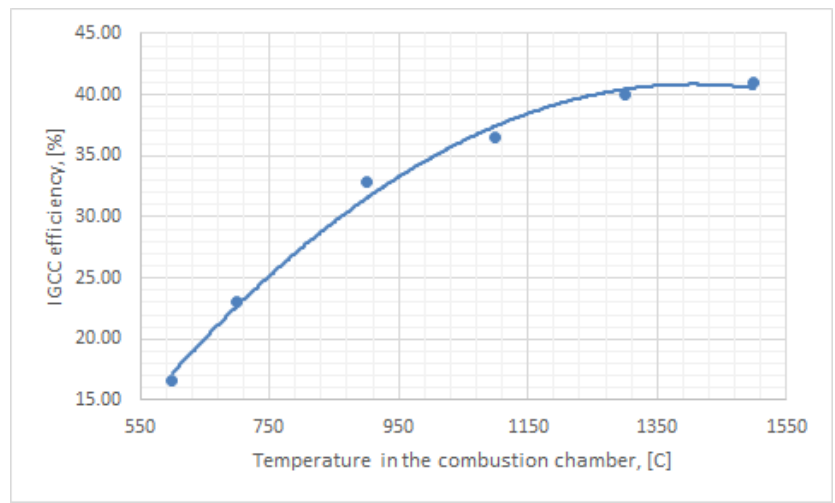

Figure 5. IGCC efficiency for $\mathrm{p}_{\mathrm{st}}=30 \mathrm{bar}$

Increasing the steam pressure at the inlet in the steam turbine from 30 to 90 bar led to a raise in the IGCC efficiency due to an excess of power in the steam turbine.

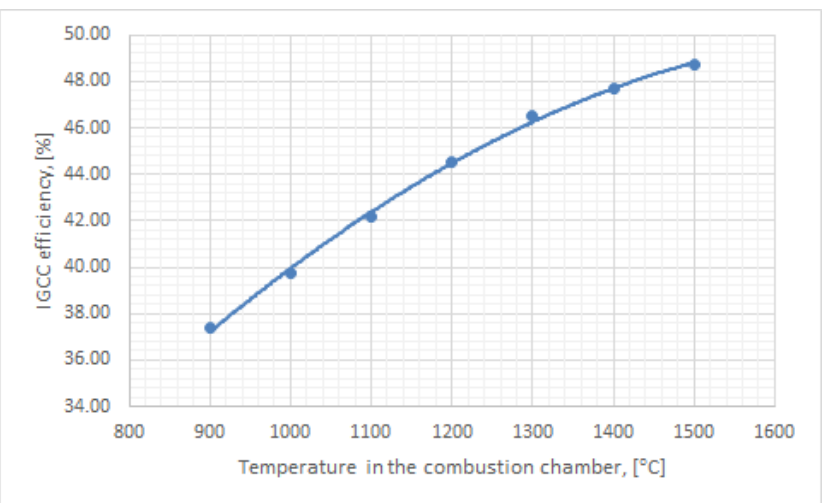

Figure 6. IGCC efficiency for $\mathrm{p}_{\mathrm{st}}=90 \mathrm{bar}$

However, a decrease of the $\mathrm{CO}_{2}$ emission factor is expected due to the IGCC efficiency increase. 

Protection (June $27^{\mathrm{TH}}-30^{\mathrm{TH}}, 2017$, BLED, SLOVENIA), RENEWABLE ENERGY SOURCES C. Dinca, N. Slavu \& A. Badea: $\mathrm{CO}_{2}$ Capture from Syngas Generated by a Biomass Gasification Power Plant with Chemical Absorption Process

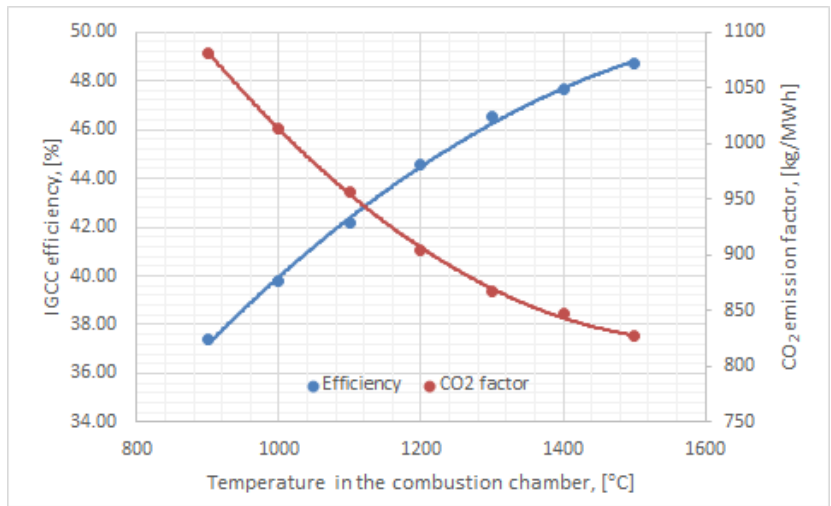

Figure 7. $\mathrm{CO}_{2}$ emission factor

In the pre-combustion case, the syngas obtained after the gasification process has a higher low heating value as a result of the $\mathrm{CO}_{2}$ removal. However, an increase of power was needed in the compression process for raising the flue gases pressure. Thus, the IGCC efficiency decreased and the $\mathrm{CO}_{2}$ emission factor increased with the syngas pressure increasing in the combustion chamber. The temperature of the syngas in the combustion chamber has been maintained at $900{ }^{\circ} \mathrm{C}$.

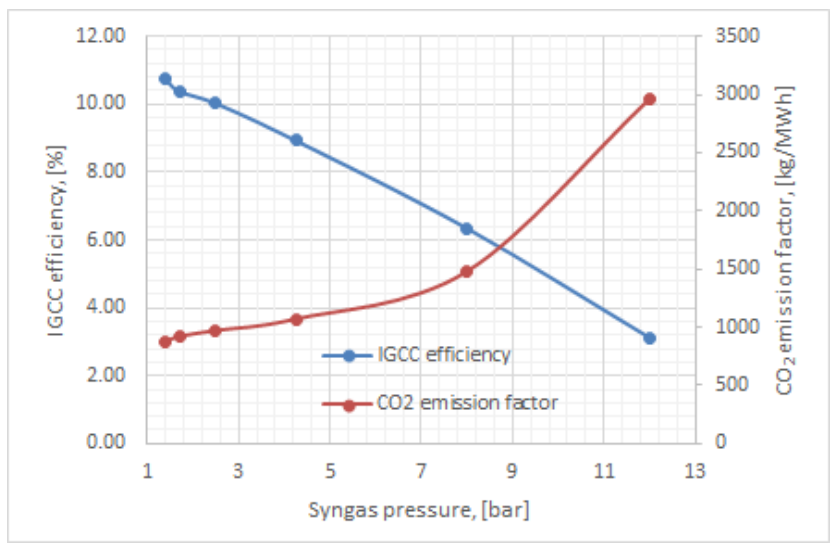

Figure $8 . \mathrm{CO}_{2}$ emission factor for pre-combustion case

The energy balance for the IGCC was highlighted in Figure 9. A higher amount of the syngas is required to have in the gas turbine $10 \mathrm{MW}$ at a low pressure of the syngas in the combustion chamber. Accordingly, the syngas temperature at the gas turbine outlet allowed to increase the power generated in the steam turbine. As a consequence, the $\mathrm{CO}_{2}$ emission factor increased as the syngas pressure increased. 
$236 \quad 10^{\text {TH }}$ InTERnATIONAL CONFERENCE ON Sustainable ENERGy AND ENVIRONMENTAL Protection (June $27^{\mathrm{TH}}-30^{\mathrm{TH}}, 2017$, Bled, SLOVENIA), RENEWABLE ENERGy SOURCES C. Dinca, N. Slavu \& A. Badea: $\mathrm{CO}_{2}$ Capture from Syngas Generated by a Biomass Gasification Power Plant with Chemical Absorption Process

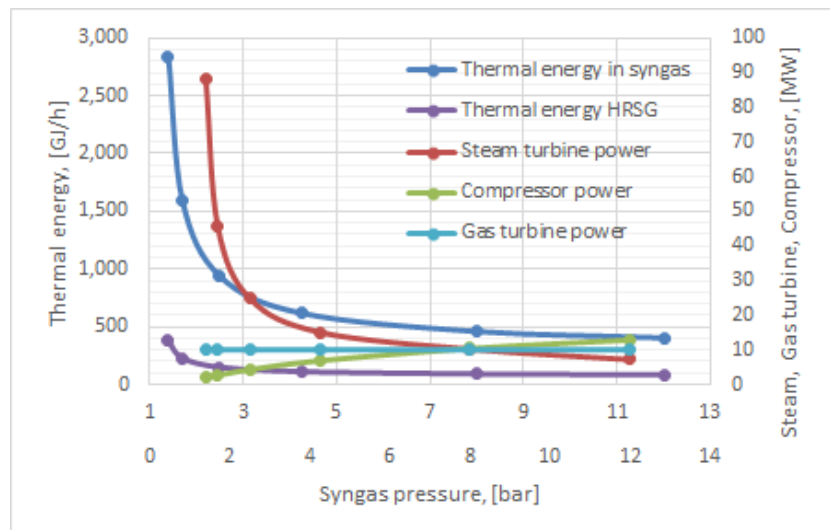

Figure 9. IGCC pre-combustion energy balance

In the post-combustion case, the IGCC efficiency (Figure 10) decreased due to the amount of steam required in the chemical absorption process for the $\mathrm{CO}_{2}$ capture. Also, the efficiency penalty compared with the reference case varied between 18-22\% according to the temperature in the combustion chamber.

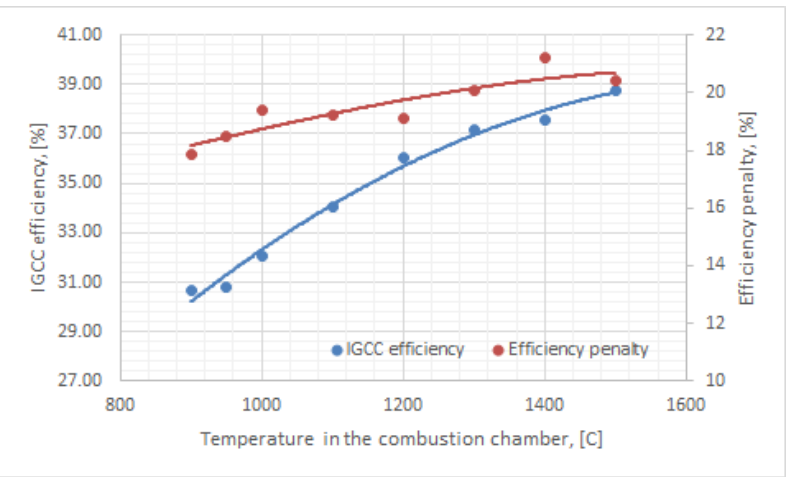

Figure 10. IGCC post-combustion efficiency 


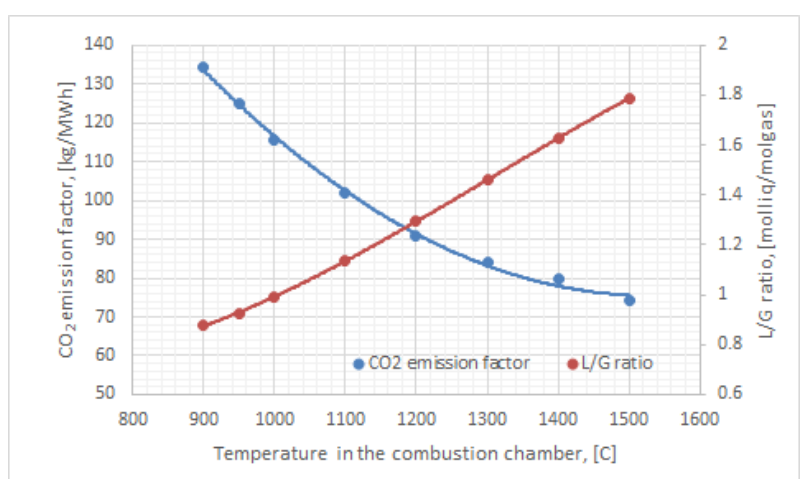

Figure 11. $\mathrm{CO}_{2}$ emission factor and $\mathrm{L} / \mathrm{G}$ ratio variation with temperature in the combustion chamber

The $\mathrm{CO}_{2}$ emission factor was reduced in the IGCC post-combustion case to 74-134 $\mathrm{kg} / \mathrm{MWh}$ (Figure 11) according to the temperature of the syngas in the combustion chamber. For maintaining the $\mathrm{CO}_{2}$ capture process efficiency of $90 \%$, the $\mathrm{L} / \mathrm{G}$ ratio increased from 0.88 to $1.78 \mathrm{~mol}$ liq/mol_gas according to the temperature in the combustion chamber. In all the simulation cases, the lean loading solvent was kept to $0.22 \mathrm{molCO}_{2} / \mathrm{molMEA}$. Due to the fact that the lean loading solvent and $\mathrm{CO}_{2}$ capture process efficiency were kept constant, the heat duty was approximately of $2.6 \mathrm{GJ} / \mathrm{tCO}_{2}$.

\section{$5 \quad$ Conclusions}

In this paper the integration of the chemical absorption process for the $\mathrm{CO}_{2}$ capture was analyzed in two cases: pre-and post-combustion. For the chemical solvent regeneration (MEA in a weight concentration of $30 \%$ ), a steam turbine uses the steam generated by the HRSG unit. The amount of steam generated depends on the syngas flow and the temperature in the combustion chamber.

The integration of the chemical absorption technology in the pre-combustion led to reducing the parameters of the syngas to $50{ }^{\circ} \mathrm{C}$ and to the atmospheric ones. In this case, a lot of energy is lost because in the combustion chamber, the process takes place at 13 bars and $900{ }^{\circ} \mathrm{C}$. Thus, in this case, the efficiency decreases mainly due to the energy consumption in the compressor unit for increasing the parameters for air and flue gases.

In the second case, when the chemical absorption is integrated in the post-combustion, the efficiency penalty varied between $18-22 \%$ compared to the reference case due to the steam amount required for chemical solvent regeneration. Thus, the steam was extracted at 6 bar and the L/G ratio varied between $0.88-1.78$ mol_liq $/$ mol_gas in order to maintain the $\mathrm{CO}_{2}$ capture process efficiency at $90 \%$ for a lean loading of $0.22 \mathrm{~mol}$ $\mathrm{CO}_{2} /$ mol MEA. In this case, the $\mathrm{CO}_{2}$ emission factor was reduced from 1081.3 to 134.5 $\mathrm{kg} / \mathrm{MWh}$ (considering the temperature in the combustion chamber of $900{ }^{\circ} \mathrm{C}$ ). 
$10^{\text {TH }}$ International Conference on Sustainable Energy and Environmental Protection (June $27^{\mathrm{TH}}-30^{\mathrm{TH}}, 2017$, Bled, Slovenia), Renewable Energy SOURCeS C. Dinca, N. Slavu \& A. Badea: $\mathrm{CO}_{2}$ Capture from Syngas Generated by a Biomass Gasification Power Plant with Chemical Absorption Process

\section{Acknowledgements}

The study has been funded by the UEFISCDI within the National Projects: number 51/2017 with the title: „Optimization and validation of the $\mathrm{CO}_{2}$ capture demonstrative pilot installation by means of the chemical absorption technology" - CHEMCAP and 95 BM/2017 with the title: "Parametric study for the optimization of the chemical absorption of the $\mathrm{CO}_{2}$ capture technology used in the energy and industrial sectors".

\section{References}

[1] European Commission, Communication from the Commission. 202020 by 2020: Europe's climate change opportunity. COM (2008) 30 final.

[2]I PCC, Climate Change 2014: Mitigation of Climate Change. Contribution of working group III to the $5^{\text {th }}$ assessment report of the inter-governmental panel on climate change. Cambridge, 2014.

[3] B. Metz, O. Davidson, H. de Coninck, M. Loos, and L. Meyer, Carbon Dioxide Capture and Storage. Intergovernmental Panel on Climate Change (IPCC), 2005, http://www.ipcc.ch.

[4] E. Tzimas, C.C. Cormos, F. Starr, and C. Garcia-Cortes, "The design of carbon capture IGCC-based plants with hydrogen co-production", Energy Procedia, vol. 1, pp. 591-598, 2009.

[5] C.C. Cormos, "Integrated assessment of IGCC power generation technology with carbon capture and storage (CCS)", Energy, vol. 42, pp. 434 - 445, 2012.

[6] C. Dinca, "Critical parametric study of circulating fluidized bed combustion with $\mathrm{CO}_{2}$ chemical absorption process using different aqueous alkanolamines", Journal of Cleaner Production, vol. 112, pp. 1136 - 1149, 2016.

[7] W. Qari, W. Chunfei, and T.W. Paul, "Hydrogen production from high temperature steam catalytic gasification of bio-char", Journal of the Energy Institute, vol. 89, pp. 222 - 230, 2016.

[8] C. Dinca, A. Badea, L. Stoica, and A. Pascu, "Absorber design for the improvement of the efficiency of post-combustion $\mathrm{CO}_{2}$ capture", Journal of the Energy Institute, vol. 88, pp. $304-313,2015$.

[9] M. Norişor, A. Badea, and C. Dincă, "Economical and technical analysis of $\mathrm{CO}_{2}$ transport ways". University" Politehnica" of Bucharest Scientific Bulletin, vol. 74, pp. 127 - 138, 2012.

[10] C. Dinca, N. Slavu, and A. Badea, "Benchmarking of the pre/post-combustion chemical absorption for the $\mathrm{CO}_{2}$ capture", Journal of the Energy Institute, vol. 88, In Press, February 2017. 
$10^{\mathrm{TH}}$ InTERnational CONFERENCE ON Sustainable ENERgy AND Environmental Protection (June 27 $7^{\mathrm{TH}}-30^{\mathrm{TH}}, 2017$, BLed, SLOVENIA), RENEWABLE ENERGy SOURCES

J. Krope, A.Ghani Olabi, D. Goričanec \& S. Božičnik

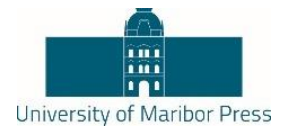

\title{
Impact of a Big Power Plant Into the Network
}

\author{
HoURIA SMAIL \& REZAK ALKAMA
}

\begin{abstract}
As the wind power penetration increases significantly, the existing network capacity is strongly requested. The ability of the power system to maintain synchronism when subjected to several fault disturbances is concerned. The aim of this paper is to describe the process to be undertaken before any integration of new plant into the network. It examines the impact of a big power plant which may represent large amounts of wind generation under fault condition influences. Several simulations are treated to examine the network behaviour after an integration of a big power plant. These simulations were performed on a real model of the power system using load flow calculations based on Newton Raphson algorithm, where an appropriate solution to reduce the constraints is also suggested.
\end{abstract}

Keywords: • impact analysis $\bullet$ power system operating $\bullet$ network $\bullet$ load flow $\bullet$ power plant $\bullet$

Correspondence AdDress: Houria Smail, Ph.D., Student, University of Bejaia, Faculty of Technology, Route de Targa Ouzemour, 06000 Bejaia, Algeria, e-mail: houria.smail2014@yahoo.com. Rezak Alkama, Professor, University of Bejaia, Faculty of Technology, Route de Targa Ouzemour, 06000 Bejaia, Algeria, e-mail: rezak_alkama@yahoo.fr.

https://doi.org/10.18690/978-961-286-061-5.22

ISBN 978-961-286-061-5

(C) 2017 University of Maribor Press

Available at: http://press.um.si. 
$10^{\text {TH }}$ International Conference on Sustainable Energy and Environmental Protection (June $27^{\mathrm{TH}}-30^{\mathrm{TH}}, 2017$, Bled, SLOVENIA), RENEWABLE ENERGY SOURCES H. Smail \& R. Alkama: Impact of a Big Power Plant Into the Network Introduction

The first objective of the electrical network is to be able to feed consumers. The integration and penetration of wind energy in power system have tended to be a dare for network managers, mainly, with wind turbines that do not tighten control of reactive power [1].

Many studies have been carried out to face the significantly increase of wind energy and its impact on power system operating [1-4]. Some authors focused their research on improving transient stability of the power system involving a distributed wind generation [1]. Others are more interesting on improving the performances of this power plant and working on various control strategies in order to optimize the extracted power from a wind energy conversion system [4].

Some other researchers are interested in solving optimal power flow problem [2,3,5-7]. However, when the system operates within its security limits, the ability of the existed network to face a severe disturbance is concerned. In order to prevent such conditions, the network managers have to examine the network behaviour before any integration of a new power plant. They have to test the network ability in case of the most probable events and act properly. This process helps them to make decisions during the planning stage of any integration. In this paper, a case study where the integration of a new power plant highlights constraints on the network was presented. It examines the impact of a big power plant $(2 \times 245 \mathrm{MW})$ whose power generation represents $8 \%$ of the total generation. The first part of the paper describes the load flow calculation used to evaluate the network behavior. The second part describes the considered hypothesis in the study. The last part of the paper deals with simulation results and analysis. In conclusion, an appropriate solution has been made to reduce the constraints on the network.

\section{Load Flow Calculation}

The load flow calculation provides information about the network behaviour to the dispatching center. It concerns the obtaining knowledge of the voltage values (in angle and magnitude) in all the buses of a network according to the following equations:

$$
\begin{aligned}
& P_{i}=V_{i} \sum_{j=1}^{n} V_{j}\left[G_{i j} \cos \left(\theta_{i}-\theta_{j}\right)+B_{i j} \sin \left(\theta_{i}-\theta_{j}\right)\right] \\
& Q_{i}=V_{i} \sum_{j=1}^{n} V_{j}\left[G_{i j} \sin \left(\theta_{i}-\theta_{j}\right)+B_{i j} \cos \left(\theta_{i}-\theta_{j}\right)\right]
\end{aligned}
$$


Four variables are associated with each network bus i :

Vi : the voltage magnitude.

$\theta \mathrm{i}$ : the voltage angle.

$\mathrm{Pi}$ : the net active power (generation-load).

Qi : the net reactive power (generation-load).

Depending on which of the above four variables are known (given) and which ones are unknown (to be calculated), three basic types of buses can be defined [8]:

$(\mathrm{P}, \mathrm{V})$ bus : $\mathrm{Pi}$ and $\mathrm{Vi}$ are specified; $\mathrm{Qi}$ and $\theta \mathrm{i}$ are calculated. $(\mathrm{P}, \mathrm{V})$ buses are normally used to represent generation buses.

$(\mathrm{P}, \mathrm{Q})$ bus : $\mathrm{Pi}$ and $\mathrm{Qi}$ are specified; $\mathrm{Vi}$ and $\theta \mathrm{i}$ are calculated. $(\mathrm{P}, \mathrm{Q})$ buses are normally used to represent load buses.

$(\mathrm{V}, \theta)$ bus : Vi and $\theta \mathrm{i}$ are specified; Pi and Qi are calculated. Generally, only one is required in the network. Known as balancing node or slack node, it equalizes the balance of networks powers.

There are various methods, all iteratives, for resolving equations describing the behavior of a network in steady state [9-12]. In this study, the resolution algorithm is based on Newton Raphson method given by the following equation:

$$
\left[\begin{array}{c}
\Delta \theta \\
\Delta \theta
\end{array}\right]=[J]^{-1} \cdot\left[\begin{array}{l}
\Delta P \\
\Delta Q
\end{array}\right] .
$$

The Jacobian matrix, whose elements are partial derivative values of either P or Q with respect to either $\mathrm{V}$ or $\theta$ :

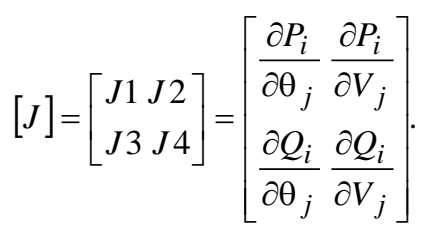

\section{Considered Hypothesis}

The power system model includes the following high voltage levels: 60, 90, 150, 220 and $400 \mathrm{kV}$. Due to the considered network immensity, only the new plant with its closest nodes is shown in Figure 1. 

$10^{\text {TH }}$ International CONFEREnce on Sustainable Energy and Environmental Protection (June $27^{\mathrm{TH}}-30^{\mathrm{TH}}, 2017$, Bled, SLOVENIA), RENEWABLE ENERGy SOURCES H. Smail \& R. Alkama: Impact of a Big Power Plant Into the Network

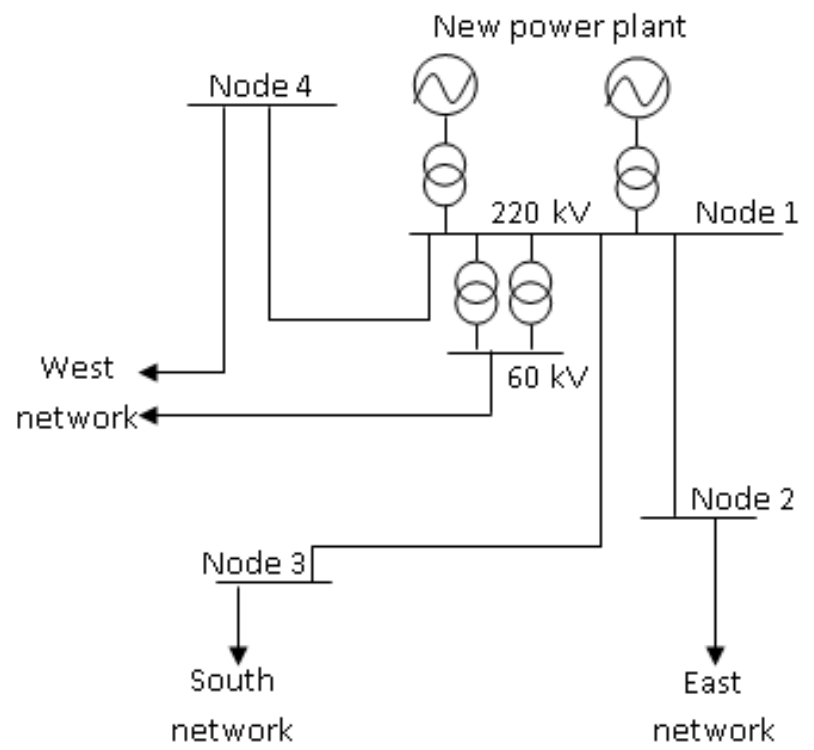

Figure 1 - Power system model.

Geographically, the network consists of four interconnected areas (Center, East, West and South). The plants 1 to 5 are located in the West, the plants 6 to 9 and the new plant in the Center, the plants 10 to 16 in the East and the plants 17 to 19 in the South.

Load hypothesis. The load curve shown in Figure 2 has an atypical background since the difference observed between the night dip, the morning load peak and the evening load peak.

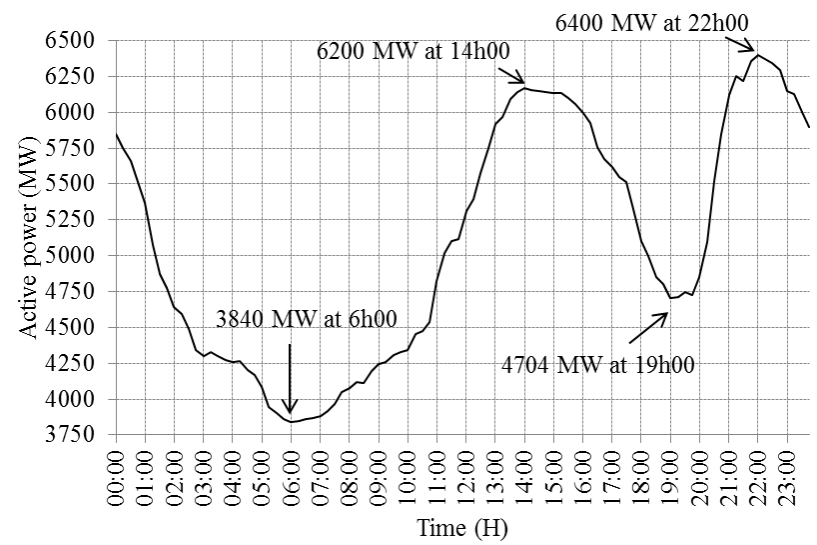

Figure 2 - Load curve. 
To satisfy such a demand, the electric system operator must mobilize quickly enough (about 5 to 7 hours) an amount of generation more than $2300 \mathrm{MW}$ to ensure the morning load peak (6200 MW at 14h00), giving an evolution close to $60 \%$. Thereafter, the demand decreases by about $31 \%$ in only 4 to 5 hours and the operator must reduce the generation by nearly $1460 \mathrm{MW}$ to reach $4704 \mathrm{MW}$ at $19 \mathrm{~h} 00$. Afterward, the operator remobilizes the generation again in record time: he must mobilize nearly $1700 \mathrm{MW}$ (an increase of $36 \%$ ) in only 2 hours to ensure the satisfaction of the evening load peak (6400 MW at 22h00).

During the evening load peak periods, the electric system operators, therefore, must pay attention to the pace of generation increase to satisfy the increasing demand by connecting, in average, $15 \mathrm{MW}$ per minute (the power of a little turbine). Thus, if power plants are uninterruptedly operating to ensure the basic load, others are required to operate during the peak periods.

The study examines the evening load peak profile of $6400 \mathrm{MW}$ and the night dip profile of $3840 \mathrm{MW}$. The profiles are examined in the healthy and disturbed states of the network.

Generation hypothesis. The start-up plan has to conciliate the load satisfaction between the evening load peak and the night dip profiles. It must be chosen regarding the lowest cost of production (steam turbine then gas turbine of large size).

The generating fleet taken into account is given in Table 1, Table 2, Table 3 and Table 4 respectively for the West, Center, East and South interconnected areas:

Table 1 Start-up plan in the West area

\begin{tabular}{|l|l|l|l|l|}
\hline Plant & Style & $\begin{array}{l}\text { Nominal } \\
\text { Capacity } \\
\text { (MW) }\end{array}$ & $\begin{array}{l}\text { Evening peak } \\
\text { (MW) }\end{array}$ & $\begin{array}{l}\text { Night dip } \\
\text { (MW) }\end{array}$ \\
\hline Plant 1 & $\begin{array}{l}\text { Steam } \\
\text { Turbine }\end{array}$ & 60 & 60 & 60 \\
\hline Plant 2 & $\begin{array}{l}\text { Steam } \\
\text { Turbine }\end{array}$ & 530 & 530 & 427 \\
\hline Plant 3 & Gas Turbine & 362 & 339 & - \\
\hline Plant 4 & Gas Turbine & 106 & 38 & - \\
\hline Plant 5 & Gas Turbine & 345 & 345 & 345 \\
\hline Total & & 1403 & 1312 & 832 \\
\hline
\end{tabular}


244 10 $10^{\mathrm{TH}}$ International CONFEREnCE on Sustainable EnERgy AND ENVIRONMENTAL Protection (June $27^{\mathrm{TH}}-30^{\mathrm{TH}}, 2017$, Bled, SLOVEnia), Renewable ENERGy SOURCES H. Smail \& R. Alkama: Impact of a Big Power Plant Into the Network

Table 2 Start-up plan in the Center area

\begin{tabular}{|l|l|l|l|l|}
\hline Plant & Style & $\begin{array}{l}\text { Nominal } \\
\text { Capacity } \\
(\mathrm{MW})\end{array}$ & $\begin{array}{l}\text { Evening peak } \\
\text { (MW) }\end{array}$ & $\begin{array}{l}\text { Night dip } \\
\text { (MW) }\end{array}$ \\
\hline Plant 6 & Gas Turbine & 60 & 60 & 60 \\
\hline Plant 7 & Gas Turbine & 428 & 428 & 150 \\
\hline Plant 8 & Gas Turbine & 172 & 172 & - \\
\hline Plant 9 & $\begin{array}{l}\text { Steam } \\
\text { Turbine }\end{array}$ & 672 & 672 & 370 \\
\hline $\begin{array}{l}\text { New } \\
\text { power } \\
\text { plant }\end{array}$ & Gas Turbine & $2 \times 245$ & $2 \times 245$ & $2 \times 230$ \\
\hline Total & & 1822 & 1822 & 1040 \\
\hline
\end{tabular}

Table 3 Start-up plan in the East area

\begin{tabular}{|l|l|l|l|l|}
\hline Plant & Style & $\begin{array}{l}\text { Nominal } \\
\text { Capacity } \\
(\text { MW) }\end{array}$ & $\begin{array}{l}\text { Evening peak } \\
(\text { MW })\end{array}$ & $\begin{array}{l}\text { Night dip } \\
(\text { MW })\end{array}$ \\
\hline Plant 10 & $\begin{array}{l}\text { Steam } \\
\text { Turbine }\end{array}$ & 190 & 190 & 190 \\
\hline Plant 11 & $\begin{array}{l}\text { Steam } \\
\text { Turbine }\end{array}$ & 85 & 85 & 85 \\
\hline Plant 12 & $\begin{array}{l}\text { Steam } \\
\text { Turbine }\end{array}$ & 290 & 290 & 90 \\
\hline Plant 13 & $\begin{array}{l}\text { Steam } \\
\text { Turbine }\end{array}$ & 840 & 840 & 840 \\
\hline Plant 14 & $\begin{array}{l}\text { Steam } \\
\text { Turbine }\end{array}$ & 588 & 588 & 496 \\
\hline Plant 15 & Gas Turbine & 321 & 291 & - \\
\hline Plant 16 & $\begin{array}{l}\text { Water } \\
\text { Turbine }\end{array}$ & 136 & 136 & - \\
\hline Total & & 2450 & 2420 & 1701 \\
\hline
\end{tabular}

Table 4 Start-up plan in the South area

\begin{tabular}{|l|l|l|l|l|}
\hline Plant & Style & $\begin{array}{l}\text { Nominal } \\
\text { Capacity } \\
(\mathrm{MW})\end{array}$ & $\begin{array}{l}\text { Evening peak } \\
(\mathrm{MW})\end{array}$ & $\begin{array}{l}\text { Night dip } \\
(\mathrm{MW})\end{array}$ \\
\hline Plant 17 & Gas Turbine & 200 & 200 & - \\
\hline Plant 18 & Gas Turbine & 460 & 460 & 180 \\
\hline Plant 19 & Gas Turbine & 190 & 190 & 90 \\
\hline \multicolumn{2}{|l|}{ Total } & 850 & 850 & 270 \\
\hline
\end{tabular}




\section{$4 \quad$ Simulation Results and Analysis}

The results are tabulated in Table 5 and Table 6 respectively for healthy and disturbed states of the network.

Table 5 Power flows during the evening load peak in a healthy state of the network

\begin{tabular}{|l|l|l|l|l|l|l|l|}
\hline & & $\begin{array}{l}100 \% \\
(2 \times\end{array}$ & $\begin{array}{l}90 \% \\
(2 \times\end{array}$ & $\begin{array}{l}95 \% \\
(2 \times\end{array}$ & & $\begin{array}{l}100 \% \\
(2 \times\end{array}$ & $\begin{array}{l}90 \% \\
(2 \times\end{array}$ \\
245 & 220 \\
(MVA) & $\begin{array}{l}\text { MW) } \\
\text { in the } \\
\text { new } \\
\text { plant }\end{array}$ & $\begin{array}{l}\text { MW) } \\
\text { in the } \\
\text { new } \\
\text { plant }\end{array}$ & $\begin{array}{l}\text { MW) } \\
\text { in the } \\
\text { new } \\
\text { plant }\end{array}$ & $\begin{array}{l}\text { Nominal } \\
\text { capacity } \\
\text { (MVA) }\end{array}$ & $\begin{array}{l}\text { MW) } \\
\text { in the } \\
\text { new } \\
\text { plant }\end{array}$ & $\begin{array}{l}\text { MW) } \\
\text { in the } \\
\text { new } \\
\text { plant }\end{array}$ \\
\hline $\begin{array}{l}\text { Line } \\
\text { Node } \\
\text { Node 2 }\end{array}$ & 118 & 75 & $-36 \%$ & 66 & $-44 \%$ & 80 & $-32 \%$ \\
\hline $\begin{array}{l}\text { Line } \\
\text { Node } \\
\text { Node 3 }\end{array}$ & 238 & 14 & $-94 \%$ & 11 & $-95 \%$ & 19 & $-92 \%$ \\
\hline $\begin{array}{l}\text { Line } \\
\text { Node } \\
\text { Node 4 }\end{array}$ & 238 & 282 & $18 \%$ & 249 & $5 \%$ & 243 & $2 \%$ \\
\hline $\begin{array}{l}\text { Transformer } \\
220 / 60 \mathrm{kV} \mathrm{1}\end{array}$ & 80 & 76 & $-4 \%$ & 74 & $-8 \%$ & 73 & $-9 \%$ \\
\hline $\begin{array}{l}\text { Transformer } \\
220 / 60 \mathrm{kV} 2\end{array}$ & 80 & 76 & $-4 \%$ & 74 & $-8 \%$ & 73 & $-9 \%$ \\
\hline
\end{tabular}

Examination of the healthy state. Taking in account of the start-up plan in the Four areas, the situation analysis highlights transmission constraints on the $220 \mathrm{kV}$ line between node 1 and node 4 in case of evening load peak. The overload of this line reaches $18 \%$ of its nominal capacity.

However, this overload can be reduced to 5\% if the generation is reduced to $90 \%$ ( $2 \times 220$ $\mathrm{MW}$ ) in the new plant and increased in the West (48 MW in the plant 4).

The overload of the line node 1 - node 4 does not disappear only if the generation is reduced in the new plant to $90 \%$, increased in the West by $90 \mathrm{MW}$ (68 MW in the plant 4 and $23 \mathrm{MW}$ in the plant 3) and reduced in the East by $36 \mathrm{MW}$ in the plant 15.

When the generation is reduced in the new plant to $95 \%$ (2x230 MW), increased in the West by $90 \mathrm{MW}$ (68 MW in the plant 4 and $23 \mathrm{MW}$ in the plant 3 ) and reduced in the East by $60 \mathrm{MW}(10 \mathrm{MW}$ in the plant $12,12 \mathrm{MW}$ in the plant 14 and $38 \mathrm{MW}$ in the plant 15) regarding to the first start-up plan, the overload of the line node 1 - node 4 will be reduced to $2 \%$. The results are presented in Table 5 . 

$10^{\mathrm{TH}}$ International Conference on Sustainable EnERgy and Environmental Protection (June $27^{\mathrm{TH}}-30^{\mathrm{TH}}, 2017$, Bled, SLOVEnia), Renewable ENERGy SOURCES H. Smail \& R. Alkama: Impact of a Big Power Plant Into the Network

Taking in account of the expected level of power at the night dip, the situation analyses provides no transmission constraint.

Examination of the disturbed state. To examine the disturbed state of the network, three different disturbances were considered; these disturbances correspond to the downfall of one of the three $220 \mathrm{kV}$ outgoing power lines node 1 - node 4 , node 1 - node 2 and node 1 - node 3 of the new power plant. The results are presented in Table 6.

Table 6 Power flows during the evening load peak in a disturbed state of the network

\begin{tabular}{|c|c|c|c|c|c|c|c|}
\hline & \multirow{2}{*}{$\begin{array}{l}\text { Nominal } \\
\text { capacity } \\
\text { (MVA) }\end{array}$} & \multicolumn{2}{|c|}{$\begin{array}{l}\text { Downfall of the line } \\
\text { Node } 1 \text { - Node } 4\end{array}$} & \multicolumn{2}{|c|}{$\begin{array}{l}\text { Downfall of } \\
\text { the line Node } 1 \\
\text { - Node } 2\end{array}$} & \multicolumn{2}{|c|}{$\begin{array}{l}\text { Downfall of } \\
\text { the line Node } 1 \\
\text { - Node } 3\end{array}$} \\
\hline & & MVA & $\%$ & MVA & $\%$ & MVA & $\%$ \\
\hline $\begin{array}{ll}\text { Line } & \\
\text { Node } & 1- \\
\text { Node 2 } & \\
\end{array}$ & 118 & 223 & $90 \%$ & - & - & 89 & $\overline{25 \%}$ \\
\hline $\begin{array}{ll}\text { Line } & \\
\text { Node } & 1- \\
\text { Node } 3 & \\
\end{array}$ & 238 & 60 & $-75 \%$ & 38 & $-84 \%$ & - & - \\
\hline $\begin{array}{ll}\text { Line } & \\
\text { Node } & 1- \\
\text { Node 4 } & \\
\end{array}$ & 238 & - & - & 288 & $21 \%$ & 249 & $5 \%$ \\
\hline $\begin{array}{l}\text { Transformer } \\
220 / 60 \mathrm{kV} 1\end{array}$ & 80 & 100 & $25 \%$ & 82 & $-2 \%$ & 75 & $-7 \%$ \\
\hline $\begin{array}{l}\text { Transformer } \\
220 / 60 \mathrm{kV} 2\end{array}$ & 80 & 100 & $25 \%$ & 82 & $-2 \%$ & 75 & $-7 \%$ \\
\hline
\end{tabular}

If the $220 \mathrm{kV}$ line node 1 - node 4 drops the two transformers $220 / 60 \mathrm{kV}$ installed in the new plant (node 1) will be overloaded by $25 \%$ and the transmission on the $220 \mathrm{kV}$ line node 1 - node 2 will increase to 223 MVA which represents $90 \%$ of its nominal capacity. An amount of $30 \mathrm{MW}$ will be required to import from the near network comparatively to the healthy state.

In case of downfall of the $220 \mathrm{kV}$ line node 1 - node 2, an important overload of $21 \%$ will be observed on the $220 \mathrm{kV}$ line node 1 - node 4 regarding to its nominal capacity. The transmission on this line will be 249 MVA which represents $5 \%$ of its nominal capacity if the line node 1 - node 3 drops.

\section{Conclusion}

The aim of this paper was to examine the impact of a new power plant into the network. The examination has been performed considering the evening load peak and the night dip profile. The profiles were examined at the healthy and disturbed states of the network.

On the basic of the achieved results, the main conclusions are: 
$10^{\text {TH }}$ InTERnAtional CONFERENCE on Sustainable EnERgy AND ENVIRonmental 247 Protection (June $27^{\mathrm{TH}}-30^{\mathrm{TH}}, 2017$, BLED, SLOVENiA), RENEWABLE ENERGY SOURCES

H. Smail \& R. Alkama: Impact of a Big Power Plant Into the Network

The start-up selected makes fewer constraints to conciliate the load satisfaction between the evening load peak and the night dip profiles. However, in order to reduce the high level of the power transmitted through the $220 \mathrm{kV}$ line between node 1 and node 4 , it is necessary to reduce the generation of the new power plant to $460 \mathrm{MW}$, giving $95 \%$ of its nominal production, and to start-up all the reserves in the West.

In case of the disturbed state, the two transformers $220 / 60 \mathrm{kV}$ installed in the new plant (node 1 ) will be overloaded by $25 \%$ if the $220 \mathrm{kV}$ line between node 1 and node 4 drops. This line will be overloaded by $21 \%$ if the $220 \mathrm{kV}$ line node 1 - node 2 drops.

From these results, one can concluded that to reduce the constraints, it will be necessary to reinforce the $220 \mathrm{kV}$ link between node 1 - node 4 .

\section{References}

[1 A. Zebar, A. Hamouda, K. Zehar, Impact of the location of fuzzy controlled static var compensator on the power system transient stability improvement in presence of distributed wind generation, Rev. Roum. Sci. Techn. - Électrotechn. Et Énerg., 60, 4, pp. 426-436 (2015).

[2] A. Bemadani, L. Benasla, M. Rahli, Amélioration d'un dispatching économique dynamique par l'introduction d'une ferme éloienne. Application au réseau électrique Ouest Algérien, Rev. Roum. Sci. Techn. - Électrotechn. Et Énerg., 57, 3, pp. 269-280 (2012).

[3] M. Abasi, M. F. Nezhadnaeini, M. Karimi, N. Yousefi, A novel metaheuristic approach to solve unit commitment problem in the presence of wind farms, Rev. Roum. Sci. Techn. Électrotechn. Et Énerg., 60, 3, pp. 253-262 (2015).

[4] M. Doumi, A. G. Aissaoui, A. Tahour, M. Abid, Commande adaptative d'un système éolien, Rev. Roum. Sci. Techn. - Électrotechn. Et Énerg., 60, 1, pp. 99-110 (2015).

[5] S. Shojaeian, J. Soltani, Low frequency oscillations damping of a power system including unified power flow controller, based on adaptative backstepping control, Rev. Roum. Sci. Techn. - Électrotechn. Et Énerg., 58, 2, pp. 193-204 (2013).

[6] M. Younes, Hybrid method for optimal power flow determination, Rev. Roum. Sci. Techn. - Électrotechn. Et Énerg., 57, 3, pp. 249-258 (2012).

[7] M. Younes, M. Rahli, M. Abid, Malika Kandouci, Optimisation d'écoulement des puissances par algorithmes intelligents, Rev. Roum. Sci. Techn. - Électrotechn. Et Énerg., 52, 1, pp. 3-12 (2007).

[8] G. Anderson, Modeling and Analysis of Electric Power Systems, ITET ETH Zürich, Inc., 2004, Lecture 227-0526-00.

[9] V. Thierry, V. Costas, Voltage Stability of Electric Power Systems. Hardcover Edition 1998 Springer Science+Business Media, LLC.

[10] A. Venkataramana, Computational Techniques for Voltage Stability Assessment and Control. Power Electronics and Power Systems Series, Editions 2006 Springer Science+Business Media, LLC.

[11] M. A. Golkar, A novel method for load flow analysis of unbalanced three-phase radial distribution networks, Turk J Elec Engin, Vol.15, No.3 2007.

[12] R. Belhachem, F. Benhamida, A. Bendaoud, Y. Ramdani, Resolution de Dispatching Optimal en combinant l'écoulement de puissance pour le calcul des pertes, ACTA ELECTROTECHNICA., 53, 1 (2012). 


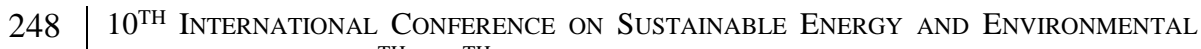
Protection (June $27^{\mathrm{TH}}-30^{\mathrm{TH}}$, 2017, Bled, Slovenia), Renewable EnERGy SourCeS 
$10^{\mathrm{TH}}$ InTERnAtional CONFERENCE ON Sustainable ENERgy AND Environmental Protection (June $27^{\mathrm{TH}}-30^{\mathrm{TH}}$, 2017, Bled, SLOVENIA), RENEWABLE ENERGy SOURCES

J. Krope, A.Ghani Olabi, D. Goričanec \& S. Božičnik

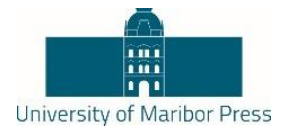

\title{
Small Kinetic Water Turbines Review, Possible Locations and Economoc Efficiency in Slovenia
}

\author{
ANDREJ PREDIN \& GORAZD HREN
}

\begin{abstract}
In the paper the review of small kinetic turbines is presented suitable for rivers in Slovenia. Varieties of technologies appear in the last decade, particularly in the world-wide regions with high hydro-electric potential. The small size hydrokinetic turbines are less economically attractive, due to the relatively low efficiency, using only dynamic potential of the river. In general, no economic evaluations of hydrokinetic turbines are considering impact on river habitat and environment. The investment into hydrokinetic turbine is consequently higher. The load efficiency could be increased with the number of aggregates what leads to carefully balanced investment, operating and maintenance cost. Only the economic reason is obstacle for wide commercial use. The responsibility to the environment impact are forcing us to apply technologies with small shortterm profit, with technologies with less long-term impact on the environment. Authors believe that this area is an opportunity for Slovenia for research and technology development.
\end{abstract}

Keywords: • water turbines $\bullet$ kinetic turbines $\bullet$ economic efficiency • Slovenia $\bullet$ technologies $\bullet$

CorRespondence AdDress: Andrej Predin, Ph.D, Full Professor, University of Maribor, Faculty of Energy Technology; Hočevarjev trg 1, 8270 Krško, Slovenia, e-mail: andrej.predin@um.si, Gorazd Hren, Ph.D., Assistant Professor, University of Maribor, Faculty of Energy Technology; Hočevarjev trg 1, 8270 Krško, Slovenia, e-mail: gorazd.hren@um.si.

https://doi.org/10.18690/978-961-286-061-5.23

ISBN 978-961-286-061-5

(C) 2017 University of Maribor Press

Available at: http://press.um.si. 
$10^{\mathrm{TH}}$ InTERnATIONAL CONFERENCE ON Sustainable ENERgy AND ENVIRONMENTAL Protection (June $27^{\mathrm{TH}}-30^{\mathrm{TH}}, 2017$, Bled, SLOVEnia), RENEWABle ENERGy SOURCES A. Predin \& G. Hren: Small Kinetic Water Turbines Review, Possible Locations and Economoc Efficiency in Slovenia

\section{Introduction}

The world's energy demand is increasing with growing population and industry needs. Addressing future energy sustenance and environment, the renewable energy resources have gain enormous attention in recent years, in order to provide energy with minimum environmental effect.

The purpose of this paper is to review few technologies of hydrokinetic turbines. All water turbines are essentially kinetic turbines, the term kinetic highlights the potential free installation of the turbine rotor in the water flow like put wind turbines in the air stream. The essential difference compared with conventional water turbines is in layout, which does not require coverage or damming of the water flow, and then the conversion of the hydrostatic pressure in the flow velocity. This kinetic energy transformed into mechanical energy, which is now a synchronous or asynchronous power generators almost exclusively transformed into electricity. Due to the exploitation of only a part of the available hydro water energy, the power production is smaller as by classic water turbines. Consequently, the lower the efficiency of production and viability, due to lower production as compared with a conventional layout. In order to achieve greater production requires a large number of aggregates, which demands larger initial investment, maintenance of the entire system, and lowers overall economic assessment, to the extent that such investments are not rentable. However, if we consider not only in time economic calculation, but affection to the environment, small aggregates, the possibility of local production, self-sufficiency in electricity and similar factors, making these turbines also economically very interesting.

\section{$2 \quad$ Principles of Kinetic Turbines}

The natural power of water and air flow is in the interest of the public from ancient history and is investigating by researchers for many decades. The technologies developed in the area of kinetic water turbines are of very different concepts, mostly following the development of wind turbines. Small turbines are very suitable for domestic applications, as they are small and inexpensive. As initially mentioned, we put the water kinetic turbines in the water flow quite similar as we put the wind turbine in to airflow. That means that on the turbine rotor affect only the dynamic part of the available energy of the flow. Up to the required pressure drop, which drives the turbine impeller, it comes on the principle of water flow stop directly at front of the rotor and, from the pressure drop in the rotor weak flow. Therefore, we should expect the highest effect or efficiency to the extent as at wind turbines. The limit for horizontal wind turbines is known as Betz low. Considering that, we can expected at higher rotation speed of the rotor, the maximum efficiency of 59\% of the available kinetic energy of the water flow. The energy lost is caused by diverting water flow from the turbine rotor blades. Due to the flow interruption, a rotor diverts part of the flow past the rotor blades in the radial direction. This fact lead to implementation of diffusors into kinetic turbines development, while diffusor with its form decrease this effect and at the same time decreases the flow velocities behind of 
turbine rotor, which increases the flow pressure drop. The diffusors effect is described in a separate chapter.

Interest in diffuser kinetic type of turbines are scattered throughout many parts of the world and the main area of applications of hydro-kinetic turbines are river flows on the tides. In this article, we are limited our research to the river current kinetic turbines. Their main advantage is that they not need dams, and they are put in the water flow stream with velocity greater than $0.5 \mathrm{~m} / \mathrm{s}$ [1]. Due to the relatively low investment and maintenance costs, this technology is seems to be the most cost-effective compared to others. This type of turbine is operating with extraordinary low environmental impact, and comparing to others renewable energy solutions primarily less dependent on the weather (as solar power), as water flow is continuous. The amount of the water is definitely year season dependent. This technology applies to renewable environmentally friendly, because the water passing through the generator directed back into the stream with a relatively small impact on the riverine environment.

Hydro-kinetic turbines produce electricity directly from water stream of the river. The energy flux is dependent on the water flow, that is, the density, the cross-section and of velocity of the water (1). Around the world has been developed several different concepts using this potential power. The major concepts are linked to a turbine system, although there are other ways that are at the stage of investigation and prototyping tests.

$P=\frac{1}{2} \rho c_{P} A v^{3}$

where

$P$... power,

$\rho$... media density,

$c_{P} \ldots$ power coefficient,

$A$... the cross-section area of rotor,

$v$... velocity of the flow;

The term "power coefficient" is usually used to define the common efficiency of the turbine power system. Generally is defined as the ratio (2) of the "electrical power produced" by kinetic-turbine" $\left(P_{\text {out }}\right)$ and the available stream kinetic energy $\left(P_{\text {in }}\right)$.

$c_{P}=\frac{P_{\text {out }}}{P_{\text {in }}}$

The power coefficient (Figure 1) also depends on the turbine type and on the ratio of circumferential velocity of the turbine rotor, at tip diameter, and of the water free stream velocity (tip-speed ratio - $\lambda$ ). 
$10^{\text {TH }}$ International Conference on Sustainable Energy and Environmental Protection (June $27^{\mathrm{TH}}-30^{\mathrm{TH}}, 2017$, Bled, SLOVEnia), Renewable ENERGy SOURCES A. Predin \& G. Hren: Small Kinetic Water Turbines Review, Possible Locations and Economoc Efficiency in Slovenia

$c_{P}$
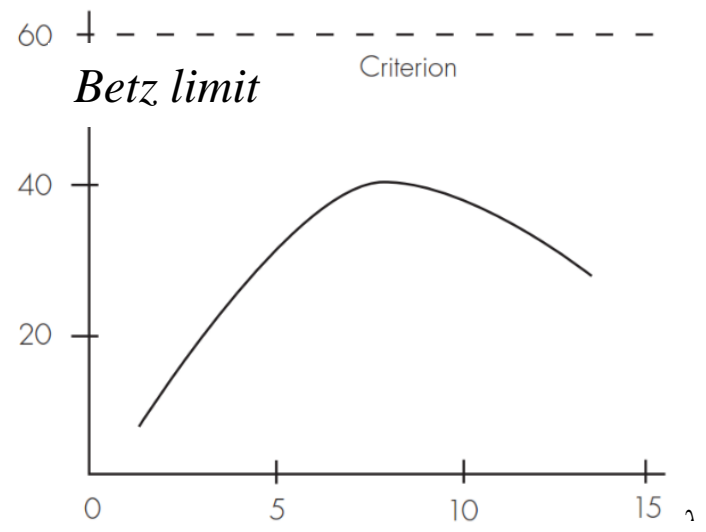

Figure 1: Power coefficient versus tip-sped ratio $\lambda$

Somewhere between $\lambda=0$ and $\lambda=10$ is an optimum value, in this particular case $\lambda=7$ which represents the maximum extracted power. This is the condition in which the average velocity on the rotor disc is $2 / 3$ of the wind speed according to Betz law.

\section{Overview of Kinetic Turbines}

Since year 2000, the kinetic water turbines are gradually developing and becoming wider interesting mainly due to lower environmental impact compared to traditional energetic systems. Therefore, various technologies emerging in the world, of course, varying in implementation success.

The choice of the turbine layout depends on many factors that could be of technical, environmental and economic efficiency nature. One of the main factors is a way of converting kinetic energy into electricity, which is taken from the concepts of wind turbines. Depending on the water flow and the axis of the rotor, there are two basic types: axial with the axis in the flow direction, and "perpendicular", having a shaft that occur an angle to the flow direction. Axial turbines with axis parallel to the flow of water and are mostly propeller-type various combinations of the basic types of spatial water flow (Figure 2). In contrast, in transverse turbines where the water flow perpendicular, or at some other acute angle, to the axis of the rotor and are mainly cylindrical shape (Figure $3)$. 


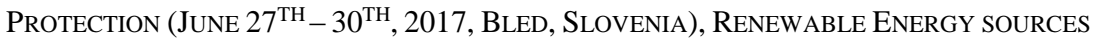
A. Predin \& G. Hren: Small Kinetic Water Turbines Review, Possible Locations and Economoc Efficiency in Slovenia
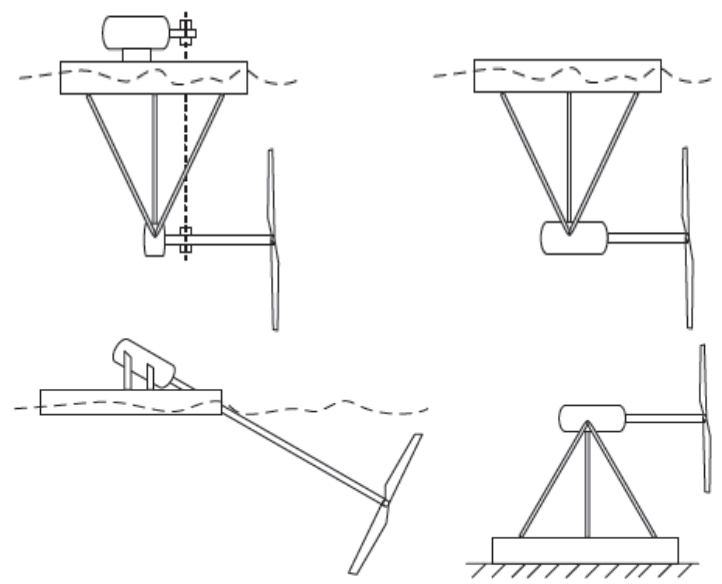

Figure 2: Axial turbines flow turbines [2]

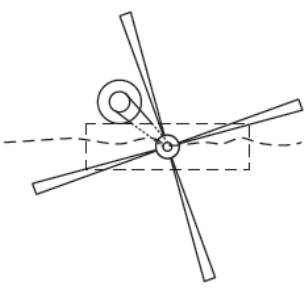

(a) In-plane axis

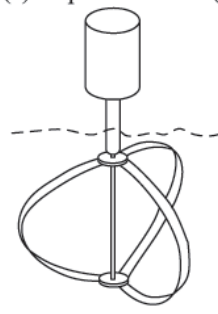

(d) Darrieus

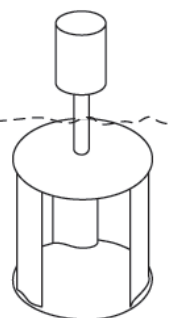

(b) Squirrel Cage Darrieus

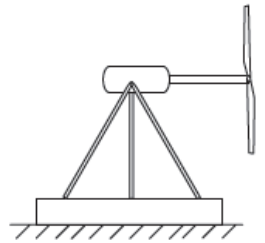

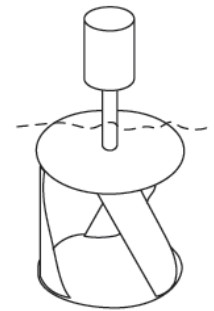

(e) Gorlov

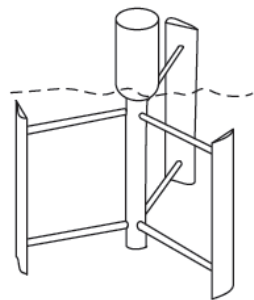

(c) H-Darrieus

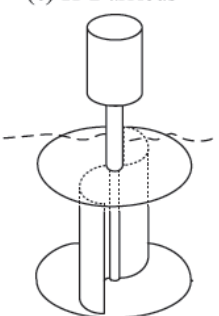

(f) Savonius

Figure 3: Cross flow turbines [2]

Each type of turbines has their own advantages and disadvantages.

Cross flow turbines are symmetrical, and have no problem with direction of flow changing; the generator may be in or out of the water. Some of them are not self-starting and the initial systemic momentum is needed. At these types, the size of operating torque varies depending on rotor angular position or angular speed. 
254 10 $10^{\text {TH }}$ InTERnAtional CONFERENCE ON Sustainable ENERGy AND ENVIRONMENTAL Protection (June $27^{\mathrm{TH}}-30^{\mathrm{TH}}, 2017$, Bled, SLOVENIA), RENEWABle ENERGy SOURCES A. Predin \& G. Hren: Small Kinetic Water Turbines Review, Possible Locations and Economoc Efficiency in Slovenia

At the axial turbine rotor types, the additional mechanisms for directing into the water flow is needed.

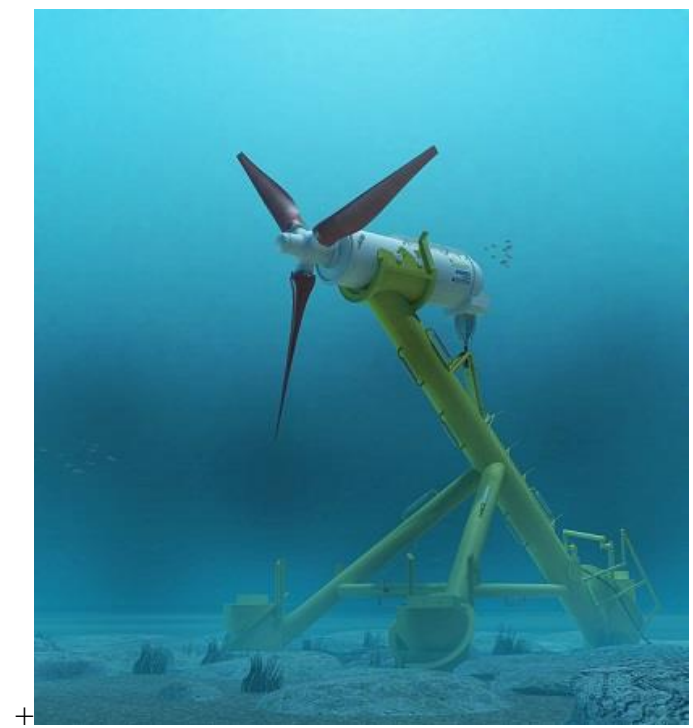

Figure 5: Example of horizontal hydro-kinetic turbine [3].

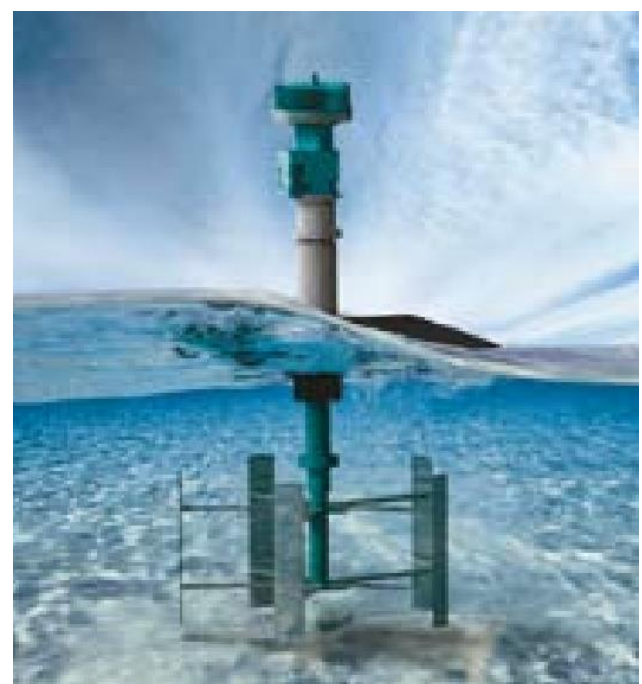

Figure 6: Example of vertical hydro-kinetic turbine [4]. 


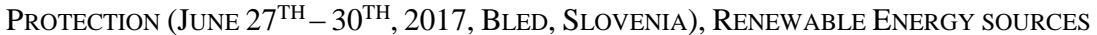
A. Predin \& G. Hren: Small Kinetic Water Turbines Review, Possible Locations and Economoc Efficiency in Slovenia

\section{The Improvements to Increase the Efficiency of Hydro-Kinetic Turbines}

In order to achieve higher efficiency of hydro-kinetic turbines and better use of the water flow the improvements were found changing blades geometry and implementing the diffuser. The analyses with computational fluid dynamics (CFD) [5] were performed finding the flow stagnation areas and the positions of flow tearing were determined. The geometry of the rotor blade profile was changed to optimise water flow on blades. Afterwards, the implementation of the diffuser was analysed which significantly increased turbine efficiency in comparison with bare turbine is. As an example, we consider a kinetic water turbine rotor with a diameter of $0.5 \mathrm{~m}$, which is freely set in a water stream with velocity of $1.5 \mathrm{~m} / \mathrm{s}$ (Figure 7 ).

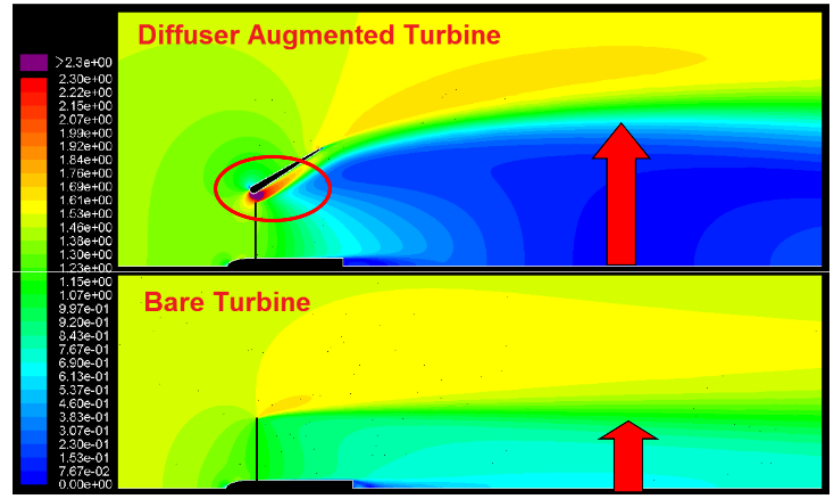

Figure 7: CFD analysis of kinetic turbine with and without diffusor [5]

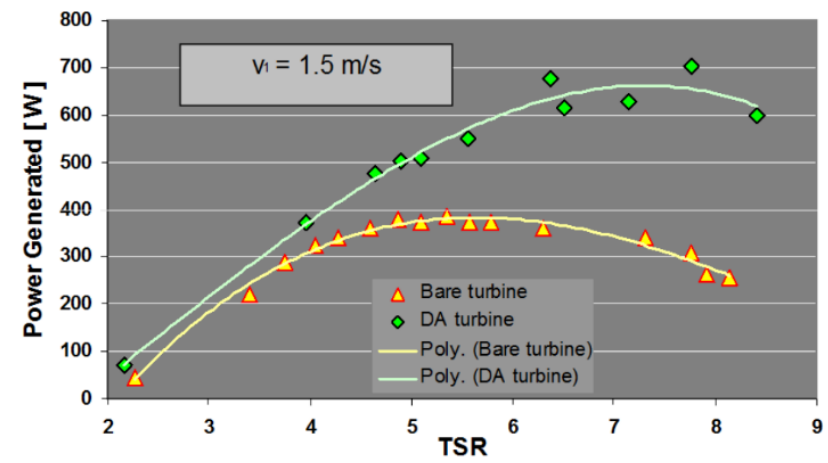

Figure 8: Operating characteristics of turbine with and without diffusor depending on the ratio of the free flow against the maximum peripheral speed (TSR) [5]

The outer band of the turbine (Figure 11), where the outlet diameter of the diffuser $50 \%$ larger than the inlet, resulted in a significantly higher-pressure drop before and after the rotor of the turbine, as in the case without the use of a diffuser. Height and the size of the 
$10^{\text {TH }}$ International CONFEREnce on Sustainable Energy and Environmental Protection (June $27^{\mathrm{TH}}-30^{\mathrm{TH}}, 2017$, Bled, SLOVEnia), RENEWABle ENERGy SOURCES A. Predin \& G. Hren: Small Kinetic Water Turbines Review, Possible Locations and Economoc Efficiency in Slovenia

stagnation zone flow to the impeller is substantially increased, which enables also a greater yield and consequently greater power at the same speed of the flow (Figure 8). At the same time, it achieves a higher rotational speed, which is evident from the increase factor of the relationship between the circumferential speed of the rotor and the speed of the free-flow.

The effect of the diffuser is therefore a twofold increase of the rotational speed of the rotor of the turbine, and achieved hydraulic power to the rotor shaft. From analyse results, from $380 \mathrm{~W}$ to $650 \mathrm{~W}$, which means the $70 \%$ increase of efficiency at the same flow rate. In reality, we can expect up to a $50 \%$ increase, because we have to take into account losses that occur as a result of the additional flow diffuser losses and loss of electrical generator. Therefore, when assessing the economic impact considering the actual rated power of approximately $600 \mathrm{~W}$ at the exit from the generator in this case.

\section{Some Commercial Implementations Suitable for Slovenian Rivers}

Hydro-kinetic turbine technologies have some advantages when compared with conventional hydropower energetic systems, the fact that it does not require large-scale construction works comparing to the classic versions of the hydro power plants. They have much lower impact on the environment and practically minimal visual impact, because the turbine is submerged and visually hidden in the river. River flow is stable and predictable source of energy with well-known parameters. Variants have some common characteristics. Provided preventive maintenance to take place every 10 years, while the estimated useful life of hydro-kinetic turbines is about 40 years. After finishing the lifetime of the turbine could be easily removed from the riverbed and leaving almost no trace. Technologies have a minimal impact on the environment, schedule works are significantly shorter compared to traditional hydro-electric projects, which naturally reduces the cost of the entire project. Unlike solar and wind energy, the energy is derived from hydro-kinetic turbines, produced continuously. It works by taking small, as well as the large river discharges; of course, by increasing the flow of increasing the flow rate of the river flow thus in turn increases the production of electricity.

Hydrokinetic potential of river flows was relatively poorly studied and therefore in present time many researches investigate possibilities and solutions, recently. Due to the rapid and effective deployment of innovative turbines these technologies are suitable for countries with large water potential. In the selection of suitable sites for the installation of turbines, we must take into account the flow speed and water depth. Minimum flow rate should be $0.5 \mathrm{~m} / \mathrm{s}$ and depth approximately $4 \mathrm{~m}$. Turbines should be constantly submerged, even at low flow rates. To confirmed the data the elaborate of field study of the existing physical environment has to be done. In field-studies we have to establish river profile of flow velocity, water depth and the possible installation site to connect the turbine with electrical network. 
Basic design parameters of hydro-kinetic turbines are:

- Minimal impact on the ecosystem.

- Minimal visual impact on the surrounding environment.

- Competitive price compared to other renewable energy sources.

- The water temperature.

- Minimum river depth.

- The volume of the river flow.

- Seasonal fluctuations in flow.

- Low maintenance.

If appropriate it is possible to gradually add more turbines, thereby contributing to sustainable development. Produced energy can be integrated into a joint or isolated electrical network.

All installations of hydro-kinetic turbines have to implement monitoring of the impact on the environment. The goals of the monitoring are:

- Confirmation of the methodology of integration in the riverbed and the merits of the entire system.

- Demonstrate the high efficiency and reliability of new technologies.

- Assess the complexity of integration into the electricity grid.

- Monitor impacts on the environment, particularly the impact on the habitat.

Installation of kinetic-turbines in the river flow is equally challenging as finding place for a wind turbine. Method of placement depends very much on the concept of hydrokinetic turbines, axial or radial direction of water stream on the turbine, access to the turbine, turbine generator connection and, of course, places available in the river. The flow of the river has a velocity profile that depends on flow type, the river depth, and of the water capacity.

\subsection{TREK turbine, renewable energy research, Canada}

These turbines are based on innovative technology extracting wave energy, tidal stream and river stream. TREK technology is intended as an alternative technology, where classical hydropower technology cannot provide satisfactory because of environmental problems. Also, the produced electricity costs are competitive to other technologies that are based on renewable energy sources. 
$10^{\text {TH }}$ International Conference on Sustainable Energy and Environmental Protection (June $27^{\mathrm{TH}}-30^{\mathrm{TH}}$, 2017, Bled, SLOVENIA), RENEWAble ENERGy SOURCES A. Predin \& G. Hren: Small Kinetic Water Turbines Review, Possible Locations and Economoc Efficiency in Slovenia

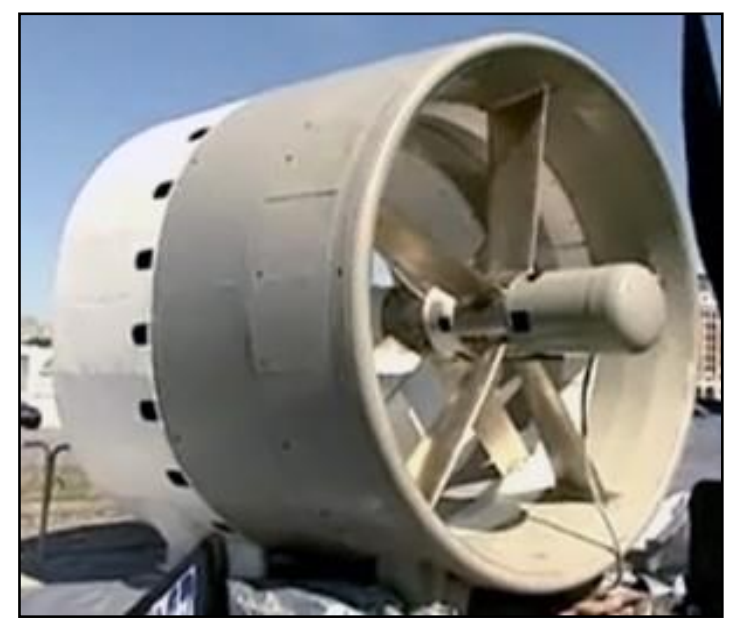

Figure 9: TREK turbine without a diffuser outlet, [6].

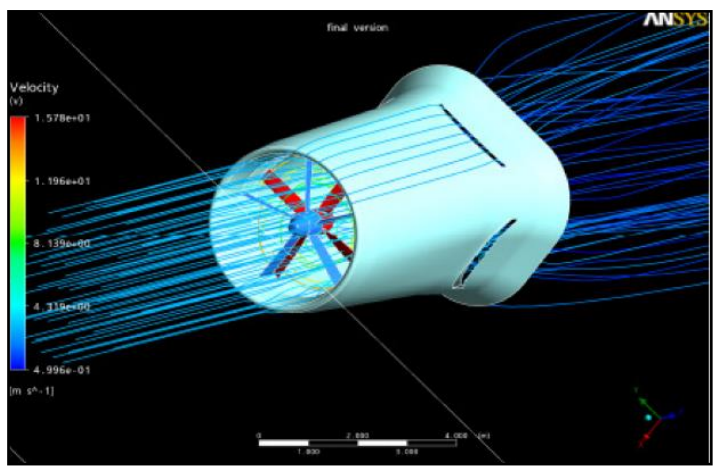

Figure 10: CFD flow presentation of TREK turbine, presented at the World energy conference [4].

TREK turbine is placed in riverbed. The generator is bulb type construction. TREK technology was specially developed primarily for the Canadian rivers, as response to market research, which showed the non-availability of technologies for Canadian colder climate, and consequently different criteria of operating conditions. The developed concept relies on the frozen surface of the river and major changes in water temperature.

In 2009, the company RER obtained government approval and financial support to test the prototype TREK turbines in practice. He started the project installation TREK technology in the Saint-Lawrence River near Montreal, Canada. Before the actual course, they were carried out numerous tests and laboratory simulations, with many advanced modelling and simulation tools. Two TREK turbines were installed with an output of $250 \mathrm{~kW}$ power each. 
$10^{\text {TH }}$ InTERnAtional CONFERENCE on Sustainable EnERgy AND ENVIRonmental 259

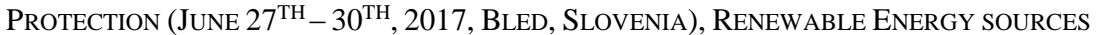
A. Predin \& G. Hren: Small Kinetic Water Turbines Review, Possible Locations and Economoc Efficiency in Slovenia

First TREK turbine was submerged in August 2010. Some technical information about this turbine TREK-I: nominal power of $250 \mathrm{~kW}$; the frequency of $100 \mathrm{~Hz}$; flow velocities between 2 and $4.5 \mathrm{~m} / \mathrm{s}$; the total efficiency up to $95 \%$.
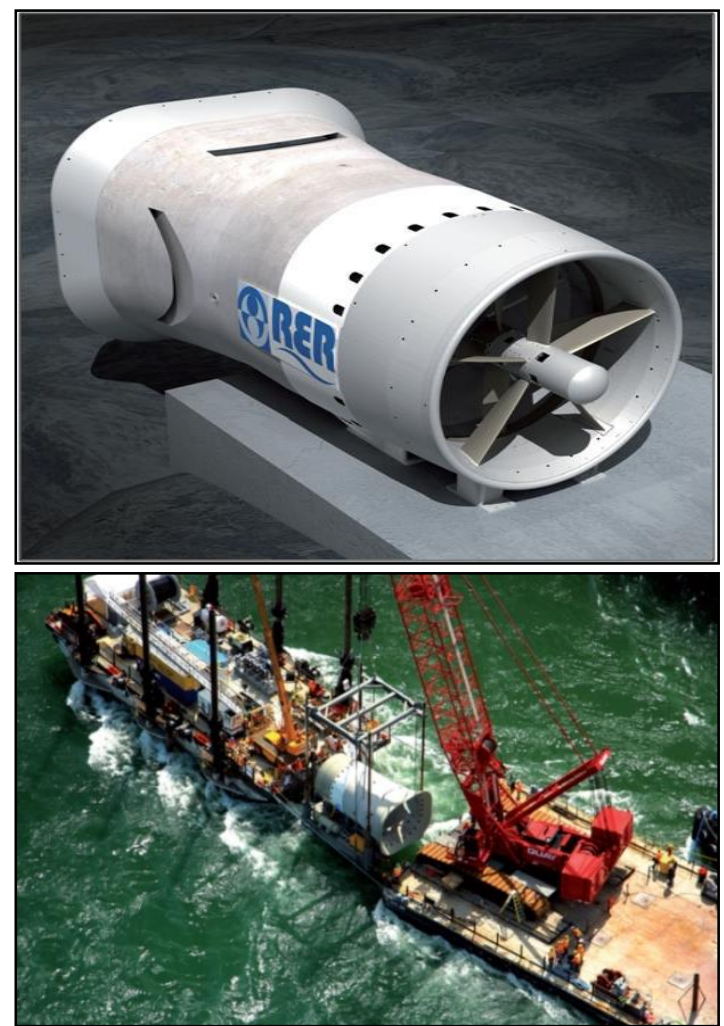

Figure 11: Installation of the turbine on the Saint-Lawrence River, Montreal [7]

\subsection{SmarTurbine, FreeFlowPower corporation, USA}

FFP Company develops hydro-kinetic solutions in the field for which it believes provides exceptional opportunities for growth. Investors provides carbon-free electricity production high production reliability and lower cost than other forms of exploitation of renewable energy sources. Specialty developed turbine SmarTurbine for the low speed of rotation (2:1 compared to water) allows the passage of fish. The turbine design avoided any high-speed rotation that could cause turbulence and shear stress. It is installed below the level of the river traffic and requires the minimal construction on the river bank. Characteristic: overall diameter $3 \mathrm{~m}$; length $4.5 \mathrm{~m}, 7$ blades with diameter of $2.25 \mathrm{~m}$; weight $1360 \mathrm{~kg}$; coated with a diffuser; power output of $10 \mathrm{~kW}$ at $60 \mathrm{~Hz}$; input water speed of $2.5 \mathrm{~m} / \mathrm{s}$. 
$10^{\text {TH }}$ InTERnATIONAL CONFERENCE ON Sustainable ENERgy AND ENVIRONMENTAL Protection (June $27^{\mathrm{TH}}-30^{\mathrm{TH}}, 2017$, BlED, SLOVENIA), RENEWABLE ENERGy SOURCES A. Predin \& G. Hren: Small Kinetic Water Turbines Review, Possible Locations and Economoc Efficiency in Slovenia

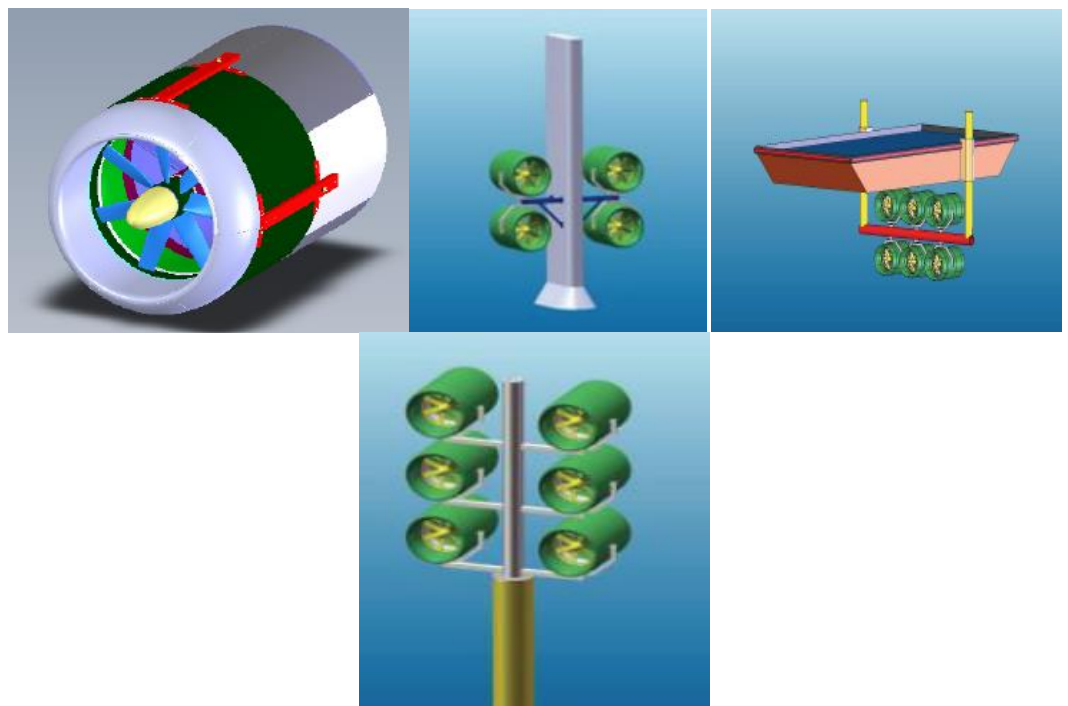

Figure 12: Turbine and a possible attachments: to bridge abutments, to pontoon, to pylon [8]

\subsection{Underwater Electric Kite - UEK corporation, USA}

The system is using the configuration of the two axial flow turbines. Each turbine is composed of five blades, which drive the common internal generator. Turbines are coated with a diffuser outlet, produced from the composite materials. The system has a built-in a common ring, which is extended in the direction of the axis, and guide the water into the turbine at a faster speed of the water flow. It creates a low-pressure area at the rear to increase the pressure difference and velocity of water through the turbine. The unit is anchored to the bottom with a mooring system in the tack. Patented anchoring system keeps the turbine in the water stream. Figure 12 is showing different types of attachment. The turbine can operate in a river or ocean currents velocity between 2 and $5 \mathrm{~m} / \mathrm{s}$.

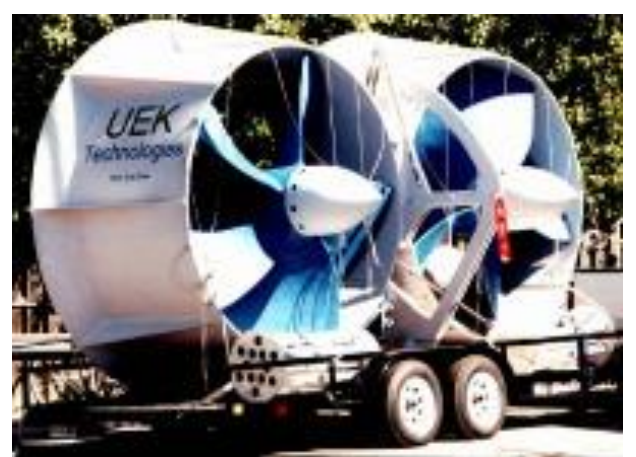

Figure 13: UEK turbine, [10] 
$10^{\mathrm{TH}}$ InTERnational CONFERENCE ON SUSTAINABle ENERgy AND ENVIRONMENTAL Protection (June 27 $7^{\mathrm{TH}}-30^{\mathrm{TH}}, 2017$, BLED, SLOVEniA), RenEwABle ENERGy SOURCES

A. Predin \& G. Hren: Small Kinetic Water Turbines Review, Possible Locations and Economoc Efficiency in Slovenia

\section{Economic Efficiency}

Investment costs such as coated kinetic water turbines were estimated based on similar projects that have already been implemented (TREK technology), the ratio of installed power and the necessary construction work. Thus, we estimate that the biggest part of the investment is $€ 6,000$ for turbine, $€ 4,000$ for construction, and $€ 3,000$ for installation costs. Cost of concession fees and land costs are not included. Our comparative investment could be estimated to $€ 13,500$ for an installed power of $0.6 \mathrm{~kW}$ per unit. Operating time is estimated to 7,000 hours per year, which means that it can produce up to 4.2MWh.

It is estimated that in the reference year 2013 the price of the produced electricity could be guaranteed as for the small hydroelectric power up to $1 \mathrm{MW}$ for $€ 92.61 / \mathrm{MWh}$, which is accounted in our example.

Annual production at a guaranteed redemption price, is $€ 388.96$, shows that the return time of the investment is close up to 35 years, if we predict that the purchase price over the years will remain the same. Return on investment itself would be minimal, which means that it would be very difficult to obtain investment funds. As already mentioned, in the case of economic valuation of environmental damage caused, the economic picture is likely to be better.

\section{$7 \quad$ Conclusions}

An overview of hydro-kinetic turbines technologies has shown that there is a great interest of the research community for these new technologies, which are on the border of the economic acceptability. Due to the relatively low yield, compared to traditional layouts water turbines, which kept at bay and make use of all available water flow, hydrokinetic turbines for the production of leaner and therefore less profitable. If we begin to evaluate the harmful interventions in the environment, improved technology and increased efficiency of the turbines will become economically viable and attractive for investors.

In Slovenia, we have some highly environmentally sensitive rivers that are not energy utilized in the conventional way. These environments are extremely interesting for the exploitation of the energy potential of hydrokinetic turbines. In addition, this is the economic arm of that in Slovenia we can technologically and commercially implemented. This means that this segment may also be one of the possible economic challenges and help recovery from the economic crisis in which our Slovenia situated. We believe that in Slovenia there is the knowledge, skills, and potential for production and installation of these turbines or entire turbine systems. 
$10^{\text {TH }}$ International Conference on Sustainable Energy and Environmental Protection (June $27^{\mathrm{TH}}-30^{\mathrm{TH}}, 2017$, Bled, SLOVEnia), RENEWABle ENERGy SOURCES A. Predin \& G. Hren: Small Kinetic Water Turbines Review, Possible Locations and Economoc Efficiency in Slovenia

\section{References}

[1] M.J. Khan, G. Bhuyan, M.T. Iqbal, J.E. Quaicoe; "Hydrokinetic energy conversion systems and assessment of horizontal and vertical axis turbines for river and tidal applications", A technology status review, Applied Energy, 2009, pp. 1823-1835.

[2] K. Sornes, “ZERO - Small-scale Water Current Turbines for River Applications”, Oslo, 2010

[3] ATB Morley, All Energy Exhibition, 2013; http://www.atbmorley.com/news/

[4] World energy conference, 13.-17.9.2010, Montreal, www.worldenergy.org;

[5] T. von Blackstom, "Axial flow turbines for ocean current and wave power systems", Department of Mechanical and Mechatronic Engineering, University of Stellenbosch, 2012

[6] Thropton Energy, United Kingdom, 2013

[7] Khan, 2006, M.J.Khan,M.T.Iqbal, J.E.Quaicoe, ”A technology review and simulation based performance analysis of river current turbine systems", Electrical and Computer Engineering, CCECE 2006, pp. 2288-2293.

[8] Run-of-Riwer Hydrokinetic Renewable Energy, Free Flow Power, april 2012 
$10^{\mathrm{TH}}$ InTERnATIONAL CONFERENCE ON Sustainable ENERgy AND ENVIRONMENTAL Protection (June $27^{\mathrm{TH}}-30^{\mathrm{TH}}$, 2017, Bled, SLOVENIA), RENEWABLE ENERGy SOURCES

J. Krope, A.Ghani Olabi, D. Goričanec \& S. Božičnik

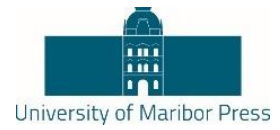

\title{
Forecasting Tool for Assessing Environmental, Technical and Economic Parameters Associated with Power Generation Alternatives
}

\author{
ANDRÉS F. LEÓn ESTEBAN, ANA M. ROSSO CERÓN, VIATCHESLAV KAFAROV \& JOHN F. \\ MONTAÑEZ
}

\begin{abstract}
This work focuses on the implementation of a forecasting tool that facilitates the data processing and the projection over a long term period of environmental, technical and economic parameters associated with power generation alternatives (solar photovoltaic, wind turbines, small hydro, gasification of residual biomass, and diesel engines) for noninterconnected zones. With the tool it will be possible to project three scenarios (high, medium and low) of parameter such as energy demand, renewable energy sources, as well as financial parameters like unit fuel cost, unit investment cost, unit fixed and variable costs for operation and maintenance. The tools will also evaluate each of the technologies taking into account economic criteria such as: Net Present Value and Internal Rate of Return. Finally, a case of study concerning solar and wind energy in San Andres Island will carry out to demonstrate the applicability of the tool.
\end{abstract}

Keywords: - Energy forecasting tool • non-interconnected zone • renewable energy sources $\bullet$ power generation alternatives $\bullet$ technical and economic parameters •

CORRESPONDENCE AdDRESS: Andrés F. León Esteban, Magister Student, Universidad Industrial de Santander, Economy and Development, Cra $27 \mathrm{Cl} \mathrm{9,} \mathrm{Bucaramanga,} \mathrm{Colombia,} \mathrm{e-mail:}$ leonest17@hotmail.com. Ana M. Rosso Cerón, Ph.D. Student, Universidad Industrial de Santander, Chemical Engineering, Cra $27 \mathrm{Cl}$ 9, Bucaramanga, Colombia, e-mail: anarosso10@gmail.com. Viatcheslav Kafarov, Dr. Sc., Associate Professor, Universidad Industrial de Santander, Chemical Engineering Department, Cra 27 Cl 9, Bucaramanga, Colombia, e-mail: kafarov@uis.edu.co. Fredy Montañez, Universidad Industrial de Santander, Electrical Engineering, Cra $27 \mathrm{Cl}$ 9, Bucaramanga, Colombia, e-mail: johnfreddyuis@ hotmail.com.

https://doi.org/10.18690/978-961-286-061-5.24

ISBN 978-961-286-061-5

(C) 2017 University of Maribor Press

Available at: http://press.um.si. 
$10^{\text {TH }}$ International CONFEREnce on Sustainable Energy and Environmental Protection (June $27^{\mathrm{TH}}-30^{\mathrm{TH}}, 2017$, Bled, SLOVEnia), RENEWABle ENERGy SOURCES A. F. León Esteban, A. M. Rosso Cerón, V. Kafarov \& J. F. Montañez: Forecasting Tool for Assessing Environmental, Technical and Economic Parameters Associated with Power Generation Alternatives

Energy plays a decisive role in the socio-economic and environmental development of a country because the access to electricity creates conditions to alleviate poverty, increase social protection, and raise its standard of living. In the same way, the energization can increase the deployment of resources that are unexploited, creating the provision of services that, in some cases, are precarious.

In the case of Colombia, the $3.3 \%$ of the population is not connected to the national grid. However, this percentage is distributed in $52 \%$ of the geographical area of the country, which means that half of the national territory is outside the interconnected system [1]. In addition, the electrical demand in Non-Interconnected Zones (NIZ) is supplied from fossil fuel plants. However, where such a solution is not possible, the use of renewable energy sources (RES) should be given. However, the expansion and penetration of new energy sources in isolated regions is a complex task, since they must consider aspects related to energy interaction and sustainable development [2].

In this sense, evaluating the different technological alternatives of energy generation based on sustainability parameters and selecting the best ones is fundamental to solve the planning problem that involves the expansion and penetration of new generation capacities. Then forecasting demand, costs associated, and assessing energy resources is a fundamental part of energy planning.

Nevertheless, forecasting energy demand is a difficult task since the process may involve independent variables associated with demand such as population growth, lifestyle, climate, gross domestic product, etc. The commonly used methods of demand forecasting are time series and the prediction of key factors are widely used methods for the prediction of consumption of electricity, fuel and RES. They consist of the collection of historical data on the energy consumption and the arrangement based on time series which allow to predict the future demand of energy from determining the variation of the trend or the relations between the independent variables and the demand. However, it must be kept in mind that these estimation processes are always subject to errors.

For the estimation of energy demand Ramirez-Castaño [3] proposes an equation of geometric growth as a function of growth rates, [4] and [5] determine the energy demand in Israel and Spain using time series. Other works consider artificial intelligence algorithms such as neural networks and evolutionary algorithms to express the relationship between dependent and independent variables [6] [7].

The process of assessing RES is also an essential task in determining the capacity of the energy resources needed to supply energy, which needs to define aspects related to the energy potential and the amount of resources that can be used with the current technologies .To evaluate energy sources, several tools have been developed Geographic Information Systems (GIS) that assess the potential of RES and biofuels around the 

Protection (June $27^{\mathrm{TH}}-30^{\mathrm{TH}}, 2017$, BLED, SLOVENiA), RENEWABLE ENERGY SOURCES A. F. León Esteban, A. M. Rosso Cerón, V. Kafarov \& J. F. Montañez: Forecasting Tool for Assessing Environmental, Technical and Economic Parameters Associated with Power Generation Alternatives

world. Some of the research done with GIS includes the measurement of energy potential, its projection and application in various case studies $[8,9,10$, and 11].

To evaluate technical and economic aspects in isolated areas, software HOMER (Software for micro grid and distributed generation power system design and optimization) is perhaps the most popular simulation tool for integrated system design. It requires as input data the load curve, resource curve, cost, and control system constraints. It gives output data on the net present value, energy cost, capital cost, excess capital and fuel consumption [12].

Though, there is no software that unifies the calculation of all the parameters necessary for energy planning.

Therefore, this work focuses on the implementation of a forecasting tool that facilitates the data processing and the projection over a long term period (10 years) of environmental, technical and economic parameters associated with power generation alternatives for NIZ. With the tool it will be possible to project three scenarios (high, medium and low) of parameters such as energy demand, peak load curve, renewable resources, as well as financial parameters like unit fuel cost, unit investment cost, unit fixed costs and variable costs of operation and maintenance. The tools will also evaluate each of the technologies taking into account economic criteria such as: Net Present Value (NPV) and Internal Rate of Return (IRR). Finally, a case of study concerning to San Andres Island in the North of the country will carry out to demonstrate the applicability of the tool.

\section{$2 \quad$ Metodology}

\subsection{Technical Parameters}

\section{Demand Forecasting}

The energy demand consumption in a specific period.

$$
r=\sqrt[n]{D_{n} / D o}-1
$$

Where, $r$ is the geometric growth rate, $D_{n}$ is the forecasting demand, $D_{i}(\mathrm{kWh})$ current demand, $o$ is the base year and $n$ is the forecasting period. 
266 10 $10^{\mathrm{TH}}$ International CONFERENCE on Sustainable ENERgy AND ENVIRONMENTAL Protection (June $27^{\mathrm{TH}}-30^{\mathrm{TH}}, 2017$, Bled, SLOVEnia), RENEWABle ENERGy SOURCES A. F. León Esteban, A. M. Rosso Cerón, V. Kafarov \& J. F. Montañez: Forecasting Tool for Assessing Environmental, Technical and Economic Parameters Associated with Power Generation Alternatives

\section{Peak Demand Forecasting}

The Maximum value of the load that can be maintained for a specified time.

$$
D P n=D E n /\left(365 * H S_{n} * F c\right)
$$

Where, $D P_{n}(\mathrm{~kW})$ is the peak demand forecasting, $D E$ is the demand forecasting of the year 2025, $n$ is the forecasting period, $H s$ is the number of service hours per year and $F c$ is the load factor.

\section{New Capacity to be installed}

Nominal power of a generation unit to be installed.

$$
\begin{aligned}
& \text { Can } \\
& =\frac{(D E n-D E o)+\left(F d p_{d} * I C a * H s_{n} * A_{d}\right)}{F d p * H S n * A * 365}
\end{aligned}
$$

Where, Can is the capacity to be install in the year n, Fdp is the capacity factor, Ica is the initial capacity, and $A$ is the availability factor.

\subsection{Economics parameters}

As economic criteria of evaluation will be taken into account: the net present value (NPV) method and the internal rate of return (IRR).

\section{Net Present Value}

The NPV is the profit (if positive) or lost (if negative) of the present value of the money, which comes from investing in the project and not investing in the opportunity interest.

$$
N P V=C A\left[\frac{1-(1+0.2)^{-n}}{0.2}\right]+\frac{V M}{(1+0.2)^{5}}
$$

Where, $C A$ is the annual costs, $V M$ is the market value and $n$ is the number of years.

\section{Internal Rate of Return}

IRR is a measure of the profitability of a project. Internal rate of return is a discount rate that makes the NPV of all cash flows from a particular project equal to zero. 


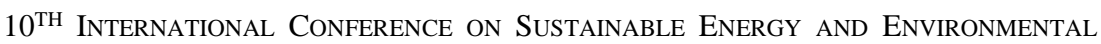
Protection (June $27^{\mathrm{TH}}-30^{\mathrm{TH}}, 2017$, BLED, SLOVENiA), RENEWABLE ENERGY SOURCES

A. F. León Esteban, A. M. Rosso Cerón, V. Kafarov \& J. F. Montañez: Forecasting

Tool for Assessing Environmental, Technical and Economic Parameters Associated with Power Generation Alternatives

$$
I R R=N P V-I I
$$

Where, $C A$ is the annual costs, $V M$ is the market value, $n$ is the number of years and II is the Initial investment.

\subsection{Environmental parameters}

\section{Primary Resource}

The theoretical multi-year average daily solar and wind potential was taken from the historical data of daily solar radiation $\left(\mathrm{kWh} / \mathrm{m}^{2}\right)$ and wind speed $(\mathrm{m} / \mathrm{s})$, from the years 2005 to 2014, obtained from the meteorological stations (found in and around the cases of study) of the NASA through the RETScreen ${ }^{\circledR}$ software [13].

Smoothing of historical data: before determining the trend of a time series, it is necessary to carry out processes to avoid the peaks that historical data may have. For this step the smoothing method of moving averages was used:

Given a time series:

$$
y_{i t} t=\left(t_{1}, t_{2}, t_{3}, \ldots, t_{k}\right), i=1,2,3, \ldots, k
$$

The method consists in averaging each value of the series with some of the observations that precede it and follows it. Subsequently, each $y_{t}$ is replaced by the moving average $\overline{y_{t}}$

The main problem with the method is to know the adequate number of data to average, it is necessary to choose a sufficient number to obtain the greatest possible smoothing but taking into account that the least amount of information possible is lost. For this reason, it is recommended that for monthly data, the number is 12 , i.e. the total observations in a year [14].

These values of the series were centered by calculating the arithmetic mean between two consecutive values of the previously calculated moving averages.

Seasonal adjustment: this process is to determine the seasonal variation index. Then, is necessary to determine the percentage of the real value with respect to the moving average, which was found by dividing each value of the real series with its corresponding centered value and multiplying it by one hundred. 
$10^{\mathrm{TH}}$ International Conference on Sustainable EnERgy and Environmental Protection (June $27^{\mathrm{TH}}-30^{\mathrm{TH}}, 2017$, Bled, SLOVEnia), RENEWABle ENERGy SOURCES A. F. León Esteban, A. M. Rosso Cerón, V. Kafarov \& J. F. Montañez: Forecasting Tool for Assessing Environmental, Technical and Economic Parameters Associated with Power Generation Alternatives

To calculate the seasonal variation index, all values of the series per month (12 values) were added, eliminating the largest and smallest value of each month. This was done to avoid values in the series that increase or decrease in an unusual way.

These results are called modified sums, which were divided by two to obtain the modified mean or mismatched seasonal index. This seasonal index was adjusted by a factor obtained by dividing the number of indexes per hundred (1200) between the sum of the modified means.

Finally, this adjustment factor is multiplied by the modified means and the seasonal variation index is obtained. This index was used for seasonal adjustment of the series, by dividing each value of the original series by the corresponding calculated index.

Forecast: this step consists of making the predictions from a trend line, first with the seasonally adjusted data, a logarithmic trend line is searched using the regression tools in Excel. With this equation the data of the future periods (forecast seasonally adjusted) are calculated. As monthly data were considering, in annual time periods, it was assumed that the cyclical component was included in the trend line. Therefore, to determine the existence of the cyclical variation of the data the percentage of the trend was calculated by dividing each value of the seasonally adjusted series between its corresponding predicted values.

Subsequently, the relative cyclic residue (percentage of the -100 trend) was determined as a percentage of variation from the trend, whose values in all cases are less than $10 \%$ and according to these forecasts are acceptable.

\section{Tool Description}

For convenience and to be within reach of any computer or laptop, the construction of the calculation tool was carried out in Microsoft Excel, which is part of the office of Microsoft Office. This application allowed the development of financial and accounting tasks, with formulas and graphics in a simple programming language.

The interface consists of five tabs: input data, results, calculations, lists and a tool guide. It is worth noting that the calculation and ready tabs will be protected and hidden to maintain the confidentiality of the tool.

To carry out the respective validation and calculation in the tool, the municipality of San Andrés (San Andrés and Providencia) has been taken as case study. In the results will be observed the respective calculations for the municipality, taking as base year the 2015 . According to [15] viable electricity generation technologies for San Andres are solar photovoltaic (PV), wind generators (WG) and diesel generators (DG). 


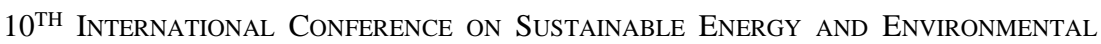
269 Protection (June 27 $7^{\mathrm{TH}}-30^{\mathrm{TH}}, 2017$, BLED, SLOVEniA), RenEwABle ENERGy SOURCES A. F. León Esteban, A. M. Rosso Cerón, V. Kafarov \& J. F. Montañez: Forecasting Tool for Assessing Environmental, Technical and Economic Parameters Associated with Power Generation Alternatives

\subsection{Input data}

In the input data the user must enter the necessary information to calculate the technical, economic and financial parameters about the implementation of RES for NIZ in Colombia.

The data that the user must enter are: department NIZ, population, current and expected hours of service, current capacity, growth rates of demand for different scenarios, energy tariff, technologies costs in dollars, consumer price index, current demand $(\mathrm{kWh})$, peak demand $(\mathrm{kW})$, and historical data of RES (solar radiation, wind speed, and mass flows) .

\section{$4 \quad$ Result and Analysis}

\subsection{Technical parameters}

In Figure 1 the demand forecasting for high, medium and low scenarios is shown. These scenarios indicate a growth of $6.71 \%$ for the high scenario, $0.79 \%$ for the low scenario and $3.75 \%$ for the medium scenario, compared to the year 2016. According to the official results reported by the (UPME in Spanish), energy consumption increased by $4.75 \%$ in the year 2016 [16], i.e., the projection had a variation of a third of standard deviation, ( $1 \%$ with respect to the average growth), thus, the average projection is valid.

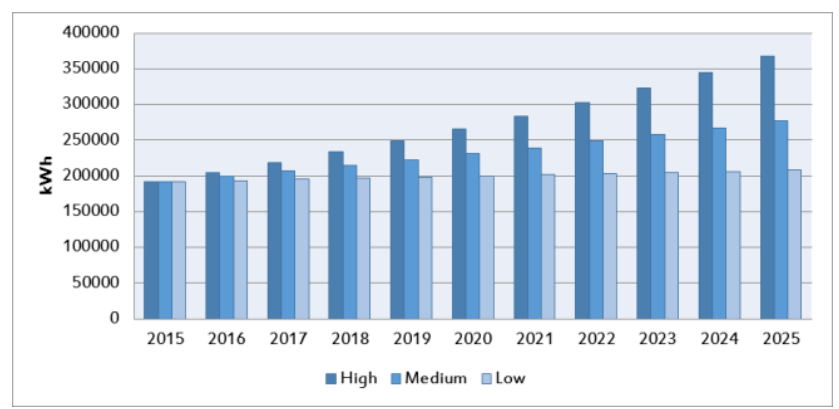

Figure 1. Demand forecasting for three scenarios

The Figure 2 shows the peak demand forecasting for high, medium and low scenarios. These scenarios indicate a growth of $3.5 \%$ for the high scenario, $2.40 \%$ for the low scenario and $3.10 \%$ for the average scenario, compared to the year 2016. According to the UPME [16] report, the peak demand for the 2016 period was $5.12 \%$. These results are distant to those projected with the tool, nevertheless in the UPME results it is also reported an unexpected growth, even greater than that projected in the present investigation. 
$270 \quad 10^{\mathrm{TH}}$ International CONFERENCE on Sustainable ENERgy AND ENVIRONMENTAL Protection (June $27^{\mathrm{TH}}-30^{\mathrm{TH}}, 2017$, Bled, SLOVEnia), RENEWABle ENERGy SOURCES A. F. León Esteban, A. M. Rosso Cerón, V. Kafarov \& J. F. Montañez: Forecasting Tool for Assessing Environmental, Technical and Economic Parameters Associated with Power Generation Alternatives

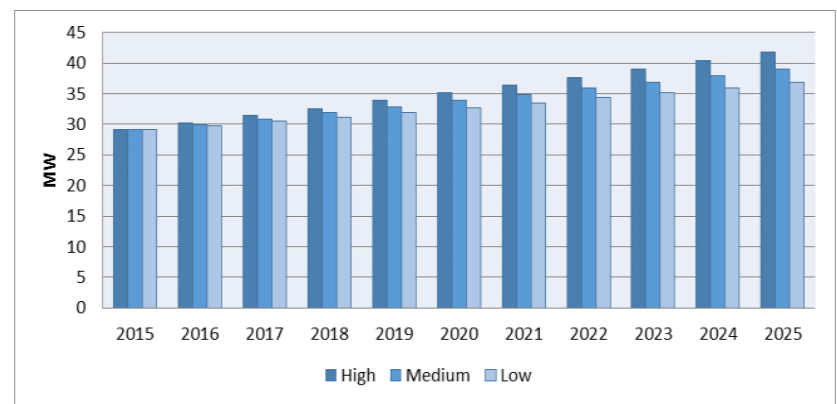

Figure 2. Peak demand forecasting.

To assest unit investment cost, new capacities were calculated, as seen in Figure 3 . It is evident that both PV and WG require identical installed capacities due to the capacity and available factors, DG systems is the technology that requires a smaller installed capacity.

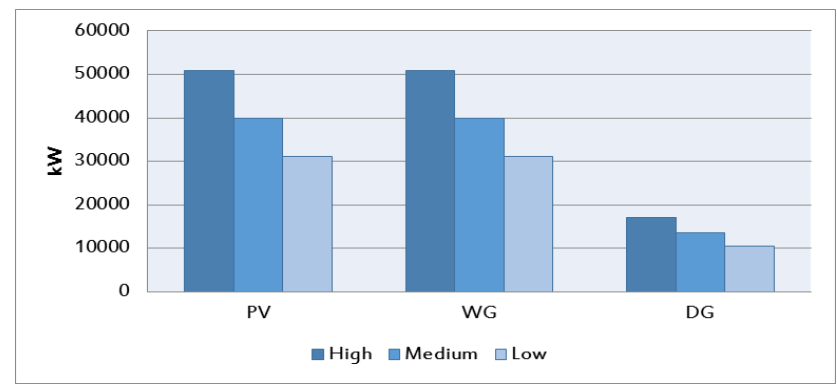

Figure 3. New capacities to be installed

For PV, WG and DG generation systems were obtained unit investment cost of 1467 , 3936 and 1057 USD/kW, respectively (Figure. 4). These values are similar to those presented by the WEO Outlook of the WEO 2016 PG Assumptions [17], however it is understandable that prices will vary depending on the type of country in which they are implemented, since infrastructure, land and other indirect costs vary.

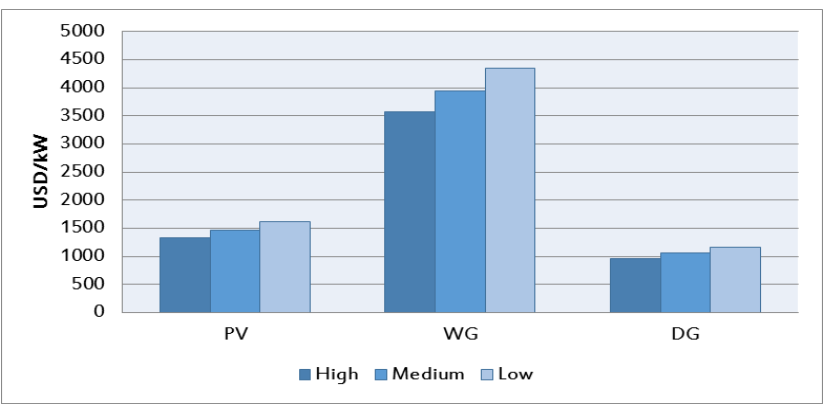

Figure 4. Unit investment costs 
$10^{\mathrm{TH}}$ InTERnational CONFERENCE ON SUSTAINABle ENERgy AND ENVIRONMENTAL Protection (June $27^{\mathrm{TH}}-30^{\mathrm{TH}}, 2017$, BLED, SLOVENiA), RENEWABLE ENERGY SOURCES A. F. León Esteban, A. M. Rosso Cerón, V. Kafarov \& J. F. Montañez: Forecasting Tool for Assessing Environmental, Technical and Economic Parameters Associated with Power Generation Alternatives

For PV, WG and DG generation systems were obtained unit O\&M costs of 89, 123 and $17 \mathrm{USD} / \mathrm{kW}$, respectively. These values are similar to those presented by the WEO Outlook of the WEO 2016 PG Assumptions [17] with values for the base year 2015. As was previously said, the prices vary depending on the type of country in which each technology is implemented.

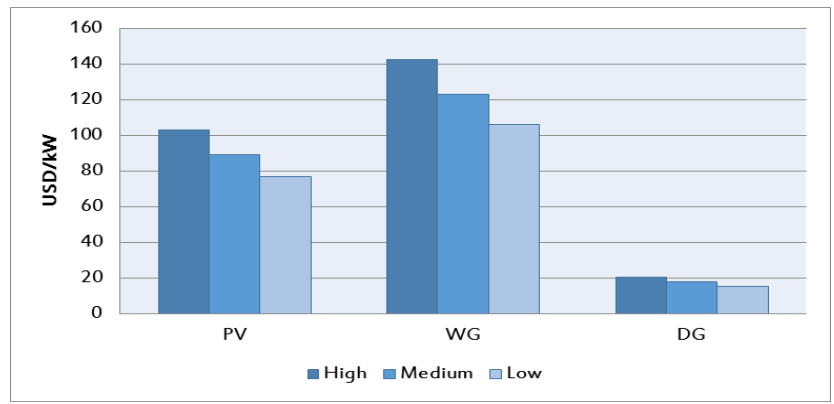

Figure 5. O \& M fixed unit costs

According to the results obtained for the NPV, Figure 6, the WG presents a value of 3.4 million dollars, PV of 3.9 million dollars and DG 8.5 million dollars. Based on this criterion it is more economical to implement energy projects of diesel generation (DG) since the investment is maximized.

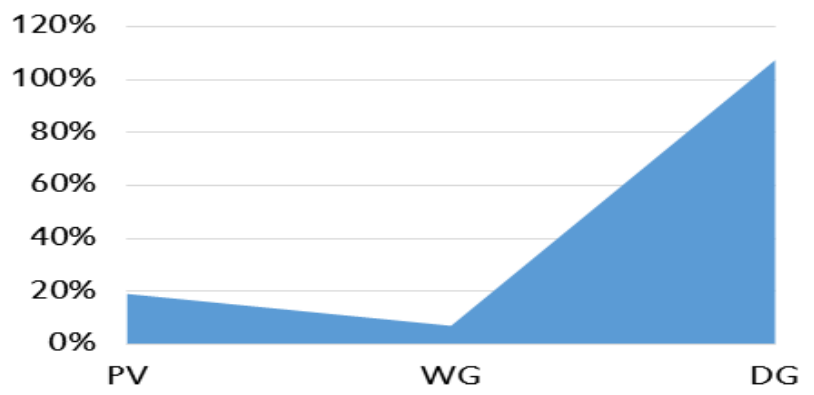

Figure 6. Internal Rate of Return

The IRR results are strong and are consistent with the NPV results, because the interest rates for the WG, PV and DG projects are $7.03 \%, 19.06 \%$ and $107.38 \%$, respectively. In fact, DG systems are more cost-effective, but PV technology has a slightly higher IRR than the opportunity cost, i.e., PV is a slightly reliable technology. 
$10^{\text {TH }}$ International Conference on Sustainable Energy and Environmental Protection (June $27^{\mathrm{TH}}-30^{\mathrm{TH}}, 2017$, BlED, SLOVENIA), RENEWABLE ENERGY SOURCES A. F. León Esteban, A. M. Rosso Cerón, V. Kafarov \& J. F. Montañez: Forecasting Tool for Assessing Environmental, Technical and Economic Parameters Associated with Power Generation Alternatives

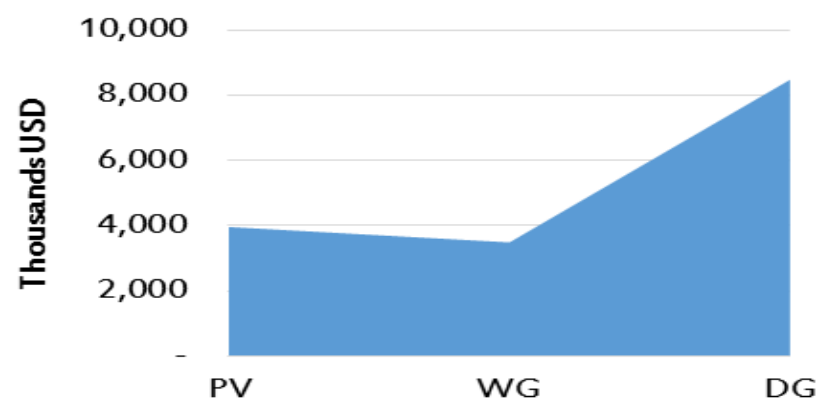

Figure 7. Net Present Value

\subsection{Environmental parameters}

Figures 8-9 show solar and wind (50 $\mathrm{m}$ high) resources forecasting. Historical data and projected scenarios show trend, seasonal and cyclical behaviour. These projections were validated with the annual average daily information presented in RETScreen [13] by the year 2016. The values of this database indicate that the solar radiation was $5.63 \mathrm{kWh} / \mathrm{m}^{2}$ in San Andrés, where the daily annual wind speed was $8.96 \mathrm{~m} / \mathrm{s}$. The aforementioned values of solar and wind resources are within the ranges of the scenarios projected to 2016. In the case of solar the values are $5.92,5.58,5,23 \mathrm{kWh} / \mathrm{m}^{2}$ for high medium and low sceneries and for wind speed are 10.22, 9.73, and $8.25 \mathrm{~m} / \mathrm{s}$ for high medium and low sceneries.

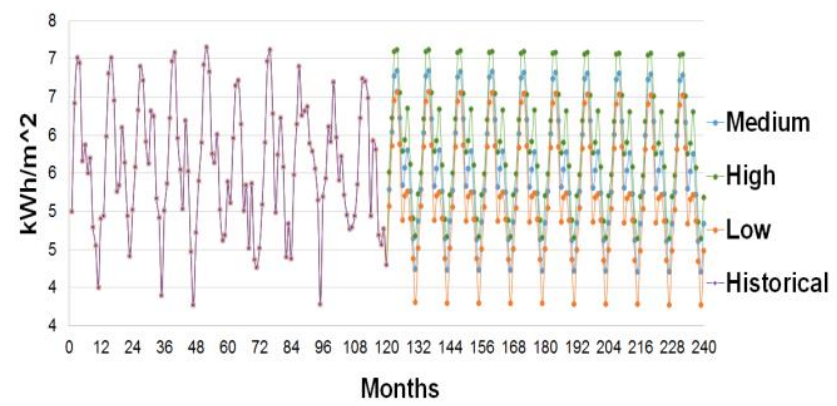

Figure 8. Solar source forecasting 

Protection (June 27 $7^{\mathrm{TH}}-30^{\mathrm{TH}}, 2017$, BLED, SLOVENiA), RENEWABLE ENERGY SOURCES A. F. León Esteban, A. M. Rosso Cerón, V. Kafarov \& J. F. Montañez: Forecasting Tool for Assessing Environmental, Technical and Economic Parameters Associated with Power Generation Alternatives

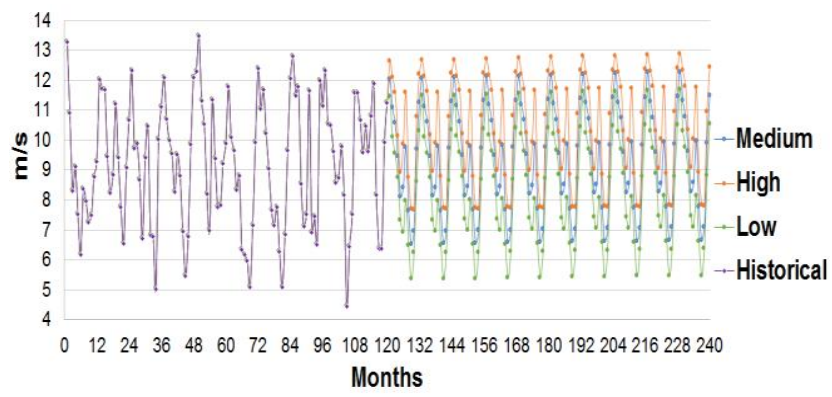

Figure 9. Wind source forecasting

\section{$5 \quad$ Conclusions}

In this paper a forecasting tool for environmental assessment, technical and economic parameters associated with power generation alternatives was proposed. This tool made it possible to determine important aspects of energy planning, such as the projection of demand, the costs associated with the generation plan, as well as the potential of available energy resources.

In the same application, a number of mathematical and logical processes are assembled together with a basic programming language to quickly determine the profitability of renewable energy projects through parameters such as NPV and IRR.

Although this forecasting tool has a great potential, however it is pertinent to say that it is susceptible to continuous improvements, which will allow in the future to be consolidated as a consultation tool for those in charge of formulating electric power generation plans in NIZ of Colombia.

\section{Acknowledgements}

The authors would like to acknowledge the financial support from the Colombian Science Council (COLCIENCIAS) and the Universidad Industrial de Santander (UIS).

\section{References}

[1] B. Bhattacharyya, "Review of Alternative Methodologies for Analysing off Grid Electricity Supply”. Renewable and Sustainable Energy Reviews, vol. 16, pp. 677-94, 2012.

[2] R. Caro, A. Salvador, and S. Alfonso, "Mathematical method to evaluate sustainability using fuzzy logic", presented at International Day: Mathematics Everywhere. Universidad Politécnica de Madrid. España, 2010.

[3] S. Ramirez Castaño, "Energy Distribution Networks", National University of Colombia, Third Edition, Manizales-Colombia, 2009. 
$10^{\text {TH }}$ International Conference on Sustainable Energy and Environmental Protection (June $27^{\mathrm{TH}}-30^{\mathrm{TH}}, 2017$, Bled, SLOVEnia), RENEWABle ENERGy SOURCES A. F. León Esteban, A. M. Rosso Cerón, V. Kafarov \& J. F. Montañez: Forecasting Tool for Assessing Environmental, Technical and Economic Parameters Associated with Power Generation Alternatives

[4] J. Bargur, and A. Mandel, "Energy consumption and economic growth in Israel: trend analysis (1960-1979)", presented at Proceedings of the third international conference on energy use management; 1981.

[5] J. Kreider, and J. Haberl, "Predicting hourly building energy use: the great energy predictor shoot-out overview and discussion of results". ASHRAE Trans, vol.94, pp.1104-18, 1994.

[6] T. Muhammad, M. Marwan, and A. Peter, "A cooling change-point model of communityaggregate electrical load" Energy Build, vol. 43, pp. 28-37, 2011.

[7] J. Kreider, et al. Building energy use prediction and system identification using recurrent neural networks. En: J Sol Energy Eng, Vol. 117, pp.161-6, 1995.

[8] M. Muselli, G. Notton, P. Poggi, and A. Louche, "Computer-aided analysis of the integration of renewable-energy systems in remote areas using a geographical-information system". Applied Energy, vol. 63, p.141-160, 1999.

[9] B. E. Sorensen, and P. Meibom, "GIS Tools for Renewable Energy Modelling". Renewable Energy, vol. 16, pp. 1262-1267, 1999.

[10] J. Amador, and J. Dominguez, "Spatial Analysis Methodology Applied to Rural Electrification Renewable". Energy, vol. 31, pp. 1505-1520, 2006.

[11] J. Domínguez Bravo, I. Pinedo Pascua, and J. Augusto González, "GIS tools for the integration of renewable energy resources in rural electrification. INTIS-GIS". Hernández, L. and Parreño, J. M. (Eds.), Geographic Information Technologies for Territorial Development. Service of Publications and Scientific Diffusion of the ULPGC, pp. 552-563, 2008.

[12] ENERGYPLAN, Advanced energy systems analysis computer models. Available: http://www.energyplan.eu/othertools/island/h2res/.

[13] RETScreen ${ }^{\circledR}$ Software, 2014. Canada: NASA Langley Research Center Science Directorate and Minister of Natural Resources Canada. Available: http://www.retscreen.net/ang/home.php.

[14] Department of applied economics, Universidad Autónoma de Madrid. Temporal series. Available: http://www.fuenterrebollo.com/Economicas/TEORICA-I/3-temporales.pdf

[15] J.A. Araque, and F.G. Blanco. Estimation of the technical energy potential of renewable resources in non - interconnected zones of Colombia, using geographic information systems, GIS - case studies. Thesis, Universidad Industrial de Santander, Bucaramanga, Colombia, 2015.

[16] UPME. "Proyección de la demanda eléctrica y potencia máxima en Colombia", Unidad de Planificación Minero energética, Bogotá, 2016.

[17] IEA. "World Energy Outlook 2016", to be released on 16 November 2016, available: http://www.worldenergyoutlook.org/weo2016/ 
$10^{\mathrm{TH}}$ InTERnational CONFERENCE ON Sustainable ENERGy AND ENVIRONMENTAL Protection (June $27^{\mathrm{TH}}-30^{\mathrm{TH}}$, 2017, Bled, SLOVENIA), RENEWABLE ENERGy SOURCES

J. Krope, A.Ghani Olabi, D. Goričanec \& S. Božičnik

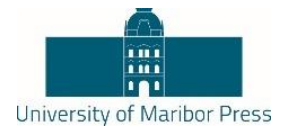

\title{
Photovoltaic Systems in Slovenia and Performance Ratios: A Review
}

\author{
SEBASTIJAN SEME, KLEMEN SREDENŠEK, BoJAN ŠTUMBERGER \& MIRALEM \\ HADŽISELIMOVIĆ
}

\begin{abstract}
This paper deals with photovoltaic systems in Slovenia and their performance ratios, with the objective of analysing the performance of operation or the performance ratio of solar power plants in different seasons and weather conditions. The performance ratio is the ratio between the actual energy produced and the theoretical energy produced by a solar power plant, which mainly depends on the intensity of solar radiation and/or temperature. As a consequence of the weather and geographical diversity of Slovenia, performance ratio is more appropriate to describe the performance of photovoltaic systems than energy yield, which describes the relationship between the energy produced and the nominal power of a solar power plant. The results show that the performance of photovoltaic systems primarily depends on the proper inclination and orientation angle of the solar modules, shading, and snow barrier on solar modules.
\end{abstract}

Keywords: • performance ratio $\bullet$ inclination angle $\bullet$ azimuth angle $\bullet$ PV system • energy yield •

CorResPondence AdDress: Sebastijan Seme, Ph.D., Associate Professor, University of Maribor, Faculty of Energy Technology, Hočevarjev trg 1, SI-8270, Krško, Slovenia, e-mail: sebastijan.seme@um.si. Klemen Sredenšek, Students, University of Maribor, Faculty of Energy Technology, Hočevarjev trg 1, SI-8270, Krško, Slovenia, e-mail: klemen.sredensek@gmail.com. Bojan Štumberger, Ph.D., Full Professor, University of Maribor, Faculty of Energy Technology, Hočevarjev trg 1, SI-8270, Krško, Slovenia, e-mail: bojan.stumberger@um.si. Miralem Hadžiselimović, Ph.D., Associate Professor, University of Maribor, Faculty of Energy Technology, Hočevarjev trg 1, SI-8270, Krško, Slovenia, e-mail: miralem.h@um.si.

https://doi.org/10.18690/978-961-286-061-5.25

ISBN 978-961-286-061-5

(C) 2017 University of Maribor Press

Available at: http://press.um.si. 
$10^{\text {TH }}$ International CONFEREnce on Sustainable Energy and Environmental Protection (June $27^{\mathrm{TH}}-30^{\mathrm{TH}}, 2017$, Bled, SLOVENIA), RENEWABle ENERGY SOURCES S. Seme, K. Sredenšek, B. Štumberger \& M. Hadžiselimović: Photovoltaic Systems in Slovenia and Performance Ratios: A Review

The system of subsidies and state grants for power generation units using renewable energy sources (RES) and cogeneration of heat and power (CHP) has led to the inclusion of many dispersed sources into public electricity networks. Energy is an essential factor in achieving sustainable development [1]. Perspectives for converting present energy systems into a $100 \%$ renewable energy system and review of renewable energy strategies can be found in [2] and [3]. Photovoltaic systems as power generation units using RES represent the largest share of dispersed sources [4]. Photovoltaic systems are most often connected to the distribution grid (low-voltage network) or the user-end grid. The obligatory target of the Slovenia is a 25\% share of renewable energy sources in the final gross consumption of energy by 2020 [5].

The maximum production of electricity from photovoltaic (PV) systems is achieved if the angle between sunbeams and the surface of PV modules is constantly $90^{\circ}$ [6]. The inclination and azimuth angle of a PV system are the most important parameters, which have been described in [7-10]. To calculate the optimal inclination and azimuth angle of a PV system, the mathematical model for predicting the global solar radiation on a tilted surface is used. Model inputs are direct, diffuse, and reflected solar radiation components, solar zenith and azimuth angles, and inclination angle, while the model's output is solar radiation on tilted surface. Models for the prediction of solar radiation can be divided into anisotropic and isotropic models. The authors of anisotropic models are B. Y. H. Liu and R. C. Jordan [11], J. I. Jimenez [12], J.E. Hay and J.A. Davies [13], Y. Castro [14], P. S. Koronakis [15] and V. Badescu [16]. The authors of isotropic models are R. Perez [17], D. T. Reindl [18], M. Iqbal [19], T. M. Klucher [20], C. J. Willmott [21], R. C. Temps and K. L. Coulson [22] and A. Skartveit, J. A. Olseth [23]. Solar radiation data used for model calculation was gained from ARSO (Slovenian Environmental Agency) [24] in the 30-min time step over a period of 10 -years. In this paper, performance ratio (PR) results from 8 photovoltaic systems (the comparison was made for most PV systems in Slovenia) are compared using different data from all (14) meteorological stations for the calculation of theoretical energy produced by PV systems, as shown in Fig. 1.

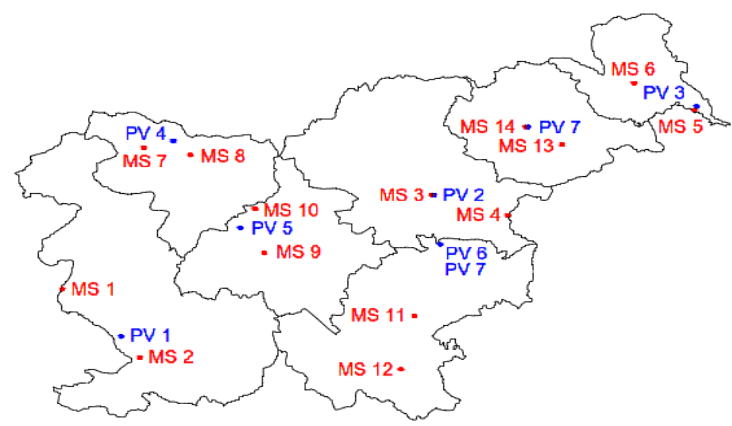

Figure 1. PV systems and meteorological stations in Slovenia. 
By estimating accurate energy production from PV systems, analysis of PR with the effect of weather conditions [25-26] and different PV technologies can be performed [27]. Since Slovenia is a very diverse and dynamic country in terms of geography, performance ratio calculation can show very different results.

This paper presents performance ratio overview of the photovoltaic systems in Slovenia. In the $2^{\text {nd }}$ section, the model for predicting the global solar radiation on a tilted surface is briefly described. The $3^{\text {rd }}$ section represents the use of the solar radiation data for calculation of optimal azimuth and inclination angle for maximum energy harvesting. In the $4^{\text {th }}$ section, the theory for performance ratio and energy yield is presented. Within the $5^{\text {th }}$ section, the obtained results are presented and described.

\section{Model For Predicting Global Solar Radiation On A Tilted Surface}

This section presents a mathematical model for predicting the global solar radiation on the tilted surface and the parameters of solar radiation. The incidence angle of the sun $i(\mathrm{t})$ is the angle between sunbeams and the normal to the surface with any azimuth angle [6]. The incidence angle of the sun $i(\mathrm{t})$ is calculated by (1).

$$
i(t)=\cos ^{-1}\left[\begin{array}{l}
\sin (\delta) \sin (L) \cos (\beta) \\
-\sin (\delta) \cos (L) \sin (\beta) \cos (\gamma) \\
+\cos (\delta) \cos (L) \cos (\beta) \cos (\omega(t)) \\
+\cos (\delta) \sin (L) \sin (\beta) \cos (\omega(t)) \cos (\gamma) \\
+\cos (\delta) \sin (\beta) \sin (\omega(t)) \sin (\gamma)
\end{array}\right]
$$

where, $\delta$ is declination angle, $L$ latitude, $\beta$ inclination angle, $\gamma$ azimuth angle, and $\omega$ hour angle.

The Liu and Jordan model is one of the earliest and simplest irradiance models. It assumes an isotropic diffuse sky model and can be calculated with (2).

$$
G_{t}(t)=G_{b, t}(t)+G_{d, t}(t)+G_{r, t}(t)
$$

Where, $G_{\mathrm{b}, \mathrm{t}}(t), G_{\mathrm{d}, \mathrm{t}}(t)$ and $\mathrm{G}_{\mathrm{r}, \mathrm{t}}(t)$ are beam, diffuse and reflected components of solar radiation on a tilted surface. These components are given by (3), (4), and (5).

$$
G_{b, t}(t)=G_{b, h}\left(\frac{\cos (i(t))}{\sin \left(\alpha_{s}(t)\right)}\right)
$$




$$
\begin{aligned}
& G_{d, t}(t)=G_{d, h}(t) \cos ^{2}\left(\frac{\beta}{2}\right)=G_{d, h}(t)\left(\frac{1+\cos (\beta)}{2}\right) \\
& G_{r, t}(t)=G_{h}(t) \sin ^{2}\left(\frac{\beta}{2}\right)=G_{h}(t) \rho\left(\frac{1+\cos (\beta)}{2}\right)
\end{aligned}
$$

Where $G_{\mathrm{b}, \mathrm{h}}(t), G_{\mathrm{d}, \mathrm{h}}(t)$ and $G_{\mathrm{h}}(t)$ are the beam, diffuse, and global components of solar radiation on a horizontal surface, $\rho$ is the diffuse reflectance $(\rho \approx 0.80$ for water surface and $\rho \approx 0.07$ for dry asphalt), $i(t)$ incidence angle and $\beta$ inclination angle [6].

If (2) is written in extended form, the equation for solar radiation on tilted surface is given by (6).

$$
\begin{aligned}
& G_{t}(t)=G_{b, h}(t)\left(\frac{\cos (i(t))}{\sin \left(\alpha_{s}(t)\right)}\right)+G_{d, h}(t)\left(\frac{1+\cos (\beta(t))}{2}\right) \\
& +G_{h}(t) \rho\left(\frac{1-\cos (\beta(t))}{2}\right)
\end{aligned}
$$

\section{Optimal Azimuth and Inclination Angle for Maximum Energy Harvesting}

Solar radiation data in the 30-min time step through the period of 10 years for global $G_{\mathrm{h}}(t)$ and diffuse $G_{\mathrm{d}, \mathrm{h}}(t)$ solar radiation on horizontal surfaces was obtained from the ARSO portal (Slovenian Environmental Agency) [24]. Calculations were made for all 14 operational meteorological stations in Slovenia for all possible azimuth and inclination angles. The results show an initial indication of the optimal azimuth and inclination angle for maximum energy in Fig. 2. The optimal azimuth and inclination angles for 14 meteorological stations across Slovenia are summarized in Table 1. 

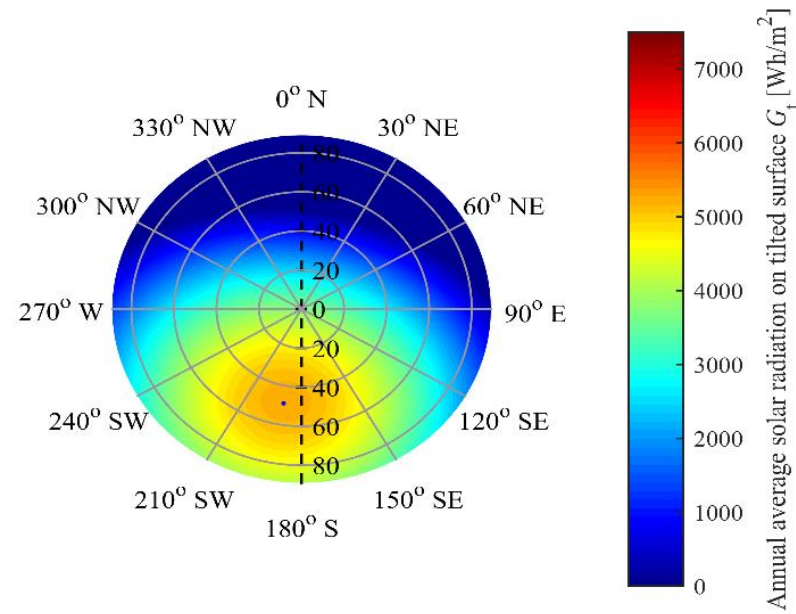

Figure 2. Polar plot of annual average solar radiation for different inclination and azimuth angles of Slovenia.

In Fig. 2, the radius indicates the inclination angle, while the polar angle refers to the azimuth angle. The highest annual average solar radiation receives surface facing $188^{\circ}$ SW with an inclination angle of $48^{\circ}$, based on global and diffuse solar radiation data of a ten-year period (2005-2015).

Table 1. Optimal azimuth and inclination angle of 14 meteorological stations.

\begin{tabular}{|c|c|c|c|}
\hline \multicolumn{2}{|c|}{$\begin{array}{c}\text { meteorological } \\
\text { station }\end{array}$} & $\begin{array}{c}\text { inclination } \\
\text { angle } \beta\left[^{\circ}\right]\end{array}$ & $\begin{array}{c}\text { azimuth angle } \\
a_{\mathrm{w}}\left[^{\circ}\right]\end{array}$ \\
\hline Bilje & MS 1 & 44 & 190 \\
\hline Škocjan & MS 2 & 50 & 193 \\
\hline Celje & MS 3 & 46 & 188 \\
\hline Podčetrtek & MS 4 & 49 & 189 \\
\hline Lendava & MS 5 & 48 & 188 \\
\hline Murska Sobota & MS 6 & 43 & 190 \\
\hline Kredarica & MS 7 & 51 & 174 \\
\hline Lesce & MS 8 & 52 & 207 \\
\hline Ljubljana & MS 9 & 46 & 201 \\
\hline Kranj & MS 10 & 54 & 205 \\
\hline Novo mesto & MS 11 & 44 & 189 \\
\hline Črnomelj & MS 12 & 49 & 191 \\
\hline Ptuj & MS 13 & 49 & 190 \\
\hline Maribor & MS 14 & 44 & 191 \\
\hline \multicolumn{2}{|c|}{} \\
\hline
\end{tabular}



$10^{\mathrm{TH}}$ International Conference on Sustainable EnERgy and Environmental Protection (June $27^{\mathrm{TH}}-30^{\mathrm{TH}}, 2017$, Bled, SLOVENIA), RENEWABle ENERGY SOURCES S. Seme, K. Sredenšek, B. Štumberger \& M. Hadžiselimović: Photovoltaic Systems in Slovenia and Performance Ratios: A Review

From Table 1 , it can be seen that inclination angles move between $43^{\circ}$ to $54^{\circ}$ and azimuth angles between $174^{\circ}$ and $207^{\circ}$. The difference of both angles can be described by the very diverse relief of Slovenia. Fig. 3 shows optimal inclination angles for 14 meteorological stations in months.

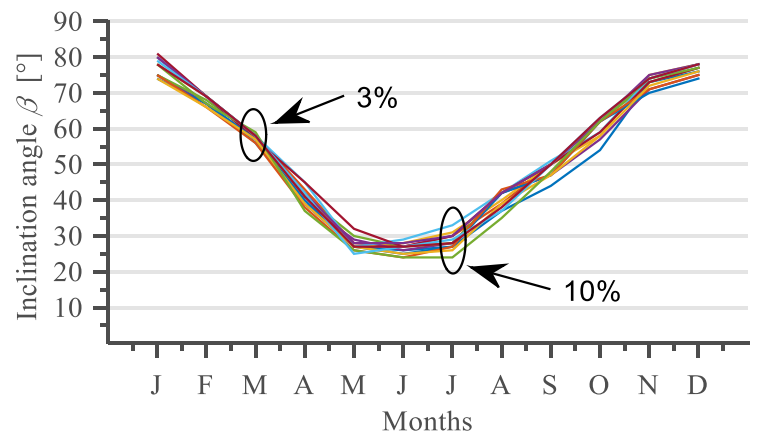

Figure 3. Optimal inclination angles for 14 meteorological stations over the year.

The highest deviation between inclination angles is $10 \%$ in July and the lowest at 3\% in March.

\section{$4 \quad$ Performance Ratio and Energy Yield}

Performance ratio (PR) is the ratio of the actual energy and theoretical energy produced by a plant. It is defined in IEC 61724 [28] and is a metric to measure how effectively the plant converts sunlight collected by the PV modules into AC energy despite the many derating factors viz. inverter inefficiency, cable losses, cell mismatch, module temperature, reflection from module glass surface, soiling losses, system down-time (grid failure), shading losses, snow barriers, dustiness of modules, and any component failures [29]. PR is calculated by (7).

$$
P R=\frac{E}{E_{\text {sim }}}=\frac{E}{\sum \eta_{S T C} \cdot G_{t}(t) \cdot \Delta t \cdot A}
$$

Where $E$ is the actual energy produced, $E_{\text {sim }}$ theoretical energy produced, $\eta_{S T C}$ efficiency of PV modules, $G_{\mathrm{t}}(t)$ solar radiation on tilted surface calculated by (6) and $A$ total PV area.

Energy yield describes the relationship between the energy produced and the nominal power of a PV system. It represents the number of hours that the PV array would need to operate at its rated power to provide the same energy. The units are hours or $\mathrm{kWh} / \mathrm{kWp}$, with the latter preferred by the authors because it describes the quantities used to derive the parameter [30]. Energy yield is calculated by (8). 


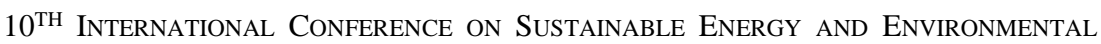
Protection (June $27^{\mathrm{TH}}-30^{\mathrm{TH}}, 2017$, BLED, SLOVENIA), RENEWABLE ENERGY SOURCES

S. Seme, K. Sredenšek, B. Štumberger \& M. Hadžiselimović: Photovoltaic Systems in Slovenia and Performance Ratios: A Review

$$
Y=\frac{E}{P_{S T C}}
$$

Where, $E$ is the actual energy produced and $P_{\text {STC }}$ the nominal power of a PV system.

Table 2. Average energy yield for $8 \mathrm{PV}$ systems in a period of 5-years.

\begin{tabular}{|c|c|c|c|c|c|c|c|c|c|}
\hline \multicolumn{2}{|c|}{ PV systems } & Year & Installed & \multicolumn{6}{|c|}{ Energy yield [kWh] } \\
\cline { 5 - 10 } & & bower [kW] & 2011 & 2012 & 2013 & 2014 & 2015 & Average \\
\hline PV 1 & $\beta=25^{\circ}$ & 2011 & 111.8 & 1224 & 1424 & 1228 & 1127 & 1293 & 1259 \\
\hline PV 2 & $\beta=25^{\circ}$ & 2010 & 47.9 & 1172 & 1144 & 997 & 842 & 1006 & 1032 \\
\hline PV 3 & $\beta=40^{\circ}$ & 2012 & 12.5 & 0 & 1298 & 1222 & 1172 & 1292 & 1251 \\
\hline PV 4 & $\beta=45^{\circ}$ & 2007 & 7.1 & 0 & 1227 & 1064 & 1047 & 1211 & 1173 \\
\hline PV 5 & $\beta=30^{\circ}$ & 2006 & 71.4 & 1140 & 1159 & 1024 & 1024 & 1082 & 1086 \\
\hline PV 6 & $\beta=30^{\circ}$ & 2008 & 355 & 1155 & 1241 & 1050 & 1008 & 1076 & 1106 \\
\hline PV 7 & $\beta=35^{\circ}$ & 2012 & 66.5 & 0 & 1325 & 1233 & 1210 & 1321 & 1272 \\
\hline PV 8 & $\beta=30^{\circ}$ & 2010 & 77.4 & 1183 & 1139 & 979 & 952 & 1066 & 1034 \\
\hline
\end{tabular}

\section{$5 \quad$ Results}

The performance analysis involves $8 \mathrm{PV}$ systems in different regions across Slovenia. To compare PR results, two PR analysis were made for each PV system. These PR analyses were made on the basis of the solar radiation measured from various meteorological stations, shown in Table 1 . Total installed power of all $8 \mathrm{PV}$ systems is $672,200 \mathrm{~kW}_{\mathrm{p}}$, the biggest PV system is PV 6 with $355,000 \mathrm{~kW}_{\mathrm{p}}$, and the smallest is PV 4 with $7,100 \mathrm{~kW}_{\mathrm{p}}$. In Table 2, average energy yield is presented for $8 \mathrm{PV}$ systems during the period from 2011 to 2015. Table 2 shows that PV system 2 has the lowest and PV system 7 the highest values of energy yield in all four years. The analysis was performed for 14 and more PV systems, but only 8 of them are presented here due to transparency.

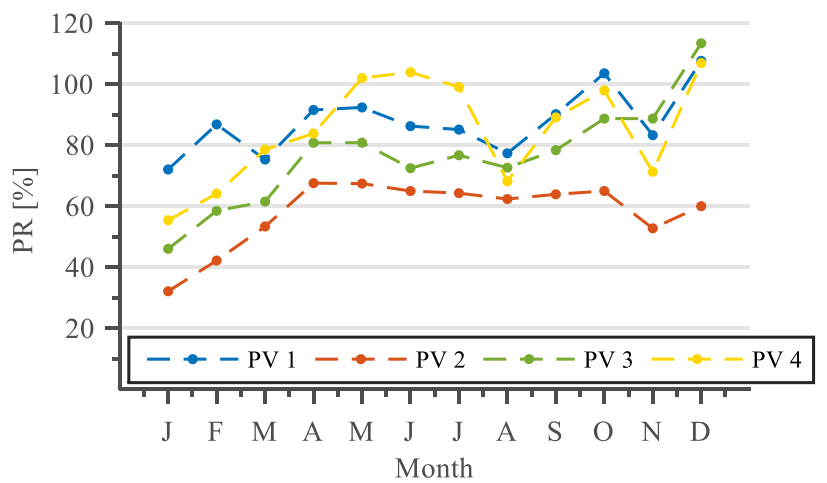

Figure 4. Performance ratio for PV system 1, 2, 3 and 4. 
$10^{\text {TH }}$ International CONFEREnce on Sustainable Energy and Environmental Protection (June $27^{\mathrm{TH}}-30^{\mathrm{TH}}, 2017$, Bled, SLOVENIA), RENEWABLE ENERGY SOURCES S. Seme, K. Sredenšek, B. Štumberger \& M. Hadžiselimović: Photovoltaic Systems in Slovenia and Performance Ratios: A Review

Fig. 4 and 5 show that PV 1 and PV 8 give the best values of PR, with $87.7 \%$ and $83.4 \%$. Lower values of PR in January, February, and March can be explained by long-existing snow barriers and in June, July, and August by the negative impact of temperature on PV modules. The largest difference of PR for PV system 4 is notable in the summer months, when the results of PR differ from other PV systems by $20 \%$ or more. The consequences of these differences are a common phenomenon of convective cloudiness on meteorological station 7 at Kredarica (altitude $2514 \mathrm{~m}$ ), due to the altitude, which reduces the global solar radiation. By reducing global solar radiation and thus the total monthly average solar radiation, the PR is extremely increased. On meteorological station 7 at Kredarica, the global solar radiation is increased in winter, late autumn, and the early spring months, unlike other meteorological stations.

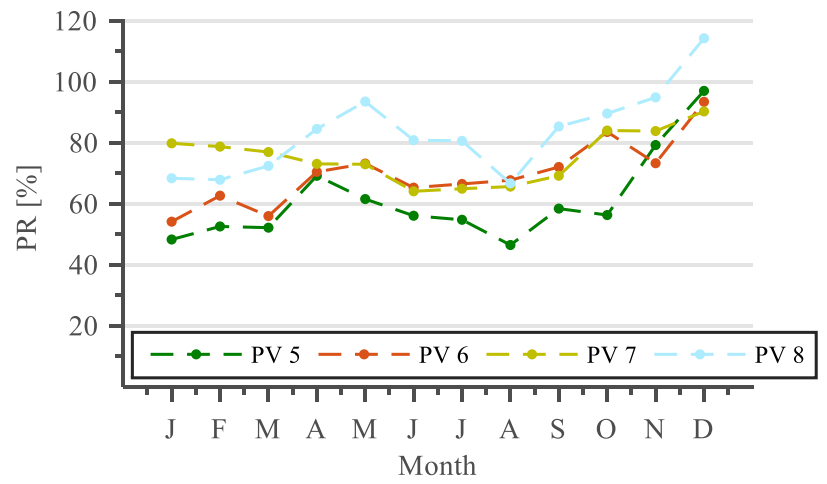

Figure 5. Performance ratio for PV system 5, 6, 7 and 8.

The PV system 7 shows the best PR analysis from all the 8 PV systems in this paper. In Fig. 6, the energy yield is presented for PV systems 1 and 4.

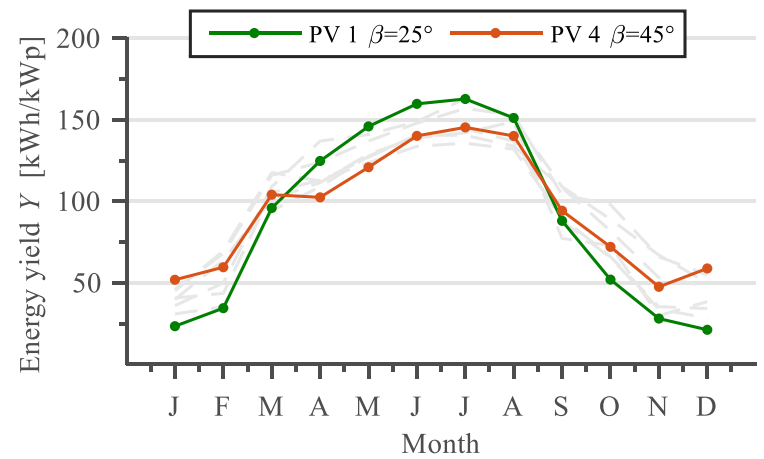

Figure 6. Energy yield for PV systems 1 and 4.

Fig. 6 shows energy yield for PV systems 1 and 4, defined by their inclination angle. PV systems with lower inclination angles have fewer operating hours or lower energy yield 
in winter months than PV systems with higher inclination angles, because of the sun's position in the sky. Fig. 7 and 8 illustrate the variation of the average energy yield versus PR for all 8 PV systems.

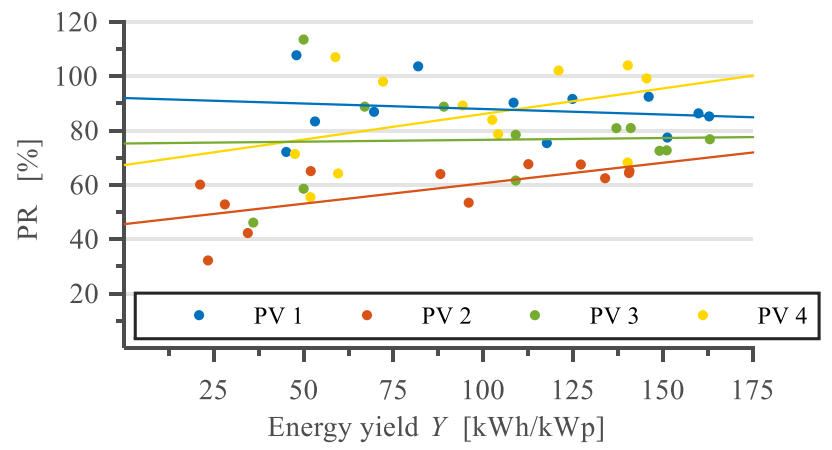

Figure 7. Energy yield and PR dependency for PV system 1, 2, 3 and 4.

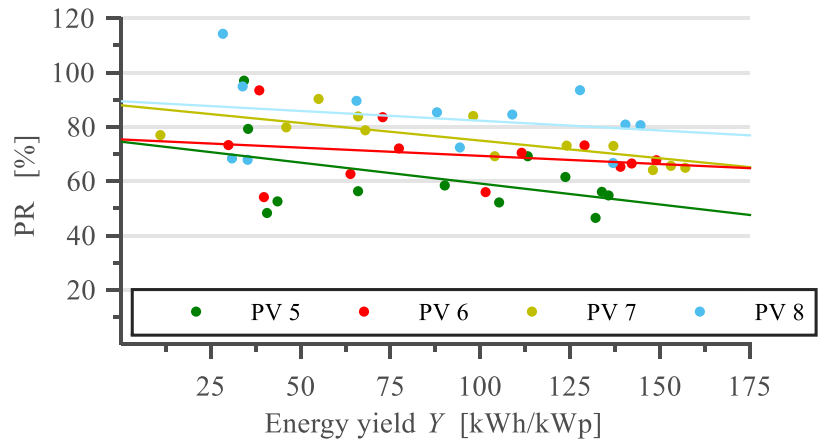

Figure 8. Energy yield and PR dependency for PV system 5, 6, 7 and 8.

From the results in Fig. 7 and 8, it is clear that in certain PV systems the regression line of the energy yield and performance ration dependency decreases and increases. The rise and fall of the regression line are mainly dependent on PR. Due to the frequent occurrence of shading and snow leads to decreasing PR in winter months, which consequently means a rise of the regression line. In summer months, the energy yield is maximum, due to the high intensity of solar radiation and the minimum PR due to the negative impact of temperature on PV modules, which gives us the correct falling regression line.

\section{Conclusion}

In this paper, the calculation of performance ratio, inclination angle and azimuth angle is discussed. Over 2.5 million data points of solar radiation on horizontal surfaces were used in the period of 10 years. The mathematical model shows that Slovenia receives the highest annual average solar radiation with a surface facing $188^{\circ} \mathrm{SW}$ and inclination 
$10^{\text {TH }}$ International Conference on Sustainable Energy and Environmental Protection (June $27^{\mathrm{TH}}-30^{\mathrm{TH}}, 2017$, Bled, SLOVENIA), RENEWABLE ENERGY SOURCES S. Seme, K. Sredenšek, B. Štumberger \& M. Hadžiselimović: Photovoltaic Systems in Slovenia and Performance Ratios: A Review

angle of $48^{\circ}$. The results show that the performance ratio reaches maximum values in winter months without snow barriers and minimum in summer months, due to the negative impact of temperature on PV modules.

\section{References}

[1] D. Streimikiene, R. Ciegis and D. Grundey,"Energy indicators for sustainable development in Baltic states," Renewable and Sustainable Energy Reviews, vol. 11, pp. 877-893, June 2012.

[2] H. Lund, "Renewable energy strategies for sustainable development, "Energy, vol. 32, pp. 912-919, June 2007.

[3] H. Lund and B. V. Mathiesen, "Energy system analysis of $100 \%$ renewable energy systems - the case of Denmark in years 2030 and 2050“, Energy, vol. 34, pp. 524-531, May 2009.

[4] S. Manju and N. Sagar, "Progressing towards the development of sustainable energy: A critical review on the status, applications, developmental barriers and prospects of solar photovoltaic systems in India, "Renewable and Sustainable Energy Reviews, " vol. 70, pp. 298-313, April 2017.

[5] F. Al-Mansour, B. Sucic and M. Pusnik, "Challenges and prospects of electricity production from renewable energy sources in Slovenia," Energy, vol. 77, pp. 73-81, 2014.

[6] S. Seme, B. Štumberger and M. Hadžiselimović, "A novel prediction algorithm for solar angles using second derivative of the energy for photovoltaic sun tracking purposes, " Solar Energy, vol. 137, pp. 201-211, 2016.

[7] Y. S. Khoo, A. Nobre, R. Malhotra, D. Yang, R. Ruther, T. Reindl and A. G. Aberle, "Optimal orientation and tilt angle for maximizing in-plane solar irradiation for PV applications in Singapore," IEEE Journal of Photovoltaics, vol. 4, no. 2, pp. 647-653, March 2014.

[8] S. A. Gharakhani and P. Pillay, "Study of optimum tilt angles for solar panels in different latitudes for urban applications, " Solar Energy, vol. 86, pp. 1920-1928, 2012.

[9] B. Kadir, "General models for optimal tilt angles of solar panels: Turkey case study," Renewable and Sustainable Energy Reviews, vol. 16, pp. 6149-6159, 2012.

[10] E. D. Mehleri, P. L. Zervas, H. Sarimveis, J. A. Palyvos and N. C. Markatos, "Determination of the optimal tilt angle and orientation for solar photovoltaic arrays, " Renewable Energy, vol. 35, pp. 2468-2475, 2010.

[11] B. Y. H. Liu and R. C. Jordan, "Daily insolation on surfaces tilted towards the equator," ASHRAE Journal, vol. 3, pp. 53-59, 1961.

[12] J. I. Jimenez, "Effects of solar radiation on the performance of pyrometers with silicon domes," Journal of atmospheric and oceanic technology, vol. 5, pp. 666-670, 1988.

[13] J. E. Hay and J. A. Davies, "Proceedings of the first Canadian solar radiation data workshop,“Ministry of supply and services, Toronto, Canada, pp. 59, 1980.

[14] Y. Castro-Diez, "Prediction of global irradiance on inclinated surfaces from horizontal global irradiance“, Energy, vol. 24, pp. 689-704, 1998.

[15] P. Koronakis, "Energy balance analysis of a stand-alone photovoltaic system, including variable system reliability impact,“ Renewable energy, vol. 7, pp. 1161-1180, 2004.

[16] V. Badescu, "Computing global and diffuse solar hourly irradiation on clear sky. Review and testing of 54 modules, " Renewable and sustainable Energy Reviews, vol. 16, pp. 16361656, April 2012.

[17] P. Perez, "Solar irradiance conversion models, " Solar cells, vol. 18, pp. 213-222, 1983. 
[18] D. T. Reindl, "Evaluation of hourly tilted surfaces radiation models, “ Solar energy, vol. 45 (1), pp. 9-17, 1990.

[19] M. Iqbal, "An introduction to solar radiation,“ New York: Academy press, pp. 101, 1983.

[20] T. M. Klucher, "Evaluation of models to predict insolation on tilted surfaces," Solar energy, vol. 23, pp. 111-114, 1979.

[21] C. J. Willmott, "Some comments on the evaluation of model performance," Bulletin American Meteorological Society, vol. 63 (11), pp. 1309-1313, 1982.

[22] R. C. Temps and K. L. Coulson, "Solar radiation incident upon slopes of different orientations," Solar energy, vol. 19, pp. 179-184, 1977.

[23] J. A. Olseth and A. Skartveit, "Solar irradiance, sunshine duration and daylight illuminance derived from METEOSAT data for some European sites," Theoretical and applied climatology, vol. 45(1), pp. 9-17, 1990.

[24] Official website of Slovenian Environmental Agency, available from: http://www.arso.gov.si/

[25] S. Rehman and I. El-Amin, "Performance evaluation of an off-grid photovoltaic system in Saudi Arabia," Energy, 46:451-8, 2012.

[26] J. Leloux, L. Narvarte and D. Trebosc, "Review of the performance of residential PV systems in France, “ Renewable and Sustainable Energy Reviews, vol. 16, no. 4-6, pp. 13691376, 2012.

[27] V. Sharma, A. Kumar, O. Sastry and S. Chandel, "Performance assessment of different solar photovoltaic technologies under similar outdoor conditions, “ Energy, 58:511-8, 2013.

[28] IEC 61724. "Photovoltaic system performance monitoring - Guidelines for measurement, data exchange and analysis. " 2017.

[29] R. Bohra, "Performance analysis of 1MW SPV plant; temperature corrected PR," energetica INDIA, pp. 4-7, September 2014.

[30] B. Marion, J. Adelstein and K. Boyle, "Performance parameters for grid-connected PV systems,“ NREL conference paper, pp. 1-9, February 2005. 


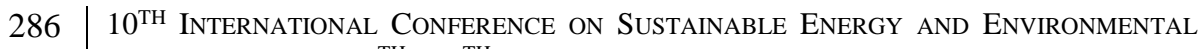
Protection (June $27^{\mathrm{TH}}-30^{\mathrm{TH}}, 2017$, Bled, Slovenia), Renewable EnERGy SourCeS 
$10^{\mathrm{TH}}$ InTERnational CONFERENCE ON Sustainable ENERgy AND

Environmental Protection (June 27 $7^{\mathrm{TH}}-30^{\mathrm{TH}}, 2017$, BLed,

SLOVENIA), RENEWABLE ENERGy SOURCES

J. Krope, A.Ghani Olabi, D. Goričanec \& S. Božičnik

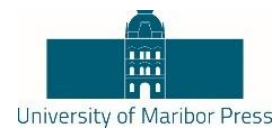

\title{
Reduction of PM Emissions by Highly Oxygenated Viscous Biofuel: Use of Glycerol in a Micro Gas Turbine
}

\author{
TINE SELJAK \& TOMAŽ KATRAŠNIK
}

\begin{abstract}
The presented paper focuses on combustion analysis of a highly oxygenated and viscous fuel in an internal combustion micro gas turbine. The goal of the study is to investigate the benefits and challenges of utilization of such fuels in engines rather than in atmospheric combustion devices, what is currently the most common approach. While technical difficulty of the proposed approach is rather high, the environmental benefits in terms of NOx emissions and PM emissions are significant as concentrations of both species are significantly reduced and efficiency of conversion to mechanical work is significantly increased. Based on the analysis presented in the study, this effect is attributed to the influence of oxygen content in the fuel, which reduces the formation of NO due to lower nitrogen presence in the flame zone. This altered local air-fuel ratio also supresses soot formation resulting in significantly reduction of PM emissions. Besides these beneficial effects, the influence of highly oxygenated and viscous fuel is also perceivable through higher $\mathrm{CO}$ and THC emissions, however results indicate that increasing turbine inlet temperatures and fuel preheating temperatures could reduce also these two species without negatively affecting other pollutants.
\end{abstract}

Keywords: • glycerol $\bullet$ micro gas turbine $\bullet$ particulate emissions $\bullet$ viscous biofuel $\bullet$ combustion $\bullet$

CORRESPONDENCE ADDRESS: Tine Seljak, University of Ljubljana, Faculty of mechanical engineering, Aškerčeva cesta 6, 1000 Ljubljana, Slovenia, e-mail: tine.seljak@fs.uni-lj.si. Tomaž Katrašnik, Ph.D., Full Professor, University of Ljubljana, Faculty of mechanical engineering, Aškerčeva cesta 6, 1000 Ljubljana, Slovenia, e-mail: tomaz.katrasnik@fs.uni-lj.si.

https://doi.org/10.18690/978-961-286-061-5.26

ISBN 978-961-286-061-5

(C) 2017 University of Maribor Press

Available at: http://press.um.si. 
$10^{\text {TH }}$ InTERnAtional CONFERENCE ON Sustainable ENERgy AND ENVIRONMENTAL Protection (June $27^{\mathrm{TH}}-30^{\mathrm{TH}}, 2017$, BlED, SLOVENIA), RENEWABLE ENERGY SOURCES T. Seljak \& T. Katrašnik: Reduction of PM Emissions by Highly Oxygenated Viscous Biofuel: Use of Glycerol in a Micro Gas Turbine Introduction

Recently, significant legislative push led to wide popularization and investments in the technology of 1st generation biofuels. As a result, demand for oils and sugars increased to the point where these fuels started to compete with food feedstock, raising the prices of arable crops. To offset this negative effect, further stimulation of 1st generation biofuels is limited and efforts are made to be displaced by subsequent generations of biofuels [1]. However, significant production capacities, particularly of biodiesel are still present and are expected to stay around since up to 7\% of FAME is allowed in the diesel fuel specified in EN590. As a result, the quantities of by-product - residual glycerol (GLY) are higher than ever [2]. Besides using it as a basic chemical, an attractive option is also to use it as an energy carrier as the requirements for purity and contaminant content could be less strict in this case. To boost its energy conversion efficiency and allow for its use on wide variety of power output scales, it is advantageous to rely on the internal combustion concepts.

Combination of internal combustion and physical and chemical properties of the glycerol, namely its high oxygen content and high viscosity [3], imposes significant technical challenges in terms of application in combustion systems with high power density which is linked relatively small combustion volumes and residence times. As modern piston engines are designed with more stringent requirements on physical and chemical properties of the fuels, gas turbines can be considered as preferred internal combustion engine type for glycerol combustion. Gas turbines namely feature continuous combustion, long residence times of the combustible mixture and possibility to use airassisted atomization nozzles, which are advantageous when using highly viscous and low-volatile fuels.

So far, a few studies were dealing with combustion of glycerol and majority of them included atmospheric continuous combustion devices [4-6]. These studies provide valuable experience in the area of combustion of highly oxygenated fuels. Possible upgrade to this approach is implementation of atmospheric combustion system to rankine cycle or to externally fired joule cycle [7]. The present study takes this to even higher level of complexity by investigating the direct combustion process of glycerol in a micro gas turbine (MGT) representing, to the best of author's knowledge, the first study in this area. The advantage of this approach is that direct conversion to mechanical energy is possible in the efficiency range of $30-37 \%$ [8].

To provide an insight into combustion process phenomena, this study focuses on the identification of the mechanisms that are influenced by high oxygen content, namely emissions of gaseous species and particulate matter. The results reveal that significant influence of bonded oxygen on $\mathrm{PM}$ and $\mathrm{NO}_{\mathrm{x}}$ emissions could be used as an advantage of this type of fuels, however challenges in atomization process of the fuel must be addressed with tailored injection nozzle design and appropriate pressure parameters to successfully control CO and THC emissions. Improvement on nozzle design are cruical 
as they allow high temperatures of fuel preheating and operation with high turbine inlet temperatures.

\subsection{Specific objectives}

Specific objectives of the study can be summarized as:

- Analyses of thermodynamic and emission responses of a MGT using glycerol as a main fuel and diesel fuel for benchmark data.

- Specific analysis of $\mathrm{NO}_{x}$ emissions and emissions of PM, which are most profoundly influenced by oxygen content of the fuel.

- Identification and discussion of important correlations between fuel chemical and physical properties and exhaust emissions.

- Identification of most important measures to obtain stable and durable combustion process in a gas turbine, namely fuel injection system design and injection parameters

\section{$2 \quad$ Methodology}

To overcome the significant technical difficulty linked to glycerol viscosity, the reduction of it is mandatory to obtain sufficient quality of atomization, which is capable of supporting combustion process under conditions present in MGT. Considering the performance of experimental system, which was developed to test various prototypes of engine components it is foreseen that innovative solutions linked to the atomization system will allow the use of crude glycerol without blending or upgrading and only by using preheating of the fuel. Particular importance is laid upon thermal protection of the nozzle, which prevents development of carbon deposits that are a limiting factor in increasing the fuel temperatures [9]. Key data of the tested GLY is presented in Table 1, together with properties of benchmark diesel fuel according to EN590:2011 (D2). The molecular structure of GLY is presented in Figure. 1.

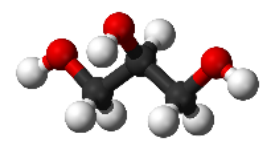

Figure. 1: Glycerol molecule C3H8O3. 
$290 \quad 10^{\text {TH }}$ International Conference on Sustainable ENERgy and ENVIRONMENTAL Protection (June $27^{\mathrm{TH}}-30^{\mathrm{TH}}, 2017$, Bled, SLOVENIA), RENEWABLE ENERGY SOURCES T. Seljak \& T. Katrašnik: Reduction of PM Emissions by Highly Oxygenated Viscous Biofuel: Use of Glycerol in a Micro Gas Turbine

Table 1: Properties of analysed fuels.

\begin{tabular}{ccc}
\hline & GLY & D2 \\
\hline $\mathrm{C}$ & Glycerol & 87.00 \\
$\mathrm{H}$ & 42.19 & 13.00 \\
$\mathrm{~N}$ & 9.14 & $/$ \\
$\mathrm{S}$ & 0 & $<0.001[10]$ \\
$\mathrm{O}$ (by diff.) & 0 & $/$ \\
Density & 48.67 & $0.820-$ \\
& & $0.845[10]$ \\
LHV & $19.0 \mathrm{MJ} / \mathrm{kg}$ & 42.2 \\
Stoichiometric & 5.19 & 14.7 \\
ratio & $50.6 \mathrm{mPa} . \mathrm{s}$ & $1.3 \mathrm{mPa} . \mathrm{s}$ \\
Viscosity at $70^{\circ} \mathrm{C}$ & $81.3 \mathrm{mPa} . \mathrm{s}$ & $1.5 \mathrm{mPa} . \mathrm{s}$ \\
Viscosity at $60^{\circ} \mathrm{C}$ & $142.0 \mathrm{mPa} . \mathrm{s}$ & $1.8 \mathrm{mPa} . \mathrm{s}$ \\
Viscosity at $50^{\circ} \mathrm{C}$ & $1412.0 \mathrm{mPa} . \mathrm{s}$ & $3.4 \mathrm{mPa} . \mathrm{s}$ \\
\hline Viscosity at $20^{\circ} \mathrm{C}$ & 14
\end{tabular}

In terms of viscosity, it is currently considered that $15 \mathrm{~mm} 2 / \mathrm{s}$ [11] is the maximum value for gas turbines, although some authors propose even lower values $12 \mathrm{~mm} 2 / \mathrm{s}$ [12] or 10 $\mathrm{mm} 2 / \mathrm{s}$ [13]. However these values are linked to pure pressure atomizers, which are known to have limited turndown ratio and are highly sensitive on viscosity as the energy for liquid jet break up should be delivered solely by fluid pressure. More suitable nozzles for high viscosity fuels are therefore twin-fluid atomizers which feature better turn down ratios (i.e. in certain interval of mass flows, the atomization ability is minimally influenced) and are less sensitive to viscosity as energy for liquid jet breakup is delivered also by atomizing air stream [9]. However, the viscosity levels of glycerol are too high to be accommodated even by twin-fluid nozzles.

According to temperature dependence of glycerol viscosity (Figure 2), the acceptable levels can be obtained by preheating the glycerol to prespecified temperature. Useful temperature interval was for the present study constrained by data, obtained in the literature [14], where fuels with high viscosity were fired in similar experimental system. Selected interval covers temperatures between $50-70^{\circ} \mathrm{C}$, yielding viscosities according to Table 1. 


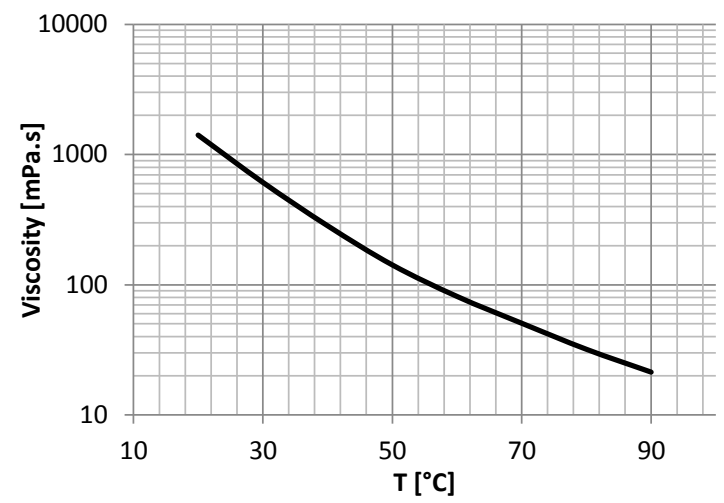

Figure. 2: Temperature dependence of GLY viscosity.

The test rig constructed here consists of a directly fired experimental gas turbine, a fuel conditioning system and emission analysis equipment. The combustion chamber was a single can design. Single stage compression was provided by a radial compressor powered by a radial single stage turbine. Details on the gas turbine setup are also presented in [14] and Figure 3. A wide range of operating parameters were accessed by operating the turbine across several different turbine inlet temperatures (TIT) which resulted in:

- different equivalence ratios (EQR) due to different degrees of enthalpy extraction on a turbine and different pressure drops on flow path,

- slightly different primary air temperatures as a result of different turbine outlet temperatures and different air mass flows.

Since the experimental setup is designed purely for combustion analyses, power output is not measured. Instead, the power withdrawal is emulated by the throttle valve in the turbine discharge duct. The pressure drop over the throttle valve increases with increased fuel flow and by this proportionally decreasing the enthalpy difference on turbine rotor. With this approach, similar thermodynamic conditions can be obtained in combustion chamber [9].

The design of injection nozzle followed the commercially available solution, however the nozzle discharge surfaces were modified in order to accommodate the thermal protective layer. By this the radiative and convective heat transfer was reduced to a point where no fuel decomposition occurred in the internal mixing chamber of the nozzle and formation of deposits on discharge surfaces was minimized. This is a key improvement which enables high preheating temperatures which otherwise cause excesive fuel coking issues as was already reported in [15] and [9]. 
$10^{\mathrm{TH}}$ InTERnational CONFERENCE on Sustainable EnERgy AND ENVIRONMENTAL Protection (June $27^{\mathrm{TH}}-30^{\mathrm{TH}}, 2017$, BlED, SLOVENIA), RENEWABLE ENERGY SOURCES T. Seljak \& T. Katrašnik: Reduction of PM Emissions by Highly Oxygenated Viscous Biofuel: Use of Glycerol in a Micro Gas Turbine

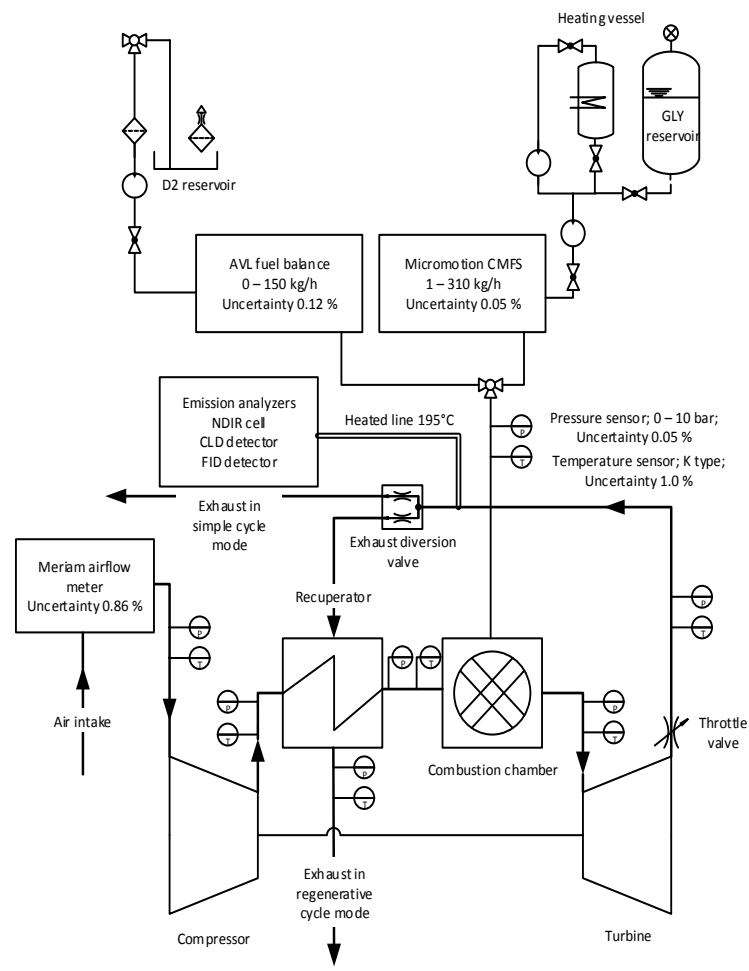

Figure. 3: Experimental system layout.

The emission equipment consisted of a wet exhaust gas analyser performing separate consecutive measurements of total hydrocarbons (THC) in an FID cell, nitrous oxides $\left(\mathrm{NO}_{\mathrm{x}}\right)$ in a CLD cell and $\mathrm{CO}, \mathrm{CO} 2$ and $\mathrm{H} 2 \mathrm{O}$ in an NDIR cell.

Particulate matter (PM) was analysed using photoacoustic method, suitable to detect particles with high absorption coefficient. Considering the technical quality of GLY with no expected ash precursor content, the emitted particles will most likely contain mainly carbon, giving the black appearance and high absorption coefficient.

\section{$3 \quad$ Results and Discussion}

The following sections present the results of key operating parameters under different operating conditions in dependency to TIT. This parameter is directly linked to EQR and temperature of combustion chamber intake air (PAT). Both linked parameters are a consequence of TIT effect on pressure ratio which increases with TIT. The presentation of thermodynamic parameters is followed by a presentation of the concentrations of emission species (CO, THC and NOx) over different TIT, supported by the explanation of underlying mechanisms of formation. Finally, PM emissions are presented. 

Protection (June $27^{\mathrm{TH}}-30^{\mathrm{TH}}, 2017$, BLED, SLOVENIA), RENEWABLE ENERGY SOURCES

T. Seljak \& T. Katrašnik: Reduction of PM Emissions by Highly Oxygenated Viscous Biofuel: Use of Glycerol in a Micro Gas Turbine

\subsection{Thermodynamic parameters}

Figure 4 presents the equivalence ratios (EQR) for different operating points. As low fuel mass flows were required to obtain the desired TIT, EQRs are relatively high. This is a consequence of high degree of exhaust heat regeneration, leading to as is visible from primary air temperatures in Figure 5.

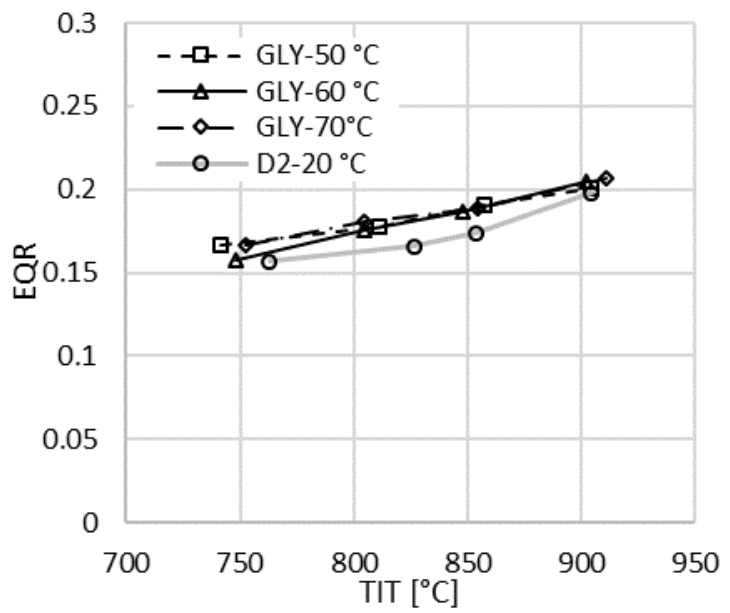

Figure. 4: Equivalence ratio for GLY and D2.

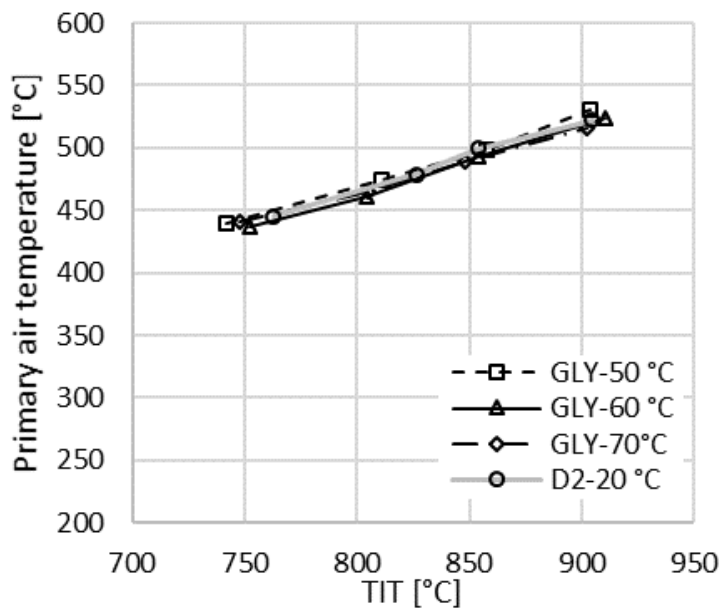

Figure. 5: Primary air temperatures for GLY and D2. 
$10^{\text {TH }}$ International Conference on Sustainable Energy and Environmental Protection (June $27^{\mathrm{TH}}-30^{\mathrm{TH}}, 2017$, Bled, SLOVENIA), RENEWABle ENERGy SOURCES T. Seljak \& T. Katrašnik: Reduction of PM Emissions by Highly Oxygenated Viscous Biofuel: Use of Glycerol in a Micro Gas Turbine

\subsection{Gaseous emissions}

Figure 6 presents $\mathrm{CO}$ emissions at different turbine inlet temperatures (TIT) for both fuels and for all tested temperatures. Based on the physical and chemical characteristics of the fuels presented in Table 1 and Fig. 2, particularly the viscosity and density of GLY and to some extent also its evaporation curve, the higher CO emissions of the GLY in Fig. 6 are expected. The nearly 10-fold higher viscosity of the GLY compared to D2 impairs the atomisation ability of this fuel, resulting in a longer life span and penetration depth of the larger and denser droplets. Increased penetration depth of the droplets is the consequence of decreased surface to mass ratio of the droplets due to the larger initial droplet diameter and due to the increased density of GLY. Furthermore, delayed evaporation of droplets (which in this case feature lower surface to volume ratio due to larger diameters) and unfavourable evaporation curve of GLY in comparison to D2, requiring higher temperatures is in this case causing prolonged time interval in which the mixture preparation takes place. As the mixture is formed relatively late in the primary zone of combustion chamber, the time available for combustion reactions before the dilution with air in dilution zone of combustion chamber can cause excessive reaction quenching. Furthermore, high autoignition temperature $\left(370{ }^{\circ} \mathrm{C}\right)$ and high boiling point $\left(290^{\circ} \mathrm{C}\right)$ of the GLY can also play a significant role (by offsetting the ignition of the mixture leading to a shift of reactive zone towards the end of primary zone. These phenomena inevitably lead to higher CO emissions in exhaust gas stream.

Another mechanism contributing to high $\mathrm{CO}$ exhaust emissions is the entrapment of mixture, which generally has longer penetration length, into liner cooling air where aforementioned quenching occurs even earlier.

Despite the fact that fuel properties indicate shift of the main reactive zone deeper downstream in the combustion chamber due to the delayed evaporation process, a surprisingly large volume of the flame was also observed near the fuel nozzle. This is mainly related to high bonded oxygen content and high degree of premixing of the fuel in the internal mixing chamber of the injection nozzle. Bonded oxygen namely accounts for $35 \%$ of the stoichiometric oxygen, hence lowering the need for external air to reach flammability limits. This can, in the case of high primary air temperatures, cause relatively early ignition of small amount of mixture which is in a suitable range of EQRs. At the same time, the phenomena linked to larger droplets are still present, thus the penetration of the mixture outside flammability limits is longer, which causes an elongated flame. 


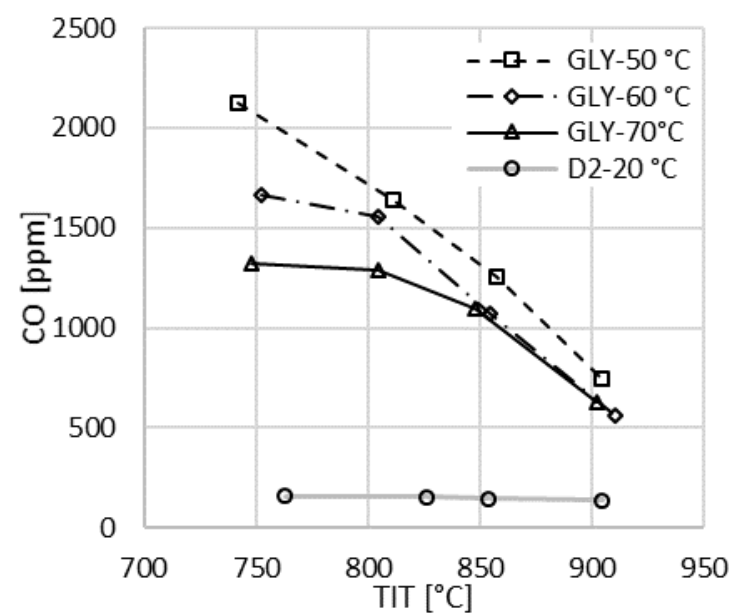

Fig. 6: CO emissions of D2 and GLY.

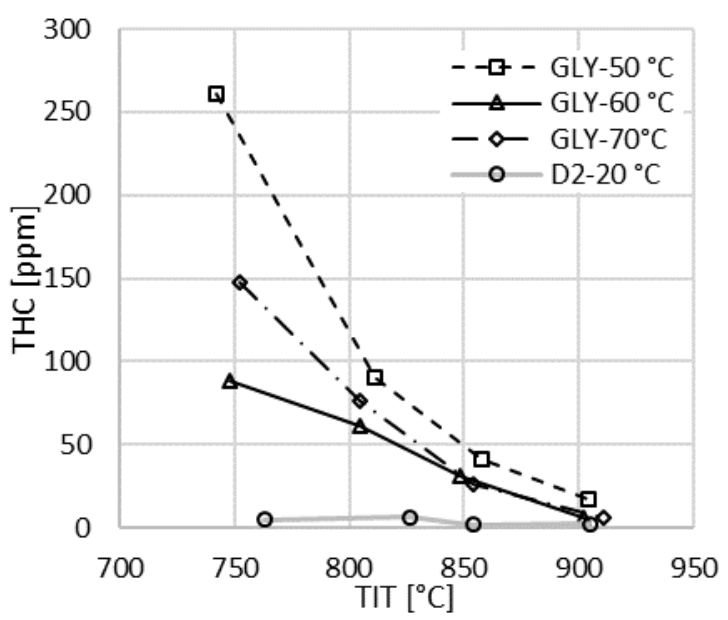

Fig 7. THC emissions of D2 and GLY

Considering the upper phenomena, responsible for formation of larger quantities of $\mathrm{CO}$ with GLY in comparison to D2 it was presumed that increasing TIT would lead to suppression of listed phenomena by increasing the temperature levels in combustion chamber and increasing the heat transfer to the droplets and consequent evaporation rate of the fuel. The increasing fuel temperature also influences the combustion process in similar manner, however in this case, the main driver is the reduction of viscosity, leading to smaller droplet diameters as well as narrower margin for droplet heating as they enter the combustion chamber at higher temperature. 
296 10 $10^{\text {TH }}$ INTERNATIONAL CONFERENCE ON Sustainable ENERGy AND ENVIRONMENTAL Protection (June $27^{\mathrm{TH}}-30^{\mathrm{TH}}, 2017$, BlED, SLOVENIA), RENEWABLE ENERGY SOURCES T. Seljak \& T. Katrašnik: Reduction of PM Emissions by Highly Oxygenated Viscous Biofuel: Use of Glycerol in a Micro Gas Turbine

Both trends are clearly visible with CO emissions - they reduce with TIT as well as with fuel temperature.

Similarly as CO emissions, THC emissions in Fig. 7 are also strongly TIT-dependent and fuel temperature dependant for GLY which is in line with phenomena discussed for CO. Also here, the difference between D2 and GLY is significant, however smaller in comparison to CO. Due to relatively low complexity of molecular structure of GLY, the number of steps required for formation of $\mathrm{CO}$ is small in comparison to diesel fuel leading to relatively fast formation of $\mathrm{CO}$ after initial preparation of combustible mixture. However the unfavourable autoignition temperature and significantly different evaporation curve still causes higher CO emissions than D2.

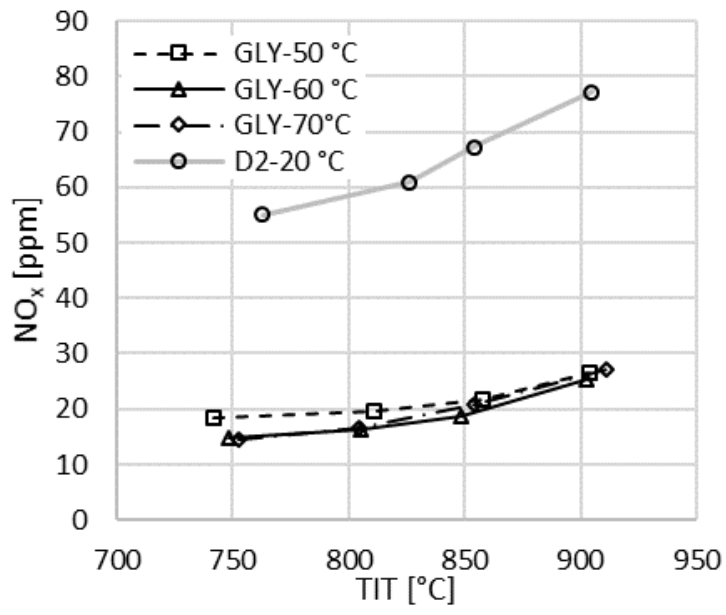

Fig. 8: $\mathrm{NO}_{\mathrm{x}}$ emissions of GLY and D2.

The $\mathrm{NO}_{\mathrm{x}}$ emissions concentrations reported in Fig. 8 demonstrate two distinctive trends. The first is linked to fuel type and the other one to TIT, which is related also to primary air temperature and EQR. The highest $\mathrm{NO}_{\mathrm{x}}$ emissions are observed with $\mathrm{D} 2$ and high TIT, followed by GLY and high TIT.

As no nitrogen is present in both tested fuels, the $\mathrm{NO}_{\mathrm{x}}$ emissions are solely a consequence of a thermal (Zeldovich) and prompt (Fenimore) mechanism. The $\mathrm{NO}_{\mathrm{x}}$ component formed through $\mathrm{N}_{2} \mathrm{O}$ can be neglected in presented cases as pressure ratios are low due to single stage compression $(1,9-2,5)$ as reaction pathway for $\mathrm{N}_{2} \mathrm{O}$ requires three-body reactions, associated with high pressures. Formation of $\mathrm{NO}_{\mathrm{x}}$ through fuel bound nitrogen $(\mathrm{FBN})$ is also very unlikely as FBN is absent in the case of D2 and GLY.

Low levels of $\mathrm{NO}_{\mathrm{x}}$ in combustion of GLY might be the consequence of high oxygen content and low stoichiometric ratio in GLY. The oxygen, contained in GLY represents as much as $35 \%$ of stoichiometric oxygen. Thus, to obtain a mixture of GLY and air 
inside a flammability interval, the amount of required air is smaller. Therefore, also lower amount of nitrogen is delivered into high temperature zone thus reducing the possibility for thermal $\mathrm{NO}_{\mathrm{x}}$ formation. Therefore temperatures on the rich side of the flame are relatively low due to sub stoichiometric conditions and at the same time concentrations of nitrogen are low, leading to slow formation of NO. The transition of the partially reacted mixture, which is now already diluted with products of partial oxidation, to lean conditions reduces the temperatures and prevents further formation of $\mathrm{NO}$ or even its dissociation. This phenomena resembles the approach of partially premixed combustion (for example RQL), although the combustor design in present study is purely diffusive single-can with single point injection and partial premixing is occurring on micro and molecular level. The premixing is achieved mainly with bonded oxygen, however addition of atomizing air might play a minor role, however this effect is also present with D2, so relative effect is not discernible from the provided results. The oxygen content in the fuel, although it has several other disadvantages, therefore has a significant potential to reduce the $\mathrm{NO}_{\mathrm{x}}$ emissions

The general trend of increasing $\mathrm{NO}_{\mathrm{x}}$ emissions of GLY with TIT can be attributed to increasing rate of thermal $\mathrm{NO}_{\mathrm{x}}$ formation, however the influence of GLY temperature is in the ppm range so no definite trend can be observed here. The same trend, although slightly more pronounced is also observed with $\mathrm{D} 2$.

\subsection{PM emissions}

Strong influence of oxygen content in the fuel is also reflected in emissions of soot, which represent the majority of PM emissions, as tested GLY was ash free.

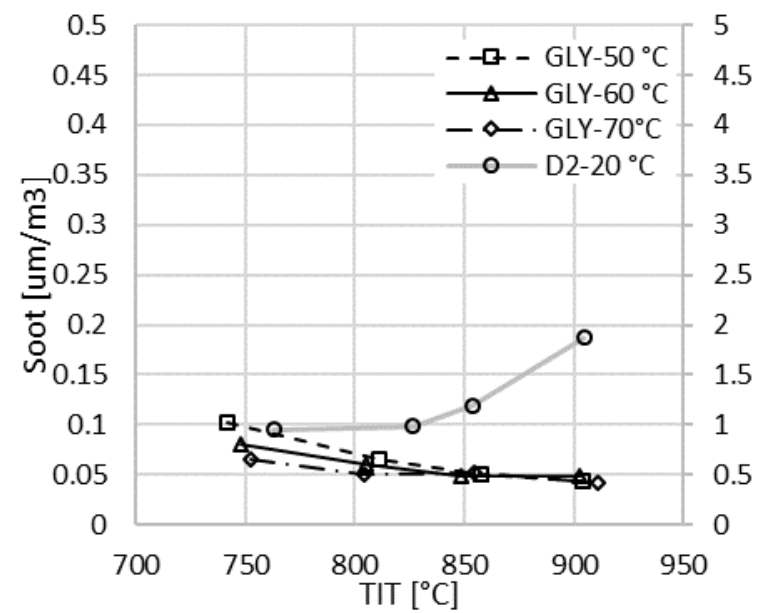

Fig. Soot emissions of D2 (right axis) and GLY (left axis) 
$10^{\mathrm{TH}}$ InTERnATIONAL CONFERENCE ON Sustainable ENERGy AND ENVIRONMENTAL Protection (June $27^{\mathrm{TH}}-30^{\mathrm{TH}}, 2017$, BlED, SLOVENIA), RENEWABLE ENERGY SOURCES T. Seljak \& T. Katrašnik: Reduction of PM Emissions by Highly Oxygenated Viscous Biofuel: Use of Glycerol in a Micro Gas Turbine

The applied method for measurement of PM relies on absorption coefficient of PM in the sample stream which is fitter to high absorbance of carbon material (soot). Detection of particles with significantly lower absorption coefficient than soot is therefore limited. The results in Fig. 9 therefore roughly corresponds to soot emissions although minor false positives might occur in case other particles are present - the quantity of these is predicted to be low, as no ash was present in the tested GLY.

The soot emissions from D2 are roughly 10-fold higher than for GLY and exhibits a pronounced dependence on TIT for D2. The changes This can mainly be attributed to changes in the EQR over TIT interval and thus the oxygen availability. In addition, variations in the temperature field in the combustion chamber also influences both soot formation and its oxidation kinetics. The soot formation threshold depends on temperature, EQR and pressure [16]. As the pressure differences between different operating points of the experimental turbine are relatively low, temperature and $\mathrm{EQR}$ are the main driver for the observed differences which are both interrelated.

The soot values of GLY are surprisingly low considering its physical and chemical properties which should increase the diffusive pathway for soot formation due to larger droplets and aggravated oxygen diffusion to fuel rich areas.

The influence of GLY temperature on soot emission is relatively low, although the accompanying changes in viscosity are quite pronounced (Table 1.) However the changes in PM are believed to be a result of lower amount of large droplets which occur more frequently at lower temperature of GLY (and higher viscosity). These are capable of reaching the quenching zone of the combustion chamber where the pyrolysis process occurs and yields small coke fragments, perceived as soot.

The TIT dependence of soot from GLY is exhibiting the opposite trend as D2 as it reduces with TIT. As the energy density of the mixture is comparable to D2 and the adiabatic flame temperature of GLY is close to that of D2, the influence of TIT on soot formation with GLY should be similar to that of D2

The reason for these surprising trends can be linked to high oxygen content in GLY. Bonded oxygen becomes during dissociation directly available in the flame zone in the form of free radicals, resulting in high local C/O As GLY contains approximately 35\% of the oxygen required for its stoichiometric combustion, the $\mathrm{C} / \mathrm{O}$ ratio is always below 1 , even in the most rich part of the mixture, whereas for D2 this value is easily exceeded on the rich side of the diffusion flame and approaches infinity where only fuel vapour is present. Thus, areas with local EQRs below the soot formation threshold are more likely to occur with GLY. Additionally, the high O/C ratio of the fuel also leads to a much earlier onset of exothermic oxidation reactions, even when a very low quantity of air is available in the fuel-air mixture. Thus, the temperatures in the fuel rich areas could be elevated above the soot formation threshold when using GLY. 
Furthermore, due to high oxygen content a widely accepted acetylene hypothesis of soot formation might not play a significant role due to oxygen disrupting the formation of acetylene. Formation of PM in the presented case with GLY most likely relies on less known diffusive hypothesis for soot formation mechanism, which relies on pyrolysis as the main process that causes soot formation [17].

Similar observations with very low soot were already made in [6], where glycerol was combusted in an atmospheric furnace and in $[15,18]$ where high preheating temperatures of similar highly oxygenated fuel also reduced soot concentration below measurable limit.

In contrast to GLY, in the case of D2, oxygen is not readily available for the early onset of exothermic reactions and the temperatures in fuel rich areas are lower, thus enabling soot formation. The temperature and EQR profile versus the $\mathrm{O} / \mathrm{C}$ ratio are therefore the main reasons for the significantly reduced soot emissions and thus BSU values for GLY. These findings suggest that with high preheating temperatures of GLY and suitable atomization process, very low soot and PM emissions could be achieved with GLY even though the viscosity of GLY is above generally acceptable limits for use in gas turbines.

\section{Conclusions}

The main objective of this work was to examine the combustion characteristics of glycerol under regenerative cycle in gas turbines. To avoid the negative impact of high viscosity, the glycerol was preheated to three different temperatures and improved injection nozzle was used. The effects of various conditions in the combustion chamber on emission and thermodynamic response were evaluated afterwards.

CO and THC emissions were strongly dependent on TIT for GLY, while baseline D2 fuel, $\mathrm{CO}$ emissions concentrations were almost independent of TIT. Strong influence of GLY preheating temperature on CO and THC emissions was also reveal. The differences were attributed to the specific physical and chemical properties of these fuels, which differed greatly between GLY and D2. The main differences were high density and viscosity for GLY when compared to D2.

This study revealed that oxygen content is the main drivers for differences in measured $\mathrm{NO}_{\mathrm{x}}$ concentrations. The elemental composition of GLY was reflected over the whole measurement range of the experimental system. The lowest $\mathrm{NO}_{\mathrm{x}}$ emissions were obtained with GLY at low TIT and were attributed to high oxygen content, which apparently reduces the diffusion of nitrogen into areas with high temperatures, as oxygen is already available within the molecular structure of the fuel.

The combustion of GLY also resulted in very low soot concentrations considering its physical properties, particularly its density and viscosity. These low values were attributed to the high amount of bonded oxygen, which acted as a suppressor of soot 
$10^{\text {TH }}$ International Conference on Sustainable Energy and Environmental Protection (June $27^{\mathrm{TH}}-30^{\mathrm{TH}}, 2017$, Bled, SLOVENIA), RENEWABle ENERGy SOURCES T. Seljak \& T. Katrašnik: Reduction of PM Emissions by Highly Oxygenated Viscous Biofuel: Use of Glycerol in a Micro Gas Turbine

formation by enlarging the areas with conditions below the soot formation threshold in terms of EQR.

Considering emissions and the stability of operation, these data suggest that the utilisation of GLY in gas turbines could be possible and even environmentally attractive; however the issue of high viscosity should be tackled solely by preheating of the fuel to maintain its economic attractiveness. Blending with other fuels or refining is increasing the cost in comparison to crude glycerol from biodiesel production which is the fuel targeted with this study.

To fully confirm the technical feasibility of crude glycerol use in gas turbines, also the influence of contaminants (catalyst residuals, mineral matter and water content) is currently being investigated, however the results will be provided in the later stages of the study. GLY can also be considered as a model for highly oxygenated viscous biofuel. In this category, liquefied wood from solvolysis process, hydrothermal liquefaction products and biomass pyrolysis oils are the most known fuels, the findings provided in this study are therefore partially transferrable also to other oxygenated viscous biofuels.

\section{References}

[1] Eggert H, Greaker M. Promoting Second Generation Biofuels: Does the First Generation Pave the Road? Energies 2014;7:4430-45. doi:10.3390/en7074430.

[2] Ciriminna R, Pina C Della, Rossi M, Pagliaro M. Understanding the glycerol market. Eur J Lipid Sci Technol 2014;116:1432-9. doi:10.1002/ejlt.201400229.

[3] Biodiesel TechNotes. Department of Biological and agricultural Engineering, Univesity of Idaho. 2006;3:3.

[4] Bohon MD, Metzger B a., Linak WP, King CJ, Roberts WL. Glycerol combustion and emissions. Proc Combust Inst 2011;33:2717-24. doi:10.1016/j.proci.2010.06.154.

[5] Steinmetz S, Herrington JS, Winterrowd CK, Roberts WL, Wendt JOL, Linak WP. Crude glycerol combustion: Particulate, acrolein, and other volatile organic emissions. Proc Combust Inst 2013;34:2749-57. doi:10.1016/j.proci.2012.07.050.

[6] Bohon MD, Roberts WL. NOx emissions from high swirl turbulent spray flames with highly oxygenated fuels. Proc Combust Inst 2013;34:1705-12. doi:10.1016/j.proci.2012.07.064.

[7] Vera D, Jurado F, de Mena B, Schories G. Comparison between externally fired gas turbine and gasifier-gas turbine system for the olive oil industry. Energy 2011;36:6720-30. doi:10.1016/j.energy.2011.10.036.

[8] Technical Documentation Microturbine Turbec T100, Turbec, 2008.

[9] Seljak T, Katrašnik T. Designing the microturbine engine for waste derived fuel. Waste Manage. 2016;47:299-310.

[10] SIST EN 590:2009/A101 Automotive fuels - Diesel - Requirements and Test Methods.

[11] Lefebvre AH, Ballal DR. Gas Turbine Combustion: Alternative Fuels and Emissions. vol. 54. CRC Press; 2011.

[12] Gupta KK, Rehman A, Sarviya RM. Bio-fuels for the gas turbine: A review. Renew Sustain Energy Rev 2010;14:2946-55. doi:10.1016/j.rser.2010.07.025.

[13] Chiaramonti D, Oasmaa A, Solantausta Y. Power generation using fast pyrolysis liquids from biomass. Renew Sustain Energy Rev 2007;11:1056-86. 
doi:10.1016/j.rser.2005.07.008.

[14] Seljak T, Rodman Oprešnik S, Kunaver M, Katrašnik T. Wood, liquefied in polyhydroxy alcohols as a fuel for gas turbines. Appl Energy 2012;99:40-9.

[15] Seljak T, Oprešnik SR, Kunaver MM, Katrašnik T. Effects of primary air temperature on emissions of a gas turbine fired by liquefied spruce wood. Biomass and Bioenergy 2014;71:394-407. doi:10.1016/j.biombioe.2014.09.016.

[16] Mansurov ZA. Soot Formation in Combustion Processes (Review). Combust Explos Shock Waves 2005;41:727-44. doi:10.1007/s10573-005-0083-2.

[17] Bechmann O. Untersuchungen zur Ablagerung von Rußpartikeln aus dem Abgas von Dieselmotoren, Doctoral Thesis, University of Hannover, 2000.

[18] Seljak T, Rodman Oprešnik S, Katrašnik T, Microturbine combustion and emission characterisation of waste polymer-derived fuels. Energy 2014;77:226-34. doi:10.1016/j.energy.2014.07.020. 
$302 \mid 10^{\mathrm{TH}}$ InTERnAtional CONFERENCE ON Sustainable ENERGy AND ENVIRONMENTAL Protection (June 27 $7^{\mathrm{TH}}-30^{\mathrm{TH}}, 2017$, Bled, Slovenia), Renewable EnERGy SOURCES 
$10^{\mathrm{TH}}$ InTERnational CONFEREnCE ON Sustainable ENERgy AND ENVIRONMENTAL Protection (June $27^{\mathrm{TH}}-30^{\mathrm{TH}}$, 2017, Bled, SLOVENIA), RENEWABLE ENERGy SOURCES

J. Krope, A.Ghani Olabi, D. Goričanec \& S. Božičnik

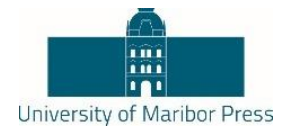

\title{
Prediction of the Daily Direct Solar Radiation Using Nonlinear Autoregressive Exogenous (Narx) Network Model
}

\author{
Zina BoussaAda, Ahmed Remaci, Octavian Curea, Haritza CAMblong \& NaJiBA \\ MRABET BELLAAJ
}

\begin{abstract}
The work presented in this paper focuses on the estimation of the direct solar radiation on a horizontal surface using Nonlinear Autoregressive Exogenous (NARX) neural network model. This study is a part of a research project which consists in supplying a sailboat with electricity using only renewable sources. Therefore the results will be used to estimate the direct solar radiation on a tilted surface and the amount of available power from Photovoltaic in the sailboat.

In this paper, the NARX neural network predicts the daily direct solar radiation using two variables: the determinist component of solar radiation and its statistical component. Due the mobility of the sailboat and the difference between the days of the year, the issue of this research is to find the best neural network to be used for the daily direct solar radiation prediction. Using several simulations, the best performance was obtained when the training phase was done periodically.
\end{abstract}

Keywords: • Estimation $\bullet$ mathematic model $\bullet$ statistical model $\bullet$ Artificial Neural Network $\bullet$ cloud cover $\bullet$

Correspondence Address: Zina Boussaada, Ph.D. Student, Ecole Nationale d'Ingénieurs de Tunis, Université de Tunis El Manar, Campus Universitaire Farhat Hached، B.P. $\mathrm{n}^{\circ} 94$ ROMMANA، Tunis 1068, Tunisia, e-mail: zina.b.88@ hotmail.fr. Ahmed Remaci, Ph.D. Student, ESTIA Recherche, Technopole Izarbel, 64210 Bidart, France, e-mail: a.remaci@ estia.fr. Octavian Curea, Ph.D., Associate Professor, ESTIA Recherche, Technopole Izarbel, 64210 Bidart, France, e-mail: o.curea@estia.fr. Haritza Camblong, Ph.D., Professor, University of the Basque Country, Faculty of Engineering, Gipuzkoa, Plaza Europa 1, 20018 Donostia- San Sebastián, Spain, e-mail: aritza.camblong@ehu.eus. Najiba Mrabet Bellaaj, Ph.D., Emeritus Professor, Institut Supérieur d'Informatique, Université de Tunis El Manar, Campus Universitaire Farhat Hached، B.P. $\mathrm{n}^{\circ} 94$ ROMMANA، Tunis 1068, Tunisia, e-mail: najiba_bm@yahoo.fr.

https://doi.org/10.18690/978-961-286-061-5.27

ISBN 978-961-286-061-5

(C) 2017 University of Maribor Press

Available at: http://press.um.si. 
$10^{\text {TH }}$ InTERnATIONAL CONFERENCE ON Sustainable ENERGy AND ENVIRONMENTAL Protection (June $27^{\mathrm{TH}}-30^{\mathrm{TH}}, 2017$, Bled, SLOVENIA), RENEWABle ENERGy SOURCES Z. Boussaada, A. Remaci, O. Curea, H. Camblong \& N. Mrabet Bellaaj: Prediction of the Daily Direct Solar Radiation Using Nonlinear Autoregressive Exogenous (Narx) Network Model

Because of environmental reasons and also the lack of fossil fuel sources in near future, using renewable energy sources e.g., Photovoltaic (PV) and wind have attracted significant attention. Amaiur Alfaro, Basque skipper has a big challenge for "Vendée Globe 2020". He would like to be the first skipper completing the race using only renewable sources as: wind turbines, PV panels, hydro generator and energy recovery system. This challenge will require the design of an advanced energy management system (EMS) which will have to consider, among other, the estimation of the available electrical energy, in order to determine when and how much energy to store. Furthermore, this EMS will require the forecasting of some variables, for instance that of the direct solar radiation.

In fact, the necessity of solar radiation prediction is related to several factors. On the one hand the solar radiation has an important influence on PV power generation; on the other hand it is greatly influenced by the mobility of the sailboat and the difference between the days of the year.

Prediction of solar radiation in particular and time series in general, has attracted important interest as a main topic of recent researches. There are several methods of prediction; they depend on the available inputs, the way of their classification and the horizon of the prediction. Among these methods, some are based on linear models such as Auto-Regressive (AR) and Auto-Regressive Moving Average (ARMA) [1]. However, because of the nonlinear behavior of the solar radiation, researchers proposed several nonlinear models such as wavelet-based methods, fuzzy models, Adaptive Neural Fuzzy Inference systems (ANFIS) and Artificial Neural Networks (ANN) [2], [3], [4]. There are also some researches which combined linear and nonlinear methods such as [5] where, authors predicted one minute ahead solar radiation using a hybrid method based on wavelet, ARMA and NARX model. In fact [5] used only the historical solar radiation as input of the predictor. So the wavelet transformation was used to decompose the historical data into the better-behaved series for prediction. Authors applied ARMA model as a linear predictor and they used NARX as a nonlinear pattern recognition tool to compensate the error of wavelet-ARMA prediction.

[2], [3] and [4] forecasted daily global solar radiation using artificial neural network. In [2], authors used correlation criteria to determine endogenous and exogenous inputs to take into account. Four endogenous time lags were taken for the clear sky modal of solar radiation. From several meteorological parameters only three were selected as exogenous inputs: relative humidity, sunshine duration and nebulosity. Based on the nature of the obtained data, authors of [3] divided data differently: predicted data and statistical data. So they combined several statistical data as: calculated cloud ratio, maximum hourly variation of the solar radiation, absolute daily variation of the solar radiation between the day (t) and the day (t-1), etc. and numerical weather prediction data which contains the one day ahead forecast of the cumulative irradiation each 3 hours. As a result a hybrid 
model was formed as neural network inputs. In [4], authors didn't classify inputs data, but they trained four neural networks with four combinations of input features in order to consider the effect of different meteorological parameters on prediction results. They concluded that the best performance was obtained when using the following inputs: the day of the year, the mean daily extraterrestrial solar radiation, the maximum possible sunshine hours, the mean daily maximum air temperature, the mean daily relative humidity and the wind speed.

The aim of our research is to find the best neural network for the daily direct solar radiation prediction on a horizontal surface. The developed NARX network model must take into account the change of location of the sailboat and the difference between the days of the year.

In our model it was assumed that the direct solar radiation model is composed of a determinist component which is calculated basing on the distance between the center of sun and the point of measurement; and a statistical component which depends on several meteorological parameters where, the most important is the cloud cover. Therefore the used NARX model has two inputs: a deterministic input which is the clear sky direct solar radiation and a statistical input which is the cloud cover. Using different evaluation criteria, results show that the training process must be done periodically.

The rest of the paper was organized as follows. In section 2, the clear sky direct solar radiation was defined. In section 3, the methodology of prediction was presented, by describing the NARX network model. Then, section 4 presented the used dataset and the evaluation criteria. Section 5 focused on the simulation results and discussions. Finally, section 6 concluded the paper.

\section{$2 \quad$ Clear Sky Direct Solar Radiation Model}

This section focuses on the determinist component of direct solar radiation. In fact, the "Clear sky" model calculates the received solar radiation when the sky is without cloud cover [6]. Several studies modelled the solar irradiation using clear sky model, including Kasten model [7], Molineaux model [8], or also SOLIS model [9]. In this study the used model to describe the deterministic component of direct solar radiation is SOLIS model because it gives excellent results when it is compared with measures realized in Europe [10]. The proposed direct solar radiation formula is as follows:

$$
G=G_{0} \times \exp \left(-\frac{\tau}{\sin ^{b}(\alpha)}\right)
$$

where, $b$ is a constant adjustment parameter, $\tau$ is the optical depth, $G_{0}$ is the solar radiation at the top of the Earth Atmosphere and $\alpha$ is the sun height. 
$306 \quad 10^{\mathrm{TH}}$ International CONFERENCE on Sustainable ENERgy AND ENVIRONMENTAL Protection (June $27^{\mathrm{TH}}-30^{\mathrm{TH}}$, 2017, Bled, SLOVENIA), RENEWABLE ENERGy SOURCES Z. Boussaada, A. Remaci, O. Curea, H. Camblong \& N. Mrabet Bellaaj: Prediction of the Daily Direct Solar Radiation Using Nonlinear Autoregressive Exogenous (Narx) Network Model

$G_{0}$ is calculated as follows:

$$
G_{0}=\left(\frac{R_{m}}{R(J)}\right)^{2} \times E_{s c} \times \sin (\alpha)
$$

where, $R_{m}$ is the mean Earth-Sun distance (Astronomical unit) and $R(J)$ is the mean distance for the $J$ 'th day. The expression $\left(\frac{R_{m}}{R(J)}\right)^{2}$ is the Earth-Sun distance correction factor: $K_{D}$, and it is calculated as:

$$
\begin{aligned}
& K_{D}=1.000138+0.03341 \cdot \cos \left(\frac{2 \cdot \pi \cdot N}{365.2422}-0.051\right) \\
& +0.000699 \cdot \sin \left(\frac{4 \cdot \pi \cdot N}{365.2422}+1.474\right) \\
& +0.000062 \cdot \sin \left(\frac{12.37 \cdot 2 \cdot \pi \cdot N}{365.2422}+2.2\right)
\end{aligned}
$$

$\alpha$ is defined as follows:

$$
\sin (\alpha)=\sin (\delta) \cdot \sin (\varphi)+\cos (\delta) \cdot \cos (\varphi) \cdot \cos (\varpi)
$$

$\delta$ is the sun's declination, $\varpi$ is the hour angle and $(\varphi)$ is the latitude in degree.

$$
\begin{aligned}
& \delta=0.38+23.26 \cdot \sin \left(\frac{2 \cdot \pi \cdot N}{365.24}-1.395\right) \\
& +0.375 \cdot \sin \left(\frac{4 \cdot \pi \cdot N}{365.24}-1.47\right)
\end{aligned}
$$

where, $N$ is the rank of the day, beginning on $1^{\text {st }}$ January 2013 (for example, $N=32$ for the $1^{\text {st }}$ February 2013).

$$
\varpi=15 \times(T S-12)
$$

$T S$ is the solar time, it is defined as: 


$$
T S=T C F-c c+\frac{E}{60} \pm \frac{L o n}{15}
$$

$T C F$ is the civil time, $c c$ is the time difference comparing to GMT (in hour), $E$ is the equation of time and Lon is the longitude in degree.

The term (Lon/15) is taken negative in the East of Greenwich and positive in the west.

The formula of $E$ is:

$$
E=(C+R) \times 4
$$

$C$ is called the equation of the center and $R$ is the influence of obliquity.

$$
C=\frac{180}{\pi}\left[\begin{array}{l}
\left(2 \cdot e-\frac{1}{4} \cdot e^{3}\right) \cdot \sin (M a)+ \\
\frac{5}{4} \cdot e^{2} \cdot \sin (2 \cdot M a)+\frac{13}{12} \cdot e^{3} \cdot \sin (3 \cdot M a)
\end{array}\right]
$$

$$
M a=357.5291+0.98560028 \times N
$$

$e=0.1671$, is the eccentricity of the ellipse.

$$
R=\frac{180}{\pi}\left(\begin{array}{l}
-y^{2} \cdot \sin (2 \cdot L)+\frac{y^{4}}{2} \cdot \sin (4 \cdot L)- \\
\frac{y^{6}}{3} \cdot \sin (6 \cdot L)
\end{array}\right)
$$

where, $y=\tan \left(\frac{\varepsilon}{2}\right), \varepsilon$ is the tilt of the Earth axis, $\varepsilon=23.4372108769$, and $L$ is the true longitude, or ecliptic longitude of the Sun in degree. Its formula is:

$$
L=280.4665+C+0.98564736 \times N
$$


$10^{\text {TH }}$ International CONFEREnce on Sustainable Energy and Environmental Protection (June $27^{\mathrm{TH}}-30^{\mathrm{TH}}, 2017$, BlED, SLOVENIA), RENEWABLE ENERGY SOURCES Z. Boussaada, A. Remaci, O. Curea, H. Camblong \& N. Mrabet Bellaaj: Prediction of the Daily Direct Solar Radiation Using Nonlinear Autoregressive Exogenous (Narx) Network Model

Considering that, on the one hand, the solar radiation is a time series, and that, on the other hand, dynamic neural networks are good predictors of time series [2], [3], [4], our research study used NARX neural network model as technique of prediction. The non linear autoregressive network with exogenous inputs (NARX) is a recurrent dynamic neural network, with feedback connections enclosing several layers of the network. The NARX model is based on the linear ARX model, which is commonly used in time-series modeling.

In order to obtain the full performances of the NARX neural network for nonlinear time series prediction, it is interesting to use its memory ability using the past values of predicted or true time series.

As can be seen in Figure 1, there are two different architectures of NARX model, seriesparallel architecture and parallel architecture given by the equations (13) and (14) respectively.

$$
\begin{aligned}
& \hat{y}(t+1)=f\left(\begin{array}{l}
y(t), y(t-1), \ldots, y\left(t-n_{y}\right), x(t+1), \\
x(t), x(t-1), \ldots, x\left(t-n_{x}\right)
\end{array}\right) \\
& \hat{y}(t+1)=f\left(\begin{array}{l}
\hat{y}(t), \hat{y}(t-1), \ldots, \hat{y}\left(t-n_{y}\right), x(t+1), \\
x(t), x(t-1), \ldots, x\left(t-n_{x}\right)
\end{array}\right)
\end{aligned}
$$

where, $f($.$) is the mapping function of the neural network, \hat{y}(t+1)$ is the output of the NARX at the time $t$ for the time $t+1, \hat{y}(t), \hat{y}(t-1), \ldots, \hat{y}\left(t-n_{y}\right)$ are the past outputs of the NARX. $y(t), y(t-1), \ldots, y\left(t-n_{y}\right)$ are the true past values of the time series. $x(t+1), x(t), \ldots$, $x\left(t-n_{x}\right)$ are the inputs of the NARX, $\mathrm{n}_{\mathrm{x}}$ is the number of input delays and $\mathrm{n}_{\mathrm{y}}$ is the number of output delays.

In the series-parallel architecture, the future value of the time series $y(t+1)$ is predicted from the present and past values of $x(t)$ and the true past values of the time series $y(t)$. However in the parallel architecture the prediction is performed from the present and past values of $x(t)$ and the past predicted values of the time series $\hat{y}(t)$. Our research study considers the parallel architecture of NARX model. 


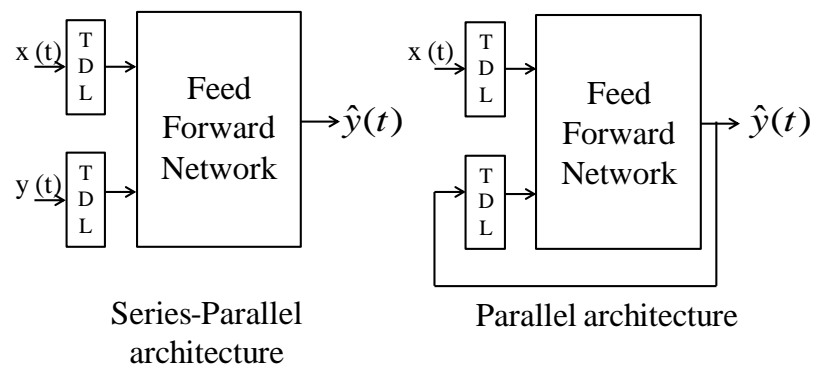

Figure 1. Architectures of NARX network

The mapping function $f($.$) is initially unknown and it is approximated during the training$ process of the prediction. In the NARX neural network model the internal architecture that performs this approximation is the Multi-Layer Perceptron (MLP). The MLP provides a powerful structure enable to learn any type of continuous nonlinear mapping. As seen in Figure 2, a typical MLP consists of an input, a hidden and an output layer. Other elements consist of neurons, transfer functions and weights. The direction of the information flow throughout the layers is from input to output layer. In each layer, each neuron multiplies the input vector $\mathrm{x}_{\mathrm{j}}$ given by the previous layer by the weights vector $\mathrm{w}_{\mathrm{ij}}$ to give the scalar product $\mathrm{x}_{\mathrm{j}} \mathrm{w}_{\mathrm{ij}}$. A transfer function $\mathrm{f}$ is then performed to obtain the output $y_{i}=\sum_{j=1}^{n} x_{j} \times w_{i j}$, where, $\mathrm{i}$ is the neuron index in the layer, and $\mathrm{j}$ is the input index in the neural network. The process of training consists in modifying the connection weights in an orderly way using a suitable algorithm. During the training process, an input and its desired output are introduced in the network and the weights are adjusted so that the neural network tries to produce the desired output. Another issue involved in the training phase is to find a globally optimal solution avoiding local minima. The principle is to initiate a number of random starting weights and to consider the one with the best value. 
$10^{\text {TH }}$ International Conference on Sustainable Energy and Environmental Protection (June $27^{\mathrm{TH}}-30^{\mathrm{TH}}, 2017$, Bled, SLovenia), Renewable EnERGy SOURCES Z. Boussaada, A. Remaci, O. Curea, H. Camblong \& N. Mrabet Bellaaj: Prediction of the Daily Direct Solar Radiation Using Nonlinear Autoregressive Exogenous (Narx)

Network Model
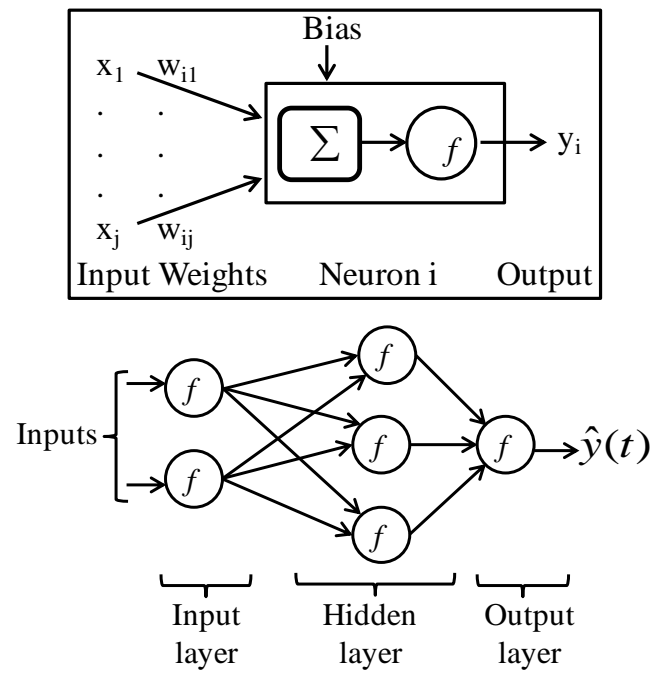

Figure 2. A MLP network (up) and details of a neuron (down)

\section{$4 \quad$ Data Description and Evaluation Criteria}

\subsection{Context and presentation of data}

The used dataset in this work consisted of:

- calculated clear sky direct solar radiation as described in section 2.

- the Cloud cover variable used as input of the neural network. It was downloaded from the website www.zygrib.org. It is the forecast of the cloud cover for a chosen number of days ahead in a defined surface. Data are spread with a step of $0.25^{\circ}$ in Latitude and Longitude, and with a step of 3 hours time interval. Thus, to obtain the cloud cover in the location of ESTIA every 5 minutes, a 2-D interpolation according to the latitude and the longitude and a 1-D interpolation according to the time were performed.

- the global solar radiation on horizontal surface. This parameter used as target of the neural network came from the weather station of ESTIA. It is measured each 5 minutes.

\subsection{Evaluation criteria}

In order to evaluate simulation results, two error criteria were used: Mean Square Error MSE and Daily Energy Error (in W) EE. 
Z. Boussaada, A. Remaci, O. Curea, H. Camblong \& N. Mrabet Bellaaj: Prediction of the Daily Direct Solar Radiation Using Nonlinear Autoregressive Exogenous (Narx)

$$
\begin{gathered}
M S E=\frac{\sum_{1}^{N}\left(y_{i}-\hat{y}_{i}\right)^{2}}{N} \\
E E=\frac{\sum_{1}^{N}\left(y_{i}-\hat{y}_{i}\right)}{N}
\end{gathered}
$$

where, $N$ is the number of pattern pairs, $y_{i}$ and $\hat{y}_{i}$ are the measured and predicted solar radiation of the $i$ th pattern pair respectively.

\section{$5 \quad$ Results and Discussions}

Several tests have been considered to select the database structure and the neural network configuration. It should be noted that before starting simulations the dataset was divided into three parts: training, testing and validation sets. The training phase uses the training set to compute the weights and bias of the neural network and the test set to test it. After finishing this phase the validation set is used to simulate the model and evaluate its performance. All simulations are performed using normalized dataset in order to adjust it and not to saturate the neurons.

\subsection{Choice of the dataset structure}

The first simulations of this research study were made using a set of test and training containing several days of the year in order to represent it. The prediction was performed for different days of the year. The MSE and the EE were in the order of 0.02 and 160 respectively. Thus, to obtain best performance the idea has been to repeat the training process one time per day to forecast solar radiation for one coming day.

Table 1. Choice of the test and training size of the database

\begin{tabular}{|l|c|c|}
\hline Database size & MSE & EE (W) \\
\hline 5 days & 0.011 & 60.228825 \\
\hline 10 days & 0.00695 & 41.19645 \\
\hline 15 days & 0.009625 & 50.2089 \\
\hline
\end{tabular}

As it can be seen in Table 1, the best result was obtained using a test and training set of 10 days. In this case, the MSE and the EE are 0.00695 and 41.19645 respectively.

The global solar radiation of the weather station was measured by a step of 5 minutes time interval. Therefore the interpolated cloud cover and the calculated direct solar radiation had the same time step interval. However the configured predictor is not meant 
$10^{\text {TH }}$ International CONFEREnce on Sustainable Energy and Environmental Protection (June $27^{\mathrm{TH}}-30^{\mathrm{TH}}, 2017$, Bled, SLOVENIA), RENEWABle ENERGY SOURCES Z. Boussaada, A. Remaci, O. Curea, H. Camblong \& N. Mrabet Bellaaj: Prediction of the Daily Direct Solar Radiation Using Nonlinear Autoregressive Exogenous (Narx) Network Model

to follow the rapid fluctuations of the measured solar radiation. Consequently, it is interesting to consider the average of this parameter as input of the neural network.

Moving averages of 10 and 30 minutes over intervals of one hour were performed. Prediction results were stored into Table 2.

Table 2. Choice of the time average of the database

\begin{tabular}{|c|c|c|}
\hline Time average & MSE & EE $(W)$ \\
\hline 10 minutes & 0.00732 & 44.4344 \\
\hline 30 minutes & 0.00695 & 41.19645 \\
\hline
\end{tabular}

From Table 2, it may be concluded that there was no a big difference between the two simulations results. Therefore for reasons of computing time optimization, the chosen interval average was 30 minutes.

\subsection{Choice of the neural network structure}

The second important step in the determination of the solar radiation predictor was to find the adequate neural network structure. Several simulations were performed in order to choose the different parameters of the NARX model. Due to the lack of the space, this part could not contain all results. Therefore some choices were presented in the Table 3, and only two parameters were presented: the choice of the neuron number in each layer and the use of weights in the different trainings.

Table 3. Parameters of the NARX model structure

\begin{tabular}{|l|l|}
\hline Property & Choice \\
\hline $\begin{array}{l}\text { Number of hidden } \\
\text { layers }\end{array}$ & 1 \\
\hline $\begin{array}{l}\text { Transfer functions in } \\
\text { each layer }\end{array}$ & $\begin{array}{l}\text { Input layer: Sigmoid } \\
\text { Hidden layer: Sigmoid } \\
\text { Output layer : Hyperbolic tangent }\end{array}$ \\
\hline $\begin{array}{l}\text { Normalization } \\
\text { Interval of dataset }\end{array}$ & {$[0.05 ; 0.95]$} \\
\hline Delay vectors & $\begin{array}{l}\text { Input data: [0 1] } \\
\text { Target: [1 2] }\end{array}$ \\
\hline Training parameters & $\begin{array}{l}\text { Error: MSE } \\
\text { Learning algorithm: Levenberg- } \\
\text { Marquardt }\end{array}$ \\
\hline
\end{tabular}

Table 4 presents the best results found when the number of neurons was varied in each layer of the NAX network. 
Table 4. Choice of the neurons number in the different layers

\begin{tabular}{|c|c|c|}
\hline Number of neurons & MSE & EE (W) \\
\hline $10 \times 10 \times 1$ & 0.00724 & 59.5724 \\
\hline $15 \times 15 \times 1$ & 0.00410 & 30.4164 \\
\hline $16 \times 16 \times 1$ & 0.01438 & 73.4646 \\
\hline $20 \times 20 \times 1$ & 0.00768 & 45.0513 \\
\hline $22 \times 22 \times 1$ & 0.00695 & 41.1964 \\
\hline
\end{tabular}

Table 3 shows that the best structure of neural network layers was obtained using 15 neurons in the input layer, 15 neurons in the hidden layer and 1 neuron in the output layer. The MSE and the EE were 0.00410 and $30.4164 \mathrm{~W}$ respectively.

These results were obtained using the same initial weights for all periodic trainings. In fact, the initial weights of the first training which predicted the first day were saved and used for other trainings. However, as shown in table 5, best performances were achieved when each periodic training started with weights initiated randomly by the neural network.

Table 5. Choice of registration of weights for periodic trainings

\begin{tabular}{|c|c|c|}
\hline $\begin{array}{c}\text { Registration } \\
\text { of weights }\end{array}$ & MSE & EE (W) \\
\hline Yes & 0.00410 & 30.4164 \\
\hline No & 0.00279 & 24.0584 \\
\hline
\end{tabular}

The best obtained error performance was 0.00279 for MSE and $24.0584 \mathrm{~W}$ for EE. The Figure 3 shows an example of predicted day using the obtained NARX model.

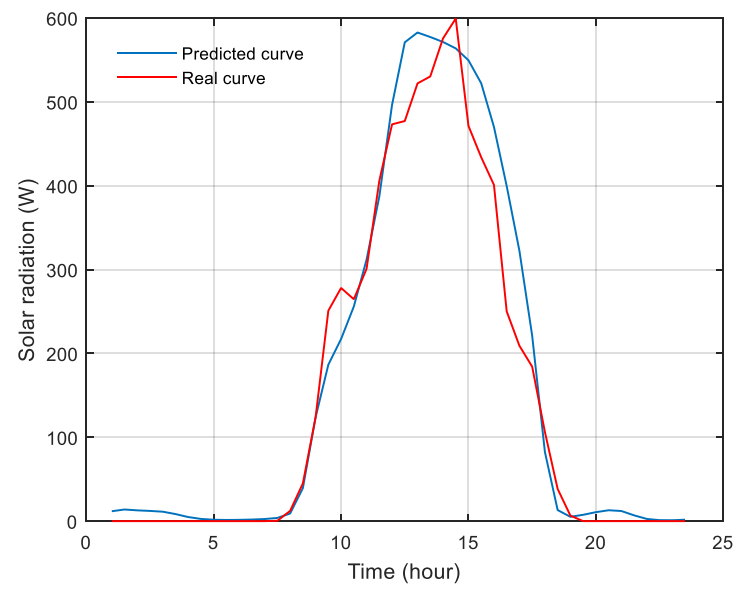

Figure 3. Predicted and 30 minutes average curves of direct solar radiation 
$10^{\text {TH }}$ International Conference on Sustainable Energy and Environmental Protection (June $27^{\mathrm{TH}}-30^{\mathrm{TH}}, 2017$, Bled, SLOVEnia), RENEWABle ENERGy SOURCES Z. Boussaada, A. Remaci, O. Curea, H. Camblong \& N. Mrabet Bellaaj: Prediction of the Daily Direct Solar Radiation Using Nonlinear Autoregressive Exogenous (Narx) Network Model

This paper proposed a NARX neural network model for direct solar radiation prediction on a horizontal surface. Several simulations varying different criteria were performed and evaluated using MSE and EE errors. First, this study focused on the choice of the dataset structure including the size and the time average of the database used for the training and testing phase. The second issue of the research was the determination of the neural network structure. Different criteria were varied, in particular the neurons number of each network layer and the way to choose the initial weights. The best results $(0.00279$ for MSE and $24.0584 \mathrm{~W}$ for EE) were obtained for: a dataset of 10 days with 30 minutes time interval, and a NARX model consisting of 15 neurons on the input and hidden layers, and random initialization of weights.

\section{References}

[1] W. Zhang, Zhao, Z. Bao, T. Han and L. Kong, "Short Term Wind Speed Forecasting for Wind Farms Using an Improved Auto regression Method," presented at the International Conference of Information Technology, Computer Engineering and Management Sciences, 24-25 Sept. 2011.

[2] C. Voyant, M. Muselli, C. Paoli, and M. Nivet, "Optimization of an artificial neural network dedicated to the multivariate forecasting of daily global radiation," Energy, vol. 36, pp. 348-359, 2011.

[3] S. Mohanty, and P.K. Patra, "Prediction of global solar radiation using nonlinear autoregressive network win exogenous inputs (narx)," presented at the 39 th National System Conference, 14-16 Dec. 2015.

[4] O. Assas, H. Bouzgou, S. Fetah, M. Salmi, and A. Boursas, "Use of the artificial neural network and meteorological data for predicting daily global solar radiation in Djelfa, Algeria," presented at the International Conference on Composite Materials \& Renewable Energy Applications (ICCMREA), Sousse, Tunisia, 22-24 Jan. 2014.

[5] H. Nazaripouya, B. Wang, Y. Wang, P. Chu, H.R. Pota, and R. Gadh, "Univariate time series prediction of solar power using a hybrid wavelet-ARMA-NARX Prediction Method,"presented at the IEEE/PES Transmission and Distribution Conference and Exposition (T\&D), Dallas, TX, USA, 3-5 May 2016.

[6] M. J. Reno, C. W. Hansen, and J. S. Stein "Global Horizontal Irradiance Clear Sky Models: Implementation and Analysis," Sandia Report Sand 2012-2389, Unlimited Release Printed, March 2012.

[7] F. Kasten "The linke turbidity factor based on improved values of the integral Rayleigh optical thickness," Solar Energy, num. 56(3), pp. 239-244, 1996.

[8] B. Molineaux, P. Ineichen, and O. N. Neill, "Equivalence of pyrheliometric and monochromatic aerosol optical depths at a single key wavelength," Applied Optics, num. 37(30), pp. 7008-7018, 1998.

[9] R. W. Mueller, K. F. Dagestad, P. Ineichen, M. Schroedter-Homscheidt, S. Cros, C. Reise, L. Wald and D. Heinemann "Rethinking satellite-based solar irradiance modelling: The SOLIS clear-sky module," Remote Sensing of Environment, num. 91(2), pp. 160-174, 2004.

[10] P. Ineichen "Comparison of eight clear sky broadband models against 16 independent data banks," Solar Energy, num. 80(4), pp. 468-478, 2006. 
$10^{\mathrm{TH}}$ InTERnATIONAL CONFERENCE ON Sustainable ENERgy AND ENVIRONMENTAL Protection (June $27^{\mathrm{TH}}-30^{\mathrm{TH}}$, 2017, Bled, SLOVENIA), RENEWABLE ENERGy SOURCES J. Krope, A.Ghani Olabi, D. Goričanec \& S. Božičnik

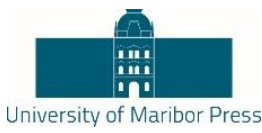

\title{
Angular Speed Control of an Induction Motor Via a Solar Powered Boost Converter-Voltage Source Inverter Combination
}

\author{
JESÚS LiNARES-FLORES, RODRIGO LESCAS-HERNÁNDEZ, JOSÉ F. GUERRERO- \\ Castellanos, Gerardo Mino-Aguilar, HebertT Sira-Ramírez, Arturo \\ HERNÁNDEZ-MÉNDEZ \& MARCO ANTONIO CONTRERAS ORDAZ
}

\begin{abstract}
This paper proposes a maximum power point tracking (MPPT) algorithm for a three-phase induction motor speed drive. The three-phase power inverter is fed by a Dc-to-Dc boost power converter, which is powered by PV Solar Panels. The input and output average power of boost converter is regulated by means of MPPT algorithm, which is based on the exact static error dynamics passive output feedback controller technique, and an algebraic estimator to estimate the impedance that exists between the boost converter and the three-phase inverter. The speed-tracking controller of the induction motor is based on the current-command field-oriented control technique. Experimental results at low-speed, with and without load, are presented to show the effectiveness and robustness of the MPPT proposed scheme.
\end{abstract}

Keywords: • MPPT Algorithm • Speed Drive Induction Motor • Algebraic Estimator • Field Oriented Control $\bullet$ solar powered $\bullet$

CoRRESPONDENCE AdDREss: Jesús Linares-Flores, Ph.D., Professor-Research, Instituto de Electrónica y Mecatrónica (IEM), Universidad Tecnológica de la Mixteca (UTM), Km. 2.5 Carretera Acatlima, Huajuapan de León, Oaxaca, México, e-mail: jlinaresflo@ gmail.com. Rodrigo Lescas-Hernández, M.Sc., Graduate of Electronic Master of Science, UTM, Km. 2.5 Carretera Acatlima, Huajuapan de León, Oaxaca, México, e-mail: rodrigolescas@hotmail.com. José F. Guerrero-Castellanos, Ph.D., Professor, Benemérita Universidad Autónoma de Puebla (BUAP), Facultad de Ciencias de la Electrónica (FCE), Ciudad Universitaria, Puebla, Puebla, México, email: fermi.guerrero@ correo.buap.mx. Gerardo Mino-Aguilar, Ph.D., Associate Professor, BUAP, FCE, Ciudad Universitaria, Puebla, Puebla, México, e-mail: gerardo.mino@correo.buap.mx. Hebertt Sira-Ramírez, Ph.D., Professor-Research, Cinvestav-Mecatronica, Av. Instituto Politécnico Nacional No. 2508, CDMX, e-mail: hsira@ cinvestav.mx. Arturo Hernández-Méndez, Unidad de Postgrado, UTM, Km. 2.5 Carretera Acatlima, Huajuapan de León, Oaxaca, México, email: arturohm54@mixteco.utm.mx. Marco Antonio Contreras-Ordaz, Ph.D., Professor-Research, Instituto de Electrónica y Mecatrónica (IEM), Universidad Tecnológica de la Mixteca (UTM), Km. 2.5 Carretera Acatlima, Huajuapan de León, Oaxaca, México, e-mail: marco.contreras@mixteco.utm.mx. 
$10^{\text {TH }}$ InTERnAtional CONFERENCE ON Sustainable ENERGy AND ENVIRONMENTAL Protection (June $27^{\mathrm{TH}}-30^{\mathrm{TH}}, 2017$, Bled, SLOVENIA), RENEWABle ENERGY SOURCES J. Linares-Flores, R. Lescas-Hernández, J. F. Guerrero-Castellanos, G. Mino-Aguilar, H. Sira-Ramírez, A. Hernández-Méndez \& M. Antonio Contreras Ordaz: Angular Speed Control of an Induction Motor Via a Solar Powered Boost Converter-Voltage Source Inverter Combination

\section{Introduction}

Photovoltaic (PV) systems produce a significant amount of the electrical energy used all over the world. PV technology will be capable of offering a great deal of support in the future to the rate of growth of advanced economies as well as developing countries [1]. On the other hand, grid-connected PV systems have gained popularity due to the feed-intariff and the reduction of battery cost. However, the intermittent PV generation varies with changes in atmospheric conditions. Maximum power point tacking (MPPT) techniques are used to deliver maximum power into the grid, micro-grid, and speed electric drive. Efficient control schemes are essential to operate with the environmental changes for the extraction of maximum power from the PV units [1]. There are many works on MPPT for PV applications [2], for instance, the Perturb and Observe Methods [3], [4] and incremental conductance methods [5] are commonly used in the community of PV system. In the PO method, the derivative of power, i.e., dp, and the derivative of voltage, i.e., $\mathrm{dv}$, require to be measured to determine the movement of the operating point. If the ratio of $\mathrm{dp}$ and $\mathrm{dv}$ is positive, the reference voltage is increased by a certain amount and vice-versa [4]. In the incremental conductance method, MPPT is achieved by comparing incremental conductance and instantaneous conductance of the PV arrays [5].

Recently some works have proposed control techniques for the three-phase induction motor using as power source a photovoltaic solar panel in an insulated grid [6]-[8], where a great interest is fixed on applications of electric water pumping [8]. This fact has motived and pushed the research developed and presented in this work.

The rest of the paper is organized as following. The section 2 introduces the problem statement. In Section 3 the system modelling, and controller design are presented. Section 4 is devoted to the experimental setup. Section 5 shows the performance of the proposed controllers. Section 6 provides the conclusions and future work.

\section{$2 \quad$ Problem Statement}

The main objective of the article is to smoothly start an induction machine using the power from a PV array. Thus, a DC-DC boost power converter combine with a DC-AC inverter to transfer the power efficiently from the panel to the induction motor using a MPPT method. This MPPT method is based on the exact static error dynamics passive output feedback (ESEDPOF) controller technique [9], and an algebraic estimator [10] to estimate the impedance between the boost converter and the DC-AC inverter. This method is in the spirit of the incremental conductance method for the extraction of maximum power from the PV units [5]. 


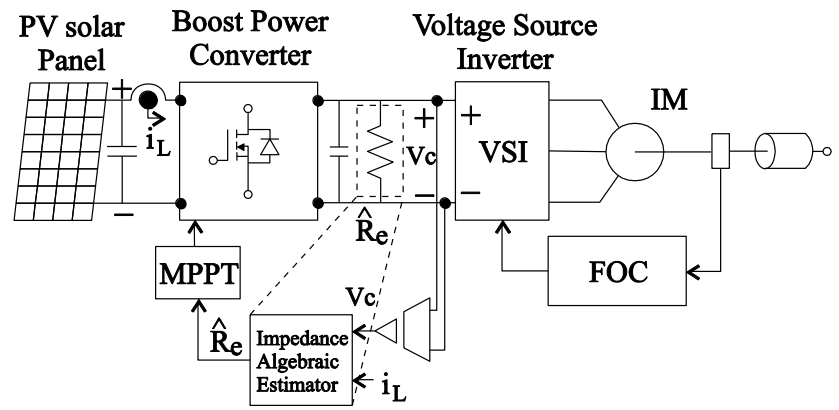

Figure 1. Proposed system's block diagram.

Fig. 1 shows the proposed system, which consists of a solar panel array followed by a power electronics interface that regulates the induction motor angular speed of smooth form. The system can see as a black box, where the input power source is the PV solar panel array and the output power source is the induction motor. To maximize the available power in the PV, a maximum power point tracker (MPPT) will be implemented.

To maximize the available power provided by the PV array, an algorithm based on the ESEDPOF technique is used together with an impedance algebraic estimator. The impedance estimated is adapted on line to the constant desired references of the MPPT controller. Thanks to the impedance estimation, it is possible to separate the PV-boost power converter model of the general model that includes to the induction motor model. Thus, one can easily design two controllers by each subsystem, that is, one for the PVboost power converter and the other for the DC-AC-inverter/induction motor.

\section{$3 \quad$ Photovoltaic System Model}

We consider the induction motor drive circuit, which is powered by PV solar panel array, this is shown in Figure 2. The IM drive system is composed of a cascade arrangement of the DC-AC inverter and the DC-to-DC boost power converter. The induction motor drive system is described by the set of differential equations, where the dynamics of a $\mathrm{n}_{\mathrm{p}}$ polepair two-phase induction motor, were obtained of a three phase motor. Thus, we have the following model dynamic

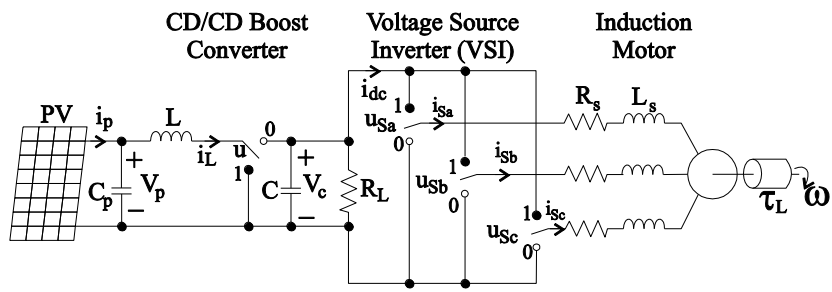

Figure 2. Induction motor drive powered via a PV solar panel array. 
J. Linares-Flores, R. Lescas-Hernández, J. F. Guerrero-Castellanos, G. Mino-Aguilar, H. Sira-Ramírez, A. Hernández-Méndez \& M. Antonio Contreras Ordaz: Angular Speed Control of an Induction Motor Via a Solar Powered Boost Converter-Voltage Source Inverter Combination

$$
\begin{aligned}
& C_{p} \frac{d v_{p}}{d t}=-i_{L}+i_{p} \\
& L \frac{d i_{L}}{d t}=-v_{C} u+v_{p} \\
& C \frac{d v_{C}}{d t}=i_{L} u-\left(\frac{v_{C}}{R_{L}}\right)-\left(i_{S a} u_{S a}+i_{S b} u_{S b}\right) \\
& L_{S} \frac{d i_{S a}}{d t}=\eta \beta \psi_{R a} L_{S}+\beta n_{p} L_{S} \omega \psi_{R b}-\gamma L_{S} i_{S a}+\frac{v_{C} u_{S a}}{\sigma} \\
& L_{S} \frac{d i_{S b}}{d t}=\eta \beta \psi_{R b} L_{S}-\beta n_{p} L_{S} \omega \psi_{R a}-\gamma L_{S} i_{S b}+\frac{v_{C} u_{S b}}{\sigma} \\
& \frac{d \psi_{R a}}{d t}=-\eta \psi_{R a}-n_{p} \omega \psi_{R b}+\eta M i_{S a} \\
& \frac{d \psi_{R b}}{d t}=-\eta \psi_{R b}+n_{p} \omega \psi_{R a}+\eta M i_{S b} \\
& J \frac{d \omega}{d t}=\mu J\left(i_{S b} \psi_{R a}-i_{S a} \psi_{R b}\right)-f \omega-\tau_{L}
\end{aligned}
$$

$\mathrm{v}_{\mathrm{p}}$ represents the voltage variable of the solar panel, $\mathrm{i}_{\mathrm{L}}$ is the inductor current and $\mathrm{v}_{\mathrm{C}}$ is the output capacitor voltage; $i_{p}$ is the output current of the solar panel, which is seen as an input of perturbation. The control input $\mathrm{u}$, representing the switch position function, is a discrete value signal taking values in the set $\{0,1\}$. The boost converter system parameters are constituted by: $\mathrm{L}$, which is the inductance of the input circuit; $\mathrm{C}_{\mathrm{p}}$ the capacitance of the input circuit, which ensures that the PV panel works as a DC voltage source; $\mathrm{R}_{\mathrm{L}}$ is the load output resistance. The detailed model of an unsaturated induction motor, which is connected in cascade to boost converter, where its variables and parameters in the a-b coordinates are given by: stator currents $\left(\mathrm{i}_{\mathrm{Sa}}, \mathrm{i}_{\mathrm{Sb}}\right)$, rotor fluxes $\left(\psi_{R a}\right.$ ,$\left.\psi_{R b}\right)$, and rotor speed $\omega$ are the states; rotor inertia $\mathrm{J}$, stator and rotor inductances $\left(\mathrm{L}_{\mathrm{S}}\right.$, $\left.L_{R}\right)$, stator and rotor resistances $\left(R_{S}, R_{R}\right)$, mutual inductance $M$, number of pole pairs $n_{p}$, load torque $\tau_{L}$, viscous friction $f$, with $\eta=R_{R} / L_{R}, \sigma=1-M^{2} / L_{S} L_{R}, \quad \mu=n_{p} M / J L_{R}$, $\gamma=\left(\mathrm{M}^{2} \mathrm{R}_{\mathrm{R}} / \sigma \mathrm{L}_{\mathrm{R}} \mathrm{L}_{\mathrm{S}}\right)+\mathrm{R}_{\mathrm{S}} / \sigma \mathrm{L}_{\mathrm{S}}$ are the IM parameters. While, $\left(\mathrm{u}_{\mathrm{Sa}}, \mathrm{u}_{\mathrm{Sb}}\right)$ are the inputs of control. 


\subsection{MPPT algorithm design based on ESEDPOF controller}

The average state model of the solar powered boost power converter circuit, the switch position function $\mathrm{u}$ with the duty radio function, denoted by $\mathrm{u}_{\mathrm{av}}$, which is now a function restricted to take values in the closed interval $[0,1]$. Figure 3 shows the demand current in the boost converter output node, which is viewed as the division between the boost output voltage and the impedance estimated value, i.e., $\mathrm{v}_{\mathrm{c}} / \mathrm{R}_{\mathrm{e}}$. Where, this value represents the equivalent impedance obtains of the parallel connection between the boost output load and the impedance load produced by the three-phase inverter/induction motor. Thus, we obtain the following decoupled average model

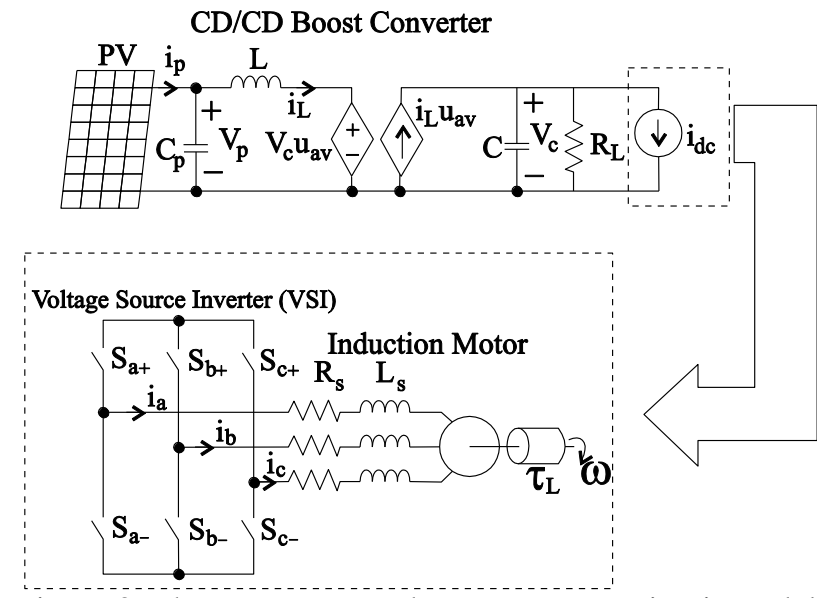

Figure 3. The average PV-boost converter circuit model.

$$
\begin{aligned}
& C_{p} \frac{d v_{p}}{d t}=-i_{L}+i_{p} \\
& L \frac{d i_{L}}{d t}=-v_{C} u_{a v}+v_{p} \\
& C \frac{d v_{C}}{d t}=i_{L} u_{a v}-\underbrace{\left(\frac{v_{C}}{R_{L}}+i_{d c}\right)}_{:=\left(\frac{v_{C}}{R_{e}}\right)}
\end{aligned}
$$

$y=v_{C}$

From (2), we design the ESTEDPOF controller based on [9] and [10], thus we obtain the MPPT control law 

$10^{\text {TH }}$ International CONFEREnce on Sustainable Energy and Environmental Protection (June $27^{\mathrm{TH}}-30^{\mathrm{TH}}, 2017$, Bled, SLOVENIA), RENEWABle ENERGy SOURCES J. Linares-Flores, R. Lescas-Hernández, J. F. Guerrero-Castellanos, G. Mino-Aguilar, H. Sira-Ramírez, A. Hernández-Méndez \& M. Antonio Contreras Ordaz: Angular Speed Control of an Induction Motor Via a Solar Powered Boost Converter-Voltage Source Inverter Combination

$u_{a v}=\overline{u_{a v}}-\gamma \overline{i_{L}}\left(v_{C}-\overline{v_{C}}\right)+\gamma \overline{v_{C}}\left(i_{L}-\overline{i_{L}}\right)-\left(i_{p}-\overline{i_{p}}\right)$

where, $\gamma>0$ is the control gain, and $\overline{u_{a v}}$ is the nominal input control value corresponding to the nominal state value, $\bar{x}=\left(\overline{v_{p}}, \overline{i_{L}}, \overline{v_{C}}\right)^{T}=\left(\mathrm{V}_{\mathrm{MPP}}, \mathrm{V}_{\mathrm{d}}^{2} / \mathrm{V}_{\mathrm{MPP}} \mathrm{R}_{\mathrm{e}}, \mathrm{V}_{\mathrm{d}}\right)^{T} \in R^{3}$, notice that the nominal value, $\overline{v_{p}}$, is the Maximum Power Point voltage given by Solar Panel datasheet. Therefore, it is very important to know the value of the output impedance of the boost power converter, especially, when this converter is connected to the three phase inverter together with the induction motor. In order to set the controller's equilibrium points at the maximum power point of the solar panel. Thus, we are going to design an algebraic estimator for the output impedance of the boost power converter.

\subsection{Algebraic estimator design of the output impedance of the boost converter}

The definition of identifiability of Diop and Flies [11], about algebraically identifiable parameters, is applied in linear systems. However, for the nonlinear case and if differentiations are forbidden, it is necessary to know the input, possibly the output, and several components in the state vector. In the case of the boost power converter, we know the state variables $\left(i_{L}, v_{C}\right)$, which solve the problem of identifying parameters in an algebraic way. The algebraic methodology requires a rather precise knowledge of the model of the plant as in every identification scheme.

The equation (2) represents the most precise available model of the plant. Assume then that $C$ is known nominal constant, the states $i_{L}$ and $v_{C}$ are measurable, and $R_{e}$ is unknown time-varying quantity. The procedure uses small calculation windows starting at the resetting time $t_{K}$ and lasting for $\varepsilon$ units of time, where $R_{e}$ can be considered nearly constant.

$$
C \frac{d v_{C}}{d t}=i_{L} u_{a v}-\left(\frac{v_{C}}{R_{e}}\right)
$$

Under these assumptions we multiplying both sides of (4) by (t- $\left.t_{k}\right)$, integrating by parts with respect to time on the interval $\left[t_{k}, t\right]$, and solving for $R_{e}$, we have

$$
R_{e}=\left\{\begin{array}{lrr}
R_{L}\left(t_{k-1}\right) & \text { for } & t \in\left[t_{k}, t_{k}+\in\right] \\
\frac{\eta_{2}\left(t_{k}+\varepsilon\right)}{d_{2}\left(t_{k}+\varepsilon\right)} & \text { for } & t_{k}+\in<t \leq t_{k+1}
\end{array}\right.
$$

where, 


$$
\begin{aligned}
& \eta_{2}(t)=\int_{t_{k}}^{t}\left(\sigma-t_{k}\right) v_{C}(\sigma) d \sigma \\
& d_{2}(t)=-C\left(t-t_{k}\right) v_{C}(t)+C \int_{t_{k}}^{t} v_{C}(\sigma) d \sigma \\
& +\int_{t_{k}}^{t}\left(\sigma-t_{k}\right)\left(1-u_{a v}(\sigma)\right)_{L}(\sigma) d \sigma
\end{aligned}
$$

The $\mathrm{R}_{\mathrm{e}}$ calculation is resetting periodically at the end of a time interval $\mathrm{T}$ of short duration. Subsequently the calculations are performed in a different interval $t_{k}=k T$. The "resetting" interval $\mathrm{T}$ should be initially adjusted to the expected time scale of the expected changes of the load. The amount $\varepsilon$ is the time required for the value of the integral terms of (5) to grow sufficiently to have a quotient as accurate as possible. The magnitude of $\varepsilon$ is relatively small in comparison with that of $\mathrm{T}[12]$.

\subsection{Current command field oriented control for the induction motor}

For field-oriented control, the new coordinate system is a rotating system whose angular position is defined by

$$
\rho=\tan ^{-1}\left(\frac{\psi_{R b}}{\psi_{R a}}\right)
$$

That is, instead of working with $\left(\psi_{R a}, \psi_{R b}\right)$, one uses the polar coordinate representation $\left(\rho, \psi_{\mathrm{d}}\right)$ given by [13]. Thus, the direct rotor field flux is given by

$$
\psi_{d}=\sqrt{\psi_{R a}^{2}+\psi_{R b}^{2}}
$$

The phase currents and voltages are then transformed into the new coordinate system as

$$
\left[\begin{array}{l}
i_{d} / u_{d} \\
i_{q} / u_{q}
\end{array}\right]=\left[\begin{array}{cc}
\cos (\rho) & \sin (\rho) \\
-\sin (\rho) & \cos (\rho)
\end{array}\right]\left[\begin{array}{l}
i_{S a} / u_{S a} \\
i_{S b} / u_{S b}
\end{array}\right]
$$

The desired reference trajectories are given by: 
$10^{\mathrm{TH}}$ International Conference on Sustainable EnERgy and Environmental Protection (June $27^{\mathrm{TH}}-30^{\mathrm{TH}}, 2017$, Bled, SLOVENIA), RENEWABle ENERGy SOURCES J. Linares-Flores, R. Lescas-Hernández, J. F. Guerrero-Castellanos, G. Mino-Aguilar, H. Sira-Ramírez, A. Hernández-Méndez \& M. Antonio Contreras Ordaz: Angular Speed Control of an Induction Motor Via a Solar Powered Boost Converter-Voltage Source Inverter Combination

$$
\begin{aligned}
& i_{d r}=K_{\psi 0} \int_{0}^{t}\left(\psi_{r e f}-\psi_{d}\right) d t+K_{\psi 1}\left(\psi_{r e f}-\psi_{d}\right) \\
& i_{q r}=K_{0} \int_{0}^{t}\left(\omega_{r e f}-\omega\right) d t+K_{1}\left(\omega_{r e f}-\omega\right)+K_{2}\left(\frac{d \omega_{r e f}}{d t}-\omega\right)+(f / J) \omega
\end{aligned}
$$

The trajectory of $\psi_{\text {ref }}$ is calculated through a constant value given by: $\psi_{\text {ref }}=\psi_{d 0} \frac{\omega_{\text {base }}}{\omega}$,

where, $\omega_{\text {base }}$ is the nominal speed of induction motor, $\omega$ is the real speed, and $\psi_{\mathrm{d} 0}$ is the initial rotor field flux. While the desired reference trajectory of the angular speed is calculated through a Bezier polynomial of tenth order:

$$
\omega_{\text {ref }}=\left\{\begin{array}{l}
\overline{\omega_{i n i}} \quad t<t_{0} \\
\overline{\omega_{i n i}}+\left(\overline{\omega_{\text {fni }}}-\overline{\omega_{\text {ini }}}\right) p\left(t, t_{0}, T\right) \quad t_{0} \leq t \leq T \\
\overline{\overline{\omega_{\text {fin }}}} \quad t \geq T
\end{array} \quad t \geq T\right.
$$

where, the polynomial $\mathrm{p}\left(\mathrm{t}, \mathrm{t}_{0}, \mathrm{~T}\right)$ has to interpolate between the zero and one values for $\mathrm{t}$ $\in\left(\mathrm{t}_{0}, \mathrm{~T}\right)$ of the following form

$$
\begin{aligned}
& p\left(t, t_{0}, T\right)=r_{1}\left(\frac{t-t_{0}}{T-t_{0}}\right)^{5}+r_{2}\left(\frac{t-t_{0}}{T-t_{0}}\right)^{6}+r_{3}\left(\frac{t-t_{0}}{T-t_{0}}\right)^{7}+ \\
& r_{4}\left(\frac{t-t_{0}}{T-t_{0}}\right)^{8}+r_{5}\left(\frac{t-t_{0}}{T-t_{0}}\right)^{9}+r_{6}\left(\frac{t-t_{0}}{T-t_{0}}\right)^{10}
\end{aligned}
$$

with, $\mathrm{r}_{1}=252, \mathrm{r}_{2}=1050, \mathrm{r}_{3}=1800, \mathrm{r}_{4}=1575, \mathrm{r}_{5}=700$ and $\mathrm{r}_{6}=126$.

The quantity $\psi_{\mathrm{d}}$ is referred to as the magnitude of the rotor field flux, while $\rho$ is the angle of the rotor field flux. This coordinate system is one that is moving (oriented) with this field flux and thus is called the rotor-flux field oriented coordinate system. The currents $i_{d}$ and $\mathrm{i}_{\mathrm{q}}$, are called the direct and quadrature currents, respectively. Similarly, the voltages $u_{d}$ and $u_{q}$, are called the direct and quadrature voltages, respectively. The rotation matrix used in (7) and (8) is called the direct quadrature or d-q transformation. Thus, the mathematical model of the induction motor in which $\omega, i_{d}, \mathrm{i}_{\mathrm{q}}, \psi_{\mathrm{d}}$ and $\rho$ are the state variables, and the inputs are $u_{d}$ and $u_{q}$ is now developed. Where, these two inputs are given by: $u_{d}=v_{C} u_{d}^{*}$ and $u_{q}=v_{C} u_{q}^{*}$. Which have a direct dependency of the output voltage of the boost power converter, due to connection between the boost converter with 
the voltage source inverter. Therefore, the decoupled model of induction motor is given as follow

$$
\begin{aligned}
& \frac{d i_{d}}{d t}=-i_{d}+\left(\eta M / \sigma L_{S} L_{R}\right) \psi_{d}+n_{p} \omega i_{q}+\eta M i_{q}^{2} / \psi_{d}+\frac{u_{d}}{\sigma L_{s}} \\
& \frac{d i_{q}}{d t}=-i_{q}+\left(M / \sigma L_{R} L_{S}\right) n_{p} \omega \psi_{d}-n_{p} \omega i_{d}-\eta M i_{d} i_{q}+\frac{u_{q}}{\sigma L_{S}} \\
& \frac{d \psi_{d}}{d t}=-\eta \psi_{d}+\eta M i_{d} \\
& \frac{d \omega}{d t}=\mu \psi_{d} i_{q}-(f / J) \omega-(1 / J) \tau_{L} \\
& \frac{d \rho}{d t}=n_{p} \omega+\eta M i_{q} / \psi_{d}
\end{aligned}
$$

From (9), we design a current-command control, one can choose,

$$
\begin{aligned}
& u_{d}=K_{d I} \int_{0}^{t}\left(i_{d r}-i_{d}\right) d t+K_{d P}\left(i_{d r}-i_{d}\right) \\
& u_{q}=K_{q I} \int_{0}^{t}\left(i_{q r}-i_{q}\right) d t+K_{q P}\left(i_{q r}-i_{q}\right)
\end{aligned}
$$

\section{Experimental Setup Of the Three-Phase Induction Motor Speed Drive}

The experimental platform is divided into two subsystems. In the first subsystem we use a DC-DC Boost power converter, powered by a PV array (PV-Converter system). In this subsystem we design a first controller that ensures the MMPT in the PV array. In the second subsystem we implemented a Voltage Source Inverter (VSI), connected to an induction motor (VSI-Motor system), where a second controller is applied, in order to track the desired speed trajectory in the induction motor. Both subsystems are coupled as is shown in Figure 5.

The PV-Boost convert subsystem employees an array of two PV panels in serial connection. The ESEDPOF controller is implemented in the TMS320F28335 DSP board and the FOC control is implemented in a dSPACE CLP1104 DSP board. The parameters values of the PV array, the Boost converter and the induction motor are summarized in the Table 1 . 
$324 \mid 10^{\text {TH }}$ InTERnAtional CONFERENCE ON Sustainable ENERGy AND ENVIRONMENTAL Protection (June $27^{\mathrm{TH}}-30^{\mathrm{TH}}, 2017$, Bled, SLovenia), RenEwable ENERGy SOURCES J. Linares-Flores, R. Lescas-Hernández, J. F. Guerrero-Castellanos, G. Mino-Aguilar, H. Sira-Ramírez, A. Hernández-Méndez \& M. Antonio Contreras Ordaz: Angular Speed Control of an Induction Motor Via a Solar Powered Boost Converter-Voltage Source Inverter Combination

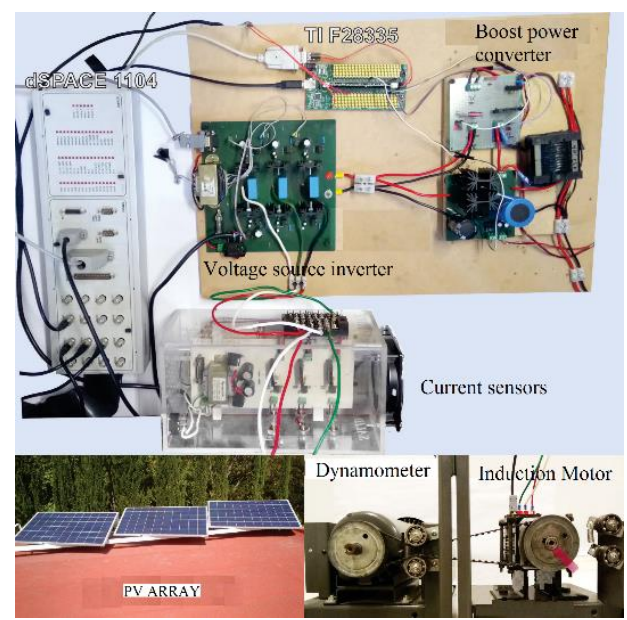

Figure 5. Experimental setup.

Table 1. PV, Boost converter and induction motor parameters

\begin{tabular}{|c|c|c|c|c|c|c|}
\hline \multicolumn{5}{|c|}{ Description } & \multicolumn{2}{|c|}{ Nominal value } \\
\hline \multicolumn{7}{|c|}{$P V$} \\
\hline \multicolumn{5}{|c|}{ Maximal nominal power $\left(\mathrm{P}_{\max }\right)$} & \multicolumn{2}{|l|}{$260 \mathrm{~W}$} \\
\hline \multicolumn{5}{|c|}{$\mathrm{P}_{\max }$ current } & \multicolumn{2}{|l|}{$8.37 \mathrm{~A}$} \\
\hline \multicolumn{5}{|c|}{$\mathrm{P}_{\max }$ voltage } & \multicolumn{2}{|l|}{$31.1 \mathrm{~V}$} \\
\hline \multicolumn{5}{|c|}{ Short circuit current } & \multicolumn{2}{|l|}{$8.98 A$} \\
\hline \multicolumn{5}{|c|}{ Short circuit voltage } & \multicolumn{2}{|l|}{$38.1 \mathrm{~V}$} \\
\hline \multicolumn{5}{|c|}{ Standart irradiation } & \multicolumn{2}{|l|}{$1000 \mathrm{~W} / \mathrm{m}^{2}$} \\
\hline \multicolumn{5}{|c|}{ Standart temperature } & \multicolumn{2}{|l|}{$25^{\circ} \mathrm{C}$} \\
\hline \multicolumn{7}{|c|}{ Boost converter } \\
\hline \multicolumn{5}{|c|}{ Input Capacitor $C_{p}$} & \multicolumn{2}{|l|}{$1000 \mu F$} \\
\hline \multicolumn{5}{|c|}{ Inductor $L$} & \multicolumn{2}{|l|}{$48.1 \mu H$} \\
\hline \multicolumn{5}{|c|}{ Output Capacitor $C$} & \multicolumn{2}{|l|}{$460 \mu F$} \\
\hline \multicolumn{5}{|c|}{ Load resistance $R_{L}$} & \multicolumn{2}{|l|}{$102 \Omega$} \\
\hline \multicolumn{7}{|c|}{ Induction motor (AMK DV 4-1-4) } \\
\hline $\begin{array}{l}V_{N} \\
{[V]}\end{array}$ & \begin{tabular}{|l|}
$M_{N}$ \\
{$[N m]$}
\end{tabular} & $\begin{array}{l}P_{N} \\
{[K w]}\end{array}$ & \begin{tabular}{|l|}
$I_{N}$ \\
{$[A]$}
\end{tabular} & \begin{tabular}{|l|}
$n_{N}$ \\
{$[1 / \mathrm{min}]$}
\end{tabular} & $\begin{array}{l}J \\
{\left[\mathrm{kgm}^{2}\right]}\end{array}$ & \begin{tabular}{|l|}
$M$ \\
{$[\mathrm{~kg}]$}
\end{tabular} \\
\hline 190 & 0.8 & 0.32 & 2.5 & 1800 & $0.09 \mathrm{E}-3$ & 4.5 \\
\hline
\end{tabular}

\section{$5 \quad$ Experimental Results}

Firstly the ESEDPOF controller performance is analysed. Reference values, constants and characteristics of the experimental setup are shown in Table 2. The estimation of output impedance in the boost converter is shows in Figure 10. When, the motor speed is 
$\omega=0 \mathrm{rad} / \mathrm{s}$, the estimated resistor has a high value. During the tracking trajectory ( $2 \mathrm{~s}$ to $6 \mathrm{~s}$ ), this value decreases. And in $t=7 \mathrm{~s}$, it value decreases again due to the load torque applied.

Table 2. Values used in the ESEDPOF controller.

\begin{tabular}{|l|l|}
\hline \multicolumn{1}{|c|}{ Description } & \multicolumn{1}{c|}{ Nominal value } \\
\hline$V_{M P P}$ reference & $26.75 \mathrm{~V}$ \\
\hline$I_{M P P}$ reference & $7.80 \mathrm{~A}$ \\
\hline$P W M_{I}$ Frequency & $300 \mathrm{kHz}$ \\
\hline$R_{L}$ & $250 \Omega$ \\
\hline Temperature & $27.5^{\circ} \mathrm{C}$ \\
\hline Irradiance & $920 \mathrm{~W} / \mathrm{m}^{2}$ \\
\hline$\gamma$ & 0.5 \\
\hline
\end{tabular}

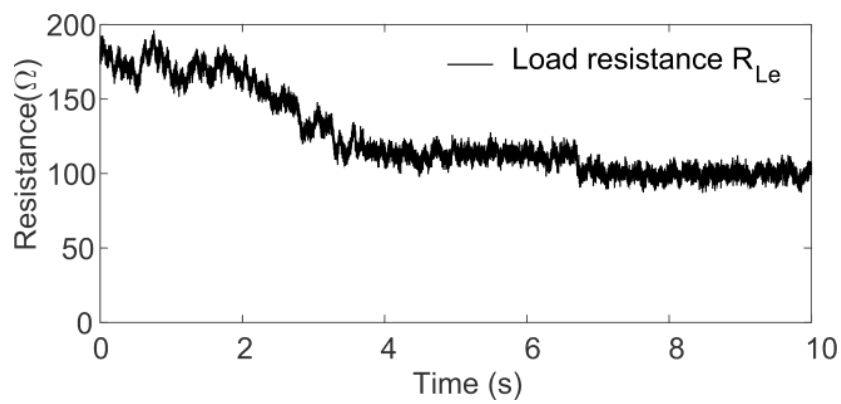

Figure 6. Load resistance estimation.

Figure 7 shows the input voltage $v_{p}$, and the inductor current $i_{L}$ responses, for the MPPT tracking trajectory. In the case of the FOC controller, we used the parameters and characteristics given by the Table 3 . Figure 8 -a) shows the angular speed tracking response. Figure 8-b) shows the angular speed error, during the trajectory tracking. It is around $0.5 \mathrm{rad} / \mathrm{s}$. 
$326 \quad 10^{\mathrm{TH}}$ International CONFERENCE on Sustainable ENERgy AND ENVIRONMENTAL Protection (June $27^{\mathrm{TH}}-30^{\mathrm{TH}}, 2017$, Bled, SLOVENIA), RENEWABLE ENERGY SOURCES J. Linares-Flores, R. Lescas-Hernández, J. F. Guerrero-Castellanos, G. Mino-Aguilar, H. Sira-Ramírez, A. Hernández-Méndez \& M. Antonio Contreras Ordaz: Angular Speed Control of an Induction Motor Via a Solar Powered Boost Converter-Voltage Source Inverter Combination
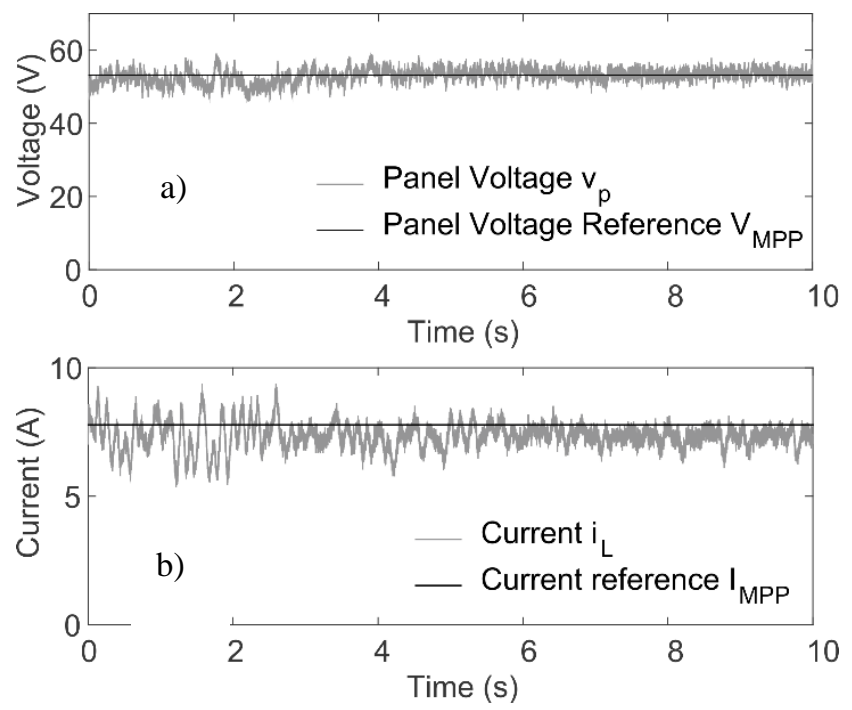

Figure 7. a) Input voltage response, and b) inductor current response for the Maximum Power Point Tracking.

Table 3. Important values to FOC controller.

\begin{tabular}{|c|c|c|c|c|c|}
\hline \multicolumn{5}{|c|}{$\begin{array}{r}\text { Description } \\
\end{array}$} & Nominal value \\
\hline \multicolumn{5}{|c|}{ Initial speed $(\omega)$} & $0 \mathrm{rad} / \mathrm{s}$ \\
\hline \multicolumn{5}{|c|}{ Final speed $(\omega)$} & $100 \mathrm{rad} / \mathrm{s}$ \\
\hline \multicolumn{5}{|c|}{ Initial time $(t)$} & $2 s$ \\
\hline \multicolumn{5}{|c|}{ Final time $(t)$} & \\
\hline \multicolumn{5}{|c|}{ PWM frequency } & $100 \mathrm{kHz}$ \\
\hline \multirow{2}{*}{\multicolumn{6}{|c|}{$\begin{array}{l}\text { Torque } \\
\text { Currents controller constants }\end{array}$}} \\
\hline & & & & & \\
\hline$K_{d I}$ & $K_{d P}$ & & $K_{q I}$ & & $K_{q P}$ \\
\hline 440 & 22.5 & & 440 & & 105 \\
\hline \multicolumn{6}{|c|}{ Reference trajectory constants } \\
\hline$K_{\psi 0}$ & $K_{\psi 1}$ & $K_{0}$ & & $K_{1}$ & $K_{2}$ \\
\hline 123 & 0.05 & 50.7 & & 400.4 & 0.5 \\
\hline
\end{tabular}



Protection (June 27 $7^{\mathrm{TH}}-30^{\mathrm{TH}}, 2017$, BLED, SLOVENIA), RENEWABLE ENERGY SOURCES

J. Linares-Flores, R. Lescas-Hernández, J. F. Guerrero-Castellanos, G. Mino-Aguilar,

H. Sira-Ramírez, A. Hernández-Méndez \& M. Antonio Contreras Ordaz: Angular Speed Control of an Induction Motor Via a Solar Powered Boost Converter-Voltage Source Inverter Combination
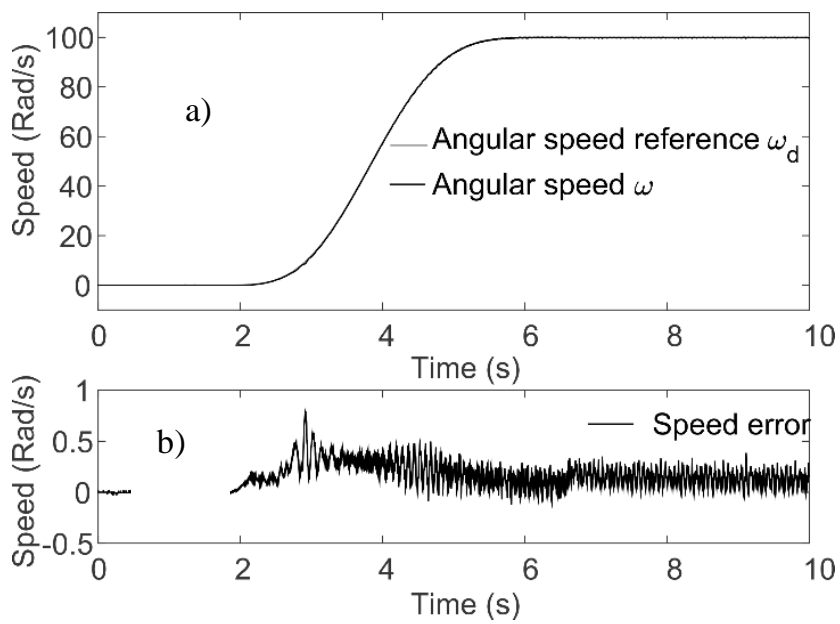

Figure 8. a) Angular speed response, b) angular speed error response, for the speed trajectory tracking.

Figure 9 shows the variation of torque applied to the induction motor. In order to carry out the FOC speed-tracking controller, we established the desired reference trajectories of magnetic field, and $i_{d}-i_{q}$ currents. Those references tracking responses are shown by the Figure 10 and Figure 11 respectively.

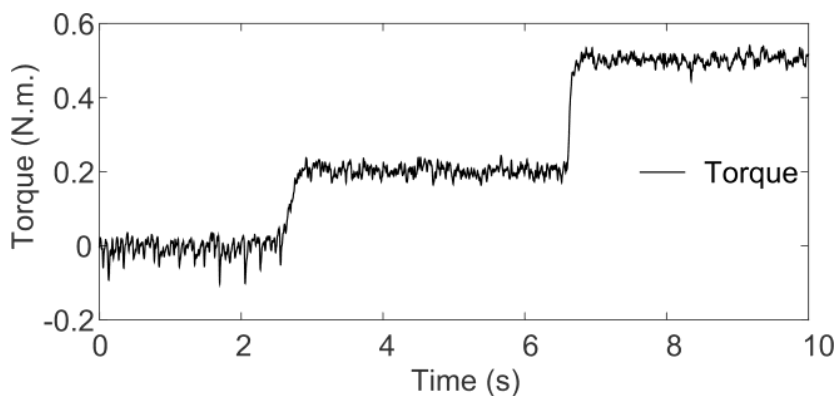

Figure 9. Torque applied. 
$10^{\text {TH }}$ International Conference on Sustainable Energy and Environmental Protection (June $27^{\mathrm{TH}}-30^{\mathrm{TH}}, 2017$, Bled, SLOVENIA), RENEWABLE ENERGY SOURCES J. Linares-Flores, R. Lescas-Hernández, J. F. Guerrero-Castellanos, G. Mino-Aguilar, H. Sira-Ramírez, A. Hernández-Méndez \& M. Antonio Contreras Ordaz: Angular Speed Control of an Induction Motor Via a Solar Powered Boost Converter-Voltage Source Inverter Combination

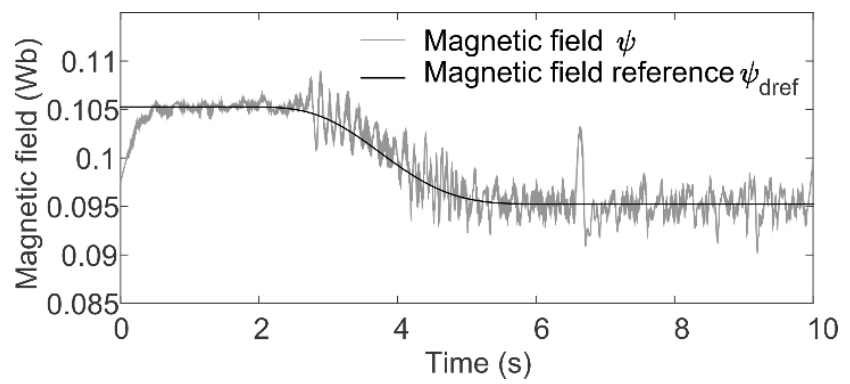

Figure 10. Magnetic field response for the speed trajectory tracking.
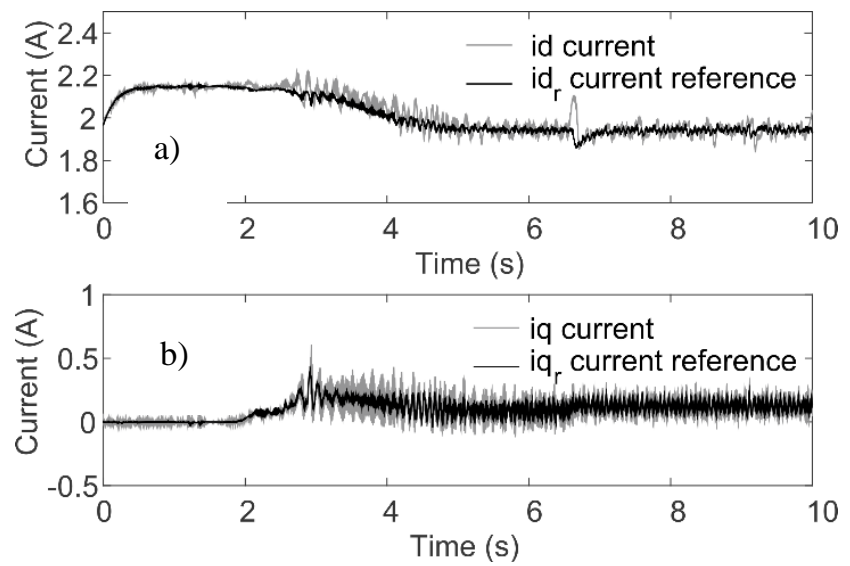

Figure 11. a) Direct current response, and b) Quadrature current response, for the speed trajectory tracking.

\section{Conclusions}

The ESEDPOF controller performance is very effective for the MPPT, whenever the estimated output resistor value of boost converter is adapted to the desired reference of the ESEDPOF controller.

The angular speed-tracking controller (FOC) shows to be robust towards the sudden load torque changes. Furthermore, the angular speed tracking error of the Field-OrientedControl showed a good performance in steady and transient state.

The algebraic estimator estimates on line the load resistor of boost power converter and helps to separate the dynamic of the boost converter of the dynamic of induction motor. This allows to design two controllers separately, one for the boost converter, and the other for the induction motor. 
Protection (June $27^{\mathrm{TH}}-30^{\mathrm{TH}}, 2017$, BLED, SLOVEniA), RENEWABle ENERGy SOURCES

J. Linares-Flores, R. Lescas-Hernández, J. F. Guerrero-Castellanos, G. Mino-Aguilar, H. Sira-Ramírez, A. Hernández-Méndez \& M. Antonio Contreras Ordaz: Angular Speed Control of an Induction Motor Via a Solar Powered Boost Converter-Voltage Source Inverter Combination

\section{Acknowledgements}

We are grateful to the SEP-PRODEP-MX for the support given to the Automatization and Mechatronic Control System Academic Bodies Network Project 2015. Which is entitled: "Modelado, análisis, diseño e implementación de un vehículo eléctrico mono plaza de autobalanceo de dos ruedas de bajo costo".

\section{References}

[1] N. Femia, G. Petrone, G. Spagnuolo and M. Vitelli, Power Electronics and Control Techniques for Maximum Energy Harvesting in Photovoltaic Systems, CRC Press Taylor \& Francis Group, 2013.

[2] M. M. Rajan Singaravel and S. Arul Daniel, "MPPT With Single DC--DC Converter and Inverter for Grid-Connected Hybrid Wind-Driven PMSG--PV System," IEEE Transactions on Industrial Electronics, vol. 62, no. 8, pp. 4849--4857, Aug. 2015.

[3] M. Ammirrul, A. M. Zainuri, M. A. Mohd--Radzi and A. Che--Soh, "Development of adaptive perturb and observe-fuzzy control maximum power point tracking for photovoltaic boost dc--dc converter," IET Renewable Power Generation Journal, vol. 8, no. 2, pp. 183--194, 2014.

[4] H. Ahmed-Sher, A. Faisal-Murtaza, A. Noman and K. E. Addoweesh, K. Al-Haddad, and M. Chiaberge, "A New Sensorless Hybrid MPPT Algorithm Based on Fractional ShortCircuit Current Measurement and P\&O MPPT," IEEE Transactions on Sustainable Energy, vol. 6, no. 4, Oct. 2015.

[5] K. B. Shah and L. P. Joshi, "Comparative Analysis of Incremental Conductance Base MPPT for Multi-String Photovoltaic System," Nirma University International Conference on Engineering (NUiCONE), pp. 1--6, 2013.

[6] J. A. Santiago-Gonzalez, J. Cruz-Colon, R. Otero-De-Leon, V. Lopez-Santiago and E.I. Ortiz-Rivera, "Three Phase Induction Motor Drive Using Flyback Converter and PWM Inverter Fed from a Single Photovoltaic Panel," IEEE Power and Energy Society General Meeting, pp. 1--6, 2011.

[7] Shruti Pandey, Bharti Dwivedi and Anurag Tripathi, "Closed Loop Boost Converter Control of Induction Motor Drive Fed by Solar Cells," International Conference on Emerging Trends in Electrical, Electronics and Sustainable Energy Systems (ICETEESES-16), pp. 286--291, 2016.

[8] Ayman S. Abdel-Khalik, Ahmed Elserougi, Ahmed M. Massoud and Shehab Ahmed, "A Cascaded Boost Inverter-Based Open-End Winding Three-Phase Induction Motor Drive for Photovoltaic-Powered Pumping Applications," 4th International Conference on Electric Power and Energy Conversion Systems (EPECS), 2015.

[9] J. Linares-Flores, J. Reger and H. Sira-Ramírez, "Load Torque Estimation and PassivityBased Control of a Boost-Converter/DC-Motor Combination," IEEE Transactions on Control Systems Technology, vol. 18, no. 6, pp. 1398-1405, Nov. 2010.

[10] J. L. Flores, J. L. B. Avalos and C. A. B. Espinoza, "Passivity-Based Controller and Online Algebraic Estimation of the Load Parameter of the DC-to-DC Power Converter Ćuk Type," IEEE Latin America Transactions, vol. 9, no. 1, pp. 50-57, March 2011.

[11] S. Diop and M. Fliess, "Nonlinear observability, identifiability and persistent trajectories" in Proc. 36th IEEE Conference on Decision and Control, Brighton, 1991, pp. 714-719.

[12] J. Linares-Flores, A. Hernández-Méndez, C. García-Rodriguez, and H. Sira-Ramírez, "Robust nonlinear adaptive control of a "boost" converter via algebraic parameter 
$330 \quad 10^{\text {TH }}$ INTERNATIONAL CONFERENCE ON Sustainable ENERGy AND ENVIRONMENTAL Protection (June $27^{\mathrm{TH}}-30^{\mathrm{TH}}, 2017$, BLED, SLOVENIA), RENEWABLE ENERGY SOURCES J. Linares-Flores, R. Lescas-Hernández, J. F. Guerrero-Castellanos, G. Mino-Aguilar, H. Sira-Ramírez, A. Hernández-Méndez \& M. Antonio Contreras Ordaz: Angular Speed Control of an Induction Motor Via a Solar Powered Boost Converter-Voltage Source Inverter Combination

identification," IEEE Transactions on Industrial Electronics, vol. 61, no. 8, pp. 4105-4114, August 2014.

[13] J. Chiasson, Modeling and High Performance Control of Electric Machines, Wiley-IEEE Press, 2005. 
$10^{\mathrm{TH}}$ InTERnational CONFERENCE ON Sustainable ENERgy AND Environmental Protection (June 27 $7^{\mathrm{TH}}-30^{\mathrm{TH}}, 2017$, BLed, SLOVENIA), RENEWABLE ENERGy SOURCES J. Krope, A.Ghani Olabi, D. Goričanec \& S. Božičnik

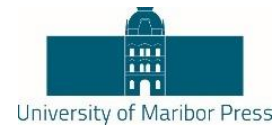

\title{
Comparative Analysis of Electricity Production from Different Technologies of PV Modules
}

\author{
JURICA PERKo, MATEJ ŽNIDAREC \& DANIJEL TOPIĆ
}

\begin{abstract}
Distributed generation of electricity from renewable energy sources has drastically grown in recent times. One of the most common types of distributed generation is photovoltaic (PV) systems. Like any other system of distributed generation, PV systems have a lot of various pros and cons. Paper deals with the comparison of electricity production for three different technologies of crystalline silicon PV modules. Comparative analysis of electricity production includes measurements on monocrystalline silicon, polycrystalline silicon and high-efficient monocrystalline silicon PV modules. At the very beginning, different technologies are compared in theory supported by measurements. Anyhow, focus is placed on measurements of several parameters of different PV module technologies under the same conditions that describe electricity production. A comparison of electricity production of PV modules based on the measurements is carried out and important conclusions were adopted.
\end{abstract}

Keywords:• photovoltaic module • monocrystalline silicon • polycrystalline silicon $\bullet$ high-efficient monocrystalline silicon $\bullet$ electricity production •

CoRReSPONDENCE AdDREss: Jurica Perko, Energy Expert, Regional Energy Agency North, Miroslava Krleže 81, 4800 Koprivnica, Croatia, e-mail: jurica.perko@rea-sjever.hr. Matej Žnidarec, Assistant, J.J Strossmayer University of Osijek, Faculty of Electrical Engineering, Computer Science and Information Technology Osijek, Department of Power Engineering, Kneza Trpimira 2B, 31000 Osijek, Croatia, e-mail: matej.znidarec@ferit.hr. Danijel Topić, Ph.D., Assistant Professor, J.J Strossmayer University of Osijek, Faculty of Electrical Engineering, Computer Science and Information Technology Osijek, Department of Power Engineering, Kneza Trpimira 2B, 31000 Osijek, Croatia, e-mail: danijel.topic@ ferit.hr.

https://doi.org/10.18690/978-961-286-061-5.29

ISBN 978-961-286-061-5

(C) 2017 University of Maribor Press

Available at: http://press.um.si. 
$10^{\text {TH }}$ International CONFEREnce on Sustainable Energy and Environmental Protection (June $27^{\mathrm{TH}}-30^{\mathrm{TH}}, 2017$, Bled, SLOVEnia), RENEWABle ENERGy SOURCES J. Perko, M. Žnidarec \& D. Topić: Comparative Analysis of Electricity Production from Different Technologies of PV Modules

\section{$1 \quad$ Introduction}

Today, electricity is globally available to approximately 4.8 billion people but 1.8 billion people are still without, or have very limited, access to electric power [1]. In recent times exploitation of solar energy is growing rapidly and it could be solution to improve the situation mentioned above. By implementation of distributed generation (DG) of electricity from photovoltaic systems, electric power can be provided to more people all around the world. Photovoltaic (PV) system market had powerful growth so far and will be continued in the upcoming years [2]. Because of that, electricity will be available even in areas with poor accessibility. An extenuating circumstance in implementation of distribution generation from solar energy is legislative framework which encourages development of such systems [3].

According to Smart Grid Technology Roadmap published by International Energy Agency, operators will require real-time system information to manage generation from renewables, balance intermittent supply with flexible demand, handle multidirectional power flows and maintain power quality. Leaders in renewables deployment are China and Europe with leadership in deployment of smart grid technologies that are trigger for expanding the use of distributed generation of electricity in reliable way [1]. The International Energy Agency forecasts that solar power could deliver between $20 \%$ and $25 \%$ of global electricity by 2050, reducing $\mathrm{CO}_{2}$ emissions by approximately 6 billion tons per year [4]. A smart grid will make possible these high level penetrations of clean renewable energy by [1]:

- balancing of supply interruption with demand side resources and storage

- forecasting and monitoring for better prediction of intermittent generation and regulation of power supply

- managing reverse power flows from distributed generation to protect the grid

- using advanced communication and control technologies to reduce power system maintenance, management and operation costs.

Very important role in sustainability of DGs have efficiency of PV modules. Production of PV modules is broadly divided on crystalline and thin-film approaches [5]. In following chapter three different technologies that are subject of conducted measurements are compared.

\section{Comparison of Different PV Module Technologies}

Crystalline PV modules are divided between monocrystalline (MC) and polycrystalline (PC) solar cells depending on PV cell production approach (single crystal or multiple crystal cells), Figure 1. In comparison to polycrystalline, monocrystalline cells are more efficient but at the same time they are more difficult to produce which results with higher costs per unit of surface area [5]. 


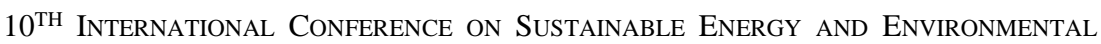
333 Protection (June 27 $7^{\mathrm{TH}}-30^{\mathrm{TH}}, 2017$, BLED, SLOVENIA), RENEWABLE ENERGY SOURCES J. Perko, M. Žnidarec \& D. Topić: Comparative Analysis of Electricity Production from Different Technologies of PV Modules
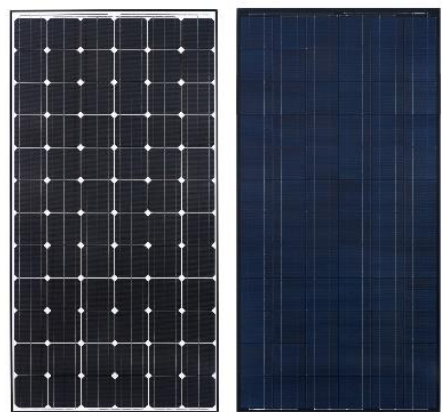

Figure 1. MC and PC PV modules [6]

Manufacturing process of thin-film (TF) PV modules is completely different than crystalline. Thin layer of photovoltaic effect capable materials (amorphous silicon or some nonsilicon combination of metals) lies on a backing material, Figure 2. They are cheaper to produce than crystalline cells due to production process which is easier to scale up than the growing and cutting of crystals. There is also PV module made of a thin monocrystalline silicon wafer surrounded by ultra-thin amorphous silicon layers (TFMC) also known as high-efficient monocrystalline silicone module, which is included in measurements of electricity production. It is more efficient than previously described crystalline modules [5].

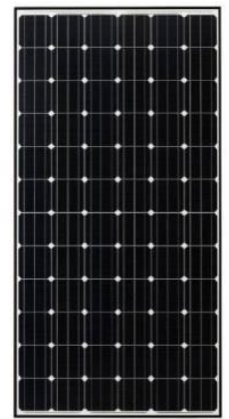

Figure 2. TF-MC PV module [7]

Comparison of characteristics of these three PV module technologies is shown in Table 1. Observed modules were BISOL BMO 250 as MC module, BISOL BMU 250 as PC module and Panasonic N240 as TF-MC module [6, 7]. 
$334 \quad 10^{\text {TH }}$ InTERnAtional CONFERENCE ON Sustainable ENERGy AND ENVIRONMENTAL Protection (June $27^{\mathrm{TH}}-30^{\mathrm{TH}}, 2017$, BlED, SLOVENIA), RENEWABLE ENERGY SOURCES J. Perko, M. Žnidarec \& D. Topić: Comparative Analysis of Electricity Production from Different Technologies of PV Modules

Table 1. Characteristics of PV modules $[6,7]$

\begin{tabular}{|l|c|r|r|r|}
\hline \multicolumn{1}{|c|}{ Module types } & $\begin{array}{c}\text { Units } \\
\text { of } \\
\text { measu } \\
\text { re }\end{array}$ & MC & PC & $\begin{array}{c}\text { TF- } \\
\text { MC }\end{array}$ \\
\hline Peak power [W] & $P_{\max }$ & 250 & 250 & 240 \\
\hline Nominal voltage [V] & $U_{\mathrm{mpp}}$ & 8.20 & 8.25 & 43.70 \\
\hline Nominal current [A] & $I_{\mathrm{mpp}}$ & 30.50 & 30.30 & 5.51 \\
\hline Short circuit current [A] & $I_{\mathrm{sc}}$ & 8.80 & 8.75 & 5.85 \\
\hline Open circuit voltage [V] & $U_{\mathrm{oc}}$ & 37.90 & 38.40 & 52.40 \\
\hline Module efficiency [\%] & $\eta_{\mathrm{m}}$ & 15.60 & 15.30 & 19.00 \\
\hline Cell efficiency [\%] & $\eta_{\mathrm{c}}$ & 17.40 & 17.10 & 21.60 \\
\hline NOCT [ $\left.{ }^{\circ} \mathrm{C}\right]$ & & 44 & 44 & 44 \\
\hline $\begin{array}{l}\text { Temperature coefficient } \\
{\left[\mathrm{mA} /{ }^{\circ} \mathrm{C}\right]}\end{array}$ & $\alpha$ & +4.50 & +4.90 & +1.76 \\
\hline $\begin{array}{l}\text { Temperature coefficient } \quad U_{\mathrm{oc}} \\
{\left[\mathrm{mV} /{ }^{\circ} \mathrm{C} \text { ] }\right.}\end{array}$ & $\beta$ & -132 & -121 & -131 \\
\hline $\begin{array}{l}\text { Temperature coefficient } P_{\mathrm{mpp}} \\
{\left[\% /{ }^{\circ} \mathrm{C}\right]}\end{array}$ & $\gamma$ & -0.35 & -0.40 & -0.30 \\
\hline Maximum system voltage [V] & & 1,000 & 1,000 & 1,000 \\
\hline Current value String fuse [A] & & 13 & 13 & 15 \\
\hline Length [mm] & & 1,649 & 1,649 & 1,580 \\
\hline Width [mm] & & 991 & 991 & 798 \\
\hline Height [mm] & & 18.50 & 18.50 & 15.00 \\
\hline Weight [kg] & & & 35 \\
\hline
\end{tabular}

$I-V$ characteristics in different conditions of irradiance for crystalline and thin-film monocrystalline modules are shown in continuation, Figure 3 and Figure 4. 


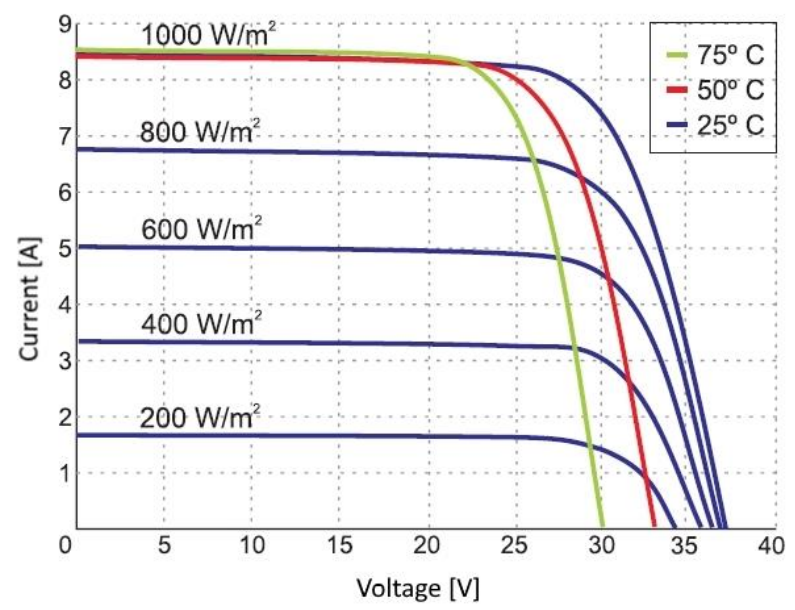

Figure 3. Crystalline $I-V$ characteristics [6]

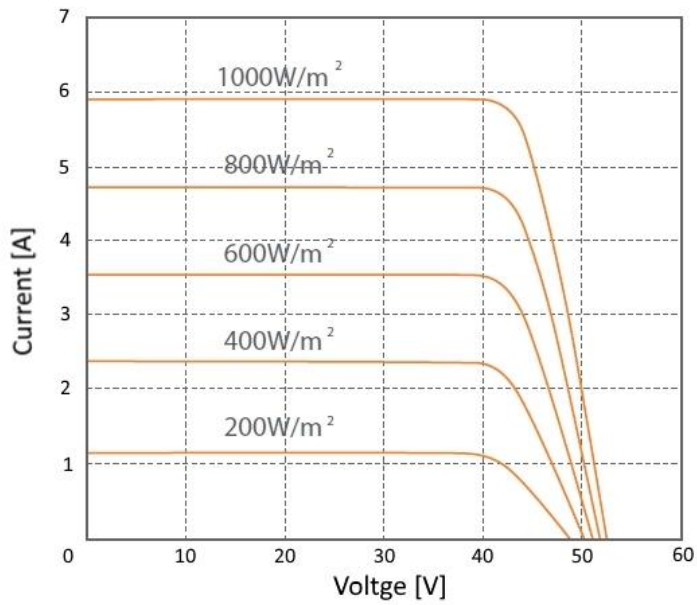

Figure 4. TF-MC I-V characteristics [7]

A photovoltaic module has two types of warranties: power output and equipment guarantee. Product warranty and output power warranty are very important because they protect customer against failures due to manufacturing defects, environmental issues, premature wear and tear etc. It can help you assure that your service and support needs will be covered if a PV module problem ever occurs.

Most common performance warranty will guarantee $90 \%$ of output power after 10 years and $80 \%$ after 20 years as TF-MC module manufacturer assures, Figure 5 [7]. 
$336 \quad 10^{\mathrm{TH}}$ INTERNATIONAL CONFERENCE ON Sustainable ENERGy AND ENVIRONMENTAL Protection (June $27^{\mathrm{TH}}-30^{\mathrm{TH}}, 2017$, Bled, SLOVENIA), RENEWABle ENERGY SOURCES J. Perko, M. Žnidarec \& D. Topić: Comparative Analysis of Electricity Production from Different Technologies of PV Modules

Likewise, some of the producers offer linear warranty for output power as MC and PC manufacturer assures, Figure 6 [6].

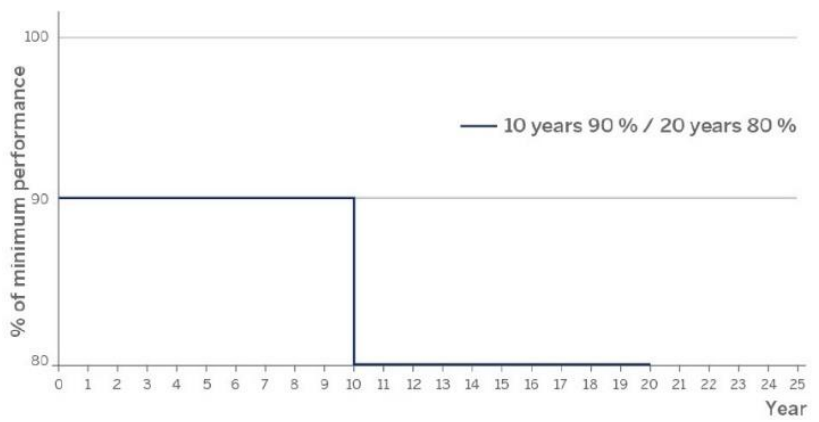

Figure 5. Power output and product warranty - TF-MC module [7]

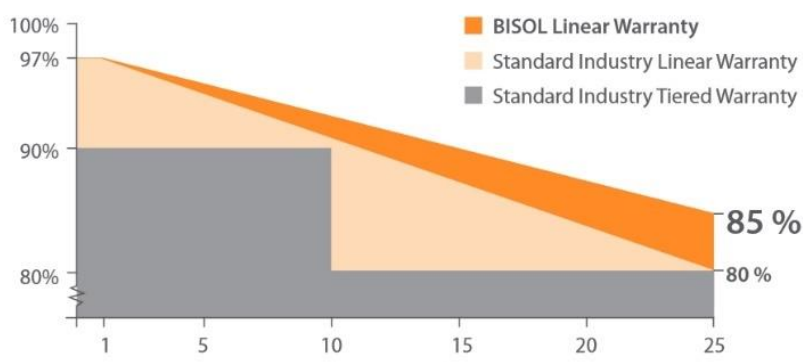

Figure 6. Power output and product warranty - MC and PC modules [6]

\section{$3 \quad$ Materials and Method}

\subsection{Equipment and measuring instruments}

Measurements were conducted on PV modules made from three different photovoltaic technologies. Measuring instruments used for measurements are Metrix PX110 Digital Wattmeter and Seaward Solar Survey 200R. Metrix PX110 Digital Wattmeter is used for output voltage, output current and PV module output power in maximum power point. Solar irradiance is measured with Seaward Solar Survey 200R irradiance meter.

\subsection{Measuring methodology}

Measurements of electrical characteristics of the PV modules are conducted from 7 a.m. to 6 p.m. for two days, with different weather conditions. Frequency of the measurement is one hour. Firstly, solar irradiation is measured. After that, maximum power point of a PV module is tracked for each module and output power with digital wattmeter is measured. Electrical circuit used for the maximum power point tracking is given in Figure $7[8]$. 


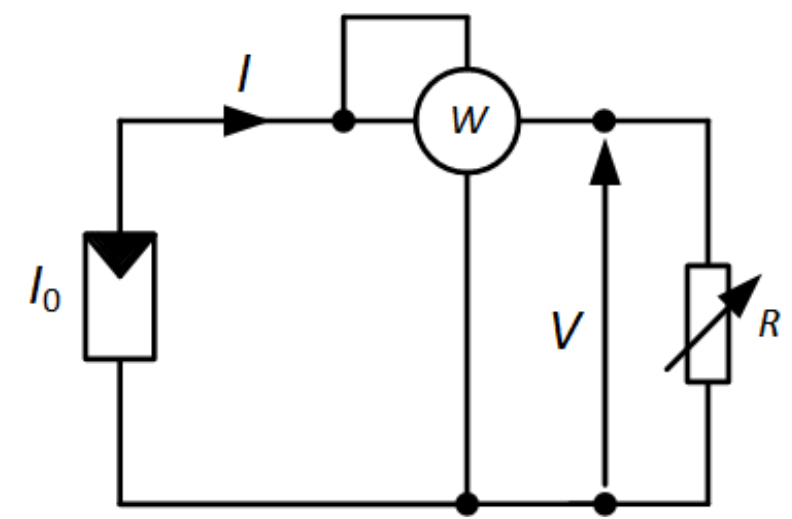

Figure 7. Maximum power point tracking electrical circuit

\section{$4 \quad$ Results and Discussion}

Figures 6-7 show output power of three different PV module technologies in the same weather condition. Two different weather conditions in a day were considered, sunny day and partly cloudy day. First type, given in Figure 8 and Figure 10, is a sunny day. Measurements for sunny day are taken on April $3^{\text {rd }}, 2014$. Second case of weather conditions, given in Figure 9 and Figure 11, is partly cloudy day. Measurements for partly cloudy day are taken on April 24 $4^{\text {th }}$,2014. Horizontal axis of the Figure 8 and Figure 9 shows time while vertical axis gives relation of output power of a PV modules $P$ and output power in standard test conditions (STC) $P_{\mathrm{MPP}}$.

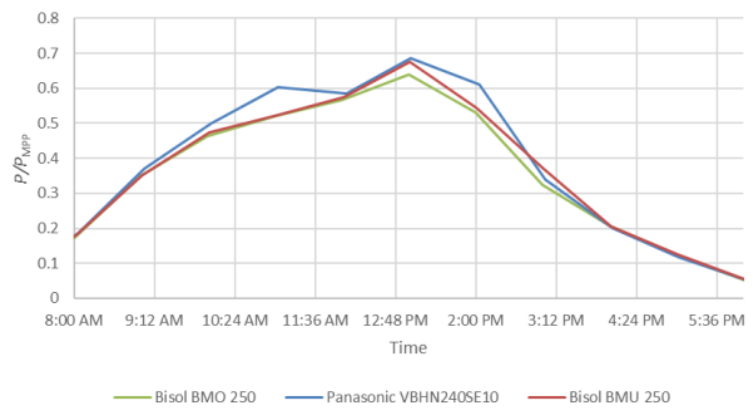

Figure 8. Output power of three different PV module technologies for a sunny day 
$10^{\mathrm{TH}}$ International Conference on Sustainable EnERgy and Environmental Protection (June $27^{\mathrm{TH}}-30^{\mathrm{TH}}, 2017$, Bled, SLOVENIA), RENEWABLE ENERGy SOURCES J. Perko, M. Žnidarec \& D. Topić: Comparative Analysis of Electricity Production from Different Technologies of PV Modules

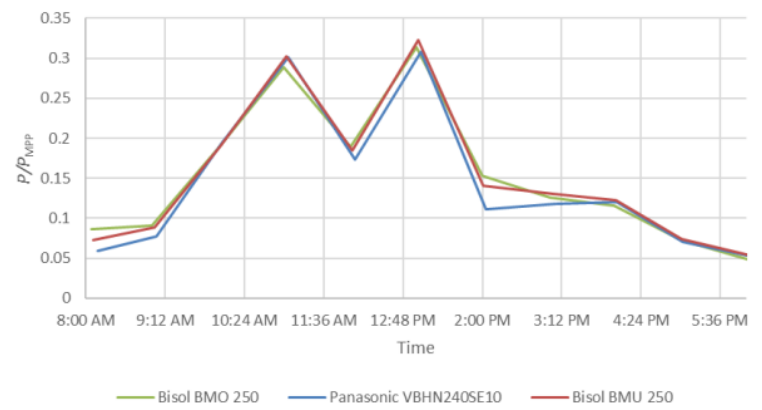

Figure 9. Output power of three different PV module technologies for partly cloudy day Efficiency of three different PV module technologies for different weather conditions is given in Figure 10 and Figure 11. Figure 10 shows efficiency of PV modules for a sunny day while Figure 11 shows efficiency for partly cloudy day.

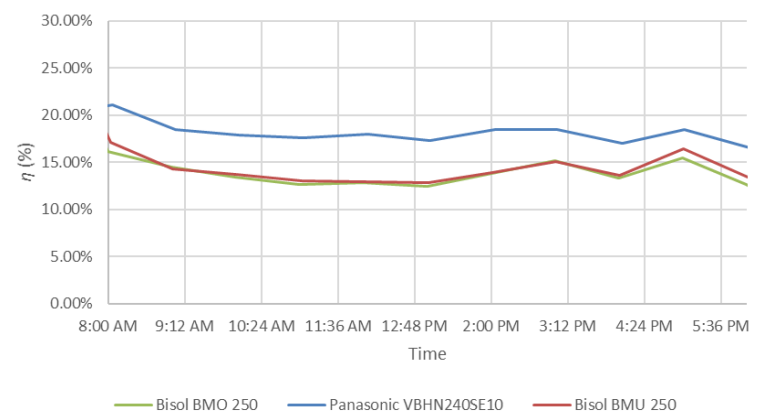

Figure 10. Efficiency of three different PV module technologies for a sunny day

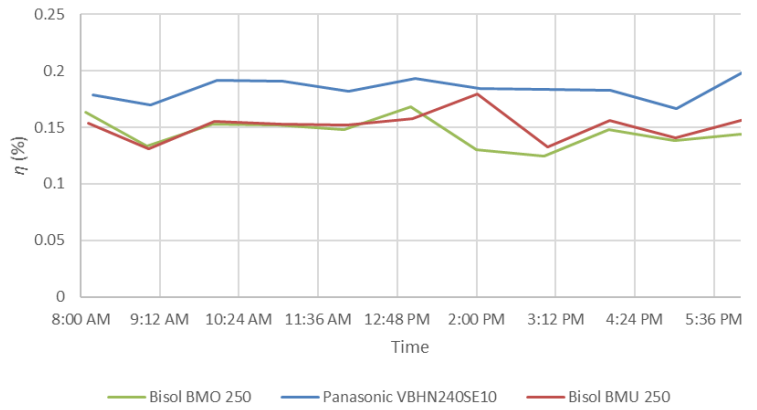

Figure 11. Efficiency of three different PV module technologies for partly cloudy day

Total daily electricity production per surface area of three different PV module technologies for different weather conditions is given in Table 5. 
$10^{\mathrm{TH}}$ InTERnational CONFerence on Sustainable EnERgy AND Environmental Protection (June 27 $7^{\mathrm{TH}}-30^{\mathrm{TH}}, 2017$, BLED, SLOVENIA), RENEWABLE ENERGY SOURCES

J. Perko, M. Žnidarec \& D. Topić: Comparative Analysis of Electricity Production from Different Technologies of PV Modules

Table 5. Total daily electricity production per surface area

\begin{tabular}{|c|c|c|}
\hline PV module & Sunny day $\left[\mathrm{Wh} / \mathrm{m}^{2}\right]$ & $\begin{array}{c}\text { Partly cloudy day } \\
{\left[\mathrm{Wh} / \mathrm{m}^{2}\right]}\end{array}$ \\
\hline Bisol BMO (MC) & 799.62 & 367.85 \\
\hline $\begin{array}{c}\text { Panasonic VBHN240SE10 (TF- } \\
\text { MC) }\end{array}$ & $1,077.11$ & 457.93 \\
\hline Bisol BMU (PC) & 830.40 & 379.72 \\
\hline
\end{tabular}

Results of output power for a sunny day given in Figure 8 show that the biggest output power gives MC-TF PV module i.e. Panasonic N240. For a partly cloudy day, the biggest output power gives PC PV module i.e. Bisol BMU 250 even though MC-TF PV panel gives slightly lower output power while its STC output power is $10 \mathrm{~W}$ lower than MC and PC STC output power. This difference in efficiency of solar energy conversion into electricity is visible in Figures 10 and Figure 11. MC-TF PV module has significantly greater efficiency of energy conversion. MC and PC PV modules have almost equal efficiency of energy conversion even though PC PV module has slightly greater efficiency than MC PV module. Deviations in output power and efficiency of energy conversions in relation to the time are results of rapid changes in solar irradiation in short time. Results given in Table 5 show that greatest energy production per surface area has MC-TF PV module. PC PV module has slightly greater production of electricity per surface area than MC PV module which confirms results analysed above.

\section{Conclusion}

Photovoltaic systems come in a wide range of sizes, from those sized to meet the needs of a single-family house to huge commercial systems [5]. Analysis of electricity production showed that high-efficient monocrystalline thin-film module has $20 \%$ to 35 $\%$ greater electricity production per square meter in comparison with classical monocrystalline and polycrystalline PV modules. The measurements have confirmed details from the PV modules datasheets. TF-MC module achieves the best performance per square meter and by that, it is particularly suited for small roof areas. This module has glass with anti-reflective coating that ensures high power output even in poor weather conditions which is showed by measurements for partly cloudy day. Polycrystalline module has little bit better performance per square meter in comparison with monocrystalline module.

\section{References}

[1] S. Borlase, Smart Grids: Infrastructure, Technology and Solutions, Boca Raton, 2013.

[2] Lj. Majdandžić, Solar Systems, Zagreb, 2010.

[3] B. Labudović, Basic application of photovoltaic systems, Zagreb, 2011.

[4] International Energy Agency, Press Release: IEA sees great potential for solar providing up to a quarter of world electricity by 2050, 2010

[5] F.M.Vanek, L.D. Albright, L.T. Angenent, Energy Systems Engineering: Evaluation and Implementation, Second Edition, New York, 2012. 
$340 \quad 10^{\text {TH }}$ International CONFERENCE ON Sustainable ENERGy AND ENVIRONMENTAL Protection (June $27^{\mathrm{TH}}-30^{\mathrm{TH}}, 2017$, Bled, SLOVEnia), RENEWABle ENERGy SOURCES J. Perko, M. Žnidarec \& D. Topić: Comparative Analysis of Electricity Production from Different Technologies of PV Modules

[6] BISOL, http://www.bisol.com/en/products/pv-modules.html, (6 April 2016)

[7] Panasonic, https://www.panasonic.com/caribbean/business/solarpanels/hit/vbhn240se10.html, (6 April 2017)

[8] M. Žnidarec, D. Topić, J. Bušić, Influence of shading on I-V characteristics of thin film PV modules, Journal Of Energy Technology, vol. 10, iss. 1, pp. 45-56, Dec. 2016. 
$10^{\mathrm{TH}}$ InTERnAtional CONFERENCE ON Sustainable ENERgy AND Environmental Protection (June 27 $7^{\mathrm{TH}}-30^{\mathrm{TH}}, 2017$, BLed, SLOVENIA), RENEWABLE ENERGy SOURCES

J. Krope, A.Ghani Olabi, D. Goričanec \& S. Božičnik

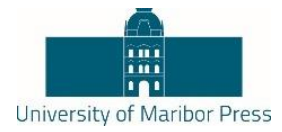

\title{
Sustainable Energy Policies for Clean Environment in Turkey
}

\author{
IBRAHIM YUKSEL, HASAN ARMAN \& IBRAHIM HALIL DEMIREL
}

\begin{abstract}
Much of the world's energy, however, is currently produced and consumed in ways that could not be sustained if technology were to remain constant and if overall quantities were to increase substantially. The need to control atmospheric emissions of greenhouse and other gases and substances will increasingly need to be based on efficiency in energy production, transmission, distribution and consumption in the country. Water is a vital resource that supports all forms of life on earth. Unfortunately, it is not evenly distributed by season or geographical region. Hydropower energy is a renewable, sustainable and clean energy in the other alternative energy sources. Moreover, it does not deprive future generations in terms of raw materials, or burdening them with pollutants or waste. This paper deals with sustainable energy policies for clean environment in Turkey.
\end{abstract}

Keywords:• renewable energy • sustainable energy • energy policy • environmental • Turkey•

CORRESPONDENCE AdDRESS: Ibrahim Yuksel, Ph.D, Prof. Dr., Yildiz Technical University, Faculty of Civil Engineering, Department of Civil Engineering, Hydraulics Division, 34220 Davutpasa, Istanbul, Turkey, e-mail: yukseli2000@yahoo.com. or iyuksel@yildiz.edu.tr. Hasan Arman, Ph.D, Prof. Dr., United Arab Emirates University, College of Science, Geology Dep., P.O. 15551, AlAin, UAE, e-mail: hasan.arman@gmail.com. Ibrahim Halil Demirel, Ph.D. student, Yildiz Technical University, Civil Engineering, 34220, Istanbul, Turkey, email: ibrahimhdemirel@gmail.com. 
$10^{\text {TH }}$ InTERnAtional CONFERENCE ON Sustainable ENERgy AND ENVIRONMENTAL Protection (June $27^{\mathrm{TH}}-30^{\mathrm{TH}}, 2017$, Bled, SLOVEnia), RENEWABle ENERGY SOURCES I. Yuksel, H. Arman \& I. Halil Demirel: Sustainable Energy Policies for Clean Environment in Turkey

Some countries such as Turkey has dynamic economic development and rapid population growth. It also has macro-economic, and especially monetary, instability. The net effect of these factors is that Turkey's energy demand has grown rapidly almost every year and is expected to continue growing, but the investment necessary to cover the growing demand has not been forthcoming at the desired pace. However meeting energy demand is of high importance in Turkey. But exploiting the country's large energy efficiency potential is also vital. Air pollution is a significant problem and, as the government's projections show, carbon emissions could rise sharply if current trends continue [1-10].

On the other hand, as would be expected, the rapid expansion of energy production and consumption has brought with it a wide range of environmental issues at the local, regional and global levels. With respect to global environmental issues, Turkey's carbon dioxide $\left(\mathrm{CO}_{2}\right)$ emissions have grown along with its energy consumption. States have played a leading role in protecting the environment by reducing emissions of greenhouse gases (GHGs). In this regard, renewable energy resources appear to be the one of the most efficient and effective solutions for clean and sustainable energy development in Turkey. Turkey's geographical location has several advantages for extensive use of most of these renewable energy sources. Hydropower is one of national and renewable resource of the country. In this reason, in the coming decades, global environmental issues could significantly affect patterns of energy use in Turkey [1-10].

Hydropower industry is closely linked to both water management and renewable energy production, and so has a unique role to play in contributing to sustainable development in a world where billions of people lack access to safe drinking water and adequate energy supplies. On the other hand, approximately 1.6 billion people have no access to electricity and about 1.1 billion are without adequate water supply. However, resources for hydropower development are widely spread around the world. Potential exists in about 150 countries and about $70 \%$ of the economically feasible potential remains to be developedmostly in developing countries where the needs are most urgent [1-10]. Although the initial investment cost of hydropower seems relatively high, the projects have the lowest production costs and do not depend on foreign capital and support, when considering environmental pollution and long-term economic evaluation. Hydropower is available in a broad range of project scales and types. Projects can be designed to suit particular needs and specific site conditions. As hydropower does not consume or pollute the water it uses to generate power, it leaves this vital resource available for other uses. At the same time, the revenues generated through electricity sales can finance other infrastructure essential for human welfare. This can include drinking water supply systems, irrigation schemes for food production, infrastructures enhancing navigation, recreational facilities and ecotourism.

It is well known that the GAP will play an important role in the development of Turkey's energy and agriculture sector in the near future. For this reason, it is suitable to examine the general structure of this project and its effects. The GAP project is one of the largest 
$10^{\mathrm{TH}}$ InTERnational CONFerence on Sustainable EnERgy AND Environmental 343 Protection (June 27 $7^{\mathrm{TH}}-30^{\mathrm{TH}}, 2017$, BLED, SLOVENiA), RenEWABLE ENERGy SOURCES I. Yuksel, H. Arman \& I. Halil Demirel: Sustainable Energy Policies for Clean Environment in Turkey

power generating, irrigation, and development projects of its kind in the world, covering 3 million hectare of agricultural land. This is over $10 \%$ of the cultivable land in Turkey; the land to be irrigated is more than half of the presently irrigated area in Turkey. The GAP project on the Euphrates and Tigris Rivers encompasses 20 dams and 17 hydroelectric plants. Once completed, 27 billion kWh of electricity will be generated annually, which is $45 \%$ of the total economically exploitable hydroelectric potential [10].

\section{The Role of Clean Energy}

Primary energy supply is projected to increase from 64.5 mtoe (1995) to 332.0 mtoe (2025). Crude oil imports remain constant at 33.0 mtoe after 2004 when the domestic refineries are forecast to run into their processing capacity, resulting in a drop in crude oil share from $44 \%$ to $10 \%$ of total supplies. Once the refining capacity is reached, net imports of refined products quickly grow from 2.6 to 52.3 mtoe (2000-2025), accounting for about $16 \%$ of total supplies by 2025 . Natural gas quickly increases its share from $10 \%$ (6.3 mtoe) in 1995 to $42 \%$ (139.8 mtoe) of total supplies in 2025. Although renewables double over 2000-2025, their share decreases from 14\% in 2000 to $7 \%$ in 2025 [7,1115]. Along with the economic growth and population increase, significant increases were observed both in primary energy and electricity consumption during the $8^{\text {th }}$ Plan period [16]. Consumption of primary energy reached 98.3 Mtoe as of the end of 2006 with an annual average increase of $2.8 \%$ while electricity consumption reached 165.3 billion $\mathrm{kWh}$ with an annual average increase of $4.6 \%$ during this period [17].

The Ministry of Energy and Natural Resources carries out the general energy planning studies, using an 'MAED' demand model, and TEIAS, (Turkish Electricity Transmission Company) carries out energy generation expansion planning studies, using the DECADES model. The MAED model [14] which was developed by the International Atomic Energy Agency (IAEA), makes projections of the medium and long-term general electricity demand. It takes into consideration a detailed analysis of social, economic and technical systems. The TEIAS, has prepared the Long-Term Energy Generation Plan, taking into consideration the MAED model demand outcome. According to the Plan, the installed capacity will increase to 57,551 MW in 2010 and to 117,240 MW in 2020. The installed hydropower capacity is anticipated to increase to $18,943 \mathrm{MW}$ in 2010 and to $34,092 \mathrm{MW}$ in 2020. Thus, an additional $1000 \mathrm{MW}$ of hydro capacity should be added to the system annually over the next 20 years. Turkey is thus seeking support for the development of all its economic potential by 2023 , which is the $100^{\text {th }}$ anniversary of the foundation of the Turkish Republic [1,12,18-20].

\section{$3 \quad$ Energy Policies in Turkey}

Turkey is an energy importing country; more than half of the energy requirement has been supplied by imports. Oil has the biggest share in total primary energy consumption. Due to the diversification efforts of energy sources, use of natural gas that was newly introduced into Turkish economy, has been growing rapidly. Turkey has large reserves of coal, particularly of lignite. The proven lignite reserves are 8.0 billion tons (Tab.1). The estimated total possible reserves are 30 billion tons. Turkey, with its young 
$10^{\mathrm{TH}}$ InTERnATIONAL CONFERENCE ON Sustainable ENERgy AND ENVIRONMENTAL Protection (June $27^{\mathrm{TH}}-30^{\mathrm{TH}}, 2017$, BlED, SLOVENIA), RENEWABLE ENERGY SOURCES I. Yuksel, H. Arman \& I. Halil Demirel: Sustainable Energy Policies for Clean Environment in Turkey

population and growing energy demand per person, its fast growing urbanization, and its economic development, has been one of the fast growing power markets of the world for the last two decades (Figures 1 and 2), [26]. It is expected that the demand for electric energy in Turkey will be 300 billion kWh by the year 2010 and 580 billion kWh by the year 2020. Turkey's electric energy demand is growing about 6-8\% yearly due to fast economic growing [15-17, 21-25]. In Turkey, primary energy production and consumption has reached 28 and 98.3 million tons of oil equivalent (Mtoe) respectively (Table2 and 3). Turkey's use of hydropower, geothermal and solar thermal energy has increased since 1990. However, the total share of renewable energy sources in total primary energy supply (TPES) has declined, owing to the declining use of noncommercial biomass and the growing role of

Table 1. Primary energy reserves in the last decade in Turkey

\begin{tabular}{|c|c|c|c|c|}
\hline Energy sources & Proven & Probable & Possible & Total \\
\hline Hard coal (Million ton) & 428 & 456 & 245 & 1129 \\
\hline Lignite (Million ton) & & & & \\
\hline Elbistan & 3357 & & & 3357 \\
\hline Others & 3982 & 626 & 110 & 4718 \\
\hline Total & 7339 & 626 & 110 & 8075 \\
\hline Asphaltite & 45 & 29 & 8 & 82 \\
\hline Bitumes & 555 & 1086 & & 1641 \\
\hline Hydropower & & & & \\
\hline GWh/yr & 126109 & & & 126109 \\
\hline MW/yr & 35539 & & & 35539 \\
\hline Petroleum (Million ton) & 39 & & & 39 \\
\hline Natural gas (Billion $\mathrm{m}^{3}$ ) & 10.2 & & & 10.2 \\
\hline Nuclear sources (ton) & & & & \\
\hline Uranium & 9129 & & & 9129 \\
\hline Thorium & 380000 & & & 380000 \\
\hline Geothermal (MW/yr) & & & & \\
\hline Electricity & 200 & & 4300 & 4500 \\
\hline Thermal & 2250 & & 28850 & 31100 \\
\hline Solar energy & & & & \\
\hline Electricity & & & & 8.8 \\
\hline Heat & & & & 26.4 \\
\hline
\end{tabular}

natural gas in the system. Turkey has recently announced that it will reopen its nuclear programme in order to respond to the growing electricity demand while avoiding increasing dependence on energy imports $[21,23,25]$. Turkey's demand for energy and electricity is increasing rapidly. Since 1990, energy 
consumption has increased at an annual average rate of $4.3 \%$. As would be expected, the rapid expansion of energy production and consumption has brought with it a wide range of environmental issues at the local, regional and global levels $[1,11,12,15]$.

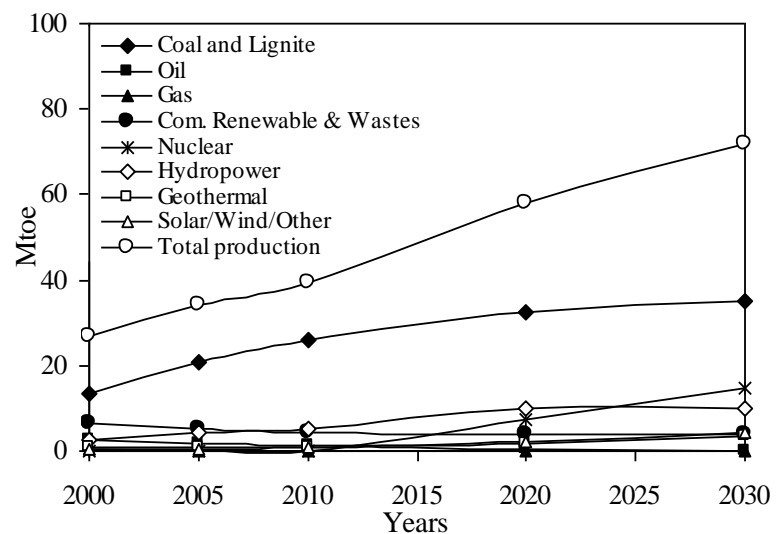

Figure 1. Turkey’s Primary Energy Production During 2000-2030

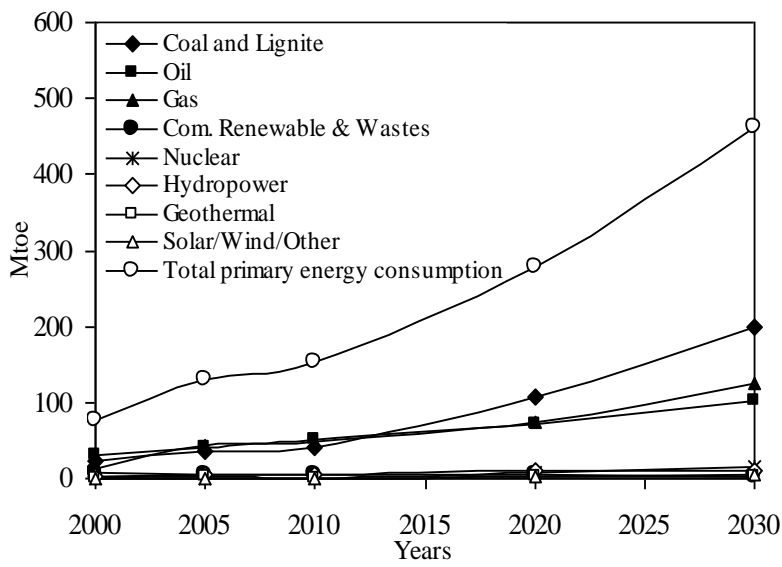

Figure 2. Turkey's Primary Energy Consumption Forecast 2000-2030 
$10^{\mathrm{TH}}$ InTERnAtional CONFERENCE ON Sustainable ENERGy AND ENVIRONMENTAL Protection (June $27^{\mathrm{TH}}-30^{\mathrm{TH}}, 2017$, BlED, SLOVENIA), RENEWABLE ENERGY SOURCES I. Yuksel, H. Arman \& I. Halil Demirel: Sustainable Energy Policies for Clean Environment in Turkey

Table 2. Selected Indicators of Primary Energy Consumption and Resources (Thousands TOE*)

\begin{tabular}{|l|l|l|l|l|l|c|}
\hline \multirow{2}{*}{ Energy Sources } & \multicolumn{2}{l|}{$\begin{array}{l}2005 \\
\text { Realization }\end{array}$} & \multicolumn{2}{l|}{2006 Realization } & \multicolumn{2}{l|}{2007 Realization } \\
\cline { 2 - 8 } & $\begin{array}{l}\text { Amoun } \\
\mathrm{t}\end{array}$ & $\begin{array}{l}\text { Amoun } \\
\mathrm{t}\end{array}$ & $\begin{array}{l}(\%) \\
\mathrm{t}\end{array}$ & $\begin{array}{l}\text { Amoun } \\
\mathrm{t}\end{array}$ & $(\%)$ \\
\hline Commercial Energy & 89,050 & 94.4 & 93,680 & 94.7 & 96,680 & 94.5 \\
\hline Hard coal & 14,805 & 15.7 & 15,052 & 15.2 & 16,052 & 15.2 \\
\hline Lignite & 10,760 & 11.4 & 11,005 & 11.1 & 12,005 & 11.1 \\
\hline Petroleum products & 32,855 & 34.8 & 35,160 & 35.6 & 37,160 & 35.6 \\
\hline Natural gas & 25,665 & 27.2 & 27,356 & 27.7 & 29,356 & 27.7 \\
\hline Hydraulic energy & 3,744 & 4.0 & 3,801 & 3.8 & 3,981 & 3.8 \\
\hline Renewable energy & 1,350 & 1.4 & 1,427 & 1.4 & 1,627 & 1.4 \\
\hline $\begin{array}{l}\text { Non-commercial } \\
\text { Energy }\end{array}$ & 5,250 & 5.6 & 5,200 & 5.3 & 5,6080 & 5.5 \\
\hline Wood & 4,100 & 4.4 & 4,100 & 4.1 & 4,100 & 4.1 \\
\hline Biomass & 1,150 & 1.2 & 1,100 & 1.1 & 1,100 & 1.4 \\
\hline Total & 94,300 & 100 & 98,880 & 100 & 102,28 & 100 \\
\hline
\end{tabular}

*TOE: Tons of Oil Equivalent; KEP: kilogram of oil equivalent

Table 3. Developments in Production and Consumption of Energy

\begin{tabular}{|c|c|c|c|c|}
\hline & 2000 & 2002 & 2004 & 2006 \\
\hline $\begin{array}{c}\text { Primary energy production } \\
\text { (TTOE) }\end{array}$ & 27,621 & 24,884 & 24,170 & 28,020 \\
\hline $\begin{array}{c}\text { Primary energy consumption } \\
\text { (TTOE) }\end{array}$ & 81,193 & 78,322 & 87,778 & 98,300 \\
\hline Consumption per capita (KOE) & 1,204 & 1,131 & 1,234 & 1,249 \\
\hline $\begin{array}{c}\text { Electricity installed capacity } \\
\text { (MW) }\end{array}$ & 27,264 & 31,846 & 36,824 & 39,596 \\
\hline Thermal (MW) & 16,070 & 19,586 & 24,160 & 26,481 \\
\hline Hydraulic (MW) & 11,194 & 12,260 & 12,664 & 13,115 \\
\hline Electricity production (GWh) & 124,922 & 129,400 & 150,698 & 165,346 \\
\hline Thermal (GWh) & 94,011 & 95,668 & 104,556 & 124,321 \\
\hline Hydraulic (GWh) & 30,912 & 33,732 & 46,142 & 41,025 \\
\hline Electricity import (GWh) & 3,786 & 3,588 & 464 & 636 \\
\hline Electricity export (GWh) & 413 & 435 & 1,144 & 1,812 \\
\hline Total Consumption (GWh) & 128,295 & 132,553 & 150,018 & 168,216 \\
\hline Consumption per capita (kWh) & 1,903 & 1,914 & 2,109 & 2,240 \\
\hline
\end{tabular}




\section{$4 \quad$ Environmental Issues in Turkey}

Turkey is a rapidly growing country whose income level is moving towards that of the rest of the OECD area. This catch-up process has been associated with a rapid growth of greenhouse gas emissions. Nonetheless, carbon emissions from any country contribute equally to the pressure on the global climate. Consequently, the major issue facing policy makers is how to contribute to reducing the burden on global resources at a low cost and without jeopardizing the rapid growth of the economy [21,15,23].

Turkey shares a number of features with some other OECD countries that suggests it would be possible to considerably moderate the growth of greenhouse gases with little or even no cost. The proportion of energy derived from carbon-intensive coal and lignite is one of the highest in the OECD area, reflecting ample reserves of lignite, while a completely liberalized market in natural gas has not existed [21].

Most greenhouse gas emissions in Turkey come from electricity generation sector that has been a largely state-owned industry operating under non-commercial criteria. Subsidies have been growing following a government decision to expand the industry in the late 1990s after a period of cutbacks in employment and output. Currently, consumer prices are held low because the government has to pay for certain imported gas whether it is used or not and also in order to encourage households to convert to gas $[21,23,25]$.

While fossil fuels are likely to become less carbon intensive, the supply of renewable energy is unlikely to keep pace with the growth in the economy. First, consumers are likely to switch away from animal waste as a fuel source as incomes grow, while wood resources are limited by deforestation concerns. In addition, even with a planned tripling of hydro capacity in the period from 2000 to 2020, the share of hydro in total electricity generation will fall. In addition, the environmental consequences of such an expansion will have to be carefully monitored as will overall costs as most of the expansion in the period to 2010 is expected to come from small-scale hydro projects $[1,7,24,27]$.

\section{$5 \quad$ Conclusions}

The environmental impacts of hydro plants are minimal compared with alternative resources. They make use of our renewable "green energy" resource, without causing pollution and $\mathrm{CO}_{2}$ emission. They have considerable advantages, since they use the renewable sources of the country, are free of fuel costs, and their design and construction can be performed by Turkish engineers and contractors. They are also easily adaptable to the system load demands.

There is no single solution to the world's quest for more, cleaner energy and effective water management. Energy and water for sustainable development depend not only on supply choices, but also on how these choices are implemented. It requires the creation of a level playing field among available energy options and global water governance involving all stakeholders in a participatory decision-making process. In adopting their own 
$10^{\text {TH }}$ InTERnational CONFERENCE ON Sustainable ENERGy AND ENVIRONMENTAL Protection (June $27^{\mathrm{TH}}-30^{\mathrm{TH}}, 2017$, BlED, SLOVENIA), RENEWABLE ENERGy SOURCES I. Yuksel, H. Arman \& I. Halil Demirel: Sustainable Energy Policies for Clean Environment in Turkey

sustainability guidelines, the members of the International Hydropower Association are committed to developing and operating their projects, in collaboration with all stakeholders, in a way that is environmentally friendly, socially responsible and economically efficient so that hydropower projects can make a major contribution to achieving sustainable energy and resource development.

Hydropower energy is a renewable, sustainable and clean energy in the other alternative energy sources. Moreover, it does not deprive future generations in terms of raw materials, or burdening them with pollutants or waste. Hydroelectric power plants utilize the basic national and renewable resource of the country. Although the initial investment cost of hydropower seems relatively high, the projects have the lowest production costs and do not depend on foreign capital and support, when considering environmental pollution and long-term economic evaluation.

\section{Acknowledgments}

This study was supported by Yildiz Technical University, Scientific Research Coordinator, Istanbul, Turkey. Project ID: 1897, Project Number: 2016-05-01-KAP01.

\section{References}

[1] Yuksel, I. and Arman, H., "Energy and Environmental Policies in Turkey", Energy Sources, Part B: Economics, Planning, and Policy, Vol. 9, Number 1, pp. 57-69, 2014.

[2] Kaygusuz, K., "Energy use and air pollution issues for Turkey", Clean 35: 539-547, 2007.

[3] Yuksel, I., "Dams and hydropower for sustainable development", Energy Sources, Part B; 4:100-110, 2009.

[4] IEA, International Energy Agency, World Energy Outlook 2002, OECD/IEA, Paris, 2002.

[5] IHA, International Hydropower Association, The role of hydropower in sustainable development, IHA White Paper, www.hydropower.org

[6] WEC, World Energy Council, Survey of Energy Resources, 2001. www.worldenergy.org

[7] Yuksel, I., "Energy utilization, renewables and climate change mitigation in Turkey", Energy Explor Exploit 26:35-52. 2008.

[8] Kaygusuz, K., "Environmental impacts of energy utilization and renewable energy sources in Turkey", Energy Exploration and Exploitation, Vol.19, pp. 497-509, 2001.

[9] Kaygusuz, K., "Energy policies and climate change mitigation in Turkey", Energy Exploration and Exploitation, Vol. 23, pp. 145-160, 2004.

[10] Yuksel, I., "Southeastern Anatolia Project (GAP) for irrigation and hydroelectric power in Turkey”, Energy Exploration and Exploitation 24: 361-370, 2006.

[11] Conzelman, G., Koritarov, V., Turkey Energy and Environmental Review, Task 7: Energy Sector Modeling, Center for Energy, Environmental, and Economic Systems Analysis (CEEESA), Argonne National Laboratory, August 2002.

[12] Yuksel, I., "Hydropower in Turkey for a clean and sustainable energy future", Renewable and Sustainable Energy Review 12: 1622-1640, 2008.

[13] UNDP/World Bank Energy Sector Management Assistance Program (ESMAP), TurkeyEnergy and the Environment, Issues and Options Paper, Report 229, 2000.

[14] MENR, Ministry of Energy and Natural Resources, Energy report of Turkey in 2004, Ankara, Turkey, 2005, http://www.enerji.gov.tr 
[15] MENR, Ministry of Energy and Natural Resources, Greenhouse Gas Mitigation in Energy Sector for Turkey, Working Group Report, Ankara, Turkey, 2005.

[16] DPT, State Planning Organization, Eighth Five-Year Development plan 2001 -2005, Ankara, Turkey, 2001.

[17] DPT, State Planning Organization, Ninth Development plan 2007-2013, Ankara, Turkey, 2006.

[18] TEIAS, Directorate-General of Turkish Electricity Transmission, Short history of electrical energy development in Turkey, 2005. http://www.teias.gov.tr

[19] IHA, International Hydropower Association, Hydropower information and country report for Turkey, www.hydropower.org

[20] Yuksek, O., Kömürcü, MI., Yuksel, I and Kaygusuz, K., "The role of hydropower meeting the electric energy demand in Turkey". Energy Policy; 34: 3093-3103, 2006.

[21] IEA, International Energy Agency, Energy Policies of IEA Countries: Turkey 2005 Review, OECD/IEA, Paris, 2005.

[22] IEA, International Energy Agency, Energy Statistics of IEA Countries: Turkey 2004 Review, OECD/IEA, Paris, 2006.

[23] MEF, Ministry of Environment and Forestry, First national Communication of Turkey on Climate Change, pp. 60-150, Ankara, Turkey, 2007.

[24] Yuksel, I., "Global warming and renewable energy sources for sustainable development in Turkey", Renewable Energy 33: 802-812, 2008.

[25] MENR, Ministry of Energy and Natural Resources, 2009, Energy Statistics in Turkey, www.enerji.gov.tr .

[26] Kaygusuz, K., "Hydropower in Turkey: the sustainable energy future", Energy Sources, Part B 4: 34-47, 2009.

[27] DSI, State Water Works, Hydropower potential in Turkey, Ankara, Turkey. 2008. 
$350 \quad 10^{\text {Th }}$ International CONFEREnCE on Sustainable EnERgy and ENVIRONMENTaL Protection (June $27^{\mathrm{TH}}-30^{\mathrm{TH}}, 2017$, Bled, Slovenia), Renewable ENERGy SOURCES 
$10^{\mathrm{TH}}$ InTERnATIONAL CONFERENCE ON Sustainable ENERgy AND ENVIRONMENTAL Protection (June $27^{\mathrm{TH}}-30^{\mathrm{TH}}$, 2017, Bled, SLOVENIA), RENEWABLE ENERGy SOURCES

J. Krope, A.Ghani Olabi, D. Goričanec \& S. Božičnik

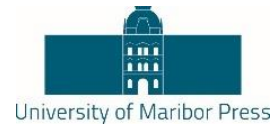

\title{
Study and Simulation of the Energy Performances of a Grid-Connected PV System Supplying a Residential House in North of Algeria
}

\author{
ISMAIL LAIB, ABDERRAHMAN HAMIDAT, MOURAD HADDADI, NAEEM RAMZAN \& \\ ABDUL G. OLABI
}

\begin{abstract}
Worldwide, building is one of the most consuming energy sectors which are contributing significantly to the greenhouse effect, climate change and negative environmental impact. In Algeria, building sector is responsible of about $42 \%$ of the final energy consumption, with about $35 \%$ in the residential houses and $6 \%$ in the tertiary. This consumption is still in expansion, due to mainly on an exceptional growth of population and urbanism. The main objective of this paper is to study and assess the contribution of the grid-connected photovoltaic system in the energy balance in the residential building. A case study is applied in the northern region of Algeria. The photovoltaic system supplies the house with electricity during the sunny days, and during the night or the cloudy days, the house is powered by grid. The calculation of energy performance is based on the optimization, rationalization and saving energy approach. This takes into account the energy profiles of residential homes, real data and meteorological conditions (ambient temperature and irradiance). The results show clearly that the use of saving energy and gridconnected photovoltaic system allows a reduction of energy demand and a positive annual electricity balance of the studied residential house. The PV system generated $67.6 \%$ of the overall energy used in the house. Only, $33.4 \%$ are purchased from the grid. An energy positive balance of $2 \mathrm{kWh} /$ day is observed.
\end{abstract}

Keywords: $\bullet$ Photovoltaic $\bullet$ Grid-connected $\bullet$ Energy performance $\bullet$ Energy balance $\bullet$ Bioclimatic housing $\bullet$ load profile $\bullet$ Energy Management $\bullet$

CORRESPONDENCE ADDRESS: Ismail Laib, Laboratory of Communication Devices and Photovoltaic, Department of Electrical Engineering, National Polytechnic School, 10 Rue des Frères OUDEK, El-Harrach 16200, Algeria, e-mail: ismail.laib@g.enp.edu.dz. Abderrahman Hamidat, Centre de Développement des Energies Renouvelables, CDER, Route de l'Observatoire, Bouzareah 16340, Algeria, e-mail: a.hamidat@cder.dz. Mourad Haddadi, Department of Electrical Engineering, National Polytechnic School, 10 Rue des Frères OUDEK, El-Harrach 16200, Algeria, e-mail: mourad.haddadi@g.enp.edu.dz. Naeem Ramzan, Institute of Engineering and Energy Technologies, University of the West of Scotland, High St, Paisley PA1 2BE, United Kingdom, e-mail: Naeem.ramzan@uws.ac.uk. Abdul G Olabi, Professor and Director of the Institute of Engineering and Energy Technologies, University of the West of Scotland, High St, Paisley PA1 2BE, United Kingdom, e-mail: Abdul.Olabi@uws.ac.uk.

https://doi.org/10.18690/978-961-286-061-5.31

ISBN 978-961-286-061-5

(C) 2017 University of Maribor Press

Available at: http://press.um.si. 
$10^{\mathrm{TH}}$ International Conference on Sustainable EnERgy and Environmental Protection (June $27^{\mathrm{TH}}-30^{\mathrm{TH}}, 2017$, Bled, SLOVENIA), RENEWABle ENERGy SOURCES I. Laib, A. Hamidat, M. Haddadi, N. Ramzan \& A.G. Olabi: Study and Simulation of the Energy Performances of a Grid-Connected PV System Supplying a Residential House in North of Algeria

\section{Introduction}

In Algeria, the energy consumption in building sector is one of the consuming energy sectors. So, it is responsible of $42 \%$ of the final energy consumption, with $35 \%$ in the residential building and $6 \%$ in the tertiary building. The rate of energy consumption in the building sector is growing rapidly for several reasons: (a) low cost of conventional energy (Government-subsidized energy), (b) substantial increase of population and housing stock, (c) increase number of electrical equipment in each house, (d) use of noneconomic electrical equipment such as incandescent lamps and very cheap air conditioners, (e) absence of awareness and lack of culture on the energy saving [1] and [2].

The integration of photovoltaic system into the building can enable self-production of electricity. At the same time, the system can help the electricity-grid by injecting the extra photovoltaic electricity produced, especially, during hot and sunny periods. Because, during these periods the electrical demand is the highest due to the use of air conditioning.

This will also help in reducing the climate and environmental impacts. However, for the feasibility of a PV system, there should be enough solar energy throughout the year. Algeria is one of many countries that have a high solar energy resource.

The techniques developed to date, depending on the place of use and the power requirements; offer the possibility of combining several energy production systems [3]. The idea of embedded generation has the advantage of not only supplying electricity from renewable energy and the grid, but exporting the generated energy to the grid. For example, the photovoltaic (PV) system can be used for a local Grid in an urban environment to supply housing, and in the event of surplus energy, the excess energy can be injected into the grid.

To give voice to this study, a separate home with a 90-m2 floor area was selected in order to analyze the house energy performances in Mediterranean climate conditions. The experimental house was built as part of a European MED-ENEC program and scientific collaboration between Renewable Energy Centre (CDER, Algeria) and National Center for the Study and Integrated Research of Buildings (CNERIB, Algeria). The building is situated in the North of Algeria in a village named Souidania (Figure 1). The house contains seven parts specifically, two rooms, living room, kitchen, restroom, and corridor [4]. 


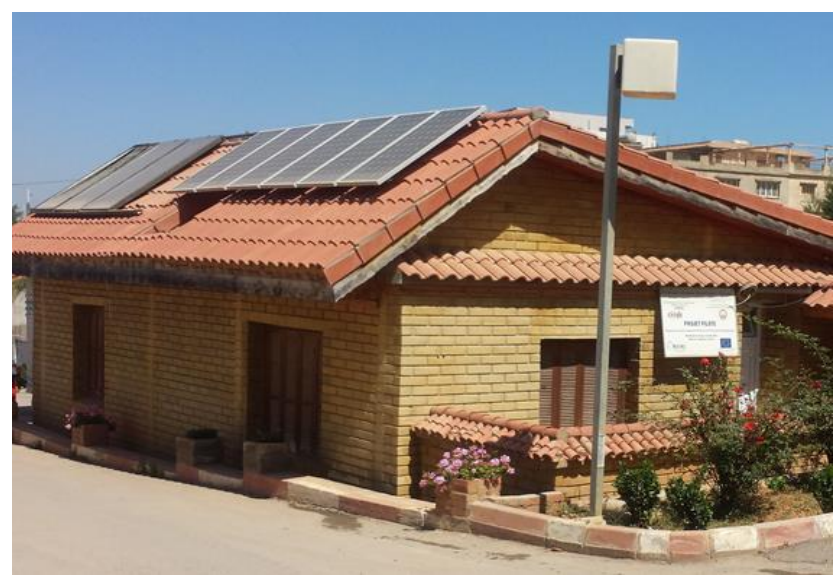

Figure1. The experimental bioclimatic house (Souidania, Algiers)

Today, solar energy and in particular photovoltaic systems are currently experiencing strong global growth $(+16.9 \%$ of the photovoltaic power installed in the world in 2015 compared to 2014) and are expected to represent a share of the future energy mix in the space of a few decades, various approaches exist to analyse installed solar PV world capacity [5] and share of grid-connected PV system [6].

Figure 2 Shows the evolution of photovoltaic power installed at the global level expresses a strong growth of the market since the beginning of the decade. It is also possible to distinguish in Figure 3 several configurations of Photovoltaic systems currently in use, grid-connected PV systems (On-grid) and stand-alone Photovoltaic systems (Off-grid) are used when the grid distribution is non-existent or when the cost of connection to this grid are prohibitive. The installation capacity for off-grid cannot be compared to the gridconnected, as the rapid development of grid-connected PV eliminates the off-grid as clearly shows Figure 3. There are two types of structures of a photovoltaic system connected to the grid: centralized and decentralized.

Centralized (Production/Sale) is a system with direct connection to the Grid, the energy produced is injected directly into the Grid. In this type of application, all the energy produced is destined to be sold to the electricity distributor at a preferential rate.

\section{Decentralized (Production/Consumption/Sale):}

The surplus energy produced by the PV system in the house is sold to the grid and to meet excess demand, when the consumption exceeds the production, the energy is provided by the Grid. It is therefore necessary to count separately the $\mathrm{kWh}$ injected and those taken from the grid, which requires installing two unidirectional (electronic) counters. 
354 10 $10^{\mathrm{TH}}$ International CONFEREnCE on Sustainable ENERgy AND ENVIRONMENTAL Protection (June $27^{\mathrm{TH}}-30^{\mathrm{TH}}, 2017$, Bled, SLOVENIA), RENEWABle ENERGy SOURCES I. Laib, A. Hamidat, M. Haddadi, N. Ramzan \& A.G. Olabi: Study and Simulation of the Energy Performances of a Grid-Connected PV System Supplying a Residential House in North of Algeria

To support the development of the sector, the purchase price of the $\mathrm{kWh}$ produced by a photovoltaic installation is higher than the price charged by the electricity companies for the sale of electricity to their customers. For example, the new German tariffs for the purchase of photovoltaic energy go in this direction, an increase of $5 €$-cts $/ \mathrm{kWh}$ of photovoltaic energy consumed on the site has been put in place (if the panels are integrated into the building) in January 2010 [7].

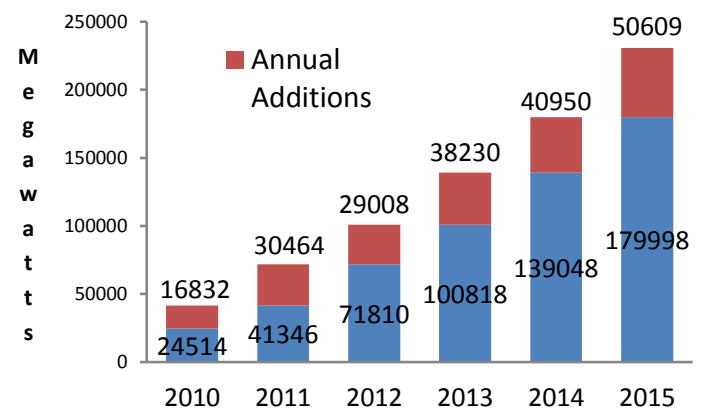

Figure 2. Solar PV global Capacity and Annual Additions, 2010-2015

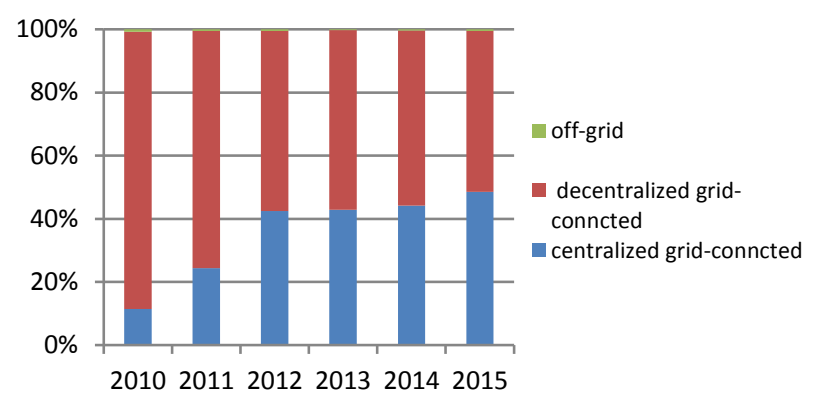

Figure 3. share of grid-connected and off-grid in world, 2010-2015

\section{Description of the System}

Photovoltaic power systems connected to the grid may change in size depending on the demand, but they have the same components, figure 4 shows grid-connected photovoltaic systems are integrated into the building [8], [9]. 


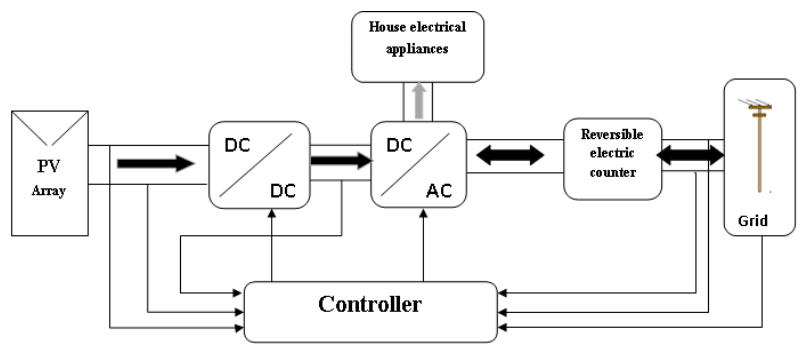

Figure 4. Power circuit of the photovoltaic system connected to the grid

This system contains 6 PV modules mono-crystalline arranged in series. Whole module area is $7.66 \mathrm{~m}^{2}$. The power conditioning device is a range of supervisor and inverter (SMA 1200). This inverter guarantees the supervision and the safety of the grid furthermore the conversion DC/AC with a power of $1.2 \mathrm{kVA}$. The nominal productivity of this inverter is $92.1 \%$. The photovoltaic array connected to the electric grid. During day time electricity is supplied by the photovoltaic system and during the night or absence of the sun, the electrical power is supplied from the electricity grid and in the event of surplus energy, the extra energy injected into the grid. Together with the house meter for calculates the energy production and consumption. All house electrical appliances are served by both the PV system and grid's power, the arrangement of the grid-connected PV system.

\section{$3 \quad$ Modelling of the System}

\subsection{Photovoltaic generator}

The mathematical modelling of the equivalent circuit of a solar cell is idealized by a junction diode $\mathrm{PN}$ by an $\mathrm{I}_{\mathrm{ph}}$ current source, a series resistor $\mathrm{R}_{\mathrm{s}}$, which models the joule losses, a parallel resistor $\mathrm{R}_{\mathrm{sh}}$, which represents the internal losses. There are numerous mathematical models but the only difference is between the mathematical measures and the amount of parameters elaborated in the calculation of the voltage and current of the photovoltaic module. In this study, two diodes were modelled. A supplementary diode is positioned in parallel with the circuit of the simple model of a diode Figure 5. This diode is included to provide a much more accurate I-V characteristic curve [10]. Equation (1) is shown the ratio between the output current I and the output voltage $\mathrm{V}$ at the terminals of the load resistor $R_{c}[11]$.

$$
\begin{aligned}
& I=I_{p h}-I_{s a t 1}\left(\exp \left(\frac{V+R_{s} I}{n_{1} V_{t h}}\right)-1\right)- \\
& I_{s a t 2}\left(\exp \left(\frac{V+R_{s} I}{n_{2} V_{t h}}\right)-1\right)-\frac{V+R_{s} I}{R_{s h}}
\end{aligned}
$$


356 1 $10^{\text {TH }}$ InTERnAtional CONFERENCE ON Sustainable ENERGy AND ENVIRONMENTAL Protection (June $27^{\mathrm{TH}}-30^{\mathrm{TH}}, 2017$, Bled, SLOVENIA), RENEWABle ENERGy SOURCES I. Laib, A. Hamidat, M. Haddadi, N. Ramzan \& A.G. Olabi: Study and Simulation of the Energy Performances of a Grid-Connected PV System Supplying a Residential House in North of Algeria

Where, $R_{s}$ is series resistor, $R_{s h}$ is shunt resistor, $I_{p h}$ is photo-current, $V_{\text {th }}$ is thermal voltage of the diode, $I_{\text {sat1 }}$ and $I_{\text {sat } 2}$ are saturation current of the diode $D_{1}$ and $D_{2}, n_{1}$ and $n_{2}$ are ideality factors of the diode $\mathrm{D}_{1}$ and $\mathrm{D}_{2}$.

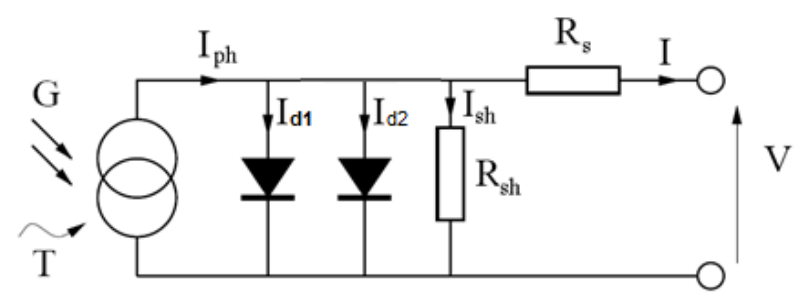

Figure 5. Equivalent circuit of a solar cell, model of two diodes

\subsection{Inverter}

In this section, an empirical model was introduced by SANDIA Laboratories (Sandia National Laboratories), the model was valid to all commercial inverters employed in PV systems. It is a simple model which allows calculating with precision the output power $\left(\mathrm{P}_{\mathrm{ac}}\right)$ according to the input power $\left(\mathrm{P}_{\mathrm{dc}}\right)$ of the inverter. This will be used model the dynamic behaviour of single-phase inverter (SMA1200) connected to the grid. The model requires an adjustment of the performance parameters (coefficients) under real conditions. The equations below describe the model of the inverter developed by the SANDIA laboratories. The DC voltage $\left(\mathrm{V}_{\mathrm{dc}}\right)$ and $\mathrm{DC}$ power $\left(\mathrm{P}_{\mathrm{dc}}\right)$ are considered as independent variables to calculate the output power of the inverter $\left(\mathrm{P}_{\mathrm{ac}}\right)[12]$.

Parameters with index "o" are constant values which are defined in reference conditions or nominal operation. The $\mathrm{C}_{0}, \mathrm{C}_{1}, \mathrm{C}_{2}$ and $\mathrm{C}_{3}$ are constant coefficients of the inverter model. The relationship between $\mathrm{P}_{\mathrm{ac}}$ as a function of $\mathrm{V}_{\mathrm{dc}}$ and $\mathrm{P}_{\mathrm{dc}}$ is given by the following equation (2).

$$
P_{a c}=\left[\frac{P_{a c 0}}{A-B}-C \cdot(A-B)\right] \cdot\left(P_{d c}-B\right)+C \cdot\left(P_{d c}-B\right)^{2}
$$

Where:

$$
\begin{aligned}
& A=P_{d c o} \times\left[1+C_{1} \times\left(V_{d c}-V_{d c o}\right)\right] \\
& B=P_{s o} \times\left[1+C_{2} \times\left(V_{d c}-V_{d c o}\right)\right] \\
& C=C_{o} \times\left[1+C_{3} \times\left(V_{d c}-V_{d c o}\right)\right]
\end{aligned}
$$



Protection (June $27^{\mathrm{TH}}-30^{\mathrm{TH}}, 2017$, BLED, SLOVENIA), RENEWABLE ENERGY SOURCES

I. Laib, A. Hamidat, M. Haddadi, N. Ramzan \& A.G. Olabi: Study and Simulation of the Energy Performances of a Grid-Connected PV System Supplying a Residential House in North of Algeria

Table 1. Performance Parameters of SMA1200

\begin{tabular}{lrrr}
\hline $\begin{array}{l}\text { Performance } \\
\text { settings }\end{array}$ & $\begin{array}{r}\text { Default } \\
\text { setting }\end{array}$ & $\begin{array}{r}\text { Laboratory } \\
\text { SANDIA }\end{array}$ & Units \\
\hline $\mathrm{P}_{\text {aco }}$ & 1200 & 1200 & $\mathrm{~W}$ \\
$\mathrm{P}_{\mathrm{dco}}$ & 1320 & 1320 & $\mathrm{~W}$ \\
$\mathrm{P}_{\text {so }}$ & 400 & 400 & $\mathrm{~W}$ \\
$\mathrm{~V}_{\mathrm{dco}}$ & 15 & 3.5 & $\mathrm{~V}$ \\
$\mathrm{C}_{0}$ & 0 & $-1.44 \mathrm{e}-8$ & $\mathrm{~W}-1$ \\
$\mathrm{C}_{1}$ & 0 & 1.385 & $\mathrm{~V}-1$ \\
$\mathrm{C}_{2}$ & 0 & -0.00284 & $\mathrm{~V}-1$ \\
$\mathrm{C}_{3}$ & 0 & 1.074 & $\mathrm{~V}-1$ \\
\hline
\end{tabular}

\subsection{Consumption profile}

The maximum power required and the daily energy consumed by the dwelling must be determined in order to realize the dimensioning of the electrification infrastructure. We estimated the mean hourly load curve of the habitat to be electrified. The consumption profile adopted in this study corresponds to the load profile generally encountered in suburban regions [13]. We chose a house equipped with all the appliances to provide comfort to the occupants. The characteristics of this house are:

- Three (3) rooms, corridor, courtyard.

- Lighting: Rooms, kitchen, toilet, bathroom, courtyard and corridor.

- Appliances: Refrigerator, TV, Radio, computer, laptop, Washing machine, Air Conditioner, and Fan.

We considered one consumption profiles for the winter and summer period. The number of hours of use of the equipment is determined according to the consumption Figure 6.

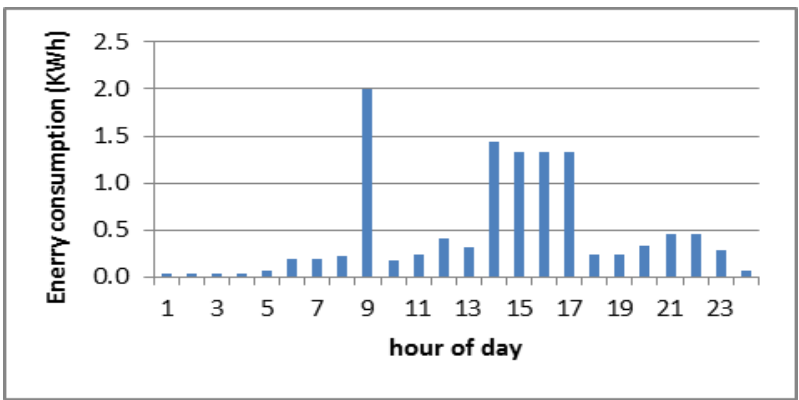

Figure 6. Daily load profile developed 
$358 \quad 10^{\text {TH }}$ InTERnAtional CONFERENCE ON Sustainable ENERGy AND ENVIRONMENTAL Protection (June $27^{\mathrm{TH}}-30^{\mathrm{TH}}, 2017$, Bled, SLOVENIA), RENEWABle ENERGy SOURCES I. Laib, A. Hamidat, M. Haddadi, N. Ramzan \& A.G. Olabi: Study and Simulation of the Energy Performances of a Grid-Connected PV System Supplying a Residential House in North of Algeria

Simulation and Results

\subsection{Simulation of electrical performances}

An elaborated Matlab-Simulink model was developed and the effect of different subsystem of a Grid-connected PV system was analysed. In the modelling, the demand side management was also considered. The simulation was performed with a real daily profile of data input from Algeria site, (the temperature, irradiance and the developed load profile). The capacity for the PV array and Inverter considered in the model was 1.2 KWp.

The daily electrical simulation results for the $1.2 \mathrm{kWp}$ PV system from two different days (One day was in summer and the author one was in winter) see Figure 7 and 8 . The following results are: the produced energy from PV, load power energy, the purchased energy, and the PV electricity exported to the grid for each hour during the day. We can notice that the PV system continues in generating the electricity on winter days (for example cloudy days), but not as much as on a summer day.

Figure 7 shows that in the summer day, the PV- electricity which is generated before 8 O'clock in the morning cannot meet the energy consumption that is needed, because the sun's irradiance was not sufficient. The PV energy begins to increase from 8 O'clock to 18 O'clock. Therefore, when the power is produced from the sun, it can effortlessly meet the need of the house's energy required. The extra energy generated by the PV system, connected to the home will be injected to the grid. After 19 O'clock the PV does not any energy thus, all the energy is bought from the grid. Figure 8 presents the production of the electricity in winter day where the power produced by the PV system could not encounter the energy consumption required between 9 O'clock to 18 O'clock. During the winter period especially when it is cloudy, the energy consumption is utterly purchased from the grid.

The daily electrical simulations results for a 1.2 kWp PV system are given in Fig 9(a) and 9(b). The total daily electricity consumption in the house from both PV system and the grid is load_ac $=6439 \mathrm{Wh} /$ day; The total daily Wh imported from the grid per (summer and winter day) which arises when the PV gives less power connected to the house electricity demand "Grid purchases" is Purchases_grid for summer 2593Wh/day and $4054 \mathrm{Wh} /$ day in winter; The total daily Wh produced by PV array for summer is $8483 \mathrm{Wh} /$ day and $3911 \mathrm{Wh} /$ day in winter, that happens when the PV produces extra energy connected to the house electricity demand "grid sales" is Injected_grid for summer $4636 \mathrm{Wh} /$ day and $1525 \mathrm{Wh} /$ day in winter.

\subsection{Daily Energy Production}

In winter, the daily rate of energy produced by the PV array was $49 \%$ of the total electric power produced in the house and daily energy imported by the grid was $51 \%$. But in 
$10^{\mathrm{TH}}$ InTERnational CONFerence on Sustainable EnERgy AND Environmental 359 Protection (June 27 $7^{\mathrm{TH}}-30^{\mathrm{TH}}, 2017$, BLED, SLOVEniA), ReNEWABLE ENERGy SOURCES

I. Laib, A. Hamidat, M. Haddadi, N. Ramzan \& A.G. Olabi: Study and Simulation of the Energy Performances of a Grid-Connected PV System Supplying a Residential House in North of Algeria

summer, daily rate of electricity produced by the PV array building was $67.6 \%$ and daily energy imported by the grid was $33.4 \%$.

\subsection{Daily Energy consumption}

In winter, the daily rate of electricity consumed by loads was $81 \%$ of the electric power consumption in the house and daily rate of electricity injected into a grid (sold to the grid) was $19 \%$. But in summer, the daily rate of electricity consumed by loads $58 \%$ and daily rate of electricity injected into a grid was $42 \%$.

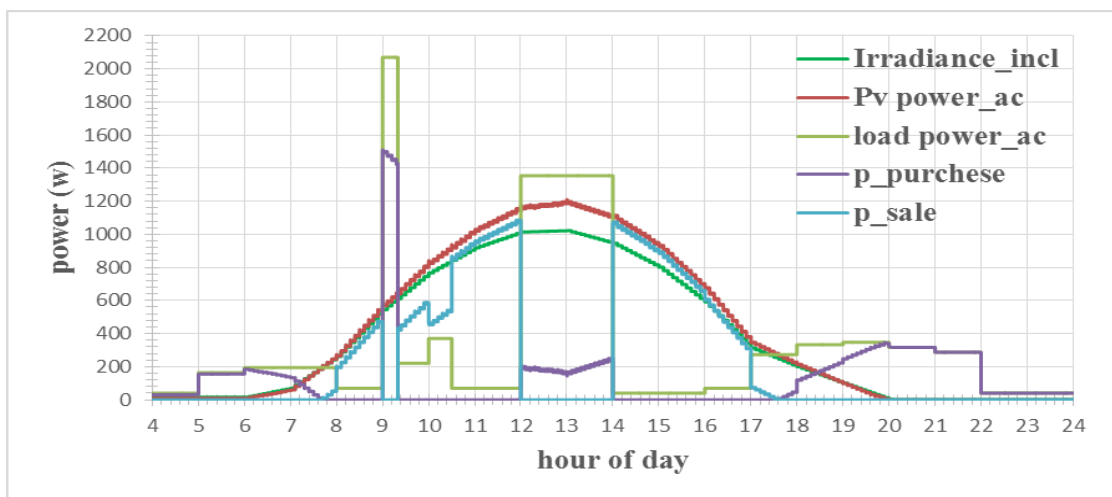

Figure 7. Matlab results for hourly electrical simulation of day in the summer

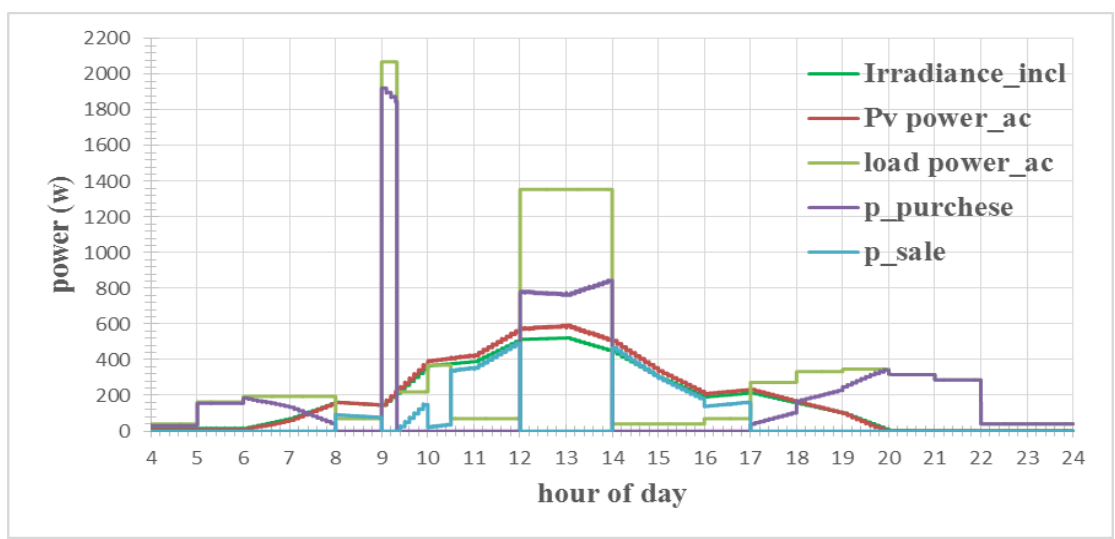

Figure 8. Matlab results for hourly electrical simulation of day in the winter 
$360 \quad 10^{\text {TH }}$ InTERnAtional CONFERENCE ON Sustainable ENERGy AND ENVIRONMENTAL Protection (June $27^{\mathrm{TH}}-30^{\mathrm{TH}}, 2017$, Bled, SLOVENIA), RENEWABle ENERGy SOURCES I. Laib, A. Hamidat, M. Haddadi, N. Ramzan \& A.G. Olabi: Study and Simulation of the Energy Performances of a Grid-Connected PV System Supplying a Residential House in North of Algeria

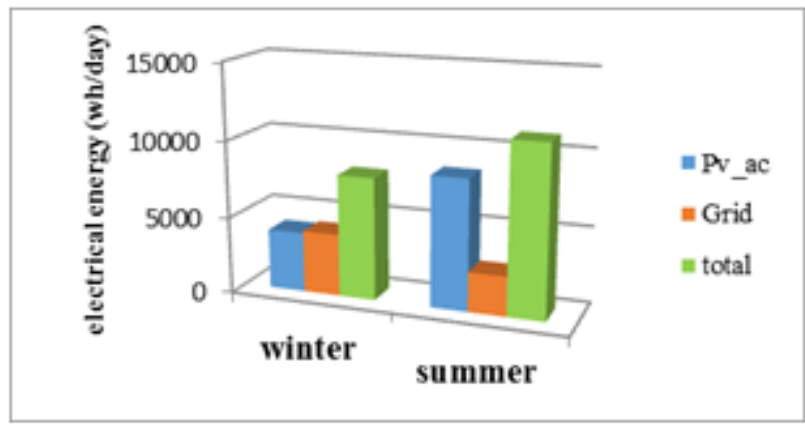

Fig 9(a) Daily electric power production

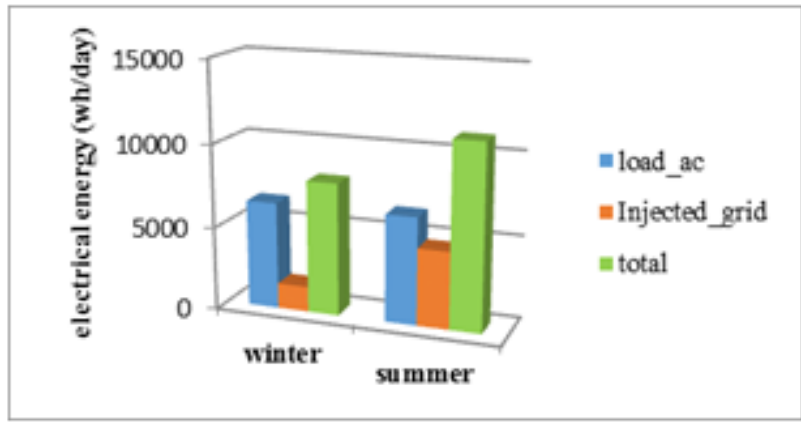

Fig 9(b) Daily electric power consumption

\section{$5 \quad$ Conclusion}

The study reveals that the grid-connected PV system might completely meet the energy needed for that house where we can still utilize the grid as a storage of electricity during night time when solar is energy is off.

The results of simulation of electrical performances are very effective and efficient. The daily energy balance on a summer day shows that photovoltaic produced more than the energy required for the house. Regarding the excess energy, it was exported to the grid for the storage. However, it was found that for a winter day, photovoltaic production is not sufficient to meet all of the demand. Nevertheless, in order to compensate the needed energy, we purchased from the provided grid.

The PV system generated the equal of $67.6 \%$ of the overall energy used in the house. The daily energy taken from the grid shows around $33.4 \%$ of the global energy utilized in the house, and the energy injected into the electricity grid is greater than the energy purchased from the grid. A positive balance of $2 \mathrm{kWh} /$ day was observed. The integration of 
I. Laib, A. Hamidat, M. Haddadi, N. Ramzan \& A.G. Olabi: Study and Simulation of the Energy Performances of a Grid-Connected PV System Supplying a Residential

House in North of Algeria

renewable energy sources in the house has shown to provide positive impact to the both the environment and to meet excess energy demands.

In addition to that, among the advantages of the system, we can find that it has no electrochemical storage and the benefits stresses on the less control and preventive maintenance of the system where also the cost can be reduced.

\section{References}

[1] M. Missoum, A. Hamidat and L. Loukarfi, "Impact of rural housing energy performance improvement on the energy balance in the North-West of Algeria", Energy and Buildings, Vol. 85, pp. 374-388, Dec. 2014.

[2] A. Semache, A.Hamidat and A. Benchatti, "Impact study of the solar energy on the energyperformances of the rural housing in Algeria", International journal of Heat and Technology, vol. 33, pp.229-236, 2015.

[3] R. Missaoui, G. Warkozek, S. Bacha, "PV Integration by Building Energy Management System”, Proceedings of the 2011 International Conference on Power Engineering, Energy and Electrical Drives, Málaga-Spain, May 2011, pp.

[4] M. Missoum, A. Hamidat, L. Loukarfi, "Impact of of a Grid-connected PV System application in a bioclimatic house toward the zero energy status in the north of Algeria", Energy and Buildings, Vol. 128, pp. 370-383, Sep. 2016.

[5] BP Statistical Review of World Energy, June 2016, http://www.bp.com/statisticalreview

[6] International Energy Agency, "IEA PVPS Trends 2016 in Photovoltaic Applications", Survey Report of Selected IEA Countries between 1992 and 2015, ISBN 978-3-90604245-9.

[7] H. Wirth, "Systems and Reliability, Recent Facts about Photovoltaics in Germany", Division Director Photovoltaic Modules, January 9, 2017,

[8] David Watts, Marcelo F. Valdés, and Andrea Watson, "Potential residential PV development in Chile: The effect of Net Metering and Net Billing schemes for gridconnected PV systems", Renewable and Sustainable Energy Reviews, Vol. 41, pp. 10371051, Jan. 2015

[9] S. Makhloufi and R. Abdessemed, "Type-2 Fuzzy Logic Optimum PV/inverter Sizing Ratio for Grid-connected PV Systems, Application to Selected Algerian Locations", Journal of Electrical Engineering and Technology, Vol. 6, pp. 731-741, Nov. 2011.

[10] A. Goetzberger and V.U. Hoffmann, "Photovoltaic solar energy generation", Springer Berlin Heidelberg New York, 2005.

[11] K. Ishaque, and Z. Salam, "Simple, fast and accurate two-diode model for photovoltaic modules", Solar Energy Materials and Solar Cells, vol. 95, pp. 586-594, 2011.

[12] D. L. King, S. Gonzalez and W.E Boyson, "Performance model for grid-connected photovoltaic inverters", Sandia National Laboratories, Tech. Rep, Sep. 2007.

[13] Y. Thiaux, J. Seigneurbieux, B. Multon and H. Ben Ahmed, "Load Profile Impact on the Gross Energy Requirement of Stand-Alone Photovoltaic System”, Renewable Energy, vol. 35, pp. 602-613, 2010. 
$362 \mid 10^{\mathrm{TH}}$ International CONFERENCE on Sustainable ENERgy AND ENVIRONMENTAL Protection (June 27 $7^{\mathrm{TH}}-30^{\mathrm{TH}}, 2017$, Bled, Slovenia), RENEWABle ENERGy SOURCES 
$10^{\mathrm{TH}}$ InTERnational Conference on Sustainable Energy and ENVIRONMENTAL Protection (June $27^{\mathrm{TH}}-30^{\mathrm{TH}}$, 2017, Bled, SLOVENIA), RENEWABLE ENERGy SOURCES

J. Krope, A.Ghani Olabi, D. Goričanec \& S. Božičnik

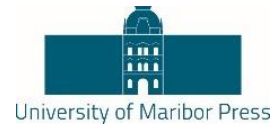

\title{
The Sustainability of Thermal Power Plant Unit Revitalization: Comparison of Two Multi-Criteria Methods
}

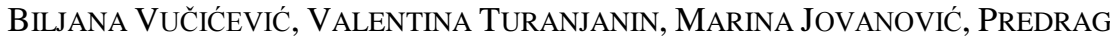 \\ ŠKOBALJ \& VUKMAN BAKIĆ
}

\begin{abstract}
Multi-Criteria Decision Making techniques provide solution for the problems involving multiple objectives with variety of indicators often in conflict with each other. The choice of multi-criteria methods that will be used to assess the sustainability of some of the observed complex system is the first step in sustainability determination. There is no ideal method and sometimes combination of methods may be required. The objective of this study is to apply two methods: Analytic Hierarchy Process (AHP) and Analysis and Synthesis of Parameters under Information Deficiency (ASPID) to the same complex system and to compare results. The energy system under investigation is the thermal power plant unit which should be revitalized. There are four options of this system presented by three indicators: economic, social and environmental, which express the essential features of the analysed options. The main difference of two multi-criteria techniques are based on different weighting factors subjective (AHP) and objective (ASPID). Rank options comparison is obtained using those two methods for the same set of priorities.
\end{abstract}

Keywords:• sustainability $\bullet$ power plant $\bullet$ AHP $\bullet$ ASPID $\bullet$ revitalization $\bullet$.

CORRESPONDENCE ADDRESS: Biljana Vučićević, Ph.D., Assistant Research Professor, University of Belgrade, Institute of Nuclear Sciences VINČA, Laboratory for Thermal Engineering and Energy, Mike Petrovića Alasa 12-14, 11351 Beograd, Serbia, e-mail: bee@vin.bg.ac.rs. Valentina Turanjanin, Ph.D., Associate Research Professor, University of Belgrade, Institute of Nuclear Sciences VINČA, Laboratory for Thermal Engineering and Energy, Mike Petrovića Alasa 12-14, 11351 Beograd, Serbia, e-mail: valentin@vin.bg.ac.rs. Marina Jovanović, Ph.D., Associate Research Professor, University of Belgrade, Institute of Nuclear Sciences VINČA, Laboratory for Thermal Engineering and Energy, Mike Petrovića Alasa 12-14, 11351 Beograd, Serbia, e-mail: marinaj@@vin.bg.ac.rs. Predrag Škobalj, Ph.D., Research Assistant, University of Belgrade, Institute of Nuclear Sciences VINCCA, Laboratory for Thermal Engineering and Energy, Mike Petrovića Alasa 12-14, 11351 Beograd, Serbia, e-mail: p.skobalj@ vin.bg.ac.rs. Vukman Bakić, Ph.D., Research Professor, University of Belgrade, Institute of Nuclear Sciences VINČA, Laboratory for Thermal Engineering and Energy, Mike Petrovića Alasa 12-14, 11351 Beograd, Serbia, e-mail: bakicv@ vin.bg.ac.rs.

https://doi.org/10.18690/978-961-286-061-5.32

ISBN 978-961-286-061-5

(C) 2017 University of Maribor Press

Available at: http://press.um.si. 
$10^{\mathrm{TH}}$ International Conference on Sustainable EnERgy and Environmental Protection (June $27^{\mathrm{TH}}-30^{\mathrm{TH}}, 2017$, BlED, SLOVENIA), RENEWABLE ENERGY SOURCES B. Vučićević, V. Turanjanin, M. Jovanović, P. Škobalj \& V. Bakić: The Sustainability of Thermal Power Plant Unit Revitalization: Comparison of Two Multi-Criteria Methods

\section{Introduction}

Sustainable development is widely used in various fields of life. Sustainability is the state of the system from economic, ecological and sociological point of view, which often have opposite effects on a given system. Therefore, to assess the sustainability of a system Multi Criteria Decision Making (MCDM) techniques are mainly used. In the past several years, the increase of using of MCDM techniques has been notable [1]. Authors have considered methodological characteristics of 15 different MCDM techniques in: number of criteria and indicators, normalization or the main economic activities related to the different case studies, published in 271 papers. Two of them are prominent: Analytical Hierarchy Process (AHP) and Weighted Arithmetic Mean (WMA). Conclusion from analysis is: there is nothing like the best suited MCDM method to be applied for any sustainability problem. For energy systems authors use different methods. In Finland [2], for a new sustainable residential area, evaluation of the best heating system for a new single-family house is done, taking into consideration different technical, economic, environmental and criteria of use. The Stochastic Multi-Criteria Acceptability (SMAA) method is used with mixed ordinal and uncertain cardinal information, and imprecise preference information. The 11 alternative heating systems were evaluated in terms of 15 criteria. The criteria have formed a two-level hierarchy of the main criteria and subcriteria.

For assessing the global sustainability of power plants [3], the problem of assessing the sustainability of different types of power plants is addressed. Recognizing the diversity of indicators and criteria to be taken into account, the paper proposed the MIVES method to assess sustainability in the energy sector. The proposed model was used to assess the sustainability of five conventional and five renewable power plants. With these techniques, authors have concluded that the differences between the electricity generation systems could be analysed in greater detail.

This indicates the need for MCDM methods comparisons to determine benefits of using certain methods in different areas of life. In this paper, for defining more preferably method in the case of thermal power revitalization, two MCDM techniques were compared: Analytical Hierarchy Process (AHP) and Analysis and Synthesis of Parameters under Information Deficiency (ASPID).

\section{Options for the Analysis of the Sustainability of Unit in Thermal Power Plant}

In this paper we have considered possibility of replacement of one old unit in the thermal power plant. Power plant unit of $32 \mathrm{MW}$ have been using lignite coal as a fuel. The four options for the revitalization of the old unit have been proposed in this paper. Sustainable development indicators, sets and subsets (indicators and sub-indicators) were formed for each proposed option. 
$10^{\mathrm{TH}}$ InTERnational CONFERENCE ON Sustainable ENERgy AND ENVIRONMENTAL 365

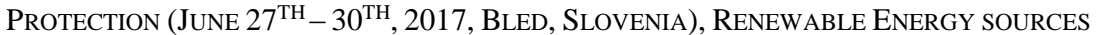

B. Vučićević, V. Turanjanin, M. Jovanović, P. Škobalj \& V. Bakić: The Sustainability of Thermal Power Plant Unit Revitalization: Comparison of Two Multi-Criteria

Methods

\subsection{Revitalization of unit in the condensational regime with coal (lignite) as a fuel - Option 1}

By improving combustion and technological process, the efficiency of the unit increases and specific consumption decreases with the same power of unit (32 MW). A fall in the specific unit consumption leads to a decrease in fuel consumption, which has an impact on the production of greenhouse gases (GHG) and reduces production cost of electric energy. The characteristics are: the combustion of lignite $(\mathrm{Hd}=7 \mathrm{MJ} / \mathrm{kg})$ in a boiler with an installed capacity of $32 \mathrm{MW}$ and specific heat consumption $12,5 \mathrm{MJ} / \mathrm{kWh}$.

\subsection{Revitalization of unit based on the co-combustion of coal (lignite) and waste matters - Option 2}

In this option considers the process of coal combustion (lignite) with waste materials (30\%) produced in the mining, transport, refilling and drying of coal which pollute the environment. Waste materials from the coal drying process are: coal dust, residue of condensate which contain tiny fractions of coal, the residue from waste water treatment resulting in the technological process of processing and refining of coal and postponed tailings in the process of cleaning coal. The possibility of co-combustion lignite and other matter created in the operating process of thermal power plant bring about numerous positive effects, especially from environmental point of view. $30 \%$ of the energy needed for the production of electricity would be received from dried coal dust and other waste material: coal dust $(27,000 \div 45,000 \mathrm{t} /$ year, $\mathrm{Hd}=15.6 \mathrm{MJ} / \mathrm{kg})$; residue of condensate $(8,000 \div 10,000 \mathrm{t} /$ year and $\mathrm{Hd}=4 \div 6 \mathrm{MJ} / \mathrm{kg})$; sludge from waste water treatment (approximately 12,500 t/year); postponed tailings $(200,000 \mathrm{t} /$ year, $\mathrm{Hd}=600 \div 3500$ $\mathrm{kJ} / \mathrm{kg}$, humidity around $35 \%$ ). Reduces greenhouse gas emissions and decreasing the amount of waste in the process of drying coal; $\mathrm{Hd}=3 \mathrm{MJ} / \mathrm{kg}$ for all waste matters [4].

\subsection{Revitalization of unit by gas-combustion in the condensational regime (combined gas-steam facility) - Option 3}

Thermal power plants with combined gas-steam facilities with power of $32 \mathrm{MW}$ have a significant decrease in the capital costs and significant increase in the overall efficiency compared to other conventional facilities. Moreover, there is the possibility of achieving production in a wide range of different levels of capacity utilization (flexibility of the facility) and a very short period is required for facility deployment [4]. The increase in the overall efficiency of combined facilities lays in the fact that heat production is realized at a significantly higher average temperature compared to a separate gas process. In Option 3, combined gas-steam facility at the threshold of $32 \mathrm{MW}$ in the condensational regime is considered. The biggest advantage of this option is the low specific heat consumption. There are other effects, such as lower investment costs, flexibility of the facility and decrease in environment pollution (decreasing $\mathrm{CO}_{2}$ emissions). 
$10^{\mathrm{TH}}$ InTERnAtional CONFERENCE ON Sustainable ENERgy AND ENVIRONMENTAL Protection (June $27^{\mathrm{TH}}-30^{\mathrm{TH}}, 2017$, Bled, SLOVEnia), RENEWABle ENERGy SOURCES B. Vučićević, V. Turanjanin, M. Jovanović, P. Škobalj \& V. Bakić: The Sustainability of Thermal Power Plant Unit Revitalization: Comparison of Two Multi-Criteria Methods

\subsection{Production of electricity from solar energy (photovoltaic) - Option 4}

Photovoltaic technology has developed at high speed and the price of the facilities has dropped significantly in the last decade. Solar energy represents $16.7 \%$ of the total exploitable potential of renewable energy sources (RES) in Serbia. The energy potential of solar radiation is about 30\% higher in Serbia than in Central Europe: the average value of the radiation is $1400\left[\mathrm{kWh} / \mathrm{m}^{2}\right.$ year]. In this option, facility with projected lifetime of 20 years, the power of $32 \mathrm{MW}$ and efficiency of $75 \%$ is considered [4].

\section{$3 \quad$ Indicators of Sustainability}

The four options have been proposed in this paper. Sustainable development indicators, sets and subsets (indicators and sub-indicators) were formed for each proposed option. In this paper, economic (Ec), environmental (En) and social (Sc) indicators were selected, defined and calculated for assessing the sustainability of thermal power plant for a projected lifetime of the plant of 20 years for the previously discussed options. To calculate these indicators, a set of sub-indicators for each of the indicators was formed (a total of 6 sub-indicators are considered in this paper).

Selected energy indicators of sustainable development:

1. $\mathrm{I}_{\mathrm{EP}}[\mathrm{kWh} / €]$ - Economic sub-indicators of electricity price: Production of electricity per all costs in a lifetime.

2. $\mathrm{I}_{\text {inv }}[\mathrm{kWh} / €]$ - Economic sub-indicators of investment: The installed capacity (MW) per investment amount of the considered option.

3. $\mathrm{I}_{\mathrm{CO} 2}[\mathrm{~kg} / \mathrm{kWh}]$ - Environmental sub-indicator of $\mathrm{CO}_{2}$ emission: Illustrative emissions of carbon-dioxide per produced of kWh of electricity.

4. $I_{\text {sal }}[€ / \mathrm{kWh}]$ - Social sub-indicator of cost of labour force: Represents cost of labour force per produced of $\mathrm{kWh}$ in lifetime of unit.

5. $\mathrm{I}_{\text {emp }}[1 / \mathrm{kWh}]$ - Social sub-indicator of employee: Represents number of employees per $\mathrm{kWh}$ produced in lifetime.

6. $I_{\text {sup }}[-]$ - Social sub-indicator of the safety of supply: Represents the value linked to resources, import of energy source and possibility of exploitation (renewable energy sources).

\section{$4 \quad$ Methodology}

Multiple-criteria decision making (MCDM) is a sub-discipline of operations research dealing with the application of advanced analytical methods to help make better decisions. Conflicting criteria, such as cost or price and, on the other hand, some measure of quality are typical in evaluating options [5]. Also, MCDM methods become very popular in decision-making for sustainable energy because of the multi-dimensionality of the sustainability goal and the system complexity. Specific advantage of MCDM 


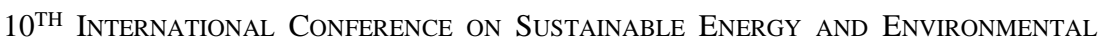

method in comparison with single criteria approach is ability to employ multi-criteria or attributes to obtain an integrated decision making result [6].

Table 1. Value of sustainability sub-indicators

\begin{tabular}{|l|c|c|c|}
\hline \multirow{2}{*}{ Option } & \multicolumn{2}{|l|}{ Economic sub-indicators } & $\begin{array}{c}\text { Environmental } \\
\text { sub-indicator }\end{array}$ \\
\cline { 2 - 4 } & $\begin{array}{c}\mathrm{I}_{\mathrm{EP}} \\
{[\mathrm{kWh} / €]}\end{array}$ & $\begin{array}{c}\mathrm{I}_{\text {inv }} \\
{[\mathrm{kWh} / €]}\end{array}$ & $\begin{array}{c}\mathrm{I}_{\mathrm{CO} 2} \\
{\left[\mathrm{kWh} / \mathrm{kgCO}_{2}\right]}\end{array}$ \\
\hline 1 (Coal) & 33.33 & 454.54 & 0.6623 \\
\hline $\begin{array}{l}2 \text { (Coal+ } \\
\text { waste) }\end{array}$ & 33.9 & 434.78 & 0.6098 \\
\hline 3 (Gas) & 11.36 & 217.39 & 2.3810 \\
\hline 4 (Sun) & 106.38 & 10 & 588.2353 \\
\hline \multirow{3}{*}{$\begin{array}{l}\text { Option } \\
\text { Social sub-indicators }\end{array}$} & $\mathrm{I}_{\text {sal }}[€ / \mathrm{kWh}]$ & $\mathrm{I}_{\mathrm{emp}}[1 / \mathrm{kWh}]$ & $\mathrm{I}_{\text {sup }}$ \\
\hline 1 (Coal) & 0.0059 & 90 & 0.95 \\
\hline $\begin{array}{l}2 \text { (Coal+ } \\
\text { waste) }\end{array}$ & 0.0065 & 100 & 0.9 \\
\hline 3 (Gas) & 0.0016 & 25 & 0.3 \\
\hline 4 (Sun) & 0.0084 & 20 & 0.3 \\
\hline
\end{tabular}

There are different multi-criteria decision-making methods for sustainable energy based on criteria selection, weighting, evaluation, and aggregation. For energy supply systems the criteria are perceived from the technical, economic, environmental and social aspects. The weighting methods of criteria are classified into three categories: subjective, objective and combination of weighting methods. Besides that, some methods based on weighted sum, priority setting, outranking, fuzzy set methodology and their combinations are employed for energy decision-making [6]. There is no ideal method and comparison of different method results, applied on the same energy system, can show us the level of their agreement.

The essence of the Analytical Hierarchy Process is decomposition of a complex problem into a hierarchy with goal at the top of the hierarchy, criterions and sub-criterions at levels and sub-levels of the hierarchy below the goal level, and decision alternatives at the bottom. Elements at given hierarchy level are compared in pairs to assess their relative preference with respect to each of the elements at the next higher level. The numeral Saaty's fundamental scale of 1-3-5-7-9 is used to assess the intensity of advantage between two elements. The first value of 1 indicates equal importance of the observed elements, then 3 means weak of moderate importance of one over another, 5 essential of strong importance, 7 very strongly and 9 indicates extremely more importance. The intermediate values between the two adjacent scale values (2-4-6-8) are used to represent compromise between the main priorities. Numeral ratio scale of comparison is used for 


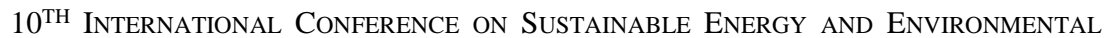
Protection (June $27^{\mathrm{TH}}-30^{\mathrm{TH}}, 2017$, Bled, SLOVEnia), RENEWABle ENERGy SOURCES B. Vučićević, V. Turanjanin, M. Jovanović, P. Škobalj \& V. Bakić: The Sustainability of Thermal Power Plant Unit Revitalization: Comparison of Two Multi-Criteria Methods

quantifiable and non-quantifiable elements' weighting. The AHP method computes and aggregates their eigenvectors until the final vector of weight coefficients for alternatives is obtained. This vector reflects the relative importance of each alternative with respect to the hierarchy top goal [7]. A decision maker may use this vector due to his particular needs and interests as a subjective way of weighting. Putting the results of pair wise comparison based on Saaty's fundamental scale, the matrix of pair wise comparison is obtained. After calculation of the weight vector, it is then multiplied with the weight coefficient of the element at a higher level (that was used as criterion for pair wise comparisons). After repetition of procedure upward for each level, the overall weight coefficient, with respect to the goal for each alternative is obtained [7].

The ASPID is a mathematical method based on the synthesis of fuzzy sets as a technique for a MCDM process [8]. Weight coefficients are determined mathematically, by choosing them from a finite set of weighting factors. The number of elements, necessary for getting finite set of weighting factors, depends on the chosen divider of segment between 0 and 1 and on initial number of specific criteria and restrictions based on the available set of non-numerical information. Restrictions are given in a form of equality and inequality to vest priority to some criteria among other and to determine different aspects of the sustainability development. In this manner, weighting factors are determined mathematically. On the other hand, the process of normalization converts absolute indicator values into a fuzzy set of normalized indicators. Numerically normalized indicator values and weight coefficients are input values for getting indicator of system quality measurement by their agglomeration using additive form of function. The sum of criteria multiplied with the corresponding weighting factor will give a sustainability assessment for all cases under consideration [9].

\section{$5 \quad$ Results and Discussion}

In this paper, four cases were selected and based on them, priority was given as in the Table 2 on two levels: the first level is for the sub-indicators, and the second one for indicators. The weight coefficients of each indicator and sub-indicator within the cases are calculated using the ASPID method. For the AHP method, pairwise comparison matrix of the main criteria (indicators) with respect to the goal and pairwise comparison matrices for the sub-criteria (sub-indicators) with respect to each criterion are formed according to weight coefficients values calculated by ASPID methodology and normalized. For the case no. 3, these values are shown in Tables 3 and 4, and they are obviously similar for both methods. The same was done for the sub-criteria (subindicators). 
Table 2. Cases Constrains

\begin{tabular}{|l|c|c|c|}
\hline & \multicolumn{2}{|c|}{ First level } & Second level \\
\hline Case 1 & $\mathrm{I}_{\mathrm{EP}}>\mathrm{I}_{\text {inv }}$ & $\mathrm{I}_{\text {sal }}>\mathrm{I}_{\text {emp }}=\mathrm{I}_{\text {sup }}$ & $\mathrm{Ec}>\mathrm{En}=\mathrm{Sc}$ \\
\hline Case 2 & $\mathrm{I}_{\mathrm{EP}}>\mathrm{I}_{\text {inv }}$ & $\mathrm{I}_{\text {sal }}=\mathrm{I}_{\text {emp }}=\mathrm{I}_{\text {sup }}$ & $\mathrm{En}>\mathrm{Sc}=\mathrm{Ec}$ \\
\hline Case 3 & $\mathrm{I}_{\mathrm{EP}} \mathrm{I}_{\text {inv }}$ & $\mathrm{I}_{\text {emp }}>\mathrm{I}_{\text {sup }}>\mathrm{I}_{\text {sal }}$ & $\mathrm{Sc}>\mathrm{En}=\mathrm{Ec}$ \\
\hline Case 4 & $\mathrm{I}_{\mathrm{EP}}>\mathrm{I}_{\text {inv }}$ & $\mathrm{I}_{\text {sup }}>\mathrm{I}_{\text {sal }}=\mathrm{I}_{\text {emp }}$ & $\mathrm{Ec}>\mathrm{Sc}>\mathrm{En}$ \\
\hline
\end{tabular}

Table 3. Indicator and sub-indicator weight coefficients and standard deviations (ASPID) - Case 3

\begin{tabular}{|l|c|c|c|}
\hline $\begin{array}{l}\text { weight } \\
\text { coefficient }\end{array}$ & Ec & En & Sc \\
\hline indicator & 0.1643 & 0.1643 & 0.6714 \\
\hline \multirow{3}{*}{ sub-indicator } & $\left(\mathrm{I}_{\mathrm{EP}}\right) 0.5$ & 1.0 & $\left(\mathrm{I}_{\text {sal }}\right) 0.104$ \\
\cline { 2 - 4 } & $\left(\mathrm{I}_{\text {inv }}\right) 0.5$ & - & $\left(\mathrm{I}_{\text {emp }}\right) 0.618$ \\
\cline { 2 - 4 } & - & - & $\left(\mathrm{I}_{\text {sup }}\right) 0.278$ \\
\hline
\end{tabular}

Table 4. Normalized value of the main criteria (indicators) with respect to the goal (AHP) - Case 3

\begin{tabular}{|l|c|c|c|}
\hline $\begin{array}{l}\text { weight } \\
\text { coefficient }\end{array}$ & Ec & En & Sc \\
\hline indicator & 0.1667 & 0.1667 & 0.6666 \\
\hline \multirow{3}{*}{ sub-indicator } & $\left(\mathrm{I}_{\mathrm{EP}}\right) 0.5$ & 1.0 & $\left(\mathrm{I}_{\text {sal }}\right) 0.10$ \\
\cline { 2 - 4 } & $\left(\mathrm{I}_{\text {inv }}\right) 0.5$ & - & $\left(\mathrm{I}_{\text {emp }}\right) 0.60$ \\
\cline { 2 - 4 } & - & - & $\left(\mathrm{I}_{\text {sup }}\right) 0.30$ \\
\hline
\end{tabular}

The results are shown in the Table 5. Due to the different ways of the problem approach, the results can not be directly compared. According to the ASPID methodology sustainability index value is from 0 to 1 range, whereas for the AHP method option rankings sum is 1 . Therefore, we can only compare the obtained option ranks.

In cases 1, 2 and 4 the same rankings were obtained, and the results are similar for both methods regardless to the obvious differences between absolute values of sustainability index options. For example: Similar evaluation of results was made by normalization of Sustainability Index values calculated by ASPID method. Results are shown in Table 6 together with option ranks by the AHP method for the Case no. 2. Based on these values it can be concluded that the AHP method gives the greatest importance to the Option 4 0.7671 , while corresponding value according to the ASPID method is 0.4860 . If we compare the ratio of other ranks in both methods, the importance of Option 1 and 2 is nearly three times higher than in Option 3. 

$10^{\text {TH }}$ International CONFEREnce on Sustainable Energy and Environmental Protection (June $27^{\mathrm{TH}}-30^{\mathrm{TH}}, 2017$, Bled, SLOVEnia), RENEWABle ENERGy SOURCES B. Vučićević, V. Turanjanin, M. Jovanović, P. Škobalj \& V. Bakić: The Sustainability of Thermal Power Plant Unit Revitalization: Comparison of Two Multi-Criteria Methods

There is a difference in option ranking in Case 3:

- According to the ASPID method the options' order is 2,1,4,3;

- According to the AHP method 2,4,1,3.

The results obtained by ASPID method show that the sustainability index value of the option 1 is almost three times higher than for the option 3 and ranks for both options by AHP differ less than 1\%. For the Case 3, restrictions are given in Table 2:

- At the first level, for the economic indicator $\mathrm{Ec}, \mathrm{I}_{\mathrm{EP}}$ is equal to $\mathrm{I}_{\mathrm{inv}}$. There is only one sub-indicator of environmental indicator, and for the social indicator Sc relations between sub-indicators are $\mathrm{I}_{\mathrm{emp}}>\mathrm{I}_{\text {sup }}>\mathrm{I}_{\text {sal }}$.

- At the second level, relations between indicators are $\mathrm{Sc}>\mathrm{En}=\mathrm{Ec}$.

The social indicator Sc has the largest weighting factor, while the weighting factors of two other indicators are equal.

If we compare the social sub-indicator values for options 1 and 4 , the conclusion is that the results obtained by ASPID method are more logical. For a more detailed analysis is necessary to carry out sensitivity analysis related to the sub-indicator values and the impact of weighting factors changes.

Table 5. Options rang

\begin{tabular}{|l|l|l|l|l|}
\hline \multirow{2}{*}{} & \multicolumn{2}{|c|}{ Case 1 } & \multicolumn{2}{c|}{ Case 2 } \\
\cline { 2 - 5 } & \multicolumn{1}{|c|}{ ASPID } & AHP & ASPID & AHP \\
\hline Option 1 & 0.5369 & 0.2088 & 0.3878 & 0.0976 \\
\hline Option 2 & 0.5494 & 0.2109 & 0.3952 & 0.0999 \\
\hline Option 3 & 0.0353 & 0.0781 & 0.1441 & 0.0351 \\
\hline Option 4 & 0.9535 & 0.5021 & 0.8767 & 0.7671 \\
\hline & \multicolumn{2}{|c}{ Case 3 } & \multicolumn{2}{c|}{ Case 4 } \\
\cline { 2 - 5 } & ASPID & AHP & ASPID & AHP \\
\hline Option 1 & 0.8398 & 0.2974 & 0.6466 & 0.2521 \\
\hline Option 2 & 0.8483 & 0.3109 & 0.6385 & 0.2502 \\
\hline Option 3 & 0.0353 & 0.0938 & 0.0223 & 0.0906 \\
\hline Option 4 & 0.2837 & 0.2978 & 0.7497 & 0.4070 \\
\hline
\end{tabular}


Table 6. Options rang for Case 2 with normalized SI for ASPID

\begin{tabular}{|l|c|c|c|}
\hline \multirow{2}{*}{} & \multicolumn{3}{|c|}{ Case 2 } \\
\cline { 2 - 4 } & ASPID & $\begin{array}{c}\text { ASPID - } \\
\text { normalized SI }\end{array}$ & AHP \\
\hline Option 1 & 0.3878 & 0.2150 & 0.0976 \\
\hline Option 2 & 0.3952 & 0.2191 & 0.0999 \\
\hline Option 3 & 0.1441 & 0.0799 & 0.0351 \\
\hline Option 4 & 0.8767 & 0.4860 & 0.7671 \\
\hline
\end{tabular}

\section{Conclusion}

Due to the large number of factors that may influence the decision-making process in the evaluation of the various options, the determination of MCDM became increasingly important.

This paper shows a comparison of results of two different methodologies (ASPID and AHP) in the process of ranking different options for power plant unit revitalization from the sustainable development point of view.

The results show a certain concurrence in considered methods but, on the other hand, some differences too. Four different cases have been taken into consideration and for three of them the same ranks were obtained as a result. Case 3 indicates that more reliable results can be obtained by ASPID method. However, to be sure that ASPID methodology is more convenient for this type of energy system, deeper analysis is necessary. Number of sub-indicators and number of cases should be increased, and sensitivity analysis of the sub-indicators and the impact of weighting factors' changes should be conducted.

It should be emphasized that the AHP methodology is not fully implemented: pairwise comparison matrix of the main criteria (indicators) with respect to the goal, and pairwise comparison matrices for the sub-criteria (sub-indicators) with respect to each criterion were not made on the basis of evaluation of one or more experts, due to our standpoint that the methodology comparison in that case will not be good enough. This is another aspect that should be included in the final conclusion of which methodology is more convenient for the analysed coal power plant revitalisation problem.

\section{Acknowledgements}

The authors would like to express their appreciation for the efforts of the Ministry of Education, Science and Technological Development of Republic of Serbia in supporting and promoting this work through scientific project referenced III42008. 
$10^{\mathrm{TH}}$ International Conference on Sustainable EnERgy and Environmental Protection (June $27^{\mathrm{TH}}-30^{\mathrm{TH}}, 2017$, BlED, SLOVENIA), RENEWABLE ENERGy SOURCES B. Vučićević, V. Turanjanin, M. Jovanović, P. Škobalj \& V. Bakić: The Sustainability of Thermal Power Plant Unit Revitalization: Comparison of Two Multi-Criteria Methods

\section{References}

[1] L. Diaz-Balteiro, J. González-Pachón, C. Romero, "Measuring systems sustainability with multi-criteria methods: A critical review", European Journal of Operational Research, vol. 258, pp. 607-616, 2017

[2] Kaisa Kontu, Samuli Rinne, Ville Olkkonen, Risto Lahdelma, Pekka Salminen, "Multicriteria evaluation of heating choices for a new sustainable residential area", Energy and Buildings, vol. 93, pp. 169-179, 2015

[3] Juan Jose Cartelle Barros, Manuel Lara Coira, María Pilar de la Cruz Lopez, Alfredo del Cano Gochi, "Assessing the global sustainability of different electricity generation systems”, Energy, vol. 89, pp. 473-489, 2015

[4] P. Skobalj, M. Kijevcanin, N. Afgan, M. Jovanovic, V. Turanjanin, B. Vucicevic, "Multicriteria sustainability analysis of thermal power plant Kolubara-A Unit 2", Energy, vol. 125, pp. 837-847, 2017

[5] https://en.wikipedia.org/wiki/Multiple-crite ria_decision_analysis

[6] J.J. Wang, Y.Y. Jing, C.F. Zhang, J.H. Zhao, "Review on multi-criteria decision analysis aid in sustainable energy decision-making", Renewable and Sustainable Energy reviews, vol.13, pp. 2263-2278, 2009

[7] S.D. Pohekar and R.M. Ramachandran, "Application of multi-criteria decision making to Sustainable energy planning-A review”, Renewable and Sustainable Energy reviews, vol. 8, pp. 365-381, 2004

[8] N. Hovanov, ASPID-METHOD: Analysis and Synthesis of Parameters Under Information Deficiency. St. Petersburg: St. Petersburg State University, 1996.

[9] N. Afgan, "Sustainability paradigm: Intelligent energy system", Sustainability, vol. 2(12), pp. 3812-3830, 2010. 
$10^{\mathrm{TH}}$ INTERNATIONAL CONFERENCE ON Sustainable ENERgy AND ENVIRONMENTAL Protection (June $27^{\mathrm{TH}}-30^{\mathrm{TH}}$, 2017, Bled, SLOVENIA), RENEWABLE ENERGy SOURCES

J. Krope, A.Ghani Olabi, D. Goričanec \& S. Božičnik

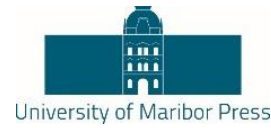

\title{
A Case Study of Solar Energy Application in Enhanced Oil Recovery
}

\author{
Hamed A. Hamed, Ahmed A. Abdel-Rehim, Attia M. Attia \& Ahmed A. A. Attia
}

\begin{abstract}
Steam process is one of the most beneficial thermal enhanced oil recovery (TEOR) techniques, which is applied for heavy oil reservoirs to decrease viscosity, thus increasing the production rate. Traditionally, producing steam for TEOR requires consumption of massive amount of natural gas. Issaran Field is one of the largest heavy and extra heavy oil field in the world that was discovered in 1981 in Egyptian Eastern Desert. The required demand of steam for Issaran field is $25,000 \mathrm{bbl}$./day at $550{ }^{\circ} \mathrm{F}$ and 1000 psi. The objective of this study is to design a parabolic trough collectors (PTC) plant, which fulfils the required steam consumption need by Issaran heavy oil field. Results showed that solar energy has the ability to generate steam at the same quality as gas-fired system. PTC plant will produce almost $44.3 \%$ of total required steam. The cost of steam produced will be $0.658 \$$ /steam bbl instead of 3 \$ from gas-fired system. The cost of producing oil from the hybrid system is in average $19.8 \$ / \mathrm{bbl}$ instead of 25 $\$ /$ bbl from gas-fired system.
\end{abstract}

Keywords:• enhanced oil recovery $\bullet$ solar energy $\bullet$ parabolic trough collector $\bullet$ steam injection $\bullet$ heat transfer fluid

CoRrespondence AdDress: Hamed A. Hamed, MSc., Teaching Assistant, The British University in Egypt, Faculty of Engineering, Petroleum Engineering Department, Misr-Ismalia Road El Sherouk City, Cairo, Egypt, e-mail: hamed.ali@bue.edu.eg. Ahmed A. Abdel-Rehim, PhD., Associated Professor, The British University in Egypt, Faculty of Engineering, Mechanical Engineering Department, Misr-Ismalia Road El Sherouk City, Cairo, Egypt, e-mail: ahmed.azim@bue.edu.eg. On business leave from Shoubra Faculty of Engineering, Benha University, Attia M. Attia, PhD., Professor, The British University in Egypt, Faculty of Engineering, Petroleum Engineering Department, Misr-Ismalia Road El Sherouk City, Cairo, Egypt, e-mail: attia.attia@bue.edu.eg. Ahmed A. A. Attia, PhD., Associated Professor, Shoubra Faculty of Engineering, Benha University, Cairo, Egypt; email: ahmed_attia72@yahoo.com.

https://doi.org/10.18690/978-961-286-061-5.33

ISBN 978-961-286-061-5

(C) 2017 University of Maribor Press

Available at: http://press.um.si. 
$10^{\text {Th }}$ International Conference on Sustainable Energy and Environmental Protection (June $27^{\mathrm{TH}}-30^{\mathrm{TH}}, 2017$, BlED, SLOVENIA), RENEWABLE ENERGY SOURCES H. A. Hamed, A. A. Abdel-Rehim, A. M. Attia \& A. A. A. Attia: A Case Study of Solar Energy Application in Enhanced Oil Recovery

\section{$1 \quad$ Introduction}

In 1981, one of the largest heavy oil field in the world was discovered. This field is called "Issaran Field". Issaran field is considered one of the few fractured carbonate heavy oil reservoirs in the world. It was discovered in the Egyptian Eastern Desert as shown in Figure (1). The location of Issaran Field is $290 \mathrm{~km}$ southeast of Cairo and $3 \mathrm{~km}$ inland from the western shore of Suez Gulf, and covering an area of 20,000 acres [1].

The initial oil in place in Issaran field is approximately $700 \mathrm{MM}$ bbl, and its estimated reserve was approximately $500 \mathrm{MM}$ bbl. This field has a viscosity range of 3,000-5,000 $\mathrm{cp}$, and API gravity range of 90-120 API, which means that it contains heavy and extra heavy oil. Issaran field has five different formations as shown in Figure (2) created in Miocene age each one has its own unique characteristics, which are Ziet Formation (sandstone), Upper Dolomite formation, Lower Dolomite formation, Ghaeandal formation, and the deepest zone called Nukhul formation that has a depth 1,000 - 2,000 ft [1].

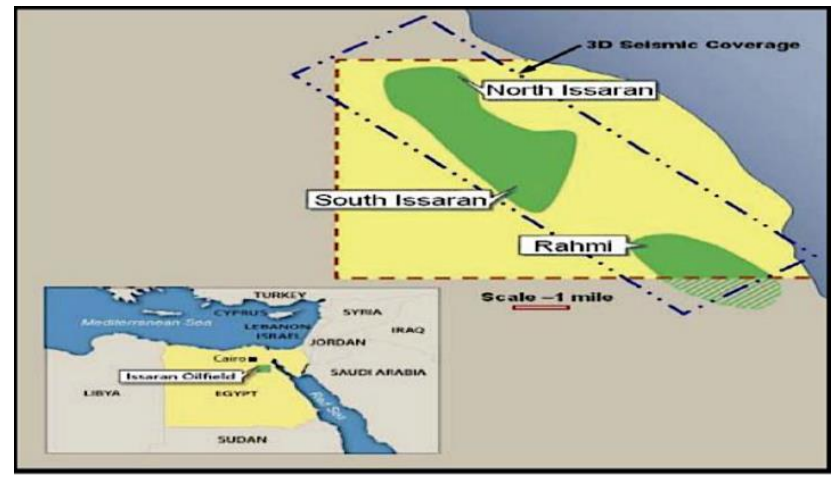

Figure 1. Issaran Field Location [1]

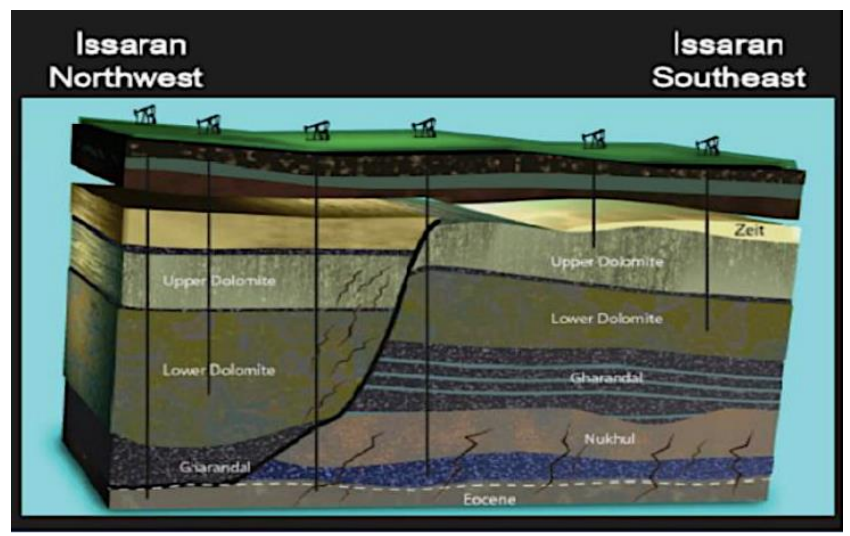

Figure 2. Issaran Field Formation [2] 
$10^{\text {TH }}$ InTERnAtional CONFERENCE on Sustainable EnERgy AND ENVIRONMENTAL 375 Protection (June $27^{\mathrm{TH}}-30^{\mathrm{TH}}, 2017$, BLED, SLOVENIA), RENEWABLE ENERGY SOURCES H. A. Hamed, A. A. Abdel-Rehim, A. M. Attia \& A. A. A. Attia: A Case Study of Solar Energy Application in Enhanced Oil Recovery

From 1981 to 1987, the initial development of Issaran field was started with the drilling of 8 wells. The cumulative production up to 1998 was $0.7 \mathrm{MM}$ bbl from 9 wells. In 1998, the heavy oil project was started, after creating a joint venture between General Petroleum Company GPC and Scimitar Production Egypt Ltd. The Initial oil in place at that time was $410 \mathrm{MM}$ BBL, reserve $0.2 \mathrm{MM} \mathrm{BBL}$, recovery factor less than $1 \%$, the average production per well was below $30 \mathrm{BOPD}$, and the total field daily production was 170 STBOPD. In 1999, nine wells had been drilled in the field with a cumulative production of about 450 STBOPD. Generally, the primary recovery from such unconventional reservoirs cannot exceed $1 \%$, with ultimate recovery less than $30 \%$. Therefore, Issaran field did not command high priority, due to its low productivity and the low prices of its heavy and extra heavy crude oil [2].

In 2000, the Egyptian government made a great effort to develop Issaran field, due to the Global price increasing of crude oil. Consequently, the production rate reached 1,800 STBOPD from 5 new-drilled wells. In Jan 2006, the production rate was approximately 2,000 STBOPD, when EGPC's interest was acquired by Rally petroleum of Canada. Rally petroleum is a company with experience in the Canadian oil sands. Canadian oil sands have almost the same fluid properties of this heavy crude oil in Issaran field. Nukhul had been planned to develop with cold, due to its high fracture permeability. However, these high permeability layers soon created unwanted water channelling to the wellbore leading to high water cuts [3].

In August 2010, it was decided to apply the continuous steam flooding technique. The main objective of the continuous steam is to inject the steam in the up-dip of the producer wells to allow for gravity drainage, with the main withdrawal points being around the "magic fault". In 2013, 74 production wells were working to produce from south upper dolomite by continuously steam injecting in 21 injection wells. The steam flooding has worked well till the instantaneous steam oil ratio ISOR was equal to 10 , which means that getting closer to uneconomical limits. ISOR is the ratio of the steam injected to the oil produced. ISOR is the key indicator of the economics of a steam drive project [3].

In 2014, a modified technique called "Steam Pulse Injection" SPI was tested in the upper dolomite south development to allow the project to continue at an economical rate. It is considered the first time using SPI technique in a dolomite formation. The main objective of using SPI technique was to minimize ISOR, and consequently minimizing the operating costs to an economical limit. After applying SPI technique, the overall ISOR was halved to an economical average of 5. Steam Pulse Injection was applied not only to minimize the operational costs, but also to get the benefits of the pressure release phenomenon that releases trapped oil from the matrix towards the fracture system and producing wells [3].

\section{Solar Thermal Enhanced Oil Recovery Techniques}

Solar thermal enhanced oil recovery is a modified technique of thermal enhanced oil recovery EOR. Solar TEOR is simply using solar energy to generate steam that will be 
$10^{\text {TH }}$ International CONFEREnce on Sustainable Energy and Environmental Protection (June $27^{\mathrm{TH}}-30^{\mathrm{TH}}, 2017$, Bled, SLOVENIA), RENEWABle ENERGy SOURCES H. A. Hamed, A. A. Abdel-Rehim, A. M. Attia \& A. A. A. Attia: A Case Study of Solar Energy Application in Enhanced Oil Recovery

injected in heavy oil reservoir instead of using gas-fired system. There are several categories of solar thermal technologies. Only two techniques are currently applied for solar EOR, which are; Enclosed Trough and Central Tower [4].

\subsection{Enclosed Trough}

Enclosed trough is simply a solar parabolic trough collector located inside a glasshouse. The purpose of this glasshouse is to protect and increase the efficiency of the solar parabolic trough collectors system. A single axis tracking system positions the collectors to track the sun and concentrate its light on the receiver pipes, also suspended from the glasshouse structure. One of the main advantage of this system is the ability of using reservoir water to generate the required amount of steam, without need of water treatment [5].

\subsection{Central tower}

Central tower has been initially designed for electrical generation. It is simply using large tracking mirrors called heliostats that will focus solar radiation in the boiler that filled with water located at the central tower to produce steam. The produced steam is then used either for steam purposes like in solar TEOR or for generating electricity [6].

\section{$3 \quad$ Solar Thermal Enhanced Oil Recovery Projects; Case Studies}

\subsection{Coalinga solar thermal EOR project}

In 2009, the cooperation between Chevron Corp. and Bright Source Energy began construction of a $29 \mathrm{MW}$ solar thermal project at the Coalinga Oil Field in Fresno County, California. In October 2011, the project has been revealed. This project has spanned 100 acres and has 3,822 large tracking heliostats, each with two $10 \mathrm{ft}$ by $7 \mathrm{ft}$ mirrors mounted on a $6 \mathrm{ft}$ steel pole concentrating the solar radiation on a $327 \mathrm{ft}$ solar central tower. The Bright Source Energy was responsible to apply its solar technology, engineering and production, and construction services, while Chevron Corp. Ventures was the project operations management. Unfortunately, Chevron Corp. spent more than 28 million US dollar on this contract, and Bright Source Energy has lost at least 40 million US dollar on this project and disclosure will lose much more [6].

\subsection{McKittrick Solar Thermal EOR projects}

In February 2011, the first commercial solar TEOR project in the world has been installed by the cooperation between GlassPoint Solar and Berry Petroleum. The project was located on McKittrick Oil Field in McKittrick, California. This solar EOR project has been installed in less than six weeks, and spanned approximately 1 acre and produce around 1 million Btu per hour of solar heat $[4,6]$. 


\subsection{Solar Thermal EOR project in Oman}

Shell Corporation has teamed with an investment fund from Oman to invest 53 million US dollar in Glasspoint Solar Inc. to fabricate an enclosed trough to generate the required demand of steam for TEOR process in Amal oilfield. This solar TEOR facility produces 50 metric tons of steam per day for injection, is a $7 \mathrm{MW}$ installation. The use of renewable energy like solar power makes great economic sense, as the fuel cost associated with this EOR technology is practically zero. However, solar steam has zero $\mathrm{CO}_{2}$ emission, instead of the steam that is produced due to natural gas burning $[7,8]$.

The main objective of this study, after finishing the literature review is to design a parabolic trough collectors (PTC) plant, which fulfils the required steam consumption need by Issaran heavy oil field.

\section{$4 \quad$ Design, Results and Discussion}

HTF is usually used in PTC systems that dealing with temperatures greater than $200{ }^{\circ} \mathrm{C}$, due to the high pressure that will be inside the receiver tubes and piping, if water is used. Therefore, it is required to use stronger joints and piping to withstand this high pressure. Actually, this will increase the PTC cost and thus the entire solar field. a mixture of water/ethylene glycol or pressurized liquid water is usually used For temperatures less than $200{ }^{\circ} \mathrm{C}$, because the required pressure to maintain fluid in liquid phase is moderate [4].

Parabolic trough collectors system has been designed as shown in Figure (3) to heat up HTF that is implemented in the system, which is BP Transcal N, and then used to transfer its heat to feedwater in heat exchanger to generate the required steam. The designing process started with identifying the demand required by Issaran Field. This process is followed by applying the mathematical calculations for designing this PTC system as illustrated and discussed in [10]. The optical and geometrical Parameters of the designed PTC are presented in Table (1).

The schematic diagram of the designed PTC is shown in figure (4).

The solar energy is varied in Issaran oil field due to the seasonal change as shown in Figure (5).

The heat gain by single PTC due to the change in solar radiation is represented in Table (2). 
$10^{\text {TH }}$ International Conference on Sustainable Energy and Environmental Protection (June $27^{\mathrm{TH}}-30^{\mathrm{TH}}, 2017$, Bled, SLOVENIA), RENEWABLE ENERGy SOURCES H. A. Hamed, A. A. Abdel-Rehim, A. M. Attia \& A. A. A. Attia: A Case Study of Solar Energy Application in Enhanced Oil Recovery

Table 1. Optical and Geometrical Parameters of PTC

\begin{tabular}{|l|c|}
\hline \multicolumn{1}{|c|}{ Parameter } & Value \\
\hline Length (m) & 9 \\
\hline Aperture width (m) & 8.2 \\
\hline Focal Distance (m) & 1.22 \\
\hline Aperture area (m $\left.{ }^{2}\right)$ & 73.629 \\
\hline Concentration ratio & 137 \\
\hline Reflector reflectivity & 0.89 \\
\hline Type of receiver & $\begin{array}{c}\text { Red coated } \\
\text { Copper }\end{array}$ \\
\hline Glass cover & $\begin{array}{c}\text { Transparent 4mm } \\
\text { glass }\end{array}$ \\
\hline Type of steel & not selected \\
\hline Receiver outer diameter (m) & 0.019 \\
\hline Receiver thickness (m) & 0.003 \\
\hline Receiver inner diameter (m) & 0.016 \\
\hline Receiver length (m) & 9 \\
\hline Absorptivity & 0.9 \\
\hline Emittance & $0.023-.052$ \\
\hline Glass transmissivity & 0.95 \\
\hline
\end{tabular}

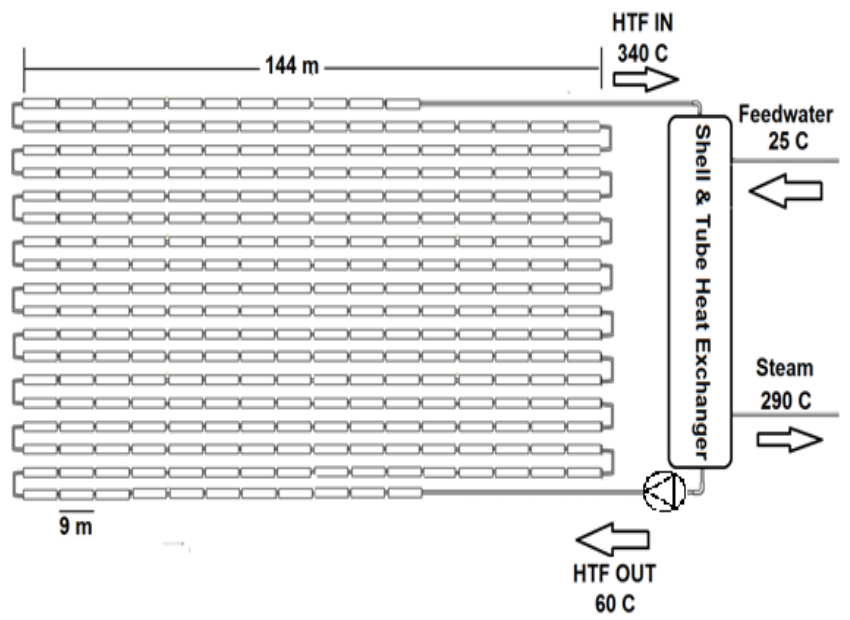

Figure 3. Schematic Diagram of Designed PTC 
$10^{\mathrm{TH}}$ International Conference on Sustainable Energy and Environmental Protection (June $27^{\mathrm{TH}}-30^{\mathrm{TH}}, 2017$, Bled, Slovenia), Renewable Energy SOURCeS H. A. Hamed, A. A. Abdel-Rehim, A. M. Attia \& A. A. A. Attia: A Case Study of Solar Energy Application in Enhanced Oil Recovery

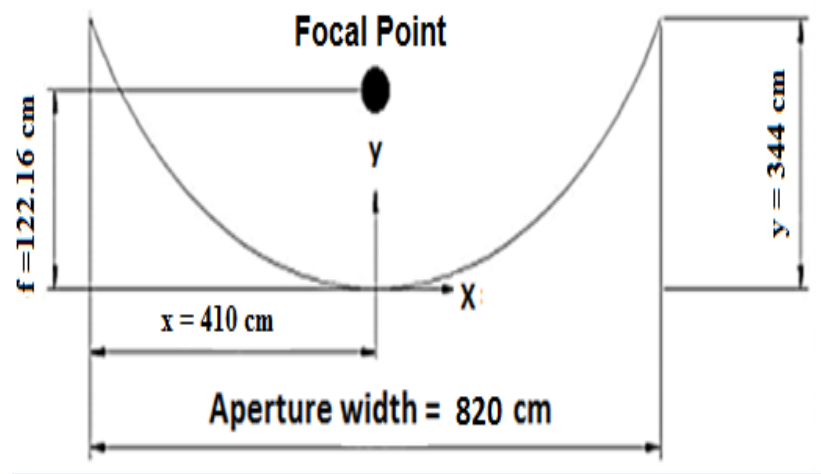

Figure 4. Schematic diagram of the designed PTC

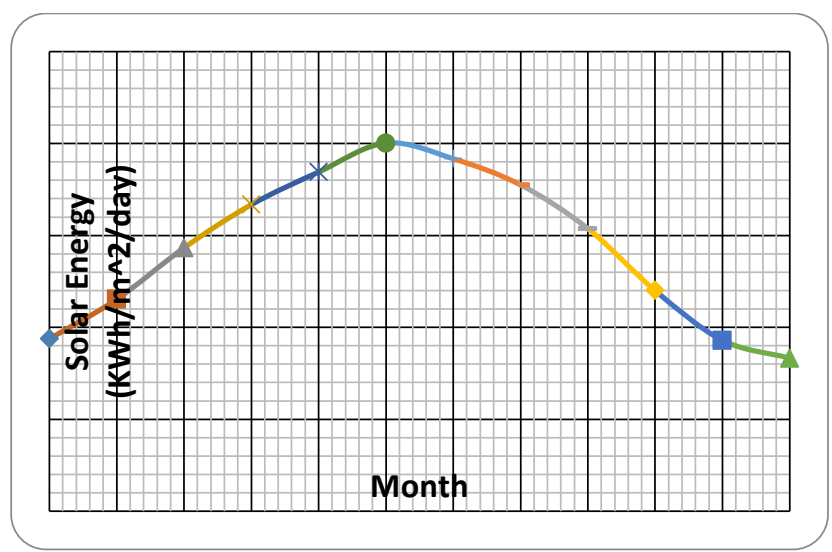

Figure 5. Solar energy during the year 
$10^{\text {TH }}$ International CONFEREnce on Sustainable Energy and Environmental Protection (June $27^{\mathrm{TH}}-30^{\mathrm{TH}}, 2017$, Bled, SLOVEniA), Renewable ENERGy SOURCES H. A. Hamed, A. A. Abdel-Rehim, A. M. Attia \& A. A. A. Attia: A Case Study of Solar Energy Application in Enhanced Oil Recovery

Table 2. Heat gain by single PTC during the year

\begin{tabular}{|l|c|}
\hline Month & $\mathrm{Q}_{\mathrm{u}}(\mathrm{W})$ \\
\hline January & 20531.92 \\
\hline February & 23777.98 \\
\hline March & 26901.57 \\
\hline April & 27129.36 \\
\hline May & 25777.05 \\
\hline June & 25741.49 \\
\hline July & 25735.51 \\
\hline August & 27257.55 \\
\hline September & 27439.75 \\
\hline October & 24085.92 \\
\hline November & 20068.1 \\
\hline December & 18492.87 \\
\hline
\end{tabular}

The amount of produced steam is mainly depend on the seasonal solar radiation, the peak is $12913 \mathrm{bbl} / \mathrm{day}$ in June and the average production is $11080 \mathrm{bbl} /$ day as shown in Figure (6).

The cost of material used to design single parabolic trough collector is calculated as represented in Table (3).

The cost reduction after using solar is $34.6 \%$, and its peak is $40.3 \%$ in June as represented in Table (4).

The cost of steam produced will be 0.658 \$steam bbl instead of $3 \$$ from gas-fired system. The total cost of producing 1 barrel of oil from the hybrid system is in average $19.8 \$ / b b l$ and its minimum cost is $18.95 \$ / b b l$ in June as presented in Table (5), where its cost conventionally was $25 \$ / b b l$. 
$10^{\mathrm{TH}}$ International Conference on Sustainable EnERgy and EnVironmental Protection (June $27^{\mathrm{TH}}-30^{\mathrm{TH}}, 2017$, Bled, Slovenia), Renewable Energy SOURCeS H. A. Hamed, A. A. Abdel-Rehim, A. M. Attia \& A. A. A. Attia: A Case Study of Solar Energy Application in Enhanced Oil Recovery

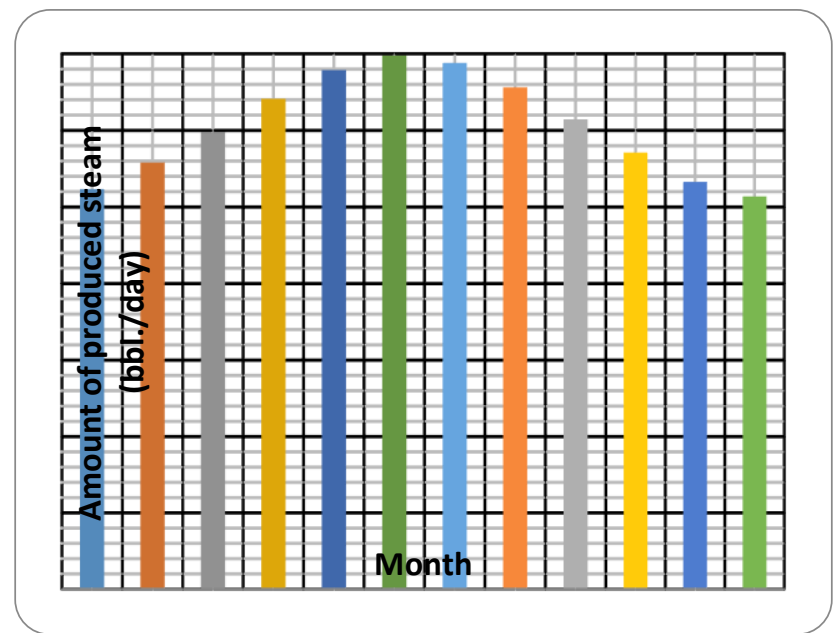

Figure 6. The amount of produced steam from PTC system (bbl./day)

Table 3. Material cost for single PTC

\begin{tabular}{|c|c|c|}
\hline Item & Used material & Cost $(\$)$ \\
\hline Trough support & Iron & 200 \\
\hline reflector & $\begin{array}{l}\text { Stainless steel with } \\
\text { mirror finish }\end{array}$ & 1600 \\
\hline Reflector chassis & Aluminium & 4850 \\
\hline Tubing & $\begin{array}{l}\text { Copper with } D_{0}= \\
19 \mathrm{~mm} D_{i}=16 \mathrm{~mm}\end{array}$ & 58.33333 \\
\hline Bearing & $\begin{array}{l}4 \text { bearing made in } \\
\text { japan }\end{array}$ & 5.555556 \\
\hline $\begin{array}{lll}\text { DC motor } & \& \\
\text { circulating Pump } & \\
\end{array}$ & - & 2000 \\
\hline Isolation & $\begin{array}{c}\text { Layers of reflective } \\
\text { material }\end{array}$ & 200 \\
\hline $\begin{array}{l}\text { Trough support } \\
\text { manufacturing }\end{array}$ & & 33.33333 \\
\hline $\begin{array}{l}\text { Arduino +wiring } \\
\text { +sensors (additional) }\end{array}$ & & 22.22222 \\
\hline \multicolumn{2}{|c|}{ Total cost of single PTC $(\$)$} & 8969.444 \\
\hline
\end{tabular}


$10^{\text {TH }}$ International Conference on Sustainable Energy and Environmental Protection (June $27^{\mathrm{TH}}-30^{\mathrm{TH}}, 2017$, BlED, SLOVENIA), RENEWABLE ENERGY SOURCES H. A. Hamed, A. A. Abdel-Rehim, A. M. Attia \& A. A. A. Attia: A Case Study of Solar Energy Application in Enhanced Oil Recovery

Table 4. Solar cost reduction

\begin{tabular}{|l|c|}
\hline \multicolumn{1}{|c|}{ Month } & Solar cost reduction (\%) \\
\hline January & 29.4268 \\
\hline February & 31.59531 \\
\hline March & 34.08911 \\
\hline April & 36.79976 \\
\hline May & 39.13092 \\
\hline June & 40.3236 \\
\hline July & 39.72726 \\
\hline August & 37.72138 \\
\hline September & 35.11916 \\
\hline October & 32.40851 \\
\hline November & 30.02314 \\
\hline December & 28.83045 \\
\hline Average & 34.59962 \\
\hline
\end{tabular}

Table 5. The cost of produced oil after using solar energy

\begin{tabular}{|l|c|}
\hline \multicolumn{1}{|c|}{ Month } & $\begin{array}{c}\text { Cost of produced oil } \\
\text { (\$/Oil bbl) }\end{array}$ \\
\hline January & 20.58598056 \\
\hline February & 20.26070278 \\
\hline March & 19.88663333 \\
\hline April & 19.48003611 \\
\hline May & 19.1303625 \\
\hline June & 18.95145972 \\
\hline July & 19.04091111 \\
\hline August & 19.34179306 \\
\hline September & 19.73212639 \\
\hline October & 20.13872361 \\
\hline November & 20.49652917 \\
\hline December & 20.67543194 \\
\hline \multicolumn{1}{|c|}{ Average } & 19.81005752 \\
\hline
\end{tabular}


$10^{\mathrm{TH}}$ InTERnational CONFerence on Sustainable EnERgy AND Environmental 383 Protection (June $27^{\mathrm{TH}}-30^{\mathrm{TH}}, 2017$, BLED, SLOVENiA), RENEWABLE ENERGY SOURCES H. A. Hamed, A. A. Abdel-Rehim, A. M. Attia \& A. A. A. Attia: A Case Study of Solar Energy Application in Enhanced Oil Recovery

\section{$5 \quad$ Conclusion}

It was found that solar energy can generate the same quality of steam as natural gas for Issaran field. The amount of steam produced from designed Parabolic trough collectors system is mainly depend on the seasonal solar radiation, the peak of produced steam is $12913.19444 \mathrm{bbl} /$ day in June and the average production is $11080.15046 \mathrm{bbl} / \mathrm{day}$. The PTC system will produce an average of $44.3 \%$ of total required steam, and its peak production will be $55.8 \%$ in June. The cost of steam produced will be $0.658 \$ /$ steam bbl instead of $3 \$$ from gas-fired system. Actually, there is a significant reduction in the daily cost of steam after applying the solar energy in Issaran heavy oil field. The cost reduction is $25,949.7 \$$ /day, and its peak is $30,242.7 \$$ /day in June. The solar cost reduction is $34.6 \%$, and its peak is $40.3 \%$ in June. The cost of producing oil from the hybrid system is $19.8 \$ / \mathrm{bbl}$ as an average instead of $25 \$ / \mathrm{bbl}$ from gas-fired system. The payback period of this project will be after 7 years. Using solar energy for producing steam could be a viable alternative to gas fired steam production for the oil industry.

\section{References}

[1] M. Samir, W. Hassan, M. Omara (Scimitar), E. Thabet, Y. Abugreen, S. Joshi (Schlumberger): "Reservoir Pathway Identification in a Fractured Carbonate Heavy Oil Reservoir", Paper SPE 126135 presented at the SPE North Africa Technical Conference and Exhibition held in Cairo, Egypt, 14-17 February 2010

[2] M. Samir (Scimitar): "Role of Steam Injection Pressure to Achieve Successful Cyclic Steam Project Issaran Field-Egypt", Paper SPE 127848 presented at the SPE North Africa Technical Conference and Exhibition held in Cairo, Egypt, 14-17 February 2010

[3] M. Rizkallha, S. A.Alfy, G. S.Basta, A. A.Ghaleb and W. T.Kortam (Scimitar Production Egypt Ltd): "Optimized Steam Pulse Injection (SPI) In a Carbonate Reservoir Issaran Egypt", Paper SPE-172877-MS presented at the SPE International Heavy Oil Conference and Exhibition held in Mangaf, Kuwait, 8-10 December 2012

[4] N. Groom,"Analysis: Oil companies go solar to tap hard-to-get supplies", "USA Edition; Reuters". Retrieved 17 August 2011

[5] B. Biermana, C. Treynora, J. O’Donnella , M. Lawrencea, M. Chandraa, A. Farvera, P. von Behrensa, W. Lindsayb, "Performance of an Enclosed Trough EOR system in South Oman", Elseiver, 2013

[5] B. Biermana, C. Treynora, J. O’Donnella, M. Lawrencea, M. Chandraa, A. Farvera , P. von Behrensa, W. Lindsayb, "Construction of an Enclosed Trough EOR system in South Oman", Elseiver, 2013

[6] E. Goossens "Chevron Uses Solar-Thermal Steam to Extract Oil in California", "Bloomberg", October 3, 2011

[7] P. Molchanov,"Solar EOR Keeps Advancing: Oman to Build First System In Mid-East", "Raymond James Energy Report". Retrieved 10 November 2011

[8] W. Mahdi, "GlassPoint Solar Sees Interest from Middle East Oil Firms". Bloomberg. Retrieved 25 June 2013.

[9] A. Khan, "PDO Commissions Solar EOR Project". Muscat Daily. Retrieved 25 June 2013.

[10] J. Duffie, \& W. Beckman, "Solar Engineering of Thermal Processes", New jersey: John Willey\&Sons,Inc., 2006 
$384 \quad 10^{\mathrm{TH}}$ InTERnAtional CONFERENCE ON Sustainable ENERGy AND ENVIRONMENTAL Protection (June $27^{\mathrm{TH}}-30^{\mathrm{TH}}, 2017$, Bled, SLOVEnia), RENEWABle ENERGy SOURCES 
$10^{\mathrm{TH}}$ InTERnational CONFEREnCE ON Sustainable ENERgy AND Environmental Protection (June $27^{\mathrm{TH}}-30^{\mathrm{TH}}$, 2017, Bled, SLOVENIA), RENEWABLE ENERGy SOURCES

J. Krope, A.Ghani Olabi, D. Goričanec \& S. Božičnik

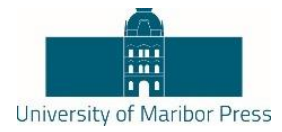

\title{
Performance Analysis of Solar Air Collector in North East Region of India
}

\author{
Suman Debnath, Abhilekh Sonowal, Biplab Das, Pitambar Randive \& K.M. \\ PANDEY
}

\begin{abstract}
The most efficient way to use free and omnipresent solar energy is by using solar collectors. Present work deals with the experimental investigation on the solar air collector for particular climatic conditions in North-East India. Effect of mass flow rate, the surface configuration of absorber plate, an angle of inclination on solar thermal efficiency is presented. Results are obtained by varying the inclination angle, velocity, and type of absorber plate for various solar radiation and ambient temperature. It has been observed that efficiency is increased with the increase the mass flow rate. It is seen that the thermal efficiency for corrugated absorber is $30 \%$ higher as compared to flat plate absorber. Experiments also show that the efficiency is maximum for the tilt angle of $45^{\circ}$. Furthermore, empirical correlations for efficiency $(\eta)$ have been suggested in the terms of slope of the collector $(\theta)$, ambient temperature (Ta), solar radiation (I), and air velocity (V). The correlation shows good agreement with the experimental results.
\end{abstract}

Keywords: $\bullet$ Solar collector $\bullet$ conversion efficiency $\bullet$ inclination angle • ambient energy $\bullet$ correlation $\bullet$

CoRRESPONDENCE AdDRESS: Suman Debnath, Ph.D. Scholar, Department of Mechanical Engineering, NIT Silchar, Assam-788010, India, e-mail: debnath.s1990@gmail.com. Abhilekh Sonowal, Graduate student, Department of Mechanical Engineering, NIT Silchar, Assam-788010, India, e-mail: abhilekh.mech001@gmail.com. Biplab Das, Ph.D., Department of Mechanical Engineering, NIT Silchar, Assam-788010, India, e-mail: biplab.2kmech@gmmail.com. Pitambar Randive, Ph.D., Department of Mechanical Engineering, NIT Silchar, Assam-788010, India, email: kp691975@gmail.com. K.M. Pandey, Ph.D., Department of Mechanical Engineering, NIT Silchar, Assam-788010, India, e-mail: kmpandey2001@yahoo.com.

https://doi.org/10.18690/978-961-286-061-5.34

ISBN 978-961-286-061-5

(C) 2017 University of Maribor Press

Available at: http://press.um.si. 
$10^{\text {TH }}$ InTERnAtional CONFERENCE ON Sustainable ENERGy AND ENVIRONMENTAL Protection (June $27^{\mathrm{TH}}-30^{\mathrm{TH}}, 2017$, Bled, SLOVEnia), RENEWABle ENERGy SOURCES S. Debnath, A. Sonowal, B. Das, P. Randive \& K.M. Pandey: Performance Analysis of Solar Air Collector in North East Region of India

Energy is mandatory to fulfill our day to day requirement and makes our life sustainable and qualitative. This free energy come from the sun is used for many applications like; water heating, distillation, cooking, space heating, refrigeration, agricultural and industrial drying, power generation, etc. All the renewable energy sources, it is seen that the solar energy is the most promising due to inexhaustibility, abundant in nature and non-polluting in nature.

Solar energy conversion devices like solar flat plate thermal collector, solar concentrators, photovoltaic cell have been used to harness this tremendous amount of energy. Solar concentrators are mostly used when higher temperature is desired. On the contrary, solar collectors are used for heating up the air which can be utilized drying applications. Major challenges in the effective use of solar collector lies mainly on its dependence on climatic conditions, limited thermal efficiency and higher pressure in case the extended devices are used. The present work discusses the effect of corrugated surface and tilt angle on the performance of solar air collector. There were several attempts by earlier investigator to improve performance of solar air collectors. Choudhury and Garg [1] designed solar air heater with corrugated and flat plate absorber with five different configurations. It was seen that by increasing the air velocity as well as mass flow rate of air yield to increase the pressure drop. So a suitable design is needed for solar air collector, air velocity, mass flow rate, dimension of the channel is too important for an efficient collector. Murphy et al. [2] carried out an investigation of three different types of solar air heater. Air flow is used over, both side and under the absorber plate and this study v-corrugated absorber plate also used. Among the three models v-corrugated absorber plate is the most efficient. Kabeel and Mecarik [3] studied about shape optimization of solar air collector having triangular shape and longitudinal fin. It has showed that shape factor is most important parameter for any types of solar air collector. Results indicate that triangular type collector is more efficient than the longitudinal one. Also found the range of triangular angle for optimum shape factor $50^{\circ}$ to $60^{\circ}$.

Hou et al. [4] studied to improve the collector efficiency of solar air collector using double flow over and under the absorber plate in a continuous manner. At the end of the experiment, it was found that the temperature of absorber plate and air bulks mainly depends on the flow direction. Hegazy [5] investigated the performance of solar air heater estimating the optimum channel geometry with constant and variable air flow rate. Three different types of configurations were considered; air flow over the absorber plate, under the absorber plate and both side of the plate. Optimum dimension of the channel was found at depth-to-length ratio $2.5 \times 10-3$. It has found that air flow over and the both sides of the plate are more efficient than the conventional one. Lin et al. [6] investigated the collector aspect ratio on solar air collector with or without fins and baffles. They showed that with fins and baffles efficiency was more, may be because of change of air flow direction and creation turbulence. The efficiency of the collector was about $69 \%$, $65 \%$ and $60 \%$ at mass flow rate of air about $80 \mathrm{~kg} / \mathrm{hr}$, for the collector with fins and baffles, the collector with fins and the collector without fins and baffles, respectively. 
Pakdaman et al. [7] investigated the performance of the solar collector involving natural convection rectangular fin attached to the absorbing plate. It has observed that with $66 \%$ increase of area the heat transfer rate increased by $22 \%$. It has observed effect of solar radiation greater than the ambient temperature effect. The angle used between the collector and the vertical line was $45^{\circ}$ and $30^{\circ}$. Shu et al. [8] investigated a mathematical model through which increase the heat transfer rate in terms of mass flow rate. It has seen that with mass flow rate efficiency increases, but after a certain value of mass flow rate thermo-hydraulic efficiency gradually decreases. It has found that for a mass flow rate of $0.050 \mathrm{~kg} / \mathrm{s}$ and intensity of $1000 \mathrm{~W} / \mathrm{m}^{2}$ the hydraulic efficiency about $55 \%$. Fudholi et al. [9] studied about the improvement potential and energy analysis of finned doublepass solar collector. The results are predicted through mathematical modeling and compared with the experimental results and it was found that for a mass flow rate of 0.09 $\mathrm{kg} / \mathrm{s}$ the optimum energy efficiency approximately $77 \%$. The optical efficiency of the finned double-pass solar collector has got approximately 70-80\% and energy efficiency is approximately $15-28 \%$. Hachemi [10] studied the thermal performance of solar collector experimentally using offset rectangular plate fins. Offset fins length are used $2.5 \mathrm{~cm}, 5 \mathrm{~cm}, 10 \mathrm{~cm}$, and $20 \mathrm{~cm}$. It was noticed that the using staggered fins in a periodic way enhance the thermal performance. Karim and Hawlader [11] experimentally and theoretically investigated flat plate, fined and V- corrugated solar air collector. It has found that v-corrugated absorber plate got highest efficiency compare to other two. The efficiencies of the collectors' increases with the mass flow rate, but beyond $0.056 \mathrm{~kg} / \mathrm{m}^{2} \mathrm{~s}$ mass flow rate efficiency saturated. Kothari et al. [12] reviewed the literature on energy and exergy analyses of solar drying systems and suggested that for utilizing low-grade energy to dry agricultural products, solar drying is the promising option.

In spite of numerous works in this area, investigation on comparative performance of solar collector for different geometrical configuration of absorber plate and tilt angle paid little attention. Further, as the performance of the collectors are environmental condition specific, thus, performance of the collector in the environmental condition of NE India is also an area of concern in this study. Hence, an experimental investigation is undertaken to explore the effect of parameters like mass flow rate, geometrical configuration (flat and corrugated) of absorber plate and tilt angle on performance of solar collector.

\section{Thermal Performance and Uncertainty}

Thermal energy balance of the solar collector can be represented as (Esen 2008):

[Rate of energy gain $]+[$ Rate of accumulated energy $]=[$ Absorbed energy $]-[$ Lost energy $]$

Rate of energy gain $=\dot{m} C_{p a}\left(T_{\text {out }}-T_{\text {in }}\right)$

Rate of accumulated energy $=M_{p} C_{p}\left(d T_{p, a v e} / d t\right)$ 
$10^{\text {TH }}$ International CONFEREnce on Sustainable Energy and Environmental Protection (June $27^{\mathrm{TH}}-30^{\mathrm{TH}}, 2017$, Bled, SLOVEnia), RENEWABle ENERGy SOURCES S. Debnath, A. Sonowal, B. Das, P. Randive \& K.M. Pandey: Performance Analysis of Solar Air Collector in North East Region of India

Absorbed energy $=\eta_{o} I A_{c}$

Lost energy $=U_{c}\left(T_{p, a v e}-T_{o}\right) A_{c}$

Collector efficiency $(\eta)=\dot{m} C_{p}\left(T_{\text {out }}-T_{a}\right) / I A_{c}$

The optical efficiency $\left(\eta_{0}\right)$ and the energy lost coefficient $\left(U_{c}\right)$ indicate the performance of the collector. $\eta_{0}$ is a function of transmittance of the glass cover and absorbance of the plate. $U_{c}$ is a function of various thermal losses through the upper cover, the side walls, and the bottom of the collector.

Mass flow rate of air $(\dot{m})=\rho_{a} A_{p} V$

Where, $\rho_{a}$, is density of air, $\mathrm{kg} / \mathrm{m}^{3}, A_{p}$, represent the blower pipe diameter (m), and $\mathrm{V}$, represent the air velocity $(\mathrm{m})$. Density of air highly varies with the temperature of the air, and is calculated as (Das and Giri 2015):

$$
\rho_{a}=\left(635.158 /\left(1.8 T_{a}+491.69\right)\right)
$$

The fractional uncertainty about the efficiency of the collector is a function of $T_{a}, V$, and $I$, considering $C_{p}$ and $A_{c}$ constant.

\section{$3 \quad$ Experimental Setup}

A detail of the experimental setup is shown in Fig.1. Total collector area is kept constant as $1.5 \mathrm{~m} \times 0.5 \mathrm{~m}$. Gap between the top glass cover and the flat plate absorber is kept fixed at $0.07 \mathrm{~m}$. However, the air gap is found out to be $0.05 \mathrm{~m}$ and $0.07 \mathrm{~m}$ from root and crest of the corrugated plate. Transparent glass cover is used as glazing at the top of the collector. The glazing with a transmittance $\tau=0.9$ and absorption coefficient $\alpha=0.05$ has been used. The rest of the collector sides are made of wooden frame of thickness of 0.015 $\mathrm{m}$, an insulator (thermocol) of $0.010 \mathrm{~m}$ thick is used in all the sides. Variable speed air blower (make: Horsepower, India) is used to blow the air through the air collector. Digital manometer (make: Precise, India) is used to measure the air velocity at the outlet. Thermocouple (make: Thermotech/Safeseed, India) are fixed at the inlet and outlet to measure the inlet and outlet temperature, respectively, measurement range -50 to $100{ }^{\circ} \mathrm{C}$; resolution $\pm 0.1{ }^{\circ} \mathrm{C}$; uncertainty $\pm 1.6{ }^{\circ} \mathrm{C}$. Along the axial direction, 5 nos. of thermocouple are fixed at equal distance to measure the temperature variation along the collector. The total solar radiation is measured with a computer integrated Pyranometer (make: Dynalab Weathertech Pvt. Ltd., Pune, India), uncertainty 0.7\%. Collector is supported with a wooden frame in such a way that variable slope can be maintained as 
$10^{\mathrm{TH}}$ InTERnational CONFERENCE on Sustainable EnERgy AND ENVIRONMENTAL 389

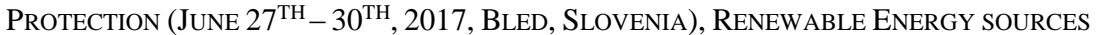
S. Debnath, A. Sonowal, B. Das, P. Randive \& K.M. Pandey: Performance Analysis of Solar Air Collector in North East Region of India

per requirement. For conformity of the results, experiments are conducted for three times for same configuration, and the average of the same is presented.
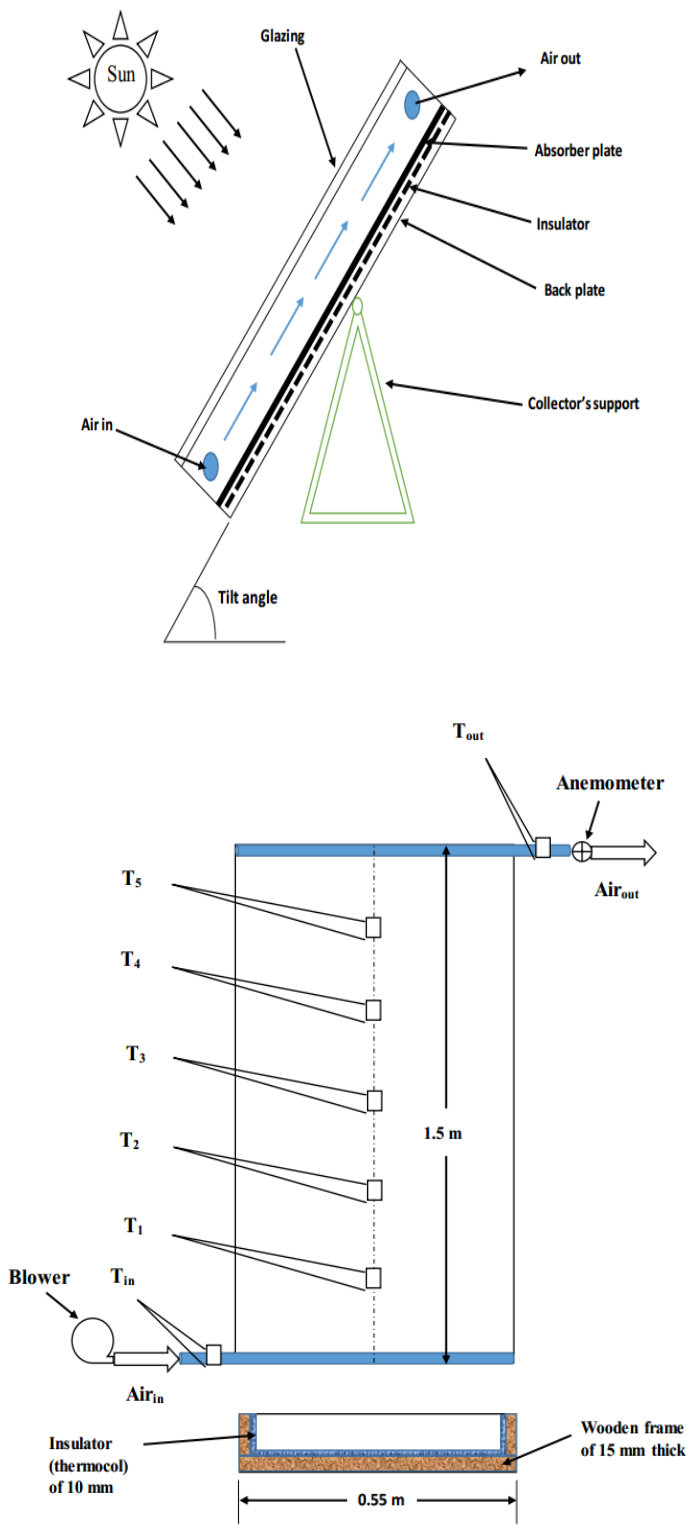

Figure 1. Schematic Diagram of Experimental Setup. 
$390 \quad 10^{\text {TH }}$ InTERnAtional CONFERENCE ON Sustainable ENERGy AND ENVIRONMENTAL Protection (June $27^{\mathrm{TH}}-30^{\mathrm{TH}}, 2017$, Bled, SLOVEnia), RENEWABle ENERGy SOURCES S. Debnath, A. Sonowal, B. Das, P. Randive \& K.M. Pandey: Performance Analysis of Solar Air Collector in North East Region of India

\section{Results and Discussions}

Experimental result of the collector with plain and corrugated plate collector is presented in this section. Figure 2 represents an hourly variation of ambient temperature during the day for the second and third week of December 2016. It is found that the maximum ambient temperature is around $25-30^{\circ} \mathrm{C}$ at $2-3$ p.m. During winter season, huge quantity of agro foods is cultivated and needs to be dried up. Hence, it is proposed to design of solar collector for this application.

Hourly variation solar radiation around the day is exemplified in Fig. 3, during this period is considered as temperature data. It is seen that variation of solar radiation increases during the morning attains a peak value near 1-2 p.m. and then starts decreasing. During all days of experimentation maximum amount of solar radiation is found to be of 740 $\mathrm{W} / \mathrm{m}^{2}$. Solar intensity indicates the weather status of the day. It is clear that $10^{\text {th }}$ and $11^{\text {th }}$ December is a sunny day $21^{\text {st }}$ December is a cloudy day.

Thermal performance of the solar air collector with flat plate absorber is depicted in Fig. 4. For the collector slope is $30^{\circ}$ to the horizontal, with air velocity $1.2 \mathrm{~m} / \mathrm{s}$ it can be seen that the maximum efficiency is obtained as $5.2 \%$ around 9.00 a.m. Intensity of solar radiation intensity increases till noon and reduces thereafter. It can be seen that the efficiency of the solar collector increases with the increase in air velocity and reaches maximum value of $7.9 \%$ at $1.8 \mathrm{~m} / \mathrm{s}$ for a fixed slope of collector.

To find the effect of slope of the collector on its thermal performance, collector slope is changed to $45^{\circ}$ to the horizontal (Fig. 4). It is found that higher thermal efficiency is observed for the same collector with slope is $45^{\circ}$. It tends to increase from an initial lower value of $4 \%$ to $11 \%$ at air velocity of $1.2 \mathrm{~m} / \mathrm{s}$. Further, with the increase in air velocity to $1.8 \mathrm{~m} / \mathrm{s}$ the efficiency is increased. This is in agreement of the work of Esen (2008). Hence it can be adjudged that performance of the solar collector is improved at higher air velocity i.e., mass flow rate of air.

Thermal performance of solar collector for corrugated plate is also analyzed and presented in Fig. 5. It is seen that for solar collector at a slope of $30^{\circ}$ and air velocity 2 $\mathrm{m} / \mathrm{s}$, efficiency increases with the increase in solar radiation. A maximum efficiency of $9 \%$ is observed at around $11 \mathrm{a}$. $\mathrm{m}$. It has been observed that there is increase in efficiency with increase in air velocity for all the cases. A maximum efficiency of the solar collector is observed to be $14 \%$. Further, corrugated plate absorber give higher collector efficiency for the same collector size as compared to flat plate absorber. This is because of higher surface area provided by the corrugated plate absorber. In addition to this, corrugated nature of the plate helps in generation secondary flow, which enhances the temperature of the working fluid because of better mixing.

Finally, efficiency of the solar collector is correlated with the governing parameters, slope of the collector $(\theta)$, ambient temperature (Ta), solar radiation (I), and air velocity (V). It is found that keeping the combination of the governing parameters same efficiency ( $\eta$ ) of 
the flat plate absorber and corrugated plate absorber shows different correlation. For flat plate collector the correlation is made with 33 data points and is shown in Eq. (8)

$\eta_{\text {flat }}=1.4 \times\left(\theta^{0.6897} \mathrm{~T}_{\mathrm{a}}^{-0.16} \mathrm{~T}^{-0.1127} \mathrm{~V}^{1.0744}\right)$

For corrugated plate collector the correlation is made with 36 data and is shown in Eq. (9)

$$
\eta_{\text {corrugated }}=1.95 \times\left(\theta^{0.6897} \mathrm{~T}_{\mathrm{a}}^{-0.16} \mathrm{I}^{-0.1127} \mathrm{~V}^{1.0744}\right)
$$

The correlation coefficient for Eq. (8) is 0.98, and for Eq. (9) is 0.94. Correlations are plotted in Fig. 6.

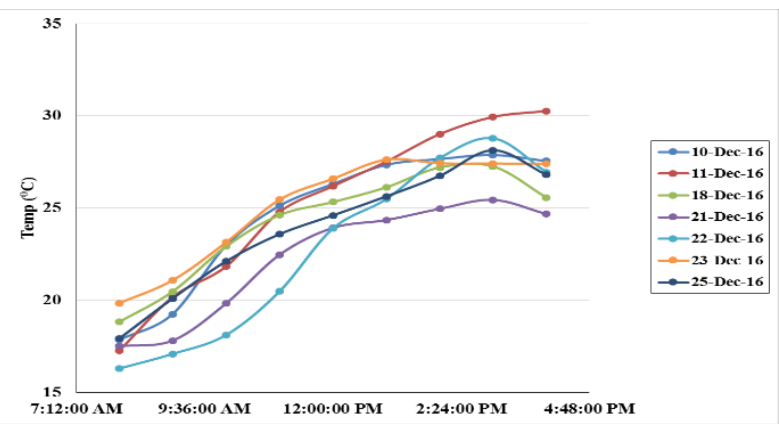

Figure 2. Variation Temperature During the Experimental Days.

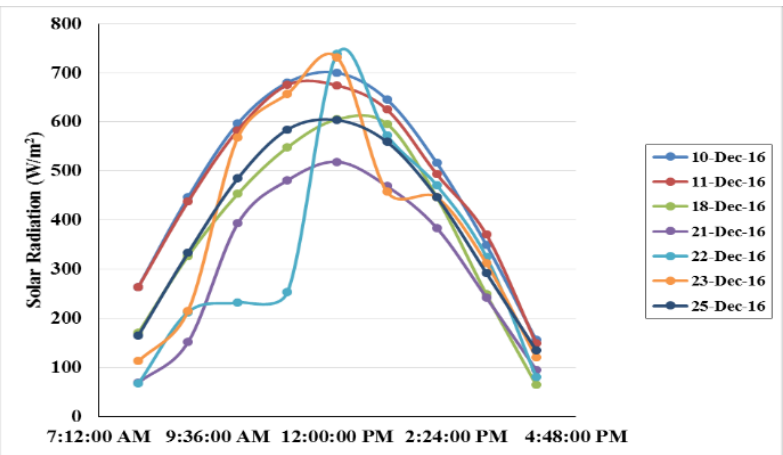

Figure 3. Variation of Solar Radiation During the Experimental Days. 
$10^{\text {TH }}$ International Conference on Sustainable Energy and Environmental Protection (June $27^{\mathrm{TH}}-30^{\mathrm{TH}}, 2017$, BlED, SLOVENIA), RENEWABLE ENERGy SOURCES S. Debnath, A. Sonowal, B. Das, P. Randive \& K.M. Pandey: Performance Analysis of Solar Air Collector in North East Region of India

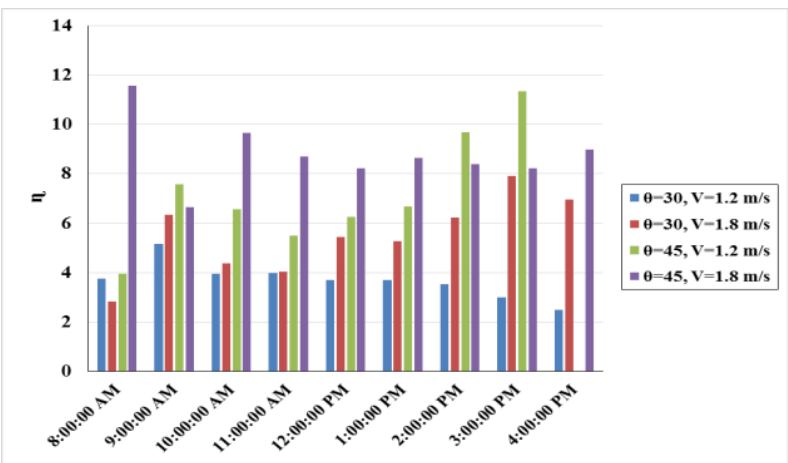

Figure 4. Variation of Instantaneous Efficiency (n) During the Day with Flat Plate Absorber Sheet.

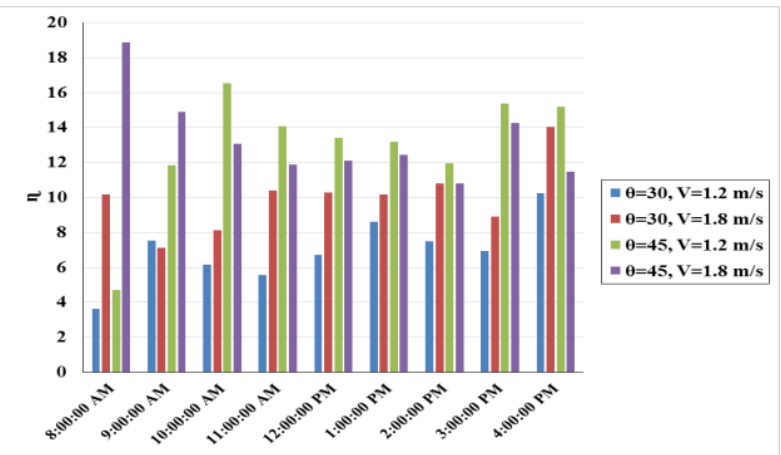

Figure 5. Variation of Instantaneous Efficiency (n) During the Day with Corrugated Absorber Sheet.

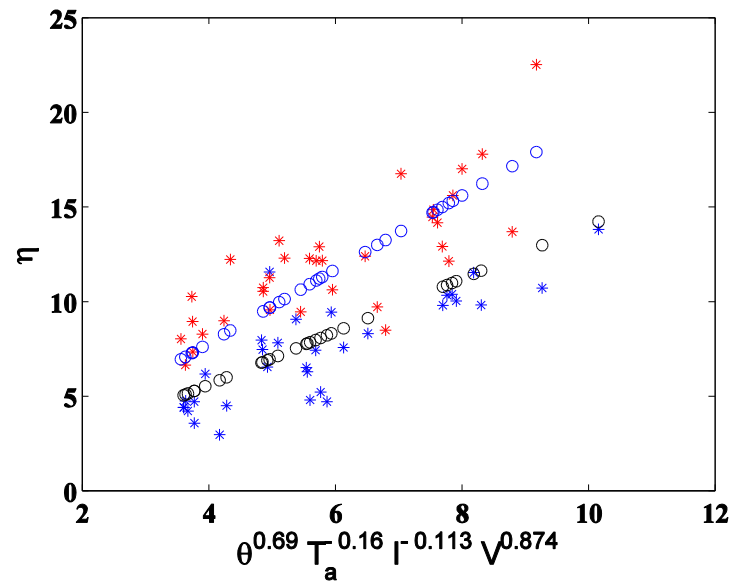

Figure 6. Correlation of Efficiency of Both Flat Plate and Corrugated Plate Collector. 


\section{$5 \quad$ Conclusions}

In the present work, performance of solar air collector has been experimentally investigated for flat and corrugated absorber. Parametric study is carried out for flat and corrugated absorber plate to get insight on the effect of mass flow rate, surface configuration of absorber plate, angle of inclination on solar thermal efficiency.

It has been observed that efficiency increases from $4 \%$ to $14 \%$ with the air velocity of 1.2 $\mathrm{m} / \mathrm{s}$ and $1.8 \mathrm{~m} / \mathrm{s}$ respectively.

Maximum efficiency of around $14 \%$ is found for the tilt angle of $45^{\circ}$. Empirical correlations have been proposed in terms of slope of the collector $(\theta)$, ambient temperature (Ta), solar radiation (I), and air velocity (V) for the flat and corrugated absorber plate efficiency $(\eta)$. Collector efficiency for corrugated absorber has been found to be more as compared to flat plate absorber. To increase the efficiency at per the other devices various losses has to be reduced like leakage losses, convection losses, etc.

\section{Acknowledgements}

The authors sincerely acknowledge the support received from DST (Govt. of India) and TEQIP-II for conducting the experiments successfully. The authors gratefully acknowledge use of the services and facilities of the RTC at the NIT Silchar, funded by MNRE.

\section{References}

[1] C. Choudhury, H. P. Garg, "Design analysis of corrugated and flat plate solar air heaters", Renewable energy, 1, pp. 595-607, 1991.

[2] W. E. Murphy, B. F. Parker, M. R. Lindley, D. G. Colliver, "Thermal performance of three solar air heaters", Solar energy, 51, pp. 467-479, 1993.

[3] A. E. Kabeel, K. Mecarik, "Shape optimization for absorber plates of solar air collector", Renewable energy, 13, pp. 121-131, 1998.

[4] J.Z. Hou, H. M. Yeh, C. D. Ho, "The improvement of collector efficiency in solar air heaters by simultaneously air flow over and under the absorbing plate", Energy, 24, pp. 857-871, 1999.

[5] A. A. Hegazy, "Performance of solar plate solar air heaters with optimum channel geometry for constant/Variable operation", Energy Conversion \& Management, 41, pp. 401-417, 2000.

[6] C.Y. Lin, H. M. Yeh, C. D. Ho, "Effect of collector aspect ratio on the collector efficiency of upward type baffled solar air heaters", Energy Conversion \& Management, 41, pp. 971981, 2000.

[7] M. F. Pakdaman, A. Lashkari, H. B. Tabrizi, R. Hosseini, "Performance evaluation of a natural-convection solar air-heater with a rectangular-finned absorber plate", Energy Conversion and Management, 52, pp. 1215-1225, 2011.

[8] S. Shu, C. Sun, Y. Liu, C. Duan, Y. Zheng, H. Chang, "A mathematical model to investigate on the thermal performance of a flat plate solar air collector and its experimental verification”, Energy Conversion and Management, 115, pp. 43-51, 2016. 
394 10 $10^{\mathrm{TH}}$ International CONFERENCE on Sustainable ENERgy AND ENVIRONMENTAL Protection (June $27^{\mathrm{TH}}-30^{\mathrm{TH}}, 2017$, Bled, SLOVEnia), RENEWABle ENERGy SOURCES S. Debnath, A. Sonowal, B. Das, P. Randive \& K.M. Pandey: Performance Analysis of Solar Air Collector in North East Region of India

[9] A. Fudholi, K. Sopian, M. H. Ruslan, M. Y. Othman, "Performance and cost benefits analysis of double-pass solar collector with and without fins", Energy Conversion and Management, 76, pp. 8-19, 2013.

[10] A. Hachemi, "Experimental study of thermal performance of offset rectangular plate fin absorber plates", Renewable Energy, 17, pp. 371- 384, 1999.

[11] M. A. Karim, M.N.A. "Hawlader, Performance investigation of flat plate, v-corrugated and finned air collectors", Energy, 31, pp. 452-470, 2006.

[12] S. Kothari, N. L. Panwara, S. C. Kaushika, "A review on energy and exergy analysis of solar dying systems", Renewable and Sustainable Energy Reviews, 16, pp. 2812- 2819, 2012.

[13] H. Esen, "Experimental energy and exergy analysis of a double-flow solar air heater having different obstacles on absorber plates," Building and Environment, 43, pp. 1046-1054, 2008.

[14] B. Das, A. Giri, "Mixed convection heat transfer from a vertical fin array in the presence of vortex generator," Int. J. Heat Mass Transfer, 82, pp. 26-41, 2015. 
$10^{\mathrm{TH}}$ InTERnational CONFERENCE ON Sustainable ENERgy AND ENVIRONMENTAL Protection (June $27^{\mathrm{TH}}-30^{\mathrm{TH}}$, 2017, Bled, SLOVENIA), RENEWABLE ENERGy SOURCES

J. Krope, A.Ghani Olabi, D. Goričanec \& S. Božičnik

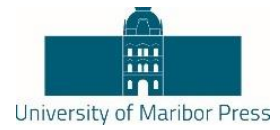

\title{
Green Diesel Synthesis by Catalytic Hydrogenation of Waste Cooking Oil: Catalyst Design and Effect of Solvent
}

\author{
ZHIXIA LI, ZHENTAO HUANG \& CHENGTONG WANG
}

\begin{abstract}
Waste cooking oil (WCO) was dispersed in tetralin or dodecane and hydrotreated over a fabricated $\mathrm{NiMo} / \gamma-\mathrm{Al} 2 \mathrm{O} 3-\beta$-zeolite catalyst. The properties of catalysts were controlled by adjusting the mass fraction of $\beta$ zeolite in support (x), the mass fraction of $\mathrm{NiO}$ and $\mathrm{MoO} 3(\mathrm{~m})$ and $\mathrm{Ni} /(\mathrm{Ni}+\mathrm{Mo})$ mol fraction $(\mathrm{y})$ in catalysts. The effects of catalytic properties and solvents on hydrodeoxygenation of WCO were investigated. The results showed that increasing $\mathrm{x}$ leads to a decrease in WCO deoxygenation ratio (DOr) and an increase in alkene selectivity of products; increasing $\mathrm{m}$ and $y$ tend to promote the formation of alkane hydrocarbons and increase DOr. Both solvents showed different effects on the DOr and product selectivity. The highest DOr was $89.9 \%$ for tetralin and $96.7 \%$ for dodecane. The total content of $\mathrm{C} 15-\mathrm{C} 18$ hydrocarbons in the hydrogenated products was about $99 \%$.
\end{abstract}

Keywords: • waste cooking oil $\bullet$ catalytic hydrogenation $\bullet$ fuel oil $\bullet$ tetalin, dodecane $\bullet$ diesel $\bullet$

CORRESPONDENCE AdDREss: Zhixia Li, Ph.D., Professor, Guangxi University, School of Chemistry and Chemical Engineering, Daxue Road 100, 530004 Nanning, China, e-mail: zhixiali@hotmail.com. Zhentao Huang, M.S., Guangxi University, School of Chemistry and Chemical Engineering, Daxue Road 100, 530004 Nanning, China, e-mail: 1605506845@qq.com. Chengtong Wang, B.A., Guangxi University, School of Chemistry and Chemical Engineering, Daxue Road 100, 530004 Nanning, China, e-mail: 295978775@qq.com. 
$10^{\mathrm{TH}}$ InTERnATIONAL CONFERENCE ON Sustainable EnERgy AND ENVIRONMENTAL Protection (June $27^{\mathrm{TH}}-30^{\mathrm{TH}}, 2017$, Bled, SLOVENIA), RENEWABle ENERGY SOURCES Z. Li, Z. Huang \& C. Wang: Green Diesel Synthesis by Catalytic Hydrogenation of Waste Cooking Oil: Catalyst Design and Effect of Solvent Introduction

Nowadays, fossil fuel is fast being consumed, which results in serious environmental problem. To develop clean and sustainable energy has drawn great attention globally. Recently, technologies such as hydrotreatment of vegetable oils to produce green diesel are proposed to be promising routes for meet the future energy demands [1]. However, most of the vegetable oils are edible, it leads to food vs. fuels problem. Therefore, waste cooking oil (WCO) has gained great importance as a feed oil to produce green diesel due to its cheapness and availability [2].

The high oxygen content of WCO has adverse effects such as low heating value, thermal and chemical instability, corrosivity, immiscibilty with fossil fuel. Hydrodeoxygenation (HDO) is a process of removing oxygen from a molecular usually in the form of water using catalyst where hydrogen is used to cleave carbon-carbon or carbon-heteroatom bonds in a molecule [1]. A lot of research has focused on developing effective catalysts and clarifying HDO process condition using different bio-oil feedstocks [3,4]. However, little research has been performed to investigate the effects of solvent on the catalytic hydrogenation process of bio-oil.

In our recent work, tetralin (a hydrogen donor) was used as solvent in the catalytic hydrogenation of stearic acid to produce diesel-range fuel oil. A nearly $90 \%$ stearic acid conversion was achieved at $350{ }^{\circ} \mathrm{C}$ under $\mathrm{H}_{2}$ at a pressure of $0.8 \mathrm{MPa}$. This indicates that tetralin probably improved hydrogenation efficiency by offering active hydrogen under a low $\mathrm{H}_{2}$ pressure condition [5]. Application of tetralin as solvent is expected to be a promising method to develop new hydrogen resource as a substitute for high-pressure hydrogen, which is currently used in catalytic hydrogenation process. In this study, we prepared a serious of supported NiMo catalysts, and examined hydrodeoxygenation of WCO in two solvents: tetralin and dedocane. The catalytic performance and effects of solvents on product composition were investigated.

\section{Experimental}

\subsection{Pretreatment of waste cooking oil}

WCO was collected from a chophouse close to Student Apartment of Guangxi University. $50 \mathrm{~g}$ of WCO was mixed with $100 \mathrm{ml}$ of saturated salt water, and heated at $80^{\circ} \mathrm{C}$ for $3 \mathrm{~h}$ under stirring. After standing and layering, the upper oil was collected, and mixed with a certain amount of distilled water and activated carbon; the mixture was heated at $80{ }^{\circ} \mathrm{C}$ for $3 \mathrm{~h}$ under stirring. The mixture was then filtered to remove insoluble material, and the liquid fraction was evaporated at $100{ }^{\circ} \mathrm{C}$ under less pressure condition to remove water. The obtained WCO sample was used in the following hydrotreatment experiments. 
$10^{\mathrm{TH}}$ InTERnational CONFERENCE ON Sustainable ENERgy AND ENVIRONMENTAL 397 Protection (June $27^{\mathrm{TH}}-30^{\mathrm{TH}}, 2017$, BLED, SLOVENIA), RENEWABLE ENERGY SOURCES Z. Li, Z. Huang \& C. Wang: Green Diesel Synthesis by Catalytic Hydrogenation of Waste Cooking Oil: Catalyst Design and Effect of Solvent

\subsection{Catalyst preparation}

$\gamma$ - $\mathrm{Al}_{2} \mathrm{O}_{3}(\mathrm{~A})$ and $\mathrm{H}$-type- $\beta$-zeolite $(\mathrm{Si} / \mathrm{Al}=25)(\mathrm{Z})$ were purchased from Nankai University Catalyst Co., Ltd. (Tianjin, China). All catalysts were prepared by a two-step method. The $\gamma-\mathrm{Al}_{2} \mathrm{O}_{3}-\beta$-zeolite (AZ) composite supports were firstly prepared by mechanically mixing $\beta$-zeolite and $\gamma-\mathrm{Al}_{2} \mathrm{O}_{3}$ with deionized water. The mixture was dried and calcined at $450{ }^{\circ} \mathrm{C}$. Afterwards, nickel (Ni) and molybdenum (Mo) with desired amounts were loaded onto the AZ composite supports by impregnation method. The details about the preparation procedure of catalysts had been revealed in our last study [6]. The catalyst samples are denoted as $m-y$-NiMo/AZ- $x$, according to the different mass fraction of $\beta$ zeolite in $\mathrm{AZ}$ supports $(x)$, the $\mathrm{NiO}+\mathrm{MoO}_{3}$ mass fractions in the catalysts $(m)$, and the $\mathrm{Ni} /(\mathrm{Mo}+\mathrm{Ni})$ molar fraction $(y) . x$ was changed from 0 to $40 \% ; m$ was changed from $10 \%$ to $30 \%$, and $y$ was changed from $10 \%$ to $30 \%$.

\subsection{Catalyst characterization}

XRD patterns were obtained at room temperature on a Rigaku MiniFlex600 diffractometer using $\mathrm{CuK} \alpha$ radiation. $\mathrm{H}_{2}$ temperature-programmed reduction $\left(\mathrm{H}_{2}-\mathrm{TPR}\right)$ and $\mathrm{NH}_{3}$ temperature-programmed desorption $\left(\mathrm{NH}_{3}-\mathrm{TPD}\right)$ were used to characterize the reducibility and acidity of catalysts.

\section{$2.4 \quad$ Hydrodeoxygenation of WCO}

All experiments were carried out in a 20 -ml stainless steel autoclave reactor. $0.1 \mathrm{~g}$ of catalyst was firstly sulfided in situ prior to the HDO experiments. Afterwards, $1.2 \mathrm{~g}$ of WCO and $4.8 \mathrm{~g}$ of solvent (tetralin or dodecane) were added into reactor, and reacted at $350{ }^{\circ} \mathrm{C}$ under $\mathrm{H}_{2}$ at a pressure of $5 \mathrm{MPa}$ for $2 \mathrm{~h}$. The details about sulfuration of the catalysts and HDO procedure had been described in our last study [5].

\subsection{Product analysis}

WCO sample and liquid products were firstly methyl esterified according to the standard methods of GB/T 17376-2008. The products were quantified by GC-FID (9792II, Fuli, China) equipped with a HP-5MS capillary column $(30 \mathrm{~m} \times 0.2 \mathrm{~mm} \times 0.3 \mu \mathrm{m})$. Qualitative analysis was performed by GC-MS (GC 7820A, MS 5977E, Agilent) with a HP-5MS column $(50 \mathrm{~m} \times 0.25 \mathrm{~mm} \times 0.25 \mu \mathrm{m})$. After methyl esterification, WCO sample includes $61.68 \%$ stearic acid (C18:0), 5.0\% oleic acid (C18:1), 31.69\% palmitic acid (C16:0) and $1.63 \%$ zoomaric acid (C16:1).

The deoxygenation ratio (DOr) of WCO and isomerization ratio (Ir) of products were used to evaluate the efficiency of the catalytic hydrogenation. Since tetralin will transfer into naphthalene after releasing the active hydrogen, the naphthalene value $(N v)$ in products was used to evaluate the dehydrogenation activity of tetralin. DOr, Ir and Nv were calculated using the following equations: 

$10^{\text {TH }}$ International CONFEREnce on Sustainable Energy and Environmental Protection (June $27^{\mathrm{TH}}-30^{\mathrm{TH}}, 2017$, BlED, SLOVENIA), RENEWABLE ENERGY SOURCES Z. Li, Z. Huang \& C. Wang: Green Diesel Synthesis by Catalytic Hydrogenation of Waste Cooking Oil: Catalyst Design and Effect of Solvent

$$
\begin{aligned}
& \operatorname{DOr}(\%)=\left[\frac{\varpi_{1}}{\varpi_{1}+\varpi_{e}}\right] \times 100 \\
& \operatorname{Ir}(\%)=\frac{\varpi_{\text {iso }}}{\varpi_{1}} \times 100 \\
& N v=\frac{\varpi_{\text {naph }}}{\varpi_{1}}
\end{aligned}
$$

Where $\omega_{1}$ is the total content of all hydrogenated products including all hydrocarbons, alcohols and aldehydes in GC analysis; $\omega_{\mathrm{e}}$ is the relative content of methyl ester; $\omega_{\text {iso }}$ is the content of isomerized compounds; $\omega_{\text {naph }}$ is the relative content of naphthalene in products. The calculation of content excludes tetralin or dodecane in liquid products.

\section{$3 \quad$ Results and Discussion}

\subsection{Characterization of catalysts}

The XRD patterns of catalysts with different $x, y$ and $m$ are shown in Figure 1 . When $m$ and $y$ were fixed at 20\% and 30\%, respectively, and $x$ was increased from $0 \%$ to $40 \%$, the peaks designated as $\beta$-zeolite $\left(2 \theta\right.$ at $7.8^{\circ}$ and $\left.22.5^{\circ}\right)$ and $\mathrm{MoO}_{3}\left(2 \theta\right.$ at $25.7^{\circ}$ and $\left.27.3^{\circ}\right)$ were significantly enhanced, and the peaks designated as $\gamma-\mathrm{Al}_{2} \mathrm{O}_{3}\left(2 \theta\right.$ at $39.5^{\circ}, 45.9^{\circ}$ and $\left.67.2^{\circ}\right)$ and $\mathrm{NiO}\left(2 \theta\right.$ at $\left.37.3^{\circ}\right)$ became weaker[6]. This indicates that the addition of $\beta$ zeolite in supports not only changes the skeleton structure, but also significantly affects the dispersity of active metal in catalyst. On increasing $y$ from $10 \%$ to $20 \%$ with $m$ and $x$ fixed at $20 \%$, the peaks due to $\mathrm{MoO}_{3}$ became weak while the peak due to $\mathrm{NiO}$ showed no various change, indicating that the introduction of $\mathrm{Ni}$ inhibits the growth of $\mathrm{MoO}_{3}$ and improves the dispersity of $\mathrm{MoO}_{3}$ crystals. When $m$ increased from $10 \%$ to $30 \%$ with $x$ and $y$ fixed at $20 \%$ and $30 \%$, respectively, the peaks due to $\gamma-\mathrm{Al}_{2} \mathrm{O}_{3}$ and $\beta$-zeolite became weaker while the peaks due to $\mathrm{MoO}_{3}$ increased slightly, indicating that the excessive addition of active components can cause damage to the Si-O-Al skeleton structure of support. This is probably attributed to the role of Mo to remove aluminum atoms from crystallographic positions [6].

Figure 2 shows the $\mathrm{H}_{2}$-TPR profiles of $m-y$-NiMo/AZ- $x$ catalysts. One big reduction peak at $580{ }^{\circ} \mathrm{C}$ can be observed on the catalyst with $x$ at $0 \%$. The peak can be assigned to the reduction of Ni species [7]. On loading $\beta$-zeolite to $40 \%$, the TPR spectrum shows two regions, a peak at $601{ }^{\circ} \mathrm{C}$ and a broad band with peaks at 630 and $665{ }^{\circ} \mathrm{C}$. The low temperature peak can be assigned to the reduction of Ni species, and the broad band may be due to the reduction of Mo species [8]. Compared with the spectrum of NiMo/AZ-0, there are more easily reducible Mo species in NiMo/AZ-40, indicating that the interaction 
between the Mo species and the AZ support is weaker than that between the Mo species and the $\gamma-\mathrm{Al}_{2} \mathrm{O}_{3}$ support $(x=0)$.

As shown in Figure 2, two obvious peaks at $650{ }^{\circ} \mathrm{C}$ and $758{ }^{\circ} \mathrm{C}$ are observed on the catalyst with $y$ at $10 \%$, which may be due to the reductions of Mo species [7, 8]. On loading nickel to $y=20 \%$, two peaks at $581^{\circ} \mathrm{C}$ and $675{ }^{\circ} \mathrm{C}$ can be observed, the former corresponds to the reduction of $\mathrm{Ni}$ species and the latter corresponds to the reduction of Mo species. The peak due to the reduction of Mo species shifted from $758^{\circ} \mathrm{C}$ to $675^{\circ} \mathrm{C}$ with increasing $y$ from $10 \%$ to $20 \%$, indicating that the addition of $\mathrm{Ni}$ promotes the reducibility of Mo species. Several small reduction peaks, centered at about 530, 597 and $681{ }^{\circ} \mathrm{C}$, observed at the catalyst with $m=10 \%$ may be due to the reductions of amorphous Mo oxides, Ni species, and the deep reduction of all Mo species, respectively. When $m$ is increased to $30 \%$, a big and broad peak ranged from 550 to $700{ }^{\circ} \mathrm{C}$ is observed, which is likely attributed to the combined reduction action of $\mathrm{Ni}$ and Mo species.

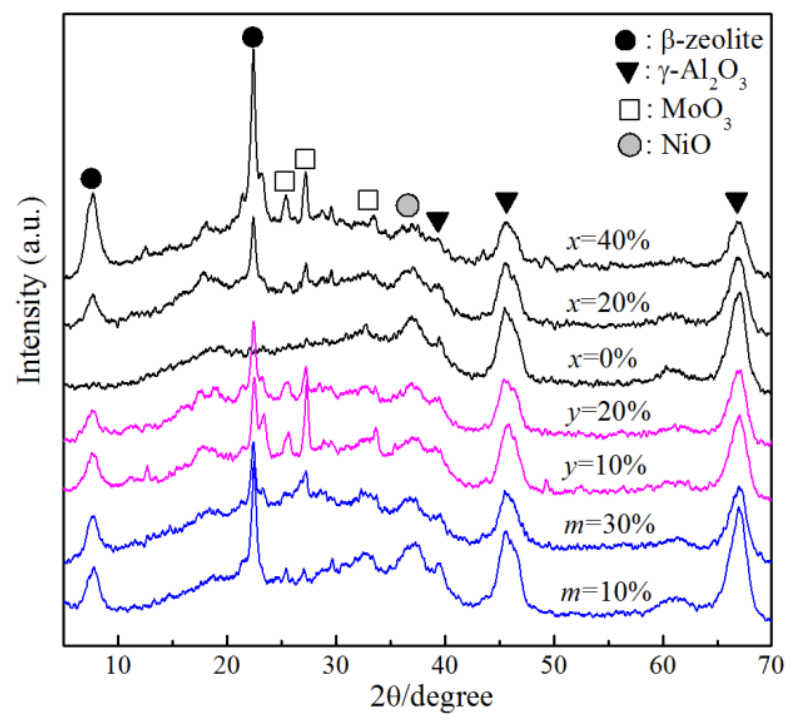

Figure 1. XRD patterns of catalysts with different $x, y$ and $m$. 

$10^{\text {TH }}$ International CONFEREnce on Sustainable Energy and Environmental Protection (June $27^{\mathrm{TH}}-30^{\mathrm{TH}}, 2017$, Bled, SLOVENIA), RENEWABle ENERGY SOURCES Z. Li, Z. Huang \& C. Wang: Green Diesel Synthesis by Catalytic Hydrogenation of Waste Cooking Oil: Catalyst Design and Effect of Solvent

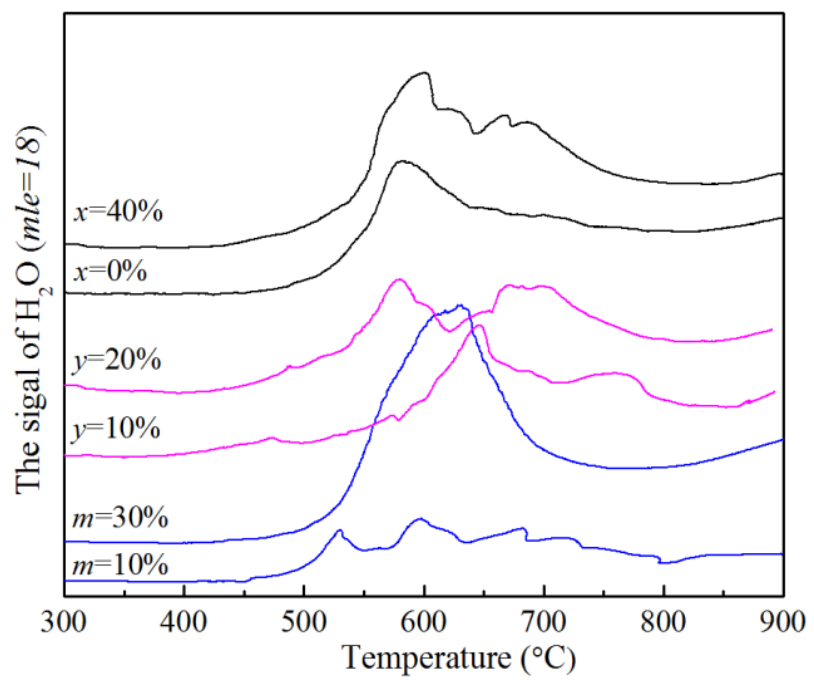

Figure $2 \mathrm{H}_{2}$-TPR profiles of catalysts with different $x, y$ and $m$.

$\mathrm{NH}_{3}$-TPD curves of catalysts with different $x, m$ and $y$ were plotted (the figures are not shown here), and the weak, medium, and strong acid were estimated from peak area derived from Gaussian Fitting of the $\mathrm{NH}_{3}$-TPD profiles in the temperature range 150 260 ${ }^{\circ} \mathrm{C}, 260 \sim 430{ }^{\circ} \mathrm{C}$ and $430 \sim 570{ }^{\circ} \mathrm{C}$, respectively. The results were depicted in Table 1. It was found that with increasing $x$ from 0 to $40 \%$, the total acidities and the acidity of strong acid sites increased while the acidity of weak acid cites decreased; similarly, increasing the $m$ value from 10 to $30 \%$ led to an increase of the total acidities and the acidity of strong acid sites and a decrease in the acidity of weak acid sites. In addition, it can be observed from Table 1 that increasing the $y$ value caused a decrease of strong acid sites but did not have significant effect on the total acidity of catalysts. These results indicate that changes to $x, y$ and $m$ values have different effects on the acidity of catalysts, which probably affects the catalytic activity of the catalysts.

Table 1. Acidity and acid strength distribution of catalysts

\begin{tabular}{cccccccccc}
\hline No. & \multicolumn{3}{c}{ Sample } & & & Total Acidity & & \multicolumn{2}{c}{ Percentage of acid sites \% of total acid) } \\
\cline { 2 - 3 } \cline { 8 - 9 } \cline { 7 - 9 } & $x / \%$ & $m / \%$ & $y / \%$ & & mmol/g & & Weak acid & Medium acid & Strong acid \\
\hline 1 & 0 & 20 & 30 & & 0.564 & & 18 & 63 & 19 \\
2 & 20 & 20 & 30 & & 0.634 & & 13 & 62 & 25 \\
3 & 40 & 20 & 30 & & 1.174 & & 12 & 55 & 33 \\
4 & 20 & 10 & 30 & & 0.473 & & 25 & 60 & 15 \\
5 & 20 & 20 & 30 & & 0.634 & & 13 & 62 & 25 \\
6 & 20 & 30 & 30 & & 0.823 & & 16 & 46 & 38 \\
7 & 20 & 20 & 10 & & 0.793 & & 10 & 53 & 37 \\
8 & 20 & 20 & 20 & & 0.610 & & 17 & 49 & 34 \\
9 & 20 & 20 & 30 & & 0.634 & & 13 & 62 & 25 \\
\hline
\end{tabular}




\subsection{Catalytic hydrodeoxygenation of WCO}

The reaction performance of catalysts with different $x, y$ and $m$ were investigated. The experiments were performed at $350{ }^{\circ} \mathrm{C}$ under $\mathrm{H}_{2}$ at a pressure of $5 \mathrm{MPa}$ for $2 \mathrm{~h}$. As seen in Figure 4, increasing $x$ led to a decrease in WCO DOr and alkane selectivity and a slight increase in alkene selectivity regardless of the solvent used. This may be attributed to the acidic properties of catalysts. As seen in Table 1, on increasing $x$ value, both the total acidities and the acidities of medium sites and strong acid sites of catalysts increased. Strong acid sites would promote the reaction pathways that produce micromolecule products (e.g., ethane carbenium ion and ethene) from heavier molecular, which probably block the pore structure and result in the deactivation of catalysts.

In addition, increasing $y$ from $10 \%$ to $30 \%$ led to an increase (more than $15 \%$ ) in WCO DOr and alkane selectivity of products, and a decrease (about 20\%) in alkene selectivity regardless of the solvent used. These findings are probably attributed to the structural properties of catalysts. Increasing $y$ value leads to a decrease in the crystallite size of $\mathrm{MoO}_{3}$ (Figure 1), and thus improves the dispersity of active sites. The main reduction peaks of catalyst at $\mathrm{y}=10 \%$ shift to a lower temperature (Figure 2, $\mathrm{y}=20 \%$ ), indicating that the increase of $\mathrm{Ni}$ content enhances the reduction ability of catalysts. The better dispersity of active components and the improved reduction properties probably result in the higher DOr and alkane selectivity of products. Meanwhile, it was found in Figure 4(d), selectivity to C17 and C15 increased while selectivity to C18 and C16 decreased with increasing $y$ value, indicating that increasing $\mathrm{Ni}$ mol fraction remarkably enhances the deoxygenation of WCO via decarboxylation or decarbonylation (DCOx) reaction pathways [9].

As seen in Figure 4, increasing $m$ promoted $D O r$ and alkane selectivity of products regardless of the solvent used, indicating that increasing metal active sites helps to promote the deoxygenation efficiency and hydrogenation activity of catalysts. However, excess addition of metal oxides may accelerate the growth of $\mathrm{MoO}_{3}$ crystals and decrease the dispersity of active sites (Figure 1). These likely result in the change in the catalysts structure that is required for effective deoxygenation and a decrease in the DOr.

Besides, for most catalysts, tetralin as solvent achieved an equal WCO DOr as dodecane, but alkane selectivity of products with dodecane was slightly higher than tetralin, indicating that tetralin likely inhibits the further hydrogenation of the hydro-cracked intermediate products of WCO. C18/C17 and C16/C15 in tetralin-derived products for most catalysts are always slightly higher than those in dodecane-derived products (see Figure $4 \mathrm{~d}$ ), indicating that tetralin as solvent trends to deoxygenate via the HDO pathway. 
$10^{\text {TH }}$ International Conference on Sustainable Energy and Environmental Protection (June $27^{\mathrm{TH}}-30^{\mathrm{TH}}, 2017$, Bled, SLOVENIA), RENEWABle ENERGY SOURCES Z. Li, Z. Huang \& C. Wang: Green Diesel Synthesis by Catalytic Hydrogenation of Waste Cooking Oil: Catalyst Design and Effect of Solvent
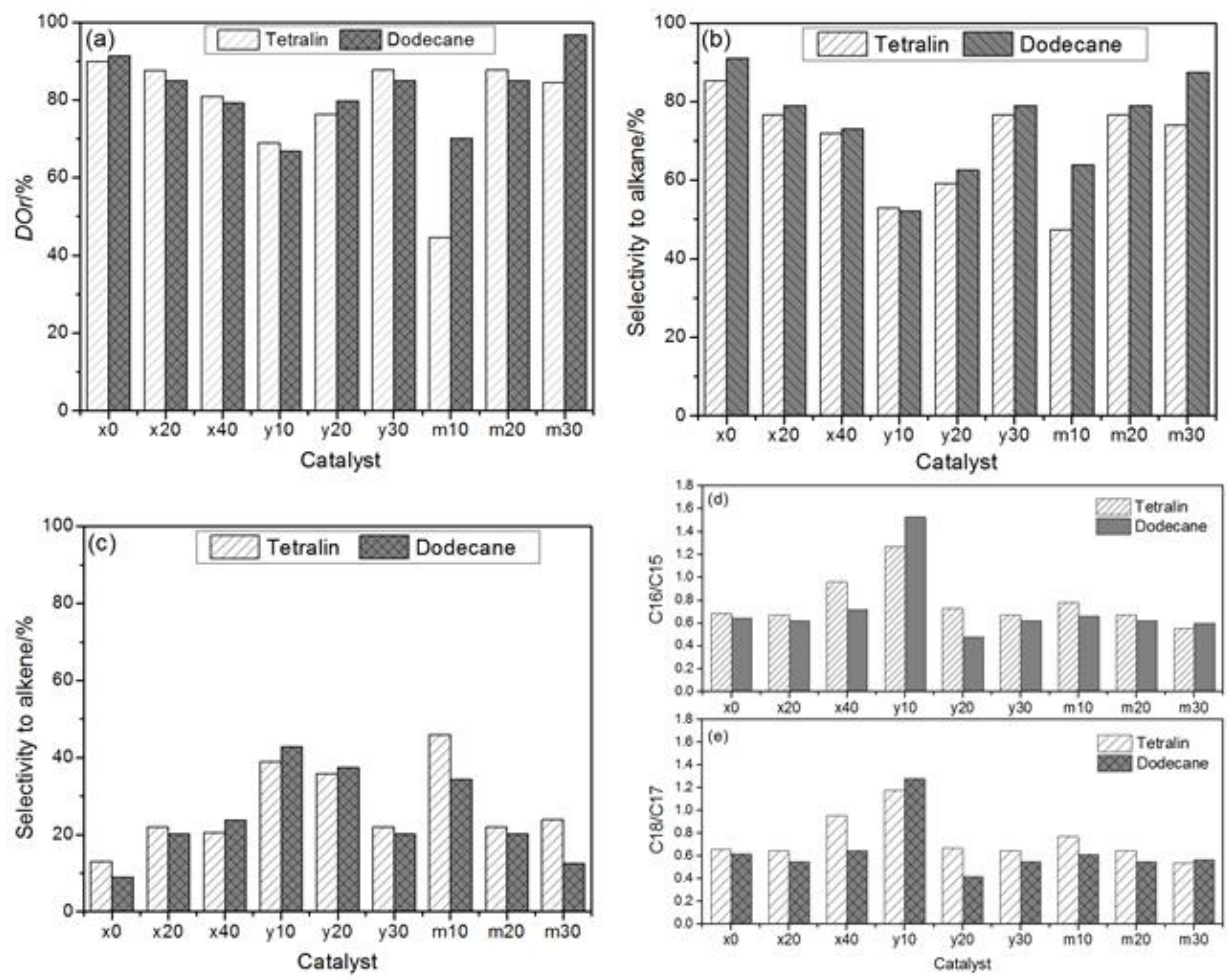

Figure 3. DOr and Product Selectivity after $2 \mathrm{~h}$ Reaction with Different Solvents and Catalysts

Table 2 shows the $D O r$ and product selectivity using different catalysts and solvents. These catalysts yield $n$-octadecane $(n$-C18), $n$-heptadecane $(n$-C17), $n$-hexadecane $(n$ C16) and $n$-pentadecane ( $n$-C15) with $n$-C17 being the favored products with selectivity in the range $28 \sim 45 \%$. $n-\mathrm{C} 17$ and $n-\mathrm{C} 15$ in product are formed via the DCOx reaction pathway, and $n-\mathrm{C} 18$ and $n-\mathrm{C} 16$ are produced via the HDO reaction pathway. DCOx and $\mathrm{HDO}$ reaction paths are attributed to the roles of Ni and Mo components, respectively [9].

\section{Conclusion}

NiMo catalysts were prepared by loading $\mathrm{NiO}$ and $\mathrm{MoO}_{3}$ onto a $\gamma-\mathrm{Al}_{2} \mathrm{O}_{3}-\beta$-zeolite composite support. The effects of the catalytic properties and solvents on the hydrogenation of WCO were investigated. The results showed that increasing the $\beta$ zeolite in the support helps to increase the acidities of catalysts but reduces WCO DOr and the formation of alkane hydrocarbons; increasing the $\mathrm{NiO}$ and $\mathrm{MoO}_{3}$ mass fraction tends to promote alkane selectivity and increase $\mathrm{DOr}$; increasing the Ni molar fraction helps to promote the reducing ability of catalysts and increase $\mathrm{DOr}$ and alkane selectivity 
of products. Both solvents showed different effects on the DOr and product selectivity. The highest DOr was $89.9 \%$ for tetralin and $96.7 \%$ for dodecane. The total content of C15-C18 hydrocarbons in the hydrogenated products was about $99 \%$.

\section{Acknowledgements}

The authors are grateful for supports from the National Natural Science Foundation of China (Nos. 21566004 and 21266002) and the Guangxi Natural Science Foundation (2015GXNSFAA139036), the Scientific Research Foundation of Guangxi University (Nos. XGZ120081 and XTZ140787) and 2016-2017 'Guangxi University college students' innovative and entrepreneurial training plan" at Guangxi autonomous region level (No. 201610593155).

Table 2. DOr and product selectivity using different catalysts and solvents.

\begin{tabular}{lcccccccc}
\hline \multirow{2}{*}{ Solvent } & Catalyst & \multirow{2}{*}{ DOr/\% } & \multirow{2}{*}{$N v$} & \multicolumn{5}{c}{ Selectivity to hydrocarbon $\%$} \\
\cline { 5 - 8 } Tetralin & $\mathrm{x} 0$ & 89.9 & 0.179 & 26.2 & 40.0 & 13.4 & 19.6 & 0 \\
& $\mathrm{x} 20$ & 87.7 & 0.192 & 25.6 & 39.4 & 13.7 & 20.4 & 0.8 \\
& $\mathrm{x} 40$ & 80.9 & 0.106 & 32.3 & 33.9 & 16.1 & 16.8 & 3.2 \\
& $\mathrm{y} 10$ & 68.9 & 0.236 & 34.4 & 29.3 & 20.3 & 16.0 & 0 \\
& $\mathrm{y} 20$ & 76.3 & 0.189 & 25.6 & 38.4 & 14.7 & 20.2 & 0 \\
& $\mathrm{y} 30$ & 87.7 & 0.192 & 25.6 & 39.4 & 13.7 & 20.4 & 0.8 \\
& $\mathrm{~m} 10$ & 44.6 & 0.136 & 29.2 & 37.9 & 14.4 & 18.5 & 0 \\
& $\mathrm{~m} 20$ & 87.7 & 0.192 & 25.6 & 39.4 & 13.7 & 20.4 & 0.8 \\
& $\mathrm{~m} 30$ & 84.5 & 0.327 & 22.5 & 41.7 & 12.0 & 21.8 & 5.6 \\
\hline Dodecanenyyyyyyyyy & $\mathrm{x} 0$ & 91.3 & - & 25.2 & 40.9 & 12.9 & 20.1 & 0 \\
& $\mathrm{x} 20$ & 85.0 & - & 23.1 & 42.4 & 12.9 & 20.7 & 0.9 \\
& $\mathrm{x} 40$ & 79.2 & - & 25.9 & 40.1 & 13.8 & 19.2 & 3.2 \\
& $\mathrm{y} 10$ & 66.8 & - & 36.0 & 28.2 & 21.6 & 14.2 & 0 \\
& $\mathrm{y} 20$ & 79.8 & - & 19.0 & 45.1 & 11.3 & 23.5 & 0 \\
& $\mathrm{y} 30$ & 85.0 & - & 23.1 & 42.4 & 12.9 & 20.7 & 0.9 \\
& $\mathrm{~m} 10$ & 70.1 & - & 24.2 & 39.5 & 14.5 & 21.9 & 0 \\
& $\mathrm{~m} 20$ & 85.0 & - & 23.1 & 42.4 & 12.9 & 20.7 & 0.9 \\
& $\mathrm{~m} 30$ & 96.7 & - & 23.5 & 41.4 & 12.8 & 21.3 & 1.8 \\
\hline
\end{tabular}

\section{References}

[1] N. Arun, R. V. Sharma, and A. K. Dalai, "Green diesel synthesis by hydrodeoxygenation of bio-based feedstocks: strategies for catalyst design and development," Renewable and Sustainable Energy Reviews, vol. 48, pp. 240-255, 2015.

[2] M. Toba, Y. Abe, H. Kuramochi, M. Osako, T. Mochizuki, and Y. Yoshimura, "Hydrodeoxygenation of waste vegetable oil over sulfide catalysts," Catalysis Today, vol. 164, pp. 533-537, 2011.

[3] J. Chen, Y. Yang, H. Shi, M. Li, Y. Chu, Z. Pan, and X. Xu, "Regulating product distribution in deoxygenation of methyl laurate on silica-supported Ni-Mo phosphides: Effect of Ni/Mo ratio," Fuel, vol. 129, pp. 1-10, 2014.

[4] L. F. Lin, S. F. Zhao, D. W. Zhang, H. Fan, Y. M. Liu, and M. Y. He, "Acid strength controlled reaction pathways for the catalytic cracking of 1-Pentene to propene over ZSM5," ACS Catalysis, vol.5, pp.4048-4059, 2015. 
$10^{\mathrm{TH}}$ International Conference on Sustainable EnERgy and Environmental Protection (June $27^{\mathrm{TH}}-30^{\mathrm{TH}}, 2017$, Bled, SLOVEnia), RENEWABle ENERGy SOURCES Z. Li, Z. Huang \& C. Wang: Green Diesel Synthesis by Catalytic Hydrogenation of Waste Cooking Oil: Catalyst Design and Effect of Solvent

[5] Z. Huang, S. Ding, Z. Li, H. Lin, F. Li, L. Li, Z. Zhong, C. Gao, C. Chen, and Y. Li, "Catalytic conversion of stearic acid to fuel oil in a hydrogen donor," International Journal of Hydrogen Energy, vol. 41, pp. 16402-16414, 2016.

[6] X. Li, W. Zhang, S. Liu, L. Xu, X. Han, and X. Bao, "The role of alumina in the supported $\mathrm{Mo} / \mathrm{HBeta}-\mathrm{Al}_{2} \mathrm{O}_{3}$ catalyst for olefin metathesis: A high-resolution solid-state NMR and electron microscopy study," Journal of Catalysis, vol. 250, pp. 55-66, 2007.

[7] L. Qu, W. Zhang, P. J. Kooyman, R. Prins, "MAS NMR, TPR, and TEM studies of the interaction of NiMo with alumina and silica-alumina supports," Journal of Catalysis, vol. 215, pp.7-13, 2003.

[8] S. Liu, S. Huang, W. Xin, J. Bai, S. Xie, L. Xu, "Metathesis of ethylene and butylene-2 to propylene with Mo on $\mathrm{H} \beta-\mathrm{Al}_{2} \mathrm{O}_{3}$ catalysts," Catalysis Today, vol. 93-95, pp. 471-476, 2004.

[9] D. Kubicka, and L. Kaluza, "Deoxygenation of vegetable oils over sulfided Ni, Mo and NiMo catalysts," Applied Catalysis A, vol. 372, pp. 199-208, 2010. 
$10^{\mathrm{TH}}$ INTERNATIONAL CONFERENCE ON Sustainable ENERGy AND ENVIRONMENTAL Protection (June $27^{\mathrm{TH}}-30^{\mathrm{TH}}$, 2017, Bled, SLOVENIA), RENEWABLE ENERGy SOURCES

J. Krope, A.Ghani Olabi, D. Goričanec \& S. Božičnik

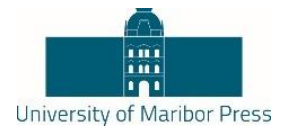

\title{
Structural Analysis of Hybrid Jute-Glass Fibre Composite Solar PTC Under Various Wind Conditions
}

\section{K.S. REDDY \& HITESH SINGLA}

\begin{abstract}
The study attempts to explore the technical feasibility of solar parabolic trough collector (PTC) with an aperture of $5.77 \mathrm{~m} \times 4 \mathrm{~m}$ made of woven jute/glass fibre-reinforced polyester hybrid composite material for both trough-alone (stiff) case and full collector (elastic) case under various wind conditions such as gravity $(\mathrm{v}=0)$ and pressure loads (vd $\square 40 \mathrm{~m} / \mathrm{s}$ ). The collector is subjected to wind speed, $\mathrm{v}=15 \mathrm{~m} / \mathrm{s}$ under operating conditions and a design wind speed, $\mathrm{vd}=40 \mathrm{~m} / \mathrm{s}$ considering return period of 50 years for Chennai $\left(13.0827^{\circ} \mathrm{N}, 80.2707^{\circ} \mathrm{E}\right)$ by varying its yaw and pitch angles from $0^{\circ}$ to $90^{\circ}$ after optimizing the trough parameters. The analysis revealed that excessive RMS local slope deviations of trough termed as SDx values, increases with increase in pitch angle from $0^{\circ}$ to $90^{\circ}$ and exhibits maxima at $0^{\circ}$ yaw angle with $\mathrm{SDx}=3.78 \mathrm{mrad}$ and $\mathrm{SDx}=22.82$ $\mathrm{mrad}$ at $\mathrm{v}=15 \mathrm{~m} / \mathrm{s}$ and $\mathrm{vd}=40 \mathrm{~m} / \mathrm{s}$ respectively in stiff case and SDx $=3.81$ $\operatorname{mrad}$ and $\mathrm{SDx}=63.15 \mathrm{mrad}$ at $\mathrm{v}=15 \mathrm{~m} / \mathrm{s}$ and $\mathrm{vd}=40 \mathrm{~m} / \mathrm{s}$ respectively in elastic case at $0^{\circ}$ collector angle. Furthermore, it has been observed that the proposed trough model is a promising substitute of conventional collector due to its better stiffness to weight and cost to performance ratios.
\end{abstract}

Keywords: • solar energy • parabolic trough collector (PTC) • woven jute/glass composite structures $\bullet$ deformation $\bullet$ wind loads $\bullet$

CORRESPONDENCE ADDRESS: K.S. Reddy, Indian Institute of Technology Madras, Heat Transfer and Thermal Power Laboratory, Department of Mechanical Engineering, Chennai-600036, India; email: ksreddy@iitm.ac.in. Hitesh Singla, Indian Institute of Technology Madras, Heat Transfer and Thermal Power Laboratory, Department of Mechanical Engineering, Chennai-600036, India; email: hiteshsingla90@gmail.com. 
$10^{\text {TH }}$ International CONFEREnce on Sustainable Energy and Environmental Protection (June $27^{\mathrm{TH}}-30^{\mathrm{TH}}, 2017$, Bled, SLOVENIA), RENEWABLE ENERGy SOURCES K.S. Reddy \& H. Singla: Structural Analysis ff Hybrid Jute-Glass Fibre Composite Solar Ptc Under Various Wind Conditions

\section{Introduction}

Parabolic Trough Collector is an important CSP technology and is deployed to produce the cost effective solar devices. It is a mature technology which has reached its second phase of development and thus, the use of composite materials are seemed as a prospect in that before it is replaced with various conventional devices for large scale applications. There are various conditions under which these equipments has to be tested before they are considered favourable for production. Conditions such as wind loading and gravity loading plays an important part in deciding the structural stability especially while working with new materials [1]. Over the years, the use of composite materials in solar technologies has been meagre due to high costs involved in fabricating its mould. But these costs can be subdued impressively if they are manufactured using natural fibres [2]. Though there are cons in using natural fibres like low fibre-matrix adhesion which can still be controlled by chemical treatments but otherwise they are recyclable and offers low density and favourable mechanical properties as compared to synthetic fibres like glass.

The use of composite materials in fabricating the trough was first used by Kalogirou et al., followed by Valan Arasu et al. and then later on Gianlucca Coccia et al. where they studied the composite collector experimentally subjected to gravity loading using different materials [3], [4], [5]. The first mention of strongest forces acting on the conventional trough (made of glass) at $0^{\circ}$ yaw angle was done by J. Paetzold et al. under wind loading alone using CFD [6].

The present work highlights the need of using hybrid jute-glass fibre composite material and the impacts that it can have on the parabolic trough collector optimized under various parameters subjected to both gravity and wind loads for operating and extreme wind conditions. The introduction of jute in the trough collector ensures significant reduction in collector costs as cost per $\mathrm{kg}$ of jute lamina is almost 10 times lesser than that of glass lamina and also jute requires only $2 \%$ of energy for its production than glass which makes it a suitable material to combat the excessive costs of moulds [7].

$2 \quad$ Methodology

\subsection{Geometrical Model}

A hybrid jute-glass fibre and polyester resin composite trough reinforced with PVC conduits having two inner mirrors and two outer mirrors in one column shown in Figure 1 is studied for both stiff case (only the effect of trough is considered) and elastic case (whole collector is considered) after optimizing the configuration. The Hybrid Trough Laminate (HTL) with configuration $\left[0^{\circ}{ }_{\mathrm{G}} / 45^{\circ} \mathrm{G} /-45^{\circ} \mathrm{J} / 90^{\circ} \mathrm{J}\right] \square\left(0^{\circ}\right.$ is parallel to $\mathrm{X}$ direction $)$ is fixed with thickness and radius of conduits as $0.75 \mathrm{~mm}$ and $10 \mathrm{~mm}$ respectively to ensure maximum bending stiffness. The reinforcement is done in both $\mathrm{X}$ and $\mathrm{Y}$ directions to counterbalance the effect of directional wind load other than gravity load. 


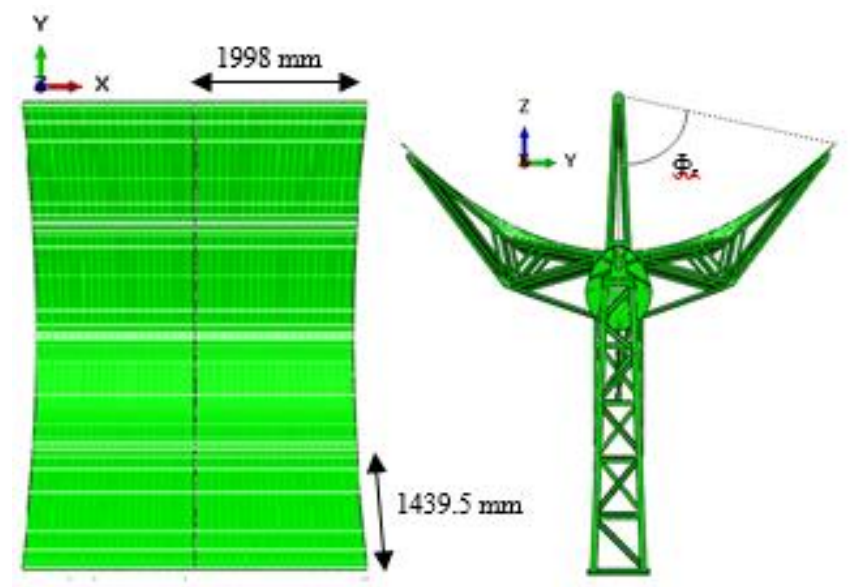

Figure 1. Stiff and elastic case of $5.77 \times 4 \times 4 \mathrm{~mm}$ hybrid trough with rim angle, $\Phi_{\mathrm{r}}=$ $80^{\circ}$.

\subsection{Numerical procedure}

The element types and meshing procedure that is followed for hybrid trough collector model using full Newton technique in Abaqus is shown in Table 1.

Table 1. Meshing details

\begin{tabular}{|c|c|c|}
\hline & Element & Element type \\
\hline HTL & S8R & Shell (quad) \\
\hline $\begin{array}{l}\text { Arm, Receiver } \\
\text { tube, Torque tube, } \\
\text { Pylons }\end{array}$ & $\begin{array}{l}\text { C3D10, } \\
\text { C3D15, } \\
\text { C3D20R }\end{array}$ & $\begin{array}{c}\text { Quad tetra, } \\
\text { Quad wedg, Quad } \\
\text { hexa }\end{array}$ \\
\hline Conduits & B31 & Linear line \\
\hline
\end{tabular}

Abaqus/Standard technique is used to solve the discretized equilibrium equations for finite element model [8].

For virtual work system considering contribution of inertia force not in body force:

$\mathrm{M}^{\mathrm{RS}} \ddot{\mathrm{u}}^{\mathrm{S}}+\mathrm{F}^{\mathrm{R}}\left(\mathrm{u}^{\mathrm{S}}\right)=0$

where $\mathrm{M}^{\mathrm{RS}} \ddot{\mathrm{u}}^{\mathrm{S}}$ is force vector due to material inertia, $\mathrm{F}$ is external force vector and $\mathrm{u}^{\mathrm{S}}$ is displacement of $S^{\text {th }}$ variable.

Using the Newton technique, Jacobian matrix becomes: 
408 10 $10^{\text {TH }}$ International Conference on Sustainable ENERgy AND ENVIRONMENTAL Protection (June $27^{\mathrm{TH}}-30^{\mathrm{TH}}, 2017$, Bled, SLOVEnia), RENEWABle ENERGy SOURCES K.S. Reddy \& H. Singla: Structural Analysis ff Hybrid Jute-Glass Fibre Composite Solar Ptc Under Various Wind Conditions

$\mathrm{K}_{\mathrm{SR}}=\mathrm{w}+\mathrm{x}+\mathrm{y}+\mathrm{z}$

where $\mathrm{w}=$ Small Displacement Stiffness matrix

$\mathrm{x}=$ Initial Stress matrix

$\mathrm{y}, \mathrm{z}=$ Load Stiffness matrix

Now $R_{a}=F^{R}-I_{a}^{R}$

where $\mathrm{R}_{\mathrm{a}}$ is force residual for next iteration and $\mathrm{I}^{\mathrm{R}}$ are internal forces.

This $R_{a}$ is compared with force residual tolerance value $\left(G_{a}\right)$ set in the model.

Also $\Delta \mathrm{u}_{\mathrm{a}}=\mathrm{u}_{\mathrm{a}}-\mathrm{u}_{\mathrm{o}}$

If displacement correction ( $c_{a}$ ) set in the model is greater than $1 \%$ of $\Delta \mathrm{u}_{a}$ and if $\mathrm{R}_{\mathrm{a}}<\mathrm{G}_{\mathrm{a}}$ then $\mathrm{F}$ and $\mathrm{I}$ are in equilibrium.

Hence next iteration is performed and are repeated in each increment until convergence is achieved.

\subsection{Boundary Conditions (BCs) and notation}

The structure modelled in CATIA V5 is given surface to surface interaction properties between HTL and reinforcement conduits, multi-point tie constraint between HTL and mirror arms and ENCASTRE BC between pylons and ground during its analysis. The collector is rotated under gravity load and wind direction is varied from $0^{\circ}$ to $90^{\circ}$ by taking different yaw angles $(\alpha)$ and pitch angles $(\beta)$ according to Figure 2 . The notation used to signify the particular configuration is denoted by $[\mathrm{A}, \mathrm{B}, \mathrm{C}]$ where $\mathrm{A}, \mathrm{B}$ and $\mathrm{C}$ represents collector angle, $\alpha$ and $\beta$ respectively. The post processing of the results is done is MATLAB where deformation values obtained from Abaqus in $\mathrm{mm}$ is converted into deformation values (or SDx values) in milliradians to further calculate optical efficiency.

\section{$3 \quad$ Results and Discussion}

\subsection{Calculation of SDx values and pressure load}

The RMS local slope deviations of the trough is calculated using modified elemental approach in form of SDx values (milliradians) under gravity 


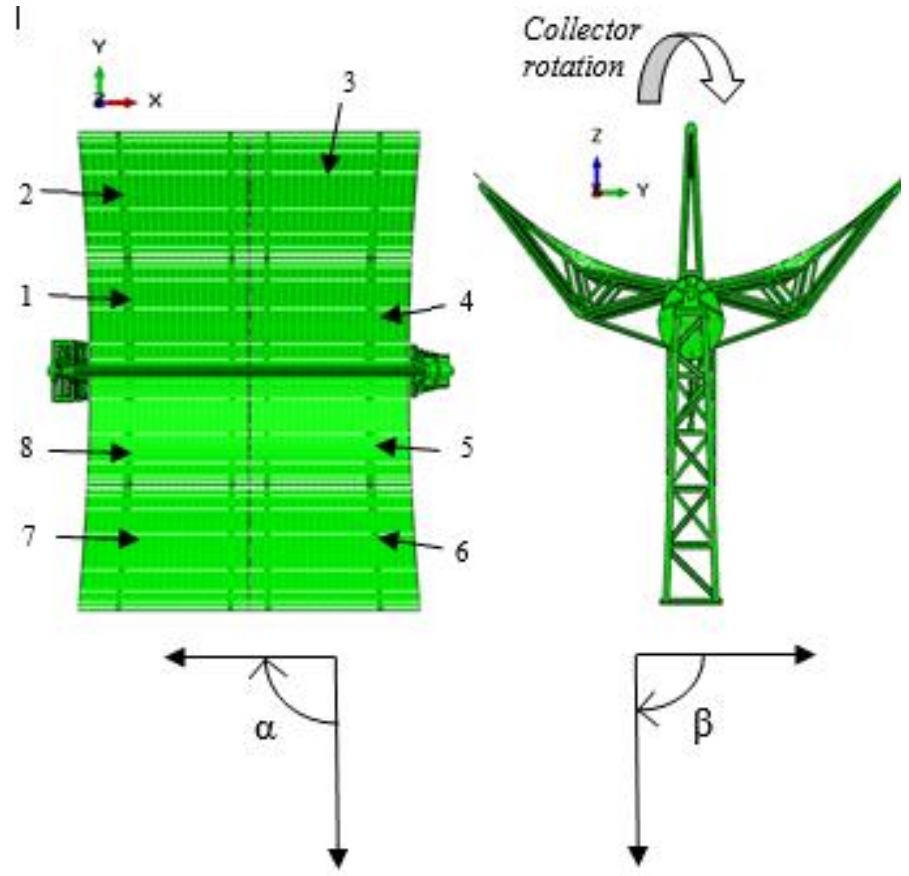

Figure 2. Representation of wind load direction in elastic case at $0^{\circ}$ collector angle with mirrors numbered from 1 to 8 .

and wind loads both from Equation (5)

$\mathrm{SD}_{\mathrm{x}}=\sqrt{\frac{\left(\sum_{\mathrm{i}, \mathrm{j}=1}^{\mathrm{n}}\left(\phi_{\mathrm{x}_{\mathrm{ij}}}^{2}+\phi_{\mathrm{y}_{\mathrm{ij}}}^{2}\right)\right.}{n}}$

where $\phi_{x i j}^{2}$ and $\phi_{y i j}^{2}$ are local slope deviation values calculated between deformed and undeformed normals of an element projected on vertical planes and $n$ is the total no. of elements. The pressure load or wind load (P) varies according to Equation (6)

$\mathrm{P}=\frac{1}{2} \rho v^{2}$

where density of air $(\rho)\left(\mathrm{kg} / \mathrm{m}^{3}\right)=1.2$ and velocity of wind $(\mathrm{v})(\mathrm{m} / \mathrm{sec})=15$ under operating conditions and design wind velocity $\left(\mathrm{v}_{\mathrm{d}}\right)(\mathrm{m} / \mathrm{sec})=40$ considering return period of 50 years for Chennai $\left(13.0827^{\circ} \mathrm{N}, 80.2707^{\circ} \mathrm{E}\right)$ or for non-operating conditions. All the mechanical properties mentioned in Table 2 are used to calculate properties like Shear modulus $(\mathrm{G})(\mathrm{GPa})$, Elastic modulus $(\mathrm{E})(\mathrm{GPa})$ and Poisson's ratio $(v)$ in in-plane and transverse directions by taking 50/50 V/V\% of fibre resin ratio [9], [10], [11], [12]. 
$410 \quad 10^{\text {TH }}$ International CONFERENCE ON Sustainable ENERGy AND ENVIRONMENTAL Protection (June $27^{\mathrm{TH}}-30^{\mathrm{TH}}, 2017$, Bled, SLOVEnia), RENEWABle ENERGy SOURCES K.S. Reddy \& H. Singla: Structural Analysis ff Hybrid Jute-Glass Fibre Composite Solar Ptc Under Various Wind Conditions

\subsection{Effect of yaw angle, pitch angle and collector angle on $\mathrm{SD}_{\mathbf{x}}$ values}

The dynamic loads on collector depends highly on the direction of wind. When the collector is subjected to wind approaching from different directions at $0^{\circ}$ collector angle, the maximum SDx value of $3.78 \mathrm{mrad}$ is obtained at $\alpha=0^{\circ}$ and

Table 2. Mechanical properties of fibres and resins used for modelling [9], [10], [11], [12].

\begin{tabular}{|c|c|c|c|c|}
\hline & $\mathrm{E}$ & $\mathrm{G}$ & $v$ & $\rho$ \\
\hline Woven glass & 72 & 29 & 0.25 & 2600 \\
\hline Woven Jute & 25 & 7.24 & 0.38 & 1450 \\
\hline $\begin{array}{c}\text { Unsaturated } \\
\text { Polyester Resin }\end{array}$ & 3.4 & 1.2 & 0.4 & 1110 \\
\hline Epoxy resin & 3.5 & 1.019 & 0.3 & 1250 \\
\hline
\end{tabular}

$\beta=90^{\circ}$ in stiff case as shown in Figure 3 due to maximum loading area of trough under gravity and wind loads in this configuration. Also this is mainly happening due to identical vector directions of both the loads for a maximum loading area.

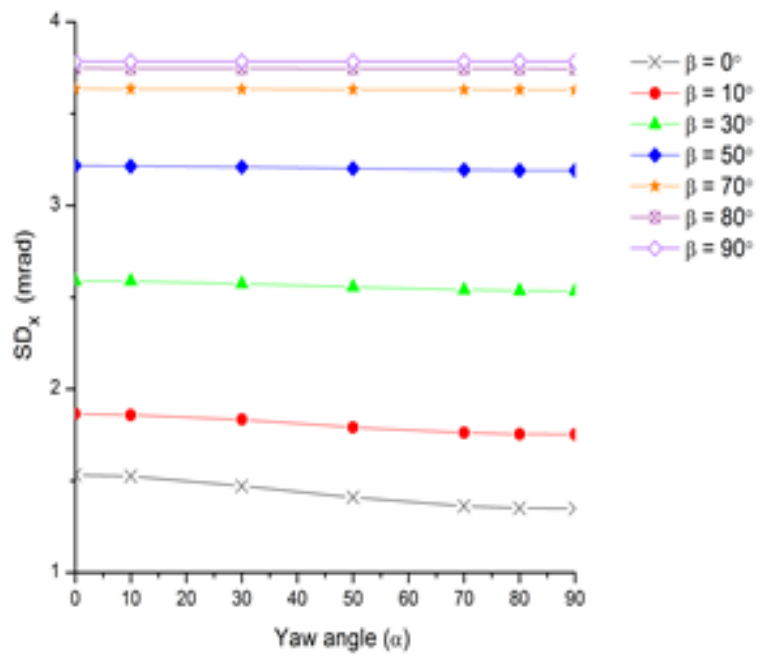

Figure 3. Effect of different $\alpha$ 's and $\beta$ 's on SDx values in stiff case at $0^{\circ}$ collector angle at $\mathrm{v}=15 \mathrm{~m} / \mathrm{sec}$.

Similar variation can be studied for collector angle variation from $0^{\circ}$ to $90^{\circ}$ at different yaw and pitch angles. But after studying 490 cases, it is seen that in all the different collector angles, maximum SDx values are obtained at $\alpha=0^{\circ}$ and $\beta=90^{\circ}$. For convenience sake, only the maximum SDx values are shown in Figure 4 for the aforementioned configuration at different collector angles. 
In elastic case, the trend observed for above two figures is same except that SDx values obtained in this case are higher than that are observed for stiff case due to increase in deformations in the former by inclusion of mirror arms, torque tube and pylons.

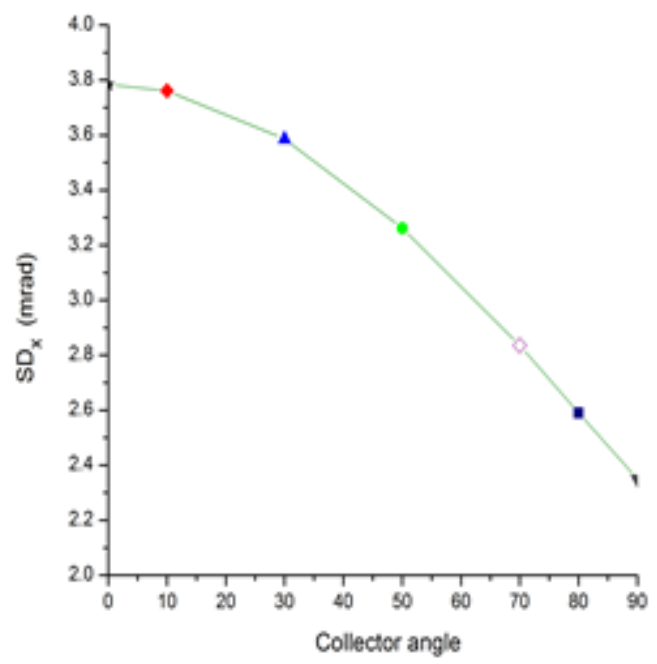

Figure 4. Effect of collector angle on SDx values at $\alpha=0^{\circ}$ and $\beta=90^{\circ}$ in stiff case at $\mathrm{v}=$ $15 \mathrm{~m} / \mathrm{sec}$.

\subsection{Comparison of present model with conventional collector in stiff and elastic} case

The variation of SDx values in elastic case under three most critical configurations i.e. $[0,0,90],[90,0,0]$ and $[90,0,90]$ is shown in Figure 5 and the results are further compared with the conventional collector. It is found that the proposed model and conventional collector shows maximum SDx value of $3.81 \mathrm{mrad}$ and SDx $=3.82 \mathrm{mrad}$ respectively at $[0,0,90]$ configuration. Also from Figure 5 , it is clear that trends for both the collectors are quite similar which proves that performance of both the collectors at $\mathrm{v}=15 \mathrm{~m} / \mathrm{sec}$ is almost same.

From Table 3, the increased impacts of adding pressure loads to the gravity loads at different configurations can be seen for both hybrid trough collector and conventional collector model in stiff and elastic case. It is shown in Figure 6 for $[90,0,0]$ and $[90,0,90]$ configurations that winds changes the deformation tendency of the collector depending upon the direction from which it is coming. The mirrors 6 and 7 undergoes righted $\mathrm{U}$ shape when

$\beta=0^{\circ}$ while they undergo inverted $\mathrm{U}$ shape when $\beta=90^{\circ}$. Thus SDx values and shape of HTL deformation are completely dependent upon wind's striking direction and gravity vector other than BCs and collector's stiffness/weight ratio. Furthermore, it is also clear 
412 10 $10^{\mathrm{TH}}$ International CONFEREnCE on Sustainable EnERgy AND ENVIRONMENTAL Protection (June $27^{\mathrm{TH}}-30^{\mathrm{TH}}, 2017$, Bled, SLOVENIA), RENEWABLE ENERGY SOURCES K.S. Reddy \& H. Singla: Structural Analysis ff Hybrid Jute-Glass Fibre Composite Solar Ptc Under Various Wind Conditions

from the Table 3 that present model shows weight reductions of upto $30 \%$ and $4.5 \%$ in stiff and elastic case

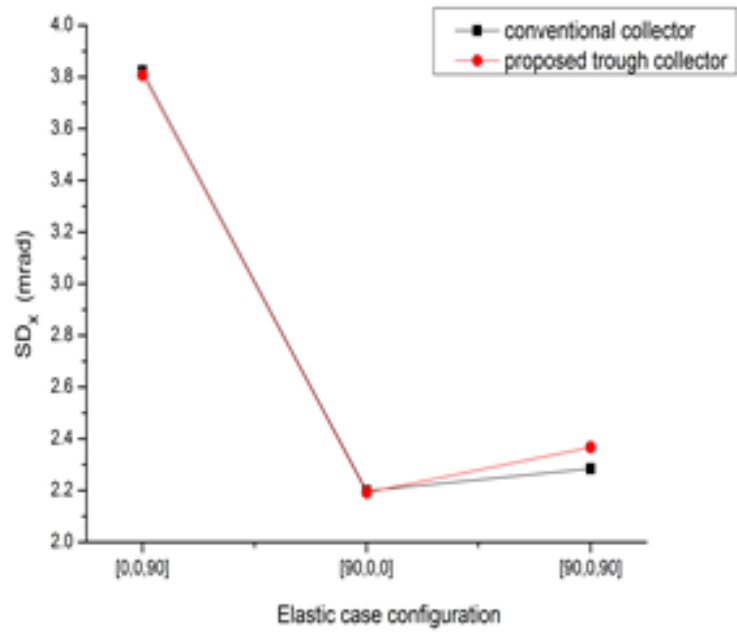

Figure 5. Comparison of SDx values of present model and conventional model for both gravity and wind loads in elastic case at $\mathrm{v}=15 \mathrm{~m} / \mathrm{sec}$.

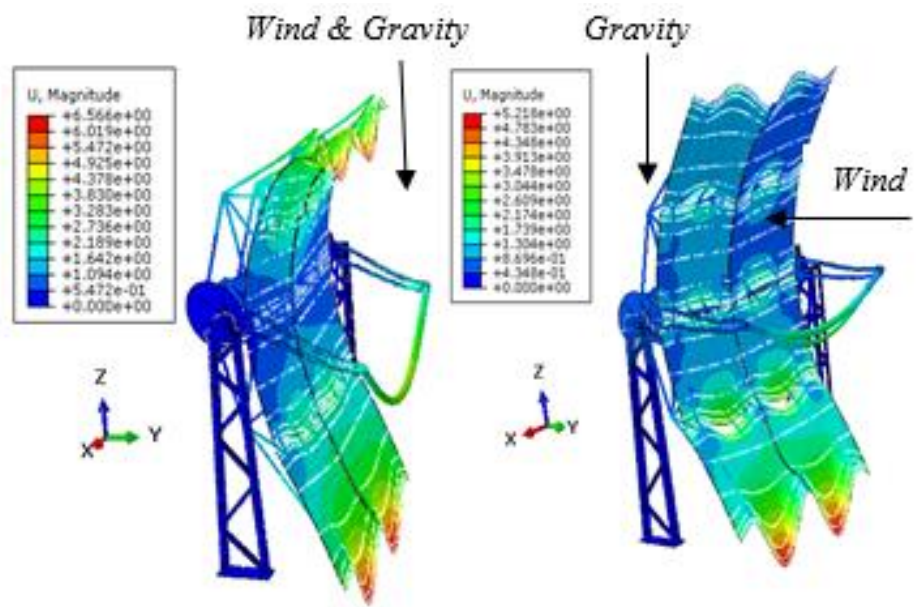

Figure 6. Deformation (in mm) of hybrid composite trough collector at $[90,0,0]$ and $[90,0,90]$ configurations in elastic case at $v=15 \mathrm{~m} / \mathrm{sec}$. Deformation scaling factor: 400 .

respectively from conventional collector. 


\subsection{Wind speed effect on SDx values for operating and non-operating conditions}

Figure 7 (a), (b) shows the impact of $\mathrm{v}=15 \mathrm{~m} / \mathrm{sec}$ and $\mathrm{v}_{\mathrm{d}}=40 \mathrm{~m} / \mathrm{sec}$ on the deformation of collector for elastic case in $[0,0,90]$ configuration. It is rightly visible here that hybrid composite collector undergoes some serious deformation of $138 \mathrm{~mm}$ while facing $\mathrm{v}_{\mathrm{d}}=40$ $\mathrm{m} / \mathrm{sec}$ as compared to significantly lower deformation value of $4.89 \mathrm{~mm}$ at $\mathrm{v}=15 \mathrm{~m} / \mathrm{sec}$ or operating conditions in this configuration.

Table 3. Weight - Performance comparison of conventional and proposed collector subjected to only gravity load and both gravity \& pressure loads $(\mathrm{v}=15 \mathrm{~m} / \mathrm{sec})$ in different configurations

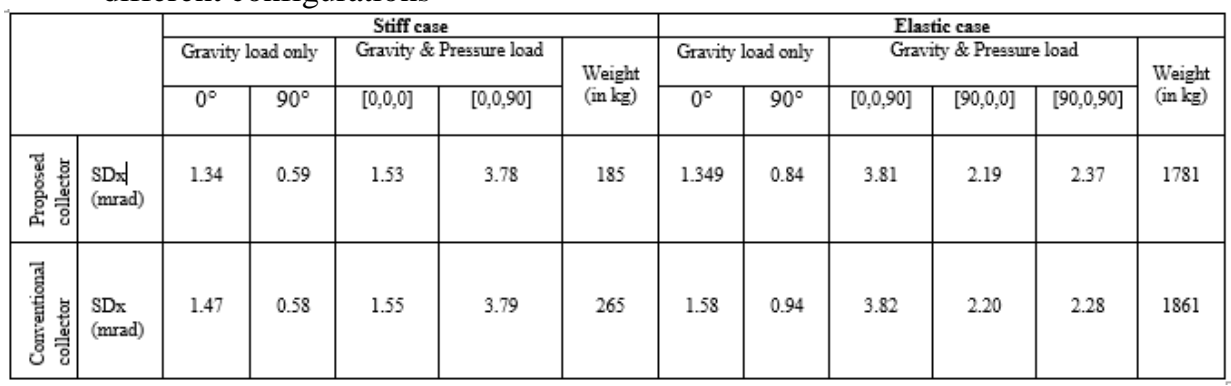


$10^{\mathrm{TH}}$ InTERnAtional CONFERENCE ON Sustainable ENERGy AND ENVIRONMENTAL Protection (June $27^{\mathrm{TH}}-30^{\mathrm{TH}}, 2017$, BlED, SLOVENIA), RENEWABLE ENERGY SOURCES K.S. Reddy \& H. Singla: Structural Analysis ff Hybrid Jute-Glass Fibre Composite Solar Ptc Under Various Wind Conditions

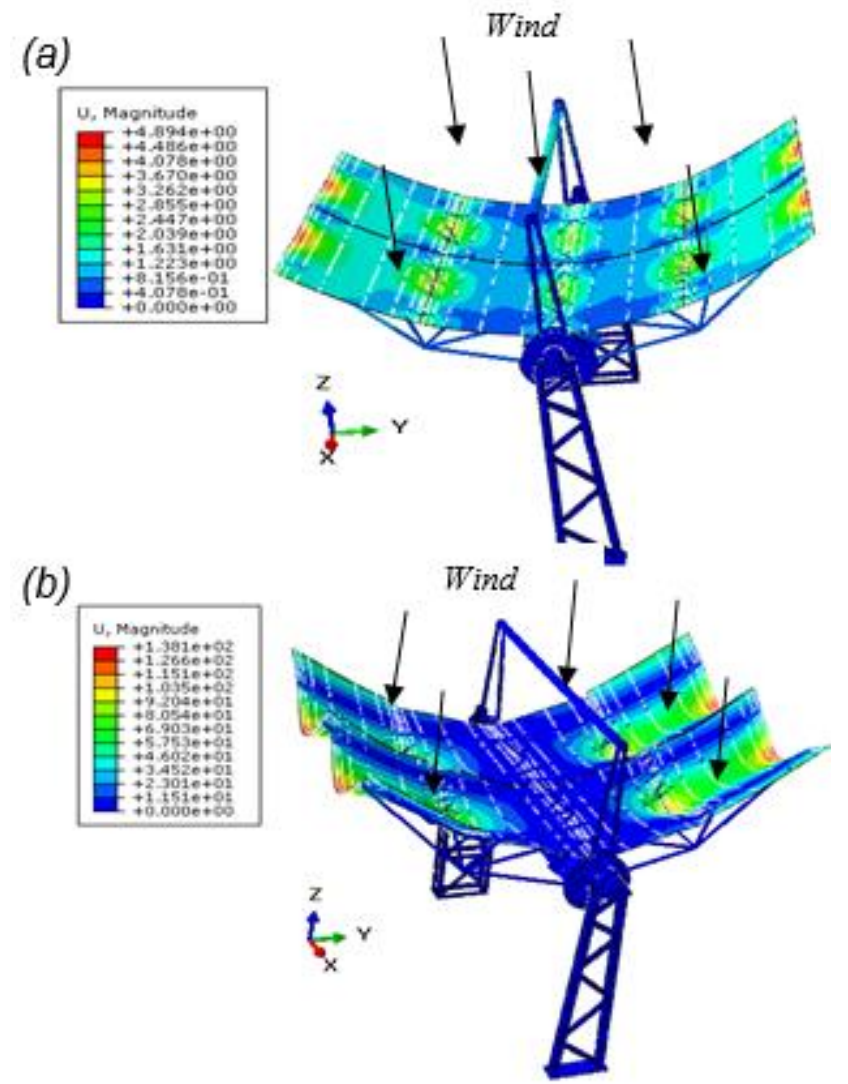

Figure 7. Deformation (in $\mathrm{mm}$ ) of hybrid composite trough collector for $[0,0,90]$ configuration in elastic case at wind velocity (a) $15 \mathrm{~m} / \mathrm{sec}$ (b) $40 \mathrm{~m} / \mathrm{sec}$. Deformation scaling factor: 10 .

From Table 4, it can be seen that adding support structure in stiff case increases the deformation values from $22.82 \mathrm{mrad}$ to $63.15 \mathrm{mrad}$ for [0,0,90] configuration at nonoperating $\left(\mathrm{v}_{\mathrm{d}}=40 \mathrm{~m} / \mathrm{sec}\right)$ conditions which confirms that greater part of stored energy is getting lost by support structure (made of stainless steel) which is recoverable though, once the load is removed due to its elasticity. Otherwise the deformation of mirror modules in stiff case under this wind velocity is within the limits and thus, they could be repaired at minimum cost due to presence of jute. Therefore, it can be said that overall structure is within the sustained limits and is stable under worst weather conditions at $[0,0,90]$. 
Table 4. SDx values for stiff and elastic case at different configurations under different loading conditions.

\begin{tabular}{|c|c|c|c|c|c|}
\hline & \multirow{3}{*}{$\begin{array}{c}\text { Stiff case } \\
\text { Gravity \& } \\
\text { Pressure } \\
\text { load } \\
{[0,0,90]}\end{array}$} & \multicolumn{3}{|c|}{$\begin{array}{c}\text { Elastic case } \\
\end{array}$} \\
\hline & & & \multicolumn{3}{|c|}{ Gravity \& Pressure load } \\
\hline & & & {$[0,0,90]$} & {$[90,0,0]$} & $\begin{array}{c}{[90,0,9} \\
0]\end{array}$ \\
\hline 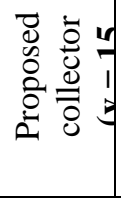 & $\begin{array}{l}\text { SD } \\
x \\
(\mathrm{mr} \\
\mathrm{ad})\end{array}$ & 3.78 & 3.81 & 2.19 & 2.37 \\
\hline 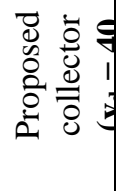 & $\begin{array}{l}\mathrm{SD} \\
\mathrm{x} \\
(\mathrm{mr} \\
\mathrm{ad})\end{array}$ & 22.82 & 63.15 & 13.81 & 58.79 \\
\hline
\end{tabular}

\section{$4 \quad$ Conclusions}

The use of conventional materials in fabricating parabolic trough reflectors (made of glass) should be replaced with hybrid composite materials because of better/equivalent performance observed under gravity and wind loads in the latter at fairly large reductions in its cost and weight. The loading conditions on hybrid composite trough collector made of jute-glass fibres reinforced with PVC conduits ensures that greatest impact of dynamic forces is observed at yaw angle of $0^{\circ}$ and pitch angle of $90^{\circ}$ at $0^{\circ}$ collector angle in both stiff and elastic case. This impact reduces as collector angle increases from $0^{\circ}$ to $90^{\circ}$ in the aforementioned wind direction in both the cases.

Also, the difference in deformation values observed in gravity loading case alone and combination of both wind loading and gravity loading case at different collector angles shows the importance of analysing the collector in pressure conditions.

The observations also suggests that under extreme wind velocities i.e. for cyclonic conditions, the hybrid collector undergoes much higher deformations to degrade its performance to the worst but not enough deformations to lose the stability due to recoverable loss in elastic energy of the supporting structure (made of stainless steel) and capability of the composite mirrors to undergo repair at the minimum cost due to presence of jute in it. However under normal wind velocities, it is a perfect replacement to the conventional collector. 
416 10 $10^{\mathrm{TH}}$ INTERNATIONAL CONFERENCE ON Sustainable ENERGy AND ENVIRONMENTAL Protection (June $27^{\mathrm{TH}}-30^{\mathrm{TH}}, 2017$, BlED, SLOVENIA), RENEWABLE ENERGY SOURCES K.S. Reddy \& H. Singla: Structural Analysis ff Hybrid Jute-Glass Fibre Composite Solar Ptc Under Various Wind Conditions

\section{References}

[1] Honghang Sun, Bo Gong, Qiang Yao, "A review of wind loads on heliostats and trough collectors,” Renewable and Sustainable Energy Reviews, vol. 32, 206-221, 2014.

[2] Dario Croccolo, Massimiliano De Agostinis, Stefano Fini, Alfredo Liverani, Nicolo Marinelli, Eugenio Nisini, Giorgio Olmi, "Mechanical Characteristics of Two Environmentally Friendly Resins Reinforced with Flax Fibres," Journal of Mechanical Engineering, 61, 227-236, 2015.

[3] Kalogirou, S., Eleftheriou, P., Lloyd, S., Ward, J, "Low cost high accuracy parabolic troughs construction and evaluation," Renewable Energy, 5 (1-4), 384-386, 1994.

[4] Valan Arasu, A., Sornakumar, T, "Design, manufacture and testing of fiberglass reinforced parabola trough for parabolic trough solar collectors," Solar Energy, 81 (10), 1273-1279, 2007.

[5] Coccia, G., Di Nicola, G., Sotte, M., "Design, manufacture, and test of a prototype for a parabolic trough collector for industrial process heat," Renewable Energy, 74, 727-736, 2014.

[6] J. Paetzold, S. Cochard, D.F.Fletcher, A. Vassallo, "Wind engineering analysis of parabolic trough collectors to optimise wind loads and heat loss," Energy Procedia, 69, 168-177, 2015.

[7] Amit Bindal, Satnam Singh, N. K. Batra, Rajesh Khanna, "Development of Glass/Jute Fibers Reinforced Polyester Composite," Indian Journal of Materials Science. Article ID 675264, 2013.

[8] Hibbit, Karlsson, Sorensen, “Abaqus Analysis User's Manual,” vol 2-Abaqus 6.10, 2010.

[9] Vinson J.R., Sierakowski R.L., "The behaviour of structures composed of composite materials", Solid Mechanics and its Applications, 105, 1-445, 2008.

[10] Akkerman, Remko, "Laminate mechanics for balanced woven fabrics," Composites Part B: Engineering, 37 (2-3), 108-116, 2006.

[11] S. Belaid, S.F. Chabira, P. Balland, M. Sebaa, S. Belhouideg, "Thermal aging effect on the mechanical properties of polyester fiberglass composites," J. Mater. Environ. Sci. 6 (10), 2795-2803, 2015.

[12] Parsaoran Hutapea, Joachim L. Grenestedt, "Effect of Temperature on Elastic Properties of Woven-Glass Epoxy Composites for Printed Circuit Board Applications," J. of Electronic Materials, Vol 32, No.4, 2003. 
$10^{\mathrm{TH}}$ INTERNATIONAL CONFERENCE ON Sustainable ENERgy AND ENVIRONMENTAL Protection (June $27^{\mathrm{TH}}-30^{\mathrm{TH}}$, 2017, Bled, SLOVENIA), RENEWABLE ENERGy SOURCES

J. Krope, A.Ghani Olabi, D. Goričanec \& S. Božičnik

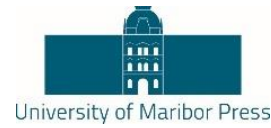

\title{
On the Stability of Natural Gas and Low Calorific Value Fuels in a Surface-Stabilized Combustion Burner
}

\author{
Carlos E. Arrieta, Alex M. García, Iván D. Bedoya \& Andrés A. Amell
}

\begin{abstract}
Synthetic gas (syngas) or low calorific value fuels are considered as one of the most promising alternative fuels, that will play a major role in the diversification of the energetic sources. Since it can be produced from the gasification of coal, whose reserves are abundant worldwide, and multiple solid feedstocks such as organic waste and biomass. However, these alternative fuels generally have lower heating values and Wobbe index than fossil fuels. Therefore, there is a strong global effort to burn mixtures of syngas and conventional fuels, such as natural gas. The objective of this work is to investigate, numerically and experimentally, the combustion of low calorific value fuels in a ceramic surfacestabilized combustion burner, in particular, to study the effects of substituting natural gas with syngas on flame stability and pollutant emissions. In this study, we evaluated three syngases with high hydrogen contents ranging from $60 \% \mathrm{H} 2$ to $75 \%$ $\mathrm{H} 2$. The experimental study was performed at different thermal input conditions (300 to $500 \mathrm{~kW} / \mathrm{m}$ ) and equivalence ratios. The results indicate that the stability ranges are dependent on laminar flame velocities and adiabatic flame temperatures. Moreover, it was found that $\mathrm{CO}$ and $\mathrm{NOx}$ emissions are highly affected by the $\mathrm{H} 2$ concentration. This behavior is attributed to the increase of $\mathrm{OH}$ radicals, which favored the net reaction rate of most of the elementary reactions that involved these species.
\end{abstract}

Keywords: • High-Hydrogen Content Syngases • Natural gas • Combustion in a Radiant Porous Media Burner • Fuel interchangeability • global •

CoRrespondence AdDress: Carlos Ernesto Arrieta, M.Sc., Universidad de Antioquia, Grupo de Ciencia y Tecnología del Gas y Uso Racional de la Energía, Facultad de Ingeniería, , Calle $67 \mathrm{~N}^{\circ}$ 53-108, Bloque 20-447, Medellín, Colombia, e-mail: ernesto.arrieta@udea.edu.co. Alex Mauricio García, M.E., Universidad de Antioquia, Grupo de Ciencia y Tecnología del Gas y Uso Racional de la Energía, Facultad de Ingeniería, Calle 67 № 53-108, Bloque 20-447, Medellín, Colombia, email: alex.garciav@udea.edu.co. Iván Dario Bedoya, PhD., Associate Professor, Universidad de Antioquia , Grupo de Ciencia y Tecnología del Gas y Uso Racional de la Energía, Facultad de Ingeniería, Calle $67 \quad \mathrm{~N}^{\circ}$ 53-108, Bloque 20-445, Medellín, Colombia, e-mail: ivan.bedoya@udea.edu.co. Andrés Amell, M.Sc, Associate Professor, Universidad de Antioquia, Grupo de Ciencia y Tecnología del Gas y Uso Racional de la Energía, Facultad de Ingeniería, Calle 67 № 53-108, Bloque 20-435, Medellín, Colombia, e-mail: andres.amell@udea.edu.co.

https://doi.org/10.18690/978-961-286-061-5.37

ISBN 978-961-286-061-5

(C) 2017 University of Maribor Press

Available at: http://press.um.si. 
$10^{\text {TH }}$ InTERnational CONFERENCE ON Sustainable ENERgy AND ENVIRONMENTAL Protection (June $27^{\mathrm{TH}}-30^{\mathrm{TH}}, 2017$, BlED, SLOVENIA), RENEWABLE ENERGy SOURCES C. E. Arrieta, A. M. García, I. D. Bedoya \& A. A. Amell: On the Stability of Natural Gas and Low Calorific Value Fuels in a Surface-Stabilized Combustion Burner

1 Introduction

Natural gas (NG), which consists primarily of $\mathrm{CH}_{4}$, is commonly used in many combustion applications such as industrial furnaces, gas turbine engines, and household appliances. NG is considered to be a clean fuel compared to other fossil fuels. However, $\mathrm{NG}$ produces $\mathrm{CO}_{2}, \mathrm{CO}$, and NOx. NOx emission is inherent to combustion with air. $\mathrm{CO}$ and $\mathrm{CO}_{2}$, on the other hand, can be reduced by improving the efficiency of the equipment. Consequently, many studies have focused on increasing process efficiencies and developing alternative fuels, which is of great interest to countries and regions with reserves of other alternative energy sources.

Synthetic gas (syngas, $S G$ ) obtained from the gasification of coal and biomass is considered to be one of the most promising alternative fuels in developed and developing countries [1], [2]. However, depending on the type of reactor and the gasifying agent, syngas can have worse properties. Lower heating values, between 1.0 and $\sim 2.6 \mathrm{kWh} / \mathrm{m}^{3}$ and Wobbe index values, between 1.5 and $\sim 4 \mathrm{kWh} / \mathrm{m}^{3}$, which are very low compared to the values for $\mathrm{NG}\left(9.425 \mathrm{kWh} / \mathrm{m}^{3}\right.$ and $14.09 \mathrm{kWh} / \mathrm{m}^{3}$, respectively). Thus, there is a strong global effort to burn mixtures of conventional fuels and syngas, which also provides alternatives to increase the use of available fuels [3].

Systems that include preheating of the reactant mixture have been shown to increase the stability range and facilitate effective combustion in these fuel mixtures [4]. One way of designing a burner with internal heat recirculation is to stabilize a premixed flame on the surface of porous inert media [5]. The energy released by the reaction is transferred to the porous surface, which in turn emits the energy to its surroundings (such as in radiant burners) and conducts the energy upstream to preheat the reactants in the preheat zone. Since the 1990s, many studies have shown the benefits of using this technique in combustion processes with high thermal powers [5]-[7]. Additionally, recent studies have demonstrated that these benefits (high thermal efficiencies, low pollutant emissions, and fuel interchangeability) can also be obtained at low thermal powers [8], [9]. Yu et al. [10] studied the behavior of a $5.8-\mathrm{kW}$ surface-stabilized combustion burner in a water heater fueled with $N G$. The burner surface consisted of a perforated steel plate (AISI 304) with a porosity of $83 \%$. Low pollutant emissions and high efficiencies $(\sim 79.7 \%)$ were achieved by operating the burner at an air-to-fuel ratio slightly greater than 1.3. Recently, the same authors [11] evaluated a similar device but varied the material of the burner surface using perforated steel (31\% porosity) and ceramic aluminum oxide plates $(49.5 \%$ porosity). Using a ceramic surface increased the thermal efficiency to nearly $85 \%$ but did not significantly change the emissions levels. Wu et al. [12] studied the performance of a metal surface-stabilized combustion burner in a cooking appliance and found that the thermal efficiency was higher than that of a conventional Bunsen burner. However, the thermal efficiency was lower than those reported for ceramic burners.

The main objective of this study is to compare the combustion of NG with an equimolar mixture of $\mathrm{CH}_{4}$ and $\mathrm{SG}$ in a ceramic surface-stabilized combustion burner. We examine the effect of the fuel composition, the air-to-fuel ratio and the thermal power input on the 
flame stability and pollutant emissions. The SGs were emulated with $\mathrm{H}_{2}-\mathrm{CO}$ mixtures, in which the $\mathrm{H}_{2}$ to $\mathrm{CO}$ ratio was varied between 1.5 and $3\left(60 \% \mathrm{H}_{2}\right.$ to $75 \% \mathrm{H}_{2}$, respectively). The thermal inputs evaluated in this study correspond to two values (300 and 500 $\left.\mathrm{kW} / \mathrm{m}^{2}\right)$.

\section{$2 \quad$ Experimental Setup}

Figure 1 is a schematic of the experimental configuration that was used to measure the temperature profiles inside the porous media and the pollutant emissions concentrations. The porous media consisted of a cylindrical ceramic honeycomb that was $70 \mathrm{~mm}$ in diameter with a nominal cell density of 18 cells per inch. The hydraulic diameter of the unit square cell was $1 \mathrm{~mm}$, and the fraction of the open frontal area was $62 \%$. The ceramic consisted primarily of alumina and had a thickness of $25 \mathrm{~mm}$.

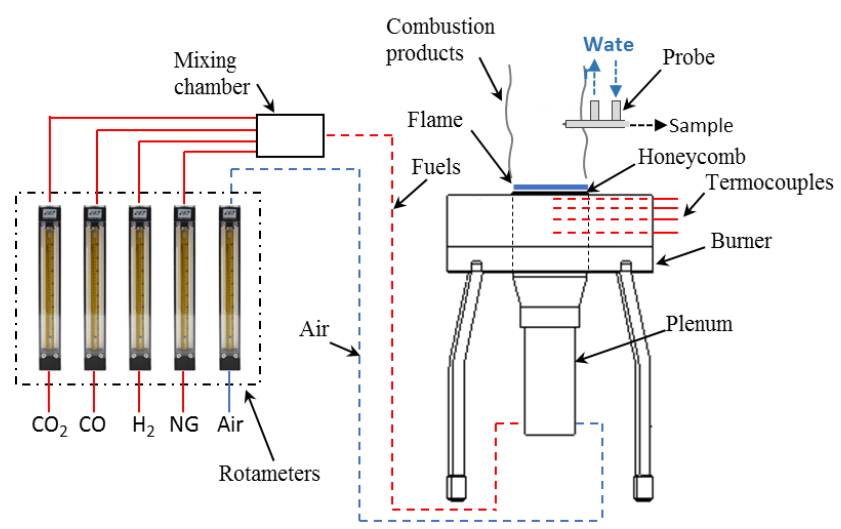

Figure 1 Schematic of experimental configuration used to measure temperature profiles inside porous media and pollutant emissions concentrations.

The fuel and air entered the mixing chamber separately. High-purity certified gases (99\% purity) were used to simulate the SGs. Table 1 lists the volumetric compositions and combustion properties of the fuel mixtures evaluated in this work. The combustion properties include the lower heat value (LHV), the adiabatic flame temperature $\left(\mathrm{T}_{\mathrm{ad}}\right)$, and the laminar burning velocity $\left(\mathrm{S}_{\mathrm{L}}\right)$ at room conditions of $22^{\circ} \mathrm{C}$ and 0.849 bar. 
$420 \quad 10^{\text {TH }}$ InTERnAtional CONFERENCE ON Sustainable ENERGy AND ENVIRONMENTAL Protection (June $27^{\mathrm{TH}}-30^{\mathrm{TH}}, 2017$, BlED, SLOVENIA), RENEWABLE ENERGy SOURCES C. E. Arrieta, A. M. García, I. D. Bedoya \& A. A. Amell: On the Stability of Natural Gas and Low Calorific Value Fuels in a Surface-Stabilized Combustion Burner

Table 5 Composition (\% vol, dry) and properties of fuel mixtures

\begin{tabular}{|c|c|c|c|c|}
\hline & GN & 50 SG1 & 50SG2 & 50SG3 \\
\hline $\mathrm{CH}_{4}$ & 94.68 & 47.34 & 47.34 & 47.34 \\
\hline $\mathrm{C}_{2} \mathrm{H}_{6}$ & 2.37 & 1.19 & 1.19 & 1.19 \\
\hline $\mathrm{C}_{3} \mathrm{H}_{8}$ & 0.81 & 0.40 & 0.40 & 0.40 \\
\hline $\mathrm{n}-\mathrm{CxHy}$ & 0.15 & 0.08 & 0.08 & 0.08 \\
\hline $\mathrm{i}-\mathrm{CxHy}_{\mathrm{CO}}$ & 0.16 & 0.08 & 0.08 & 0.08 \\
\hline $\mathrm{CO}_{2}$ & 0.56 & 0.28 & 0.28 & 0.28 \\
\hline $\mathrm{N}_{2}$ & 1.27 & 0.63 & 0.63 & 0.63 \\
\hline $\mathrm{H}_{2}$ & -- & 30.00 & 33.35 & 37.50 \\
\hline $\mathrm{CO}$ & -- & 20.00 & 16.85 & 12.50 \\
\hline $\mathrm{SL}(\phi=1)$ & 0.39 & 0.61 & 0.64 & 0.66 \\
\hline $\mathrm{Tad}(\phi=1)$ & 2221 & 2255 & 2255 & 2255 \\
\hline $\mathrm{LHV}$ & 9.43 & 6.23 & 6.21 & 6.19 \\
\hline
\end{tabular}

$$
\mathrm{S}_{\mathrm{L}}[=] \mathrm{m} / \mathrm{s} ; \mathrm{T}_{\mathrm{ad}}[=] \mathrm{K} ; \mathrm{LHV}[=] \mathrm{kWh} / \mathrm{m}^{3} \mathrm{st} \text {. }
$$

A water-cooled stainless-steel probe was placed above the burner to measure the $\mathrm{O}_{2}, \mathrm{CO}$, $\mathrm{CO}_{2}$, and NOx concentrations in the combustion products. The sample was cleaned and dried before reaching the analyzers. The analytical instrumentation included a paramagnetic analyzer for the $\mathrm{O}_{2}$ measurements, non-dispersive infrared gas analyzers (SICK MAIHAK s710 analyzers) for the $\mathrm{CO}$ and $\mathrm{CO}_{2}$ measurements and a chemiluminescent analyzer for the NOx measurements (THERMO SCIENTIFIC 42i-HL analyzer). The relative measurement errors were $6 \%$ for $\mathrm{CO}, 3 \%$ for $\mathrm{CO}_{2}, 3 \%$ for $\mathrm{O}_{2}$ and approximately $5 \%$ for NOx.

The temperature profiles within the porous media were measured using some $\mathrm{K}$ thermocouples positioned along the centerline (T@5mm, T@10mm, T@15mm, and T@20mm), as shown in Figure 2. Thermal equilibrium was established among the thermocouple hot junction, the gas, and the solid phase; thus, the measurements provided by these sensors should be interpreted as the mean temperatures of the gas and solid phases.

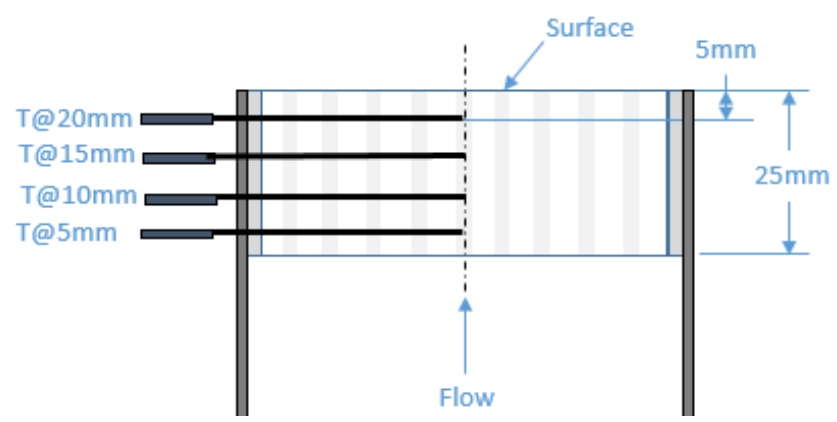

Figure 2 Schematic of experimental configuration used to measure temperature profiles inside porous media and pollutant emissions concentrations. 
$10^{\mathrm{TH}}$ InTERnational CONFerence on Sustainable EnERgy AND Environmental 421 Protection (June 27 $7^{\mathrm{TH}}-30^{\mathrm{TH}}, 2017$, BLed, Slovenia), Renewable Energy SOURCeS

C. E. Arrieta, A. M. García, I. D. Bedoya \& A. A. Amell: On the Stability of Natural Gas and Low Calorific Value Fuels in a Surface-Stabilized Combustion Burner

\section{$3 \quad$ Numerical Model}

Numerical simulations for the different fuel mixtures were performed in Ansys Fluent 16 using detailed chemical kinetics (GriMech 3.0). Figure 3 present the computational domain implemented in this work. The resultant grid resolution was $0.1 \times 0.1 \times 0.1 \mathrm{~mm}^{3}$. Governing equations are mass continuity, Navier-Stokes, species conservation and state equations. Additionally, two energy equations were considered for the solid and gas phases, similar to what has been reported in other studies [13].

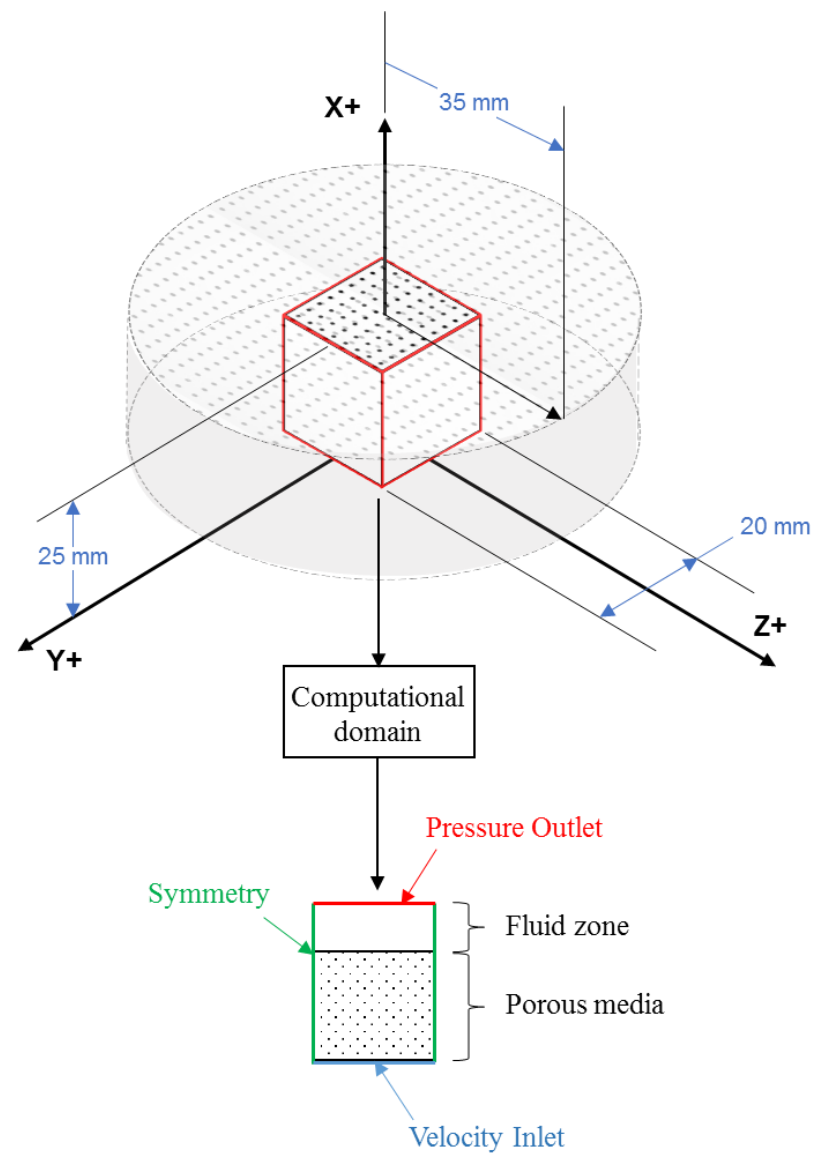

Figure 3 Schematic of the computational domain. 
$10^{\mathrm{TH}}$ InTERnATIONAL CONFERENCE ON Sustainable EnERgy AND ENVIRONMENTAL Protection (June $27^{\mathrm{TH}}-30^{\mathrm{TH}}, 2017$, Bled, Slovenia), Renewable ENERGy SOURCES C. E. Arrieta, A. M. García, I. D. Bedoya \& A. A. Amell: On the Stability of Natural Gas and Low Calorific Value Fuels in a Surface-Stabilized Combustion Burner

\section{$4 \quad$ Results and Discussion}

\subsection{Flame stability}

Figure 4 shows the flame stability limits, which correspond to NG and the NG-SGs blends. The figure represents several operating conditions that were evaluated. Three types of operating conditions can be observed in the figures: the blowout region (to the left of the blowout limit, BL), the flashback region (to the right of the flashback limit, FL) and the stable region (between the BL and FL).

As is shown in Figure 4, the operation of the burner was characterized by the occurrence of flashback when SG substituted the NG. This indicates that the operating conditions change from fuel to fuel when NG is substituted by the high hydrogen content SG. This behavior can be explained by observing the combustion properties listed in Table 1. As shown in Table 1, the SG concentration in the fuel mixture increases the laminar flame speed, as a consequence the tendency toward flashback increases.

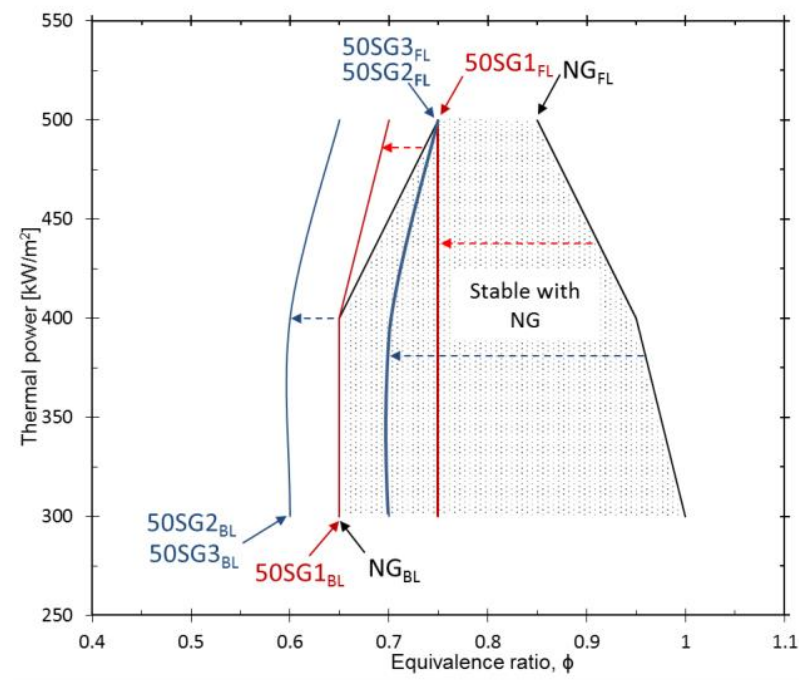

Figure 4 Flame stability diagram. BL: blowout limit. FL: flashback limit.

As a particular case, no variation was found between the operations with SG2 and SG3.

The trends described above were also registered numerically, as shown in Figure 5 and 6. 

Protection (June $27^{\mathrm{TH}}-30^{\mathrm{TH}}, 2017$, BLed, Slovenia), RenEwable ENERGY SOURCES

C. E. Arrieta, A. M. García, I. D. Bedoya \& A. A. Amell: On the Stability of Natural Gas and Low Calorific Value Fuels in a Surface-Stabilized Combustion Burner
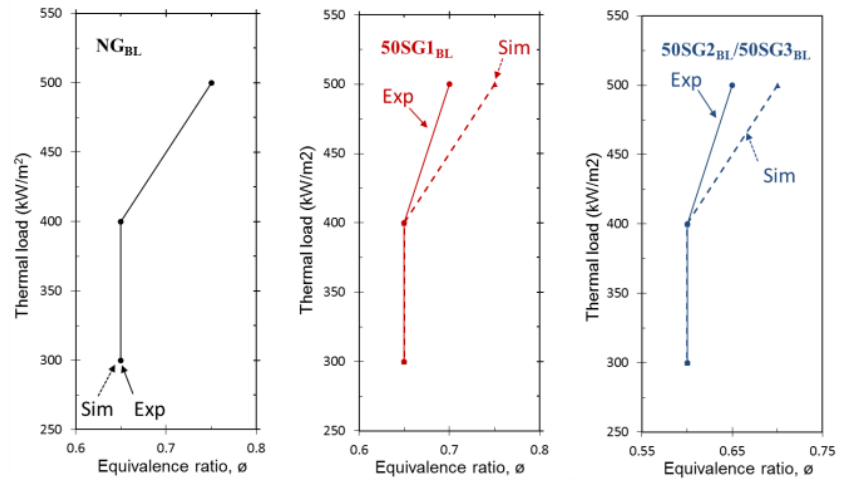

Figure 5 Blowout limit. Experimental vs numerical results.
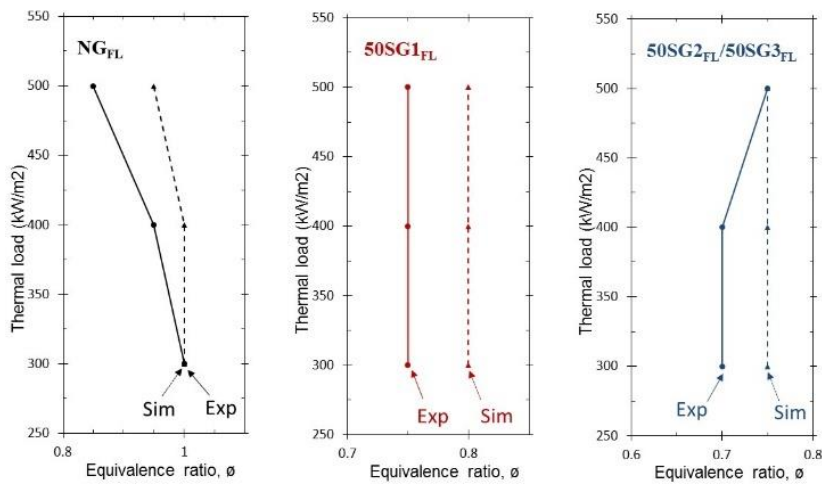

Figure 6 Flashback limit. Experimental vs numerical results.

\subsection{Temperature profile}

Figure 7 shows the temperature profiles obtained in the porous. The distances indicated in figure 6 were measured across the porous media, where $0 \mathrm{~mm}$ corresponds to the porous media inlet and $25 \mathrm{~mm}$ corresponds to the outlet surface. Because of the great $S_{L}$ and $\mathrm{Tad}$ of this high hydrogen $\mathrm{SG}$ compared to $\mathrm{CH}_{4}$, variations in the temperature profile were expected. However, the differences were lower than the anticipated. 
$10^{\text {TH }}$ International Conference on Sustainable Energy and Environmental Protection (June $27^{\mathrm{TH}}-30^{\mathrm{TH}}, 2017$, Bled, Slovenia), Renewable ENERGy SOURCES C. E. Arrieta, A. M. García, I. D. Bedoya \& A. A. Amell: On the Stability of Natural Gas and Low Calorific Value Fuels in a Surface-Stabilized Combustion Burner

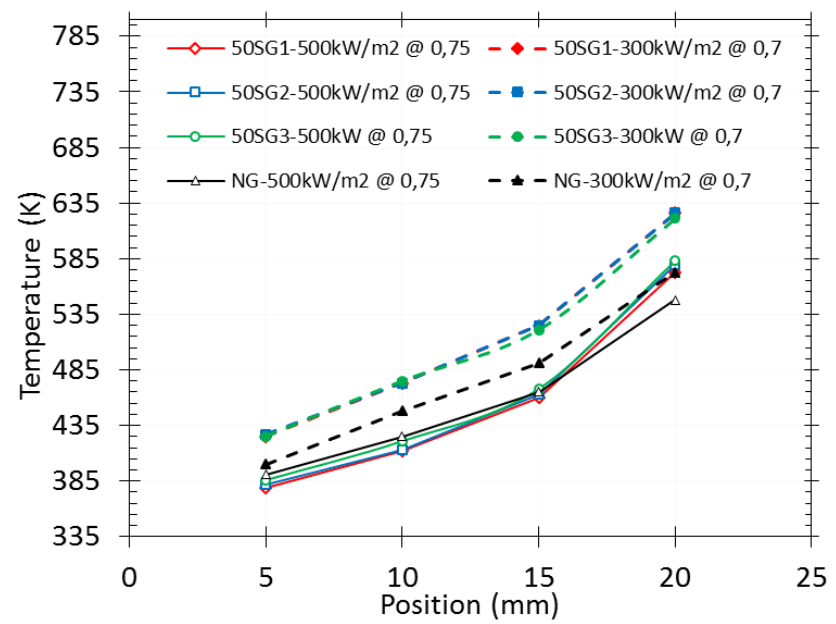

Figure 7 Flashback limit. Experimental vs numerical results.

As expected, increasing the thermal power decreased the preheating temperature for a given equivalence ratio. This result can be explained by the increase in the unburned gases velocity to $S_{L}$ ratio, which caused the flame front to move further downstream from the burner surface, as shown in [14].

Additionally, numerical results are in agreement with the corresponding experimental results, as it is shown in Figure 8 for the operation with $\mathrm{NG}$ at $500 \mathrm{~kW} / \mathrm{m} 2$ and $\phi=0.75$. Comparing numerical temperature profiles with the one measured experimentally, we can see the experimental measurements do not correspond to just one phase but are a combination of both the gas and the solid phases.

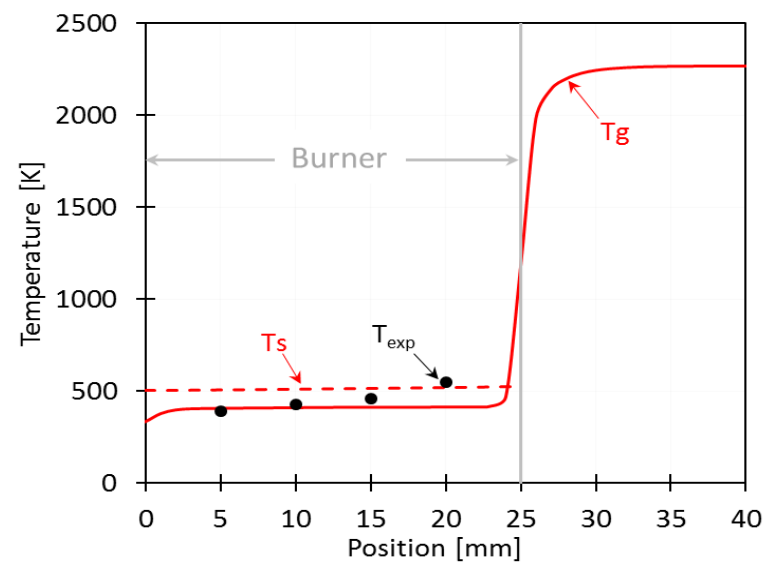



Protection (June 27 $7^{\mathrm{TH}}-30^{\mathrm{TH}}, 2017$, BLED, Slovenia), RenEWABle ENERGy SOURCES

C. E. Arrieta, A. M. García, I. D. Bedoya \& A. A. Amell: On the Stability of Natural Gas and Low Calorific Value Fuels in a Surface-Stabilized Combustion Burner

Figure 8 Temperature profile. Experimental vs numerical results. NG-500kW/m2-

\subsection{CO and NOx emissions}

$$
\phi=0.75
$$

Figure 9 shows the $\mathrm{CO}_{\text {free }}$ emissions for $\mathrm{NG}$ and the blending of $\mathrm{NG}$ with the high hydrogen SGs. Generally, The CO increases when the equivalence ratio is near the FL. Moreover, increasing the hydrogen concentration resulted in no significant change in the $\mathrm{CO}$ emissions for the different SGs. These trends are difficult to explain. However, some observations can be drawn by focusing on the set of chain branching and chain propagating reactions shown in Table 2, which are included in Gri-Mech 3.0.

Table 2 Some elementary reactions involved in the consumption of $\mathrm{CH}_{4}, \mathrm{CO}$ and $\mathrm{H}_{2}$

\begin{tabular}{|c|c|}
\hline Elementary reaction & $\mathrm{Ea}\left(\mathrm{cal} \cdot \mathrm{mol}^{-1}\right)$ \\
\hline $\mathrm{CH}_{4}+\mathrm{O} \leftrightarrows \mathrm{CH}_{3}+\mathrm{OH} \quad(\mathrm{R} 1)$ & 8600 \\
\hline $\mathrm{CH}_{4}+\mathrm{OH} \leftrightarrows \mathrm{CH}_{3}+\mathrm{H}_{2} \mathrm{O} \quad(\mathrm{R} 2)$ & 3120 \\
\hline $\boldsymbol{C O}+\boldsymbol{O H} \leftrightarrows \boldsymbol{C O}_{2}+\boldsymbol{H} \quad(\mathrm{R} 3)$ & 70 \\
\hline $\boldsymbol{C O}+\boldsymbol{O}_{2} \leftrightarrows \boldsymbol{C O}_{2}+\boldsymbol{O}$ & 47800 \\
\hline $\boldsymbol{C O}+\boldsymbol{O}+\boldsymbol{M} \leftrightarrows \mathrm{CO}_{2}+\boldsymbol{M}$ (R5) & 2385 \\
\hline $\mathrm{H}_{2}+\mathrm{O} \leftrightarrows \mathrm{H}+\mathrm{OH}$ & 6260 \\
\hline
\end{tabular}

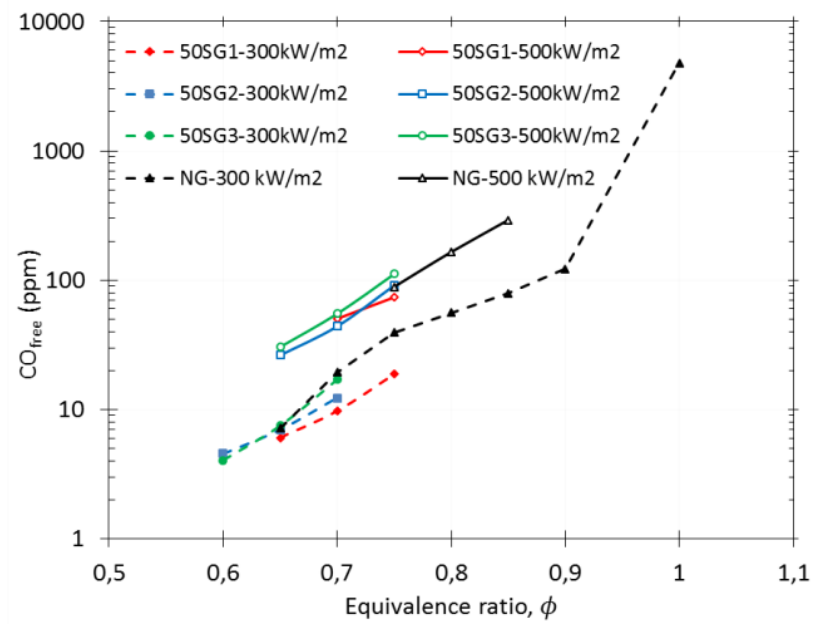

Figure $9 \mathrm{CO}$ emissions.

The complete conversion of $\mathrm{CO}$ to $\mathrm{CO}_{2}$ depends on the availability of oxygen, as indicated by $\mathrm{R} 4$ and R5. Therefore the $\mathrm{CO}$ emissions increase near the FL, where the availability of $\mathrm{O}_{2}$ decreases. Moreover, as it has also been highlighted by Huang et al. [22], it is worth mentioning that the activation energy (Ea) of reactions involving $\mathrm{OH}$ (R3) are much lower than those with $\mathrm{O}$ or $\mathrm{O}_{2}(\mathrm{R} 4$ and $\mathrm{R} 3)$. This is valid not only for $\mathrm{CO}$, but also for $\mathrm{CH}_{4}(\mathrm{R} 2)$ and $\mathrm{H}_{2}$ (R6). To increase the $\mathrm{H}_{2}$ concentration leads to higher $\mathrm{OH}$ production, therefore, generally, $\mathrm{CO}$ emissions decrease in the operations with the SGs. 
$10^{\text {TH }}$ International CONFEREnce on Sustainable Energy and Environmental Protection (June $27^{\mathrm{TH}}-30^{\mathrm{TH}}, 2017$, Bled, SLOVENIA), RENEWABle ENERGy SOURCES C. E. Arrieta, A. M. García, I. D. Bedoya \& A. A. Amell: On the Stability of Natural Gas and Low Calorific Value Fuels in a Surface-Stabilized Combustion Burner

Figure 10 shows the NOx emissions for NG and the blending of NG with the high hydrogen SGs. The NOx emission obtained is lower than $5 \mathrm{ppm}$. It was obtained that increasing the hydrogen concentration resulted in no significant change in the NOx emissions for the different SGs. In the other hand, increasing both the equivalence ratio and the thermal load increases the NOx emissions because the Tad increases.

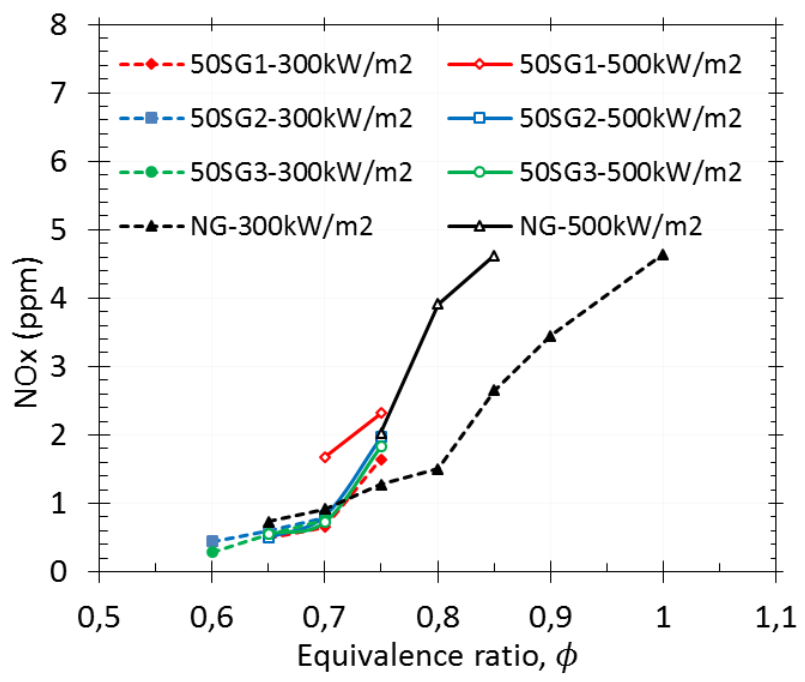

Figure 10 NOx emissions.

\section{$5 \quad$ Conclusions}

In this work, the performance of a surface-stabilized combustion burner operating with natural gas and the blending of natural gas with three high hydrogen content syngases in equimolar proportions was studied. We examined the effects of the composition of the syngases, the fuel-to-air ratio and the thermal input on the flame stability, the radiation efficiency and the pollutant emissions $(\mathrm{CO})$. The $\mathrm{H}_{2}$ to $\mathrm{CO}$ ratio for the syngases was varied between 1.5 and 3 . The following conclusions can be drawn from the results obtained in this work:

- The composition of the fuel used has a significant effect on the flame stability limits. The major change produced by replacing NG with NG-SGs blends occurs in the FL, which moves toward lean-mixture zone. Even more, for the high hydrogen SGs.

- As a result of the flame stability limits study for NG, and NG-SGs blends in a ceramic surface-stabilized combustion burner, we can conclude that, despite the significant change in FL's, there is an operation region that exhibits considerable potential for the interchangeable use of the gases studied without 
modifications in the burner. This operation region coincides with the lower $\mathrm{CO}$ and NOx emission conditions.

- The equivalence ratio had a considerable effect on the flame stability, temperature profile, and the pollutant emissions for all the fuels studied in this work. This is attributed to its effect on variables like adiabatic flame temperature, laminar flame speed, and mean flow velocity, which affects the burner performance.

- For the blends that contained syngases, the pollutant emissions were not considerably influenced by the thermal load. CO emissions lower than $\sim 100$ ppm and NOx emissions lower than $\sim 2.5 \mathrm{ppm}$ were obtained with these fuels.

- Numerical model shows a good prediction capacity of the flame stability limits and temperature profile. Flame stability limits determined numerically and experimentally disagree at most in 0.05 of equivalent ratio. This result demonstrates this simulation can be a useful tool for the design of this kind of burners.

\section{Acknowledgements}

The authors thank COLCIENCIAS for financing the Unión Temporal de Investigación e Innovación en Combustión Avanzada de Uso Industrial (UT. INCOMBUSTION), the project "Desarrollo y Evaluación de un Sistema de Combustión Sumergida." The authors also thank the Universidad de Antioquia for the valuable economic contribution to the development of this research through the program "Sostenibilidad 2016-2017 de la Vicerrectoría de Investigación".

\section{References}

[1] K. H. Casleton, R. W. Breault, and G. A. Richards, "System Issues and Tradeoffs Associated with Syngas Production and Combustion," Combust. Sci. Technol., vol. 180, no. 6, pp. 1013-1052, May 2008.

[2] M. Chaos and F. L. Dryer, "Syngas Combustion Kinetics and Applications," Combust. Sci. Technol., vol. 180, no. 6, pp. 1053-1096, May 2008.

[3] D. E. Giles, S. Som, and S. K. Aggarwal, "NOx emission characteristics of counterflow syngas diffusion flames with airstream dilution," Fuel, vol. 85, no. 12, pp. 1729-1742, 2006.

[4] S. Wood and A. T. Harris, "Porous burners for lean-burn applications," Prog. Energy Combust. Sci., vol. 34, no. 5, pp. 667-684, 2008.

[5] M. A. Mujeebu, M. Z. Abdullah, M. Z. A. Bakar, A. A. Mohamad, R. M. N. Muhad, and M. K. Abdullah, "Combustion in porous media and its applications - A comprehensive survey,” J. Environ. Manage., vol. 90, no. 8, pp. 2287-2312, 2009.

[6] D. Dunn-Rankin, R. K. Cheng, and H. Levinsky, "Lean Premixed Burners," in Lean Combustion, 2008, p. 161-V.

[7] F. Lammers, "Ceramic-foam surface burners in high-temperature environments," Int. J. Prod. Econ. - INT J PROD ECON, 2001.

[8] T. L. MARBACH, V. SADASIVUNI, and A. K. AGRAWAL, "INVESTIGATION OF A MINIATURE COMBUSTOR USING POROUS MEDIA SURFACE STABILIZED FLAME," Combust. Sci. Technol., vol. 179, no. 9, pp. 1901-1922, Aug. 2007.

[9] M. A. Mujeebu, M. Z. Abdullah, and A. A. Mohamad, "Development of energy ef fi cient 
$10^{\mathrm{TH}}$ International Conference on Sustainable EnERgy and Environmental Protection (June $27^{\mathrm{TH}}-30^{\mathrm{TH}}, 2017$, Bled, Slovenia), Renewable ENERGy SOURCES C. E. Arrieta, A. M. García, I. D. Bedoya \& A. A. Amell: On the Stability of Natural Gas and Low Calorific Value Fuels in a Surface-Stabilized Combustion Burner

porous medium burners on surface and submerged combustion modes," Energy, vol. 36, no. 8, pp. 5132-5139, 2011.

[10] B. Yu, S.-M. Kum, C.-E. Lee, and S. Lee, "An experimental study of heat transfer and pollutant emission characteristics at varying distances between the burner and the heat exchanger in a compact combustion system," Energy, vol. 42, no. 1, pp. 350-357, 2012.

[11] B. Yu, S. Kum, C. Lee, and S. Lee, "Combustion characteristics and thermal ef fi ciency for premixed porous-media types of burners," Energy, vol. 53, pp. 343-350, 2013.

[12] C.-Y. Wu, K.-H. Chen, and S. Y. Yang, "Experimental study of porous metal burners for domestic stove applications," Energy Convers. Manag., vol. 77, pp. 380-388, 2014.

[13] M. A. Mujeebu, M.Z. Abdullah, A. A. Mohamad, and M. Z. A. Bakar, "Trends in modeling of porous media combustion,” Prog. Energy Combust. Sci., vol. 36, no. 6, pp. 627-650, Dec. 2010.

[14] C. E. Arrieta and A. A. Amell, "Combustion analysis of an equimolar mixture of methane and syngas in a surface-stabilized combustion burner for household appliances," Fuel, vol. 137, pp. 11-20, 2014. 
$10^{\mathrm{TH}}$ INTERNATIONAL CONFERENCE ON Sustainable ENERgy AND ENVIRONMENTAL Protection (June $27^{\mathrm{TH}}-30^{\mathrm{TH}}$, 2017, Bled, SLOVENIA), RENEWABLE ENERGy SOURCES

J. Krope, A.Ghani Olabi, D. Goričanec \& S. Božičnik

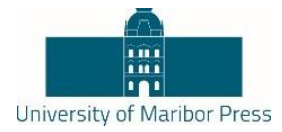

\title{
Challenges in the Practical Implementation of Concentrating Solar Thermal Power Projects
}

\author{
Yosef Elia, Dorin LuCACHE, MARCEL ISTRATE \& VALENTIN NiTA
}

\begin{abstract}
In the last decades, concentrating Solar Thermal Power (CSP) plants received a growing interest due to both need for more renewable sources of energy and the permanent improvements in thermal solar generation technologies. Even that CSP do not transform sunlight directly into electricity as in the photovoltaic (PV) generation, its conversion efficiency remains higher and proves competitive advantages in the locations with an important direct component of solar irradiance, usually found in arid and semi-arid areas.
\end{abstract}

Among the available technologies for CSP, the most economically valid options are parabolic trough and central tower ones. Even the first one is considered a proven commercial technology, so 'bankable', from the project developer's perspective, the advantages of tower over trough are primarily in the areas of cost and design flexibility.

The paper purpose is to review and examine some engineering considerations on the CSP technologies design that lead to more profitable CSP projects.

Keywords: • Concentrated Solar Power $\bullet$ Parabolic trough $\bullet$ Central tower

- Optimizing solar reflecting area $\bullet$ Levelized cost of energy •

CoRRESPONDENCE AdDRESS: Yosef Elia, Vice President Electrical Control and Solar Field Products Engineering, BrightSource Industries Israel, 11 Kiryat Mada, St., 91450 Jerusalem, Israel, e-mail: yelia@brightsourceenergy.com. Dorin Lucache, Ph.D., Professor, "Gheorghe Asachi” Technical University of Iasi, Faculty of Electrical Engineering, Str. Prof. D. Mangeron 21-23, 700050 Iasi, Romania, e-mail: dorin.lucache@tuiasi.ro. Marcel Istrate, Ph.D., Professor, "Gheorghe Asachi" Technical University of Iasi, Faculty of Electrical Engineering, Str. Prof. D. Mangeron 21-23, 700050 Iasi, Romania, e-mail: mistrate@tuiasi.ro. Valentin Nita, Ph.D., Professor, "A.I.Cuza" University of Iasi, Faculty of Economics and Business Administration, B-dul Carol I 11, 700506, Iaşi, Romania, e-mail: valnit@uaic.ro. 
$10^{\text {TH }}$ International CONFEREnce on Sustainable Energy and Environmental Protection (June $27^{\mathrm{TH}}-30^{\mathrm{TH}}, 2017$, BlED, SLOVENIA), RENEWABLE ENERGY SOURCES Y. Elia, D. Lucache, M. Istrate \& V. Nita: Challenges in the Practical Implementation of Concentrating Solar Thermal Power Projects

Solar energy can be transformed into electricity through two methods: photovoltaic (PV) and concentrating solar power (CSP). Each technology has multiple types of implementations.

As an example, the CSP- Tower power plants includes 50,000 to 65,000 of heliostats includes dual trackers, motion controllers and communication. It is a big challenge to design the electrical lay-out which are not mention in the literature such as others consideration related to the CSP as grid connection, CSP Turbo-Generator design and more.

The CSP literature focuses on the various technologies of the CSP power plants. The literature describes the principle of operation, physics and thermodynamics phenomenon, advantages and disadvantages, system optimization and adapting different world areas, but no engineering design considerations.

There is no process that integrates the traditional theory with practical knowledge gained in the field. This process should simplify and clarify the specific power systems design.

The paper purpose is to examine some engineering considerations on the CSP technologies design, in order to reduce repeated failures and increase profit, based on the experience got by BrightSource Energy, Jerusalem.

\section{Solar Power Generation Technologies}

The sunlight hits the Earth's surface both directly and indirectly, through numerous reflections and deviations in the atmosphere. On clear days, direct irradiance represents $80 \%$ to $90 \%$ of the solar energy reaching the Earth's surface. On a cloudy or foggy day, the direct component is essentially zero. The direct component of solar irradiance (direct normal irradiance - DNI) is of the greatest interest to designers of high-temperature solar energy systems because it can be concentrated on small areas using mirrors or lenses, whereas the diffuse component cannot.

Concentrating the sun's rays thus requires reliably clear skies, which are usually found in semi-arid, hot regions. DNI measures provide only a first approximation of a CSP plant's electrical output potential. In practice, what matters most is the variation in sunlight over the course of a day: below a certain threshold of daily direct sunlight, CSP plants have no net production, due to constant heat losses in the solar field.

CSP developers typically set a bottom threshold for DNI of $1850 \mathrm{kWh} / \mathrm{m}^{2} /$ year to 2150 $\mathrm{kWh} / \mathrm{m}^{2} /$ year. Below that, other solar electric technologies that take advantage of both direct and diffuse irradiance, such as photovoltaics, are assumed to have a competitive advantage [1]. 
Among the solar power generation technologies, there are two main competitors.

\subsection{Parabolic trough technology}

The parabolic trough technology is proven and bankable - but too inefficient and expensive to compete in the electricity market. There have been attempts to develop and commercialize higher-temperature trough technologies using either direct-steam generation or molten salts, which would allow trough plants to work at higher steam cycle efficiencies.

Much research has been invested in molten salts with lower freezing temperatures to make the idea somewhat more practical. However, to date none of these efforts have paid off with a commercial product.

The first commercial, utility-scale solar thermal plants were built in California's Mohave Desert in the 1980s, using 9 parabolic-trough mirrors of Jerusalem-based Luz Industries. These Solar Electric Generating Systems (SEGS) are still operating today, showing that solar thermal technology has the same long plant life expectation as conventional power plants.

Today, more than 2,500 MW of first-generation parabolic trough-based solar thermal power plants are operating around the world - including the original $354 \mathrm{MW}$ built by Luz.

Among these, molten-salt thermal energy storage is operating at 8 of the locations, totalling nearly 1,000 MW of electrical generating capacity with storage, with the storage system most commonly sized for 7-7.5 hours.

\subsection{Central tower technology}

In recent years, central tower technology has emerged as the most efficient and least expensive solar thermal technology. This assessment is true for both direct-solar (steam) tower plants where no thermal storage - or storage of only 2-3 hours - is required, and for molten-salt tower plants capable of 10 hours or even more of storage capacity [2].

From the project developer's perspective, the advantages of tower over trough are primarily in the areas of cost and design flexibility.

The key factors contributing to tower's lower cost of electricity produced include [3]:

- Higher steam cycle efficiency because of higher working temperatures and pressures;

- Lower parasitic energy consumption - parabolic trough systems use large amounts of energy to pump heat transfer fluid through the solar field;

- Higher annual capacity factors than parabolic trough plant; 
$10^{\mathrm{TH}}$ International Conference on Sustainable EnERgy and Environmental Protection (June $27^{\mathrm{TH}}-30^{\mathrm{TH}}, 2017$, Bled, SLOVEnia), RENEWABle ENERGy SOURCES Y. Elia, D. Lucache, M. Istrate \& V. Nita: Challenges in the Practical Implementation of Concentrating Solar Thermal Power Projects

- Lower-cost collectors (heliostats/receiver), starting with flat vs. curved glass, then with less structural steel per square meter, and finally vacuum-insulated receiver;

- Less need for civil works (grading, terracing, etc.);

- Two axis tracking, providing higher year-round optical efficiencies.

The greater design flexibility of tower in comparison to trough is notable:

- Tower has less restriction on site slope, opening more sites to solar thermal development;

- Trough is restricted to rectangular sites of a certain aspect ratio, or to sites that can contain a small number of contiguous rectangular sites. The solar field design of tower systems is far more flexible and can support nearly any shape of available land;

- Tower can have less environmental impact on surface water flow, vegetation and soil retention.

In addition to the projects built and currently operating in China, about $447 \mathrm{MW}$ of central tower projects are currently operating elsewhere around the world. Most of this capacity is represented by the 3-tower project of BrightSource Energy at Ivanpah, California, in the United States, which commenced commercial operation in February 2014.

In 2014-5 an additional 160 MW, The facility was commissioned in February 2016 and will ramp up production and expected to reach the performance contract guaranty during 2017. The $110 \mathrm{MW}$ Tonopah (molten salt, 10 hours full load storage power plant) project in the US, and the 50 MW Khi Solar One project in South Africa. Other central tower projects with signed power purchase agreements totalling nearly $800 \mathrm{MW}$ of power are in the advanced planning stages in the US, Chile and Israel.

But what can be learned from the experience of BrightSource Energy at Ivanpah, California. Being a new and innovative technology project, an initial shakeout and ramp up period must be taken into consideration when the plant displaced into operation. The initial performance will be less than full design and followed by an increase towards designed full rated annual performance, as seen in Figure 1. This increase is caused by the realization of the operator's learning curve, procedural optimization, and fine-tuning of equipment and systems for increased plant performance. In the case of Ivanpah project, the ramp up period lasted three years [4] 


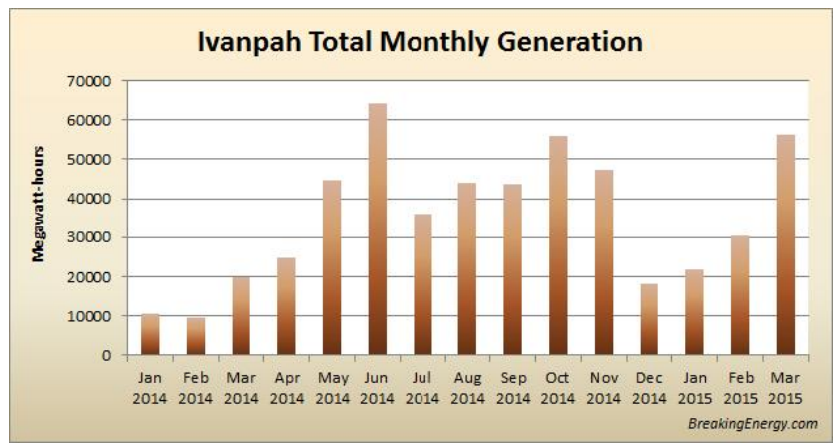

Figure 1. Electricity production of the Ivanpah plant during the ramp up period

\section{$3 \quad$ Optimizing Solar Reflecting Area}

The principles for optimizing the solar reflecting area is divided into two stages once the land area allocated to the project is known: optimization of solar field size, and optimization of the layout.

Optimization of solar field size is done by iteratively simulating annual project performance until an optimal size - based on lowest electricity cost - is reached. Very broad ranges of values are tested in order to ensure that the optimal point is not merely a local optimum.

Previous attempts at solar field size optimization discussed in the literature included two approaches: the arbitrary selection of a "solar multiple" (the ratio of the solar field size to a nominal solar field size required for peak insolation) or constructing a set of "representative days" such as March 31, June 30, September 30 and December 31. Both approaches cannot lied to an optimized solar field size but rather an arbitrary size.

Optimally, the measure used for optimization will be the levelized cost of electricity (LCOE) in terms of cost per $\mathrm{kWh}$ delivered, based on the fixed project internal rate of return (IRR) of $10 \%$. This calculation requires not only the cost of the solar field, but the financial cash flows as well as taxation on profits of the project.

In cases where not all of the financial parameters are known, an appropriate measure can be cost per kWh-year - the average unit cost of the solar field for each $\mathrm{kWh}$ of annual performance. This criterion will also yield an optimal point where electricity tariff is minimized. Including operations and maintenance $(\mathrm{O} \& M)$ in the calculation is preferable but not necessary.

In practice, this approach ensures optimal utilization of the power plant and maximal economic performance of the project - over the course of a simulated year that is statistically representative of the life of the project, barring long-term changes in climate 
$10^{\text {TH }}$ International Conference on Sustainable Energy and Environmental Protection (June $27^{\mathrm{TH}}-30^{\mathrm{TH}}, 2017$, BlED, SLOVENIA), RENEWABLE ENERGY SOURCES Y. Elia, D. Lucache, M. Istrate \& V. Nita: Challenges in the Practical Implementation of Concentrating Solar Thermal Power Projects

patterns or local air quality. In order to illustrate the optimization process, Figure 2 below shows an example of how DNI can be distributed over the hours of the year.

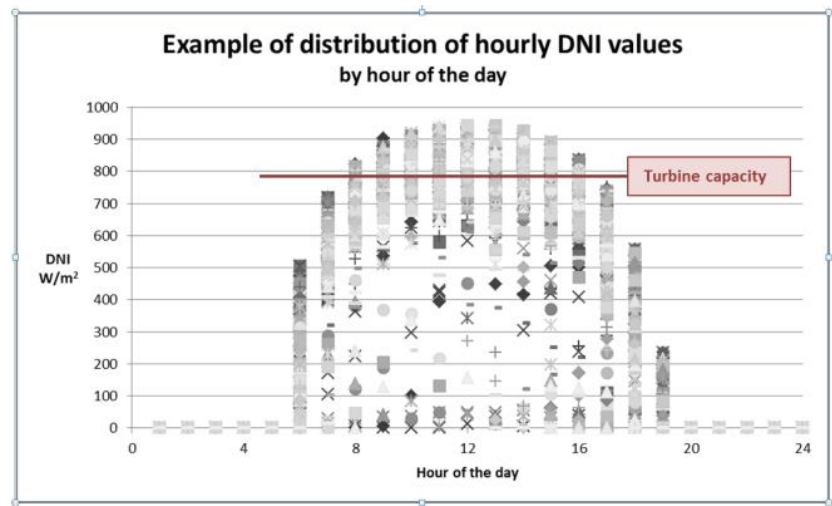

Figure 2. DNI values distribution depending the hours of the day [5]

In this example, the graph shows the hourly DNI of 180 different days in the AprilSeptember period from a California, USA, project site - all plotted on the same axes. As can be seen, there are many hours of the year in which peak DNI of over $900 \mathrm{~W} / \mathrm{m}^{2}$ is measured, but also many hours with far less DNI. The same dataset, but now for all daylight hours during all 365 days of the year, can be re-sorted for a distribution graph as in Figure 3. This graph shows that at the California site, there are more than 4,000 hours per year with measurable DNI, and nearly 3,500 hours in which average DNI is at least $300 \mathrm{~W} / \mathrm{m}^{2}$, which is a typical minimum value, for planning purposes, for hours in which it is possible to generate electricity.

A simplistic approach to project design would match the capacity of the power block (turbine and generator, etc.) with the capacity of the solar field. In this case, the turbine will work at full load only a few hundred hours each year. For all the other daylight hours of the year, the turbine will work at partial load. Because the power block represents a substantial portion of the capital investment in the project, this would obviously lead to the investment in the power block being underutilized. 


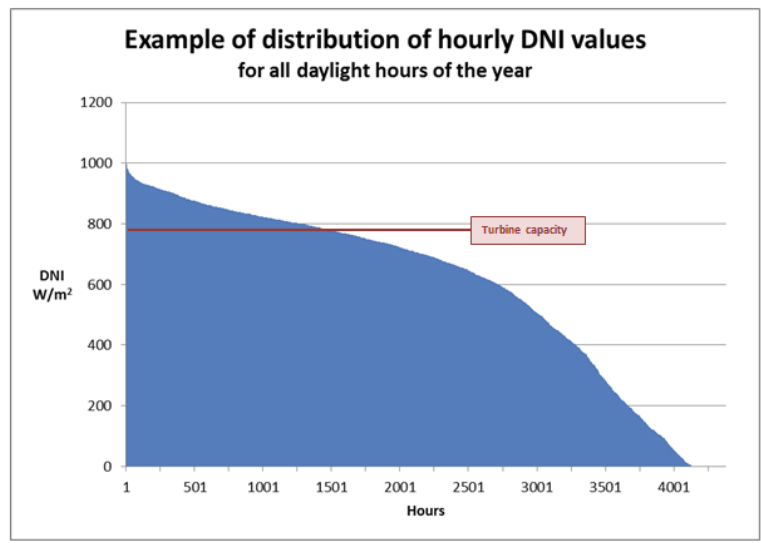

Figure 3. DNI values distribution depending the hours of presence in a year [5]

Instead, the optimization process changes the relationship of the solar field size to the power block capacity by finding the financially optimal point, the optimal "Turbine capacity" on Figure 2 and 3. The solar field is larger than the point where it 'matches' the turbine capacity, but the power block can operate at full load for a much greater number of hours.

In the case of a project with storage, the same concept would apply, and "turbine capacity + storage charging capacity" would replace "turbine capacity". On average there will be less dumping in a plant with storage unless a differential tariff places a very high value on electricity during non-solar hours [6].

Heliostats that are not used during peak solar hours are valuable during other hours of the day; as long as their marginal contribution to project value (incremental lifetime revenues and tax benefits, net of incremental capital expenditures - CAPEX and O\&M) is positive, it is worth having them. More heliostats are added to the simulation as long as each additional one generates a positive present value; when the next heliostat to be added does not have a positive present value, the solar field size is considered optimized.

Beside the optimization process, it may be advisable to add more heliostats than the optimal number as a contingency against potential performance issues due to weather extremes, project construction issues, or other unforeseen circumstances. Because incremental heliostats are relatively inexpensive, this approach is often the cheapest way of providing insurance against possible performance shortfalls.

Determining the best layout is the most important step in optimizing the solar reflecting area. The difference in annual electricity output can be boosted by as much as 5-15\% with an optimized layout, compared with a non-optimized, geometric layout. 
$10^{\text {TH }}$ International CONFEREnce on Sustainable Energy and Environmental Protection (June $27^{\mathrm{TH}}-30^{\mathrm{TH}}, 2017$, Bled, SLOVEnia), RENEWABle ENERGy SOURCES Y. Elia, D. Lucache, M. Istrate \& V. Nita: Challenges in the Practical Implementation of Concentrating Solar Thermal Power Projects

Most power tower projects were designed and built with geometric layouts, in order to minimize energy efficiency losses due to shadowing (part of a heliostat's reflecting mirror is not illuminated by the sun because a neighbouring heliostat casts a partial shadow) and blocking (light reflected by a heliostat in the direction of the receiver atop the tower is blocked by the heliostat in front of it). Most tower projects have used the so-called sunflower patterns to create solar field layouts.

A new concept was developed by BrightSource for more efferent heliostat layouts yielded an optimized solar reflecting area. Those developers were trying to minimize shadowing and/or blocking at certain specific times of year instead of trying to maximize energy output - and associated revenues - over the life of the project.

The optimization process takes into account the annual contribution of each heliostat (for a given annual set of hourly DNI and weather data values) in terms of energy delivered to the receiver, where the simulation takes into account different parameters (Sun position, Cosine losses, Shadowing, Blocking, Reflectivity, Atmospheric attenuation) calculated for each heliostat for at least every hour of the year. This resulted in higher energy density per square meter (1/3 less land per MWh).

\section{$4 \quad$ Energy LCOE Reduction}

Many factors influence the LCOE of CSP plants, the main ways for reduction being:

\subsection{Increasing plant capacity}

Because equipment cost does not increase linearly with size or capacity, by increasing plant capacity to a target of $250 \mathrm{MW}$ will yield lower unit costs and LCOE contribution for the power block, receiver and the main components of the storage system [3].

Additional cost savings will result from supplying and constructing a larger solar field, including a reduction in the indirect costs.

The practical limit of power plant capacity is related to the optical efficiency of the marginal heliostats being added at the periphery of the solar field. This is greatly affected by the linear distance and correspondent atmospheric attenuation and by statistical aiming losses. The solution to limit this is the shrinking of the solar field physical footprint.

Increasing the tower height would be the first choice for reducing solar field dimensions and increasing heliostat density. A 200+m tower height allowed BrightSource to shrink the solar field in the Ivanpah project. Further on, to increase the plant capacity will depend on increasing the density of the solar field through improved layout and control algorithms, doubled by improving heliostat design and manufacturing parameters that govern aiming accuracy, and better calibration techniques. 


\subsection{Increasing capacity factor}

The capacity factor reflects the annual energy production relative to a plant that would run at nominal power 24 hours a day for all 365 days of the year. Increasing capacity factor can be done by increasing storage capacity that will lower the unit cost and LCOE contribution of the power block and balance of plant (ancillary equipment supporting the process) by amortizing the same equipment over a larger number of MWh produced. The lowest LCOE can be reached with 12-18 hours energy storage delivering capacity factors of $60-80 \%$ [7]. Whether making use of molten salts or hydrogen fuel cells, the integration of grid-scale storage capacity in CSP plants is a game-changer.

The technical ability to increase capacity factor depends also on the ability to increase the reflecting area of the solar field while maintaining acceptable levels of optical efficiency at the margin.

\subsection{Improving plant efficiencies}

Any increase in an efficiency along the chain of energy conversion from solar to electricity will generally be reflected in a corresponding reduction in the LCOE contribution of upstream system components. In some cases, all of the LCOE reduction is realized as a reduction in CAPEX, and in some cases there is both a reduction in CAPEX and an increase in annual electricity production [8].

One factor can be the increasing of optical efficiency (the proportion of solar energy absorbed by the receiver). This can be done by:

- layout optimization by reducing total blocking and shadowing, atmospheric attenuation and cosine losses;

- improvements in heliostat design, aiming algorithms and calibration techniques;

- increasing solar absorptivity;

- better mirror reflectivity through heliostat thinner front glass;

- anti-fouling coatings or other dust-removal/prevention technologies for mirror surfaces.

The same benefits accrue from any increase in the thermal efficiency of the receiver. Thermal efficiency can be increased through reduction of convective (by reducing the total exposed receiver's surface area) or radiative (applying solar-selective coatings) heat losses. BrightSource solutions for long-life high-temperature receiver coatings led to higher efficiency and lower maintenance costs [3].

An increase in thermal-to-electric conversion efficiency will enable a reduction in both receiver capacity and solar field size. But a reduction in receiver capacity can have an additional impact on solar field downsizing because of higher thermal efficiency (less heat losses). Thermal-to-electric conversion effi-ciency can be increased by increasing 
$10^{\text {TH }}$ InTERnAtional CONFERENCE ON Sustainable ENERgy AND ENVIRONMENTAL Protection (June $27^{\mathrm{TH}}-30^{\mathrm{TH}}, 2017$, Bled, SLOVEnia), RENEWABle ENERGy SOURCES Y. Elia, D. Lucache, M. Istrate \& V. Nita: Challenges in the Practical Implementation of Concentrating Solar Thermal Power Projects

the plant's rated capacity (as mentioned in 4.1), or - in the case of a direct-steam receiver - by configuring the steam turbine to accommodate increased steam temperatures and pressures from the receiver and/or the steam generators of the thermal energy storage system.

Not ultimately, applying a solar field integrated control system (close loop, real time optimization) will improve the efficiency generating more power.

\subsection{Lower cost engineering}

Important reductions in LCOE could further obtained by the engineering of lower-cost component and system designs. Lower-cost motors and drive systems, and lightweight mirrors using thinner glass and preformed support structures are among the ongoing efforts expected to contribute to reducing solar field component costs. This reduction is expected to contribute more than half of all the LCOE reduction attributable to engineering and $R \& D$.

\subsection{Other reduction factors}

An important impact for LCOE reduction has the low construction cost and fast commissioning (by design standardization regarding manufactu-rability and assembly), and introduction of the wireless technology that needs less materials ( $85 \%$ less cabling) leading to faster build and rapid communication commissioning.

Also important is the financial management, meaning lowering of the unleveraged cost of capital (reducing technology and project risk) and cost reduction both in the area of component procurement and supply and in terms of EPC contracts.

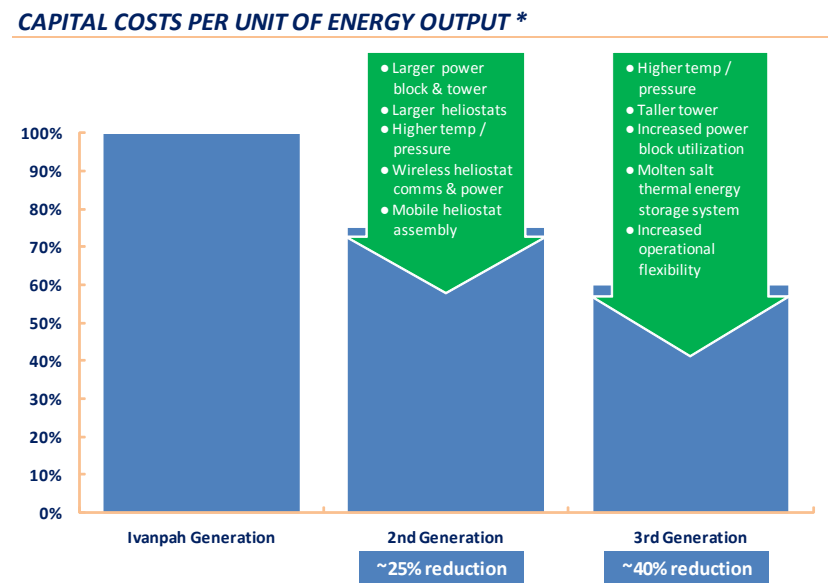

Figure 4. Capital Costs per Unit of Energy Output [3] 
As an example, Figure 4 describes the improvement get by BrightSource by applying the above mentioned solutions, from Ivanpah technology (first generation) up today (3rd generation) which reduced the cost per MWh (40\% reduction).

\section{Acknowledgements}

The authors would like to thank to BrightSource Energy for sharing the vast experience over 30 years in the design, construction, operation and maintenance of CSP Thermo-solar power stations.

\section{References}

[1] Cédric Philibert, Technology Roadmap Concentrating Solar Power, International Energy Agency, Paris, 2010.

[2] N. C. Thirumalai, Global Review of Solar Tower Technology, Center for Study of Science, Technology and Policy (CSTEP), 2014.

[3] BrightSource Energy, Inc., Company Overview "A Better Kind of Solar" - internal presentation, 2013.

[4] https://www.bloomberg.com/news/articles/2017-02-01/nrg-s-massive-california-solarplant-finally-making-enough-power.

[5] Lazard, Levelized Cost of Storage Analysis, Version 1.0, November 2015.

[6] http://helioscsp.com/brightsource-and-shanghai-electric-to-build-concentrated-solarpower-projects-in-china/.

[7] Frenell GmbH, Solar Power on Demand. Least Cost Opportunity for Sun-rich Countries, Whitepaper Version 1.0, 2016.

[8] G. J. Kolb, C. K. Ho, T. R. Mancini, and J. A. Gary, Power Tower Technology Roadmap and Cost Reduction Plan, Sandia National Laboratories Albuquerque, New Mexico and Livermore, California, 2011.

[9] G. Owens, Economic \& Financial Evaluation of Renewable Energy Projects, Global Bureau Environment Center Washington, DC 20523-1810, 2002

[10] DOE Global Energy Storage Database, http://www.energystorageexchange.org/projects (last website visit April 19th, 2016). 
$440 \quad 10^{\text {TH }}$ International CONFERENCE on Sustainable ENERgy AND ENVIRONMENTaL Protection (June 27 $7^{\mathrm{TH}}-30^{\mathrm{TH}}, 2017$, Bled, SLOVEnia), RENEWABLE ENERGy SOURCES 
$10^{\mathrm{TH}}$ InTERnational CONFEREnCE ON Sustainable ENERgy AND ENVIRONMENTAL Protection (June $27^{\mathrm{TH}}-30^{\mathrm{TH}}$, 2017, Bled, SLOVENIA), RENEWABLE ENERGy SOURCES

J. Krope, A.Ghani Olabi, D. Goričanec \& S. Božičnik

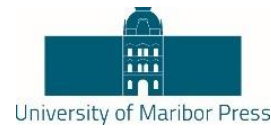

\title{
Spatio-Temporal Assessment of Integrating Intermittent Electricity in the EU Power Sector
}

\author{
Sennai Mesfun, Sylvain Leduc, Piera Patrizio, Ping Yowargana \& Florian \\ KRAXNER
}

\begin{abstract}
The integration of solar and wind technologies into the energy supply system is becoming increasingly attractive as their costs per unit capacity drop and tight policies are being implemented against greenhouse gas emissions. However, their contribution to a power system is uncertain due to the intermittent nature of wind and insolation. Here, we investigate a power dispatch system that aims to supply the power demand of the EU based on low-carbon generation units enabled with expansion of biomass, solar, and wind energy. A spatially explicit techno-economic optimization tool simulates the EU power sector to explore policies for renewable energy deployment. Results show utility-scale deployment of intermittent electricity is feasible when incentivized with carbon tax. Expansion of transmissions capacity helps even-out intermittency of solar and wind technologies. Spatial assessment of bio-electricity potential (based on forest and crops residues) has small contribution to the optimal generation mix, limiting its effect as baseload.
\end{abstract}

Keywords: • decarbonization • renewable electricity • intermittency • optimization • geospatial modeling •

CORRESPONDENCE ADDRESS: Sennai Mesfun, International Institute for Applied Systems Analysis (IIASA), Schlossplatz 1, A-2361 Laxenburg, Austria, e-mail: Mesfun@iiasa.ac.at. Sylvain Leduc, International Institute for Applied Systems Analysis (IIASA), Schlossplatz 1, A-2361 Laxenburg, Austria, e-mail: Leduc@iiasa.ac.at. Piera Patrizio, International Institute for Applied Systems Analysis (IIASA), Schlossplatz 1, A-2361 Laxenburg, Austria, e-mail: Patrizip@iiasa.ac.at. Ping Yowargana, International Institute for Applied Systems Analysis (IIASA), Schlossplatz 1, A-2361 Laxenburg, Austria, e-mail: Yowargana@iiasa.ac.at. Florian Kraxner, International Institute for Applied Systems Analysis (IIASA), Schlossplatz 1, A-2361 Laxenburg, Austria, e-mail: Kraxner@iiasa.ac.at. 
$10^{\text {TH }}$ International CONFEREnce on Sustainable Energy and Environmental Protection (June $27^{\mathrm{TH}}-30^{\mathrm{TH}}, 2017$, BlED, SLOVENIA), RENEWABLE ENERGY SOURCES S. Mesfun, S. Leduc, P. Patrizio, P. Yowargana \& F. Kraxner: Spatio-Temporal Assessment of Integrating Intermittent Electricity in the EU Power Sector

\section{$1 \quad$ Introduction}

Integration of Renewable Electricity (RE) is expected to play essential role in transforming the carbon intensive supply chain of the exiting energy infrastructure into a low-carbon one. Today, the energy supply (i.e. power, heat and transportation sectors) of the EU is largely met from fossil fuels and nuclear technologies.

Decarbonization of the energy sector through integration of intermittent renewables is often discussed as a mitigation measure. However, challenges remain to relying on intermittent energy sources like the sun or the wind for power. Still, it is widely believed that coupling solar and wind plants to thermal generators, and using new load management technologies to align demand for power with the variable supply, offer a promising path for aggressively reducing the amount of carbon the power industry disposes into the atmosphere. A system-level approach with adequate representation of spatial and temporal features of renewable energy sources is absolutely essential to provide sufficient insight to address these issues.

In the absence of sizable energy storage, power systems with high-share of intermittent $\mathrm{RE}$ rely on flexible baseload to maintain stability. This work highlights on the importance of low-carbon baseload, such as biomass, nuclear and hydropower.

To assess the potential for reducing $\mathrm{CO}_{2}$-emissions, the $\mathrm{CO}_{2}$-emitting technologies in the existing generation fleet of the EU electricity sector are explicitly targeted and competed with a spatio-temporally explicit RE portfolio supplemented with a state-of-the-art natural gas combined cycle (NGCC).

Our assessment approach has high spatial and temporal resolution representing a period of one year. This approach is able to capture reasonably high-resolution load-matching often overlooked by dynamic models used for planning long-term consequences, e.g. [1].

\section{$2 \quad$ Methodology}

BeWhere $^{1}$, a geographically explicit MILP optimization model, is used to simulate highly renewable power dispatch system. BeWhere minimizes the total cost of an energy supply chain in order to meet a known demand while providing information on optimal localization of new plant installations. The objective function is evaluated according to equation (1).

$\min \mathrm{f}=\sum_{\mathrm{c}}\left(\operatorname{cost}_{\mathrm{c}}^{\text {supply chain }}+\right.$ emissions $\left._{\mathrm{c}}^{\mathrm{CO}_{2}} \times \operatorname{cost}_{\mathrm{c}}^{\mathrm{CO}_{2}}\right)$

In this study, the model simulates expansion of three RE generation technologies namely bioenergy, solar and wind. The model is formulated based on a $0.4^{\circ}$ spatial resolution. Historical data are used to simulate RE generation potentials with a time resolution 
consistent to the meteorological dataset of choice over a period of one year. A brief description on the data processing of each category is presented in this section. In addition, the model reproduces the existing power dispatch system.

\subsection{Bioenergy}

Two categories of biomass feedstock are investigated in this study, namely forest and crops residues. 10 types of forest residues and 5 types of crop residuals are considered. The availability of these feedstock is extrapolated at the grid level, based on the regional biomass atlas [2].

Table 1. Technical parameters

\begin{tabular}{|c|c|c|c|c|}
\hline Type & Description & PJ/year & Output & Efficiency \\
\hline \multirow{6}{*}{ 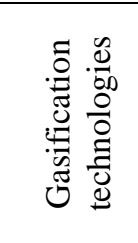 } & Circulating Fluidized bed & & Power & 0.35 \\
\hline & for CHP & 0.72 & Heat & 0.5 \\
\hline & Circulating Fluidized bed & 50 & Power & 0.4 \\
\hline & for IGCC & 5.0 & Heat & 0.45 \\
\hline & Bubbling fluidized bed for & ( 30 & Power & 0.3 \\
\hline & CHP & 0.09 & Heat & 0.52 \\
\hline \multirow{4}{*}{ 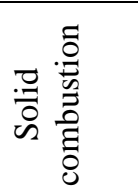 } & Circulating Fluidized bed & 324 & \multirow{4}{*}{$\begin{array}{l}\text { Power } \\
\text { Heat } \\
\text { Power } \\
\text { Heat }\end{array}$} & 0.35 \\
\hline & for CHP & 3.24 & & 0.5 \\
\hline & Fixed bed combustion for & 036 & & 0.25 \\
\hline & CHP & 0.50 & & 0.6 \\
\hline \multirow{4}{*}{ 营 } & \multirow{2}{*}{ Fast pyrolysis for CHP } & \multirow{2}{*}{0.18} & Power & 0.24 \\
\hline & & & Heat & 0.6 \\
\hline & \multirow{2}{*}{$\begin{array}{l}\text { Dry wood chips to pyrolysis } \\
\text { oil, heat and steam }\end{array}$} & \multirow{2}{*}{0.60} & Power & 0.21 \\
\hline & & & Heat & 0.26 \\
\hline
\end{tabular}

Table 1 summarizes the different biomass conversion technologies considered along with their respective plant capacities and efficiencies. The efficiency refers to the energy content of the biomass feed, LHV basis.

\subsubsection{Biomass logistics}

The model also accounts for the logistics of biomass transport from source to plants and biomass trade within and outside the regions studied.

Possible routes for transport, the corresponding specific costs and GHG emissions are parametrized based on a geospatial transport network developed in the ArcGIS Network Analyst. Three modes of transport are considered: road, rail or shipping. The transportation parameters used in this work are presented in Table 2. 
$10^{\mathrm{TH}}$ InTERnAtional CONFERENCE ON Sustainable ENERgy AND ENVIRONMENTAL Protection (June $27^{\mathrm{TH}}-30^{\mathrm{TH}}, 2017$, Bled, SLOVEnia), RENEWABle ENERGy SOURCES S. Mesfun, S. Leduc, P. Patrizio, P. Yowargana \& F. Kraxner: Spatio-Temporal Assessment of Integrating Intermittent Electricity in the EU Power Sector

Table 2. Transportation parameters

\begin{tabular}{lcccc}
\hline & Unit & Truck & Rail & Boat \\
\hline Load & Vehicle/t & 27 & 1625 & 5700 \\
Load factor & $\%$ & 0.94 & 0.95 & 0.79 \\
Fuel use & $1 / \mathrm{vehicle} / \mathrm{km}$ & 0.31 & 5.1 & 35.3 \\
Loading cost & $€ / \mathrm{t}$ & 3.66 & 2.97 & 3.50 \\
emissions & $\mathrm{gCO}_{2} / \mathrm{t} / \mathrm{km}$ & 68 & 2.97 & 24 \\
\hline
\end{tabular}

\subsection{Meteorological data}

The hourly electricity generation potential from solar PV and wind technologies are derived based on the meteorological dataset [3]. The dataset has global coverage with a 3 -hourly temporal and a 0.25 degree spatial resolution.

Details for the data processing to derive the power generation estimates are reported in [4]. The hourly mean capacity factors of solar PV and wind sites for the sampled hours are presented in Fig 1. The factors shown represent hourly mean values, as obtained from the data source. In total, about 2900 sites are considered for each technology.

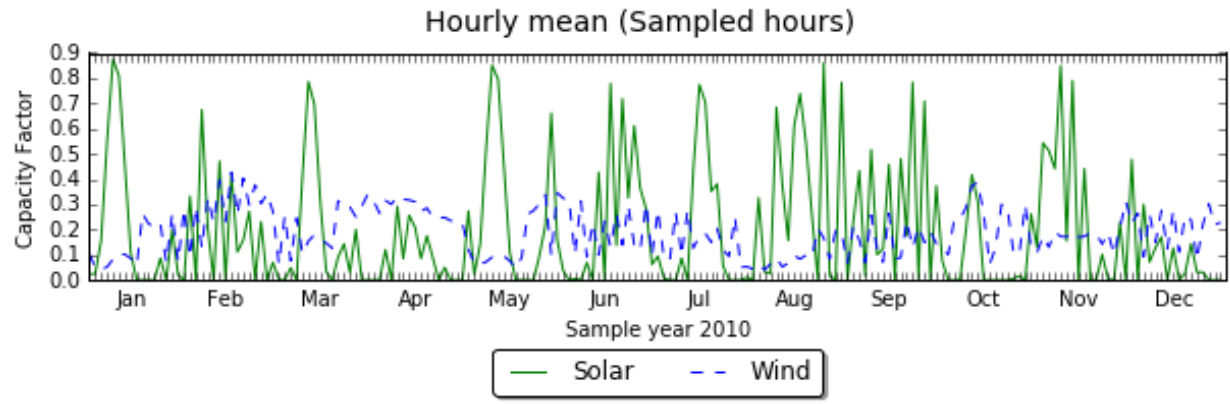

Figure 1. Hourly mean capacity factors for solar and wind technologies

\subsection{Business As Usual (BAU)}

To establish a reference case, the model uses country respective annual mean capacity factors and the corresponding installed capacities for each of the existing technologies in power supply system. These data are parameterized in the model. The average annual capacity factors of the major three technologies are shown in Fig 2.

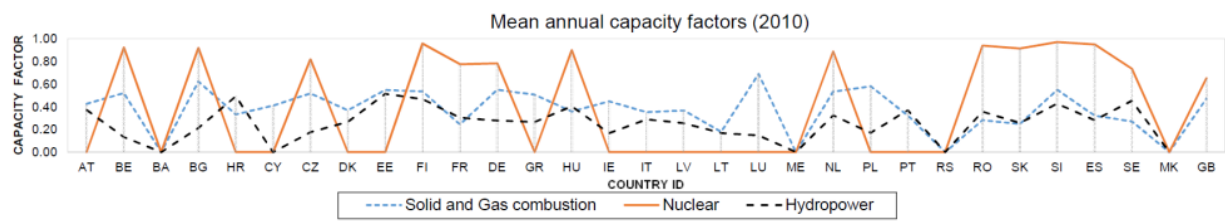

Figure 2. Annual mean capacity factors for the three major technologies in 2010 


\subsection{Power demand and transmissions}

The hourly power demand for each country and the existing transmission capacities between countries are derived from the European Network of Transmission System Operators for Electricity (ENTSO-E). ENTSO-E reports historical demand and transmissions at the country level. The year 2010 is chosen in order to be consistent with the meteorological data. When demand data is unavailable in a specific hour, the data from the previous hour is used, or the same hour in the previous day, depending on data availability.

The power demand is sampled every three hours from the peak and median day in each month. Doing so reduces the computational complexity by compensating for the high spatial resolution. This is consistent with sampling methods from previous highresolution electricity sector planning models [5]. To represent the entire year, the sampled days are weighted to represent multiple days by fixing peak days to represent one day of the month and median days to represent the remaining days in the month (i.e., days in a month minus one) [5]. This ensures peak conditions are included in the power constraint while economic assessment is dominated by the typical demand profile, as peak demand occurrences are rare. Accordingly, all samples (i.e. 8 samples per selected day) represent three hours each, peak days represent a day of the corresponding month and median days represent the remaining days in the month. This procedure is included in the model by means of a time-indexed weighting parameter.

\subsection{Assessment approach}

A number of countries in Europe enforce national policy measures for mapping decarbonization pathways of their energy sector. This, of course, is in addition to the EU ETS, a policy cornerstone to combat climate change. For instance carbon tax (additional tax on fossil fuels), bioenergy support (biofuels subsidy), green electricity certificate (a program that rewards a tradable certificate for every MWh of RE generation, e.g. in Sweden, Norway, and the UK). Due to the investigative nature of this study, we opted for a simplified approach that assumes a regionally enforced carbon tax in the range of 0 to $150 € / \mathrm{tCO}_{2}$ at an interval of $25 € / \mathrm{tCO}_{2}$. Particular attention is given to the role of transmission network in stabilizing intermittency. The optimization procedure considers the transmissions to be a direct power flow balance. There is no attempt to mimic the voltage phase shift, which is highly nonlinear. However, the power flow balance approximation is a reasonable representation for a high-voltage direct-current (HVDC) transmissions network [6]. The use of an HVDC transmissions instead of high-voltage alternating-current (HVAC) is because of the nonlinear nature of HVAC, which significantly complicates the optimization. However, the HVDC transmissions can be thought of as an approximation of HVAC in terms of power flow because it includes electrical losses and describes transmissions at a high level.

Furthermore, the optimization is set such that the model has to select least expensive generation mix based on the existing generation fleet that emit $\mathrm{CO}_{2}$, a state of the art 
$10^{\text {TH }}$ InTERnAtional CONFERENCE ON Sustainable ENERGy AND ENVIRONMENTAL Protection (June $27^{\mathrm{TH}}-30^{\mathrm{TH}}, 2017$, Bled, SLOVENIA), RENEWABle ENERGY SOURCES S. Mesfun, S. Leduc, P. Patrizio, P. Yowargana \& F. Kraxner: Spatio-Temporal Assessment of Integrating Intermittent Electricity in the EU Power Sector

natural gas combined cycle (NGCC) or deploy RE units to meet the demand at any given time. Cost minimization is superior to a load-matching optimization for real world applications, as cost is a primary driver of integration of variable generation into an electricity sector.

\section{$3 \quad$ Results and Discussions}

The integration of RE in the power sector is influenced by different factors, most notably their generation costs relative to the conventional technologies they compete with and the assumed policies to motivate their deployment. Consequently, the results presented here primarily explore the influence of carbon taxing based on a 2020 cost projection scenario for solar and wind technologies, Table A1. Additionally, the results are discussed in contrast to potential expansion of the existing transmissions capacity between the countries in the EU. A BAU network of transmissions is established for 2010, the year this study refers to, based on historical indicative capacities, Fig A1.

\subsection{Electricity generation mix}

Figure 3 shows the power generation mix of the BAU case and the optimal cases for carbon tax range of 0 to $150 € / \mathrm{tCO}_{2}$. The dashed-line indicates the power demand. Accordingly, intermittent RE starts to appear in the mix even without carbon incentive. A carbon tax of $25 € / \mathrm{tCO}_{2}$ results in total replacement of coal and oil with RE and NGCC, as NGCC emissions are about 50\% lower per unit output. This is consistent with the general consensus that new fossil based technologies need to achieve at least 50\% reduction in carbon emissions compared to their conventional counterparts. It is worth noting that the price of electricity from NGCC plant assumes a levelized cost for a stateof-art technology, which in this case is about 1.47 times higher than the market prices.

Apart from that, with increasing carbon tax a steady increase in intermittent power is observed, comprising between $10 \%$ and $49 \%$ of the total generation. Of course, increased share of variable power induces grid balancing problems, often leading to increased curtailment. This phenomenon is clearly observed in Fig 3, the supply progressively exceeds demand with increasing carbon tax. In the following subsection we explore the role of expanding existing transmission capacities in reducing curtailment. Figure 4 shows a spatial distribution map of the optimal power generation mix for carbon tax 50 $€ / \mathrm{tCO}_{2}$. In comparison to the $\mathrm{BAU}$ case, Fig $\mathrm{A} 1$, wind and solar displace significant portion of $\mathrm{CO}_{2}$ emitting technologies across the entire region. 
S. Mesfun, S. Leduc, P. Patrizio, P. Yowargana \& F. Kraxner: Spatio-Temporal Assessment of Integrating Intermittent Electricity in the EU Power Sector
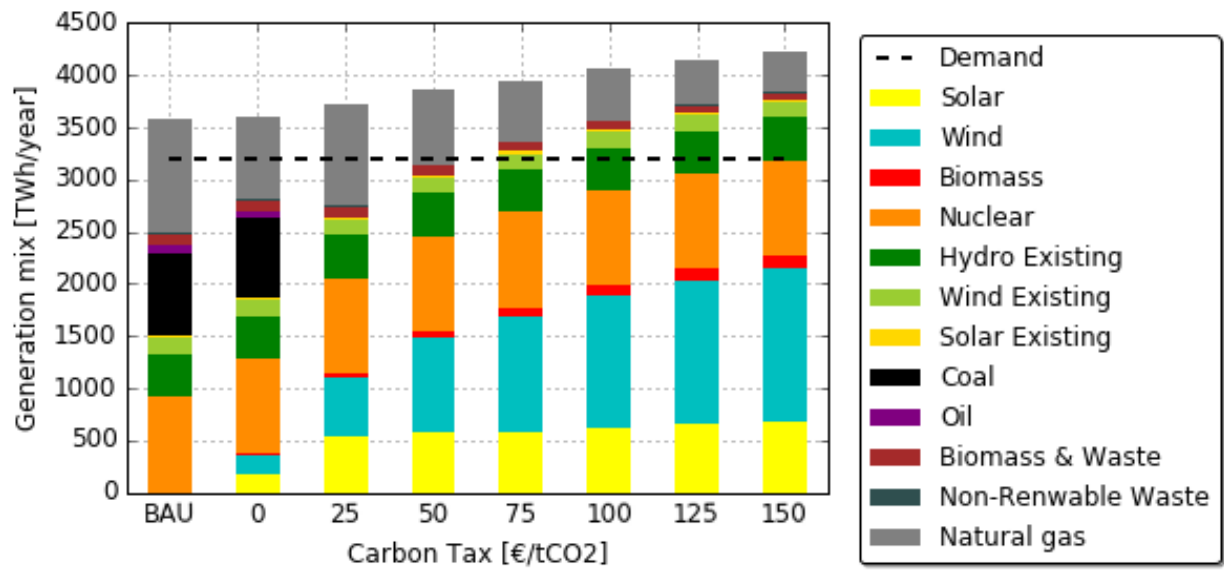

Figure 3. EU power generation mix, BAU and carbon tax range of 0 to $150 € / \mathrm{tCO}_{2}$

\subsection{Transmissions capacity expansion}

In this assessment, the transmissions expansion allowance is limited to the existing indicative capacities, as reported by ENTSO-E for 2010. It doesn't not reflect factual capacities under expansion, construction or planning phases, see e.g. [7]. Scenarios assuming expansion factors of 1.5, 2, 5 and 10 are considered in addition to an ideally interconnected EU case (which assumes no limitation of transmissions capacity for the existing connections). Moreover, the discussions in this section focus on the impacts of transmissions on wind and solar generations due to their variable nature.

According to Fig 5, with expansion of transmissions capacity further deployment of wind technology becomes feasible and dominates generation in countries where the resource appears to be abundant, e.g. the UK, Italy and Greece, as presented in Fig 6. Whereas, solar generation is localized to regions endowed with insolation, e.g. Spain. Wind technology deployment is favoured over solar because wind has better geographic distribution and the technology requires lower capital investment. 
$10^{\mathrm{TH}}$ InTERnATIONAL CONFERENCE ON Sustainable EnERgy AND ENVIRONMENTAL Protection (June $27^{\mathrm{TH}}-30^{\mathrm{TH}}, 2017$, Bled, SLOVEnia), RENEWABle ENERGy SOURCES S. Mesfun, S. Leduc, P. Patrizio, P. Yowargana \& F. Kraxner: Spatio-Temporal Assessment of Integrating Intermittent Electricity in the EU Power Sector

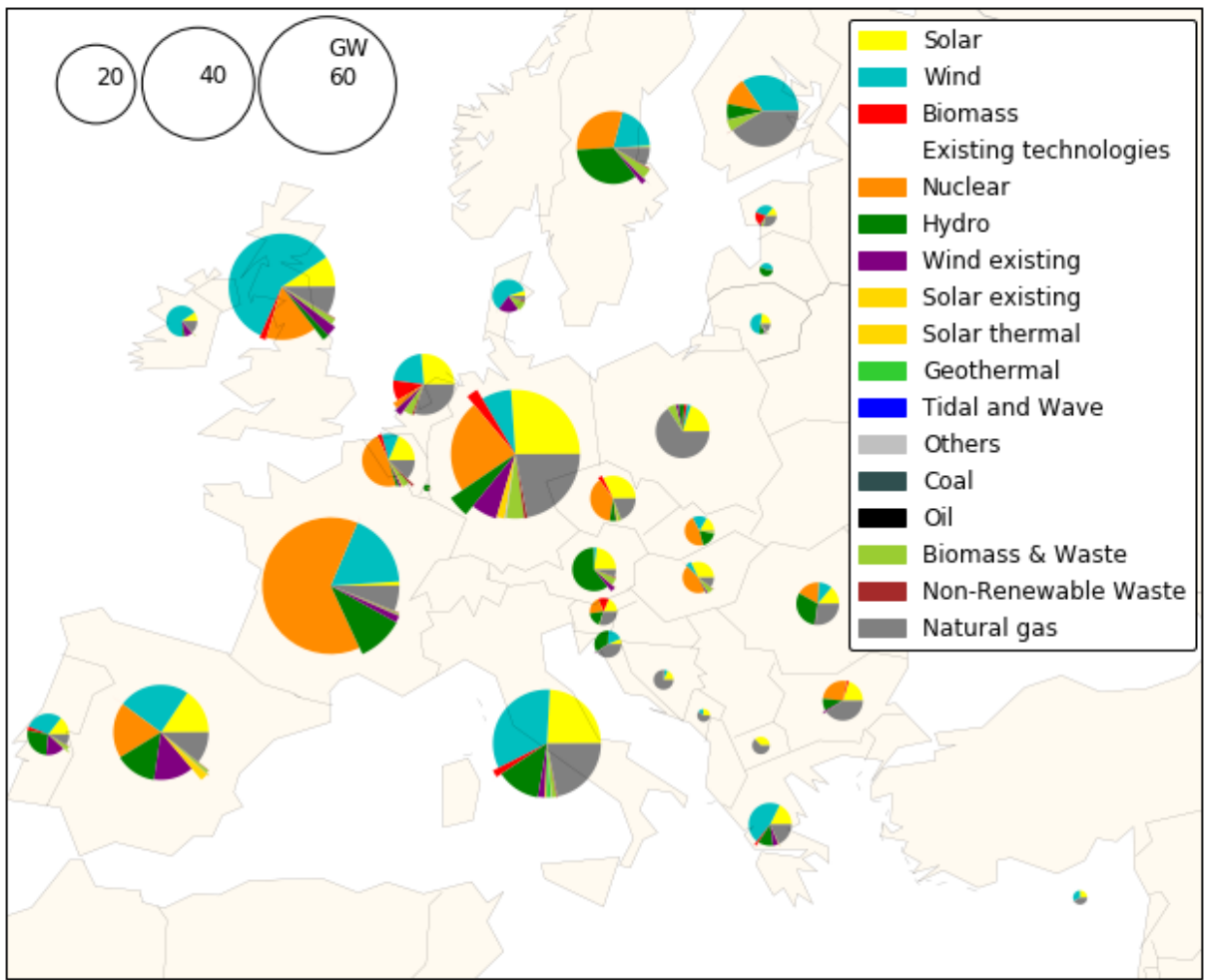

Figure 4. Spatial distribution of EU power generation mix, carbon tax $50 € / \mathrm{tCO}_{2}$

Another aspect is that the gain in wind generation due to the expansion of transmissions capacity is countered with about the same amount reduction in solar energy, Fig 5. This is mainly because the competing technologies are constrained to $\mathrm{CO}_{2}$-emitting technologies in the existing fleet, NGCC, wind, solar and biomass technologies. It should be noted that an optimization with full access to the entire existing generation fleet would likely lead to a different generation mix. This option is, however, ruled irrelevant as the aim of this study is to explicitly target $\mathrm{CO}_{2}$-emitting technologies in the EU electricity sector.

Furthermore, a five-fold expansion of the existing transmissions capacity achieves about half of the additional wind power that an ideally interconnected EU would deploy. This indicates that an optimal expansion in transmissions can be realized by considering an economic assessment in comparison to expanding country respective deployment of RE technologies. 

Protection (June 27 $7^{\mathrm{TH}}-30^{\mathrm{TH}}, 2017$, BLed, Slovenia), RenEWAble EnERGY SOURCES

S. Mesfun, S. Leduc, P. Patrizio, P. Yowargana \& F. Kraxner: Spatio-Temporal Assessment of Integrating Intermittent Electricity in the EU Power Sector
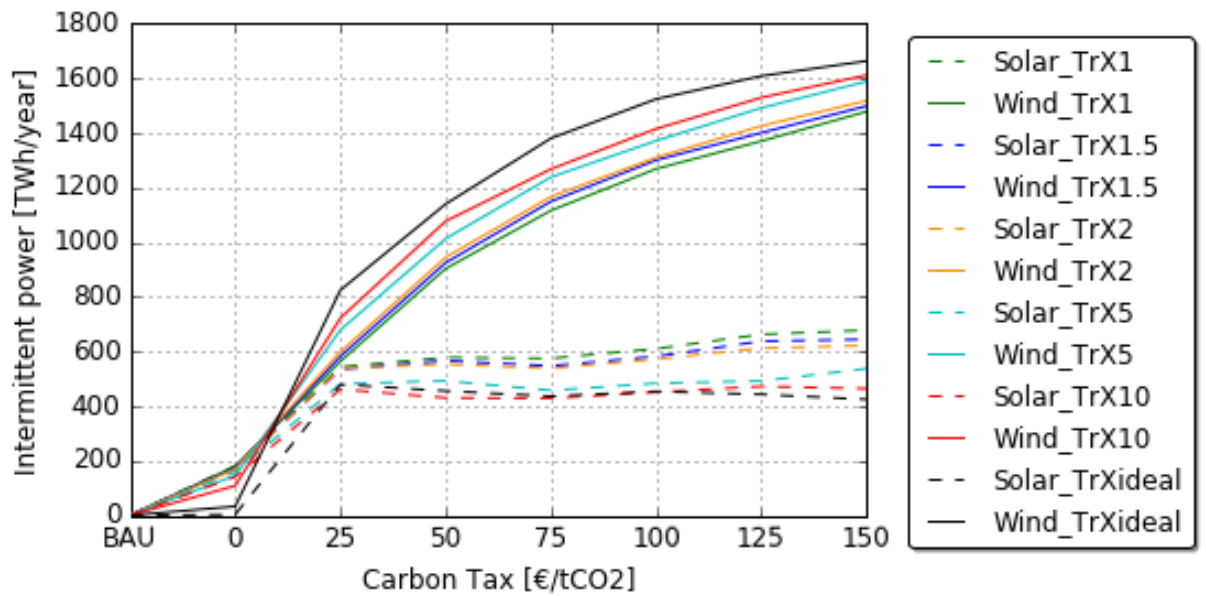

Figure 5. Variation of wind and solar generation as function of transmissions

For an ideally interconnected EU, Fig 6, the country respective shrinking generation capacities, most notably for Germany, are compensated with the increase in the UK, France and Sweden (wind) and Spain (solar). Even though, the UK and Spain do not have direct transmission corridor connecting them to Germany, France, which has the largest connection to Germany, appears to play the power balancing role.

However, it is worth mentioning that for an ideally interconnected EU the combined generation in the EU is expected to reduce because the variability of wind is managed better with the expansion of transmissions capacity. 
$450 \quad 10^{\text {TH }}$ InTERnAtional CONFERENCE ON Sustainable ENERGy AND ENVIRONMENTAL Protection (June $27^{\mathrm{TH}}-30^{\mathrm{TH}}, 2017$, BLED, SLOVENIA), RENEWABLE ENERGY SOURCES S. Mesfun, S. Leduc, P. Patrizio, P. Yowargana \& F. Kraxner: Spatio-Temporal Assessment of Integrating Intermittent Electricity in the EU Power Sector

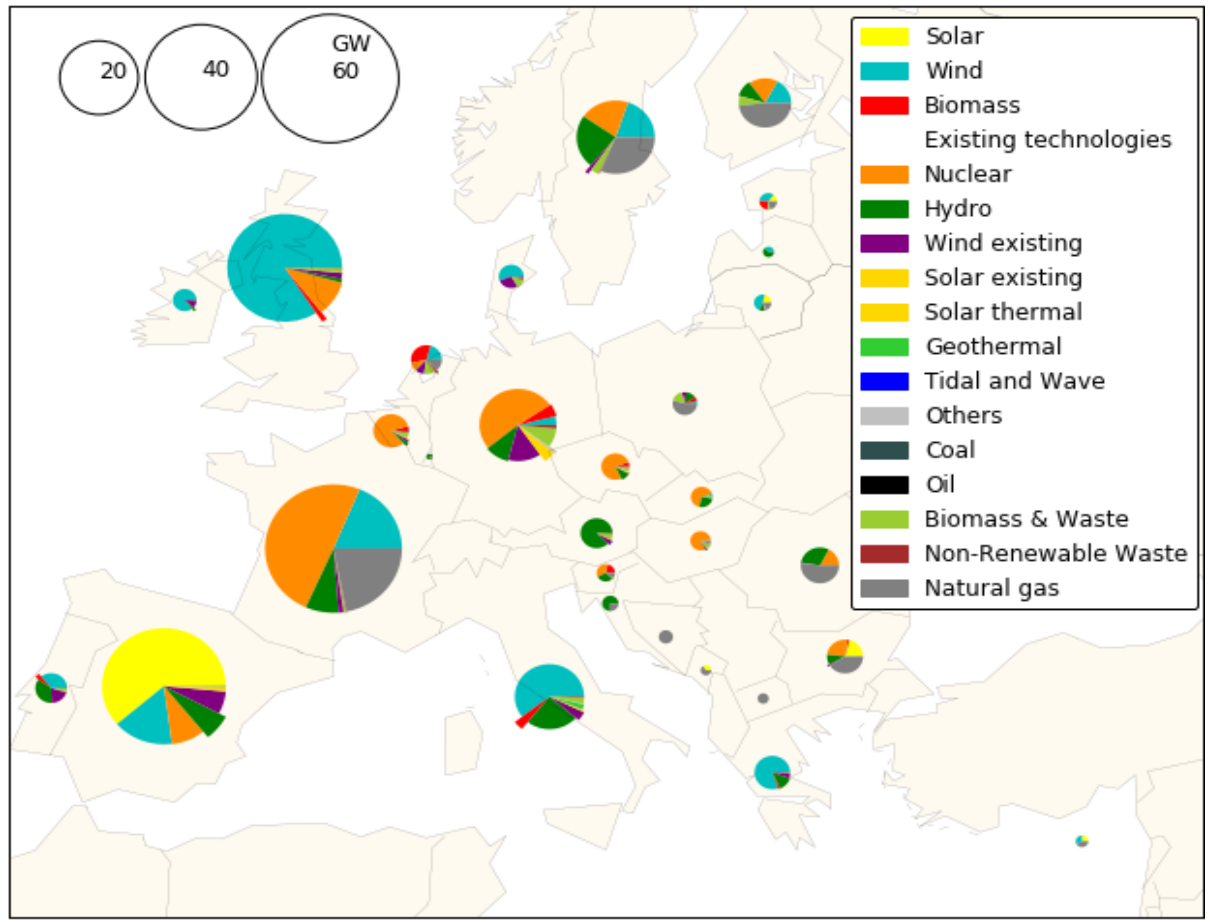

Figure 6. Spatial distribution of generation mix for an ideally interconnected EU at $50 € / \mathrm{tCO}_{2}$

\section{3 $\mathrm{CO}_{2}$ emissions}

The ultimate goal of this work is to assess the role of RE in decarbonizing the existing generation fleet in the EU.

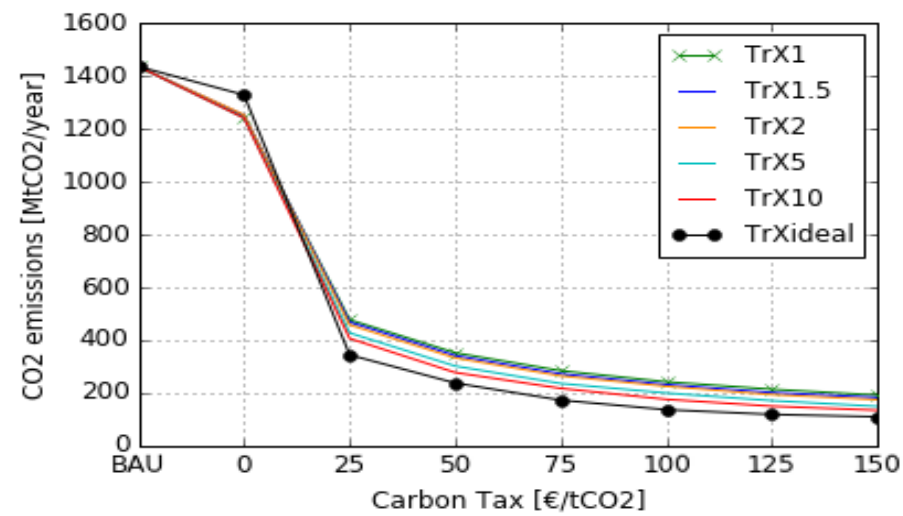

Figure 7. $\mathrm{CO}_{2}$ emissions 
Figure 7 presents the aggregated $\mathrm{CO}_{2}$ emissions, assuming biomass and waste, both renewable and non-renewable, as emission neutral sources. This is a reasonable assumption to make because forest and crop residuals as well as waste if left unutilized would contribute to landfill emissions. Besides, their contribution to the generation mix is trivial. Referring to Fig 7, EU-scale deployment of intermittent $\mathrm{RE}$ would result in $\mathrm{CO}_{2}$ emissions reduction ranging between 15 and $85 \%$ compared to BAU depending on the carbon tax.

In addition, a margin of about $50 \mathrm{MtCO}_{2} /$ year is observed between the $\mathrm{BAU}$ transmissions case and an ideally interconnected EU for carbon tax range of 25 to 150 $€ / \mathrm{tCO}_{2}$.

\section{$4 \quad$ Concluding Remarks}

This assessment illustrates the potential of deploying utility-scale intermittent RE to aggressively reduce $\mathrm{CO}_{2}$ emissions in the EU electricity sector. The findings showed the least expensive generation mix turns into a low-carbon system, particularly when incentivized with carbon tax. Integration of intermittent RE can make important contribution, comprising between $10 \%$ and $49 \%$ of the total generation with the existing transmissions capacity. Previous studies have shown that industrial application of $\mathrm{CO}_{2}$, such as power-to-gas/liquid [4], [8], could help marginalize carbon tax.

The results further indicated expansion of existing transmission capacities could help even-out the intermittency of wind and solar technologies.

\section{Acknowledgements}

M. S. is grateful for the financial support of the Kempe foundation, Sweden.

\section{Notes}

1 http://www.iiasa.ac.at/bewhere 
$10^{\mathrm{TH}}$ InTERnAtional CONFERENCE ON Sustainable ENERgy AND ENVIRONMENTAL Protection (June $27^{\mathrm{TH}}-30^{\mathrm{TH}}, 2017$, Bled, SLOVENIA), RENEWABle ENERGY SOURCES S. Mesfun, S. Leduc, P. Patrizio, P. Yowargana \& F. Kraxner: Spatio-Temporal Assessment of Integrating Intermittent Electricity in the EU Power Sector

\section{Appendix A}

Table A1. Technology economic parameters

\begin{tabular}{llll}
\hline Parameter & Solar & Wind & Unit \\
\hline Capital cost & $3750^{\mathrm{a}}$ & $1980^{\mathrm{c}}$ & $€ / \mathrm{kW}$ \\
Economic life time & 25 & 25 & years \\
O\&M fixed & $5.14^{\mathrm{b}}$ & $6.84^{\mathrm{b}}$ & \\
Transmission cost & 1 & 1 & $€ / \mathrm{kW}-\mathrm{km}$ \\
Grid connection cost & 0.2 & 0.2 & $€ / \mathrm{kW}$
\end{tabular}

${ }^{a}$ Non-tracking commercial solar PV technology with $4 \mathrm{~kW}(\mathrm{DC})$ installed capacity is considered for this study. The capital, fixed $O \& M$ cost are adopted from [9]. The capital cost estimates are expected to have uncertainties of $+25 \%$.

${ }^{b}$ Fixed $O \& M$ cost for solar and wind technologies in $€ / M W h$ [9].

${ }^{c}$ Capital cost estimate reported here is for onshore wind turbines, with expected uncertainties of less than $+25 \%[9]$.

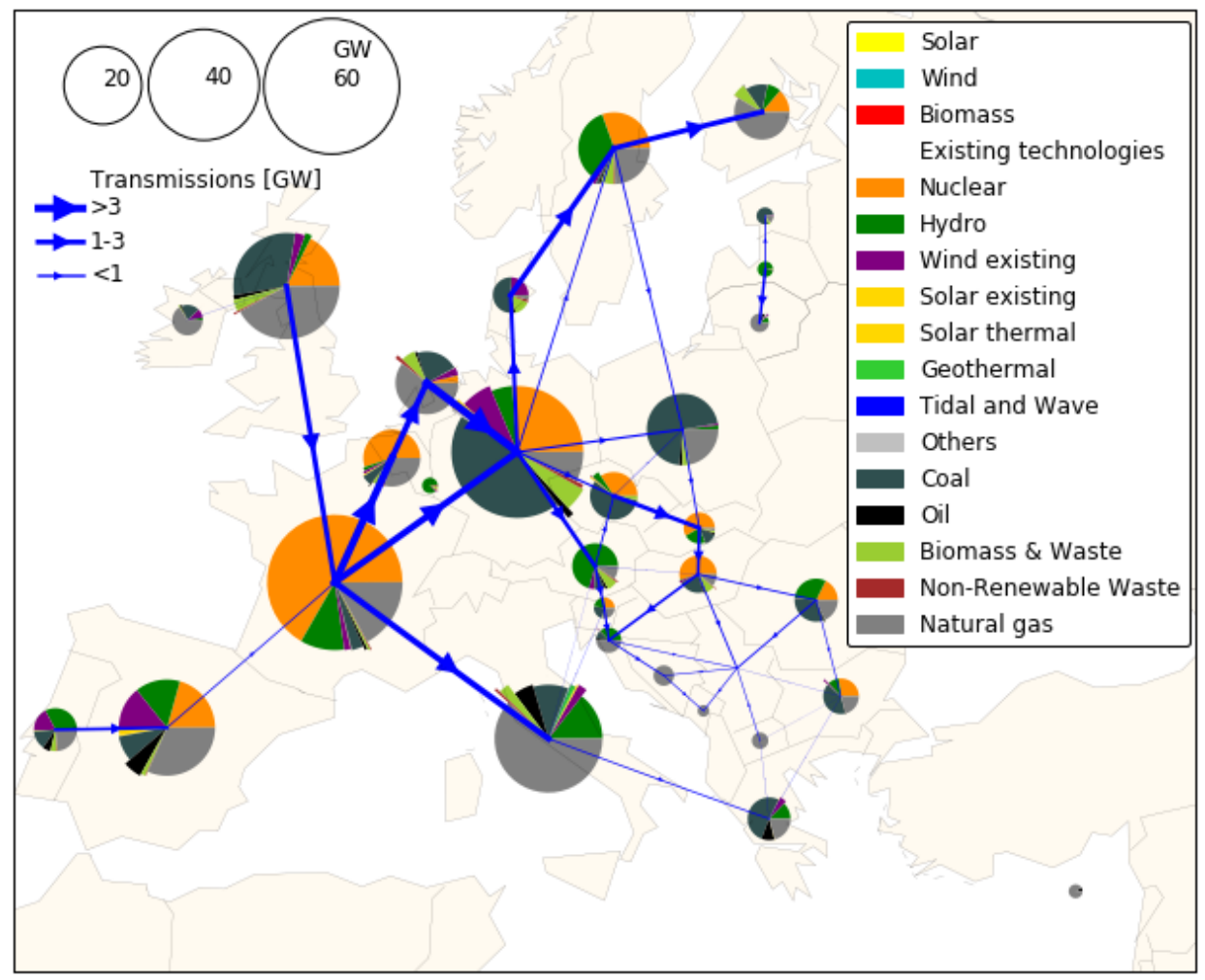




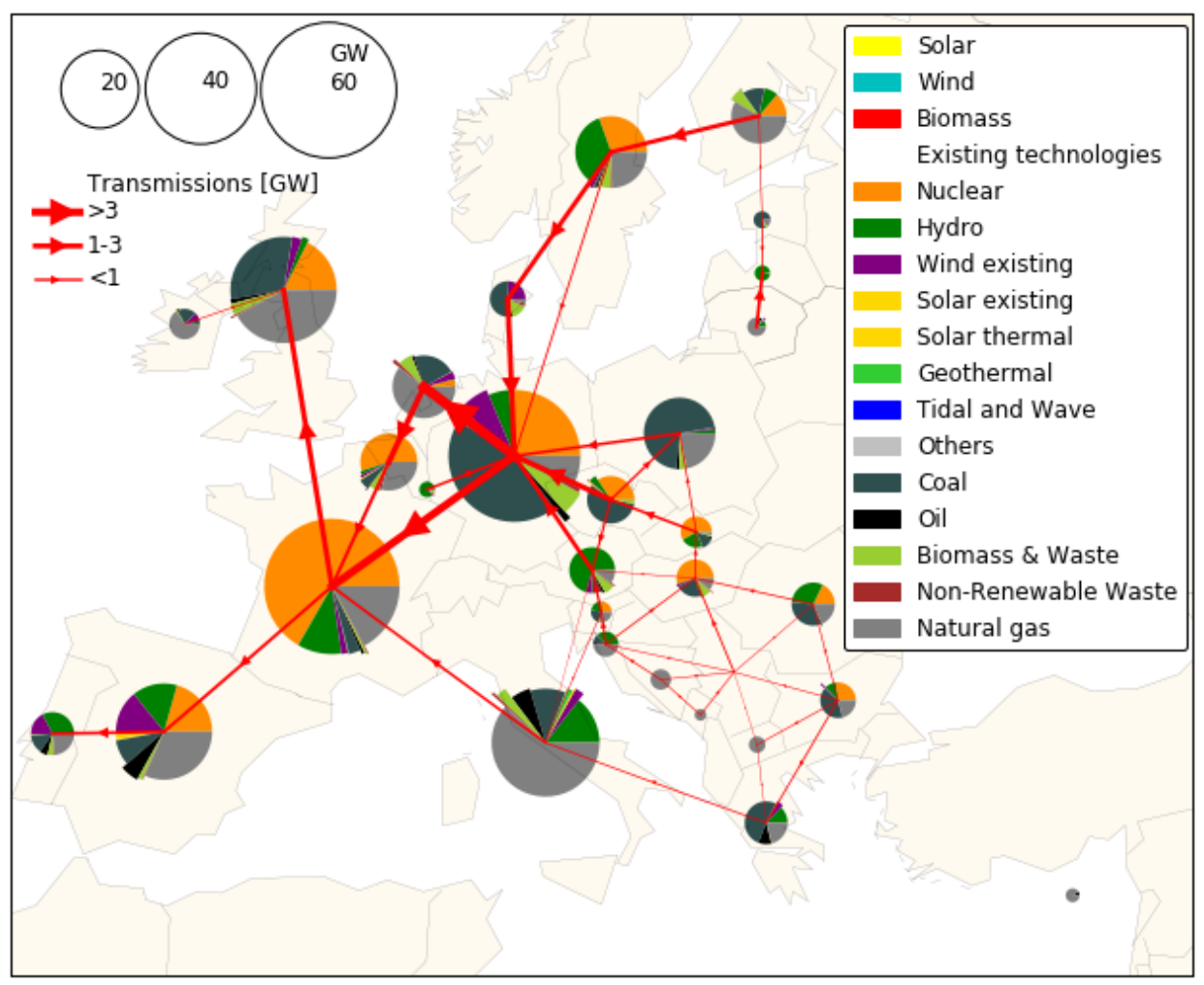

\section{References}

[1] C. Jägemann, M. Fürsch, S. Hagspiel, and S. Nagl, "Decarbonizing Europe's power sector by 2050 - Analyzing the economic implications of alternative decarbonization pathways," Energy Econ., vol. 40, pp. 622-636, 2013.

[2] M. Dees, B. Elbersen, J. Fitzgerald, M. Vis, P. Anttila, N. Forsell, J. Ramirez-Almeyda, B. Glavonjic, I. Staritsky, H. Verkerk, R. Prinz, S. Leduc, P. Datta, M. Lindner, S. Zudin, and M. Höhl, "Atlas with regional cost supply biomass potentials for EU 28 , Western Balkan Countries , Moldavia , Turkey and Ukraine," Project Report. S2BIOM - a project funded under the European Union 7th Framework Programme for Research. Grant Agreement no. 608622. Chair of Remote Sensing and Landscape Information Systems, Institute of Forest Sciences, University of Freiburg. 103 p., 2017.

[3] J. Sheffield, G. Goteti, and E. F. Wood, "Development of a 50-year high-resolution global dataset of meteorological forcings for land surface modeling," J. Clim., vol. 19, no. 13, pp. 3088-3111, 2006.

[4] S. Mesfun, D. L. Sanchez, S. Leduc, E. Wetterlund, J. Lundgren, M. Biberacher, and F. Kraxner, "Power-to-gas and power-to-liquid for managing renewable electricity intermittency in the Alpine Region," Renew. Energy, vol. 107, pp. 361-372, Jul. 2017.

[5] J. Nelson, J. Johnston, A. Mileva, M. Fripp, I. Hoffman, A. Petros-Good, C. Blanco, and D. M. Kammen, "High-resolution modeling of the western North American power system demonstrates low-cost and low-carbon futures," Energy Policy, vol. 43, pp. 436-447, 2012. 
454 10 $10^{\mathrm{TH}}$ International CONFEREnCE on Sustainable EnERgy AND ENVIRONMENTAL Protection (June $27^{\mathrm{TH}}-30^{\mathrm{TH}}, 2017$, Bled, Slovenia), RENEWABLE ENERGY SOURCES S. Mesfun, S. Leduc, P. Patrizio, P. Yowargana \& F. Kraxner: Spatio-Temporal Assessment of Integrating Intermittent Electricity in the EU Power Sector

[6] C. T. M. T. M. Clack, Y. Xie, and a. E. E. MacDonald, "Linear programming techniques for developing an optimal electrical system including high-voltage direct-current transmission and storage," Int. J. Electr. Power Energy Syst., vol. 68, pp. 103-114, 2015.

[7] A. Malvaldi, S. Weiss, D. Infield, J. Browell, P. Leahy, and A. M. Foley, "A spatial and temporal correlation analysis of aggregate wind power in an ideally interconnected Europe," Wind Energy, vol. 17, no. April 2013, pp. 657-669, 2017.

[8] A. Varone and M. Ferrari, "Power to liquid and power to gas: An option for the German Energiewende,” Renew. Sustain. Energy Rev., vol. 45, pp. 207-218, 2015.

[9] Black \& Veatch, "Cost and Performance data for Power Generation Technologies," 2012. 
$10^{\mathrm{TH}}$ InTERnAtional CONFERENCE ON Sustainable ENERgy AND ENVIRONMENTAL Protection (June $27^{\mathrm{TH}}-30^{\mathrm{TH}}$, 2017, Bled, SLOVENIA), RENEWABLE ENERGy SOURCES

J. Krope, A.Ghani Olabi, D. Goričanec \& S. Božičnik

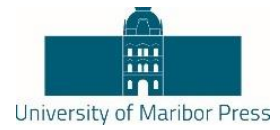

\title{
Production of Biogas from Effluent of Pigs. Case Study
}

\author{
EugÊnia LeAndro Almeida, Cid Marcos GonçAlves AndRAdE \& José Ozinaldo \\ ALVES DE SENA
}

\begin{abstract}
The increased demand for pork, both domestically and for export, has led to increased hog breeding in feedlot. The large volume of waste generated has become a frequent environmental problem. Anaerobic biodigestion is one of the methods that can be used to treat this effluent, where organic matter is converted through biological decomposition into biogas and biofertilizer. The objective of this work is to propose the construction of a biodigestor, using as a study the experimental farm of the State University of Maringá, which has approximately 250 pigs in a feedlot system. The Canadian model was the one that presented the greatest cost benefit in relation to the treatment and production of biogas from swine effluent. Their dimensions were calculated using the model proposed in the literature. It was also evaluated the energy potential that can be generated with the implantation of the biodigester in the unit..
\end{abstract}

Keywords: • Biogas $\bullet$ bioenergy $\bullet$ biomass $・$ swine effluent $\bullet$ anaerobic digestion •

CORRESPONDENCE ADDRESs: Eugênia Leandro Almeida, M.Sc, Universidade Estadual de Maringá, Chemical Engineering Department, Av. Colombo, 5790 - Vila Esperança, Maringá - Paraná, Brasil, email: eugenia-almeida@hotmail.com. Cid Marcos Gonçalves Andrade, Ph.D, Universidade Estadual de Maringá Chemical Engineering Department, Av. Colombo, 5790 - Vila Esperanca, Maringá - Paraná, Brasil,email: cid@deq.uem.br. José Ozinaldo Alves de Sena, Ph.D, Universidade Estadual de Maringá, Department of Agronomy, Av. Colombo, 5790 - Vila Esperanca, Maringá - Paraná, Brasil,email: ozisena@gmail.com. 
$10^{\text {TH }}$ International CONFEREnce on Sustainable Energy and Environmental Protection (June $27^{\mathrm{TH}}-30^{\mathrm{TH}}, 2017$, BlED, SLOVENIA), RENEWABLE ENERGY SOURCES E. Leandro Almeida, C. Marcos Gonçalves Andrade \& J. Ozinaldo Alves de Sena: Production of Biogas from Effluent of Pigs. Case Study

For many years swine farming in Brazil was considered an activity that did not cause environmental damage, since production was low, guaranteeing that the environment itself would absorb the generated effluents without causing major environmental impacts. Currently, according to the Confederation of Agriculture and Livestock of Brazil, the country is the fourth largest producer and exporter of pork in the world and should remain in this position until 2018 [1]. This position has brought with it an increase in demand for pork in order to supply both domestic and foreign markets. However, this increase did not accompany the availability of land, forcing farmers to use the breeding system in confinement. This system produces a large volume of waste, which is usually not treated properly and is often discarded in water bodies, causing serious problems for the environment and for people who use water from these rivers for consumption and / or irrigation [2][3].

One of the alternatives for treatment of swine manure is anaerobic biodigestion, which is an efficient technology, allowing to treat the effluent and to produce biogas and biofertilizer [4][5][6].

Biogas is obtained from the biological decomposition of organic matter in the absence of oxygen, in the case of biogas production from swine effluents, this decomposition reaction occurs through microorganisms present in the effluents themselves. Biogas consists of a mixture of gases, predominating in its composition of methane and carbon dioxide, and may be a potential substitute for non-renewable fuels, such as natural gas and gasoline [7]. The advantage of the use of biogas is the reduction of the need to import energy using local energy and in some cases where there is excess production of energy, it can be commercialized, for example in a unit where it has power generation Electric power, it can be sold to the local power grid [8][9][10].

The biofertilizer that remains of the organic matter conversion reaction in gas is a nutrient rich material, presenting in abundance nitrogen. Biofertilizer, besides being an economically viable alternative, is also an environmentally advantageous alternative, since it allows to reduce or even to replace the use of pesticides using small, medium and large crops. Another advantage of the use of the biofertilizer is the fact that it presents characteristic of agricultural defensive, combating pest, diseases and insects. As the biofertilizer has a basic $\mathrm{pH}$ range, it also acts as a soil $\mathrm{pH}$ corrector [11][12].

In this work we investigated the possibility of constructing a biodigestor at the Experimental Farm of Iguatemi, belonging to the State University of Maringá, located in the district of Iguatemi, in the State of Paraná - Brazil. Anaerobic biodigestion leads to an adequate treatment of the effluent generated by the breeding of pigs in confinement in the unit. As well as the production of biogas and biofertilizer.

\section{$2 \quad$ Materials and Methods}

The work was carried out from the observation of the large volume of effluent generated by the swine breeding in confinement at the farm located in the Experimental Farm Iguatemi - FEI, 
belonging to the State University of Maringá and the environmental and social problems that these wastes are causing for the lack of Treatment. The biodigester is a proposal to solve the presented problems.

Studies demonstrate that the biodigester can be an efficient system for the treatment of organic wastes at the same time an economically viable system. The biodigestor produces biogas and biofertilizer, which can be used in the unit itself [13][14]. There are three types of biodigesters that are often used: the Chinese, Indian and Canadian model. These biodigesters can be operated in batch or fed batch.

The biodigestor model chosen for the development of the work was the Canadian model. According to the work carried out by Calza et al. (2015) the model presents lower cost of construction, operation and greater efficiency for the production of biogas from swine effluent [15].

The Canadian model has a rectangular base excavated in the ground, constructed of masonry, and a gasometer made of a flexible PVC blanke [15]. This biodigestor model is often used in warmer regions, where the ambient temperature favors the organic matter decomposition process. Figure 01 shows the schematic drawing of a Canadian biodigester.

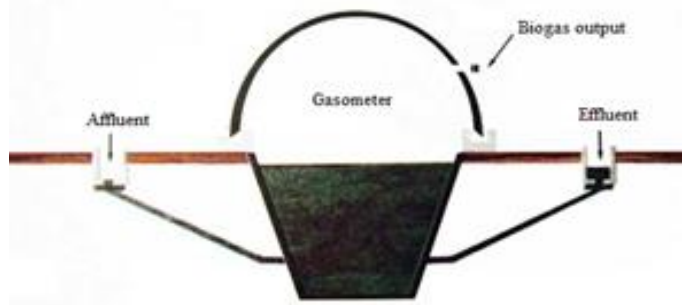

Figure 01: Canadian model biodigester

The volume of the biodigester can be calculated by multiplying the daily load of organic matter by the hydraulic retention time. The effluent inlet should have a volume equal to the volume of the daily effluent load. The outlet box must have a volume of at least three times the volume of the daily charge of entry, because this way the outlet box will still contain possible accumulations of biofertilizer. In order to size the biodigestor of the case study, the model proposed by Ribeiro (2011) was used [16]. It follows the equations developed by the author:

$P e=2 r \pi$

Where, $P e$ represents the transverse total perimeter and $r$ is the radius of the plastic bag.

$A \%=0.621 p^{2}-0.042 p+0.352$ 
458 10 $10^{\mathrm{TH}}$ International CONFERENCE on Sustainable ENERgy AND ENVIRONMENTAL Protection (June $27^{\mathrm{TH}}-30^{\mathrm{TH}}, 2017$, BLED, SLOVENIA), RENEWABLE ENERGY SOURCES E. Leandro Almeida, C. Marcos Gonçalves Andrade \& J. Ozinaldo Alves de Sena: Production of Biogas from Effluent of Pigs. Case Study

Where, $A \%$ represents the percentage of the transverse perimeter for the arc and $p$ the desired gas phase proportion $(\mathrm{p} \leq 0.4)$.

$b=(-1 / 3 A \%+1 / 3) p$

Where, $b$ is the smallest width of the pit

$a=1.618 b$

Where, $a$ is the largest width of the pit.

$h=0.951 b$

where, $h$ is the depth of the cesspool.

$A f=0.4755(a+b) b$

where $A f$ is the cross-sectional area of the pit.

$A t=A f /(1-p)$

where, At is the total transverse area.

$A g=A t-A f$

where, $A g$ is the gaseous cross-sectional area.

$V t=A t L$

where, $V t$ is the total volume of the biodigester and $L$ the length of the biodigester.

$V f=A f L$

Where, $V f$ is the total volume of the pit.

$V g=A g L$

Where, $V g$ is the total volume of gas.

$V e=C . T R H$

Where $V e$ is the estimated volume of the fossil, $C$ is the organic charge and $T R H$ hydraulic retention time. 


\section{$3 \quad$ Results and Discussion}

It was reported by staff working on the pig farm, from the case study, that there are approximately 250 pigs.

Second Oliver et al. (2008) the daily production of desire per pig is on average $4 \mathrm{~kg}$. The dilution of this desire in water is $1: 1.3$. The hydraulic retention time is 35 days [17].

The dimensions of the Canadian biodigestor were calculated using the mathematical model developed by Ribeiro et al. (2011). The author concluded that for tubular biodigesters such as the Canadian model, the model does not apply to ratios greater than $40 \%$, since the volume of the liquid phase will not be sufficient to keep the hood full of air. Therefore, the desired gas phase ratio is assumed to be $40 \%$ [16]. The results were simulated and calculated in Excel 2010 software and presented in table 1.

Table 1: Calculated dimensions for the construction of a Canadian model biodigester

\begin{tabular}{|c|c|}
\hline Parameters & Result \\
\hline$r$ & $2.00 \mathrm{~m}$ \\
\hline$L$ & $8.00 \mathrm{~m}$ \\
\hline$P e$ & 0.40 \\
\hline$A \%$ & $12.56 \mathrm{~m}$ \\
\hline$b$ & 0.43 \\
\hline$a$ & $2.37 \mathrm{~m}$ \\
\hline$h$ & $3.83 \mathrm{~m}$ \\
\hline$A f$ & $2.25 \mathrm{~m}$ \\
\hline$A t$ & $11.29 \mathrm{~m}^{2}$ \\
\hline$A g$ & $18.81 \mathrm{~m}^{2}$ \\
\hline$V t$ & $7.53 \mathrm{~m}^{2}$ \\
\hline$V f$ & $150.50 \mathrm{~m}^{3}$ \\
\hline$V g$ & $90.30 \mathrm{~m}^{3}$ \\
\hline$V e$ & $60.20 \mathrm{~m}^{3}$ \\
\hline$V c l$ & $88.00 \mathrm{~m}^{3}$ \\
\hline$V c 2$ & $2.5 \mathrm{~m}^{3}$ \\
\hline & $7.5 \mathrm{~m}^{3}$ \\
\hline
\end{tabular}

According to Oliver et al. (2008) the daily production of biogas from swine effluent is $0.356 \mathrm{~m}^{3} /$ animal. Knowing that the calorific value of the biogas is $5.5 \mathrm{kWh} / \mathrm{m}^{3}$, we can 
$460 \quad 10^{\text {TH }}$ InTERnAtional CONFERENCE ON Sustainable ENERGy AND ENVIRONMENTAL Protection (June $27^{\mathrm{TH}}-30^{\mathrm{TH}}, 2017$, BlED, SLOVENIA), RENEWABLE ENERGY SOURCES E. Leandro Almeida, C. Marcos Gonçalves Andrade \& J. Ozinaldo Alves de Sena: Production of Biogas from Effluent of Pigs. Case Study

estimate that the annual energy production at Fazenda Experimenta de Iguatemi, coming from an effluent of 250 pigs, will be $178667.5 \mathrm{kWh}$ or $178.7 \mathrm{MWh}$ [17] [18].

\section{Conclusion}

It is possible to conclude that the treatment of swine effluent from anaerobic biodigestion can be an environmentally and economically viable alternative. The installation of a biodigester in a rural property reduces the environmental impact caused by swine in confinement. Biogas produced from anaerobic biodigestion is a way to get local renewable energy, both thermal and electrical. The remaining organic matter from the conversion can be used as a biofertilizer, since it is a nutrient rich material. In this way, the Experimental Farm of Iguatemi, has energy potential that can be explored and used in the unit itself. We can estimate that the annual energy production at Fazenda Experimenta de Iguatemi, coming from an effluent of 250 pigs, will be $178667.5 \mathrm{kWh}$ or 178.7 MWh

\section{Acknowledgements}

The authors would like to thank Coordenação de Aperfeiçoamento de Pessoal de Nível Superior (CAPES) for the financial support.

\section{References}

[1] CNA. Confederação da Agricultura e Pecuária do Brasil . Accessed: 02/03/ 2017. http://www.cnabrasil.org.br/central-comunicacao/comissoes-nacionais/suinocultura.

[2] S. G. Sommer, G. Mathanpaal and G. T. Dass, A Simple Biofilter for Treatment of Pig Slurry In Malaysia. Environmental Technology, Vol. 26, pp. 303-312, 2010.

[3] A. Kunz, M. Miele and R.LR.Steinment, Advanced swine manure treatment and utilization in Brazil. Bioresource Technology, Vol. 100, pp. 5485-5489, 2009.

[4] C. Chen et al., Continuous dry fermentation of swine manure for biogas production. Waste Management, Vol. 38, pp. 436-442, 2015.

[5] D. Yang et al., Separation of swine wastewater into solid fraction, concentrated slurry and dilute liquid and its influence on biogas production. Fuel, , Vol. 144, pp. 237-243, 2015.

[6] R. Dhanalakshmi and S. Ramanujam, Biogas generation in a vegetable waste anaerobic digester: An analytical approach. Research Journal of Recent Sciences, Vol. 1, pp. 41-47, 2012.

[7] P. Weiland, Biogas production: current state and perspectives. Appl Microbiol Biotechnol, , Vol. 85, pp. 849-860, 2010.

[8] M.E. Montingelli, S. Tedesco and A.G. Olabi, Biogas production from algal biomass: A review. Renewable and Sustainable Energy Reviews, Vol. 43, pp. 961-972, 2015.

[9] J. Fierro, X. Gómez and J. Murphy, What is the resource of second generation gaseous transport biofuels based on pig slurries in Spain? Applied Energy, Vol. 114, pp. 783$789,2014$.

[10] K.R. Salomon and E.E.S. Lora, Estimate of the electric energy generating potential or different sources of biogas in Brazil. Biomass and Bioenergy, Vol. 33, pp. 1101-1107,2009.

[11] G. Fongaro et al., Utility of specific biomarkers to assess safety of swine manure for biofertilizing purposes. Science of the Total Environment, Vol. 480, pp. 277-283, 2014. 
[12] EMBRAPA. Empresa Brasileira de Pesquisa Agropecuária - EMBRAPA. Accessed: 01/03/2017. http://www.agencia.cnptia.embrapa.br/gestor/agroenergia.

[13] L. Dong, Y. Zhenhong and S. Yongming, Semi-dry mesophilic anaerobic digestion of water sorted organic fraction of municipal solid waste. Bioresource Technology, Vol. 101, pp. 2722-2728, 2010.

[14] A. Teghamma et al., Pretreatment of paper tube residuals for improved biogas production. Bioresource Technology, Vol. 101, pp. 1206-1212, 2010.

[15] L.F. Calza et al., Cost assessment of biodigester implementation and biogas - produced energy. Journal of the Brazilian Association of Agricultural Engineering, , Vol. 35, pp. 990-997, 2015.

[16] D.S. Ribeiro, Determinação das dimensões de biodigestor em função da proporção da gás/fase líquida, Holos, Vol. 1, pp. 49-56, 2011.

[17] A.P.M. Oliver et al., Manual de treinamento em biodigestão. Access: 24/01/2017. http://docplayer.com.br/3948560-Manual-de-treinamento-em-biodigestao.html

[18] F. Martins and P. Oliveira, Economic analysis of the generation od eletric energy from biogas in pig production. Journal of the Brazilian Association of Agricultural Engineering, Vol. 31, pp. 477-486, 2011. 
462 10 $10^{\mathrm{TH}}$ International CONFERENCE on Sustainable ENERgy AND ENVIRONMENTAL Protection (June 27 $7^{\mathrm{TH}}-30^{\mathrm{TH}}, 2017$, Bled, Slovenia), Renewable EnERGy SOURCES 
$10^{\mathrm{TH}}$ InTERnational CONFERENCE ON Sustainable ENERgy AND ENVIRONMENTAL Protection (June $27^{\mathrm{TH}}-30^{\mathrm{TH}}$, 2017, Bled, SLOVENIA), RENEWABLE ENERGy SOURCES

J. Krope, A.Ghani Olabi, D. Goričanec \& S. Božičnik

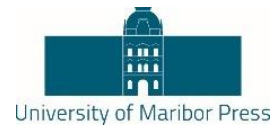

\title{
A Review on Solar Dryer - Economic and Environmental Investigation for the Lebanese Case
}

\author{
Amal Herez, Mahmoud Khaled, Hasan BaZI \& MoHAmad RAmadaN
}

Abstract In the present paper, a review on solar dryer is presented. The review comprises the principle and main components, classifications of solar dryer as well as its advantages and disadvantages. Moreover, an economic study is implemented for Lebanese case. The main purpose of the economic study is to compute the amount of money that will be saved by using solar dryers and its payback period where the affecting parameter is the percentage of time where solar dryer is utilized, and type of dried food. The results obtained showed that for Pr equal to 0.6, when drying 600 $\mathrm{kg}$ of bananas, cherries and peaches, the payback period was about 1.28 months, 0.48 months and 0.64 months respectively. Besides, an environmental analysis is developed to estimate the amount of carbon dioxide emission mitigated as function of percentage of time where solar dryer is used and type of food to be dried. It was obtained that for Pr equal to $60 \%$, drying $600 \mathrm{Kg}$ of bananas, cherries and peaches, leads to decrease in the amount of $\mathrm{CO} 2$ emissions by about $51120 \mathrm{Kg} / \mathrm{month}, 134190$ $\mathrm{Kg} / \mathrm{month}$ and $102240 \mathrm{Kg} / \mathrm{month}$ respectively.

Keywords: $\bullet$ Classification $\bullet$ Economy $\bullet$ Environment $\bullet$ Renewable Energy

- Review・Solar Dryers •

CORRESPONDENCE AdDRESS: Amal Herez, Ph.D student, Lebanese International University, School of Engineering, PO Box 146404 Beirut, Lebanon, amal.herez@liu.edu.lb. Mahmoud Khaled, Associate Professor, Lebanese International University, School of Engineering, PO Box 146404 Beirut, Lebanon, Univ Paris Diderot, Sorbonne Paris Cité, Interdisciplinary Energy Research Institute (PIERI), 10, rue Alice Domon \& Léonie Duquet, 75013 Paris, France, e-mail: mahmoud.khaled@liu.edu.lb. Mohamad Ramadan, Assistant Professor, Lebanese International University, School of Engineering, PO Box 146404 Beirut, Lebanon, Associate member at FCLAB, CNRS, Univ. Bourgogne Franche-Comte , 19 Avenue du Maréchal, Juin, 90016 Belfort cedex, France, e-mail: mohamad.ramadan@liu.edu.lb. Hasan Bazi, Associate Professor, Lebanese International University, School of Engineering, PO Box 146404 Beirut Lebanon, ahmad.haddad@liu.edu.lb. 
$10^{\text {TH }}$ International CONFEREnce on Sustainable Energy and Environmental Protection (June $27^{\mathrm{TH}}-30^{\mathrm{TH}}, 2017$, Bled, SLOVENIA), RENEWABle ENERGy SOURCES A. Herez, M. Khaled, H. Bazi \& M. Ramadan: A Review on Solar Dryer - Economic and Environmental Investigation for the Lebanese Case

\section{$1 \quad$ Introduction}

Due to the great tendency of rising cost of conventional sources of energy, and concerning there availability in the coming future, energy management [1-7] and utilization of renewable sources of energy [8-13] became the optimum solutions to solve energy crisis. Solar energy [14-19] is a renewable energy source which can be used to preserve food and simultaneously save energy for a sustainable world. Solar dryers [20-25] are an elegant technology derived from solar energy whose function is to dry agricultural products and preserve food. The key of drying is removing moisture from a product without affecting its flavour, texture and colour.

Due to the fact that Lebanon is one of the countries that suffers from fuel scarcity and economical deficiency, solar dryers must be utilized in Lebanon due to its great influence. From this point, this study aims to present a review on solar dryer concerning its principle and components, classification, advantages and disadvantages. Besides, economic and environmental analyses are developed to shed light on the significant role of solar dryers.

\section{Principle and Components of Solar Dryers}

The basic function of solar dryer is to rise the vapour pressure of moisture found inside the product and increase moisture carrying capacity of the drying air by decreasing its relative humidity [26].

In general, solar dryer is composed of three prime components which are the drying chamber where dried food are placed, air heater which heats the drying air and air flow system which exhausts the moist air to the surrounding.

\section{$3 \quad$ Classifications of Solar Dryers}

In this work solar dryers are classified according to method of air flow, mode of transferring heat from sun to the product and type of drying chamber. Figure 1 illustrates the different categories of solar dryers. Table 1 summarizes the comparison between passive and active solar dryers. 

Protection (June 27 $7^{\mathrm{TH}}-30^{\mathrm{TH}}, 2017$, BLED, Slovenia), RenEwABle ENERGy SOURCES A. Herez, M. Khaled, H. Bazi \& M. Ramadan: A Review on Solar Dryer - Economic and Environmental Investigation for the Lebanese Case

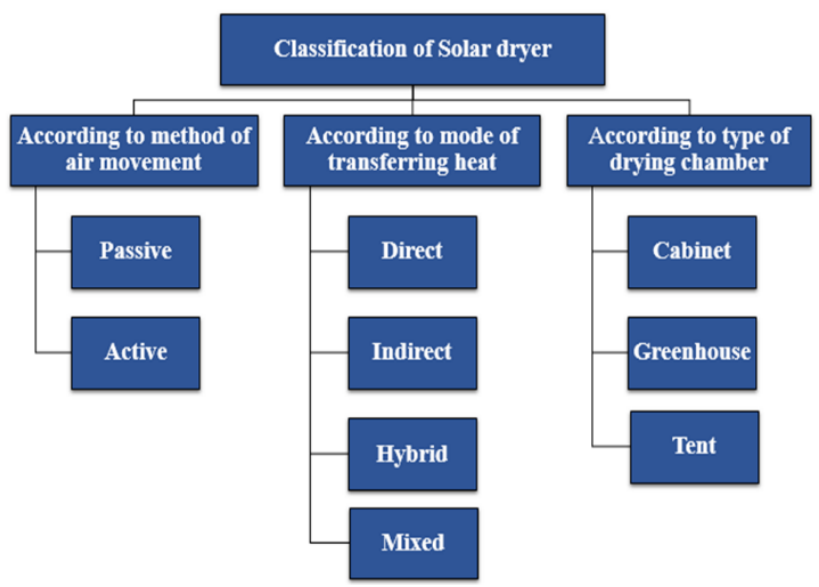

Figure 1. Classifications of solar dryers.

Table 1. Comparison between passive and active solar dryers

\begin{tabular}{|c|c|}
\hline Passive solar dryer & Active solar dryer \\
\hline $\begin{array}{l}\text { Depends on the natural movement of } \\
\text { air due to buoyancy force, wind } \\
\text { pressure difference, or combination } \\
\text { of them } \\
\text { - Known as natural convection solar } \\
\text { dryers } \\
\text { slow drying rate due to the slow } \\
\text { movement of air }\end{array}$ & $\begin{array}{l}\text { - Requires fans to duct air through the } \\
\text { dryer components which can be } \\
\text { mounted either at the inlet or at the } \\
\text { exit } \\
\text { - } \\
\text { higher drying rate compared to the } \\
\text { passive mode } \\
\text { needs electrical energy to drive the } \\
\text { fan }\end{array}$ \\
\hline
\end{tabular}

\subsection{Direct solar dryers}

Direct solar dryer is composed of a drying chamber which is covered by transparent glazing made up of plastic or glass [27]. In direct solar dryer, the product is placed in an enclosure of transparent cover. Solar radiation is absorbed by the material and the internal surfaces of the drying chamber, generating heat. Then heat evaporates moisture from the product and thus it is dried. Figure 2 presents a schematics of direct passive and direct active solar dryers respectively. 
$466 \quad 10^{\mathrm{TH}}$ International CONFERENCE on Sustainable ENERgy AND ENVIRONMENTAL Protection (June $27^{\mathrm{TH}}-30^{\mathrm{TH}}, 2017$, Bled, SLOVENIA), RENEWABle ENERGy SOURCES A. Herez, M. Khaled, H. Bazi \& M. Ramadan: A Review on Solar Dryer - Economic and Environmental Investigation for the Lebanese Case
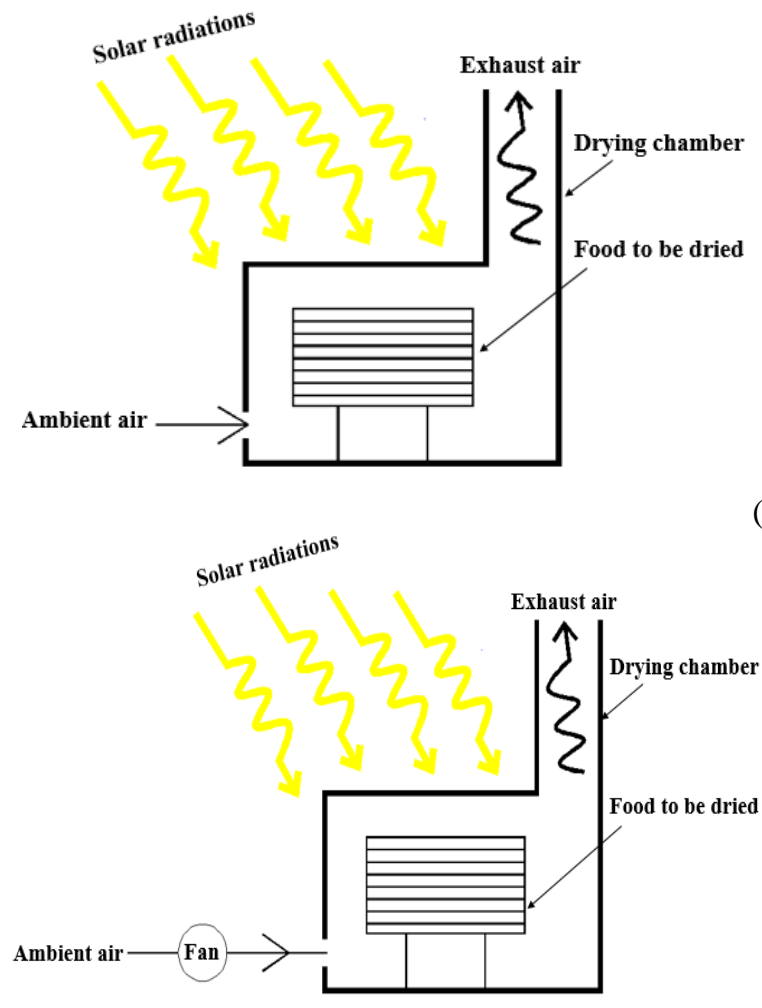

(a)

(b)

Figure 2. (a) Direct passive and (b) direct active solar dryers.

\subsection{Indirect solar dryers}

Indirect solar dryer [28] is made up of drying chamber which has opaque cover, fan and solar air heater/solar collector. Solar collector heats the atmospheric air, then warm air is ducted to the drying chamber by the fan (in active type) where it transfers heat to the material and evaporates moisture from it. Figure 3 shows a schematics of indirect passive and indirect active solar dryers respectively. 

Protection (June 27 $7^{\mathrm{TH}}-30^{\mathrm{TH}}, 2017$, BLed, Slovenia), RenEwable ENERGY SOURCES A. Herez, M. Khaled, H. Bazi \& M. Ramadan: A Review on Solar Dryer - Economic and Environmental Investigation for the Lebanese Case
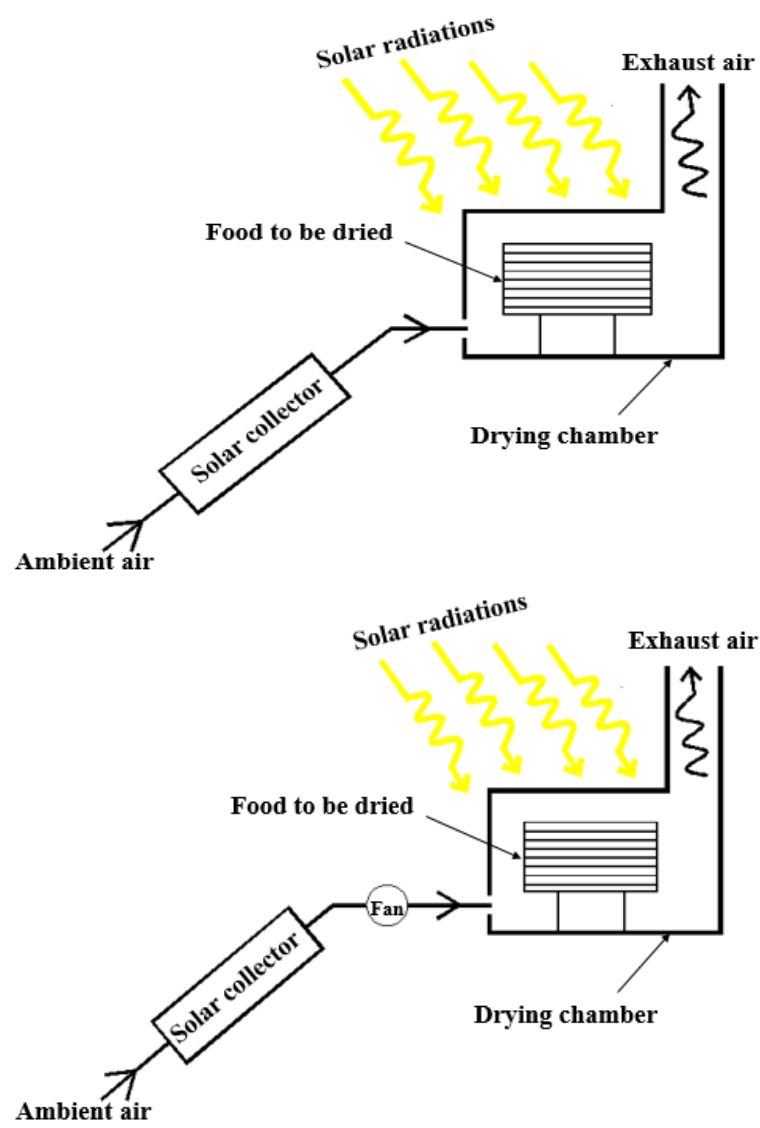

(a)

(b)

Figure 3. (a) Indirect passive and (b) indirect active solar dryers.

\subsection{Mixed solar dryers}

Mixed solar dryer is a combination of the direct and indirect types [29]. The cover of drying chamber in mixed dryer is transparent. In such dryer a separate collector preheats air before entering drying chamber and then sunlight adds heat to the products which will be dried.

\subsection{Hybrid solar dryers}

Hybrid solar dryers [30] are dryers that depend on solar energy and another source such as biomass or fossil fuel. Such dryers have the ability to operate without solar energy which reduce the risk of losing food. 
468 10 $10^{\mathrm{TH}}$ INTERNATIONAL CONFERENCE ON Sustainable ENERGy AND ENVIRONMENTAL Protection (June $27^{\mathrm{TH}}-30^{\mathrm{TH}}, 2017$, Bled, SLOVENiA), RENEWABle ENERGy SOURCES A. Herez, M. Khaled, H. Bazi \& M. Ramadan: A Review on Solar Dryer - Economic and Environmental Investigation for the Lebanese Case

\subsection{Cabinet solar dryers}

Cabinet solar dryer [31] is a large box made up of metal or wood. The products that will be dried are placed in shelves inside the chamber. Cabinet dryers may be of direct (transparent drying chamber) or indirect type (opaque drying chamber). Figure 4 demonstrates schematic diagrams for direct and indirect cabinet solar dryer respectively.

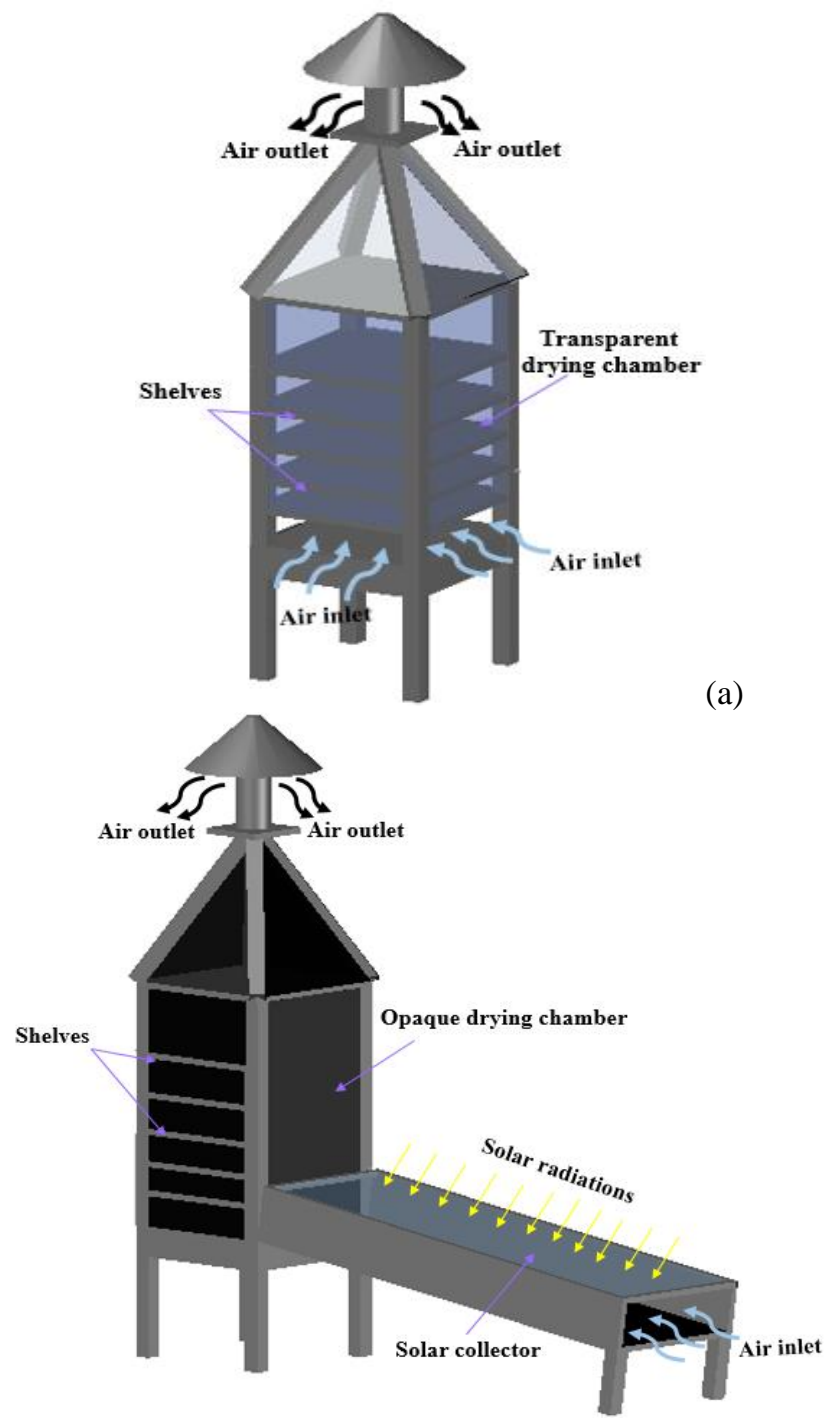

(b)

Figure 4. (a) Direct and (b) indirect cabinet solar dryers. 

Protection (June $27^{\mathrm{TH}}-30^{\mathrm{TH}}, 2017$, BLed, Slovenia), RenEwable Energy SOURCeS A. Herez, M. Khaled, H. Bazi \& M. Ramadan: A Review on Solar Dryer - Economic and Environmental Investigation for the Lebanese Case

\subsection{Greenhouse solar dryers}

Greenhouse dryer [32] is shown in figure 5, such dryer combines the operation of solar collector with greenhouse system. The dryer`s walls and roofs are manufactured from a transparent material such as glass, fiber glass, UV stabilized plastic or polycarbonate sheets.

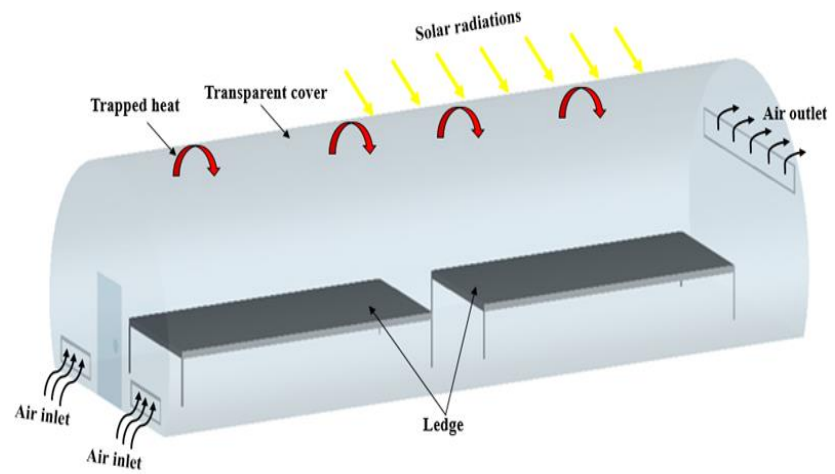

Figure 5. Green house solar dryer.

\subsection{Tent solar dryers}

Tent solar dryer consists of wooden pillars covered with plastic sheet, where the background plastic sheet has black colour to absorb more solar radiation. At the upper side of the tent a vent is applied to allow flow of air stream inside it. The products to be dried are located on a ledge above the ground [33]. Figure 6 illustrates a schematic diagram of tent solar dryer.

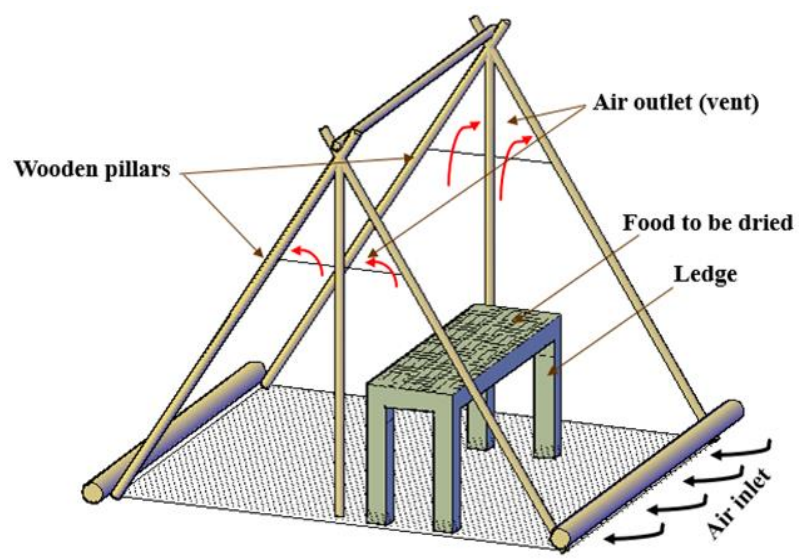

Figure 6. Tent solar dryer. 
$10^{\text {TH }}$ InTERnAtional CONFERENCE ON Sustainable ENERGy AND ENVIRONMENTAL Protection (June $27^{\mathrm{TH}}-30^{\mathrm{TH}}, 2017$, BlED, SLOVENIA), RENEWABLE ENERGy SOURCES A. Herez, M. Khaled, H. Bazi \& M. Ramadan: A Review on Solar Dryer - Economic and Environmental Investigation for the Lebanese Case

\section{$4 \quad$ Benefits and Limitations of Solar DRYERS}

Solar dryers are in general of relatively low cost and they are simply constructed [34, 35]. They dry food without affecting its flavour, texture or colour. Besides, solar dryers protect food from animals, insects, birds, rain and dust. Moreover, solar dryers reduce losses of products, promote longer storage duration and prevent spoilage of stored materials. Also, solar dryers mitigates consumption of conventional sources of energy such as fossil fuels, thus they save environment from drawbacks caused by fossil fuel usage. On the other hand, some limiting issues deteriorates the performance of solar dryers and affect negatively the drying rate. Solar dryers can be utilized only during day time where sufficient amount of solar radiation is available.

\section{$5 \quad$ Economic Analysis}

A typical dryer of $15 \mathrm{Kw}$ input power, $120 \mathrm{Kg} / \mathrm{batch}$ capacity and $50-140^{\circ} \mathrm{C}$ working temperature was taken under study. The study is performed to compute the amount of electrical energy consumed when drying several types of fruits and vegetables. Then, the cost of electric energy is calculated to estimate the money saved when replacing this conventional dryer by solar dryer. Besides, the payback period of solar dryer is calculated depending on the amount of saved money and the cost of solar dryer which have similar specifications as conventional dryer.

The energy consumed by electric dryer can be calculated using formulas of equations (1) and (2).

$$
E=P_{\text {input }} \cdot t
$$

where "E" is the energy consumed per day (Kw.hr/day), "Pinput" is the input power (Kw) and " $\mathrm{t}$ " is the time where the dryer is used per day (hr/day), it can be calculating from equation (2)

$$
t=\frac{M}{C} \cdot d
$$

where "M" is the mass of food that will be dried per day (it is equal to $600 \mathrm{Kg} /$ day). "C" is the capacity of the dryer $(\mathrm{Kg} / \mathrm{batch})$ and "d" is the duration needed for each batch to finish (hr/batch), it defers according to type of food. The studied food are bananas, cherries and peaches where each one requires 8,21 and 16 hours to be dried.

After computing energy consumed per day, energy consumed per month must be calculated to estimate the amount of money that could be saved monthly when utilizing solar dryer. Equations (3) and (4) represent calculations of energy consumed per month and amount of saved money, respectively. 
$E_{\text {month }}=E_{d a y} \cdot n_{w d}$

where "Emonth" is the energy consumed per month (Kw.hr/month) and "nwd" is the number of working days per month, it is equal to 20 days/month.

$S M=\operatorname{Pr} \cdot E_{m o n t h} \cdot P_{1 K w h r}$

Where "SM" is the saved money per month, "Pr" is the percentage where solar dryer is utilized where it is varied from 0.1 to 1 and "P1Kwhr" is the price of $1 \mathrm{Kw} . \mathrm{hr}$, in Lebanon it is equal to $0.0867 \$ / \mathrm{Kwhr}$ for industrial sectors

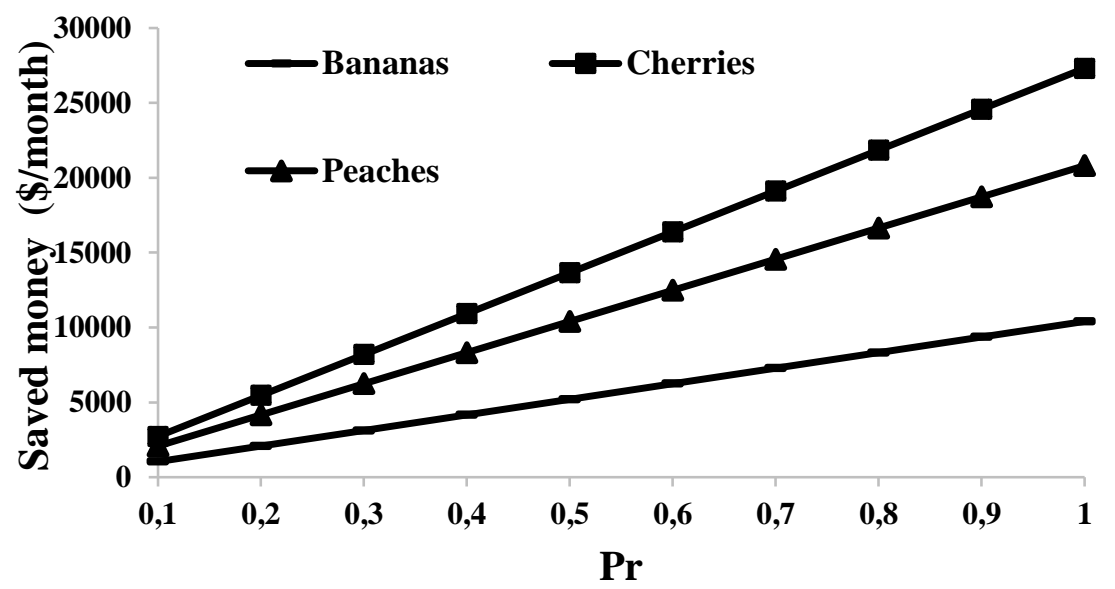

Figure 7. Variation of amount of saved money as function of Pr.

Figure 7 describes the variation of saved money as function of Pr for each type of food. It was obtained that the amount of saved money is dependent on Pr and type of dried food. In order of magnitudes, as Pr increased from 0.1 to 1 , the amount of saved money raised from $1040.4 \$$ month, $2731.05 \$ /$ month and 2080.8 \$ month to $10404 \$ /$ month, 27310.5 \$/month and 20808 \$/month for drying bananas, cherries and peaches respectively. For Pr equal to 0.6, the amount of saved money was $6242.4 \$ /$ month, 16386.3 \$/month and 12484.8 \$/month for drying bananas, cherries and peaches respectively.

The studied solar dryer is an indirect cabinet solar dryer type which has similar specifications as the electric dryer. Its cost is $8000 \$$. To calculate the payback period of such dryer formula of equation (5) can be used.

$P P=\frac{C_{s d}}{S M}$ 
$10^{\text {TH }}$ International CONFEREnce on Sustainable Energy and Environmental Protection (June $27^{\mathrm{TH}}-30^{\mathrm{TH}}, 2017$, Bled, Slovenia), RenEwable ENERGy SOURCES A. Herez, M. Khaled, H. Bazi \& M. Ramadan: A Review on Solar Dryer - Economic and Environmental Investigation for the Lebanese Case

where "PP" is the payback period and "Csd" is the cost of solar dryer (8000\$).

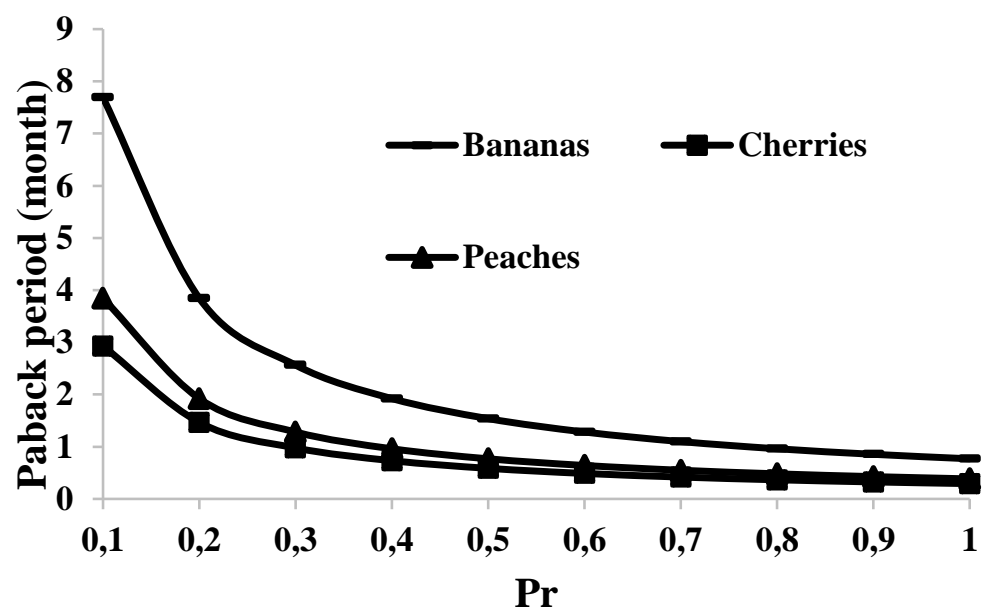

Figure 8. Variation of payback period as function of $\mathrm{Pr}$.

Figure 8 presents the payback period as function of Pr for each type of food. The results reveals that the payback period is affected by $\mathrm{Pr}$ and type of dried food. For illustration, as $\mathrm{Pr}$ increased from 0.1 to 1 , the payback period decreased from approximately 7.7 months, 2.9 months and 3.8 months to 0.76 months, 0.29 months and 0.38 months for drying bananas, cherries and peaches respectively. For Pr equal to 0.6, the amount of payback period was about 1.28 months, 0.48 months and 0.64 months for drying bananas, cherries and peaches respectively.

\section{Environmental Analysis}

To size the environmental influence of solar dryer, a study is done on the aforementioned electrical dryer to compute the amount of carbon dioxide produced per month. Thus, by replacing this dryer by a solar dryer carbon dioxide emission will be mitigated.

The amount of $\mathrm{CO}_{2}$ produced ( $M_{\text {produced }} \mathrm{CO}_{2}$ ) and amount of minimization in carbon dioxide emission $\left(M_{\text {reduced } \mathrm{CO}_{2}}\right)$ can be calculated from equations (5) and (6) respectively.

$$
M_{\text {produced } \mathrm{CO}_{2}}=E_{\text {month }} \cdot M_{\mathrm{CO}_{2} / 1 \mathrm{Kwhr}}
$$

where " " is the amount of $\mathrm{CO} 2$ produced from $1 \mathrm{kWhr}$ electricity. In Lebanon it is estimated to be about $0.71 \mathrm{Kg} \mathrm{CO} 2 / 1 \mathrm{kWhr}$ 
$M_{\text {reduced } \mathrm{CO}_{2}}=P_{r} \cdot M_{\text {produced } \mathrm{CO}_{2}}$

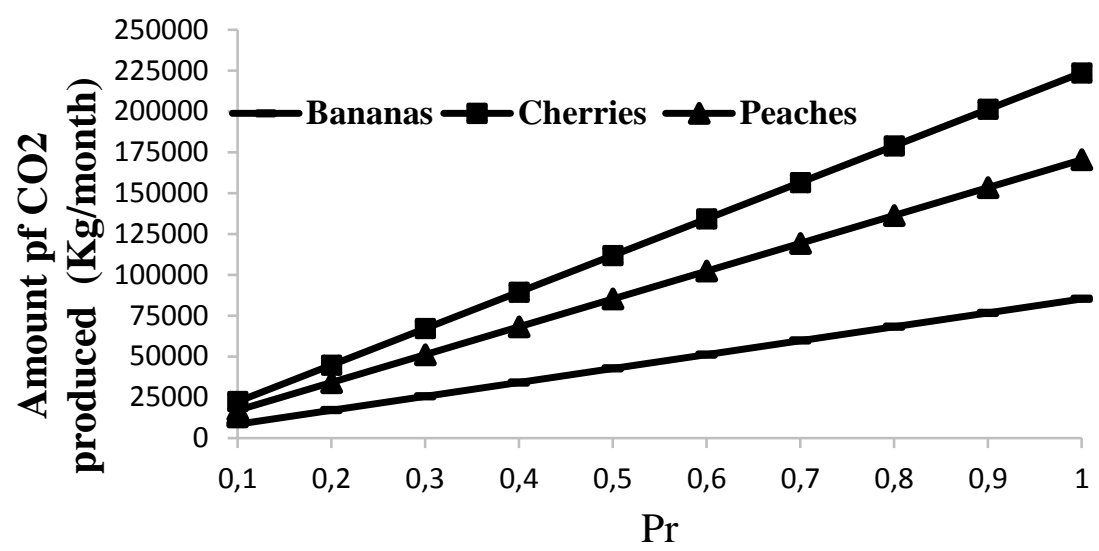

Figure 9. Variation of amount of reduced $\mathrm{CO}_{2}$ emissions as function of $\mathrm{Pr}$.

Figure 9 represents the variation of reduced $\mathrm{CO}_{2}$ emissions as function of Pr. For drying $600 \mathrm{Kg}$ of food, utilizing solar dryer for $60 \%$ of the drying time will lead to decrease in carbon dioxide emissions approximately $51120 \mathrm{Kg} / \mathrm{month}, 134190 \mathrm{Kg} / \mathrm{month}$ and $102240 \mathrm{Kg} / \mathrm{month}$ for bananas, cherries and peaches respectively. While 76680 $\mathrm{Kg} /$ month, $201285 \mathrm{Kg} / \mathrm{month}$ and $153360 \mathrm{Kg} /$ month of $\mathrm{CO}_{2}$ emissions will be minimized from drying the aforementioned foods and for Pr equal to $90 \%$. Thus, it can be concluded from the analysis above that the amount of reduced $\mathrm{CO}_{2}$ emissions increases as solar dryer is more utilized.

\section{$7 \quad$ Conclusions}

A review on solar dryers was presented in this work. Principle, components and various classifications of solar dryer has been reported. In addition to that, benefits and limitations of solar dryers has been described. Besides, an economic and environmental analyses has been conducted to quantify the effects of utilizing solar dryer.

A typical electrical dryer was taken under consideration to compute the amount of electric energy consumed when drying $600 \mathrm{Kg}$ of bananas, cherries and peaches. Then, the amount of saved money was calculated when replacing this dryer by solar dryer. An indirect cabinet solar dryer of similar specifications of electrical dryer has been studied to calculate the payback period. It was shown that the payback period decreased from approximately 7.7 months, 2.9 months and 3.8 months to 0.76 months, 0.29 months and 0.38 months for drying $600 \mathrm{~kg}$ of bananas, cherries and peaches respectively, when $\mathrm{Pr}$ increased from 0.1 to 1 . 
$10^{\text {TH }}$ International Conference on Sustainable Energy and Environmental Protection (June $27^{\mathrm{TH}}-30^{\mathrm{TH}}, 2017$, Bled, SLOVEnia), RENEWABle ENERGy SOURCES A. Herez, M. Khaled, H. Bazi \& M. Ramadan: A Review on Solar Dryer - Economic and Environmental Investigation for the Lebanese Case

Besides, the environmental study was performed on the aforementioned dryers to estimate the decrease in the amount of $\mathrm{CO} 2$ gas produced when using solar dryer instead of electrical one. It was shown that for drying $600 \mathrm{Kg}$ of bananas, cherries and peaches, $51120 \mathrm{Kg} /$ month, $134190 \mathrm{Kg} / \mathrm{month}$ and $102240 \mathrm{Kg} / \mathrm{month}$ of $\mathrm{CO} 2$ emissions will be minimized respectively, for Pr equal to $60 \%$.

\section{References}

[1] M. Ramadan, T. Lemenand, and M. Khaled, "Recovering heat from hot drain waterExperimental evaluation, parametric analysis and new calculation procedure," Energy and Buildings, vol. 128, pp. 575-632, 2016.

[2] M. Ramadan, M. Gad El Rab, and M. Khaled, "Parametric analysis of air-water heat recovery concept applied to HVAC systems: Effect of mass flow rates," Case Studies in Thermal Engineering, vol. 6, pp. 61-68, 2015.

[3] M. Khaled, M. Ramadan, and H. El Hage, "Parametric analysis of heat recovery from exhaust gases of generators," Energy Procedia, vol. 75, pp. 3295-3300, 2015.

[4] M. Khaled, M. Ramadan, K. Chahine, and A. Assi, "Prototype implementation and experimental analysis of water heating using recovered waste heat of chimneys," Case Studies in Thermal Engineering, vol. 5, pp. 127-133, 2015.

[5] H. Jaber, M. Khaled, T. Lemenand, and M. Ramadan, "Short review on heat recovery from exhaust gas," presented at International Conference on Technologies and Materials for Renewable Energy, Environment and Sustainability, Beirut, Lebanon, 2016.

[6] M. Ramadan, M. Khaled, and H. El Hage, "Using speed bump for power generation Modeling and experimental study,” Energy Procedia, vol. 75, pp. 867-872, 2015.

[7] M. Khaled, and M. Ramadan, "Heating fresh air by hot exhaust air of HVAC systems," Case Studies in Thermal Engineering, vol. 8, pp. 398-402, 2016.

[8] Y. He, Y. Xu, Y. Pang, H. Tian, and R. Wu, "A regulatory policy to promote renewable energy consumption in China: Review and future evolutionary path," Renewable Energy, vol.89, pp. 695-705, 2016.

[9] D. Li, J. He, and L. Li, "A review of renewable energy applications in buildings in the hotsummer and warm-winter region of China," Renewable and Sustainable Energy Reviews, vol.57, pp. 327-336, 2016.

[10] M. Pacesila, S. G. Burcea, and S. E. Colesca, "Analysis of renewable energies in European Union,” Renewable and Sustainable Energy Reviews, vol. 56, pp. 156-170, 2016.

[11] Y. Kuang, Y. Zhang, B. Zhou, C. Li, Y. Cao, L. Li, and L. Zeng, "A review of renewable energy utilization in islands," Renewable and Sustainable Energy Reviews, vol. 59, pp. 504-513, 2016.

[12] A. Zamfir, S. E. Colesca, and R. A. Corbos, "Public policies to support the development of renewable energy in Romania: A review," Renewable and Sustainable Energy Reviews, vol. 58, pp. 87-106, 2016.

[13] Y. C. Solorzano, J. P. Sanchez, A. J. Trashorras, and J. X. Bernat, "The development of renewable energy resources in the State of Veracruz, Mexico," Utilities Policy, vol. 39, pp. 1-4, 2016.

[14] A. Herez, M. Ramadan, B. Abdulhay, and M. Khaled, "Short review on solar energy systems," presented at International Conference on Technologies and Materials for Renewable Energy, Environment and Sustainability, Beirut, Lebanon, 2016. 
[15] M. Ramadan, M. Khaled, H. S. Ramadan, and M. Becherif, "Modeling and sizing of combined fuel cell-thermal solar system for energy generation," International Journal of Hydrogen Energy, vol. 41, pp. 19929-19935, 2016.

[16] M. Grágeda, M. Escudero, W. Alavia, S. Ushak, and V. Fthenakis, "Review and multicriteria assessment of solar energy projects in Chile," Renewable and Sustainable Energy Reviews, vol. 59, pp. 583-596, June. 2016.

[17] A. Qazi, H. Fayaz, A. Wadi, R. G. Raj, N.A. Rahim, and W. A. Khan, "The artificial neural network for solar radiation prediction and designing solar systems: a systematic literature review," Journal of Cleaner Production, vol. 104, pp. 1-12, 2015.

[18] A. Meskani, A. Haddi, and M. Becherif, "Modeling and simulation of a hybrid energy source based on solar energy and battery," International Journal of Hydrogen Energy, vol. 40, pp. 13702-13707, 2015.

[19] D. M. Plaza, I. C. Martinez, G. M. Gasch, F. T. Sufrategui, and J. R. García, “A case study of the feasibility of using solar concentrating technologies for manufacturing ceramics," Journal of Cleaner Production, vol. 87, pp. 977-991, 2015.

[20] O. Prakash, V. Laguri, A. Pandey, A. Kumar, and A. Kumar, "Review on various modelling techniques for the solar dryers," Renewable and Sustainable Energy Reviews vol. 62, pp. 396-417, 2016.

[21] P. S. Chauhan, A. Kumar, and P. Tekasakul, "Applications of software in solar drying systems: A review," Renewable and Sustainable Energy Reviews, vol. 51, pp. 1326-1337, 2015.

[22] G. Pirasteh, R. Saidur, S. M. A. Rahman, and N. A. Rahim, "A review on development of solar drying applications," Renewable and Sustainable Energy Reviews, vol. 31, pp. 133148, 2014.

[23] M. Hedayatizadeh and H. Chaji, "A review on plum drying," Renewable and Sustainable Energy Reviews, vol. 56, pp. 362-367, 2016.

[24] A. D. Chaudhari and S. P. Salve, "A Review of Solar Dryer Technologies," International Journal of Research in Advent Technology, vol. 2, pp. 218-232, 2014

[25] M. Kumar, S. K. Sansaniwal, and P. Khatak, "Progress in solar dryers for drying various commodities," Renewable and Sustainable Energy Reviews, vol. 55, pp. 346-360, 2016.

[26] A. Sangamithra, G. J. Swamy, R. S. Prema, R. Priyavarshini, V. Chandrasekar, and S. Sasikala, "An overview of a polyhouse dryer," Renewable and Sustainable Energy Reviews, vol. 40, pp. 902-910, 2014.

[27] M. Zarezade, and A. Mostafaeipour, "Identifying the effective factors on implementing the solar dryers for Yazd province, Iran," Renewable and Sustainable Energy Reviews, vol. 57, pp. 765-775, 2016.

[28] B. K. Bala, and N. Debnath, "Solar Drying Technology: Potentials and Developments," Journal of Fundamentals of Renewable Energy and Applications, vol. 2, pp. 1-5, 2012.

[29] J. Stiling, S. Li, P. Stroeve, J. Thompson, B. Mjawa, K. Kornbluth, and D. M. Barrett, "Performance evaluation of an enhanced fruit solar dryer using concentrating panels," Energy for Sustainable Development, vol. 16, pp. 224-230, 2012.

[30] A. Reyes, A. Mahn, and F. Vásquez, "Mushrooms dehydration in a hybrid-solar dryer, using a phase change material," Energy Conversion and Management, vol. 83, pp. 241248, 2014.

[31] A. Ghaffari and R. Mehdipour, "Modeling and Improving the Performance of Cabinet Solar Dryer Using Computational Fluid Dynamics," Int. J. Food Eng., vol. 11, pp. 157-172, 2015.

[32] R. Patil and R. Gawande, “A review on solar tunnel greenhouse drying system," Renewable and Sustainable Energy Reviews, vol. 56, pp. 196-214, 2016. 
476 10 $10^{\mathrm{TH}}$ INTERNATIONAL CONFERENCE ON Sustainable ENERGy AND ENVIRONMENTAL Protection (June $27^{\mathrm{TH}}-30^{\mathrm{TH}}, 2017$, BLED, Slovenia), RENEWABLE ENERGY SOURCES A. Herez, M. Khaled, H. Bazi \& M. Ramadan: A Review on Solar Dryer - Economic and Environmental Investigation for the Lebanese Case

[33] U. Toshniwal and S. R. Karale, “A review paper on solar dryer," International Journal of Engineering Research and Applications, vol. 3, pp.896-902, 2013.

[34] A. Yataganbaba and İ. Kurtbaş, "A scientific approach with bibliometric analysis related to brick and tile drying: A review," Renewable and Sustainable Energy Reviews, vol. 59, pp. 206-224, 2016.

[35] A. Tiwari, "A Review on Solar Drying of Agricultural Produce," Journal of Food Processing \& Technology, vol. 7, pp. 1-12, 2016. 
$10^{\mathrm{TH}}$ InTERnational CONFERENCE ON Sustainable ENERgy AND ENVIRONMENTAL Protection (June $27^{\mathrm{TH}}-30^{\mathrm{TH}}$, 2017, Bled, SLOVENIA), RENEWABLE ENERGy SOURCES

J. Krope, A.Ghani Olabi, D. Goričanec \& S. Božičnik

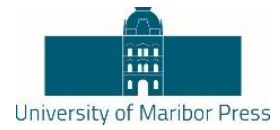

\title{
Geospatial Characteristics Investigation of Suitable Area for Photovoltaic Water Pumping Erections, in the Southern Area of Ghardaia, Algeria
}

\author{
AZZEDINE BouTELHIG \& AICHA MELIT
}

\begin{abstract}
When sizing a pumping system fed by renewable source, the onsite feasibility of the system has to be assessed. The standard sizing of a photovoltaic water pumping system (PVPS) is generally based on the required daily quantity of water and the total dynamic head of the well or borehole. However, the feedback following different on-site operating tests proved that any deficiency of information, regarding the specifics of the soil, water source behaviour, the materials, the techniques used in irrigation and domestic consumption result an imbalance in the system performance. Accordingly, geospatial characteristics investigation has been conducted in the Mansoura desert area, about $70 \mathrm{~km}$ south of Ghardaia headquarter. The main goal was to select the feasibility areas suitable for implementing PVPS installations. The evaluation study has been carried out on six zones; namely: Ain Losseik, Old Mansoura, New Mansoura, Oued Ghazalat, Khanget-fedj and Zawiat Lacheikh. The study consists on census and classifying the wells or boreholes according to the statistical water source levels, the land specifics and kind of activity. The obtained results averred that the water averages level vary between $20 \mathrm{~m}$ and $45 \mathrm{~m}$, for renewable aquifer, in small scale irrigated land and livestock grassland. However, the Albian borehole static level varies between $3 \mathrm{~m}$ and $8 \mathrm{~m}$, in large irrigated areas. The classification of different DC pump models indicate that the photovoltaic powered water pumping systems can provide high contribution to supply water for different purposes.
\end{abstract}

Keywords: - on-site feasibility $\bullet$ geospatial characteristics $\bullet$ suitable • implementing PVPS • Algeria •

CORRESPONDENCE ADDRESS: Azzedine Boutelhig, Senior researcher, Unité de Recherche Appliquée en Energies Renouvelables, URAER, Centre de Développement des Energies Renouvelables, CDER, 47133, Ghardaïa, Algeria, e-mail: boutelhig@yahoo.com. Aicha Melit, researcher, Unité de Recherche Appliquée en Energies Renouvelables, URAER, Centre de Développement des Energies Renouvelables, CDER, 47133, Ghardaïa, Algeria, e-mail: m_maicha1555@yahoo.fr. 
$10^{\text {TH }}$ InTERnAtional CONFERENCE ON Sustainable ENERgy AND ENVIRONMENTAL Protection (June $27^{\mathrm{TH}}-30^{\mathrm{TH}}, 2017$, Bled, SLOVENIA), RENEWABle ENERGY SOURCES A. Boutelhig \& A. Melit: Geospatial Characteristics Investigation of Suitable Area for Photovoltaic Water Pumping Erections, in the Southern Area of Ghardaia, Algeria

Algeria is one among the solar belt countries that enjoys with high availability of solar intensity, wind and huge water potential sources, in particular in the desert region. However, the lack of access to energy and to safe water in these areas causes the instability of the citizen and then the phenomenon of rural depopulation is appeared as great challenge. As consequence, it affects land degradation and desertification, including reduction in the crop yield and livestock ranching, loss of biodiversity, food and water insecurity, threat of climate changes, particularly, in the arid, semi-arid and sub-humid areas $[1,2]$. Recently, Algeria is engaged to go straight ahead towards the sustainable energy whereas, an ambitious program to develop and promote the renewable energy systems has been set [3]. As a target, the country aims to generate $40 \%$ of its total electricity production from renewable sources by the year 2030. Within the objective among the world target to reach the $100 \%$ renewable energy [4,5], the promotion of the standalone Photovoltaic/Wind Pumping Systems (PVPS) for domestic use, livestock and in irrigation presents a promising option for stretching it through the large remote desert areas. Indeed, various studies were conducted on the design and implementation of photovoltaic water pumping systems (PVPS), in the goal to be erected in the remote high lands and Sahara, especially in the zones far away from the national electrical grid connection [6,7]. However, various unexpected constraints and problems arose when the system is on-site operated which led to deficiency and then ended to total failure. In this view, different research works have been reported to promote the on-site system performances upon the experimental through the Algerian territory $[8,9]$. The unforeseen problems emerged during the on-site real operating system prompt the advanced research on the real time control of the system performances. Accordingly, a review of research works has been conducted by Dhiaa H. Muhsena et al [10], which concluded several PVPS findings performance whereas the overall system's efficiency average is about $3.4 \%$ and average annual productivity rate of $6580.611 \mathrm{~m}^{3} / \mathrm{kWp}$. P.E. Campana et al. [11] proposed a novel optimization procedure taking into consideration the investment cost of the PVPS as well as the income from crop sale, beyond the effect of water supply on crop yield and the availability of groundwater. In the meanwhile, Campana and Yan [12] applied a model to compare the technical and economic suitability of such systems on degraded grassland in China, based on irrigation water requirements (IWR) solar irradiation and wind speed. They found that the crop yield is essential for both economic assessment and the selection of the technology. Ayub et al. [13] have studies the technical and economic suitability of four submersible solar pumps $(1050 \mathrm{Wp})$ for irrigating rice, wheat and vegetables, in different locations of Bangladesh and they concluded that PVPS is economically suitable for tomato but not for rice. The divergences of various objectives prompt the PVPS optimal sizing researches to require more information data on multiobjective, as reliability and cost parameters. In this view, an algorithm to optimize three multi-objectives has been developed by Dhiaa H. Muhsena et al. [14], where, the performance results show that the loss of load probability and the water flow rate average over a year time are around $0.5 \%$ and $3.297 \mathrm{~m}^{3} / \mathrm{h}$, respectively. The same author, proposed a multi-objective optimization algorithm which combines technical and economic objectives to optimally size PVPS installations (Loss of load probability and 
life cycle cost), whereas the loss of load probability has attained around $0.5 \%$. Ceyda Olcan [15] has extended the techno-economic optimization of the PVPS by developing a model which able to find a compromise solution, using water storage tank, in Antalya, Turkey. Thus on basis the 5-years applications, it has been shown that sizing results are technically and economically more suitable than computational algorithm. Nevertheless, in recent years the dimensioning of such system becomes a complex task, due to the increased demanded information data. Hence, beyond a long solar radiation assessment and accurate estimation of crop needs on water, the soil aridity, the degree of salinity, technique and period of irrigation, the seasonal variation of the optimum tilt angle, kind of activity, kind of vegetation and livestock, as well as the citizenship social life, etc... need to be involved a complete feasibility study. Within this frame, a feasibility study to set up a solar irrigation in Mongolia of China, conducted by $\mathrm{He} \mathrm{Xu}$ et al. [16] whereas, the coefficients and parameters data are related to meteorological factors, vegetation types, kind of areas and soil properties. This method has been adopted in the feasibility, undertaken on a standalone direct PV-powered water pumping system for irrigation in Mediterranean greenhouses. In this meanwhile, geospatial characteristics has been carried out on Mansoura area, the southern part of Ghardaia, in the purpose to census and quantify the renewable water sources, suitable for eventual PV water pumping system installations.

\section{Area of the Case Study}

The map of studied area "Mansoura" is illustrated by the map of the Fig.1, in the below. 

$10^{\text {TH }}$ International CONFEREnce on Sustainable Energy and Environmental Protection (June $27^{\mathrm{TH}}-30^{\mathrm{TH}}, 2017$, Bled, SLOVENIA), RENEWABle ENERGy SOURCES A. Boutelhig \& A. Melit: Geospatial Characteristics Investigation of Suitable Area for Photovoltaic Water Pumping Erections, in the Southern Area of Ghardaia, Algeria

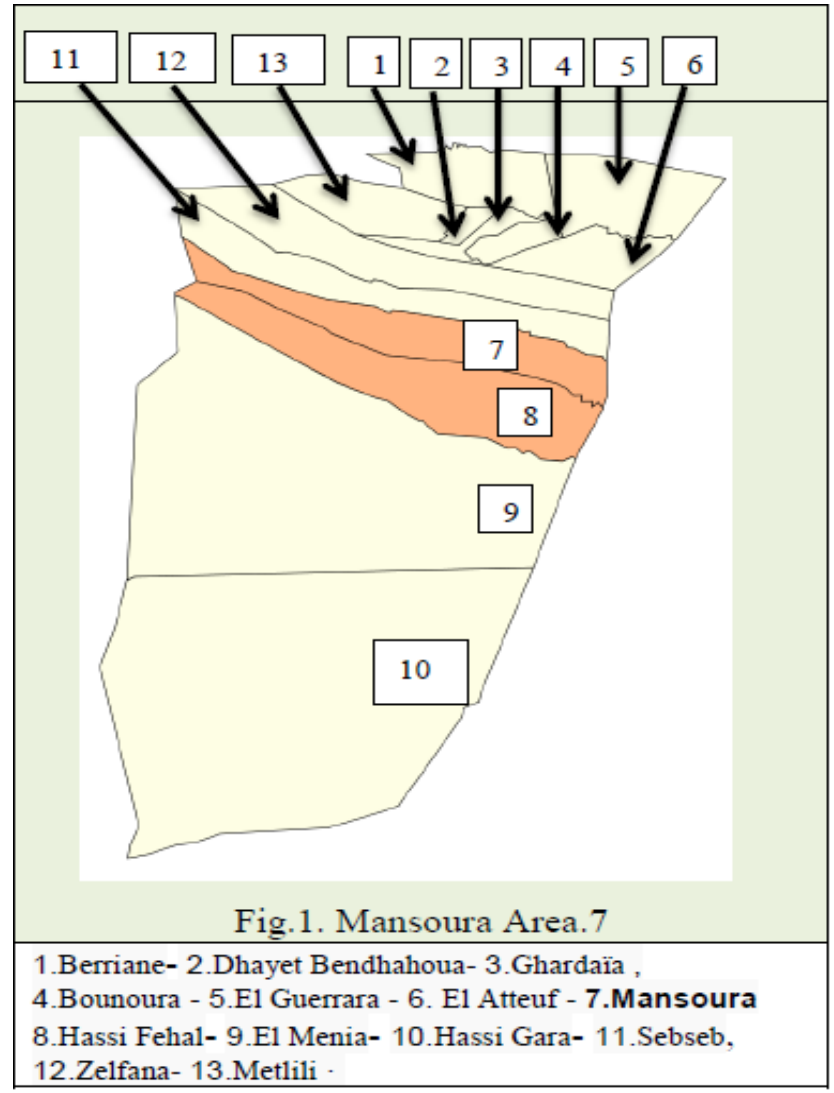

Daira of Mansoura is an administrative division of Ghardaia Wilaya (Province), situated in the middle southern part of Ghardaia headquarter city. It consists of two municipalities (Mansoura and Hassi-Lafhal) and extended on total area of about $13215 \mathrm{~km}^{2}$. Mansoura municipality is the area of study which stretched on area of about $6500 \mathrm{~km}^{2}$. The municipality headquarter is located about $70 \mathrm{~km}$ south of Ghardaia city, between Latitude $31^{\circ} 58^{\prime} 46^{\prime \prime}$ north and Longitude $3^{\circ} 44^{\prime} 46^{\prime \prime}$ east, at an altitude of about $700 \mathrm{~m}$. The area consists of rocky land in the north part involving different valleys, as old Mansoura valley, Oued Ghazalat and Ain Losseik. The area is sandy and fertile in the southern part. It is among the largest groundwater reservoir "Albian", called Tidikelt region which includes El-Ménéa, Adrar and Ghardaia and it contains pure water lying at small depths $(100-400 \mathrm{~m})$ from the surface. The area has also great abundant phreatic water sources, in shallow static depths varying between $20 \mathrm{~m}$ and $45 \mathrm{~m}$.

The methodology consists onto three main parts: the first is identifying of the studied zones, according to the location and geospatial characteristic distribution. The second 
part is the field analysis which focuses on census and classifying the wells and boreholes according to their types, static levels, the techniques used in irrigation and the kind of activity. Finally the third part consists on the evaluation of the optimal locations suitable for implementing the PV water pumping systems.

\subsection{Identification of the studied zones}

The total studied area is divided into six geographical zones. Each zone has its own geospatial characteristics, involving the same soil type, same groundwater depth and same activity. Spatial map of the mentioned zones is depicted in the fig.2.

\section{Zone 1. Ain Losseik}

Ain Losseik depicted in the map as the Zone 1, is an excellent agricultural area, situated about $3 \mathrm{Km}$, in the south of Mansoura headquarter at the side of the National road $\mathrm{N}^{\circ} 1$. It involves various farmlands and grasslands. The zone has huge phreatic water source as well as an Albian water reserve. The supply of water is intaken from a number of new boreholes. The soil is sandy and favourable for different kind of agriculture.

\section{Zone 2. Oued Ghazalat}

The Zone 2, called Oued Ghazalat is new large rehabilitated farmlands, located in the north east of the Municipality headquarter, at about $7 \mathrm{~km}$ far away. The soil is sandy and fertile, where different kind farms have been created, due to the huge abundance of both Albian and phreatic groundwater sources. The drip irrigated modern of large scale agriculture is the most dominant activity. The used dynamic head of bores is generally around an average of $100 \mathrm{~m}$.

\section{Zone 3. Old Mansoura}

Old Mansoura, depicted by the Zone 3, situated at $23 \mathrm{~km}$ in the west of Mansoura headquarter. It is the main old discovered area, due to its important spatial data of population and livestock density, taking into account the low static level average forage intake. Small and large scale agriculture activities extended along the old Mansoura valley (Oasis, peanuts and local vegetables), adding to livestock ranching of various kind of cattle. The supply of water is generally extracted from traditional wells.

\section{Zone 4. New Mansoura}

New Mansoura, depicted by the Zone.4, has the same geospatial characteristic area as the zone 3.It is divided in two areas; the first area is extension of the old Mansoura valley which have the same static water levels, the second is an another valley where, the water static level wings between 35 and $40 \mathrm{~m}$. The large scale agriculture and livestock ranching is the main activity. 
$10^{\text {TH }}$ International Conference on Sustainable Energy and Environmental Protection (June $27^{\mathrm{TH}}-30^{\mathrm{TH}}, 2017$, Bled, SLOVENIA), RENEWABLE ENERGy SOURCES A. Boutelhig \& A. Melit: Geospatial Characteristics Investigation of Suitable Area for Photovoltaic Water Pumping Erections, in the Southern Area of Ghardaia, Algeria

\section{Zone 5. Khanguet-fedj}

Khnaguet-fedj, depicted by the Zone 5, is new area offered by the Mansoura Municipality for large scale irrigated agriculture, situated about $16 \mathrm{~km}$ south of the headquarter. Currently two farms started in exploiting the area for different kind of flora. The albian borehole static level varies between $3 \mathrm{~m}$ and $8 \mathrm{~m}$.

\section{Zone 6. Zawiat Lacheikh}

Located in extension of sebseb valley, $17 \mathrm{Km}$, far away from the Mansoura headquarter, the 6th zone, called Zawiat Lacheikh It is an isolated site which involves small citizen agglomeration, mosque and Coranic Zawia as well as raw of traditional houses for visitor accommodation.

\subsection{Groundwater field assessment}

The field study consists on field census of the number and type of boreholes, water static level, techniques used in irrigation and kind of irrigated crops. The distribution of the number wells or boreholes and the rate of distribution according to each zone are illustrated in the following fig. 3 and fig. 4 , respectively.

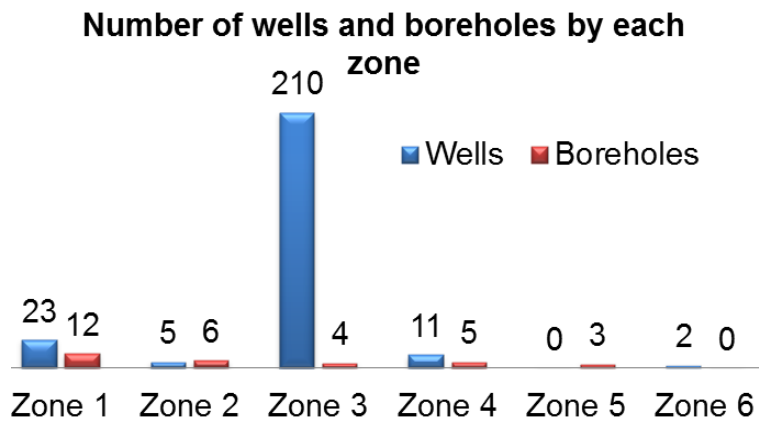

Fig. 3. Distribution of the wells and boreholes 


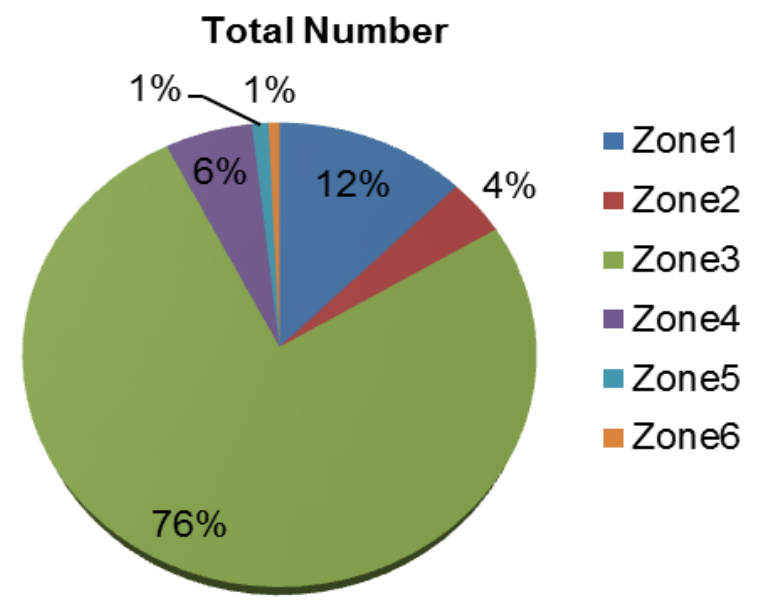

Fig. 4. Rate distribution of each zone

Zone 1: Ain losseik involves a total number of 35 bores, divided into 23 bores within static level average is about $45 \mathrm{~m}$ and dynamic head average of about $90 \mathrm{~m}$ and 12 Albian boreholes, whereas, the static water level of 4 boreholes are within average nexus $20 \mathrm{~m}$. Both drop irrigation and water gravity supply from storage tank are the used techniques in irrigation.

Zone 2: Oued Ghazalat has a total number of 11 bores comprising 5 wells and 6 boreholes. The static water levels of wells vary between $40 \mathrm{~m}$ and $45 \mathrm{~m}$. Large scale irrigation

Zone 3: Old Mansoura has total number of 214 bores, whereas 210 traditional wells, 4 bores and Albian boreholes. The static water level average varies between $20 \mathrm{~m}$ and 25 $\mathrm{m}$. The gravity water irrigation from stored tank is the old used technique, but due to the increased lack of the ground water table, the drip irrigation is currently adopted.

Zone 4: New Mansoura has 16 bores involving 11 wells and 5 boreholes. The static water level average varies between $35 \mathrm{~m}$ and $40 \mathrm{~m}$. In this zone the modern technique is adopted for both irrigation and in water supply for citizen.

Zone 5: Khnaguet-fedj comprises 3 boreholes. 2 boreholes are exploited by their owners and the third belongs to the Municipality service for urgent water supply. The static water level varies between $3 \mathrm{~m}$ and $8 \mathrm{~m}$. Drip irrigation is the most used technique. The energy supply is undertaken by electromagnetic pump.

Zone 6: Zawiat lacheikh comprises two wells with water static level of about $50 \mathrm{~m}$. used for local domestic consumption. 
$10^{\text {Th }}$ International Conference on Sustainable Energy and Environmental Protection (June $27^{\mathrm{TH}}-30^{\mathrm{TH}}, 2017$, Bled, SLOVENIA), RENEWABle ENERGy SOURCES A. Boutelhig \& A. Melit: Geospatial Characteristics Investigation of Suitable Area for Photovoltaic Water Pumping Erections, in the Southern Area of Ghardaia, Algeria

\subsection{Evaluation of the optimal locations}

Based on the geospatial characteristics data obtained following the feasibility study carried out on the Mansoura area, the optimal locations suitable for implementing the PVPS can be selected, according to the average static levels and the irrigation water requirement, the effect of water on crop yield and cost. The average static water levels for each zone are presented by the following histograms of the fig.5.

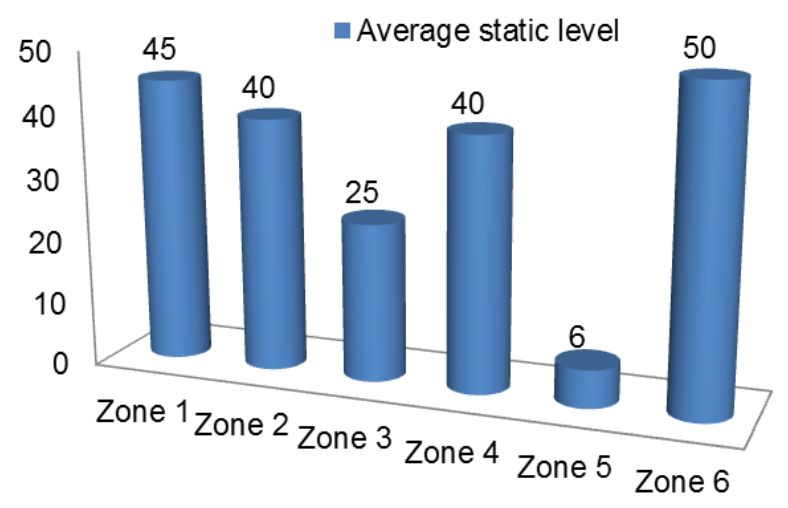

Fig. 5. Averages of static level per zone

Since the optimal areas have been identified, the PVPS can be technically selected according to the appropriate well or borehole. Following the current investigated study, the pump model has been selected according to the appropriate depth of the water source (well or borehole) and the flow-rate of extraction. Hence complete information involving the geospatial optimality characteristics of the studied area and the eventual appropriate model pumps, are assembled in the table 1. 
$10^{\mathrm{TH}}$ InTERnational CONFERENCE ON Sustainable ENERgy AND ENVIRONMENTAL Protection (June 27 $7^{\mathrm{TH}}-30^{\mathrm{TH}}, 2017$, BLED, SLOVENIA), RENEWABLE ENERGY SOURCES

A. Boutelhig \& A. Melit: Geospatial Characteristics Investigation of Suitable Area for Photovoltaic Water Pumping Erections, in the Southern Area of Ghardaia, Algeria

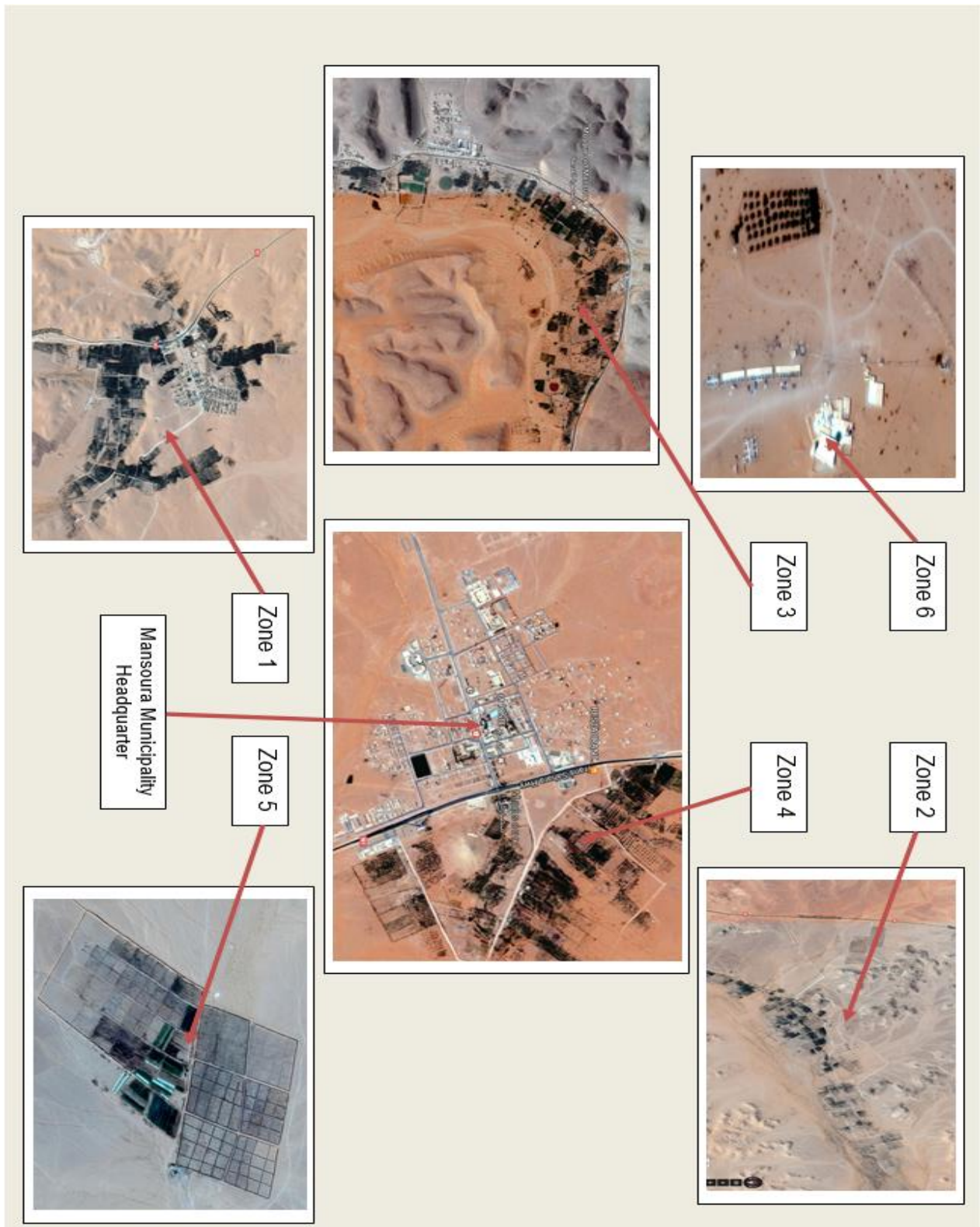

Fig.2. Spatial map of the studied zones 
$10^{\text {TH }}$ International Conference on Sustainable Energy and Environmental Protection (June $27^{\mathrm{TH}}-30^{\mathrm{TH}}, 2017$, Bled, SLOVEnia), RENEWABle ENERGy SOURCES A. Boutelhig \& A. Melit: Geospatial Characteristics Investigation of Suitable Area for Photovoltaic Water Pumping Erections, in the Southern Area of Ghardaia, Algeria

Table.1. Geospatial characteristics of the studied areas

\begin{tabular}{|c|c|c|c|c|c|c|c|c|c|c|c|}
\hline \multirow{3}{*}{$\begin{array}{l}\text { Studied } \\
\text { area }\end{array}$} & \multirow{2}{*}{\multicolumn{2}{|c|}{ Infrastructure }} & \multicolumn{5}{|c|}{ Groundwater assessment } & \multirow{2}{*}{\multicolumn{3}{|c|}{ Spatial characteristics of the area }} & \multirow{3}{*}{$\begin{array}{c}\text { Suitable } \\
\text { Pump } \\
\text { type }\end{array}$} \\
\hline & & & \multicolumn{2}{|c|}{ Wells } & \multicolumn{2}{|c|}{ Boreholes } & \multirow[b]{2}{*}{$\begin{array}{c}\text { Average } \\
\text { level }\end{array}$} & & & & \\
\hline & $\begin{array}{c}\text { From } \\
\text { Mansoura }\end{array}$ & $\begin{array}{c}\text { National } \\
\text { Grid }\end{array}$ & Number & $\begin{array}{l}\text { Static } \\
\text { level }\end{array}$ & Number & $\begin{array}{l}\text { Static } \\
\text { level }\end{array}$ & & $\begin{array}{c}\text { Nature of } \\
\text { area }\end{array}$ & $\begin{array}{l}\text { Kind of } \\
\text { activity }\end{array}$ & $\begin{array}{c}\text { Kind of } \\
\text { crop }\end{array}$ & \\
\hline Zone 1 & $3 \mathrm{~km}$ & $\mathrm{GC}$ & 23 & $45 \mathrm{~m}$ & 12 & $4 / 20 \mathrm{~m}$ & $45 \mathrm{~m}$ & $\begin{array}{c}\text { Sandy soil } \\
\text { valley }\end{array}$ & $\begin{array}{l}\text { LR } \\
\text { SSA }\end{array}$ & $\begin{array}{c}\text { Oasis } \\
\text { Other } \\
\text { kind. SSI }\end{array}$ & $\begin{array}{l}\text { Lorentz } \\
\text { PS200 }\end{array}$ \\
\hline Zone 2 & $7 \mathrm{~km}$ & $\mathrm{GC}$ & 05 & $40 \mathrm{~m}$ & 06 & $0 \mathrm{~m}$ & $40 \mathrm{~m}$ & $\begin{array}{l}\text { Sandy } \\
\text { clay soil } \\
\text { plateaus }\end{array}$ & $\begin{array}{c}\text { LR } \\
\text { LSA }\end{array}$ & $\begin{array}{c}\text { Oasis } \\
\text { Cereal } \\
\text { Other } \\
\text { kind. LSI }\end{array}$ & $\begin{array}{l}\text { Lorentz } \\
\text { PS1200 }\end{array}$ \\
\hline Zone 3 & $23 \mathrm{~km}$ & $\mathrm{GC}$ & 210 & $20-25 \mathrm{~m}$ & 04 & $0 \mathrm{~m}$ & $25 \mathrm{~m}$ & $\begin{array}{c}\text { Sandy soil } \\
\text { valley }\end{array}$ & $\begin{array}{l}\text { LR } \\
\text { SSA } \\
\text { LSA }\end{array}$ & $\begin{array}{c}\text { Oasis } \\
\text { Peanuts } \\
\text { Other } \\
\text { kind. LSI }\end{array}$ & $\begin{array}{c}\text { Grundfos } \\
900-1.4\end{array}$ \\
\hline Zone 4 & $0 \mathrm{~km}$ & $\mathrm{GC}$ & 11 & $35-40 \mathrm{~m}$ & 05 & $0 \mathrm{~m}$ & $40 \mathrm{~m}$ & $\begin{array}{c}\text { Sandy soil } \\
\text { valley }\end{array}$ & $\begin{array}{l}\text { LR } \\
\text { SSA }\end{array}$ & $\begin{array}{c}\text { Oasis } \\
\text { Peanuts } \\
\text { Other } \\
\text { kind. SSI }\end{array}$ & $\begin{array}{l}\text { Lorentz } \\
\text { PS200 }\end{array}$ \\
\hline Zone 5 & $16 \mathrm{~km}$ & NGC & 0 & 0 & 03 & $3-8 \mathrm{~m}$ & $5 \mathrm{~m}$ & $\begin{array}{l}\text { Sandy } \\
\text { clay soil } \\
\text { plateaus }\end{array}$ & LSA & $\begin{array}{c}\text { Cereal } \\
\text { Peanuts } \\
\text { Other } \\
\text { kind. LSI }\end{array}$ & $\begin{array}{c}\text { Lorentz } \\
\text { PS600 } \\
\text { PS1200 }\end{array}$ \\
\hline Zone 6 & $17 \mathrm{~km}$ & $\mathrm{GC}$ & 02 & $50 \mathrm{~m}$ & 0 & $0 \mathrm{~m}$ & $50 \mathrm{~m}$ & $\begin{array}{c}\text { Rocky } \\
\text { soil valley }\end{array}$ & $\begin{array}{r}\text { LR } \\
\text { SSA }\end{array}$ & $\begin{array}{c}\text { Oasis, } \\
\text { Livestock } \\
\text { LW }\end{array}$ & $\begin{array}{l}\text { Lorentz } \\
\text { PS200 }\end{array}$ \\
\hline
\end{tabular}

\section{$4 \quad$ Conclusions}

Geospatial characteristics investigation has been conducted on Mansoura desert area of the southern part of Ghardaia region. The purpose was to select the optimal areas suitable to erect the PV water pumping systems. Six different zones have been investigated according to the spatial characteristics, kind of activity, the groundwater source behaviour and the kind of irrigation. Accordingly, numbers of model pumps are selected to match each groundwater of suitable area. It has been averred that the old Mansoura area depicted by the Zone 3 seems to be the medium optimal location for PV water pumping erections. Nevertheless, future studies on the groundwater refill are required to determine the average peak powers needed.

\section{References}

[1] Millennium Ecosystem Assessment, "Ecosystems and human well-being: Desertification synthesis", World Resources Institute, Washington, DC, 2005.

[2] United Nations, "UNCCD-United Nations convention to combat desertification in those countries experiencing serious drought and/or desertification, particularly in Africa", United Nations, 1997.

[3] Algerian Ministry of Energy and mines. Renewable energy program and energy efficiency. Annual report, March 2011.

[4] Brian V.Mathiesen, Henrik Lund, Kenneth Karlsson. 100\% Renewable energy systems, climate mitigation and economic growth. Applied Energy 88 (2011) 488-501.

[5] A.G.Olabi. State of the art on renewable and sustainable energy editorial. Energy 61 (2013) $2-5$. 
A. Boutelhig \& A. Melit: Geospatial Characteristics Investigation of Suitable Area for Photovoltaic Water Pumping Erections, in the Southern Area of Ghardaia, Algeria

[6] Azzedine Boutelhig, Yahia Bakelly and Amar Hadj Arab. Promotion of photovoltaic water pumping systems (PVPS) for irrigation in desert regions, Ghardaia (Algeria). Journal of Agriculture Machinery Science, Turkey 2008, 4(2), 137-142.

[7] S. Benbelkacem, M. Belhocine, A. Bellarbi, Nadia Z.Henda. Augmented reality for photovoltaic pumping systems maintenance Tasks (Algeria). Renewable Energy 55 (2013) 428-437.

[8] A.Boutelhig, Y.Bakelli, I. H. Mahammed, Hadj Arab. Performances study of different PV powered DC pump configurations for an optimum energy rating at different heads under the outdoor conditions of a desert area. Energy 39 (2012) 33-39.

[9] A. Boutelhig, A. Hadjarab, Y. Bakelli. Comparison Study to Select an Optimum PV Pumping System Configuration upon Experimental Performances Data of Two Different DC Pumps Tested at Ghardaïa Site. Energy Procedia 6 (2011) 769-776.

[10] Dhiaa Halboot Muhsena, Tamer Khatib \& Farrukh Nagi. A review of photovoltaic water pumping system designing methods, control strategies and field performance. Renewable and Sustainable Energy Reviews 68 (2017) 70-86

[11] P.E. Campana, H. Li, J. Zhang, R. Zhang, J. Liu, J. Yan. Economic optimization of PV water pumping systems for irrigation. Energy Conversion and Management 95 (2015) 3241.

[12] P.E. Campana, Hailong Li, Jinyue Yan. Techno-economic feasibility of the irrigation system for the grassland and farmland conservation in China. Energy Conversion and Management 103 (2015) 311-320.

[13] M. Ayub Hossain, M. Shoeb Hassan, M. Abdul Mottalib, Sultan Ahmmed. Technical and economic feasibility of solar pump irrigations for eco-friendly environment. Procedia Engineering 105 (2015) 670 - 678.

[14] Dhiaa H. Muhsen, A.B. Ghazali, T. Khatib. Multi-objective differential evolution algorithm-based sizing of a standalone photovoltaic water pumping system. Energy Conversion and Management 118 (2016) 32-43.

[15] C.Olcan. Multi-objective analytical model for optimal sizing of stand-alone photovoltaic water pumping systems. Energy Conversion and Management 100 (2015) 358-369.

[16] He Xu, J. Liu, Dayong Qin, Xuerui Gao, Jinyue Yan. Feasibility analysis of solar irrigation system for pastures conservation in a demonstration area in Inner Mongolia. Applied Energy 112 (2013) 697 


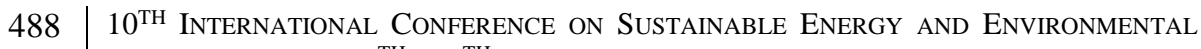
Protection (June $27^{\mathrm{TH}}-30^{\mathrm{TH}}, 2017$, Bled, SLOVEnia), Renewable ENERGy SOURCES 
$10^{\mathrm{TH}}$ InTERnAtional CONFERENCE ON Sustainable ENERgy AND Environmental Protection (June $27^{\mathrm{TH}}-30^{\mathrm{TH}}$, 2017, Bled, SLOVENIA), RENEWABLE ENERGy SOURCES

J. Krope, A.Ghani Olabi, D. Goričanec \& S. Božičnik

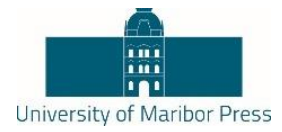

\title{
PV Power Prediction to Provide Energy Demand by Load Forecasting
}

\author{
SAMIR H.OUdJANA, IDRISS H. MAHAMMED \& KHENNANE M. BENBITOUR
}

Abstract Photovoltaic power prediction is indispensable in renewable energy, for optimal operation of power system, planning and operating, and sizing system. The paper objective is to predict PV power by load forecasting in Ghardaia (Algeria), using irradiance parameters. The PV power plant capacity is $1.1 \mathrm{MW}$, connected to power system for satisfy the energy demand. We are tested different forecasting models; depend on historical loads and irradiance, by using neural networks (NN) method. The Simulations results were run and discussed, it is proving that forecasting error depend on model choice, irradiance, and loads. The mean absolute forecasting error is precise using $\mathrm{NN}$, and may be improved by the other optimization techniques and models.

Keywords: • PV prediction • load Forecasting • neural networks $\bullet$ power system $\bullet$ Algeria $\bullet$

CorRespondence AdDress: Samir H.Oudjana, Ph.D., Researcher Assistant, Unité de Recherche Appliquée en Energies Renouvelables, URAER, Centre de Développement des Energies Renouvelables, CDER, 47133, Ghardaïa, Algeria, e-mail: samirehamid@yahoo.fr. Idriss H. Mahammed, Ph.D., Unité de Recherche Appliquée en Energies Renouvelables, URAER, Centre de Développement des Energies Renouvelables, CDER, 47133, Ghardaïa, Algeria, e-mail: hmidriss65@yahoo.fr. Khennane M. Benbitour, Ph.D., Unité de Recherche Appliquée en Energies Renouvelables, URAER, Centre de Développement des Energies Renouvelables, CDER, 47133, Ghardaïa, Algeria, e-mail: hmidriss65@yahoo.fr.

https://doi.org/10.18690/978-961-286-061-5.43

ISBN 978-961-286-061-5

(C) 2017 University of Maribor Press

Available at: http://press.um.si. 
$490 \quad 10^{\text {TH }}$ InTERnAtional CONFERENCE ON Sustainable ENERGy AND ENVIRONMENTAL Protection (June $27^{\mathrm{TH}}-30^{\mathrm{TH}}, 2017$, Bled, SLOVEnia), RENEWABle ENERGy SOURCES S. H.Oudjana, I. H. Mahammed \& K. M. Benbitour: PV Power Prediction to Provide Energy Demand by Load Forecasting Introduction

Renewable energies studies have described the most modern desired sources, where solar energy is one of the major and most dominant in Algeria, namely photovoltaic solar panels that receive extended interest on their use, where multiple projects have been bet by the Energy Source Ministry that used prediction program to have 30\% of national production from renewable sources ensure the horizon of 2030. Many sources types are interested in this program are: solar photovoltaic, solar thermal, wind, biomass, and geothermal energy. About $1168 \mathrm{MW}$ in the horizon of 2020 will benefit by photovoltaic energy [1].

PV prediction is necessary to have a reliable system and cost effective for large scale integration power system. In addition, the PV electrical prediction is also required for the resizing and planning of large scale PV power plants, balancing control, green electrical transactions, electrical interruption warnings, and power system stabilization [2][3].

There are many predictions and forecasting methods, such as experience forecast (electricity elasticity coefficient), output and growth rate of consumption, integrated electrical consumption, extrapolation forecast and district load density index method. Such methods need to the value, yield and growth rate [4].

Statistical methods used in the PV forecasting are time series and regression analysis, such as linear regression model, multiple linear regressions model, nonlinear regression analysis, autoregressive (AR) model, moving average (MA) models, autoregressive moving average (ARMA) model and nonstationary time-series. These methods need some relationship of values and the changes among identify consumption, load, time, total output value of industry in power gross domestic product, and then use mathematical models to prediction[5][6].

Artificial intelligent methods used in forecasting and prediction are grey generation, expert system, fuzzy logic, artificial neural networks, which used in the economic environment changes, and other random factors interfere with the power system under load accurately forecast, which widely used to analyze numerous uncertainties and the electrical load forecast correlation. But how accurate will describe the criteria adopted for the artificial uncertainties are relatively difficult. This work provides a neural network models based on irradiance parameters [7][8].

The paper contribution is establish an accurate PV power prediction to provide energy demand

by load forecasting (Ghardaia, Algeria), based irradiance parameter by develop a forecasting model which will be able to consistently forecast the energy generated by photovoltaic modules using explanatory variables available at most weather stations. PV energy prediction contributes to a better integration of renewable energy into the existing 
$10^{\mathrm{TH}}$ InTERnational CONFerence on Sustainable EnERgy AND Environmental 491

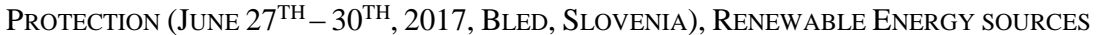

S. H.Oudjana, I. H. Mahammed \& K. M. Benbitour: PV Power Prediction to Provide Energy Demand by Load Forecasting

power sources. This study capable to enable future PV projects in Ghardaia city to be deployed at a lower costs and at much faster rate.

\section{$2 \quad$ Materials and Methods}

The PV power plant is located in Ghardaia based on the type of polycrystalline panels, inclined at $32^{\circ}$ with a total capacity of $1.1 \mathrm{MW}$ (Figure 1).

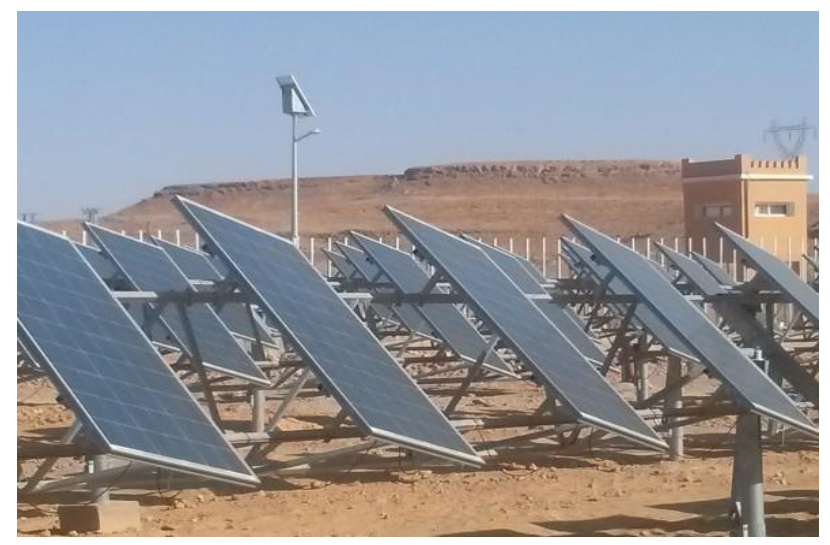

Figure 1. PV power plant in Ghardaia

The equivalent schematic network (PV micro grid) is presented in Figure 2.

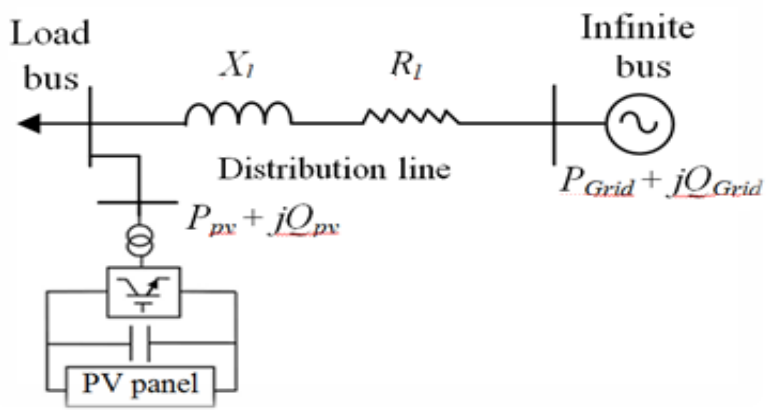

Figure 2. Micro grid of Ghardaia

The estimation of the real value of photovoltaics (PV) power aid the dispatching center to forecast the total power production. It should be have at any moment the balance between power supply and load demand which is given by the following formula:

Load $=$ Classical power + PV Power + losses 
492 10 $10^{\mathrm{TH}}$ International CONFERENCE on Sustainable ENERgy AND ENVIRONMENTAL Protection (June $27^{\mathrm{TH}}-30^{\mathrm{TH}}, 2017$, Bled, SLOVEnia), RENEWABle ENERGy SOURCES S. H.Oudjana, I. H. Mahammed \& K. M. Benbitour: PV Power Prediction to Provide Energy Demand by Load Forecasting

$L=P_{C}+P_{P V}+P_{L}$

$L:$ Load

$P_{C}:$ Classical power

$P_{P V}:$ PV power

$P_{L}:$ Losses power

$\mathrm{PV}$ power variation requires monitoring by an expert system to ensure better management of our electricity grid. The broad penetration of intermittent sources can cause significant impact on the power system operation, for example the coordination of voltage adjustment which related to injections of active and reactive power of different existing sources on the network, so the forecasting objective is to minimize the gap between production/consumption and optimize the production power plants.

The mathematical model of an artificial neuron (Figure 3) consists essentially of an integrator that performs a weighted sum of its inputs. The result $n$ of this sum is then transformed by a transfer function $f$ which produces the output of $a$ neuron. The $R$ input neurons correspond to the vector $P=[p 1, p 2, \ldots, p R]^{T}$, whereas $W=[w 11, w 12, \ldots, w 1 R]^{T}$ represents the vector of the weights of the neuron. The output $n$ of the integrator is given by the following equation:

$n=\sum_{j=1}^{R} w_{i j} p_{j}-b$

To verify the performance of the forecasting model, we can calculate the mean absolute error:

$M A E=\frac{1}{n} \sum_{i=t}^{n}\left|P_{t}-\widehat{P}\right|$

$P_{t}$ : Desired Power

$\hat{P}_{t}$ : Forecast Power

$\mathrm{n}$ : Number of samples 

Protection (June $27^{\mathrm{TH}}-30^{\mathrm{TH}}, 2017$, Bled, Slovenia), RenEwable ENERGY SOURCES S. H.Oudjana, I. H. Mahammed \& K. M. Benbitour: PV Power Prediction to Provide Energy Demand by Load Forecasting

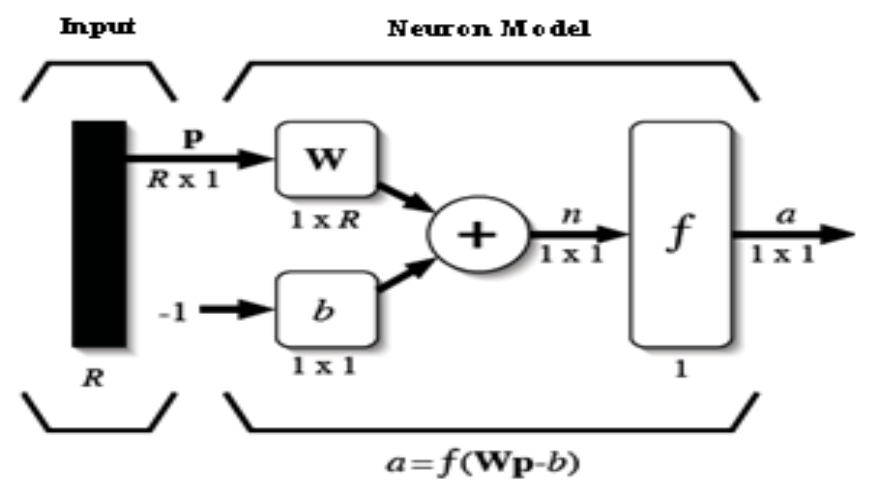

Figure 3. Model of an artificial neuron

The load forecasting model depends on historical load data as follow:

$\hat{L}=f(L)$

$\hat{L}$ : Forecast load

$L$ : Actual load

The PV forecast model depend on irradiance parameter in winter season and in summer:

$$
\hat{P}_{p v}=f(I)
$$

$\hat{P}_{p v}:$ Forecast power PV

$I$ : Irradiance

The winter irradiation period is from $9 \mathrm{~h} 00$ until $18 \mathrm{~h} 00$, the maximum radiation value is $951 \mathrm{~W} / \mathrm{m} 2$ at $13 \mathrm{~h} 00$ (figure 4 ).

The irradiance in summer begins from $8 \mathrm{~h} 00$ until 20h00; the range of irradiance is 12 hours. The cloud makes the minimum irradiance of $33 \mathrm{~W} / \mathrm{m} 2$ at $14 \mathrm{~h} 00$ (figure 5). 
494 10 $10^{\text {TH }}$ International Conference on Sustainable ENERgy AND ENVIRONMENTAL Protection (June $27^{\mathrm{TH}}-30^{\mathrm{TH}}, 2017$, Bled, SLOVENIA), RENEWABLE ENERGy SOURCES S. H.Oudjana, I. H. Mahammed \& K. M. Benbitour: PV Power Prediction to Provide Energy Demand by Load Forecasting

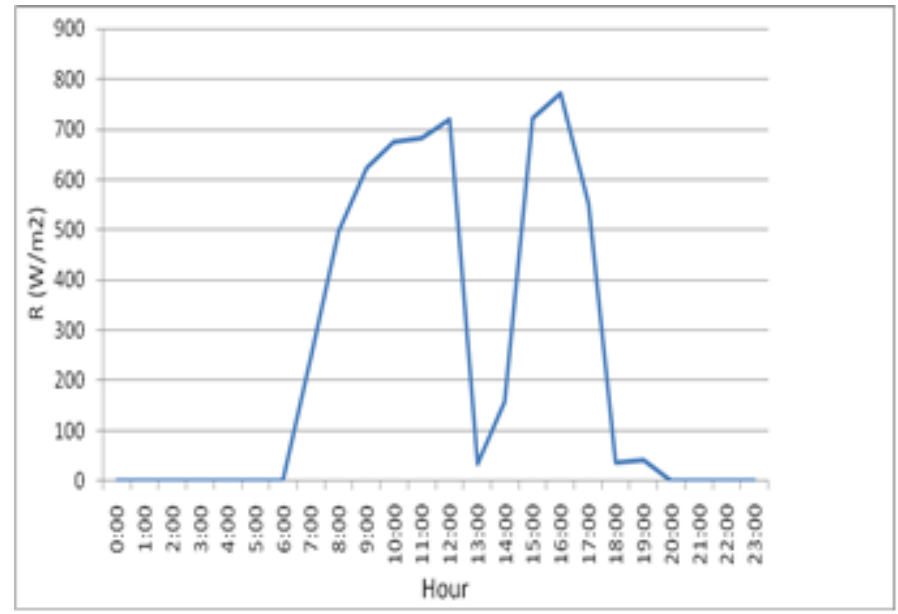

Figure 4. Irradiance 15/07/2014

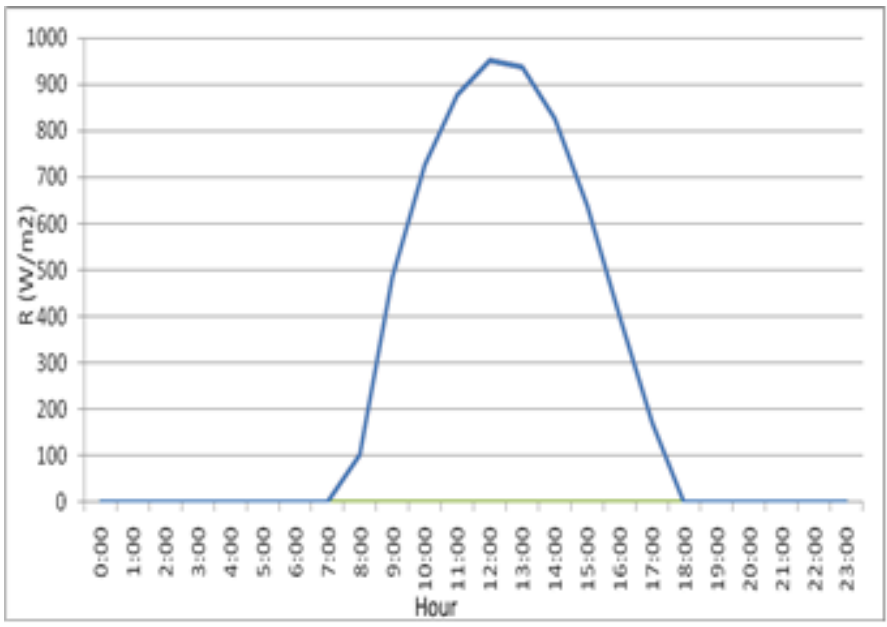

Figure 5. Irradiance 13/01/2015

\section{$3 \quad$ Simulations}

To validate the forecasting models, in terms of the mean absolute error, we must test its in differents seasons (summer, and winter), to predict the PV power and load in one day ahead.

The relationship between the PV power and radiation is proportional, so as soon as the irradiance increases, the PV production increases and vice versa. The average error of PV power forecast is $45 \mathrm{KW}$ in summer (Table 1). The forecast is accurate except in peak hours and in hollow ones (Figure 6). 
The load forecast pace is almost superimposed on the current load profile (Figure 7); the average forecast error is $21.8 \mathrm{KW}$ in summer (Table 1).

The missing power in summer varies between $54.3 \mathrm{KW}$ and $1458.1 \mathrm{KW}$ (Table 1); the $\mathrm{PV}$ production is low in the extremities of the day, either at sunrise or at sun layer (Figure $8)$.

Table 1. PV power and load forecast in summer

\begin{tabular}{|c|c|c|c|}
\hline Hour & $\begin{array}{c}\text { PV } \\
\text { Forecast } \\
(\mathrm{kW})\end{array}$ & $\begin{array}{c}\text { Load } \\
\text { Forecast } \\
(\mathrm{kW})\end{array}$ & $\begin{array}{c}\text { power missing } \\
(\mathrm{kW})\end{array}$ \\
\hline 8 & 76,3 & 1197,2 & 1120,9 \\
\hline 9 & 529,0 & 1024,4 & 495,4 \\
\hline 10 & 680,5 & 814,7 & 134,2 \\
\hline 11 & 750,1 & 814,7 & 64,6 \\
\hline 12 & 754,3 & 822,2 & 68,0 \\
\hline 13 & 765,0 & 819,3 & 54,3 \\
\hline 14 & 45,8 & 814,7 & 768,9 \\
\hline 15 & 61,5 & 872,4 & 810,9 \\
\hline 16 & 765,3 & 1197,2 & 432,0 \\
\hline 17 & 764,6 & 1197,2 & 432,6 \\
\hline 18 & 600,3 & 1408,5 & 808,2 \\
\hline 19 & 46,2 & 1504,3 & 1458,1 \\
\hline 20 & 46,7 & 1504,3 & 1457,6 \\
\hline$M A E(\mathrm{~kW})$ & 45,0 & 21,8 & \\
\hline
\end{tabular}

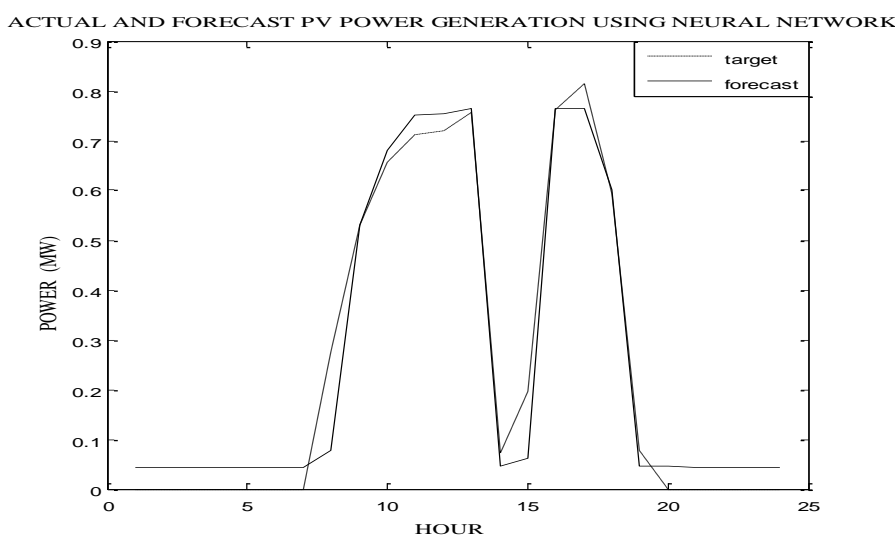

Figure 6. PV power forecasting in summer 
496 1 $10^{\mathrm{TH}}$ INTERNATIONAL CONFERENCE ON Sustainable ENERGy AND ENVIRONMENTAL Protection (June $27^{\mathrm{TH}}-30^{\mathrm{TH}}, 2017$, BlED, SLOVENIA), RENEWABLE ENERGy SOURCES S. H.Oudjana, I. H. Mahammed \& K. M. Benbitour: PV Power Prediction to Provide Energy Demand by Load Forecasting

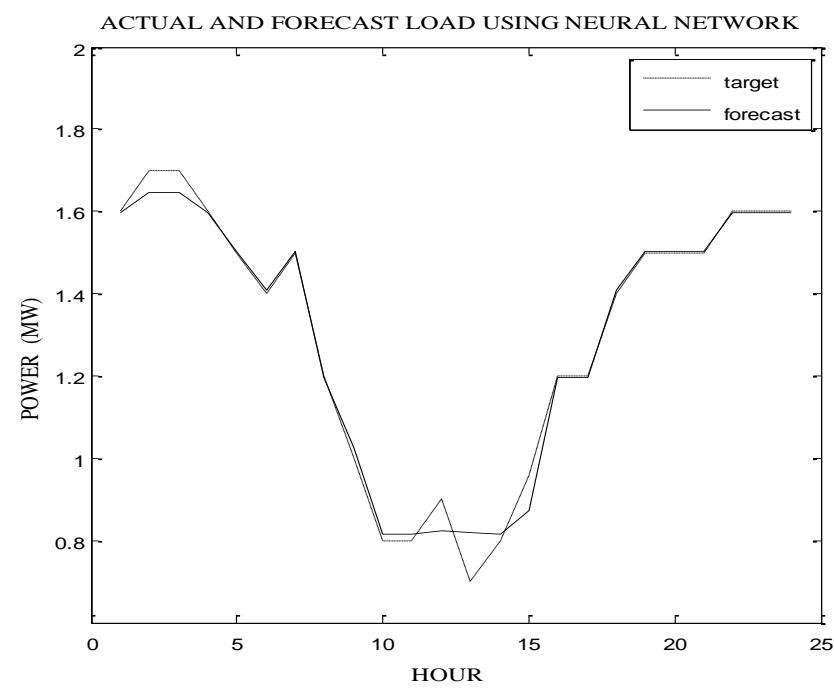

Figure 7. Load forecasting in summer

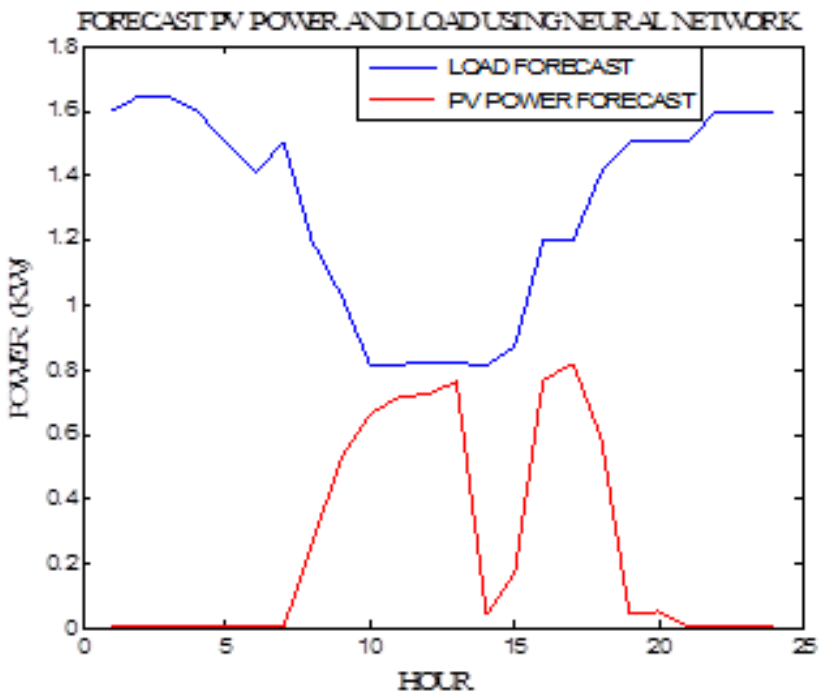

Figure 8.Power and load forecast in summer

In winter, the PV production increases gradually up to $900 \mathrm{KW}$ at $14 \mathrm{~h} 00$ (figure 9), the average error of PV power forecast is $56.02 \mathrm{KW}$ (Table 2).

The peak load is $1,400 \mathrm{KW}$ in morning at $6 \mathrm{~h} 00$, and the afternoon is $1,200 \mathrm{KW}$ at $19 \mathrm{~h} 00$ (Figure 10), the average error of load forecast is $17.7 \mathrm{KW}$ in winter (Table 2). 

Protection (June 27 $7^{\mathrm{TH}}-30^{\mathrm{TH}}, 2017$, BLED, SLOVENIA), RENEWABLE ENERGY SOURCES S. H.Oudjana, I. H. Mahammed \& K. M. Benbitour: PV Power Prediction to Provide Energy Demand by Load Forecasting

The missing power at $12 \mathrm{~h} 00$ until $15 \mathrm{~h} 00$ is negative (Table 2), it means that the PV production is more than electrical consumption (figure 11), in this case the PV power plant is sufficient for the load in Oued nechou (Ghardaia).

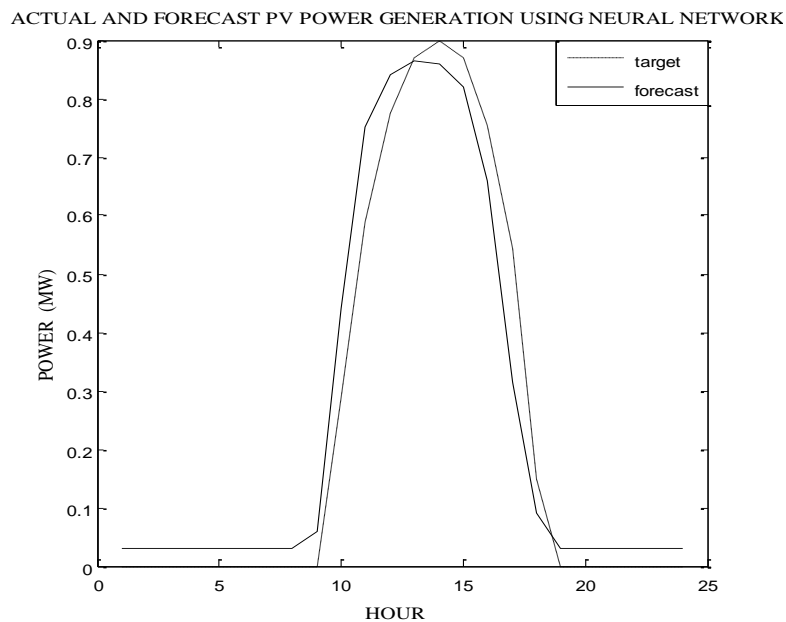

Figure 9. PV power forecasting in winter

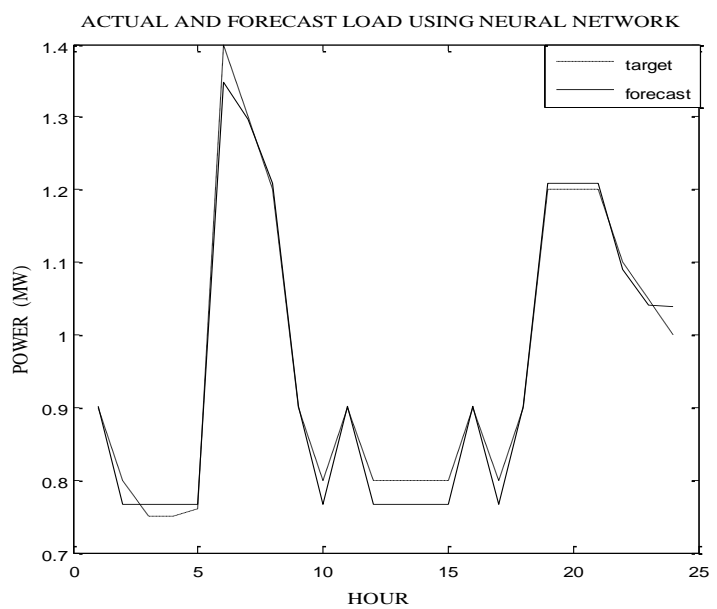

Figure 10. Load forecasting in winter 
498 10 $10^{\text {TH }}$ International Conference on Sustainable ENERgy AND ENVIRONMENTAL Protection (June $27^{\mathrm{TH}}-30^{\mathrm{TH}}, 2017$, Bled, SLOVEnia), RENEWABle ENERGy SOURCES S. H.Oudjana, I. H. Mahammed \& K. M. Benbitour: PV Power Prediction to Provide Energy Demand by Load Forecasting

Table 1. PV power and load forecast in Winter

\begin{tabular}{|c|c|c|c|}
\hline Hour & $\begin{array}{c}\text { PV } \\
\text { Forecast } \\
(\mathrm{kW})\end{array}$ & $\begin{array}{c}\text { Load Forecast } \\
(\mathrm{kW})\end{array}$ & $\begin{array}{c}\text { power missing } \\
(\mathrm{kW})\end{array}$ \\
\hline 9 & 59,0 & 901,2 & 842,2 \\
\hline 10 & 441,6 & 766,8 & 325,2 \\
\hline 11 & 752,0 & 901,2 & 149,1 \\
\hline 12 & 840,8 & 766,8 & $-74,0$ \\
\hline 13 & 863,5 & 766,8 & $-96,7$ \\
\hline 14 & 860,3 & 766,8 & $-93,4$ \\
\hline 15 & 818,7 & 766,8 & $-51,9$ \\
\hline 16 & 660,3 & 901,2 & 240,8 \\
\hline 17 & 314,5 & 766,8 & 452,3 \\
\hline 18 & 90,8 & 901,2 & 810,4 \\
\hline MAE kW) & 56,02 & 17,7 & \\
\hline
\end{tabular}

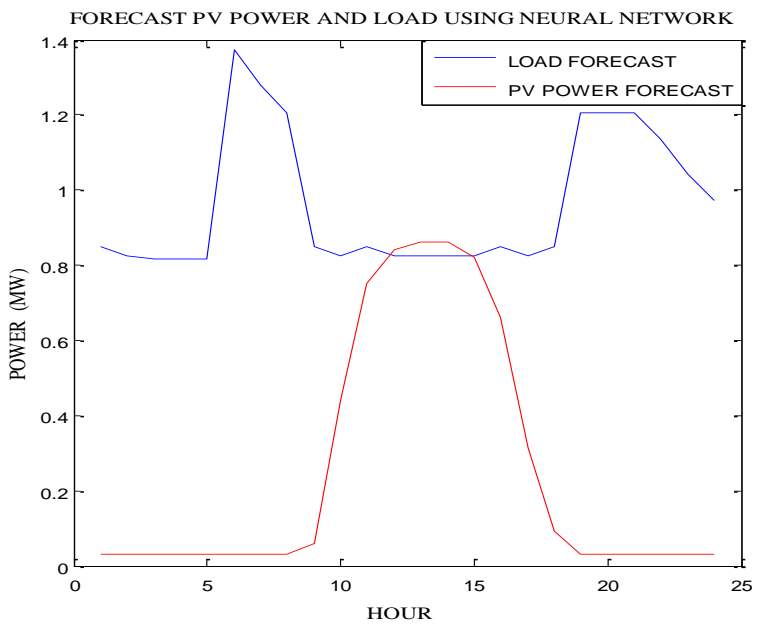

Figure 11. Power and load forecast in winter

\section{Conclusions}

Photovoltaic power forecasting is important to the operation of electrical system to make decisions by the dispatching center that cares to ensure electrical network security management while having a reliable and cost effective production system that meets specific environmental constraints. 
The work initiated in this paper aimed to achieve a program that can predict the electrical generated by a PV power plant to one day ahead in Ghardaia (Algeria), and analyze the relationship between meteorological factors and the electrical supplied by applying the neural network technique. The neural networks does not require a mathematical model, but is based on artificial intelligence.

Power consumption in summer is longer than that in winter due to use of air conditioning, which is why the load forecast error is big in the summer season. PV production linked directly with the irradiance factor, the irradiation time in summer is 12 hours, but the PV power plant is not able to satisfy the electricity demand. Irradiation in winter is low, but it meets the load from $12 \mathrm{~h} 00$ until $15 \mathrm{~h} 00$. The forecast error of PV power depends on irradiation, but it may be improved by the other models and optimization techniques that train the neural network.

\section{References}

[1] M. Mosbah, M. Kobbi, "Introduction of the renewable energy and SDC Experience" presented at the 1st Conference of Districts Engineers Electrical Company of Distribution Electricity and the Gas Centre, Blida Technical School, 2015, pp. 20-21.

[2] S. H.Oudjana, A.Hellal, I.H.Mahammed " Neural Network Based Photovoltaic Electrical Forecasting in South Algeria " Applied Solar Energy, vol. 50, No. 4, pp. 273-277, 2014.

[3] K. Mitsuru, T.Akira, N.Yousuke, Elect. Eng. in Japan, vol. 167, no. 4, 2009.

[4] Z. L.Ying, N. Jinc, IEEE Conf. Electr. Energ. Eng. APPEEC, pp.1-4, 2009.

[5] Y. Jingfei, "Electrical System Short-term Load Forecasting", M. Sc. Thesis, Beijing University, China, 2006.

[6] Z.G. Zhang, Z.L.Yang, Electr. Syst. Autom., vo 1. 18, no. 5, pp. 79-83, 2006.

[7] A. Yona, T. Senjyu, A.Y. Saber, In Proc. IEEE Gener. Meet. Electr. Enrg. Socie. Conver. Deliv. Electr Enrg 21st Cent, 2008, pp.1-6.

[8] Y.Mao, F.Yang, C.Wang, Trans. China Electrot. Soci., 2011. 
$500 \quad 10^{\text {Th }}$ International CONFEREnCE on Sustainable EnERgy and ENVIRONMENTaL Protection (June 27 $7^{\mathrm{TH}}-30^{\mathrm{TH}}, 2017$, Bled, SLOVEnia), RENEWABLE ENERGy SOURCES 
$10^{\mathrm{TH}}$ InTERnATIONAL CONFERENCE ON Sustainable ENERgy AND ENVIRONMENTAL Protection (June $27^{\mathrm{TH}}-30^{\mathrm{TH}}$, 2017, Bled, SLOVENIA), RENEWABLE ENERGy SOURCES

J. Krope, A.Ghani Olabi, D. Goričanec \& S. Božičnik

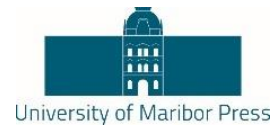

\title{
Comparison Study to Select an Optimum Photovoltaic PV Module Model Under Experimental Performances
}

\author{
IDRISS HADJ MAHAMMED, AMAR HADJ ARAB, SMAIL BERRAH, YAHIA BAKELLI, \\ Messaouda Khennane Benbitour, SAmir Hamid OudJana, AMOR FEZZANi \& \\ LAYBACHI ZAGHBA
}

\begin{abstract}
There is a wide range of publications reported in modeling the I-V characteristics of the PV module. However the outdoor conditions variations is a relatively new and hot research area and has attracted notable attention of the researchers in the past decade. In this work, a new approach proposed to reconstruct the I-V characteristic of a PV module under various real conditions of irradiance and temperature. Based on the characterization tests data, carried out on four different PV modules technologies (monocrystalline silicon, polycrystalline silicon, thin film CIS and amorphous silicon), under semi-arid environment conditions of Ghardaïa site, a developed methodology has been presented. It consists of exploiting a set of the five parameters data versus irradiance and temperature obtained via the five parameters model. The assembled data have been reconstructed via analytical and Firefly Algorithm (FA) models, for each PV module technology. Based on the computational results and convergence capabilities we concluded FA is a very powerful algorithm that gives a good precision for all tested PV module types, in comparison to the analytical model.
\end{abstract}

Keywords: $\bullet$ model $\bullet$ module photovoltaic $\bullet$ firefly $\bullet \mathrm{I}-\mathrm{V}$ characteristic $\bullet \bullet$ $\mathrm{PV} \bullet$

CORRESPONDENCE ADDRESS: Idriss Hadj Mahammed, Unité de Recherche Appliquée en Energies

Renouvelables URAER, Centre de Développement des Energies Renouvelables, CDER, 47133, Ghardaïa, Algeria, A. Mira University, Electronics Lab/ Faculty of Electronics,, Route de Targua Ouzemour, Béjaia 06000, Algeria, e-mail: hmidriss65@yahoo.fr. Amar Hadj Arab, Centre de Développement des Energies Renouvelables, CDER, 47133, Ghardaïa, Algiers, Algeria e-mail: hadjarab@ hotmail.com. Smail Berrah, A. Mira University, Electronics Lab/ Faculty of Electronics,, Route de Targua Ouzemour, Béjaia 06000, Algeria, e-mail: sberrah@yahoo.fr. Yahia Bakelli, Centre de Développement des Energies Renouvelables, CDER, 16340, Algiers, Algeria, e-mial: bakelli@hotmail.com. Messaouda Khennane Benbitour, Unité de Recherche Appliquée en Energies Renouvelables URAER, Centre de Développement des Energies Renouvelables, CDER Ghardaïa, Algeria, e-mail: khennanemessa@yahoo.fr. Samir Hamid Oudjana, Unité de Recherche Appliquée en Energies Renouvelables URAER, Centre de Développement des Energies Renouvelables, CDER Ghardaïa, Algeria, e-mail : samirehamid@yahoo.fr. Amor Fezzani, University of Batna, Rue Cahid med El-Hadi Boukhlof Batna 05000, Algeria, e-mail : amorfezzani@yahoo.fr Laybachi Zaghba, Unité de Recherche Appliquée en Energies Renouvelables URAER, Centre de Développement des Energies Renouvelables, CDER, 47133, Ghardaïa, Algeria, e-mail : Layachi40@yahoo.fr 
$10^{\text {TH }}$ International CONFEREnce on Sustainable Energy and Environmental Protection (June $27^{\mathrm{TH}}-30^{\mathrm{TH}}, 2017$, Bled, SLOVENIA), Renewable ENERGy SOURCES I. Hadj Mahammed, A. Hadj Arab, S. berrah, Y. Bakelli, M. Khennane Benbitour, S. Hamid Oudjana, A. Fezzani \& L. Zaghba: Comparison Study to Select an Optimum Photovoltaic PV Module Model Under Experimental Performances

Currently renewable energies resources represent an interesting alternative of fossil fuels. Solar photovoltaic (PV) power production can be considered as one of the most practical resources, especially for high-level irradiation regions. Due to its geographical position among the solar belt countries, Algeria is blessed with an abundance of solar energy that can be exploited and promoted as clean and environmental friendly technologies. In this context, an ambitious program is adopted to develop clean and efficient energy. The program aims to achieve renewable power installations reaching the $22(\mathrm{GW})$ between 2011 and 2030, from which 12 (GW) will be devoted to cover the national demand and $10(\mathrm{GW})$ is for export. Currently, Algeria plans to produce $400(\mathrm{MW})$ of electricity from photovoltaic technology in different regions of the country [1], [2]

In this context, the first pilot PV plant has been installed in Algeria by Electricity and renewable energies Company (SKTM) with a capacity of $1.1 \mathrm{MW}$, for testing the four PV technologies in the real weather conditions (arid and semi-arid climate). However, the renewable energies development Center (CDER) has accompanied this project in order to give solutions to the real problems encountered during the implementation of this power plant. For this purpose, the work proposed in this study considers one of photovoltaic related topics, namely the development of reliable methods for modeling the cell, module and PV generator in the outdoor conditions.

Generally, an equivalent model describes the behavior of PV cells. Therefore, numerous works treating the equivalent electrical circuit models of solar cell have been proposed to present its current-voltage (I-V) characteristics. Within this frame, researchers start generally with a simple model of solar cells then improve the circuit with other electrical components, in order to make a comprehensive model. Authors accordingly, have been developed several models throughout different parameters types, namely: four; five, six and seven parameters model.[4]

According to bibliographic review, many researches have been carried out for modeling the solar cell current-voltage characteristics (I-V) based on classical models, De soto et al.have dealt with five model parameters in the aim to determine the current-voltage of four different type cell technologies and have compared the predicted data with the experimental ones. They found that the predictions from the five-parameter model are in agreement with measurements and can be an accurate tool for the prediction of energy production.[4].

Celik and Acikgoz to estimate the operating current of a $120 \mathrm{~W}$ monocrystalline photovoltaic module in the southern part of Turkey have discussed four and five parameter models. The obtained results show that the complete five-parameter model predicts the operating current better than the simplified four-parameter model based on the determination coefficient (R2), especially around solar noon when most of the power is produced.[5]. 
The PV cell performances are strongly influenced by irradiance and temperature. Therefore, it is necessary to determine the PV model parameters according to operational conditions. Thus, several approaches are then frequently used for determining these parameters. We can find the well-known standard current and voltage translation methods[5], the analytic generalized model parameters expressed as a function of irradiance and temperature [6] and AI methods including artificial neural networ $\mathrm{k}$ and genetic algorithms. [8-11].

Within this frame, the current work investigates the five parameters model throughout diode circuit configuration, for seven PV modules of different technologies. The investigation study used an analytical and firefly algorithm model, for wide range of irradiance and temperature. A case study of Ghardaïa region has been taken as an example of application.

The paper has the following structure: section II present experimental setup and methodologies used for estimating the PV module model characteristics ((monocrystalline silicon, polycrystalline silicon, thin film CIS and amorphous silicon). Discussion of the results is described in the section 5; finally, the last section was devoted to the conclusion of the work.

\section{Location and Characteristics of the Site}

Located in the southern of Algeria, about $600 \mathrm{~km}$ South of Algiers, Ghardaïa site is considered as an arid and dry area. It is characterized by the following geographical coordinates: latitude of $32^{\circ} 36^{\prime} \mathrm{N}$, longitude of $3^{\circ} 48^{\prime} \mathrm{E}$ and altitude of $450 \mathrm{~m}$ above the sea level. The site is specified by a huge sunshine where the rate of insolation is significant; the mean annual global solar radiation measured on a horizontal plane exceeds $6000(\mathrm{Wh} / \mathrm{m} 2 /$ day) and the sunshine duration is more than 3000 (hours/year). The minimum and maximum summer average temperatures are $26^{\circ} \mathrm{C}$ and $42^{\circ} \mathrm{C}$ respectively.

\section{$3 \quad$ Test Bench and Experimental Setup}

The test characterization has been performed at outdoor conditions of the site under consideration (Applied Research Unit for Renewable Energies).

Photovoltaic modules characterization bench is equipped with the following components:

Photovoltaic Field Array Tracer (PVPM 2540C) 250V 40A model, for recording IVcharacteristics Duration of single measurement: $20 \mathrm{~ms}$ up to 2 seconds, avoiding the influence of capacitive properties of the module under test 
$10^{\mathrm{TH}}$ International Conference on Sustainable Energy and Environmental Protection (June $27^{\mathrm{TH}}-30^{\mathrm{TH}}, 2017$, BlED, SLOVENIA), RENEWABLE ENERGY SOURCES I. Hadj Mahammed, A. Hadj Arab, S. berrah, Y. Bakelli, M. Khennane Benbitour, S. Hamid Oudjana, A. Fezzani \& L. Zaghba: Comparison Study to Select an Optimum Photovoltaic PV Module Model Under Experimental Performances

Calibrated reference $\mathrm{m}$-Si solar cell used for measuring irradiance and a Pt1000 temperature sensor is glued to the backside of the center cell. The Pt1000 sensor gives directly the cell temperature. Support structure for mounting the PV modules. Monitoring PC The synoptic of the test bench is shown in the Figure 1.

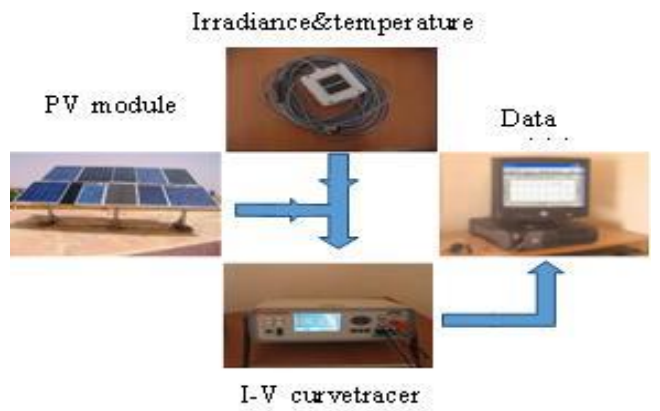

Figure 1. Synoptic of the test bench

Table 1. Standard conditions tested modules Characteristics

\begin{tabular}{|l|l|l|l|l|l|l|l|}
\hline Module & SLK72M & SHARP175 & ASE95 & SLK60P & BP3160 & US64 & ST40 \\
\hline Techn. & mc-Si & mc-Si & mc-Si & pc-Si & pc-Si & a-Si TJ & TF (CIS) \\
\hline ISC (A) & 5.48 & 5.4 & 3.2 & 7.38 & 4.8 & 5.1 & 2.68 \\
\hline VOC (V) & 44.4 & 44.4 & 42.3 & 36.9 & 44.2 & 21.3 & 23.3 \\
\hline Im (A) & 4.85 & 4.95 & 2.8 & 6.7 & 4.55 & 4.1 & 2.41 \\
\hline Vm (V) & 36.8 & 35.4 & 34.1 & 30 & 35.1 & 15.6 & 16.6 \\
\hline P (W) & 180 & 175 & 95 & 200 & 160 & 64 & 40 \\
\hline
\end{tabular}

4

Modeling

The used models for estimating the I-V characteristics of the PV modulesare described in below.

\subsection{Five Parameters Model}

Many models have been employed for estimating the PV module I-V characteristics, among them we find the five parameters models seems to be the best one $[5,6,12]$ The photovoltaic generator may be closely represented by the five parameters model based on one diode equivalent circuit of a solar cell; it consists on a diode, a current source (IL), a series resistance (Rs), and a parallel resistance (Rsh).The current source generates photocurrent (IL) which is a function of incident solar irradiation and cell temperature.

The diode represents $\mathrm{p}-\mathrm{n}$ junction of the solar cell. At real solar cells, the voltage loss on the way to the external contacts is observed, and it is expressed by a series resistance 
I. Hadj Mahammed, A. Hadj Arab, S. berrah, Y. Bakelli, M. Khennane Benbitour, S. Hamid Oudjana, A. Fezzani \& L. Zaghba: Comparison Study to Select an Optimum Photovoltaic PV Module Model Under Experimental Performances

(Rs). Furthermore, a shunt resistance (Rsh) describes leakage currents. Using Kirchhoff's first law, the equation for the extended I-V curve is derived as shown by Equation. 1 .

$$
I=I_{L}-I_{0}\left[\exp \left(\frac{V+I R_{s}}{m V_{t}}\right)-1\right]-\frac{V+I R_{s}}{R_{s h}}
$$

Where I is the output current of the PV cell or module, $\mathrm{V}$ is the terminal voltage, $\mathrm{q}$ is the electric charge $(1.610-19 \mathrm{C}), \mathrm{K}$ is the Boltzmann constant $(1.3810-23 \mathrm{~J} / \mathrm{K})$, and $\mathrm{T}$ is the cell temperature $(\mathrm{K}), \mathrm{m}$ is the ideality factor, IL the photo-generated current under insulation, Rsh: shunt resistance; Rs: series resistance and I0 is the diode saturation current. The five equivalent circuit parameters can be determined using the available operating points on the I-V curve by analytical equations as mentioned in [5]

\subsection{Analytical parametermodels}

To be able to obtain the changing of the parameters over the whole range of operating conditions, analytical parametermodelshas been used as described in Eqs. (2-1).

The light-generated current of the PV cell depends linearly on the solar irradiance and is also affected by the module temperature.[13,14].

$$
I_{L}(E, T)=I_{L r e f} * \frac{E}{E_{\text {ref }}}\left(1+\alpha_{I S C} *\left(T-T_{\text {ref }}\right)\right)
$$

introduce another expression [7]:

$$
I_{L}(E, T)=I_{S C \text { ref }} * \frac{E}{E_{r e f}}+\alpha_{I S C} *\left(T-T_{r e f}\right)
$$

performed the following expression [8]:

$$
\left.I_{L}(E, T)=P_{1}^{*} E * \mid 1-P_{2} *\left(E-E_{r e f}\right)+P_{3} *\left(T-T_{r e f}\right)\right\rfloor
$$

The saturation current on PV module calculated as follow[7, 17, 18]

$$
I_{0}(T)=I_{0 r e f}\left(\frac{T}{T_{r e f}}\right)^{3} * \exp \left(\frac{1}{k}\left(\frac{E_{g r e f}}{T_{r e f}}-\frac{E_{g}(T)}{T}\right)\right)
$$


$506 \quad 10^{\mathrm{TH}}$ International CONFERENCE on Sustainable ENERgy AND ENVIRONMENTAL Protection (June $27^{\mathrm{TH}}-30^{\mathrm{TH}}, 2017$, BlED, SLOVENIA), RENEWABLE ENERGY SOURCES I. Hadj Mahammed, A. Hadj Arab, S. berrah, Y. Bakelli, M. Khennane Benbitour, S. Hamid Oudjana, A. Fezzani \& L. Zaghba: Comparison Study to Select an Optimum Photovoltaic PV Module Model Under Experimental Performances

$$
\frac{E_{g}(T)}{E_{\text {gref }}}=1-0.0002677 *\left(T-T_{\text {ref }}\right)
$$

Villalva confirmed that the PV model can be improved using the following saturation current equation:[9]

$$
I_{0}(T)=\left(\frac{I_{S C}+\alpha_{I S C} *\left(T-T_{r e f}\right)}{\exp \left(\frac{\left(I_{S C}+\beta_{I S C} *\left(T-T_{r e f}\right)\right)}{m^{*} V_{t}}\right)-1}\right)
$$

Series resistance has been determined by: $[5,18]$

$$
R_{s}(E, T)=R_{\text {sref }} *\left(\frac{T}{T_{r e f}}\right) *\left(1-\beta * \ln \left(\frac{E}{E_{r e f}}\right)\right)
$$

and :[15,17]

$$
R_{s}(T)=R_{\text {sref }} * \exp (\delta *(T-T r e f))
$$

$[3,7,18]$ have introduced the given equation for shunt resistance estimation as function of irradiance:

$$
\begin{aligned}
& R_{\text {sh }}(E)=R_{\text {sh ref }} *\left(\frac{E_{\text {ref }}}{E}\right) \\
& R_{\text {sh }}(T)=R_{\text {shref }} * \exp (\delta *(T-\text { Tref }))
\end{aligned}
$$

Based on experimental results, ideality factor $(\mathrm{m})$ presents quite variations with irradiance and temperature. However, there is no mathematical formula describing $\mathrm{m}$ as a function of irradiance and/or temperature hence, many authors adopt it constant. [12,19, 20]

\subsection{Firefly model}

This model has been used to extract the five parameters model is as described below 


\subsubsection{Firefly algorithm}

Firefly Algorithm (FA) is a metaheuristic algorithm for global optimization, proposed by Xin-She Yang in late 2007/early 2008 at Cambridge University [21, 22]. The Firefly Algorithm was inspired by the flashing of fireflies in nature. There are over 2000 species of fireflies, most of which produce a bioluminescence from their abdomen [23]. Each species of firefly produces its own pattern of flashes, and although the complete function of these flashes is not known, the main purpose for their flashing is to attract a mate. For several species, the male is attracted to a sedentary female. In other species, the female can copy the signal of a different species, so that the males of that species are lured in. The female then preys on these males. The flashing can also be used to send information between fireflies. The idea of this attractiveness and information passing is what leads to the inspiration for the FA. The FA idealizes several aspects of firefly in nature. First, real fireflies flash in discrete patterns, whereas the modeled fireflies will be treated as always glowing. Then, three rules can be made to govern the algorithm, and create a modeled firefly's behavior [20].

1- All fireflies are unisexual that is one firefly will be attracted by all others.

2- The attractiveness is proportional to the brightness, and they both decrease as their distance increases. Thus for any two flashing fireflies, the less brighter one will move towards the brighter one. If there is no brighter one than a particular firefly, it will move randomly.

3- The brightness/attractiveness is governed by its objective function that requires to be optimized. Hence, the brightness is proportional to the objective function.

The light intensity varies monotonically and exponentially with distance hence,

$$
I(r)=I_{0} \exp (-\gamma r)
$$

Where $I(r)$ is the light intensity; $r$ is distance between two flies; $I_{0}$ is the initial or original light intensity; $Y$ is light absorption coefficient.

As a firefly's attractiveness is proportional to the light intensity seen by adjacent fireflies, we can now define the variation of attractiveness $\beta$ with the distance $\mathrm{r}$ by:

$$
\beta(r)=\beta_{0} \exp \left(-\gamma r^{2}\right)
$$

Where, $\beta_{0}$ is the initial attractiveness at $\mathrm{r}=0$.

The distance between any two fireflies $i$ and $j$ at $x_{i}$ and $x_{j}$ respectively, is given by the Cartesian equation, 
$r_{i j}=\left\|x_{i}-x_{j}\right\|=\sqrt{\sum_{k=1}^{d}\left(x_{i, k}-x_{j, k}\right)^{2}}$

Where $x_{i, k}$ is the $k^{\text {th }}$ component of the spatial coordinate $x_{i}$ of $\mathrm{i}^{\text {th }}$ firefly.

The movement of a firefly $i$ is attracted to another, more attractive (brighter) firefly $j$ as determined by:

$$
x_{i}^{t+1}=x_{i}^{t}+\beta_{0} \exp \left(-\gamma r^{2}\right)\left(x_{j}^{t}-x_{i}^{t}\right)+\alpha_{t} \varepsilon_{i}^{t}
$$

Where the second term is due to the attraction. The third term is randomization with $\alpha_{\mathrm{t}}$ being the randomization parameter (is a parameter controlling the step size), and $\epsilon_{i}^{t}$ is a vector of random numbers drawn from a Gaussian or other distribution at time $t$.

Based on these three rules described above, the basic steps of the firefly algorithm (FA) has been applied to extract the five parameters model.

\subsubsection{Firefly five parameters model extraction}

In the proposed algorithm, the number of PV panels, are considered as the control variables. Firefly-inspired metaheuristic algorithm is applied for the problem of the five parameters model extraction.

\subsection{Statistical performance}

The accuracy of the estimated models is judged by the statistical indicators, such as the determination coefficient (R2), mean bias error (MBE), the mean absolute error (MAE), root mean square error (RMSE) and statistical test (t-stat). The root mean square error provides information about the performance of correlations, which allows comparison of the real differences between the estimated values and the measured ones, a low RMSE is desirable. The determination coefficient reflects the quality of the model; more R2 close to one, more model quality is better. The expression of each statistical indicator is given by Equation 16 and equation 17.

$$
R^{2}=\frac{\sum_{i=1}^{N}\left(c_{i}-c_{a}\right)\left(m_{i}-m_{a}\right)}{\sqrt{\sum_{i=1}^{N}\left(c_{i}-c_{a}\right)^{2} \sum_{i=1}^{N}\left(m_{i}-m_{a}\right)^{2}}}
$$


I. Hadj Mahammed, A. Hadj Arab, S. berrah, Y. Bakelli, M. Khennane Benbitour, S. Hamid Oudjana, A. Fezzani \& L. Zaghba: Comparison Study to Select an Optimum Photovoltaic PV Module Model Under Experimental Performances

$$
R M S E=\left[\frac{\sum_{i=1}^{N}\left(c_{i}-m_{i}\right)^{2}}{n}\right]^{1 / 2}
$$

With: ci and mi are the ith calculated and measured parameters respectively, ca and ma are the average of the calculated and measured parameters respectively and $n$ number of experimental points.

\section{$5 \quad$ Results and Discussion}

As mentioned above, the five parameters model has been used for estimating the PV module I-V characteristics.

Figs 6-9 give the shape of the IV characteristics measured (in errors bars) and calculated with the five parameters model (in solid line) for different levels of irradiance and temperature and four technologies.

(polycrystalline silicon, monocrystalline silicon, thin film CIS and amorphous silicon) . It can be seen clearly that the five parameters model adjust with a significant accuracy with the entire experimental curve for different levels of irradiance and temperature. These observations are also consistent with $[8,, 17$,$] Upon the obtained results, a database$ involving the PV module parameters has been constructed, for different solar irradiance and temperature levels. The mentioned database is then exploited to determine the appropriate model parameters under outdoor conditions.

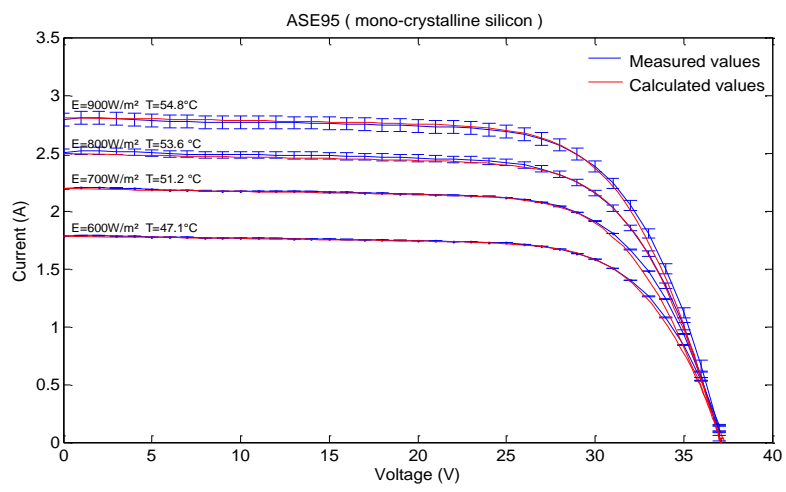

Figure 7. Errors bars and simulated I-V curves for different irradiances and temperatures for: ASE95 

$10^{\text {TH }}$ International CONFEREnce on Sustainable Energy and Environmental Protection (June $27^{\mathrm{TH}}-30^{\mathrm{TH}}, 2017$, Bled, SLOVEnia), RENEWABle ENERGy SOURCES I. Hadj Mahammed, A. Hadj Arab, S. berrah, Y. Bakelli, M. Khennane Benbitour, S. Hamid Oudjana, A. Fezzani \& L. Zaghba: Comparison Study to Select an Optimum Photovoltaic PV Module Model Under Experimental Performances

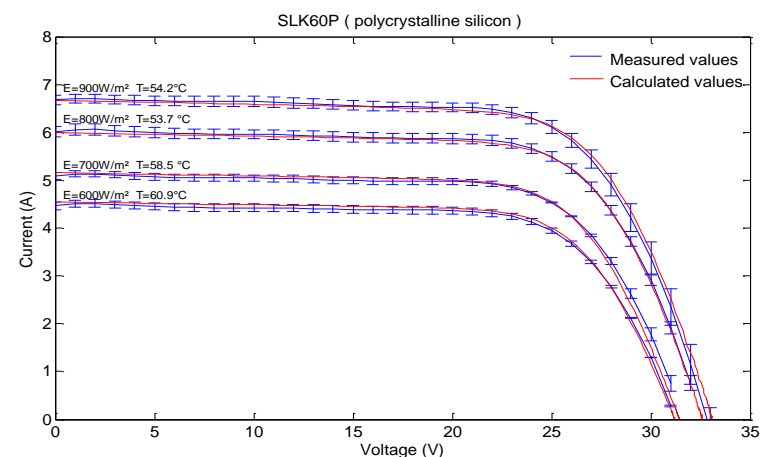

Figure 8. Errors bars and simulated I-V curves for different irradiances and temperatures for: SLK60P

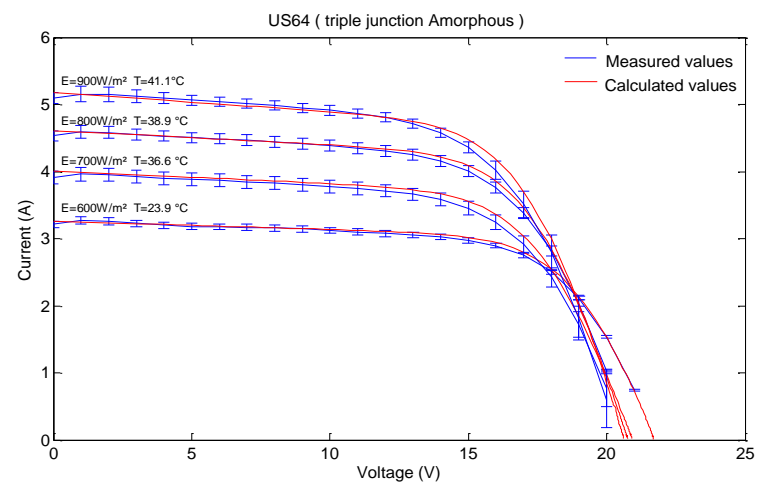

Figure 9. Errors bars and simulated I-V curves for different irradiances and temperatures for: US64

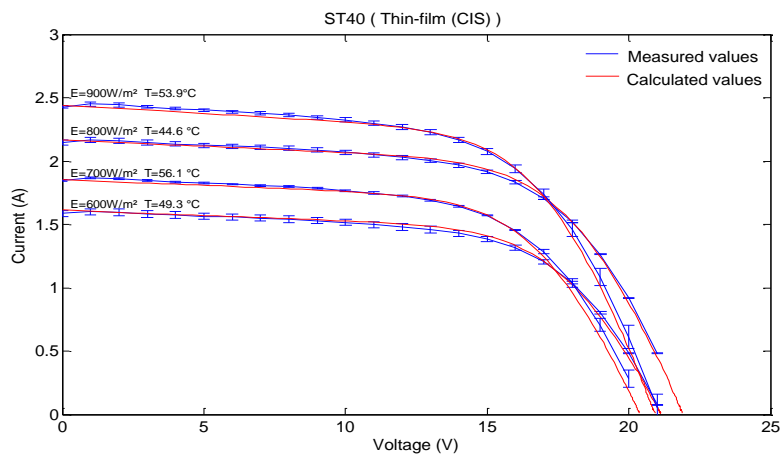

Figure 10. Errors bars and simulated I-V curves for different irradiances and temperatures for: ST40 
For an objective evaluation of the correlation existing between experimental data and the simulation results obtained via analytical and FA models, for all five parameters model, the accuracy of the proposed methods was evaluated through the calculation of four different statistical indicators described in the section 4.4.

The findings regarding the photogenerated current (IL) illustrate a good correlation between observed and calculated values for the three used Equations (2-4). However, the third Equation 4 provides the best precisions according employed statistical criteria for most of the tested modules.

Regarding the diode saturation current (I0) calculated by Equation.5 and Equation.7, the statistical parameters show more significant estimation for Equation.7. Whereas, the mentioned outcomes is achieved when $\mathrm{m}$ is considered variable.

Rs: the first tested Equation 8 gives better result for all statistical criterions against the second equation.

The Rsh values obtained by Equation.10 and Equation.11, respectively, illustrate that the first Equation 10 present moderate precisions. However, despite these little accuracies, the both equations give generally weak estimation of Rsh, proved by their low correlations coefficient $\left(\mathrm{R}^{2}\right)$.

- The results obtained by the FA show better accuracy compared to those analytical model and those obtained by empirical model, as reported in Table 3

- The RMSE makes a comparison test between the estimated and measured values. It has been averred that the FA structure provide good fit.

- In addition, the comparison between models upon R2 gives a perfect determination coefficient close to one, mainly in the case of IL parameters for both methods (FA) and empirical model). The comparison between the obtained findings shows that the improvements of correlation of model parameters are then observed in term of I0 and Rsh for all tested modules, and less significant amelioration for IL parameter.

- The RMSE makes a comparison test between the estimated and measured values. It has been averred that the FA structure provide good fit.

\section{Conclusion}

The contribution proposed in this study provides a practical model that predicts the PV module characteristics, in precise and convenient manner. The adopted methodology consists of using two approaches: FA and analytical models that have been applied through five parameters PV module model. In addition, a comparative study between experimental and simulated data has been carried out. The required parameters of currentvoltage (I-V) curve such as the light-generated current, diode reverse saturation current, 
512 10 $10^{\mathrm{TH}}$ INTERNATIONAL CONFERENCE ON Sustainable ENERGy AND ENVIRONMENTAL Protection (June $27^{\mathrm{TH}}-30^{\mathrm{TH}}, 2017$, BlED, SLOVENIA), RENEWABLE ENERGY SOURCES I. Hadj Mahammed, A. Hadj Arab, S. berrah, Y. Bakelli, M. Khennane Benbitour, S. Hamid Oudjana, A. Fezzani \& L. Zaghba: Comparison Study to Select an Optimum Photovoltaic PV Module Model Under Experimental Performances

serial resistors and shunt resistors were computed according to the outdoor conditions. The statistical test has indicated the high ability of FA model to estimate the variation of the PV module parameters according to the irradiance and temperature. As another future work, a comparative study with the other metaheuristic algorithm can be carried out.

Table 2 Analytical models performance of tested PV modules

\begin{tabular}{|c|c|c|c|c|c|c|c|c|c|c|}
\hline & \multicolumn{3}{|c|}{ IL } & \multicolumn{3}{|c|}{$\mathrm{I}_{0}$} & \multicolumn{2}{|c|}{ Rs } & \multicolumn{2}{|c|}{ Rsh } \\
\hline & Eq.(8) & Eq.(9) & Eq.(10) & Eq.(11) & $\begin{array}{l}\text { Eq.(13) } \\
\mathrm{m}=1.3\end{array}$ & $\begin{array}{c}\text { Eq.(13) } \\
\mathrm{m}=\mathrm{Eq} .(4)\end{array}$ & Eq.(14) & Eq.(15) & Eq.(16) & Eq.(17) \\
\hline $\mathrm{R}^{2}$ & 0.9997 & 0.9997 & 0.9997 & 0.727 & 0.726 & 0.992 & 0.824 & 0.008 & 0.596 & 0.236 \\
\hline RMSE & 0.0266 & 0.0263 & 0.0262 & $3.74 \mathrm{E}-07$ & $7.82 \mathrm{E}-07$ & $3.30 \mathrm{E}-07$ & 0.166 & 0.808 & 184.986 & 174.485 \\
\hline $\mathrm{R}^{2}$ & 0.9926 & 0.9927 & 0.9928 & 0.087 & 0.076 & 0.870 & 0.731 & 0.002 & 0.455 & 0.007 \\
\hline RMSE & 0.1020 & 0.1021 & 0.1008 & $1.27 \mathrm{E}-06$ & $1.54 \mathrm{E}-06$ & $4.59 \mathrm{E}-07$ & 0.128 & 14.374 & 117.589 & 297.592 \\
\hline $\mathrm{R}^{2}$ & 0.9962 & 0.9962 & 0.9963 & 0.280 & 0.267 & 0.963 & 0.919 & 0.006 & 0.671 & 0.008 \\
\hline RMSE & 0.0369 & 0.0353 & 0.0345 & $2.22 \mathrm{E}-08$ & $3.97 \mathrm{E}-08$ & $5.09 \mathrm{E}-09$ & 0.071 & 17.535 & 84.263 & 2896.140 \\
\hline $\mathrm{R}^{2}$ & 0.9990 & 0.9988 & 0.9989 & 0.593 & 0.568 & 0.967 & 0.835 & 0.003 & 0.697 & 0.004 \\
\hline RMSE & 0.0534 & 0.0448 & 0.0424 & $6.07 \mathrm{E}-09$ & $7.12 \mathrm{E}-07$ & $4.60 \mathrm{E}-09$ & 0.023 & 0.934 & 22.120 & 3680.671 \\
\hline $\mathrm{R}^{2}$ & 0.9968 & 0.9967 & 0.9969 & 0.006 & 0.009 & 0.991 & 0.621 & 0.002 & 0.118 & 0.001 \\
\hline RMSE & 0.0638 & 0.0701 & 0.0612 & $4.04 \mathrm{E}-07$ & $6.44 \mathrm{E}-07$ & $9.09 \mathrm{E}-08$ & 0.208 & 13.429 & 219.610 & 326.724 \\
\hline $\mathrm{R}^{2}$ & 0.9954 & 0.9957 & 0.9957 & 0.000 & 0.001 & 0.895 & 0.510 & 0.019 & 0.320 & 0.066 \\
\hline RMSE & 0.0753 & 0.0796 & 0.0589 & $2.54 \mathrm{E}-07$ & $3.62 \mathrm{E}-07$ & $2.58 \mathrm{E}-07$ & 0.061 & 0.512 & 30.908 & 34.900 \\
\hline $\mathrm{R}^{2}$ & 0.9991 & 0.9990 & 0.9990 & 0.361 & 0.386 & 0.837 & 0.875 & 0.002 & 0.826 & 0.121 \\
\hline RMSE & 0.0163 & 0.0142 & 0.0109 & $3.63 \mathrm{E}-07$ & $2.79 \mathrm{E}-06$ & $6.56 \mathrm{E}-07$ & 0.032 & 22.488 & 8.525 & 87.512 \\
\hline
\end{tabular}

Table 3 firefly performance of tested PV modules

\begin{tabular}{|c|c|c|c|c|c|c|}
\hline & \multicolumn{5}{|c|}{ Firefly model algorithm } \\
\hline & & $\mathrm{I}_{\mathrm{L}}$ & $\mathrm{m}$ & $\mathrm{I}_{0}$ & Rs & Rsh \\
\hline \multirow{2}{*}{ SLK 72M } & $\mathrm{R}^{2}$ & 0.9999 & 0.9579 & 0.9540 & 0.9961 & 0.8751 \\
\hline & RMSE & 0.0106 & 0.0169 & $1.38 \mathrm{E}-07$ & 0.0256 & 70.8201 \\
\hline \multirow{2}{*}{ SHARP175 } & $\mathrm{R}^{2}$ & 0.9971 & 0.7439 & 0.5109 & 0.9179 & 0.8248 \\
\hline & RMSE & 0.0701 & 0.0468 & 7.40E-07 & 0.0701 & 63.7949 \\
\hline \multirow{2}{*}{ ASE95 } & $\mathrm{R}^{2}$ & 0.9998 & 0.6597 & 0.7624 & 0.9565 & 0.8897 \\
\hline & RMSE & 0.0228 & 0.0228 & $4.58 \mathrm{E}-09$ & 0.0119 & 13.3121 \\
\hline \multirow{2}{*}{ SLK60P } & $\mathrm{R}^{2}$ & 0.9999 & 0.6240 & 0.7694 & 0.9569 & 0.9141 \\
\hline & RMSE & 0.0238 & 0.0299 & $4.44 \mathrm{E}-09$ & 0.0110 & 11.7719 \\
\hline \multirow{2}{*}{ BP3160 } & \begin{tabular}{|l|}
$\mathrm{R}^{2}$ \\
\end{tabular} & 0.9988 & 0.8788 & 0.8339 & 0.9847 & 0.9442 \\
\hline & RMSE & 0.0389 & 0.0415 & $1.54 \mathrm{E}-07$ & 0.0419 & 55.9180 \\
\hline \multirow{2}{*}{ US64 } & $\mathrm{R}^{2}$ & 0.9987 & 0.7377 & 0.4666 & 0.7654 & 0.8618 \\
\hline & RMSE & 0.0350 & 0.0841 & $1.07 \mathrm{E}-07$ & 0.0402 & 13.4330 \\
\hline \multirow{2}{*}{ ST40 } & $\mathrm{R}^{2}$ & 0.9998 & 0.9788 & 0.6961 & 0.9747 & 0.9879 \\
\hline & RMSE & 0.0061 & 0.0111 & $8.31 \mathrm{E}-08$ & 0.0141 & 2.0927 \\
\hline
\end{tabular}



Protection (June $27^{\mathrm{TH}}-30^{\mathrm{TH}}, 2017$, BLED, SLOVENiA), RENEWABLE ENERGY SOURCES

I. Hadj Mahammed, A. Hadj Arab, S. berrah, Y. Bakelli, M. Khennane Benbitour, S. Hamid Oudjana, A. Fezzani \& L. Zaghba: Comparison Study to Select an Optimum Photovoltaic PV Module Model Under Experimental Performances

\section{References}

[1] "Shariket Kahraba wa Taket Moutadjadida.” [Online]. Available: http://www.sktm.dz.

[2] "Ministère de l’Énergie - Algérie - Bienvenue." [Online]. Available: http://www.energy.gov.dz/francais/.

[3] M. U. Siddiqui and M. Abido, "Parameter estimation for five- and seven-parameter photovoltaic electrical models using evolutionary algorithms," Appl. Soft Comput., vol. 13, no. 12, pp. 4608-4621, Dec. 2013.

[4] W. De Soto, "Improvement and validation of a model for photovoltaic array performance," Master of Science in Mechanical Engineering, University of Wisconsin, Madison, 2004.

[5] A. N. Celik and N. Acikgoz, "Modelling and experimental verification of the operating current of mono-crystalline photovoltaic modules using four- and five-parameter models," Appl. Energy, vol. 84, no. 1, pp. 1-15, 2007.

[6] A. Hadj Arab, F. Chenlo, and M. Benghanem, "Loss-of-load probability of photovoltaic water pumping systems," Sol. Energy, vol. 76, no. 6, pp. 713-723, 2004.

[7] W. De Soto, S. A. Klein, and W. A. Beckman, "Improvement and validation of a model for photovoltaic array performance,” Sol. Energy, vol. 80, no. 1, pp. 78-88, 2006.

[8] L. Zhang and Y. Fei Bai, "Genetic algorithm-trained radial basis function neural networks for modelling photovoltaic panels," Eng. Appl. Artif. Intell., vol. 18, no. 7, pp. 833-844, Oct. 2005.

[9] E. Karatepe, M. Boztepe, and M. Colak, "Neural network based solar cell model," Energy Convers. Manag., vol. 47, no. 9-10, pp. 1159-1178, 2006.

[10] A. N. Celik, "Artificial neural network modelling and experimental verification of the operating current of mono-crystalline photovoltaic modules," Sol. Energy, vol. 85, no. 10, pp. 2507-2517, 2011.

[11] R. K. Kharb, S. L. Shimi, S. Chatterji, and M. F. Ansari, "Modeling of solar PV module and maximum power point tracking using ANFIS," Renew. Sustain. Energy Rev., vol. 33, pp. 602-612, May 2014.

[12] V. Lo Brano, A. Orioli, and G. Ciulla, "On the experimental validation of an improved fiveparameter model for silicon photovoltaic modules," Sol. Energy Mater. Sol. Cells, vol. 105, pp. 27-39, 2012.

[13] J. A. Gow and C. D. Manning, "Development of a photovoltaic array model for use in power-electronics simulation studies.," IEE Proc. Electr. Power Appl., vol. 146, no. 2, pp. 193-200, Mar. 1999.

[14] A. Goetzberger and V. U. Hoffmann, Photovoltaic Solar Energy Generation. Springer, 2005.

[15] T. Ikegami, T. Maezono, F. Nakanishi, Y. Yamagata, and K. Ebihara, "Estimation of equivalent circuit parameters of PV module and its application to optimal operation of PV system,” Sol. Energy Mater. Sol. Cells, vol. 67, no. 1-4, pp. 389-395, 2001.

[16] Y. Sukamongkol, S. Chungpaibulpatana, and W. Ongsakul, "A simulation model for predicting the performance of a solar photovoltaic system with alternating current loads," Renew. Energy, vol. 27, pp. 237-258, 2002.

[17] F. Bonanno, G. Capizzi, G. Graditi, C. Napoli, and G. M. Tina, "A radial basis function neural network based approach for the electrical characteristics estimation of a photovoltaic module," Appl. Energy, vol. 97, pp. 956-961, Sep. 2012.

[18] A. K. Tossa, Y. M. Soro, Y. Azoumah, and D. Yamegueu, "A new approach to estimate the performance and energy productivity of photovoltaic modules in real operating conditions," Sol. Energy, vol. 110, pp. 543-560, 2014.

[19] M. G. Villalva, J. R. Gazoli, and E. R. Filho, "Comprehensive Approach to Modeling and 
$514 \quad 10^{\text {TH }}$ INTERNATIONAL CONFERENCE ON Sustainable ENERGy AND ENVIRONMENTAL Protection (June $27^{\mathrm{TH}}-30^{\mathrm{TH}}, 2017$, Bled, SLOVENIA), RENEWABLE ENERGY SOURCES I. Hadj Mahammed, A. Hadj Arab, S. berrah, Y. Bakelli, M. Khennane Benbitour, S. Hamid Oudjana, A. Fezzani \& L. Zaghba: Comparison Study to Select an Optimum Photovoltaic PV Module Model Under Experimental Performances

Simulation of Photovoltaic Arrays," Power Electron. IEEE Trans., vol. 24, no. 5, pp. 1198 1208, 2009.

[20] H. Tian, F. Mancilla-David, K. Ellis, E. Muljadi, and P. Jenkins, "A cell-to-module-toarray detailed model for photovoltaic panels," Sol. Energy, vol. 86, no. 9, pp. 2695-2706, Sep. 2012.

[21] Baykasoğlu, Adil, and Fehmi Burcin Ozsoydan. 'An Improved Firefly Algorithm for Solving Dynamic Multidimensional Knapsack Problems'. Expert Systems with Applications 41, no. 8 pp. 3712-3725 June 2014.

[22] Fister, ztok, Iztok Fister, Xin-She Yang, and Janez Brest. 'A Comprehensive Review of Firefly Algorithms'. Swarm and Evolutionary Computation pp 34-46, December 2013:.

[23] Jrodehi, A. Rezaee. 'Parameter Estimation of Solar Photovoltaic (PV) Cells: A Review'. Renewable and Sustainable Energy Reviews 61, pp: 354-371 August 2016. 
$10^{\mathrm{TH}}$ InTERnATIONAL CONFERENCE ON Sustainable ENERgy AND ENVIRONMENTAL Protection (June $27^{\mathrm{TH}}-30^{\mathrm{TH}}$, 2017, Bled, SLOVENIA), RENEWABLE ENERGy SOURCES

J. Krope, A.Ghani Olabi, D. Goričanec \& S. Božičnik

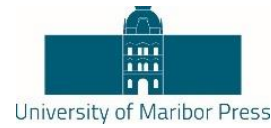

\title{
Technical and Economical Part of Investments in Solar Power Plants and Small Hydro Power Plants - Comparison Between Technologies
}

\author{
SEBASTIJAN SEME, KLEMEN SREDENŠEK, BoJAn ŠTuMBERGER \& MiRALEM \\ HADŽISELIMOVIĆ
}

\begin{abstract}
This paper deals with multi-criteria evaluation of the technical and economical part of the investment in construction of solar power plant and small hydro power plant. The objective of this article is to show advantages and disadvantages of each technology in terms of technical and economical part of the placement in an area. The input parameters of the technical part, when considering solar power plants, are: intensity of solar radiation, the slope and efficiency of solar modules, while the output parameters of the technical part are power and produced electrical energy. The input parameters of the technical part, when considering small hydroelectric power plants, are: head, flow, the type of turbine and efficiency of a generator, while the output parameters of the technical part are power and produced electrical energy. When considering the economic part the eligibility of the construction of solar power plants and small hydroelectric power plants is verified based on technical data. On the basis of the investment and operating costs an analysis of the viability of investment at different purchase prices of electricity is implemented, with the help of dynamic indicators. This paper presents a new approach to multi-criteria single aim valuation giving the estimation of suitability for the construction of solar power plants and small hydroelectric power plants as a result. Single aim multi-criteria evaluation gives us the basis for deciding which technology is appropriate for placement in an area.
\end{abstract}

Keywords: • Solar power plant $\bullet$ Small hydro power plant $\bullet$ Net present value $\bullet$ Internal rate of return $\bullet$ technologies $\bullet$

CoRReSPONDENCE AdDRESS: Sebastijan Seme, Ph.D., Associate Professor, University of Maribor, Faculty of Energy Technology, Hočevarjev trg 1, SI-8270, Krško, Slovenia, e-mail: sebastijan.seme@um.si. Klemen Sredenšek, Students, University of Maribor, Faculty of Energy Technology, Hočevarjev trg 1, SI-8270, Krško, Slovenia, e-mail: klemen.sredensek@gmail.com. Bojan Štumberger, Ph.D., Full Professor, University of Maribor, Faculty of Energy Technology, Hočevarjev trg 1, SI-8270, Krško, Slovenia, e-mail: bojan.stumberger@um.si. Miralem Hadžiselimović, Ph.D., Associate Professor, University of Maribor, Faculty of Energy Technology, Hočevarjev trg 1, SI-8270, Krško, Slovenia, e-mail: miralem.h@um.si.

https://doi.org/10.18690/978-961-286-061-5.45

ISBN 978-961-286-061-5

(C) 2017 University of Maribor Press

Available at: http://press.um.si. 
$10^{\text {TH }}$ International CONFEREnce on Sustainable Energy and Environmental Protection (JuNE $27^{\mathrm{TH}}-30^{\mathrm{TH}}, 2017$, BlED, SLOVENIA), RENEWABLE ENERGY SOURCES S. Seme, K. Sredenšek, B. Štumberger \& M. Hadžiselimović: Technical and Economical Part of Investments in Solar Power Plants and Small Hydro Power Plants Comparison Between Technologies

The share of distributed electricity produced from renewable energy sources (RES) has been increasing recently [1-2]. This is mainly a consequence of the support schemes to production units up to $125 \mathrm{MW}$ of electricity from RES and combined heat and power (CHP). Slovenia also strives to commitments in the context of the adoption of the climate and energy legislative package (decision 406/2009/EC) [3], however it is necessary in Slovenia to take advantages of those energy sources that are available to us. Energy can be harnessed on many rooftops for construction of solar power plants (SPP) [4-5] and on many small rivers for construction of small hydro power plants (SHPP) [6-7], which are based on proven, mature technology [8].

This paper presents the process of degerming the eligibility of investments in SPP [9] and SHPP [10] and by changes in the support mechanism for renewable energy production. The support mechanisms for RES changes exist, not only in other European countries and in the world, but in Slovenia as well. In Slovenia, the energy agency is responsible for changes in support mechanism of RES, which is with article 373 of the Energy act obliged to annually publish a public invitation to investors to submit the proposal for RES and CHP generating plants, to enter the support scheme. Investors in the notified projects for generating plants RES and CHP offer price of electricity in $€ / \mathrm{MWh}$ of production unit, within which electrical energy will be successfully produced. Based on technical data we conducted multi-criteria evaluation of technical and economic analysis of the viability of investment in the construction of SPP and SHPP at different prices to purchase electricity [11-14]. We used the dynamic indicators for calculation of the economic viability of constructing SPP and SHPP. The results of the economic analysis indicate that investments in SPP [15] and SHPP [16-17] make sense, but the eligibility of investments significantly affects the price of the support provided purchase of electricity. We found that the price of electricity is proportional to the indicators of eligibility of the investment, which means the higher the price of electricity, the more positive the indicators are. In the case of the reference price of electricity in Slovenia for $2017,41.94 € / \mathrm{kWh}$, the construction is not paid off, while investment in SHPP is returned in 9.3 years. Investors are advised to decide for investment only if the price of provided purchase is achieved at which the payback period is shorter than 10 years. Thus, the provided purchase price for the SPP is $146.79 € / \mathrm{kWh}$, while for SHPP is $33.55 € / \mathrm{kWh}$.

The goal of this paper is to present a multi-criteria evaluation of the advisability of construction the SPP on the roof of the building and SHPP on a small river with a known flow rate. This paper is composed of technical (second section) and economical part (third section). The fourth section is about multi-criteria evaluation of investments in SPP and SHPP. 

Protection (June 27 $7^{\mathrm{TH}}-30^{\mathrm{TH}}, 2017$, BLED, SLOVENIA), RENEWABLE ENERGY SOURCES

S. Seme, K. Sredenšek, B. Štumberger \& M. Hadžiselimović: Technical and Economical Part of Investments in Solar Power Plants and Small Hydro Power Plants Comparison Between Technologies

\section{Tehnical Part of the Investment}

This section presents the technical part of the investment, which ultimately gives the amount of electricity produced by SPP and SHPP.

\subsection{Tehnical part of the investment in solar power plants}

In the technical part of the SPP calculation the emphasis is on the intensity of solar radiation on horizontal surface, the inclination angle, efficiency of solar module and efficiency of inverters, calculated estimated production of electricity.

The intensity of solar radiation on horizontal surface is shown in Fig. 1.

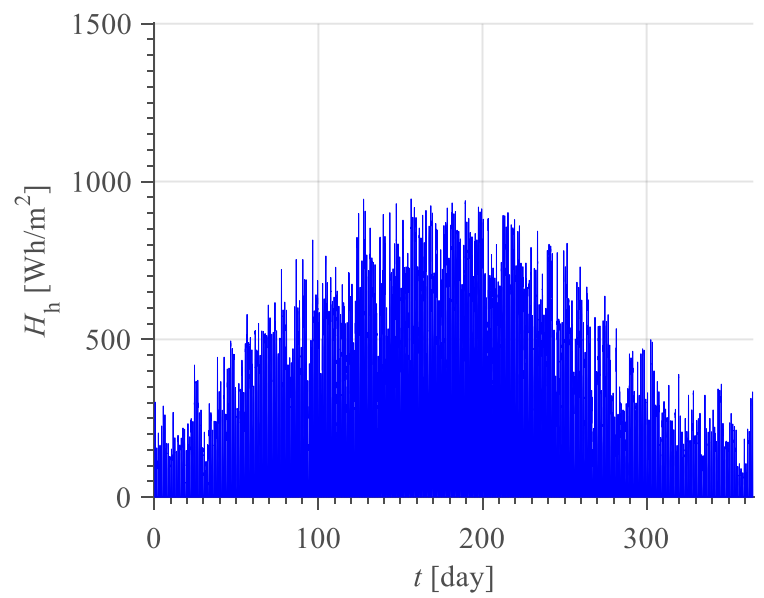

Figure 1. Intensity of solar radiation on horizontal surface.

Based on the known methods for the calculation of the intensity of solar radiation on any oriented surface [18-22], we determined the most suitable inclination and azimuth angles for Slovenia. The highest intensity of solar radiation is received when the surface is facing $188^{\circ} \mathrm{SW}$ with an inclination angle of $48^{\circ}$. The production of electricity of SPP can now be calculated with the help of the efficiencies of solar modules and inverters. In doing so, we have chosen the installed power of the SPP $P_{\mathrm{SE}}=300 \mathrm{~kW}$. 
$10^{\text {TH }}$ International CONFEREnce on Sustainable Energy and Environmental Protection (June $27^{\mathrm{TH}}-30^{\mathrm{TH}}, 2017$, Bled, SLOVENIA), Renewable ENERGy SOURCES S. Seme, K. Sredenšek, B. Štumberger \& M. Hadžiselimović: Technical and Economical Part of Investments in Solar Power Plants and Small Hydro Power Plants Comparison Between Technologies

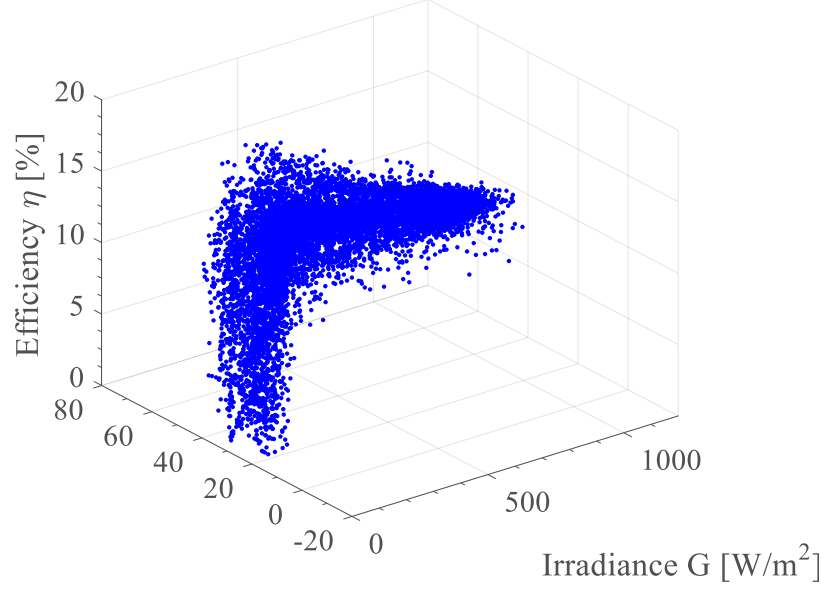

Module temperature $\mathrm{T}\left[{ }^{\circ} \mathrm{C}\right]$

Figure 2. Solar power plant efficiency as a function of intensity of solar radiation and temperature.

Depending on the intensity of solar radiation and selected installed power $P_{\mathrm{SE}}=300 \mathrm{~kW}$, we can calculate the expected annual production of electricity, which is in this case $364 \mathrm{MWh}$.

\subsection{Tehnical part of the investment in small hydro power plants}

In the technical part, all the major constituent elements of SHPP are calculated on basis of specified gross head and water flow: calculation of the pipeline diameter, construction components of coverage, selection of appropriate elements and calculation of SHPP connection to the grid. Based on these results, the production of electricity in SHPP is estimated.

The gross head $\left(H_{\mathrm{b}}\right)$ differential elevation of intended coverage ( $\left.A l t_{\text {coverage }}\right)$ provided to the engine (Alt $\left.t_{\text {engine }}\right)$. With the help of the altimeter the altitude of intended coverage and provided engine was measured, $A l t_{\text {coverage }}=903 \mathrm{~m}$ and $A l t_{\text {engine }}=840 \mathrm{~m}$, which means that the gross head $H_{\mathrm{b}}=63 \mathrm{~m}$.

The river is torrential type, but nevertheless it is suitable for energy use, as it has constant flow in dry periods. Characteristic hydrological data of the water flow profile are: mean annual flow: $0.70 \mathrm{~m}^{3} / \mathrm{s}$, minimal flow rate: $0.20 \mathrm{~m}^{3} / \mathrm{s}$ and maximum flow rate: $0.75 \mathrm{~m}^{3} / \mathrm{s}$ (100 annual water). Information on flow rates are determined based on the rainfall areas, average annual rainfall, discharge coefficient, or on the basis of measurements and observations made in the previous period. The water flow is determined on the basis of 
assigned concession. In this paper, it was assumed that the water flow through the SHPP must not exceed $0.60 \mathrm{~m}^{3} / \mathrm{s}$. It is also obligation of concessionaire to pay concession each year, which is proportional to the availability of water and electrical price on the market.

Coverage and engine will be connected with the pressure line. The measured length of the planed pipeline between the intended coverage and the engine is 750 meters. Depending on the calculated input data the cost-effective pipeline diameter $(D)$ is $D=0.65 \mathrm{~m}$. In the given economical pipeline diameter, the net head $\left(H_{\mathrm{n}}\right)$ is $H_{\mathrm{n}}=57.87 \mathrm{~m}$. The net head is calculated by subtracting the gross head losses in the pipeline, the loss of the fall of the flow and return lines. The inlet has no losses, however, we must consider the loss of 1 meter drop in the outlet, since the engine room must be placed slightly above the channel because of the extremely high water. Thus, the proportion of the net head is the percentage of the gross head $H(\%)=91.86 \%$.

In the given economical pipeline, the net head is $H_{\mathrm{n}}=4774 \mathrm{~m}$. Based on the calculations Fig. 3 shows the percentage of the net head in the percentage of the gross head at different pipe diameters, which diameter of the pipeline is reduced from $0.40 \mathrm{~m}$ in the step of $0.02 \mathrm{~m}$ up to the diameter of $1.00 \mathrm{~m}$. Further reduction does not make sense because the losses in small pipe diameters are too big.

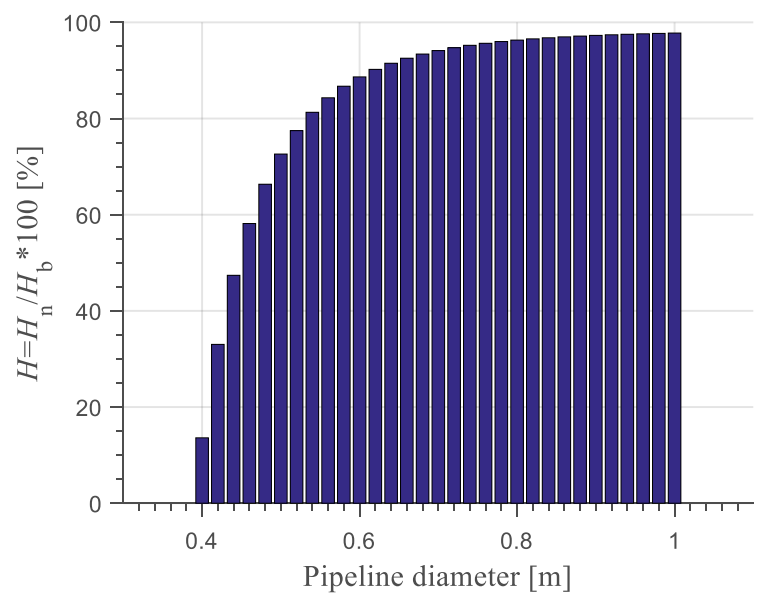

Figure 3. The share of net head in the comparison of the gross head in different pipe diameters.

Rated output power depends on the choice of the diameter of the pipeline. So we calculated the power at the generator terminals in case of selecting the pipeline from $0.40 \mathrm{~m}$ to $1.00 \mathrm{~m}$. The power at the generator terminals $P[\mathrm{~kW}]$ is the product of the nominal water flow, the net head, gravitational acceleration, the density of water, the efficiency of the turbine and the efficiency of generator and as shown in Fig. 4. 
$520 \quad 10^{\text {TH }}$ InTERnAtional CONFERENCE ON Sustainable ENERGy AND ENVIRONMENTAL Protection (JuNE $27^{\mathrm{TH}}-30^{\mathrm{TH}}, 2017$, BlED, SLOVENIA), RENEWABLE ENERGY SOURCES S. Seme, K. Sredenšek, B. Štumberger \& M. Hadžiselimović: Technical and Economical Part of Investments in Solar Power Plants and Small Hydro Power Plants Comparison Between Technologies

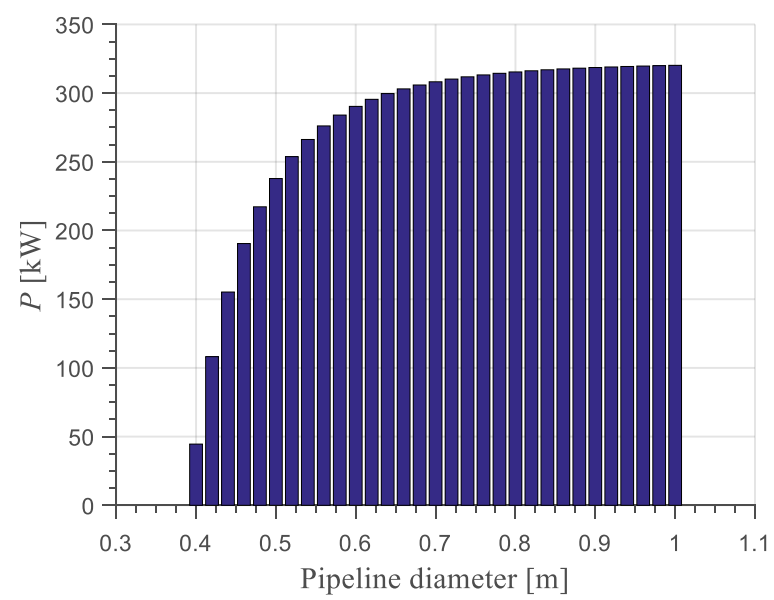

Figure 4. Power on generator terminals for different pipe diameters.

Due to economical pipeline diameter $(0.65 \mathrm{~m})$ and power at the generator terminals $(300 \mathrm{~kW})$ we can calculate the expected annual production of electricity which is in our case $1342 \mathrm{MWh}$.

\section{Economic Part of the Investment}

Based on data calculated in the technical part of the investment (second section), economic viability analysis of investment for SPP and SHPP is conducted. The economic viability of the investment is determined by both static and dynamic indicators. The economic calculation was for both cases (SPP and SHPP) assumed with input data such as project financing mode (share of own founds and bank load), interest rate, period of credit repayment, inflation rate, discount rate, lifetime of the project. The provided electricity production was calculated in section 2.1 and 2.2. The investment stake is evaluated in the followings. The calculation of economic indicators, which is based on different prices of electricity, is made. We also observed what happens if the provided investment stake increases or decreases.

22. 9. 2014, Borzen (electricity market) provided subsidies in the form of guaranteed purchase or operational support in order to increase the share of renewable energy sources in the new operational units. For SPP and SHPP was possible to obtain support for 15 years from the beginning of the operation, after this period the produced electricity was sold at market price. Provided purchase price for the SPP up to $1 \mathrm{MW}$ amounted to 89.75 $€ / \mathrm{MWh}$ and $92.61 € / \mathrm{MWh}$ for SHPP up to $1 \mathrm{MW}$ in the period of 15 years.

With the new energy law, the granting support is carried out through a public tender, which will be published by the energy agency. In the system of granting support will be 
selected projects that will determine the level of support by themselves but the support scheme will include only those who will offer the lowest price. The economic analysis also notes which purchase price of electricity is acceptable to the investor to decide for the realization of the project.

For the analysis, we assumed the following input data: installed power (SPP and SHPP) is $300 \mathrm{~kW}$, the inflation rate is $2 \%$, the discount rate is $5 \%$, the ratio of the funding is $80 \%$ the loan and $20 \%$ are own resources, the interest rate is $2.8 \%$, the return period of the loan is 10 years and the lifetime of the project is 25 years.

We considered that in Slovenia the reference price of electricity in 2017 amounted to $41.94 € / \mathrm{MWh}$.

Estimated investment stake in SPP amounts $357.429,00 €$. Depending on the rated power of the SPP, the estimated contribution amounts to $1,191.43 € / \mathrm{kW}$. Estimated investment stake in SHPP amounts 540,000.00 €. Depending on the rated power of the SHPP, the estimated contribution amounts to $1,800.00 € / \mathrm{kW}$.

Net present value (NPV) decided whether the implementation of the investment is worthwhile. It is calculated in a way that all returns and capital inputs are discounted to the start of the term (1).

$$
N P V=\sum_{t} \frac{D_{t}}{\left(1+r_{i}\right)^{t}}-I V
$$

Where $N P V$ is net present value $(€), D_{\mathrm{t}}$ income in the period $t(€)$ and $r_{\mathrm{i}}$ discount rate $(\%)$. If the NPV is positive, the investment is acceptable, otherwise the investment is rejected.

Internal rate of return is a method by which we observe the maximum discount rate at which the investment is reasonable to be accepted. Internal rate of return (IRR) is calculated by iteration, wherein the calculation is repeated as long as the net present value is zero. IRR is calculated as (2):

$$
0=\sum_{t} \frac{D_{t}}{(1+I R R)^{t}}-I V
$$

If the IRR is higher than the discount rate, which was assumed in the calculation of NPV, then the investment is acceptable, otherwise rejected. If we have more investments available, we decide for one that has the highest internal rate of return. 
522 10 $10^{\mathrm{TH}}$ INTERNATIONAL CONFERENCE ON Sustainable ENERGy AND ENVIRONMENTAL Protection (June $27^{\mathrm{TH}}-30^{\mathrm{TH}}$, 2017, Bled, SLOVENIA), RENEWABLE ENERGY SOURCES S. Seme, K. Sredenšek, B. Štumberger \& M. Hadžiselimović: Technical and Economical Part of Investments in Solar Power Plants and Small Hydro Power Plants Comparison Between Technologies

\section{$4 \quad$ Results}

The results show the viability of investments in SPP and SHPP by which we change the reference price of electricity and capital stake.

Fig. 5 and 6 show a dynamic indicator of NPV as a function of electricity price and investment stake. Observing NPV at different electricity prices (starting price is $41.94 € / \mathrm{MWh}$ and is gradually increased up to 4.5 times of the reference price) and various investment stake. The initial stake (SPP is 357,429.00€ and SHPP is 540,000.00€) was increased by $40 \%$ and reduced by $20 \%$. In the implementation phase of the project unplanned costs may occur.

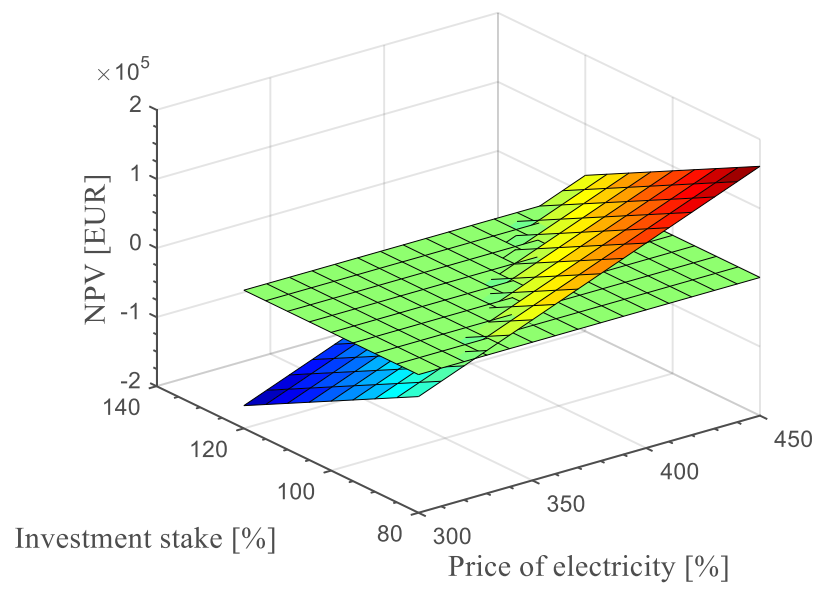

Figure 5. NPV as a function of electricity price and investment stake for solar power plant. 

Protection (June $27^{\mathrm{TH}}-30^{\mathrm{TH}}, 2017$, BLed, Slovenia), RenEwable ENERGY SOURCES

S. Seme, K. Sredenšek, B. Štumberger \& M. Hadžiselimović: Technical and Economical Part of Investments in Solar Power Plants and Small Hydro Power Plants -

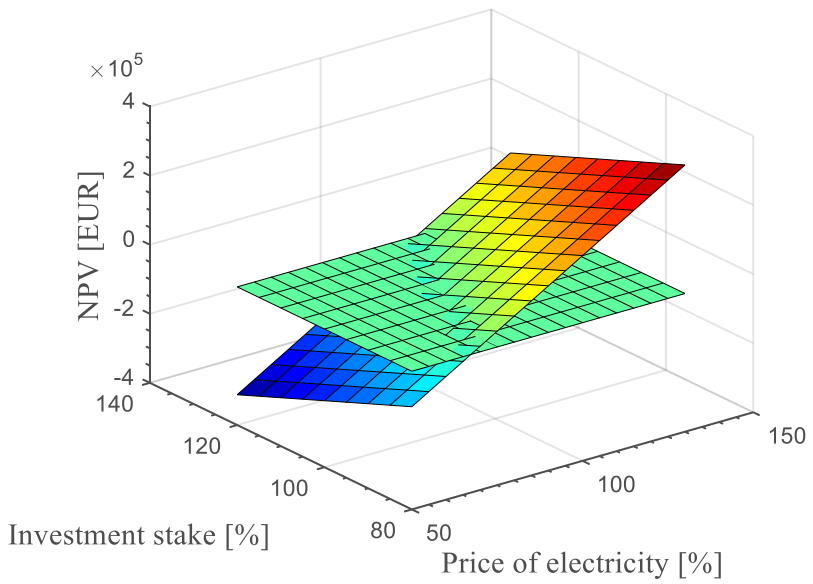

Figure 6. NPV as a function of electricity price and investment stake for small hydro power plant.

Fig. 5 and 6 show that the lower the price of electricity and the higher the investment stake, the lower is the value of NPV which is in some cases even negative. In the area of the graph with dark blue colours, the investment is not economically justified. The results are much better with high electricity prices and lower investment stakes.

Fig. 7 and 8 show a dynamic indicator of IRR as a function of electricity price and investment stake. Same as in Fig. 5 and 6 the base prices are increased up to 4.5 times of the reference price, also the starting input is increased by $40 \%$ and decreased by $20 \%$.

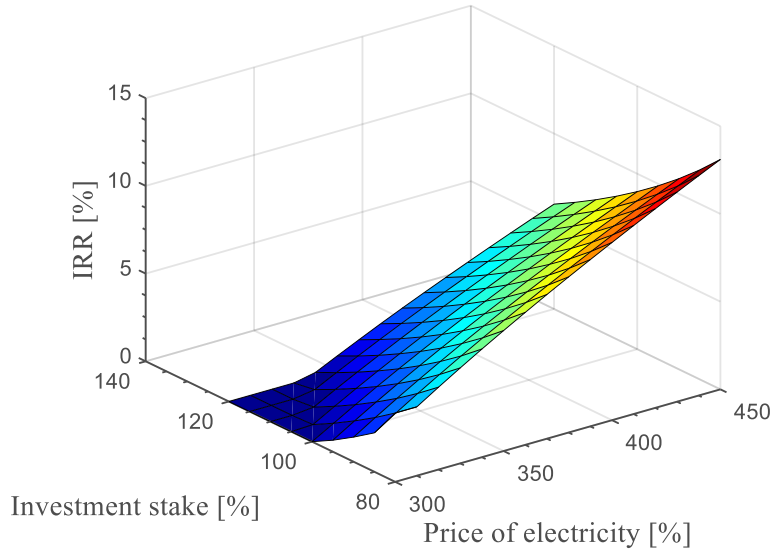

Figure 7. IRR as a function of electricity price and investment stake for solar power plant. 
$10^{\mathrm{TH}}$ International Conference on Sustainable EnERgy and Environmental Protection (June $27^{\mathrm{TH}}-30^{\mathrm{TH}}, 2017$, Bled, SLOVENIA), RENEWABle ENERGY SOURCES S. Seme, K. Sredenšek, B. Štumberger \& M. Hadžiselimović: Technical and Economical Part of Investments in Solar Power Plants and Small Hydro Power Plants Comparison Between Technologies

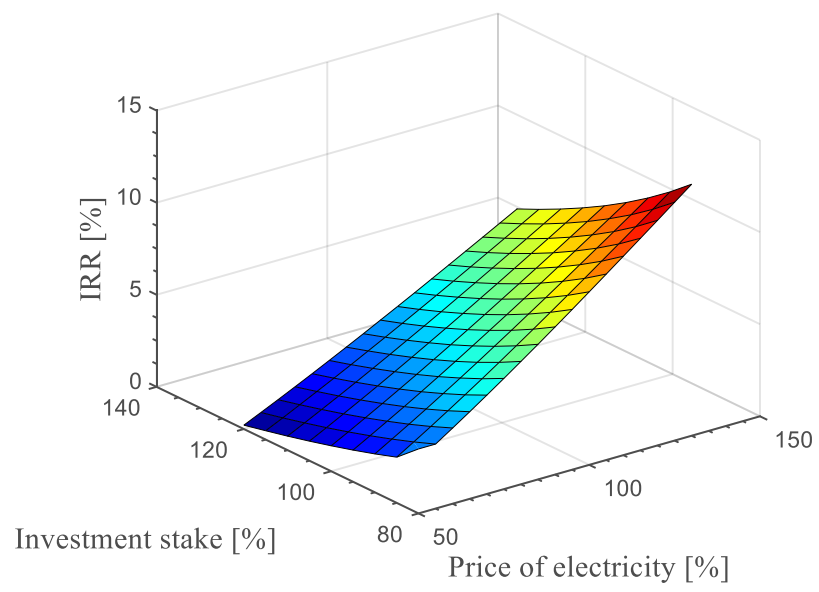

Figure 8. IRR as a function of electricity price and investment stake for small hydro power plant.

The lower the prices of electricity and the higher the investment stake, the lower is the value of IRR. In the area of the graph with dark blue colours, the investment is not economically justified because the IRR is lower than 5\%. The indicator of IRR reaches quite high levels in areas of high electricity prices and in low investment stake.

\section{$5 \quad$ Conclusion}

This paper deals with multi-criteria evaluation of advisability for constructing SPP and SHPP. In the economic part, we found out that the investment is reasonable, but the purchase price of electricity strongly influences on eligibility. As expected, we found out that the higher the purchase prices, more positive the indicators of eligibility of the investment. It turns out that the eligibility in the investment for SPP is 3.5 times of the reference price, while for SHPP it is 0.8 times of the reference price. In this case, the payback period for SPP is 9.2 years and for SHPP 12.7 years. Based on multi-criteria evaluation, it was concluded that the project must be implemented with the minimum investment stake for justified investment, during the construction phase. It turns out that the investment in SPP is much cheaper (almost half) compared to the investment in SHPP but the purchase price of electricity for SPP is 3-4 times higher than the purchase price of electricity for SHPP. 
Protection (June $27^{\mathrm{TH}}-30^{\mathrm{TH}}, 2017$, BLED, SLOVEniA), ReNEWABle ENERGy SOURCES

S. Seme, K. Sredenšek, B. Štumberger \& M. Hadžiselimović: Technical and Economical Part of Investments in Solar Power Plants and Small Hydro Power Plants Comparison Between Technologies

\section{References}

[1] S. K. Sahoo, »Renewable and sustainable energy reviews solar photovoltaic energy progress in India: A review, «Renewable and sustainable energy reviews, vol. 59, pp. 927939, 2016.

[2] S. Thapar, S. Sharma, A. Verma, »Economic and environmental effectiveness of renewable energy policy instruments: Best practices from India, « Renewable and sustainable energy reviews, vol. 66, pp. 487-498, 2016.

[3] $\gg$ Decision No. 406/2009/EC of the european parliament and the council of 23 April 2009, «Official Journal of the European Union, pp. 136-148.

[4] N. Sommerfeldt, H. Madani, $\gg$ Revisiting the techno-economic analysis proces for buildingmounted, grid connected solar photovoltaic systems: Part two - Application, « Renewable and sustainable energy reviews, article in press.

[5] D. Turney, V. Fthenakis, »Environmental impacts from the installation and operation of large-scale solar power pants, Renewable and sustainable energy reviews, vol. 15, pp. 3261-3270, 2011.

[6] O. Paish, »Small hydro power: technology and current status, « Renewable and sustainable energy reviews, vol. 6, pp. 537-556, 2002.

[7] T. Abbasi, S. A. Abbasi, »Small hydro and the environmental implications of its extensive utilization, "Renewable and sustainable energy reviews, vol. 15, pp. 2134-2143, 2011.

[8] D. Kumar, S. Sarkar, » A review on the technology, performance, design optimization, reliability, techno-economics and environmental impacts of hydrokinetic energy conversion systems, «Renewable and sustainable energy reviews, vol. 58, pp. 796-813, 2016.

[9] V. Tomar, G. N. Tiwari, »Techno-economic evaluation of grid connected PV system for households with feed and time of day tariff regulation in New Delhi - A sustainable approach, « Renewable and sustainable energy reviews, vol. 70, pp. 822-835, 2017.

[10] V. K. Singh, S. K. Singal, »Operation of hydro power plants-a review, « Renewable and sustainable energy reviews, vol. 69, pp. 610-619, 2017.

[11] J. P. Deane, B. P. O Gallachoir, E. J. McKeogh, »Techno-economic review of existing and new pumped hydro energy storage plant, «Renewable and sustainable energy reviews, vol. 14, pp. 1293-1302, 2010.

[12] J. K. Kaldellis, »Techno-economic evaluation of small hydro power plants in Greece: a complete sensitivity analysis, « Energy Policy, vol. 33, pp. 1969-1985, 2005.

[13] R. Carapellucci, L. Giordano, F. Pierguidi, »Techno-economic evaluation of small-hydro power plants: Modelling and characterisation of the Abruzzo region in Italy, « Renewable Energy, vol. 75, pp. 395-406, 2015.

[14] Z. Girma, »Techno-economic feasibility of small scale hydropower in Ethiopia: The case of the Kulfo river, in southern Ethiopia, « Journal of renewable energy, vol. 1, pp. 1-12, 2016.

[15] A. H. Mirzahosseini, T. Taheri, »Environmental, technical and financial feasibility study of solar power plants by RETScreen, according to the targeting of energy subsides in Iran, «Renewable and sustainable energy reviews, Vol. 16, pp. 2806-2811, 2012.

[16] N. F. Yah, A. N. Oumer, M. S. Idris, »Small scale hydro-power as a source of renewable energy in Malaysia: A review, « Renewable and sustainable energy reviews, vol. 72, pp. 228-239, 2017.

[17] S. Stevovic, Z. Milanovic, M. Stamatovic, »Sustainable model of hydro power development-Drina river case study, «Renewable and sustainable energy reviews, Vol. 50, pp. 363-371, 2015 
$526 \quad 10^{\mathrm{TH}}$ INTERNATIONAL CONFERENCE ON Sustainable ENERGy AND ENVIRONMENTAL Protection (June $27^{\mathrm{TH}}-30^{\mathrm{TH}}, 2017$, BLED, SLOVENIA), RENEWABLE ENERGY SOURCES S. Seme, K. Sredenšek, B. Štumberger \& M. Hadžiselimović: Technical and Economical Part of Investments in Solar Power Plants and Small Hydro Power Plants Comparison Between Technologies

[18] B. Y. H. Liu and R. C. Jordan, "Daily insolation on surfaces tilted towards the equator," ASHRAE Journal, vol. 3, pp. 53-59, 1961.

[19] J. E. Hay and J. A. Davies, "Proceedings of the first Canadian solar radiation data workshop,“Ministry of supply and services, Toronto, Canada, pp. 59, 1980.

[20] P. Koronakis, "Energy balance analysis of a stand-alone photovoltaic system, including variable system reliability impact,“ Renewable energy, vol. 7, pp. 1161-1180, 2004.

[21] P. Perez, "Solar irradiance conversion models, " Solar cells, vol. 18, pp. 213-222, 1983.

[22] T. M. Klucher, "Evaluation of models to predict insolation on tilted surfaces," Solar energy, vol. 23, pp. 111-114, 1979. 
$10^{\mathrm{TH}}$ InTERnational CONFERENCE ON Sustainable ENERgy AND ENVIRONMENTAL Protection (June $27^{\mathrm{TH}}-30^{\mathrm{TH}}$, 2017, Bled, SLOVENIA), RENEWABLE ENERGy SOURCES

J. Krope, A.Ghani Olabi, D. Goričanec \& S. Božičnik

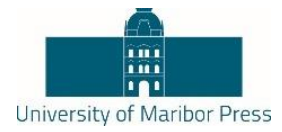

\title{
An Innovative Low Enthalpy Geothermal System: Ground Source Heat Pump and Underground Tank for Heating and Cooling of Buildings
}

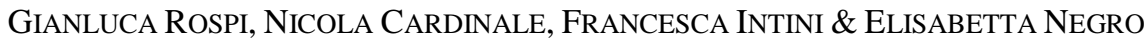

\begin{abstract}
Geothermal heat pumps (GCHP) use the soil (closed loop system) or the ground water of a well (open loop systems) as heat exchanger. The coefficient of performance (COP) and the energy efficiency ration (EER) indicate the heat pump efficiency and they are greater when the difference between of fluid outlet temperature and the ground temperature is smaller. In this paper, an innovative low enthalpy geothermal system was studied. This system uses a simple heat pump and an underground tank, filled with water or a mixture of water and glycol, as geothermal well. An experimental prototype was built in laboratory and analysed with the finite element method FEM.
\end{abstract}

In the first phase of research it was validated the FEM model. In the second phase different analysis were performed.

Keywords: • Geothermal $\bullet$ Low enthalpy $\bullet$ underground tank $\bullet$ FEM model - GCHP •

CoRRESPONDENCE AdDRESs: Gianluca Rospi, Ph.D., adjunct professor, University of Basilicata, Department of European and Mediterranean Cultures, via San Rocco 3, 75100 Matera, Italy, email: gianluca.rospi@unibas.it. Nicola Cardinale, Professor, University of Basilicata, Department of European and Mediterranean Cultures, via San Rocco 3, 75100 Matera, Italy, Francesca Intini, Ph.D., University of Basilicata, Department of European and Mediterranean Cultures, via San Rocco 3, 75100 Matera, Italy, Elisabetta Negro, Ph.D student, University of Basilicata, Department of European and Mediterranean Cultures, via San Rocco 3, 75100 Matera, Italy,

https://doi.org/10.18690/978-961-286-061-5.46

ISBN 978-961-286-061-5

(C) 2017 University of Maribor Press

Available at: http://press.um.si. 
$528 \quad 10^{\text {TH }}$ InTERnAtional CONFERENCE ON Sustainable ENERGy AND ENVIRONMENTAL Protection (June $27^{\mathrm{TH}}-30^{\mathrm{TH}}, 2017$, BlED, SLOVENIA), RENEWABLE ENERGY SOURCES G. Rospi, N. Cardinale, F. Intini \& E. Negro: An Innovative Low Enthalpy Geothermal System: Ground Source Heat Pump and Underground Tank for Heating and Cooling of Buildings

\section{Introduction}

To find an alternative source of fossil fuels is no longer a choice, but an obligation. The European Union Energy Efficiency Action Plan (EC, 2006) set a target of reducing global primary energy use by $20 \%$ by the year 2020 and reversing the trend under current energy and transport policies for $\mathrm{CO} 2$ emissions to increase by about $5 \%$ by 2030 $(\mathrm{EC}, 2007)[1,2]$. This, together with the increasing of costs of non-renewable (fossil) energy resources, has stimulated efforts by public administrations and private stakeholders to investigate new technologies by means of research activities and industrial applications.

Allen A. et al. stated that the rapid development of renewable sources of energy, over the last decade, are caused by the continued uncertainty in Europe over the stability of oil and gas. [3]

The exploitation of geothermal energy is becoming increasingly widespread, as a form of renewable, clean, economically viable energy, and with a just energy policy, could make an important contribution to renewable energy. Respect of the various sustainable energy sources, geothermal energy is one of the easiest to exploit and can be readily developed due to the relatively simple technology involved. Low-enthalpy geothermal resources are much more widespread geographically, but have fewer applications, and generally are not suitable for conversion to electricity. [3]

However, there are factors to not underestimate, the installation and operation of geothermal systems for heating or cooling buildings can cause alterations to the surrounding environment and the aquifers.

The successful implementation of very low-enthalpy geothermal plants for heating and cooling buildings in several European countries has highlighted one such technology.

There are two basic ground source heat pump systems: an earth-coupled (closed-loop) type and a groundwater (open-loop) type (Rafferty, 2000). [4]

In the first type heat exchangers are located underground either horizontally (ground source heat pump, GSHP), vertically (downhole heat exchanger, DHE) or obliquely, and a heat-carrying medium is circulated within the exchanger, transferring the heat from or to the ground via a heat pump.

The operating principle of a GSHP is extremely simple. The subsoil below the surface of the homothermal (15-20m) no longer suffers the influence of daily, seasonal and climatological variations. The temperature at these depths, less than small oscillations (tenths of degree), remains constant over time. 

Protection (June $27^{\mathrm{TH}}-30^{\mathrm{TH}}, 2017$, BLED, SLOVEniA), RENEWABle ENERGy SOURCES G. Rospi, N. Cardinale, F. Intini \& E. Negro: An Innovative Low Enthalpy Geothermal System: Ground Source Heat Pump and Underground Tank for Heating and Cooling of Buildings

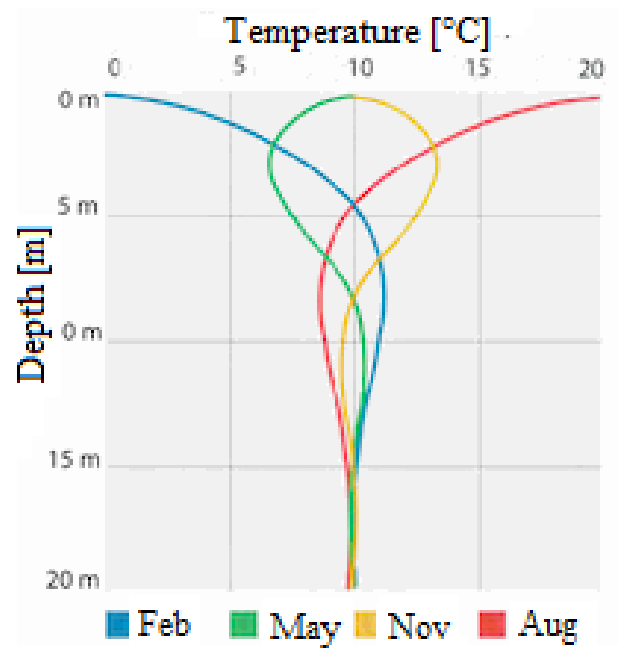

Figure 1 . Trend of montly temperature variation with depth

The GSHP configuration is usually the most cost-effective when adequate yard space is available and trenches are easy to dig, especially while a building is under construction.

DHEs are used when there is a need to install sufficient heat exchange capacity under a confined surface area, such as when the soil is rocky close to the surface. [5]

Studies on Open-loop groundwater heat pumps (GWHP) shown whom these systems typically withdraw groundwater to provide heat (PDEP, 1996) [6]. In the winter, in fact, the GWHP extracts heat from the water to provide space heating. With reversible heat pumps, the heat-transfer process can be reversed in th summer and the groundwater absorbs heat from the living or working space and cools the air (DOE, 1999) [7] . GWHPs are suited to regions with extended shallow aquifers, from which it is relatively easy and not very expensive to extract groundwater (Drijver and Willemsen, 2001) [8].

The open-loop system can be of three types:

- Direct open-loop heat pumps.

- Standing column systems (SCW)

- Indirect open-loop

In the first case, water is passed directly through the heat exchangers of the heat pump, are largely used for residential and very small commercial applications (Rafferty, 2001) [9]. 
$530 \quad 10^{\text {TH }}$ InTERnAtional CONFERENCE ON Sustainable ENERGy AND ENVIRONMENTAL Protection (June $27^{\mathrm{TH}}-30^{\mathrm{TH}}, 2017$, Bled, SLOVENIA), RENEWABle ENERGY SOURCES G. Rospi, N. Cardinale, F. Intini \& E. Negro: An Innovative Low Enthalpy Geothermal System: Ground Source Heat Pump and Underground Tank for Heating and Cooling of Buildings

This system can be used only in low-salinity groundwaters, because the direct use of high-salinity waters can cause scaling, i.e. the deposition of mineral scales in pipes, valves and/or heat exchangers (PDEP, 1996) [6]. The second system, SCW, are used in locations where groundwater wells do not produce sufficient water for a conventional open-loop system and where water quality is good. In SCW systems, groundwater is recirculated from one end of the column well (static water level) to the heat pump, and back to the other end (bottom) of the deep bore. SCW systems can be thought of as a cross between closed-loop earth-coupled systems and open-loop groundwater source systems.

In the third case it is involved a heat exchanger between the building loop and the groundwater, which eliminates exposure of any building components to groundwater (Rafferty, 2001) [9].

However, the lack of national or regional legal frameworks made the application of these systems difficult for administrative point of view. It is necessary to take several actions by the regional environmental authority in order to know the environmental effects due to GWHP installation and operation. One of this effect which has to be taken into account, is the characterization of the aquifers in the region, determination of their potential, and the evaluation of what improvement of the building stock might be feasible on the regional scale, the aim being to estimate what reduction of fossil fuel use might be achieved by the installation of DHE and GWHP systems. Often in open loop system, water cannot return into the aquifer because some undue environmental effects. In the case of an aquifer with a high values of transmissivity and saturated and characterized by thickness which can ensure good heat dispersion in a restricted area around the injection wells, thermal interference between wells will be limited and the environmental effects on the aquifer are absent.

\section{$2 \quad$ Methodology}

The study was performed into two phases an experimental phase and a Numerical computing phase.

To create an innovative low enthalpy geothermal system to cooling the buildings was the primary object of this study and then we analysed the system to heating.

Primarily we analysed different low enthalpy geothermal system used today.

Like told, the low enthalpy geothermal system to heating and cooling are two and which most efficiency is the open circuit system.

For this reason, the first object of this research was to create a system that uses the geothermal open circuit principle to cooling the buildings. 

Protection (June $27^{\mathrm{TH}}-30^{\mathrm{TH}}, 2017$, BLED, SLOVEniA), RENEWABle ENERGy SOURCES G. Rospi, N. Cardinale, F. Intini \& E. Negro: An Innovative Low Enthalpy Geothermal System: Ground Source Heat Pump and Underground Tank for Heating and Cooling of Buildings

We started the research analysed the solution to cooling the buildings because today the low enthalpy geothermal systems have a few problems when they are used to cooling.

In fact, these systems have a low efficiency when produce cool due to the earth heating around the geothermal loop; this problem reduces the energy efficiency ration (EER) because the temperature difference between the ground loop and heat pump evaporator is higher.

This problem could be result by using or a material with a higher thermal capacity than the earth or by increasing the thermal heat exchanger between the probe and the earth.

To solve these problem a prototype of geothermal heat pump was created in laboratory by using a small cylindrical water tank filled of water. To heating the tank a natural gas boiler was used. The water tank has a volume of 20 litres while the boiler has the following features: a max thermal power of $24,1 \mathrm{~kW}$, a min thermal power of $3,1 \mathrm{~kW}$ and a thermal efficiency of 0,975 .

The boiler and the tank were connected with inlet and outlet pipe of diameter 1,905 cm.

A data logger with a different probe were used to analyse the prototype. In particular, six thermocouples, a psychrometric probe, a mean radiant temperature probe and an anemometer probe were used. In addition, the energy inlet into the tank was measured.

Two different measurement campaign were performed and then the measurements were analysed.

After this phase, a finite element model was created by Comsol multiphysic software.

Then the model was setting and validating by the relation between the measurement simulated and measured.

In the and different analysis were performed. In particular, we analysed the relation between $1 \mathrm{MW}$ of the energy inlet and the volume on the water into the tank, the different shape of the tank and the different boundary condition.

\section{Experimental Phase}

A prototype of small low enthalpy geothermal system with open loop was created in laboratory at University of Basilicata in Matera.

To create this system, we used a small iron tank connect to boiler by inlet and outlet pipes. The tank has a cylindrical shape and a volume of 20 litres. The Boiler has a max thermal power of $24,1 \mathrm{~kW}$, a min thermal power of $3,1 \mathrm{~kW}$ and a thermal efficiency of 0,975 . The pipe diameter was $1,905 \mathrm{~cm}$. 
$10^{\text {TH }}$ International CONFEREnce on Sustainable Energy and Environmental Protection (June $27^{\mathrm{TH}}-30^{\mathrm{TH}}, 2017$, Bled, SLOVENIA), RENEWABle ENERGY SOURCES G. Rospi, N. Cardinale, F. Intini \& E. Negro: An Innovative Low Enthalpy Geothermal System: Ground Source Heat Pump and Underground Tank for Heating and Cooling of Buildings

The figure 2 show the experimental prototype.

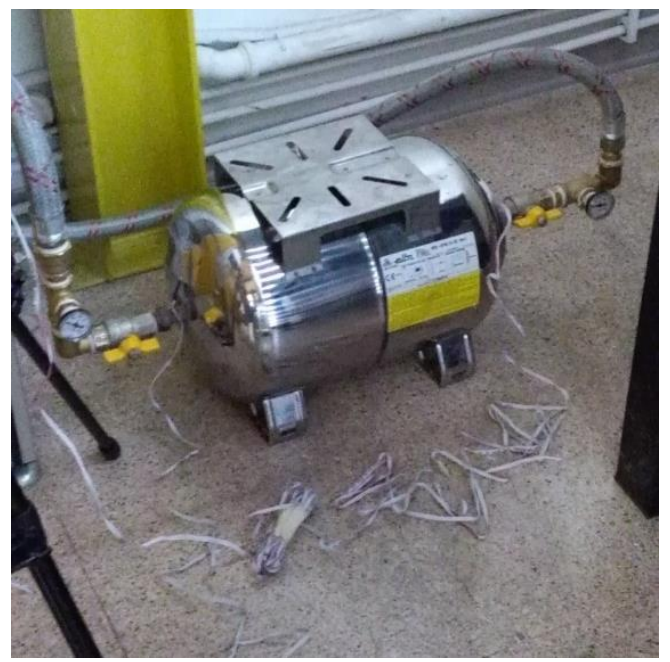

Figure 1. Experimental prototype

This system was filled with water and we had used a hydraulic pump to set a flow rate of $3.5 \mathrm{~m} 3 / \mathrm{h}$ and a flow velocity of $2 \mathrm{~m} / \mathrm{s}$.

A data logger and thermal probes were used to monitor the system. We used six thermocouples, a flow rate probe, two psychometric probes and an air speed probe. We had also measured the inlet energy to heating the water into the tank by a thermal energy indicator.

The thermocouples were used to evaluate the water temperature into the tank and on the tank boundary. Two to four thermocouples were used to measure the water temperature into the tank.

The air temperature and the air speed neat the tank were measured by the psychometric and air speed probes.

The air temperature and the air speed measurement near the tank is important to obtain the convective heat transfer between the boundary of the water tank and the near air.

The initial conditions were the equal temperature of the air and the water into the tank with a value of $21,54^{\circ} \mathrm{C}$ and an air speed value of $1 \mathrm{~m} / \mathrm{s}$.

The experiment was performed into two different step. In first step, the water of the tank was heating until $74^{\circ} \mathrm{C}$; this value was obtained after 30 minutes. 

Protection (June $27^{\mathrm{TH}}-30^{\mathrm{TH}}, 2017$, BLED, SLOVENIA), RENEWABLE ENERGY SOURCES G. Rospi, N. Cardinale, F. Intini \& E. Negro: An Innovative Low Enthalpy Geothermal System: Ground Source Heat Pump and Underground Tank for Heating and Cooling of Buildings

In this phase we measured the air and water temperature trend and the inlet energy to heating the water. The graph following show these temperature trend.

An inlet energy quantity of $1,7 \mathrm{kWh}$ was utilised to reach the temperature value of $74{ }^{\circ} \mathrm{C}$ and a time of 30 minutes.

In the second step, the boiler was tuned off, and the water and air temperature trend were measured for other 30 minute.

The tables following describe the inlet and outlet temperature trend during the heating of water and after thirty minutes.

Table 1. Temperature values measured during the experimental phase (air temperature $\left.19^{\circ}\right)$

\begin{tabular}{|c|c|c|c|}
\hline $\begin{array}{c}\text { MEASU- } \\
\text { REMENT }\end{array}$ & TIME & $\begin{array}{c}\text { POINT OF } \\
\text { MEASURE- } \\
\text { MENT }\end{array}$ & $\begin{array}{c}\text { WATER } \\
\text { TEMPERA- } \\
\text { TURE }\left[{ }^{\circ} \text { C] }\right.\end{array}$ \\
\hline $1^{\circ}$ & $15: 45$ & inlet & 21,54 \\
\hline & & outlet & 21,54 \\
\hline $2^{\circ}$ & $15: 55$ & inlet & 39,24 \\
\hline & & outlet & 35,44 \\
\hline $3^{\circ}$ & $16: 05$ & inlet & 66,14 \\
\hline & & outlet & 64,11 \\
\hline $4^{\circ}$ & $16: 15$ & inlet & 72,08 \\
\hline & & outlet & 73,96 \\
\hline $5^{\circ}$ & $16: 25$ & inlet & 70,55 \\
\hline & & outlet & 72,2 \\
\hline $6^{\circ}$ & $16: 35$ & inlet & 68,67 \\
\hline & & outlet & 69,67 \\
\hline
\end{tabular}

\section{$4 \quad$ Numerical phase}

In this phase we have created a finite element model by the Comsol Multiphysics software. This software uses more physic to analyse the finite element model. We used two physical combinations to study the model: the heat transfer in fluid and the Laminar flow with the RANS turbulent model. 
$534 \quad 10^{\text {TH }}$ InTERnAtional CONFERENCE ON Sustainable ENERGy AND ENVIRONMENTAL Protection (June $27^{\mathrm{TH}}-30^{\mathrm{TH}}, 2017$, Bled, SLOVENIA), RENEWABle ENERGY SOURCES G. Rospi, N. Cardinale, F. Intini \& E. Negro: An Innovative Low Enthalpy Geothermal System: Ground Source Heat Pump and Underground Tank for Heating and Cooling of Buildings

For the tank envelope, the boundary condition used are the conductivity heat transfer and the convective heat transfer. A heat conductivity coefficient value of $76,2 \mathrm{~W} / \mathrm{m} * \mathrm{~K}$ (typical conductivity heat coefficient of iron) was used, while, a conductivity heat coefficient was calculated by the calculating the convective coefficient $h$ between the surface tank and the air. The $h$ coefficient was estimated by the Nusselt number and the values of air speed, air temperature and surface temperature measured in laboratory.

By calculating the Reynolds number we obtained a value less to critical Reynolds number, so the fluid flow situation is laminar flow.

After, calculating the Reynolds number the Nusselt number was calculating.

In laboratory we measured three values of surface temperature of tank, of which we obtained three value of $h$ coefficient values: $h 1=6,14, h 2=6,19$ and $h 3=6,23$. We used an average value of 6,19 .

We used a heat flux value of $5400 \mathrm{~W}$ and a flow rete value of $3,5 \mathrm{~m} 3 / \mathrm{h}$; there values were measured in laboratory.

\section{$5 \quad$ Results and Application}

In the first phase, by numerical model we realise the model FEM of experimental prototype. We have insert the same boundary conditions measured in laboratory and then, we calculated the temperature trend of the water into the tank. After, the temperature trends simulated and measured were compared.

In the table 2, the inlet and outlet temperature measured and simulated were indicated for a period of twenty minutes. The error percentage is low. 

Protection (June 27 $7^{\mathrm{TH}}-30^{\mathrm{TH}}, 2017$, BLED, SLOVENIA), RENEWABLE ENERGY SOURCES G. Rospi, N. Cardinale, F. Intini \& E. Negro: An Innovative Low Enthalpy Geothermal System: Ground Source Heat Pump and Underground Tank for Heating and Cooling of

Table 2. Temperature values measured and simulated

\begin{tabular}{|c|c|c|c|}
\hline $\begin{array}{c}\text { TIME } \\
\text { [s] }\end{array}$ & 0 & 10 & 20 \\
\hline $\begin{array}{c}\text { INLET } \\
\text { TEMPERATURE } \\
\text { measured }\end{array}$ & 21,54 & 39,24 & 66,14 \\
\hline $\begin{array}{c}\text { INLET } \\
\text { TEMPERATURE } \\
\text { simulated }\end{array}$ & 21,54 & 49,6 & 74,99 \\
\hline Error & $0 \%$ & $26 \%$ & $13 \%$ \\
\hline $\begin{array}{c}\text { OUTLET } \\
\text { TEMPERATURE } \\
\text { measured }\end{array}$ & 21,54 & 50 & 75 \\
\hline $\begin{array}{c}\text { OUTLET } \\
\text { TEMPERATURE } \\
\text { simulated }\end{array}$ & 21,54 & 49,09 & 74,52 \\
\hline Error & $0 \%$ & $-2 \%$ & $-1 \%$ \\
\hline
\end{tabular}

The table show a good estimate of the FEM model. The inlet temperature has a small difference between temperature measured and simulated because in the model FEM we considered the inlet surface of pipe as an heat source.

\section{References}

[1] EC, 2006. Action Plan for Energy Efficiency: Realising the Potential. European Commission, COM, 2006, 545 Final, Brussels, Belgium, 25 pp. http://ec.europa.eu/energy/action_plan_energy_efficiency/doc/com 2006_0545_en.pdf

[2] EC, 2007. An energy policy for Europe. Communication from the Commission to the European Council and the European Parliament. European Commission, SEC COM, 2007, 12, Brussels, Belgium, 27 pp. http://ec.europa.eu/energy/energy policy/doc/01 energy policy for europe en.pdf

[3] Alistair Allen*, Dejan Milenic, Low-enthalpy geothermal energy resources from groundwater in fluvioglacial gravels of buried valleys, Applied Energy 74 (2003) 9-19

[4] Rafferty, K., 2000. Scaling in geothermal heat pump systems. GeoHeat Centre Quarterly Bulletin 21, 11-15.

[5] Lo Russo S.,*, Boffa C., Civita M.V., Low-enthalpy geothermal energy: An. opportunity to meet increasing energy needs and reduce $\mathrm{CO} 2$ and atmospheric pollutant emissions in Piemonte, Italy, Geothermics 38 (2009) 254-262 
$536 \quad 10^{\mathrm{TH}}$ International CONFERENCE on Sustainable ENERgy AND ENVIRONMENTAL Protection (June $27^{\mathrm{TH}}-30^{\mathrm{TH}}, 2017$, Bled, SLOVENIA), RENEWABle ENERGY SOURCES G. Rospi, N. Cardinale, F. Intini \& E. Negro: An Innovative Low Enthalpy Geothermal System: Ground Source Heat Pump and Underground Tank for Heating and Cooling of Buildings

[6] PDEP, 1996. Ground Source Heat Pump. Pennsylvania Department of Environmental Protection Fact Sheet, Harrisburg, PA, USA, 2 pp.

[7] DOE, 1999. Renewable Energy Annual 1998: Issues and Trends. U.S. Department of Energy, Office of Coal, Nuclear, Electric and Alternate Fuels, Report DOE/EIA- 0603(99), Washington, $\mathrm{DC}$, USA, 117 pp. http://tonto.eia.doe.gov/FTPROOT/renewables/060399.pdf

[8] Drijver, B., Willemsen, A., 2001. Groundwater as a heat source for geothermal heat pumps. In: International Summer School on Direct Application of Geothermal Energy, International Geothermal Association, Bad Urach, Germany, September 17-20, pp. 156166.

[9] Rafferty, K., 2001. Design aspects of commercial open-loop heat pump systems. GeoHeat Centre Quarterly Bulletin 22, 16-24. 



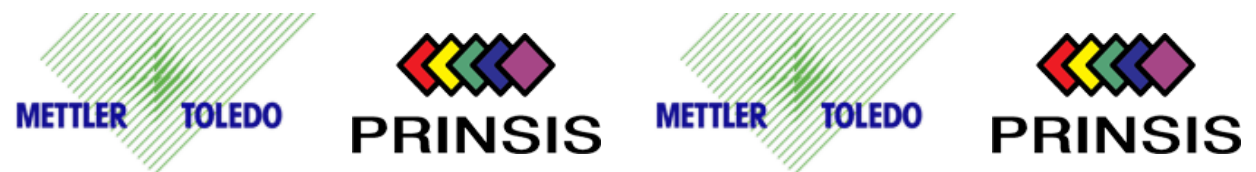

$€$ energetika ljubljana $€$ energetika ljubljana

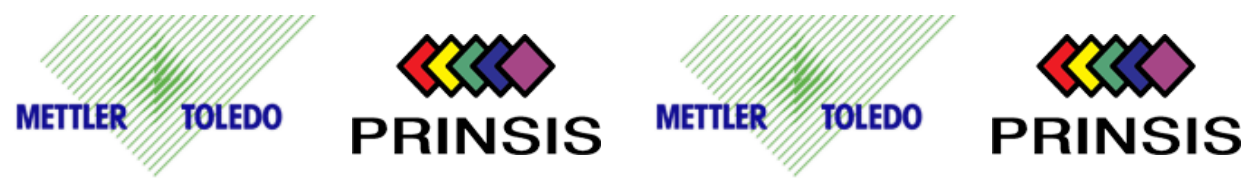

$€$ energetika ljubljana $€$ energetika ljubljana

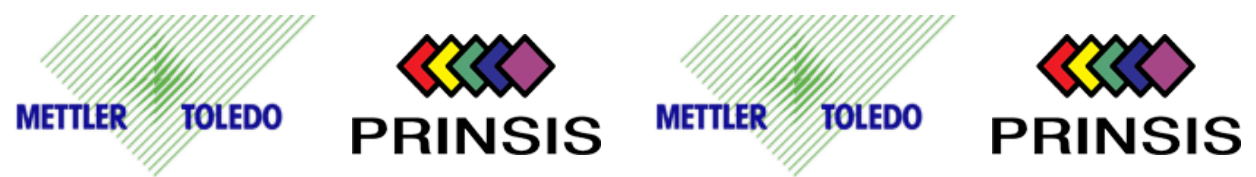

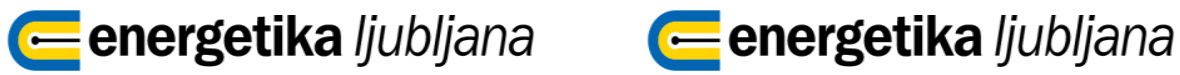

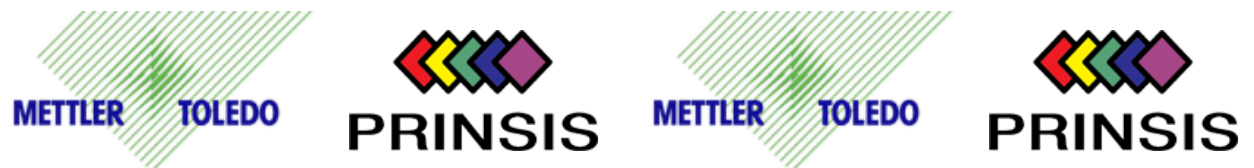

$€$ energetika ljubljana $€$ energetika ljubljana

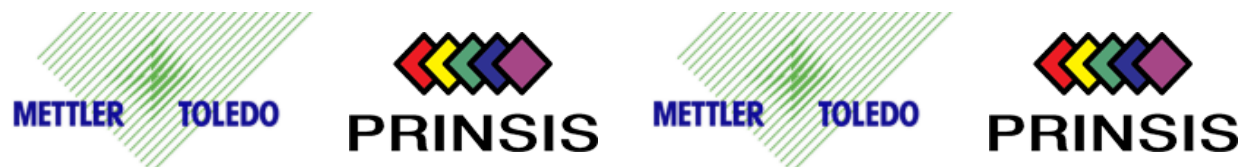

$€$ energetika ljubljana $€$ energetika ljubljana 